CITIZEN SCIENCEREDUCNG

RISK AND BUILDING RESILIENCE

TONATURAL HAZARDS

EDITED BY: Jonathan D. Paul, David M. Hannah and Wei Liu PUBLISHED IN: Frontiers in Earth Science

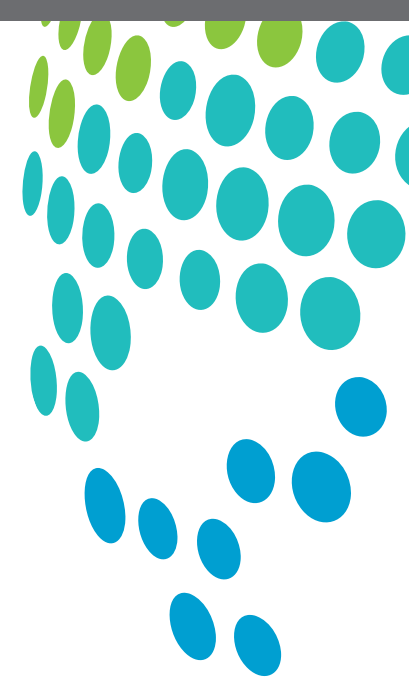

0000
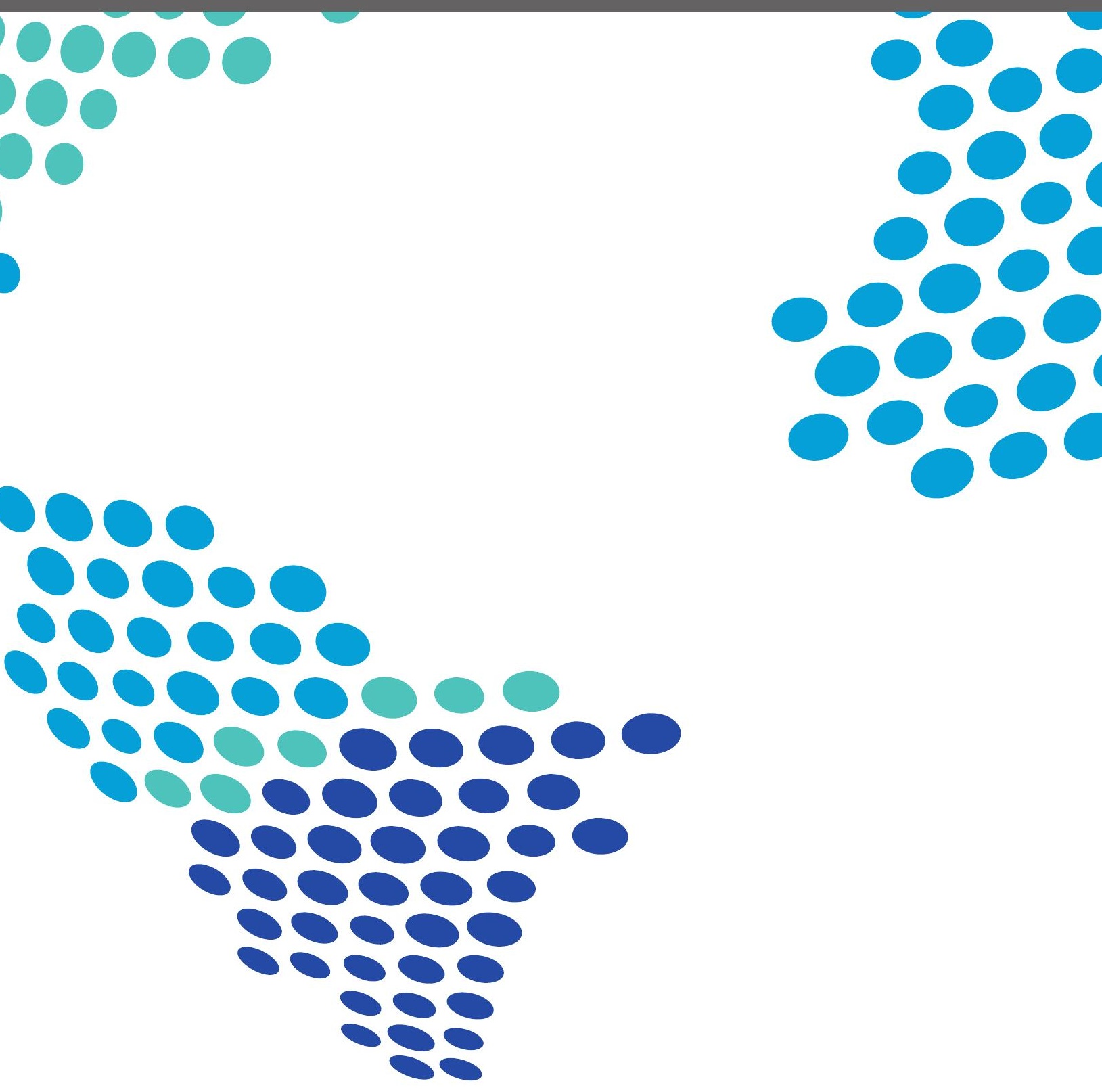

frontiers Research Topics 


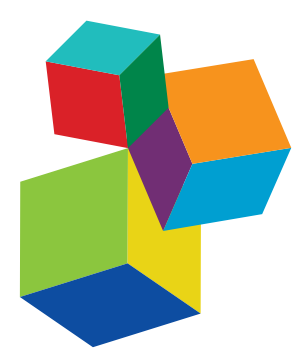

Frontiers eBook Copyright Statement

The copyright in the text of individual articles in this eBook is the property of their respective authors or their respective institutions or funders. The copyright in graphics and images within each article may be subject to copyright of other parties. In both cases this is subject to a license granted to Frontiers.

The compilation of articles constituting this eBook is the property of Frontiers.

Each article within this eBook, and the eBook itself, are published under the most recent version of the Creative Commons CC-BY licence. The version current at the date of publication of this eBook is CC-BY 4.0. If the CC-BY licence is updated, the licence granted by Frontiers is automatically updated to the new version.

When exercising any right under the CC-BY licence, Frontiers must be attributed as the original publisher of the article or eBook, as applicable.

Authors have the responsibility of ensuring that any graphics or other materials which are the property of others may be included in the

CC-BY licence, but this should be checked before relying on the

CC-BY licence to reproduce those materials. Any copyright notices relating to those materials must be complied with.

Copyright and source acknowledgement notices may not be removed and must be displayed in any copy, derivative work or partial copy which includes the elements in question.

All copyright, and all rights therein, are protected by national and international copyright laws. The above represents a summary only.

For further information please read Frontiers' Conditions for Website

Use and Copyright Statement, and the applicable CC-BY licence.

ISSN 1664-8714

ISBN 978-2-88963-401-9

DOI 10.3389/978-2-88963-401-9

\section{About Frontiers}

Frontiers is more than just an open-access publisher of scholarly articles: it is a pioneering approach to the world of academia, radically improving the way scholarly research is managed. The grand vision of Frontiers is a world where all people have an equal opportunity to seek, share and generate knowledge. Frontiers provides immediate and permanent online open access to all its publications, but this alone is not enough to realize our grand goals.

\section{Frontiers Journal Series}

The Frontiers Journal Series is a multi-tier and interdisciplinary set of open-access, online journals, promising a paradigm shift from the current review, selection and dissemination processes in academic publishing. All Frontiers journals are driven by researchers for researchers; therefore, they constitute a service to the scholarly community. At the same time, the Frontiers Journal Series operates on a revolutionary invention, the tiered publishing system, initially addressing specific communities of scholars, and gradually climbing up to broader public understanding, thus serving the interests of the lay society, too.

\section{Dedication to Quality}

Each Frontiers article is a landmark of the highest quality, thanks to genuinely collaborative interactions between authors and review editors, who include some of the world's best academicians. Research must be certified by peers before entering a stream of knowledge that may eventually reach the public - and shape society; therefore, Frontiers only applies the most rigorous and unbiased reviews.

Frontiers revolutionizes research publishing by freely delivering the most outstanding research, evaluated with no bias from both the academic and social point of view. By applying the most advanced information technologies, Frontiers is catapulting scholarly publishing into a new generation.

\section{What are Frontiers Research Topics?}

Frontiers Research Topics are very popular trademarks of the Frontiers Journals Series: they are collections of at least ten articles, all centered on a particular subject. With their unique mix of varied contributions from Original Research to Review Articles, Frontiers Research Topics unify the most influential researchers, the latest key findings and historical advances in a hot research area! Find out more on how to host your own Frontiers Research Topic or contribute to one as an author by contacting the Frontiers Editorial Office: researchtopics@frontiersin.org 


\section{CITIZEN SCIENCE: REDUCING RISK AND BUILDING RESILIENCE TO NATURAL HAZARDS}

Topic Editors:

Jonathan D. Paul, Imperial College London, United Kingdom David M. Hannah, University of Birmingham, United Kingdom Wei Liu, International Institute for Applied Systems Analysis (IIASA), Austria

Citation: Paul, J. D., Hannah, D. M., Liu, W., eds. (2020). Citizen Science: Reducing Risk and Building Resilience to Natural Hazards. Lausanne: Frontiers Media SA. doi: 10.3389/978-2-88963-401-9 


\section{Table of Contents}

04 Editorial: Citizen Science: Reducing Risk and Building Resilience to Natural Hazards

Jonathan D. Paul, David M. Hannah and Wei Liu

07 The Good, the Bad, and the Uncertain: Contributions of Volunteered Geographic Information to Community Disaster Resilience

Billy Tusker Haworth, Eleanor Bruce, Joshua Whittaker and Róisín Read

22 Living With Earthquake and Flood Hazards in Jammu and Kashmir, NW Himalaya

Afroz Ahmad Shah, Sheeba Khwaja, Bilal A. Shah, Qibah Reduan and Zirah Jawi

35 A Review of Studies on Participatory Early Warning Systems (P-EWS):

Pathways to Support Citizen Science Initiatives

Victor Marchezini, Flávio Eduardo Aoki Horita, Patricia Mie Matsuo,

Rachel Trajber, Miguel Angel Trejo-Rangel and Débora Olivato

53 MyShake: Using Human-Centered Design Methods to Promote

Engagement in a Smartphone-Based Global Seismic Network

Kaylin Rochford, Jennifer A. Strauss, Qingkai Kong and Richard M. Allen

67 The Leadership Void for Climate Adaptation Planning: Case Study of the Port of Providence (Rhode Island, United States)

Austin Becker and Eric Kretsch

80 A Review of Citizen Science and Crowdsourcing in Applications of Pluvial Flooding

Linda See

87 Earthquake Education Through the Use of Documentary Movies Batmanathan Navakanesh, Afroz Ahmad Shah and M. V. Prasanna

103 Virtual Staff Gauges for Crowd-Based Stream Level Observations Jan Seibert, Barbara Strobl, Simon Etter, Philipp Hummer and H. J. (Ilja) van Meerveld

113 Crowdsourcing Platform Toward Seismic Disaster Reduction: The Taiwan Scientific Earthquake Reporting (TSER) System

Wen-Tzong Liang, Jian-Cheng Lee and Nai-Chi Hsiao

125 Growing Pains of Crowdsourced Stream Stage Monitoring Using Mobile Phones: The Development of CrowdHydrology

Christopher S. Lowry, Michael N. Fienen, Damon M. Hall and Kristine F. Stepenuck

135 Developing Consequence Thresholds for Storm Models Through Participatory Processes: Case Study of Westerly Rhode Island Robert Witkop, Austin Becker, Peter Stempel and Isaac Ginis

150 Global Mapping of Citizen Science Projects for Disaster Risk Reduction Anna Hicks, Jenni Barclay, Jason Chilvers, M. Teresa Armijos, Katie Oven, Peter Simmons and Muki Haklay

168 Building Resilience to Chronic Landslide Hazard Through Citizen Science Katarzyna Cieslik, Puja Shakya, Madhab Uprety, Art Dewulf, Caroline Russell, Julian Clark, Megh Raj Dhital and Amrit Dhakal 


\title{
Editorial: Citizen Science: Reducing Risk and Building Resilience to Natural Hazards
}

\author{
Jonathan D. Paul ${ }^{1 *}$, David M. Hannah ${ }^{2}$ and Wei Liu ${ }^{3}$ \\ ${ }^{1}$ Department of Civil and Environmental Engineering, Imperial College London, London, United Kingdom, ${ }^{2}$ School of \\ Geography, Earth and Environmental Sciences, University of Birmingham, Birmingham, United Kingdom, ${ }^{3}$ International \\ Institute for Applied Systems Analysis, Laxenburg, Austria
}

Keywords: citizen science (CS), natural hazards (NH), VGI (volunteered geographic information), participatory monitoring, flooding management, resilience building, risk reduction and mitigation measures

\section{Editorial on the Research Topic}

Citizen Science: Reducing Risk and Building Resilience to Natural Hazards

\section{RATIONALE}

Natural hazards are becoming increasingly frequent within the context of climate changemaking reducing risk and building resilience against these hazards more crucial than ever. An emerging shift has been noted from broad-scale, top-down risk and resilience assessments toward more participatory, community-based, bottom-up approaches. Arguably, non-scientist local stakeholders have always played an important role in risk knowledge management and resilience building. Rapidly developing information and communication technologies such as the Internet, smartphones, and social media have already demonstrated their sizeable potential to make knowledge creation more multidirectional, decentralized, diverse, and inclusive (Paul et al., 2018). Combined with technologies for robust and low-cost sensor networks, various citizen science approaches have emerged recently (e.g., Haklay, 2012; Paul et al., 2018) as a promising direction in the provision of extensive, real-time information for risk management (as well as improving data provision in data-scarce regions). It can serve as a means of educating and empowering communities and stakeholders that are bypassed by more traditional knowledge generation processes.

This Research Topic compiles 13 contributions that interrogate the manifold ways in which citizen science has been interpreted to reduce risk against hazards that are (i) water-related (i.e., floods, hurricanes, drought, landslides); (ii) deep-earth-related (i.e., earthquakes and volcanoes); and (iii) responding to global environmental change such as sea-level rise. We have sought to analyse the particular failures and successes of natural hazards-related citizen science projects: the objective is to obtain a clearer understanding of "best practice" in a citizen science context.

\section{HYDROLOGICAL HAZARDS} Accepted: 18 November 2019 Published: 04 December 2019

See notes a major gap in the literature regarding the contribution of citizen science to pluvial flooding. Her article reviews the role of crowdsourced data in flood early-warning systems (EWS) and in the development and validation of forecasting models; such data have the potential to yield greatly enhanced resilience at the community level. If pre- and post-flood applications were integrated, developments in one could benefit the other, e.g., technological innovation in flood reporting apps and automated flood detection systems will yield data useful for model validation. 
The validity of citizen science approaches to expand the shrinking observational database is becoming increasingly apparent: Lowry et al. and Seibert et al. detail two projects that seek to increase the number of observations of water level and (indirectly) streamflow, respectively. Established in 2010, the CrowdHydrology network of Lowry et al. has recently expanded to a national scope, involving a huge database of river and lake level data sent via text messages. The relatively early genesis of this project has allowed the authors to draw useful conclusions regarding the highly variable contribution rates of citizen scientists, while also offering reasons for potential barriers to participation, and suggestions as to the best ways to expand a citizen science network sustainably.

By contrast, public engagement in streamflow observations has, so far, been limited. Seibert et al. discuss this difference in terms of the relative complexity of data and instrumentation needed. As a means of obviating this complexity, the authors present a smartphone app-a virtual staff gauge-that allows stream level to be estimated, as an alternative approach. While the degree of uptake was encouraging, certain "birthing problems" were encountered, the discussion of which will benefit workers involved in the development and deployment of new smartphone apps.

Two further hydrology-flavored papers propose more general methodologies for citizen-led data collection and knowledge co-production. Witkop et al. provide a new framework to incorporate the knowledge of emergency managers into the hazard modeling process. In essence, the purpose is to enable local experts to contribute actionable knowledge to otherwise "black box" numerical modeling approaches. This framework-involving semi-structured interviews and participatory mapping-can usefully be combined with climate models to assess potential hazard consequences; in their case study, for hurricanes on the eastern US seaboard.

Similarly, Cieslik et al. argue for the immediate inclusion of indigenous knowledge in the co-production of knowledge: specifically in generating and supporting resilience to landslides in western Nepal. Cieslik et al. propose a new typology of citizen science interventions (in hydrology and beyond), distinguishing between community science, participatory environmental monitoring and virtual citizen science, and provide examples of how they can benefit stakeholders at different levels and/or different types of research.

\section{GEOPHYSICAL HAZARDS}

Geohazards like earthquakes and volcanic eruptions have rich potential to be monitored and reported upon using recent technological innovations, like the accelerometers present in most smartphones. Through their presentation of the MyShake global platform, Rochford et al. contribute one of the largest examples in terms of datapoints of a citizen science project in the special issue. They discuss the components of the platform, which includes both ground shaking data and qualitative descriptions of users' experiences, with the goal of reducing earthquake risk and enhancing environmental awareness. The authors discuss barriers to, and successes of, continuing participation, including an interrogation of the iterative process of re-designing the platform in response to users' views from interviews and surveys.

In Taiwan, Liang et al. describe a similar yet more localized system, where non-scientists are actively encouraged to visit the epicentral area of an earthquake when safe, to document variations in ground damage via text and smartphone image upload. This platform also serves as a means of passively sharing educational materials (e.g., geological maps) to the volunteers.

Moving away from specific platforms, Navakanesh et al. focus in greater detail on enhancing situational awareness (rather than participatory monitoring). Citing a disconnect between subjective perception and scientific knowledge of earthquake hazard in a region of Malaysia, the authors describe a process of integrating stories from earthquake victims with updated scientific data, culminating in a documentary movie that is used to educate affected communities about the causes and nature of earthquake hazards.

Shah et al. agree that emphasis should be shifted to local preparedness from prediction, in the case of earthquakes and flooding in Jammu and Kashmir. Similar to the findings of Navakanesh et al., these authors identify an urgent need to educate local students and community leaders about the science and mitigation of natural hazards. They propose a framework involving a series of workshops, training sessions, public talks, and international conferences.

\section{GLOBAL ENVIRONMENTAL CHANGE}

Our final four contributions do not focus on particular case studies or hazards; rather, they interrogate the use and usefulness of citizen science approaches in the context of global environmental change. Hicks et al. conduct a systematic mapping of 106 citizen science projects in the realm of disaster risk reduction (DRR). Analyzing the effectiveness of each example, they underline the importance of building connections between different methods of citizen science and practitioners; and of ensuring both scientific rigor and attending to questions of responsibility, empowerment, and equity of those most vulnerable to disaster risk.

Marchezini et al. review projects that directly link a citizen science component to hazard EWS (people-centered or participatory EWS). Importantly, they identify a gap in the literature between citizen science and disaster prevention: most effort has been concentrated on developing new technologies, platforms, and methodologies, rather than understanding the livelihoods of non-scientist stakeholders, or elucidating ways of better engaging them. The authors provide a social science framework to bridge the gap between citizen science and participatory EWS globally.

Becker and Kretsch and Haworth et al. both focus on resilience building. Becker and Kretsch stress the difficulty in securing resilience investment against the effects of climate change on coastal communities. In a diverse group of stakeholders, 
conflicting perceptions of leadership responsibility must be reconciled; else, they contribute to an institutional void, which impedes long-term planning efforts. In contrast, Haworth et al. discuss the emergence of volunteered geographic information (VGI) and its role in changing the nature of community involvement in DRR and resilience building. They present a nuanced picture in which VGI and social media have the potential to undermine resilience (e.g., compromised privacy and highly variable data quality). In conclusion, training individuals in the use of VGI in DRR will foster greater inclusivity, reliability, and complementarity with scientifically generated datasets.

\section{REFERENCES}

Haklay, M. (2012). "Citizen science and volunteered geographic information overview and typology of participation," in Volunteered Geographic Information, Public Participation, and Crowdsourced Production of Geographic Knowledge, eds D. Z. Sui, S. Elwood, and M. F. Goodchild (Berlin: Springer). p. 105-122.

Paul, J. D., Buytaert, W., Allen, S., Ballesteros-Cánovas, J. A., Bhusal, J., Cieslik, K., et al. (2018). Citizen science for hydrological risk reduction and resilience building. Wiley Interdiscip. Rev. Water 5:e1262. doi: 10.1002/wat2.1262

\section{AUTHOR CONTRIBUTIONS}

All authors listed have made a substantial, direct and intellectual contribution to the work, and have approved it for publication.

\section{ACKNOWLEDGMENTS}

We would like to thank all reviewers for their contributions to the manuscripts. We would also like to thank Editor-in-Chief Gordon Woo, and the entire Frontiers Team for their support throughout the conception and design of the special issue.

Conflict of Interest: The authors declare that the research was conducted in the absence of any commercial or financial relationships that could be construed as a potential conflict of interest.

Copyright (C) 2019 Paul, Hannah and Liu. This is an open-access article distributed under the terms of the Creative Commons Attribution License (CC BY). The use, distribution or reproduction in other forums is permitted, provided the original author(s) and the copyright owner(s) are credited and that the original publication in this journal is cited, in accordance with accepted academic practice. No use, distribution or reproduction is permitted which does not comply with these terms. 


\title{
The Good, the Bad, and the
} Uncertain: Contributions of Volunteered Geographic Information to Community Disaster Resilience

\author{
Billy Tusker Haworth ${ }^{1 *}$, Eleanor Bruce ${ }^{2}$, Joshua Whittaker ${ }^{3}$ and Róisín Read \\ ${ }^{1}$ Humanitarian and Conflict Response Institute, School of Arts, Languages and Cultures, University of Manchester, \\ Manchester, United Kingdom, ${ }^{2}$ School of Geosciences, University of Sydney, Sydney, NSW, Australia, ${ }^{3}$ Centre \\ for Environmental Risk Management of Bushfires, University of Wollongong, Wollongong, NSW, Australia
}

\section{OPEN ACCESS}

Edited by:

Jonathan D. Paul,

Imperial College London,

United Kingdom

Reviewed by:

Sultan Kocaman,

Hacettepe University, Turkey

Emanuele Intrieri,

Università di Firenze, Italy

*Correspondence:

Billy Tusker Haworth

billy.haworth@manchester.ac.uk

Specialty section:

This article was submitted to

Geohazards and Georisks,

a section of the journal

Frontiers in Earth Science

Received: 14 August 2018 Accepted: 12 October 2018 Published: 01 November 2018

Citation:

Haworth BT, Bruce E, Whittaker J and Read $R$ (2018) The Good,

the Bad, and the Uncertain:

Contributions of Volunteered

Geographic Information

to Community Disaster Resilience.

Front. Earth Sci. 6:183.

doi: 10.3389/feart.2018.00183
The adoption of location-based information sharing technologies, and the emergence of volunteered geographic information (VGI), has seen changes to community involvement in disaster management. The concept of resilience, and recognition of the capacity for renewal, re-organization, and societal development, has gained currency in disaster management. However, the opportunities presented by spatially referenced data for sourcing contextual information for understanding processes of socialecological resilience and fostering local inclusion has not been examined. We examine how web 2.0 platforms, including VGI and social media, can support resilience building, and critically evaluate how these technologies potentially undermine resilience. We concentrate our analysis on factors deemed important for community disaster resilience through review of recent literature, policy documents, and author experience. Establishing which elements of VGl in disaster management should be emphasized, such as increased flexibility or individual empowerment, and which require careful management, such as compromised privacy or data quality, will enable VGl to become less opportunistic, data-centric, disruptive, and exclusionary, and allow for more reliable, community-centric, complementary, and socially inclusive practices. Incorporating awareness and training on collaborative geoweb technologies into disaster preparedness programs will equip individuals to make informed judgments on VGI content and reduce unintended consequences of social media initiatives.

Keywords: disaster management, resilience, social media, volunteered geographic information (VGI), geoweb, digital volunteering

\section{INTRODUCTION}

The adoption of social media and location-based information-sharing technologies, and the emergence of volunteered geographic information (VGI), has seen a shift in the spatio-temporal scales of community involvement in disaster management. Often associated with the related concept of citizen science ${ }^{1}$ (e.g., Haklay, 2013), VGI is widely understood to involve the

\footnotetext{
${ }^{1}$ While citizen science and VGI both involve members of the general public participating in what have been traditionally "expert" or professional activities, such as science or map-making, an important distinction is that citizen science involves participation in defined scientific projects and VGI occurs in a wider range of contexts, with a variety of participant motivations, and is not necessarily attached to a specific project. Further, citizen science data and activities do not always involve a geographic component, as is always the case for VGI.
} 
growing practices of private citizens voluntarily generating (Goodchild, 2007) and subsequently disseminating (Ricker et al., 2014) geographic information, predominantly through dedicated online platforms. VGI contributors may explicitly volunteer information through focused mapping activities using platforms such as OpenStreetMap (OSM) or generate data that are implicitly associated with geographic location such as geotagged photographs (shared via Flickr) or microblogs (e.g., Tweets) (Craglia et al., 2012; Senaratne et al., 2017).The increasingly widespread use of such technologies by private individuals for participation in emergency and disaster management has been termed digital volunteering (Whittaker et al., 2015). However, social media and VGI efforts tend to focus on reactive response initiatives, such as the use of Facebook to connect community members during bushfires (wildfires) in Australia (Irons et al., 2015), rather than preparedness and participatory practices for promoting community resilience. The concept of resilience, and the recognition of the capacity for renewal, re-organization, and societal development, following system disturbance has gained currency in disaster management research. This paper examines how resilience thinking can better inform the development of public participation geoweb platforms and shape understandings of the motivations and requirements of such initiatives. The resilience perspective is adopted here to provide a contextual framework for critical evaluation of the role of VGI practices and digital volunteering in disaster management.

The aim of many current emergency management policies is to use the Prevention, Preparedness, Response, and Recovery (PPRR) model to work toward a more disaster-resilient population, that is, one that is able to recognize current and future risk, reduce and manage those risks, and is better-able to recover from disasters (Council of Australian Governments [COAG], 2011; Prosser and Peters, 2011). Increased emphasis on resilience requires emergency practitioners to shift focus from a top-down "command-and-control" model to one more strategic, participatory, and dialogic with communities and stakeholders; where value is increasingly recognized in both authoritative and citizen information and practices (Burnside-Lawry et al., 2013). This has led to a focus on implementing initiatives centered on community engagement (e.g., Frandsen et al., 2011) and innovations in information and communication technologies, such as social media, that can empower citizens in disaster response (e.g., Taylor et al., 2012).

Allowing ordinary citizens to voluntarily create and share geographic information - through technologies such as the Internet and Web 2.0, global positioning systems, personal locational devices such as smartphones, inexpensive map-making platforms open to public contributions (e.g., OSM, Ushahidi Crowdmap), cloud storage, and broadband communication - has transformed the traditional model of authoritative production of geographic information, with particular pertinence to disaster management (see for examples Zook et al., 2010; Haworth and Bruce, 2015). The production of geographic knowledge is no longer exclusive to experts, such as geographers (Elwood et al., 2012). The central discourse of Web 2.0 technology and practices like VGI is public participation and interactivity - a key element in crisis literature aimed at building resilience and increasing the involvement of the general public in disaster management (Bittner et al., 2016).

Although recent work has argued for the role of Web 2.0 information sharing platforms in building community disaster resilience (Dufty, 2012; Taylor et al., 2012), this is often focused on disaster response or a single platform in isolation, such as a social-media site like Facebook or Twitter, at the exclusion of other VGI practices, including crowdsourced web-mapping. The opportunities presented by spatially referenced (geotagged) data for sourcing contextual information at geographical and temporal scales relevant in understanding processes of resilience and fostering local inclusion have not been critically examined. We consider Web 2.0 information sharing platforms more broadly in community disaster resilience to include social media-based exchange of information and resources as well as more participatory enterprises such as crowdsourced disaster risk mapping. We also include here the concept of participatory mapping, as conceptualized by Brown and Fagerholm (2015) to collectively denote any process whereby citizens contribute to the creation of maps, which includes VGI. Further, while there are exceptions, much existing work on VGI and disasters has tended to be somewhat boosterish, at times exuding "techno-optimism" (Read et al., 2016). The optimism and promise of mapping and big data have been critiqued in the context of digital humanitarianism (Read et al., 2016), but similar analyses in relation to disaster resilience are lacking.

Thus, the intent of this paper is to examine how Web 2.0 information sharing platforms for VGI generation can support resilience-building in disaster management and, critically, evaluate how these technologies potentially undermine resilience building. We include social media beyond strict VGI in our analysis. While we recognize some social media information is not strictly VGI (i.e., data may not be geographical), commonalities such as the nature of large-scale online networking, information sharing by private citizens, and disruption to traditional systems catalyzed by technological advancements and associated practices warrant inclusion of this literature. The novelty of our approach lies in the explicit linking of VGI data and practices, including their promise, limitations, and implications, with conceptual understandings of resilience - an important endeavor as resilience remains high on international disaster management agendas.

\section{RESILIENCE}

\section{Social-Ecological Resilience and Emergence in Disaster Management}

A resilience concept has been embraced by various disciplines, including anthropology, engineering, urban planning, and geography (Weichselgartner and Kelman, 2015), with origins in physics (Van der Leeuw and Aschan-Leygonie, 2005), development psychology, and ecology (Manyena, 2006). The resilience perspective emerged from the ecology literature in the 1960-1970s with the discovery of multi-stable states in natural systems and non-linear forms of functional response (Folke, 2006). In challenging the dominant assumption of static 
equilibrium, Holling (1973) introduced the concept of multiple basins of attraction in which the size of stability domains (basin) or amount of disturbance a system can tolerate before shifting into another regime provides a measure of resilience (Folke, 2006). The recognized importance of process dynamics across multiple and interacting spatio-temporal scales later placed the resilience perspective in the context of complex adaptive systems (Folke, 2006). Integration of the social dimension in resilience thinking led to the concept of social-ecological resilience (SER). SER considers the amount of disturbance the system can absorb, the system's ability for self-organization, and the degree to which the system can build and increase capacity for learning and adaptation (transformability) (Carpenter and Gunderson, 2001; Folke, 2006). Rather than focusing on ecosystems or societies as separated entities, recognition of the dynamic interplay between the social and ecological components is critical in understanding system resilience (Gallopín, 2006).

In ecology, resilience emphasizes efficiency, control, constancy, and predictability as attributes of reliable systems (Holling and Gunderson, 2002). Another perspective considers the persistence, adaptability, variability, and unpredictability of ecological systems (Holling, 1973). The first definition is a measure of the speed at which a system "bounces back" after disturbance (Pimm, 1984); while the second measures the degree of disturbance that can be absorbed by a system before undergoing structural change (Holling and Gunderson, 2002). More recently, interpretations of resilience have encompassed elements such as capacity and capability, moving from the early engineering-based "bounce back" perspective to something that suggests doing better than before, or "bouncing forward" (Manyena et al., 2011; Weichselgartner and Kelman, 2015).

The term resilience has come into vogue in disaster management in recent decades with concern the language of "vulnerability" in disaster management was disempowering. Often resilience is treated as an antonym of vulnerability, a more positive way to talk about the same problem, but there are important differences (Whittaker, 2008). Vulnerability is constructed in the social and economic circumstances of everyday living and describes the ways people are differentially exposed to hazards and have varying capacities to reduce risks and withstand potential impacts (Morrow, 1999; Whittaker, 2008). Recognizing the terms are related, Zhou et al. (2010) attempt to contrast vulnerability and resilience, placing the emphasis of resilience on the process of enhancing capacity to respond and recover from disaster impacts in the shortest possible time with minimal outside assistance. Disaster resilience considered from a geographer's perspective is "the capacity of hazard-affected bodies to resist loss during disaster and to regenerate and reorganize after disaster in a specific area in a given period" (Zhou et al., 2010, p. 28).

Understandings and management of disasters since the 1970s has shifted focus from hazard identification and response to the drivers of vulnerability that turn hazards into disasters (Collier et al., 2009). Promotion of the Disaster Risk Reduction (DRR) framework by the practitioner community, both internationally (Hyogo Framework for Action and Sendai Framework) and at national levels, has highlighted the importance of SER thinking, the need for indicators of effective disaster preparedness, and participatory approaches that ensure local inclusion (Collier et al., 2009). Emergency management is shifting away from models of "command and control" and is beginning to diversify into a more collaborative activity and dynamic enterprise that facilitates multi-organizational, intergovernmental, and intersectoral co-operation (Waugh and Streib, 2006). This shift has led to philosophies such as "shared responsibility" (McLennan and Handmer, 2012). Shared responsibility itself has evolved from the notion of community responsibility and self-reliance (Elsworth et al., 2009) to a principle that implies increased responsibility for all concerned (being the state, municipal councils, individuals, household members, and the broader community) and a focus on community safety.

Despite its prevalence, the concept of resilience has undergone considerable critique. A basic criticism of the social-ecological systems approach is the assumption that the ecological and social domains of such systems can be addressed in a common conceptual, theoretical, and modeling framework (Welsh, 2014). A key problem here relates to the issue of defining the parameters of "the system" and locating human action within it. MacKinnon and Derickson (2012) note that resilience privileges spatial sites and scales such as cities, regions, and local communities, which are implicitly equated with ecosystems, and are viewed as autonomous and subject to the same principles of self-organization. They argue that a focus on the local scale neglects consideration of more powerful, global scale processes that enable and constrain action in specific places. Another criticism of resilience in disaster management concerns the transferral of responsibility for risk from the state to communities, households, and individuals. Welsh (2014) notes that resilience approaches assume that communities can and should self-organize to manage risk, and that the role of government is limited to facilitating and supporting, rather than funding, these processes. Much resilience research has ignored questions of politics, governance, and the unequal distribution of power and resources in disaster preparedness and response (Cretney, 2014). Insufficient attention has also been paid to the value judgments that underpin resilience: what elements of the system should be protected, and for whom? (Handmer and Dovers, 1992; Davoudi, 2012). Weichselgartner and Kelman (2015) have questioned why people would want to "bounce back" to a situation that is anywhere near the original circumstances that produced their vulnerability. Despite these critiques, resilience persists as a core goal in international disaster management.

\section{The Resilience Goals of Disaster Management}

Resilience approaches aim to reduce the likelihood of disruption, damage, and death caused by disasters and enable communities to absorb change and recover quickly while exhausting the least amount of resources (United Nations International Strategy for Disaster Risk Reduction [UNISDR], 2009; Intergovernmental Panel on Climate Change [IPCC], 2012). But little consensus or formal clarity has been provided on the specific elements 
required for resilience or how to achieve them (Arbon, 2014; Neely, 2014; Goode et al., 2015). It is not our intention to review and translate all interpretations of resilience goals, nor to provide an alternative unifying consensus. Instead, we have identified common elements and goals of resilience found throughout previous interpretations, focusing on social resilience, institutional resilience, and community capital (Cutter et al., 2010), and elements most relevant to communities and individuals (as opposed to the natural environment, economics, or infrastructure). Factors deemed important for community disaster resilience were determined through examination and review of relevant resilience policy documents (e.g., United Nations International Strategy for Disaster Risk Reduction [UNISDR], 2005, 2015; Council of Australian Governments [COAG], 2011; Barnes et al., 2014), recent academic literature relating to community disaster resilience (e.g., Paton, 2006; Cutter et al., 2010; Renschler et al., 2010; Dufty, 2012; McLennan and Handmer, 2012, 2013; Taylor et al., 2012; Arbon, 2014; Neely, 2014; Goode et al., 2015), and through research experience of the authors gained via collaboration with DRR and community development units within formal emergency management organizations. For the purpose of this article, the contributions of VGI and digital volunteerism to community disaster resilience are summarized and discussed through the elements depicted in Figure 1.

\section{THE GOOD: POTENTIAL FOR VGI TO ENHANCE COMMUNITY RESILIENCE}

Resilience thinking recognizes that multiple environmental and social stressors influence a community's adaptive capacity, and different context-dependent factors will determine whether a community is adversely impacted by a hazard (Murphy, 2015). Numerous published articles in recent years describe the benefits of VGI in disaster management, particularly in crisis response, often implying (and sometimes boasting) that VGI aids in building community resilience. What follows in this section is a brief discussion of how VGI may contribute to enhancing each of the elements of community disaster resilience presented in Figure 1.

\section{Effective Communication}

Resilience is intimately associated with good communication, whereby two-way dialog delivers both resources to communities and intelligence regarding community needs to relevant agencies

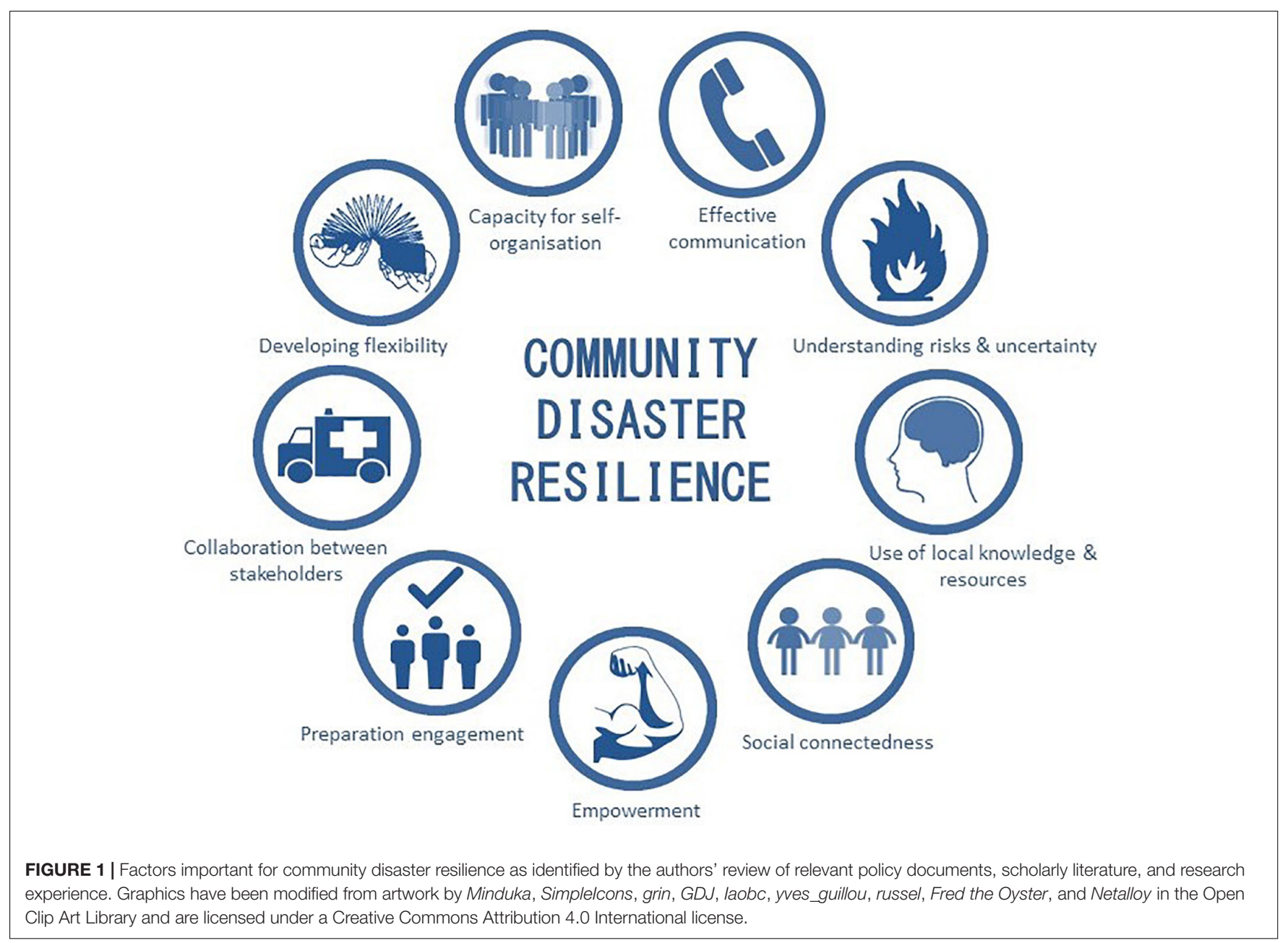


(Nicholls, 2012). The most effective disaster communication is locally relevant, so those at risk can access and act upon specific information about their household and risk reduction (Boon, 2014). Information transfer and knowledge networks, both formal and informal, required for resilience building, are dependent on effective communication. In a study of emergency management professionals in Australia, increased levels of communication were identified as the most significant opportunity presented by VGI (Haworth, 2016). Social media platforms, in particular, increase the speed and reach of communication between community members and emergency organizations, as demonstrated during the 2011 Cyclone Yasi and Queensland flood disaster (Taylor et al., 2012). Social media and other mechanisms for timely communication help spread important information, such as emergency warnings (Dufty, 2012), and are vital components of resilient communities (Nicholls, 2012). Further, online VGI platforms can reduce potential barriers to resilience building, including the inaccessibility of traditional communication forums, such as community meetings due to other commitments.

\section{Understanding Risks and Associated Uncertainty}

Increased awareness of local risk, hazards, and vulnerability shared through VGI enables individuals to make informed assessments about their individual and community preparation, planning, and likelihood of danger or damage. VGI through participatory mapping was useful for increasing risk awareness among youth in the Philippines (Gaillard and Pangilinan, 2010). Rather than simply trying to educate on risk through one-way communication, participatory mapping increases risk awareness and engagement in DRR by involving marginalized groups, valorizing their inputs, and materializing the hazard and risk as something personally relevant to the participants (Gaillard and Pangilinan, 2010).

Flanagin and Metzger (2008) report on the manifold increase in the number of information sources provided through social media and VGI. Research indicates that community perceptions and actions are influenced by exposure to risk and preparedness information, with Basolo et al. (2009) arguing individuals exposed to multiple sources of information may feel more knowledgeable about disaster preparedness. They found that receiving preparedness information from multiple sources was correlated with an individual taking protective actions.

\section{Local Knowledge and Resource Sharing}

The building and transmission of local knowledge ${ }^{2}$ has been associated with increased adaptive capacity in social-ecological

\footnotetext{
${ }^{2}$ The authors adopt a broad definition of "local knowledge" to mean any individual or collective knowledge possessed by local people for a particular location or community group, which may include, but is not limited to, knowledge of past events, indigenous knowledge, environmental and resource knowledge, and/or local social, economic, and political knowledge. Broadly, local knowledge is distinct from other forms of knowledge (i.e., scientific or professional) in that it typically derives from personal and lived experiences, and is often informal, tacit, and associated with shared values and histories (see Raymond et al., 2010; Giordano et al., 2013).
}

systems (Folke et al., 1998). Inclusion of local knowledge is crucial for increasing community disaster resilience (Council of Australian Governments [COAG], 2011; Giordano et al., 2013), and resilience-building strategies with an emphasis on local knowledge have positive impacts (Manyena, 2006). Yet, the integration of local and scientific knowledge to support disaster monitoring is not standard practice (Giordano et al., 2013). VGI has potential to facilitate increased collection, exchange, and use of local knowledge and resources in disaster management and resilience building. The ability of VGI to capture local observations and interpretations provides contextual data at fine spatio-temporal scales of relevance to communities that is otherwise unavailable in aggregate data. The merging of local knowledge and authoritative information sources can demonstrate differences in opinions and perspectives on risk or vulnerability, providing new insight for improving disaster planning. Participatory mapping can facilitate co-learning and encourage communication between stakeholders (Lynam et al., 2007). Giordano et al. (2013) demonstrated a participatory methodology for improving the usability of local knowledge from different stakeholders in analyzing drought impacts at Lake Trasimeno in Italy. Synthesis of knowledge from different sources allowed for identification of the impacts most relevant to local communities. Haworth et al. (2016) demonstrated both individual and community level benefits of community-based participatory mapping for bushfire disaster resilience, with participants reporting the personal relevance of shared knowledge and improved understanding of broader community bushfire risk and preparation levels as valuable to both community members and authorities.

\section{Social Connectedness}

Involvement in activities that engender a sense of community (feelings of belonging and attachment for people and places), efficacy, and problem solving, strengthen peoples' disaster-resilience (Paton and Johnston, 2001). Sense of community fosters involvement in community disaster response and increases access to social networks (Paton and Johnston, 2001). Well-connected communities are able to draw on internal resources and competencies that will allow them to manage the challenges of future hazards (Frandsen, 2012) and the role of VGI in fostering social connectedness is well documented (e.g., Taylor et al., 2012). The social aspect of VGI, with people collectively sharing geographic information, has been shown to be even more valuable for community DRR and resilience building than local knowledge (Haworth et al., 2016). Removing constraints of time or geography, social media have made it simpler to interact with community members (Dufty, 2012). Analysis of usage trends during response to cyclones and floods found social media directly contributed to increased disaster resilience through promoting connectedness, with individuals feeling supported and encouraged by others, and was identified as a source of psychological first aid for those directly and indirectly affected by the disaster (Taylor et al., 2012). Social media can increase and improve social networks, leadership and support systems, and provide support to people during and after a disaster (Dufty, 2012). Social capital in the form of trust and social networks is 
a recognized source of resilience, enabling a social-ecological system's capacity to adapt and shape change (Folke, 2006). Social media can preserve and strengthen existing ties and also facilitate the creation of new social relations (Dufty, 2012).

\section{Empowerment}

Volunteered geographic information promotes decentralization of top-down power held by disaster authorities and disrupts control over the production, handling, and dissemination of information (Haworth, 2016). McLennan and Handmer (2013) argue that for shared responsibility to be effective in developing community disaster resilience, control over decisions must also be shared. Through these shifts in control and power, citizens may become more empowered in their own disaster management decision-making, choices, and capacities.

Elwood (2002) framework for assessing three forms of empowerment associated with community-based participatory geographic information systems (GISs) can help to understand how VGI and social media can contribute to empowerment. The first element, distributive empowerment, relates to material changes and outcomes allied with greater access to goods and services and increased participation opportunities (Elwood, 2002). VGI has been shown to increase opportunities for public involvement in disaster management through tasks such as volunteer-mapping to assist with humanitarian aid efforts, including for individuals located outside the disaster location (e.g., Meier, 2012). Social media resources like Twitter have also empowered individuals with the desire to help in response to crisis events by enabling remote assistance provision (Starbird and Palen, 2011).

Procedural change involves shifts in processes resulting in communities' contributions and knowledge being granted greater legitimacy in decision-making (Elwood, 2002). Responding to the 2010 Haiti earthquake crisis, VGI and the global citizen-volunteer mapping effort harnessing OSM, the Ushahidi Crowdmap platform, social media data, and information collected via SMS from impacted individuals (see Meier, 2012; Crawford and Finn, 2015) influenced decision-making in an unprecedented way. In this event, and inspired cases since, VGI technologies and practices facilitated collection, use, and legitimation of citizen contributions in ways previously unseen, demonstrating capacity for VGI to support procedural dimensions of empowerment.

And finally, capacity building improves the ability of communities to take action on their own behalf through skill acquisition, community-based knowledge production, or new understandings of community conditions (Elwood, 2002). VGI empowers citizens to georegister and transmit their own observations through the Internet (Goodchild and Glennon, 2010) and provides mechanisms for empowering people to help themselves and each other, thus enhancing community autonomy and capacity for independence from emergency authorities for various tasks (e.g., Paton and Irons, 2016). Community-based knowledge production and new understandings of community conditions have been associated with VGI through participatory mapping in community bushfire preparation (Haworth et al., 2016). Similarly, Taylor et al. (2012) described the empowerment of individuals and communities to help themselves during cyclones and floods where social media delivered a new mechanism for connecting with others, which for many constituted skill acquisition.

\section{Preparation Engagement}

Individual and community disaster preparation to enable effective emergency response broadly involves both physical preparedness activities (e.g., making changes to the home, storing emergency supplies, identifying safe areas) and psychological processes (e.g., formulating household plans, engaging with neighbors, considering how one might feel, or be affected emotionally during and after a crisis) (Frandsen, 2012). Frandsen (2012) demonstrated that community engagement is an effective, sustainable, and economical approach to increasing bushfire preparedness and disaster resilience. However, merely providing relevant information and community education doesn't translate to meaningful engagement in disaster preparation (Lindell and Perry, 2000; McGee, 2005; Frandsen et al., 2011; McFarlane et al., 2011). Engaged preparation is dependent on inclusive and participatory approaches to DRR (Frandsen et al., 2011).

Volunteered geographic information provides diverse mechanisms for individuals to engage in DRR at multiple spatial scales. For example, global mapping efforts like the Humanitarian OpenStreetMap Team (HOT) utilize volunteers to co-create, curate, and disseminate free and up-to-date spatial information for disaster management ${ }^{3}$. These projects involving map creation for disaster preparedness (e.g., Malawi Flood Preparedness) harness the potential of the crowd, allowing large numbers of people to engage, improving broader disaster awareness, and increasing feelings of self-worth for contributors. The activities also provide geospatial products to assist local people and authorities to effectively engage in DRR. Although collaborative online mapping provides greater flexibility for individual involvement by removing geographical and temporal constraints (Haworth et al., 2016), participatory mapping through less technologically sophisticated platforms, such as paper sketch maps and three-dimensional maps using pushpins, have also been demonstrated to contribute to engagement in DRR (Gaillard and Pangilinan, 2010).

\section{Collaboration Between Stakeholders}

Collaborative disaster management is recognized as an important contributor to resilience but requires coordination and pre-existing trust between multiple government agencies, NGOs, private sector, and the community (Kapucu, 2008). Through VGI technologies and practices, opportunities are created for collaborative disaster management between individuals, communities, and authorities, where increased value placed on citizen-information and bottom-up activities can lead to co-operation.

The 2010 Haiti earthquake disaster, which occurred with a dearth of official high-quality spatial information, saw the emergence of crowdsourced and volunteered mapping to meet the needs of the humanitarian response (see Meier, 2012).

\footnotetext{
${ }^{3}$ https://hotosm.org
} 
Volunteers used OSM and the Ushahidi platform, Crowdmap, to trace satellite imagery, collate information from other online sources, and capture reports from people directly in the disaster area via SMS from mobile phones (Meier, 2012). Here, VGI created a new disaster response paradigm in which citizens (in this case largely citizens from other countries) take the lead (Levental, 2012), or at least complement the activities of authorities (Heinzelman and Waters, 2010), in emergency operations with consequences for disaster management globally.

\section{Developing Flexibility}

A resilient system must be flexible to avoid undesirable transformation (Allison and Hobbs, 2004), with inflexibility eroding adaptive capacity and leading to what have been termed "rigidity traps" (Carpenter and Brock, 2008). In a "rigidity trap," strong self-reinforcing controls prevent the flexibility required for systems to adapt to change, thereby increasing the risk of system breakdown (Carpenter and Brock, 2008) and preventing movement to a more desirable regime if the current state becomes untenable. A potential rigidity trap lies in the top-down, "command and control" style of authoritative emergency management. The hierarchical, bureaucratic approach of emergency management, centered on agency control of information, risks limiting resilience through inflexibility and an inability to adapt to change. Web 2.0 and VGI assist in deconstructing this rigid system by redistributing power over information creation and sharing among other stakeholders, including private individuals (Haworth, 2016). Through VGI, people are able to contribute alternative representations of and responses to risk, increasing flexibility in the system with diversity of information.

For instance, social media provided flexibility in crisis communication for earthquakes in Japan and Haiti, bombings in India, and severe storms in North America and Australia, particularly when power and telecommunications were disrupted. Sites like Facebook and Twitter became more reliable with robust capacity to handle much larger activity volumes than other services (Yates and Paquette, 2011; Bird et al., 2012). Through exposing people to new ways of doing things, VGI and social media can add to future flexibility and resilience by improving citizens' ability to be agile in other contexts.

Inclusion of alternate viewpoints enabled by VGI through participatory mapping can lead to greater flexibility incorporated into decision-making over disaster planning and response strategies. For example, local knowledge shared on a community preparation map showing potential evacuation sites may reveal alternative and improved site options to those designated by authorities. Participatory mapping provides an enabling environment for assessing risks, identifying solutions, and the integration of various strategy options into action plans (Cadag and Gaillard, 2012), and thus aids in building flexibility into community and authoritative disaster management.

\section{Capacity for Self-Organization}

The Internet and mobile devices are empowering individuals to organize themselves in ways previously unimaginable, as evidenced by activities such as Wikileaks, Twitter, and citizen journalism, or the formation of spontaneous volunteering groups like the Student Volunteer Army in response to the 2011 Christchurch earthquake (Neely, 2014). Social media platforms provided a space for volunteers to mutually self-organize with others in sharing information and resources in response to the 2010 Haiti earthquake (Starbird and Palen, 2011) and bushfires in Australia in 2013 (Irons et al., 2015), where VGI enabled a form of self-sufficiency and self-responsibility in sharing and coordinating people and resources previously not possible through more traditional disaster response approaches or communication media. A capacity for self-organization is particularly important in disaster management, where citizen-led initiatives are often more timely, responsive to local needs, and effective over the longer term than external responses (Scanlon et al., 2014; Whittaker et al., 2015).

\section{THE BAD: POTENTIAL FOR VGI TO UNDERMINE COMMUNITY RESILIENCE}

Next we shift focus to the challenges presented by VGI for resilience-building in disaster management, which have potential to lead to undesirable action or erode a community's capacity to adapt to the inherent uncertainty associated with living in high risk areas.

\section{Compounding Risk}

It is important to consider the compounding processes in which VGI practices may exacerbate disaster risk and the consequences for disaster response planning and resourcing. VGI initiatives with recognized benefits can also provide mechanisms for precipitating other events with potentially negative consequences. For example, in January 2013, a request for help posted on the Tassie Fires We Can Help (TFWCH) Facebook page (established by a community member to coordinate the sharing of information and resources related to a bushfire emergency in Tasmania, Australia) identified several people who had become isolated and needed supplies delivered (Australian Broadcasting Corporation [ABC], 2013). The only access route was via boat across open water. In response to the Facebook post, hundreds of people gathered together geographically with donated goods, and 35 boats were involved in delivering supplies (Australian Broadcasting Corporation [ABC], 2013). But when water conditions became dangerous, several boats required rescuing, thus diverting emergency response efforts and resources. In this instance, VGI practices triggered unsafe actions and increased the risk of harm to VGI users and others.

During the Parliament Hill shooting crisis in Ottawa in 2014 social media posts unintentionally endangered others (Zoltick, 2014). It was reported that individuals geotagged at the scene were tweeting live about the events as they unfolded to indicate they were safe and to keep people informed. This practice publicized their locations as well as the location of police response activities for potential exploitation by the then still-active gunman. These practices also have liability implications for emergency response agencies potentially 
acting on misinformation (see the section "Responsibility for Community-Led Initiatives").

\section{Data Quality and Trust}

Data quality is a recognized challenge associated with VGI, including elements such as positional accuracy and content inaccuracies (see Ostermann and Spinsanti, 2011; Bird et al., 2012; Goodchild and Li, 2012; Haworth, 2016; Senaratne et al., 2017). During the Haiti earthquake response, locational uncertainty constrained the publishing of reports on Crowdmap to just 3,854 of the 15,000-60,000 reports collected (Morrow et al., 2011) and only 202 of those published reports were marked as "verified" (Heinzelman and Waters, 2010). In the 2011 Queensland floods Crowdmap, 75\% of reports were verified by the map conveners, but many of these had been submitted by identifiable organizations, and, significantly, anonymous individuals were responsible for almost all of the unverified messages (Bittner et al., 2016). Pond (2016) argues that treating verification of crowdsourced data as a binary variable (verified or unverified) on platforms such as Ushahidi may limit the quantity of information that can be used for situational awareness. There is a need to consider the cognitive dimension of uncertainty and how perceptions of reported accuracy translate in decision-making processes (Bruce, 2004). Alternative approaches for communicating data uncertainty extending beyond standard authentication criteria for determining "truthfulness" and categories of data verification would allow the context-specific value of the information to be judged by end users. Methods for qualifying VGI-derived data, which are informed by the communities relying on those data, would not restrict the publishing of crowdsourced reports to those considered by "experts" as verified and would engage people in critical assessment of data sources as part of the disaster preparation process. Although this will assume a level of data literacy that may not always be present in end users such as responders, journalists, or the general public.

There is also potential for people to intentionally share information that is false or misleading, particularly through social media platforms, with demonstrated implications for disaster management (Mendoza et al., 2010), responses to terror incidents (Starbird et al., 2014), and financial markets (Rapoza, 2017). Vosoughi et al. (2018) studied news stories distributed on Twitter from 2006 to 2017 and found that false information diffused farther, faster, deeper, and more broadly than true information, although effects were stronger for false political news than for news related to terrorism or disasters ${ }^{4}$. Gupta et al. (2013) studied the role of Twitter in spreading fake images during Hurricane Sandy, such as images of sharks swimming in flooded motorways. They found that most (86\%) of the tweets spreading fake images were retweets (as opposed to original tweets) by a very small proportion $(.3 \%)$ of Twitter users. While some research exists on classifying, measuring, and filtering false information, further work is needed to elucidate why people are motivated to share

\footnotetext{
${ }^{4}$ The authors adopt a broad definition of "news," which refers to any story or claim with an assertion in it. News was classified as true or false using information from six independent fact-checking organizations that exhibited $95-98 \%$ agreement on classifications (see Vosoughi et al., 2018).
}

misinformation and to comprehend the wider implications of this behavior for community disaster resilience.

For resilience, uncertainties in data quality and source trustworthiness have important implications. Trust is important for social capital and is necessary for individuals to engage with collective activities, such as community or neighborhood groups, either online or offline (Valenzuela et al., 2009). Much of the uncertainty around VGI is due to a lack of known credibility of information sources and, therefore, trust (Flanagin and Metzger, 2008; Hung et al., 2016; Haworth, 2018). Low levels of trust in information provided by the general public were a rationale for Tasmanian community members' limited willingness to engage on social media for bushfire communication (Haworth et al., 2015). Public perceptions of community-supplied information on Facebook during flooding events revealed VGI was more up-to-date than government information, but was considered less accurate and less trustworthy (Bird et al., 2012).

If trust in VGI is nurtured, for example through past positive experiences, future complications may arise if an initiative is not sustainable, platforms are not maintained, past key individuals are absent, or a community becomes reliant on a single system. If people expect a particular previous source of VGI (e.g., a Crowdmap or social media page) to be present this may cause tensions in communities, disappointment, or anxiety, all of which negatively impact elements of community resilience, such as social capital, empowerment, and individual and community confidence. Further, precedence does not necessarily equate to perceived reliability or future proof VGI initiatives.

Exposure to VGI and social media could be embedded in disaster preparedness programs, involving techniques for using, interpreting, evaluating, and contributing content to these platforms, and management of issues of data quality and trust. Encouraging learning and flexibility to engage effectively in these new technologies when confronted with a disaster event would strengthen community and individual resilience.

\section{Under-Representing the "Crowd"}

Due to the phenomenon of participant inequality (Haklay, 2016) we argue that VGI does not provide adequate opportunity for inclusive community participation. VGI inherently discriminates based on technology access and usage patterns associated with demographics, socioeconomic circumstances, and technical skills, knowledge, and interest (see the "digital divide"; Chinn and Fairlie, 2007; Sui et al., 2013). It is also important to remember that the platforms and tools used for VGI data collection and analysis have traditionally been created by an elite technology industry dominated by mainly Western men. As such, just as critical GIS has highlighted, "the uneven spatial distribution of technologies across the globe suggests an uneven representativeness of participation in the determination of how those technologies will be developed" (Burns, 2014, p. 3). Thus, the marginalized are under-represented in VGI and the tools and modes of data collection and analysis. Information gained through social media or other VGI sources will therefore only present partial and skewed representations (Crawford and Finn, 2015; Klonner et al., 2016; Haworth, 2018). Exclusion of some groups and individuals (Zook et al., 2010; Burns, 2015) means 
VGI practices may operate at the detriment of resilience building for some community members.

We must consider who can and does contribute VGI (and who creates the platforms they rely on). Bittner et al. (2016) critique the idea that crisis maps are the product of "ordinary citizens" pooling their expertise. VGI often represents the elite over the ordinary, as only those people with time, access to necessary social and technological systems, and required skills are able to contribute (Bittner et al., 2016). Less privileged individuals may be unable to participate, thus being excluded from the resilience-building benefits of VGI. Marginalized groups and individuals are often not represented on maps, and, particularly troubling for resilience, those people already marginalized are often the most vulnerable to disasters (Hewitt, 1997), especially since preparedness information is often not directed at vulnerable groups (Verrucci et al., 2016). Echoing critiques in the mid-1990s of the uneven community access to GIS technologies (e.g., Sawicki and Craig, 1996) as well as critique of participatory GIS in the 2000s (Elwood, 2006), Haworth (2018) recognizes the importance of understanding barriers to participation in community applications of VGI, and Burns (2018) urges us to recognize the social and political imbalances of big data, understanding that representations of the "real world" in data are rooted in spatial inequalities.

Volunteered geographic information may in fact enhance existing inequalities and vulnerabilities by further isolating those already economically, socially, or technologically disadvantaged, as has also been described for other technologies such as mobile phones (Read et al., 2016). Crawford and Finn (2015) showed how the crowdmapping efforts of the Haiti earthquake response exacerbated power differentials between the rich and the Haitian poor as VGI submitted in the local Kreyòl language was mapped in English only, excluding non-English speakers from benefiting from their own contributions. Thus, VGI curation practices and who is responsible may impact what is included in "ordinary voices" (Bittner et al., 2016). Furthermore, the geography of technology access has been linked with the geography of risk, whereby those in urban areas with greater Internet access also experience lower disaster risk in contrast to those in rural or isolated areas with poor Internet and mobile coverage but potentially greater disaster risk (Haworth, 2016). Even those with stable Internet access may have their contributions limited through forms of online censorship, language barriers, or page ranking algorithms, and hence in disaster scenarios VGI may represent only a privileged minority (Bittner et al., 2016).

The nature and characteristics of the "offline community" may also influence participation in an "online community," particularly for social media, potentially limiting resilience building. For example, differences between urban and rural environments, whereby sense of community has been shown to be greater in rural communities, positively associated with social joining and negatively related to antisocial actions (Roussi et al., 2006), may impact online participation in more dispersed city communities, reducing the number of people who view, let alone contribute specific VGI together, undermining potential benefits such as increased social connectedness. This coupled with geographic disparities in Internet access further distorts the picture of who VGI actually represents and in what capacity (i.e., as passive viewers, information recipients, contributors). Further, it has been shown that strong offline community groups do not necessarily translate online, being unable to attract large numbers of friends and followers, with key stakeholders remaining passive in social media networks like Twitter (Williamson and Ruming, 2015). It has also been argued that VGI activities may be most useful for DRR at local community scales (Haworth, 2018).

Critiques of public participation GIS (PPGIS), where complexity of the technologies can contribute to marginalization of individuals contrary to the promise of citizen-empowerment (Corbett and Keller, 2005), also apply to VGI. Use of technologies required for participation in VGI practices, such as computers, the Internet, smartphones, social media platforms, location enabled mobile devices, satellite imagery, and online map-making software may result in a technological learning curve effect that precludes "non-experts," potentially negatively impacting community disaster resilience with some people disproportionally benefiting while others are left off the maps.

\section{Compromised Privacy and Security}

The focus on community empowerment and democratic participation in much of the geoweb and VGI narrative has tended to equate power with public visibility and neglected to consider the potential for exploitation of VGI-derived data by external groups (Young and Gilmore, 2014). VGI is often publically available once contributed, potentially increasing vulnerability and risk exposure. Contributors' information may be exposed to unintended uses, either by governments, companies, other individuals, or those with malicious intent. Greater openness exposes users to increased online security threats, such as malware, inappropriate content, and breaches of confidential information (Shanley et al., 2013).

Many people are not confident in their understanding of how and by whom their data can be accessed (Crawford and Finn, 2015). Moreover, in high-stress situations like disasters privacy may be less of a priority for individuals than in "normal" settings, and thus individuals may be increasingly vulnerable (Crawford and Finn, 2015). Lack of awareness of VGI features, such as image geotags captured from GPS-enabled smartphones, has had demonstrable implications for privacy, personal safety, and the protection of assets (Kruszelnicki, 2012). As data remain on the Internet after their initial use and can be repurposed in other ways, privacy and ethical issues persist into the future (Shanley et al., 2013). While some digital humanitarian initiatives have been designed to protect identities (e.g., the Libya Crisis Map; Meier, 2012), further critical research on ethical and technical dimensions is needed to establish methods for acquisitioning the value of geoweb-enabled platforms for disaster-prone communities while maintaining their privacy and security (Young and Gilmore, 2014).

\section{Increased Community Tensions}

Tension within communities generated or exacerbated by mapping activities or outcomes can undermine the resilience of disaster-prone communities. The TFWCH example in which 
well-intended vessel owners responded to a VGI-enabled request for assistance highlights the potential for serious negative outcomes and resultant tensions between those involved. Although facilitating capacity for self-organization, the outcomes of poorly orchestrated logistical response actions such as this may lead to feelings of blame and resentment; community ties could be broken, thus reducing community disaster resilience. Carroll et al. (2006) examined sources of social conflict following wildfires in the American West, finding that conflict can occur when social relations are disturbed by non-local entities, leading to a perceived loss of local agency. VGI can facilitate greater participation of "outsiders" in community responses to disaster, and therefore creates potential for increased community tension or conflict.

Using VGI and participatory mapping for disaster preparation can involve the identification of particular residents, properties, or areas as unprepared or problematic in the wider community context. This process may motivate residents to improve their level of preparedness, but may also provoke feelings of shame, guilt, or resentment toward those involved in the mapping. A sense of inadequacy in meeting the standards of others more actively engaged in DRR may weaken community connectedness and reduce an individual's confidence in their ability to respond to disaster. Furthermore, VGI contributions may disclose personal or sensitive information unrelated to disaster potentially leading to tension.

Capacity to participate varies depending on status and position within the networks producing maps (Bittner et al., 2016). Therefore, VGI in disaster management is linked to the wealth, class status, community connections, reputation, politics, and power of particular community members. Disparities between individuals may be highlighted or aggravated by who can and cannot contribute. Berkes and Ross (2013) argue that a community resilience approach that integrates socio-ecological systems research and developmental psychology would give greater recognition to the importance of the ability to cope with divisions within community (Kulig, 2000 as cited in Berkes and Ross, 2013) and key resilience dimensions of community resources and collective action.

\section{Responsibility for Community-Led Initiatives}

Community-led VGI initiatives promote resilience benefits, including a sense of ownership and power, and foster innovation and projects that work for specific communities. But with ownership also comes responsibility and expectations, including project establishment, site/platform maintenance, and data management. Community-led social media pages, community maps, or other VGI initiatives require some knowledge and expertise in use of these technologies, and individuals with some level of autonomy and community trust who can champion these efforts. Not all communities will have access to this social capital - a further limitation to the broader social inclusiveness potential of VGI. In addition to knowledge and technological skills, responsibility for VGI project and data maintenance also requires considerable time and resources, which may become burdensome leading to volunteer fatigue (Deutsch and RuizCórdova, 2015), thus reducing community connectedness and disaster resilience.

Failure or abandonment of VGI initiatives when contributions cease, or if the responsible personnel change or leave, can have consequences. It is important to anticipate potential turnovers which may lead to the abandoning of map updates or shifts in objectives or data use (Gaillard and Maceda, 2009). The sustainability of a small-scale bushfire risk mapping project across Australia, Bushfire Connect, was dependent on not only the sustainability of the volunteers, but the relationship of these volunteers with supportive emergency management professionals and how the participating/viewing public regarded the project and outputs, which ultimately affected its long-term viability (Bittner et al., 2016).

In line with shared responsibility, organizations and communities could work together on VGI initiatives in fostering community disaster resilience. However, consideration needs to be given to well-documented obstacles associated with agency involvement in participatory style mapping projects. These include undervaluing of community input, regularity barriers, unpredictability associated with public activities, lack of effective administrative structures, and lack of genuine community participation (Corbett and Keller, 2005; Brown, 2012). Further research is needed on the social learning value of community-led VGI initiatives, and community preparedness efforts will benefit from dissemination of positive outcome stories, a strategy known to aid in reducing barriers to participatory approaches such as volunteer dropout (Deutsch and Ruiz-Córdova, 2015).

\section{Disruptions to Authoritative Emergency Management}

The potential for VGI practices to disrupt official disaster management activities can reduce resilience in impacted or at-risk communities. Public trust gained for social media pages or VGI contributions for a disaster event presents the risk that the public will give precedence to these information sources over official disaster information. Disaster messaging is designed to be clear, concise, and consistent to provide the public with accurate and understandable information for given scenarios. Deviations from this messaging can be detrimental to community safety. Further, the accelerated rate of information exchange enabled by social media and VGI during an event may become incompatible with the logistics involved in coordinating response activities (Pond, 2016). Public preference for multiple disaster information sources emphasizes that VGI should not aim to replace more traditional forms of disaster communication (Taylor et al., 2012; Haworth et al., 2015). A balance between bottom-up and top-down practices needs to be maintained where appropriate value is procured from both systems for effective resilience development.

\section{The Limits of Data as Knowledge}

As has been noted, "data is not knowledge, nor is it capacity to analyse it" (Read et al., 2016, p. 1315). In order for VGI to contribute to building individual and community disaster 
resilience, it is important to recognize the blind spots and limitations of dominant ways of thinking about data. One of the key issues is practical; that the capacity to increase the amount of information collected about disasters through VGI and other crowdsourcing techniques has grown faster than the concurrent increase in the capacity to analyze that information, in many cases. This can lead to an expectations gap, where people believe sharing information in disasters will lead directly to receiving aid, when capacity to respond may not match demand. It also invites a focus on the new and novel in regards to data, often driven by advances in technology not response to need (Read et al., 2016), which can exacerbate the problems identified in the section "Responsibility for Community-Led Initiatives" around maintenance of platforms and ownership of data.

Additionally, increased and increasingly diverse data, which VGI offers, invite more technological solutions to the problem of analyzing those data. The computational techniques which define these new data forms (Boyd and Crawford, 2012), far from automatically empowering affected communities, can make possible the governance of disaster at a distance, through a reliance on "a cybernetic rationality" that "eschews causality or a need to acknowledge the motives and beliefs that shape actual behaviour" (Duffield, 2016, p. 147). The resilience that these developments offer is not progressive but a "case of survivalism through encouraging improvisation, making do, and inventive bricolage with existing communications infrastructure, architecture and social capital" (Duffield, 2016, p. 148). From this perspective, the optimism around both VGI and resilience is bound up with neoliberalism which "rework[s] disasters as a positive development opportunity" which requires communities experiencing disasters to take responsibility for their recovery (Duffield, 2016, p. 153).

Instead of leading to a growth in the inclusion of local knowledge, there is the potential for a loss of "ground truth" (Duffield, 2014) and a reliance on technological forms which, drawing on financial modeling and intelligence analysis are "concerned with rendering perceptible and actionable that which would otherwise be beyond the threshold of human observation" (Amoore, 2018, p. 1). This has contributed to what Burns (2014) describes as "moments of closure" through a fixing of the politics of knowledge in which these new technologies privilege and encode as more legitimate certain data forms and a "cybernetic rationality" (Halpern, 2015). This sediments a system in which data that can be analyzed computationally are privileged, and so too are those who have the skills to analyze it, undermining the valuing of local knowledge and knowledge exchange which, as earlier sections noted, have been cited as key to building community disaster resilience.

\section{THE UNCERTAIN: AREAS FOR FURTHER RESEARCH}

The application and relevance of emergent VGI practices to building community resilience require continuing critical debate involving disaster-prone communities, researchers, practitioners, and policy makers. Drawing on recent literature and policy documents, we considered key elements of resilience to examine the community disaster resilience-building potential of VGI practices, and obstacles that may undermine resilience-building processes. In this concluding section, we focus on areas of uncertainty where we perceive further work is needed. In doing so, we discuss various points of relevance to both practice-based disaster management and the disciplines of geography and disaster management.

Although beyond the scope of this paper, indicators and frameworks have been offered for measuring community resilience (Cutter et al., 2010; Renschler et al., 2010). Future work to examine the impacts of VGI practices on resilience through alignment with these indices may clarify, for example, whether the increased risk to personal safety and issues associated with the digital divide outweigh the potential benefits of VGI, such as community connectedness and risk awareness.

The evolving and relatively embryonic nature of VGI in disaster management means practical adoption of VGI into current emergency management approaches has been limited to date and harnessing of VGI has often been ad hoc or opportunistic. Despite a growing body of literature (Goodchild and Glennon, 2010; Ostermann and Spinsanti, 2011; Bird et al., 2012; Dufty, 2012; Meier, 2012; Taylor et al., 2012; Shanley et al., 2013; Paton and Irons, 2016; Pond, 2016; Haworth, 2018) and identified opportunities associated with VGI, on-going cultural change involving adaption by authoritative emergency management to less information control and increased citizen participation may be required before VGI in disaster management becomes a more established field with measurable outcomes for community disaster resilience.

With much research on the data and technological components (Granell and Ostermann, 2016), the social and behavioral elements of VGI are lacking critical analyses; directing greater attention to issues such as underrepresentation of the "crowd" and the nuances of power relations in online and offline social networks will build confidence in VGI as a resource in developing community resilience. Further research on the ethical and technical dimensions of VGI practices is required to inform the development of novel methods for maintaining the privacy and security of disaster-prone communities. Incorporating awareness and training on collaborative geoweb technologies, including data ethics, effective VGI practice, and potential digital footprint, into community preparedness programs will equip individuals to make informed judgments on VGI content during a disaster event and reduce unintended consequences of social media initiatives.

The positioning of VGI within critical GIS has been contested (McCall et al., 2015), but drawing on established approaches to community mapping from within the discipline of geography, such as PPGIS or participatory mapping (Brown and Fagerholm, 2015), may offer promise for understanding the social and behavioral elements of VGI and confining the use of VGI technologies to spatial scales most conducive to achieving the aim of increased community disaster resilience. By establishing which elements of VGI should be emphasized and which require careful management, a form of "controlled" or "facilitated" VGI at community scales with pre-established data systems, protocols, 
intended outcomes, and appropriate links to authoritative emergency management may be implemented. This can enable VGI in disaster management to be less opportunistic, data-centric, disruptive to authoritative activities and exclusionary, and allow for more reliable, community-centric, complementary, and socially inclusive practices. Recognition of the consequences of these divergent outcomes is critical for ensuring effective resilience strategies that encourage flexibility to cope with disaster, self-organizing responses, and inclusive participation.

\section{AUTHOR CONTRIBUTIONS}

$\mathrm{BH}$ was responsible for defining the research aims, collating and reviewing the literature and previous research for the discussion, conceptualizing the article structure, writing the manuscript

\section{REFERENCES}

Allison, H. E., and Hobbs, R. J. (2004). Resilience, adaptive capacity, and the "lock-in trap" of the Western Australian agricultural region. Ecol. Soc. 9:3. doi: 10.5751/ES-00641-090103

Amoore, L. (2018). Cloud geographies: computing, data, sovereignty. Prog. Hum. Geogr. 42, 4-24. doi: 10.1177/0309132516662147

Arbon, P. (2014). Developing a model and tool to measure community disaster resilience. Aust. J. Emerg. Manag. 29, 12-16.

Australian Broadcasting Corporation [ABC] (2013). Australian Story: Irons in the Fire. PROGRAM TRANSCRIPT. Available at: http://www.abc.net.au/austory/ content/2012/s3803164.htm

Barnes, P., Bergin, A., and Nichola, D. (2014). Working as one: A Road Map to Disaster Resilience for Australia. Special report, SR73. Canberra, ACT: The Australian Strategic Policy Institute. doi: 10.1177/001391650831 7222

Basolo, V., Steinberg, L. J., Burby, R. J., Levine, J., Cruz, A. M., and Huang, C. (2009). The effects of confidence in government and information on perceived and actual preparedness for disasters. Environ. Behav. 41, 338-364. doi: 10. $1177 / 0013916508317222$

Berkes, F., and Ross, H. (2013). Community resilience: toward an integrated approach. Soc. Nat. Resour. 26, 5-20. doi: 10.1080/08941920.2012.736605

Bird, D., Ling, M., and Hayes, K. (2012). Flooding Facebook - the use of social media during the Queensland and Victorian floods. Aust. J. Emerg. Manag. 27, 27-33.

Bittner, C., Michel, B., and Turk, C. (2016). Turning the spotlight on the crowd: examining the participatory ethics and practices of crisis mapping. ACME 15, 207-229.

Boon, H. (2014). Investigating rural community communication for flood and bushfire preparedness. Aust. J. Emerg. Manag. 29, 17-25.

Boyd, D., and Crawford, K. (2012). Critical questions for big data. Inf. Commun. Soc. 15, 662-679. doi: 10.1080/1369118X.2012.678878

Brown, G. (2012). Public participation GIS (PPGIS) for regional and environmental planning: reflections on a decade of empirical research. URISA J. 25, 7-18.

Brown, G., and Fagerholm, N. (2015). Empirical PPGIS/PGIS mapping of ecosystem services: a review and evaluation. Ecosyst. Serv. 13, 119-133. doi: 10.1016/j.ecoser.2014.10.007

Bruce, E. (2004). "Spatial uncertainty in marine and coastal GIS," in GIS for Coastal Zone Management, eds D. Bartlett and J. Smith (Boca Raton, FL: CRC Press), 51-62.

Burns, R. (2014). Moments of closure in the knowledge politics of digital humanitarianism. Geoforum 53, 51-62. doi: 10.1016/j.geoforum.2014.02.002

Burns, R. (2015). Rethinking big data in digital humanitarianism: practices, epistemologies, and social relations. GeoJournal 80, 477-490. doi: 10.1007/ s10708-014-9599-x draft, and figure conception and execution. EB and JW jointly agreed upon the research objectives; provided supportive analyses and interpretations; and contributed, reviewed, and edited text. $\mathrm{RR}$ contributed and edited text, and critically reviewed the article aims, analyses, and discussion.

\section{FUNDING}

The Bushfire and Natural Hazards Cooperative Research Centre (Australia) supported parts of this research.

\section{ACKNOWLEDGMENTS}

We thank the journal editors and reviewers for their constructive feedback and support.

Burns, R. (2018). Datafying disaster: institutional framings of data production following Superstorm Sandy. Ann. Am. Assoc. Geogr. 108, 569-578. doi: 10. 1080/24694452.2017.1402673

Burnside-Lawry, J., Akama, Y., and Rogers, P. (2013). Communication research needs for building societal disaster resilience. Aust. J. Emerg. Manag. 28, 29-35.

Cadag, J. R. D., and Gaillard, J. C. (2012). Integrating knowledge and actions in disaster risk reduction: the contribution of participatory mapping. Area 44, 100-109. doi: 10.1111/j.1475-4762.2011.01065.x

Carpenter, S. R., and Brock, W. A. (2008). Adaptive capacity and traps. Ecol. Soc. 13, 40. doi: 10.5751/ES-02716-130240

Carpenter, S. R., and Gunderson, L. H. (2001). Coping with collapse: ecological and social dynamics in ecosystem management. BioScience 51, 451-457. doi: 10.1641/0006-3568(2001)051[0451:CWCEAS]2.0.CO;2

Carroll, M. S., Higgins, L. L., Cohn, P. J., and Burchfield, J. (2006). Community wildfire events as a source of social conflict. Rural Sociol. 71, 261-280. doi: 10.1526/003601106777789701

Chinn, M., and Fairlie, R. (2007). The determinants of the global digital divide: a cross-country analysis of computer and internet penetration. Oxford Econ. Pap. 59, 16-44. doi: 10.1093/oep/gpl024

Collier, W. M., Jacobs, K. R., Saxena, A., Baker-Gallegos, J., Carroll, M., and Yohe, G. W. (2009). Strengthening socio-ecological resilience through disaster risk reduction and climate change adaptation: Identifying gaps in an uncertain world. Environ. Hazards 8, 171-186. doi: 10.3763/ehaz.20 09.0021

Corbett, J. M., and Keller, C. P. (2005). An analytical framework to examine empowerment associated with participatory geographic information systems (PGIS). Cartographica 40, 91-102. doi: 10.3138/J590-6354-P38V4269

Council of Australian Governments [COAG] (2011). National Strategy for Disaster Resilience: Building our Nation's Resilience to Disasters. Available at: https://www.coag.gov.au/sites/default/files/national_strategy_disaster_ resilience.pdf

Craglia, M., Ostermann, F., and Spinsanti, L. (2012). Digital Earth from vision to practice: making sense of citizen-generated content. Int. J. Dig. Earth 5, 398-416. doi: 10.1080/17538947.2012.712273

Crawford, K., and Finn, M. (2015). The limits of crisis data: analytical and ethical challenges of using social and mobile data to understand disasters. GeoJournal 80, 491-502. doi: 10.1007/s10708-014-9597-z

Cretney, R. (2014). Resilience for whom? Emerging critical geographies of socio-ecological resilience. Geogr. Compass 8, 627-640. doi: 10.1111/gec3. 12154

Cutter, S., Burton, C., and Emrich, C. (2010). Disaster resilience indicators for benchmarking baseline conditions. J. Homel. Secur. Emerg. Manag. 7, 1-24. doi: $10.2202 / 1547-7355.1732$

Davoudi, S. (2012). Resilience: a bridging concept or a dead end? Plan. Theory Pract. 13, 299-233. doi: 10.1080/14649357.2012.677124 
Deutsch, W. G., and Ruiz-Córdova, S. S. (2015). Trends, challenges, and responses of a 20-year, volunteer water monitoring program in Alabama. Ecol. Soc. 20:14. doi: 10.5751/ES-07578-200314

Duffield, M. (2014). From immersion to simulation: remote methodologies and the decline of area studies. Rev. Afr. Polit. Econ. 41, S75-S94. doi: 10.1080/03056244. 2014.976366

Duffield, M. (2016). The resilience of the ruins: towards a critique of digital humanitarianism. Resilience 4, 147-165. doi: 10.1080/21693293.2016.1153772

Dufty, N. (2012). Using social media to build community disaster resilience. Aust. J. Emerg. Manag. 27, 40-45.

Elsworth, G., Gilbert, J., Rhodes, A., and Goodman, H. (2009). Community safety programs for bushfire: what do they achieve, and how? Aust. J. Emerg. Manag. $24,17-25$.

Elwood, S. (2002). GIS use in community planning: a multidimensional analysis of empowerment. Environ. Plan. A 34, 905-922. doi: 10.1068/a34117

Elwood, S. (2006). Critical issues in participatory GIS: deconstructions, reconstructions, and new research directions. Trans. GIS 10, 693-708. doi: 10.1111/j.1467-9671.2006.01023.x

Elwood, S., Goodchild, M. F., and Sui, D. (2012). Researching volunteered geographic information: Spatial data, geographic research, and new social practice. Ann. Assoc. Am. Geogr. 102, 571-590. doi: 10.1080/00045608.2011. 595657

Flanagin, A., and Metzger, M. (2008). The credibility of volunteered geographic information. GeoJournal 72, 137-148. doi: 10.1007/s10708-008-9188-y

Folke, C. (2006). Resilience: the emergence of a perspective for social-ecological systems analyses. Glob. Environ. Change 16, 253-267. doi: 10.1016/j.gloenvcha. 2006.04.002

Folke, C., Berkes, F., and Colding, J. (1998). "Ecological practices and social mechanisms for building resilience and sustainability," in Linking Social and Ecological Systems, eds F. Berkes and C. Folke (London: Cambridge University Press), 414-436.

Frandsen, M. (2012). Promoting Community Bushfire Preparedness: Bridging the Theory-Practice Divide. Doctoral dissertation, University of Tasmania, Tasmania.

Frandsen, M., Paton, D., and Sakariassen, K. (2011). Fostering community bushfire preparedness through engagement and empowerment. Aust. J. Emerg. Manag. 26, 23-30.

Gaillard, J. C., and Maceda, E. A. (2009). Participatory three-dimensional mapping for disaster risk reduction. Particip. Learn. Action 60, 109-118.

Gaillard, J. C., and Pangilinan, M. L. C. J. D. (2010). Participatory mapping for raising disaster risk awareness among the youth. J. Contingen. Crisis Manag. 18, 175-179. doi: 10.1111/j.1468-5973.2010.00614.x

Gallopín, G. C. (2006). Linkages between vulnerability, resilience, and adaptive capacity. Glob. Environ. Change 16, 293-303. doi: 10.1016/j.crm.2014.05.002

Giordano, R., Preziosi, E., and Romano, E. (2013). Integration of local and scientific knowledge to support drought impact monitoring: some hints from an Italian case study. Nat. Hazards 69, 523-544. doi: 10.1007/s11069-013-0724-9

Goodchild, M. F. (2007). Citizens as sensors: the world of volunteered geography. GeoJournal 69, 211-221. doi: 10.1007/s10708-007-9111-y

Goodchild, M. F., and Glennon, J. A. (2010). Crowd sourcing geographic information for disaster response: a research frontier. Int. J. Dig. Earth 3, 231-241. doi: 10.1080/17538941003759255

Goodchild, M. F., and Li, L. (2012). Assuring the quality of volunteered geographic information. Spatial Stat. 1, 110-120. doi: 10.1016/j.spasta.2012.03.002

Goode, N., McArdle, D., Archer, F., Salmon, P., and Spencer, C. (2015). Characteristics of a disaster resilient Victoria: consensus from those involved in emergency management activities. Aust. J. Emerg. Manag. 30, 42-47.

Granell, C., and Ostermann, F. O. (2016). Beyond data collection: objectives and methods of research using VGI and geo-social media for disaster management. Comput. Environ. Urban Syst. 59, 231-243. doi: 10.1016/j.compenvurbsys.2016. 01.006

Gupta, A., Lamba, H., Kumaraguru, P., and Joshi, A. (2013). "Faking Sandy: characterizing and identifying fake images on Twitter during Hurricane Sandy," in Proceedings of the 22nd International Conference on World Wide Web, Rio de Janeiro, 729-736. doi: 10.1145/2487788.2488033

Haklay, M. (2013). "Citizen Science and Volunteered Geographic Information overview and typology of participation," in Crowdsourcing Geographic
Knowledge: Volunteered Geographic Information (VGI) in Theory and Practice, eds D. Z. Sui, S. Elwood, and M. F. Goodchild (Berlin: Springer), 105-122.

Haklay, M. (2016). "Why is participation inequality important?", in European Handbook of Crowdsourced Geographic Information, eds C. Capineri, M. Haklay, H. Huang, V. Antoniou, J. Kettunen, F. Ostermann, et al. (London: Ubiquity Press), 35-44.

Halpern, O. (2015). Beautiful Data: A History of Vision and Reason since 1945 Durham, NC: Duke University Press. doi: 10.1215/9780822376323

Handmer, J. W., and Dovers, S. R. (1992). A typology of resilience: rethinking institutions for sustainable development. Org. Environ. 9, 482-511.

Haworth, B. (2016). Emergency management perspectives on volunteered geographic information: opportunities, challenges and change. Comput. Environ. Urban Syst. 57, 189-198. doi: 10.1016/j.compenvurbsys.2016.02.009

Haworth, B. (2018). Implications of volunteered geographic information for disaster management and GIScience: a more complex world of volunteered geography. Ann. Am. Assoc. Geogr. 108, 226-240. doi: 10.1080/24694452.2017. 1321979

Haworth, B., and Bruce, E. (2015). A review of volunteered geographic information for disaster management. Geogr. Compass 9, 237-250. doi: 10.1186/1476-072x10-67

Haworth, B., Bruce, E., and Middleton, P. (2015). Emerging technologies for risk reduction: assessing the potential use of social media and VGI for increasing community engagement. Aust. J. Emerg. Manag. 30, 36-41.

Haworth, B., Whittaker, J., and Bruce, E. (2016). Assessing the application and value of VGI and participatory mapping for community bushfire preparation. Appl. Geogr. 76, 115-127. doi: 10.1016/j.apgeog.2016.09.019

Heinzelman, J., and Waters, C. (2010). Crowdsourcing Crisis Information in Disaster-Affected Haiti. Special Report. Washington: United States Institute of Peace.

Hewitt, K. (1997). Regions of Risk: A Geographical Introduction to Disasters. Harlow: Longman.

Holling, C. S. (1973). Resilience and stability of ecological systems. Annu. Rev. Ecol. Syst. 4, 1-23. doi: 10.1146/annurev.es.04.110173.000245

Holling, C. S., and Gunderson, J. H. (2002). “Resilience and adaptive cycles”, in Panarchy: Understanding Transformations in Human and Natural Systems, eds L. H. Gunderson and C. S. Holling (Washington: Island Press), 25-62.

Hung, K., Kalantari, M., and Rajabifard, A. (2016). Methods for assessing the credibility of volunteered geographic information in flood response: a case study in Brisbane. Aust. Appl. Geogr. 68, 37-47. doi: 10.1016/j.apgeog.2016. 01.005

Intergovernmental Panel on Climate Change [IPCC] (2012). Managing the. (risks )of Extreme Events and Disasters to Advance Climate Change Adaptation: A Special Report of Working Groups I and II of the Intergovernmental Panel on Climate Change. Cambridge: Cambridge University Press.

Irons, M., Paton, D., Lester, L., Scott, J., and Martin, A. (2015). "Social media, crisis communication and community-led response and recovery: an Australian case study," in Research Forum ath the Bushfire and Natural Hazards CRC \& AFAC Conference 2014, ed. M. Rumsewicz (Wellington: Bushfire and Natural Hazards CRC).

Kapucu, N. (2008). Collaborative emergency management: better community organising, better public preparedness and response. Disasters 32, 239-262. doi: 10.1111/j.1467-7717.2008.01037.x

Klonner, C., Marx, S., Usón, T., De Albuquerque, J. P., and Höfle, B. (2016). Volunteered geographic information in natural hazard analysis: a systematic literature review of current approaches with a focus on preparedness and mitigation. Int. J. Geoinf. 5:103. doi: 10.3390/ijgi5070103

Kruszelnicki, K. (2012). Geotagging: How Much Do Your Photos Give Away? ABC Science. Available at: http://www.abc.net.au/science/articles/2012/06/05/ 3517805.htm

Kulig, J. C. (2000). Community resiliency: the potential for community health nursing theory development. Public Health Nurs. 17, 374-385. doi: 10.1046/j. 1525-1446.2000.00374.x

Levental, S. (2012). A new geospatial services framework: How disaster preparedness efforts should integrate neogeography. J. Map Geogr. Libr. 8, 134-162. doi: 10.1080/15420353.2012.670084

Lindell, M. K., and Perry, R. W. (2000). Household adjustment to earthquake hazard: a review of research. Environ. Behav. 32, 461-501. doi: 10.1177/ 00139160021972621 
Lynam, T., De Jong, W., Sheil, D., Kusumanto, T., and Evans, K. (2007). A review of tools for incorporating community knowledge, preferences, and values into decision making in natural resources management. Ecol. Soc. 12:5. doi: 10.5751/ ES-01987-120105

MacKinnon, D., and Derickson, K. D. (2012). From resilience to resourcefulness: a critique of resilience policy and activism. Prog. Hum. Geogr. 37, 253-270. doi: $10.1177 / 0309132512454775$

Manyena, S. B. (2006). The concept of resilience revisited. Disasters 30, 433-450. doi: 10.1111/j.0361-3666.2006.00331.x

Manyena, S. B., O’Brien, G., O'Keefe, P., and Rose, J. (2011). Disaster resilience: a bounce back or bounce forward ability? Local Environ. 16, 417-424. doi: 10.1080/13549839.2011.583049

McCall, M. K., Martinez, J., and Verplanke, J. (2015). Shifting boundaries of volunteered geographic information systems and modalities: learning from PGIS. ACME 14, 791-826.

McFarlane, B. L., McGee, T. K., and Faulkner, H. (2011). Complexity of homeowner wildfire risk mitigation: an integration of hazard theories. Int. J. Wildland Fire 20, 921-931. doi: 10.1071/WF10096

McGee, T. K. (2005). Completion of recommended WUI fire mitigation measures within urban households in Edmonton. Can. Environ. Hazards 6, 147-157. doi: 10.1016/j.hazards.2006.05.002

McLennan, B., and Handmer, J. (2012). Reframing responsibility-sharing for bushfire risk management in Australia after Black Saturday. Environ. Hazards 11, 1-15. doi: 10.1080/17477891.2011.608835

McLennan, B., and Handmer, J. (2013). "Visions of sharing responsibility for disaster resilience: sharing control," in Proceedings of Bushfire CRC \& AFAC 2012 Conference Research Forum, eds R. P. Thornton and L. J. Wright (Perth, WA: Bushfire CRC),

Meier, P. (2012). Crisismapping in action: how open source software and global volunteer networks are changing the world, one map at a time. J. Map Geogr. Libr. 8, 89-100. doi: 10.1080/15420353.2012.663739

Mendoza, M., Poblete, B., and Castillo, C. (2010). "Twitter under crisis: Can we trust what we RT?" in Proceedings of the First Workshop on Social Media Analytics, (Washington, DC: Association for Computing Machinery), 71-79. doi: $10.1145 / 1964858.1964869$

Morrow, B. H. (1999). Identifying and mapping community vulnerability. Disasters 23, 1-18. doi: 10.1111/1467-7717.00102

Morrow, N., Mock, N., Papendieck, A., and Kocmich, N. (2011). Independent evaluation of the Ushahidi Haiti project, Development Information Systems International. Available at: http:/ggs684.pbworks.com/w/file/fetch/60819963/ 1282.pdf

Murphy, D. W. A. (2015). Theorizing climate change, (im)mobility and socioecological systems resilience in low-elevation coastal zones. Climate Develop. 7, 380-397. doi: 10.1080/17565529.2014.953904

Neely, D. (2014). Enhancing community resilience: What emergency management can learn from Vanilla Ice. Aust. J. Emerg. Manag. 29, 55-58.

Nicholls, S. (2012). The resilient community and communication practice. Aust. J. Emerg. Manag. 27, 46-51.

Ostermann, F., and Spinsanti, L. (2011). “A conceptual workflow for automatically assessing the quality of volunteered geographic information for crisis management," in Proceedings of the 14th AGILE International Conference on Geographic Information Science, Utrecht.

Paton, D. (2006). "Disaster resilience: Integrating individual, community, institutional and environmental perspectives," in Disaster Resilience: An Integrated Approach, eds D. Paton and D. Johnston (Springfield, IL: Charles C Thomas), 305-318.

Paton, D., and Irons, M. (2016). Communication, sense of community, and disaster recovery: a Facebook case study. Front. Commun. 1:4. doi: 10.3389/fcomm.2016. 00004

Paton, D., and Johnston, D. (2001). Disasters and communities: vulnerability, resilience and preparedness. Disaster Prev. Manag. 10, 270-277. doi: 10.1108/ EUM0000000005930

Pimm, S. L. (1984). The complexity and stability of ecosystems. Nature 307, 321-326. doi: 10.1038/307321a0

Pond, P. (2016). The space between us: Twitter and crisis communication. Int. J. Disaster Resil. Built Environ. 7, 40-48. doi: 10.1108/IJDRBE-08-2013-0030

Prosser, B., and Peters, C. (2011). Directions in disaster resilience policy. Aust. J. Emerg. Manag. 25, 8-11.
Rapoza, K. (2017). Can 'Fake News' Impact the Stock Market?. Available at: www.forbes.com/sites/kenrapoza/2017/02/26/can-fake-news-impact-the-stock -market/

Raymond, C. M., Fazey, I., Reed, M. S., Stringer, L. C., Robinson, G. M., and Evely, A. C. (2010). Integrating local and scientific knowledge for environmental management. J. Environ. Manage. 91, 1766-1777. doi: 10.1016/j.jenvman.2010. 03.023

Read, R., Taithe, B., and Mac Ginty, R. (2016). Data hubris? Humanitarian information systems and the mirage of technology. Third World Q. 37, 1314-1331. doi: 10.1080/01436597.2015.1136208

Renschler, C. S., Frazier, A. E., Adrendt, L. A., Cimellaro, G. P., Reinhorn, A. M., and Bruneau, M. (2010). "Developing the 'PEOPLES' resilience framework for defining and measuring disaster resilience at the community scale," in Proceedings of the 9th U.S. and 10th Canadian Conference on Earthquake Engineering, Toronto, ON, 25-29.

Ricker, B., Daniel, S., and Hedley, N. (2014). Fuzzy boundaries: hybridizing location-based services, volunteered geographic information and geovisualization literature. Geogr. Compass 8, 490-504. doi: 10.1111/gec3.12138

Roussi, P., Rapti, F., and Kiosseoglou, G. (2006). Coping and psychological sense of community: an exploratory study of urban and rural areas in Greece. Anxiety Stress Coping 19, 161-173. doi: 10.1080/10615800600593304

Sawicki, D., and Craig, W. (1996). The democratization of data: bridging the gap for community groups. J. Am. Plan. Assoc. 62, 512-523. doi: 10.1080/ 01944369608975715

Scanlon, J., Helsloot, I., and Groenendaal, J. (2014). Putting it all together: integrating ordinary people into emergency response. Int. J. Mass Emerg. Disasters 32, 43-63.

Senaratne, H., Mobasheri, A., Ali, A. L., Capineri, C., and Haklay, M. (2017). A review of volunteered geographic information quality assessment methods. Int. J. Geogr. Inf. Sci. 31, 139-167. doi: 10.1080/13658816.2016.118 9556

Shanley, L. A., Burns, R., Bastian, Z., and Robson, E. S. (2013). Tweeting up a storm: The promise and perils of crisis mapping. Photogramm. Eng. Remote Sensing 79, 865-879. doi: 10.2139/ssrn.2464599

Starbird, K., Maddock, J., Orand, M., Achterman, P., and Mason, R. M. (2014). "Rumors, false flags, and digital vigilantes: Misinformation on Twitter after the 2013 Boston Marathon bombing," in Proceedings of the iConference 2014, Berlin, 654-662. doi: 10.9776/14308

Starbird, K., and Palen, L. (2011). "Voluntweeters: self-organizing by digital volunteers in times of crisis," in Proceedings of the SIGCHI Conference on Human Factors in Computing Systems, (New York, NY: ACM), 1071-1080. doi: 10.1145/1978942.1979102

Sui, D., Goodchild, M. F., and Elwood, S. (2013). "Volunteered geographic information, the exaflood, and the growing digital divide," in Crowdsourcing Geographic Knowledge: Volunteered Geographic Information (VGI) in Theory and Practice, eds D. Z. Sui, S. Elwood, and M. F. Goodchild (Berlin: Springer), 1-12. doi: 10.1007/978-94-007-4587-2

Taylor, M., Wells, G., Howell, G., and Raphael, B. (2012). The role of social media as psychological first aid as a support to community resilience building. Aust. J. Emerg. Manag. 27, 20-26.

United Nations International Strategy for Disaster Risk Reduction [UNISDR] (2005). Building the Resilience of Nations and Communities to Disasters: Hyogo Framework for Action 2005-2015. Available at: http://www.unisdr.org/2005/wcdr/intergover/official-doc/L-docs/Hyogoframework-for-action-english.pdf

United Nations International Strategy for Disaster Risk Reduction [UNISDR] (2009). Terminology on Disaster Risk Reduction. Geneva: UNISDR. Available at: http://www.unisdr.org/we/inform/publications/7817

United Nations International Strategy for Disaster Risk Reduction [UNISDR] (2015). Sendai Framework for Disaster Risk Reduction 2015-2030. Geneva: UNISDR. Available at: http://www.preventionweb.net/files/43291_ sendaiframeworkfordrren.pdf

Valenzuela, S., Park, N., and Kee, K. (2009). Is there social capital in a social network site?: Facebook use and college students' life satisfaction, trust, and participation. J. Comput. Mediat. Commun. 14, 875-901. doi: 10.1111/j.10836101.2009.01474.x

Van der Leeuw, S. E., and Aschan-Leygonie, C. (2005). "A long-term perspective on resilience in socio-natural systems," in Micro, Meso, Macro: Addressing Complex 
Systems Couplings, eds H. Liljeström and U. Svedin (Hackensack, NJ: World Scientific), 227-264. doi: 10.1142/9789812701404_0013

Verrucci, E., Perez-Fuentes, G., Rossetto, T., Bisby, L., Haklay, M., Rush, D., et al. (2016). Digital engagement methods for earthquake and fire preparedness: a review. Nat. Hazards 83, 1583-1604. doi: 10.1007/s11069-016-2378-x

Vosoughi, S., Roy, D., and Aral, S. (2018). The spread of true and false news online. Science 359, 1146-1151. doi: 10.1126/science.a ap9559

Waugh, W. L. Jr., and Streib, G. (2006). Collaboration and leadership for effective emergency management. Public Adm. Rev. 66, 132-140. doi: 10.1111/j.15406210.2006.00673.x

Weichselgartner, J., and Kelman, I. (2015). Geographies of resilience Challenges and opportunities of a descriptive concept. Prog. Hum. Geogr. 39, 249-267. doi: $10.1177 / 0309132513518834$

Welsh, M. (2014). Resilience and responsibility: governing uncertainty in a complex world. Geogr. J. 180, 15-26. doi: 10.1111/geoj.12012

Whittaker, J. (2008). Vulnerability to Bushfires in South-Eastern Australia: a Case Study From East Gippsland, Victoria. Ph.D. thesis, RMIT University, Melbourne.

Whittaker, J., McLennan, B., and Handmer, J. (2015). A review of informal volunteerism in emergencies and disasters: definition, opportunities and challenges. Int. J. Disaster Risk Reduct. 13, 358-368. doi: 10.1016/j.ijdrr.2015. 07.010

Williamson, W., and Ruming, K. (2015). "Who's talking, who's listening: exploring social media use by community groups using social network analysis," in Proceedings of the 14th International Conference on Computers in Urban Planning and Urban Management (CUPUM 2015), Cambridge, MA.
Yates, D., and Paquette, S. (2011). Emergency knowledge management and social media technologies: a case study of the 2010 Haitian earthquake. Int. J. Inf. Manag. 31, 6-13. doi: 10.1016/j.ijinfomgt.2010.10.001

Young, J. C., and Gilmore, M. P. (2014). Subaltern empowerment in the geoweb: tensions between publicity and privacy. Antipode 46, 574-591. doi: 10.1111/ anti.12056

Zhou, H., Wang, J., Wan, J., and Jia, H. (2010). Resilience to natural hazards: a geographic perspective. Nat. Hazards 53, 21-41. doi: 10.1007/s11069-0099407-y

Zoltick, L. (2014). The Good, Bad, and in-Between of Social Media in Crisis Situations. Strategy, Aside. ISL. Available at: https://isl.co/2014/10/the-goodbad-and-in-between-of-social-media-in-crisis-situations/

Zook, M., Graham, M., Shelton, T., and Gorman, S. (2010). Volunteered geographic information and crowdsourcing disaster relief: a case study of the Haitian earthquake. World Med. Health Policy 2, 7-33. doi: 10.2202/1948-4682. 1069

Conflict of Interest Statement: The authors declare that the research was conducted in the absence of any commercial or financial relationships that could be construed as a potential conflict of interest.

Copyright (c) 2018 Haworth, Bruce, Whittaker and Read. This is an open-access article distributed under the terms of the Creative Commons Attribution License (CC BY). The use, distribution or reproduction in other forums is permitted, provided the original author(s) and the copyright owner(s) are credited and that the original publication in this journal is cited, in accordance with accepted academic practice. No use, distribution or reproduction is permitted which does not comply with these terms. 


\section{OPEN ACCESS}

Edited by:

Jonathan D. Paul,

Imperial College London,

United Kingdom

Reviewed by:

Ashutosh Mohanty,

Shoolini University, India

Anatoly Rostislavovich Ischuk,

Academy of Sciences of the Republic

of Tajikistan, Tajikistan

*Correspondence:

Afroz Ahmad Shah

afroz.shah@ubd.edu.bn

afroz.shah@gmail.com

Specialty section:

This article was submitted to

Geohazards and Georisks,

a section of the journal

Frontiers in Earth Science

Received: 16 August 2018

Accepted: 10 October 2018

Published: 02 November 2018

Citation:

Shah AA, Khwaja S, Shah BA, Reduan Q and Jawi Z (2018) Living With Earthquake and Flood Hazards

in Jammu and Kashmir, NW

Himalaya. Front. Earth Sci. 6:179.

doi: 10.3389/feart.2018.00179

\section{Living With Earthquake and Flood Hazards in Jammu and Kashmir, NW Himalaya}

\author{
Afroz Ahmad Shah ${ }^{1 *}$, Sheeba Khwaja ${ }^{2}$, Bilal A. Shah', Qibah Reduan ${ }^{1}$ and Zirah Jawi ${ }^{1}$ \\ ${ }^{1}$ Department of Physical and Geological Sciences, University of Brunei Darussalam, Bandar Seri Begawan, Brunei, \\ ${ }^{2}$ Department of Historical Studies, University of Brunei Darussalam, Bandar Seri Begawan, Brunei, ${ }^{3}$ Department \\ of Humanities and Social Sciences, Indian Institute of Technology Kharagpur, Kharagpur, India
}

Jammu and Kashmir is one of the most politically challenged regions in NW Himalaya, and perhaps also one of the most unfortunate portions of the planet Earth where political and natural disasters have greatly devastated the progressive development of the region. The geological past of this region suggests that it was formed when Indian tectonic plate collided with the Eurasian plate, and this also developed some intermontane basins, which house most of the population of the region. As the tectonics is still actively shaping the topography, geology, geomorphology, and climate of the region, the occurrence of earthquakes and floods in the area is potentially unavoidable. Our knowledge about the causes of earthquakes tells us that it is time to put more emphasis on preparedness rather than on the prediction, which is partly true of flood hazards as well. This paper aims to highlight the urgent need to educate local students and community leaders about the science of earthquakes, and floods, and how to live with such hazards in Jammu and Kashmir. This is backed by the field evidence where interactions will locals suggest an urgent need of comprehensive planning to educate, engage, and train local students about the science of earthquake and flood hazards. The entire population of Jammu and Kashmir is $>12$ million, and the vulnerability to hazards is unavoidable unless a robust framework is planned for the region. Our fieldwork clearly shows that Kashmir conflict, which is more than 71 years old political problem, has a negative impact on the mindset of people because they take earthquake and flood hazards as of secondary importance than the resolution of the political issue. Therefore, we conclude that scientific work related to hazards is highly required to educate local people by organizing a series of workshops, training sessions, course modules, international conferences, public talks, together with the dissemination of awareness about adopting earthquake resistant construction model. However, such efforts will only be effective on the ground if the political problem is resolved. Hence India and Pakistan ought to sit on the table and address the long-standing Kashmir problem for the safety and security of everyone in the region.

\footnotetext{
Keywords: Kashmir basin, Leh basin, earthquakes, floods, Kashmir conflict
} 


\section{INTRODUCTION}

The Jammu and Kashmir region is located in NW Himalaya (Figure 1) and its geology, geomorphology, and structures preserve evidence of collisional tectonics that involved India and Asia (Burbank and Johnson, 1983; Yin, 2006; Shah, 2013, 2016; Gavillot et al., 2016). During the northward journey of greater India, the plate velocity dramatically decreased from 15 to $4 \mathrm{~cm} /$ year at 50 and $35 \mathrm{Ma}$. And this change corresponds with the jamming of India against Asia, which resulted in the formation of the Himalayas and the Tibetan plateau (Copley et al., 2010). Although the exact timing of the collision remains a subject of debate, and for obvious reasons (e.g., Ding et al., 2005) still the popular consensus places the initial timing of collision somewhere between 55 and $52 \mathrm{Ma}$ (Searle et al., 1997; Ding et al., 2005). The aftermath of collision is mainly represented by large-scale faults and folds (Gavillot et al., 2016; Shah, 2016), and some of these faults are still actively participating in the ongoing collisional deformation, and therefore occasionally medium to large magnitude earthquakes occur in the region (Burbank and Johnson, 1983; Ambraseys and Bilham, 2000, 2011; Yin, 2006). Since the region owes its existence to collision hence the occurrence of earthquake events is part of the tectonic evolution of the Himalaya and shall continue in the future. Some of the past earthquake events have unfortunately caused significant loss of life and property and these are: the 2015 Nepal earthquake $(\mathrm{Mw}=7.9)$, the $2005 \mathrm{Kashmir}$ earthquake $(\mathrm{Mw}=7.6)$, the 1950 Assam earthquake $(\mathrm{Mw}=8.4)$, the 1934 Bihar-Nepal earthquake $(\mathrm{Mw}=8.1)$, the 1905 Kangra earthquake $(\mathrm{Mw}=7.7)$, and the 1879 Shillong earthquake of $\mathrm{Mw}=8.1$ (Nakata, 1989; Kumar et al., 2001; Ambraseys and Douglas, 2004; Naseer et al., 2010; Avouac et al., 2015; Shah, 2016). The repercussion of collisional deformation is also the reason for the formation of some intermontane basins (Burbank and Johnson, 1982; Yin, 2006), which house most of the population in Jammu and Kashmir (Figure 1). The beautiful Kashmir basin is one of the several examples of intermontane basins that are formed during the period of collisional orogeny, and have undergone structural and geomorphic modifications to accommodate the ongoing tectonic convergence (Burbank and Johnson, 1982; Shah, 2013). The Kashmir and Leh basins are two examples of intermontane basins that reflect the contribution of tectonic and climatic conditions that led to their formation (e.g., Burbank and Johnson, 1982). Both basins are filled with unconsolidated fluvial, lacustrine, and glacial sediments that are now exposed as ridges and valleys. Since the basins are carved out of mountains, therefore, the geographic location is also vulnerable to flood hazards. Historical data show that floods in Jammu and Kashmir are usually caused by excess precipitation, and some events are associated with earthquakes and landslides (e.g., Lawrence, 1895; Bilham et al., 2010; Bilham and Bali, 2014; Meraj et al., 2015; Shah, 2015).

Therefore, the vulnerability of Jammu and Kashmir to earthquake and flood hazards is now well established (e.g., Bilham et al., 2010; Schiffman et al., 2013; Shah, 2013, 2015; Bilham and Bali, 2014; Meraj et al., 2015; Shah and Malik, 2017; Chandra et al., 2018; Romshoo et al., 2018), and the historical records go back to at least $1100 \mathrm{BC}$ or earlier (Lawrence, 1895; Shah,
2016). This suggests that data and scientific wisdom about these hazards existed but without a proper roadmap of planning and action. The present situation on the ground is even worst. Therefore, this contribution aims to initiate a discussion on the fundamental question of why robust planning to handle earthquake and flood hazards on the ground is missing in Jammu and Kashmir, and what has stopped administrative and local people from achieving the goal of becoming a resilient society to fight these hazards. It also highlights the urgent need for awareness, preparedness, and scientifically sound education in winning the war on earthquake and flood hazards. This is particularly important because the understanding of earthquake sciences (e.g., occurrences, causes, and what controls the regional distribution, etc.) has grown in both quantity and quality but the prediction has not reached so far, and for understandable reasons (Hough, 2010). Therefore, earthquake forecasting is now more popular in the earthquake science domain (Hough, 2010; Shah et al., 2018) because it is scientifically more accurate and vigorously researched. Since the prediction of a future earthquake event is difficult and challenging, therefore, more weight should be given to various types of outreach activities, which will remain one of the most important steps to educate people on how to live with earthquakes (e.g., Paton et al., 2010; Shah et al., 2018). Same is true to flood hazards, which can be efficiently managed if proper scientific framework and education are implemented. Unfortunately, Jammu and Kashmir region has a long history of severe political problems which dates back to pre and postindependence of British India (Shah, 2016; Gilmartin, 1998). Therefore, here we will also try to understand the role of political conflicts in developing of a robust scientific and administrative framework to achieve full control over the reduction of the impact of earthquake and flood hazards.

\section{TECTONIC AND GEOLOGICAL FRAMEWORK}

Tectonics largely control the topography and geology of Jammu and Kashmir region (Figure 1), and it preserves evidence of pre and post-collisional histrionics of India and Eurasia tectonic plates, which are still actively contributing toward the overall development of the region (Le Fort, 1975; Burbank and Johnson, 1982). Therefore, the tales of past geological and tectonic events are preserved in rocks, sediments, landforms, and drainage. For example, the topographic and geomorphic expression of Leh valley is dominantly shaped by one major river, the Indus River (Figure 2) that originates at Mount Kailash in Tibet, and flows westward through the regions of Jammu and Kashmir until it reaches Pakistan. The river exposes deep gorges and incised valleys filled with a variety of fluvial, lacustrine, and glacial deposits, which are underlain by rock units of varying age. Broadly the northeastern portions of the river valley are comprised of the omnipresent Ladakh Batholith, which is the significant landforms that greets when one lands in Leh. The lack of vegetation at high altitude in cold arid climate exposes the barren, and rusty look of the batholith, which exposes rock outcrops, almost, wherever you go. The batholith is part of the 


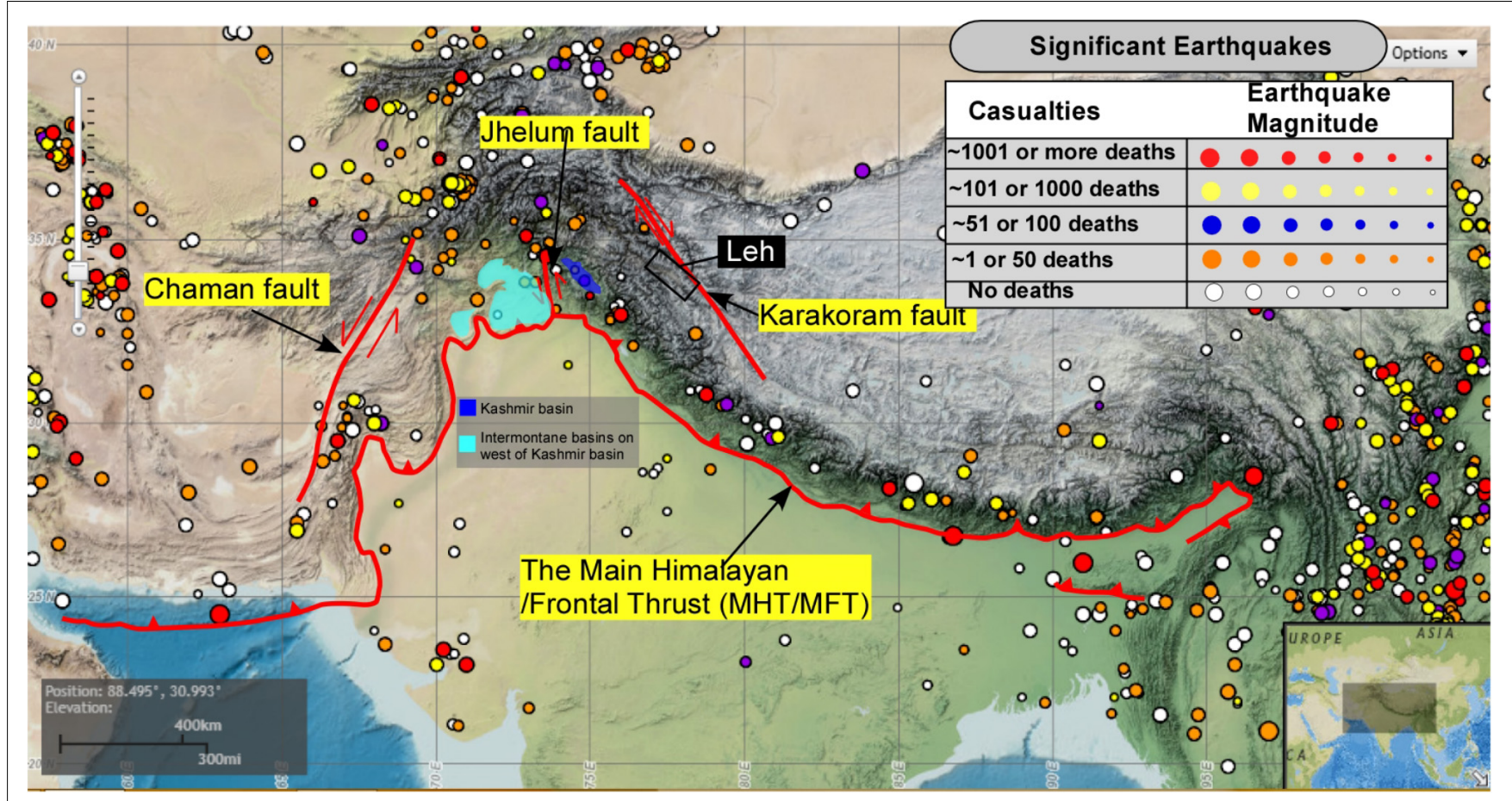

FIGURE 1 | Shows the distribution of significant earthquakes (as colored dots) and the associated casualties (color indicates the number of deaths) on the satellite image of the Himalayas. The Leh and Kashmir basin are shown as colored polygons. The major active faults are highlighted in red lines. The figure is prepared from the freely available data on NOAA's Natural Hazard Viewer. It is retrieved on 20th July 2018 from NOAA National Centers for Environmental Information at: https://maps.ngdc.noaa.gov/viewers/hazards/?layers=2\&extent=-180,70,180,-70.

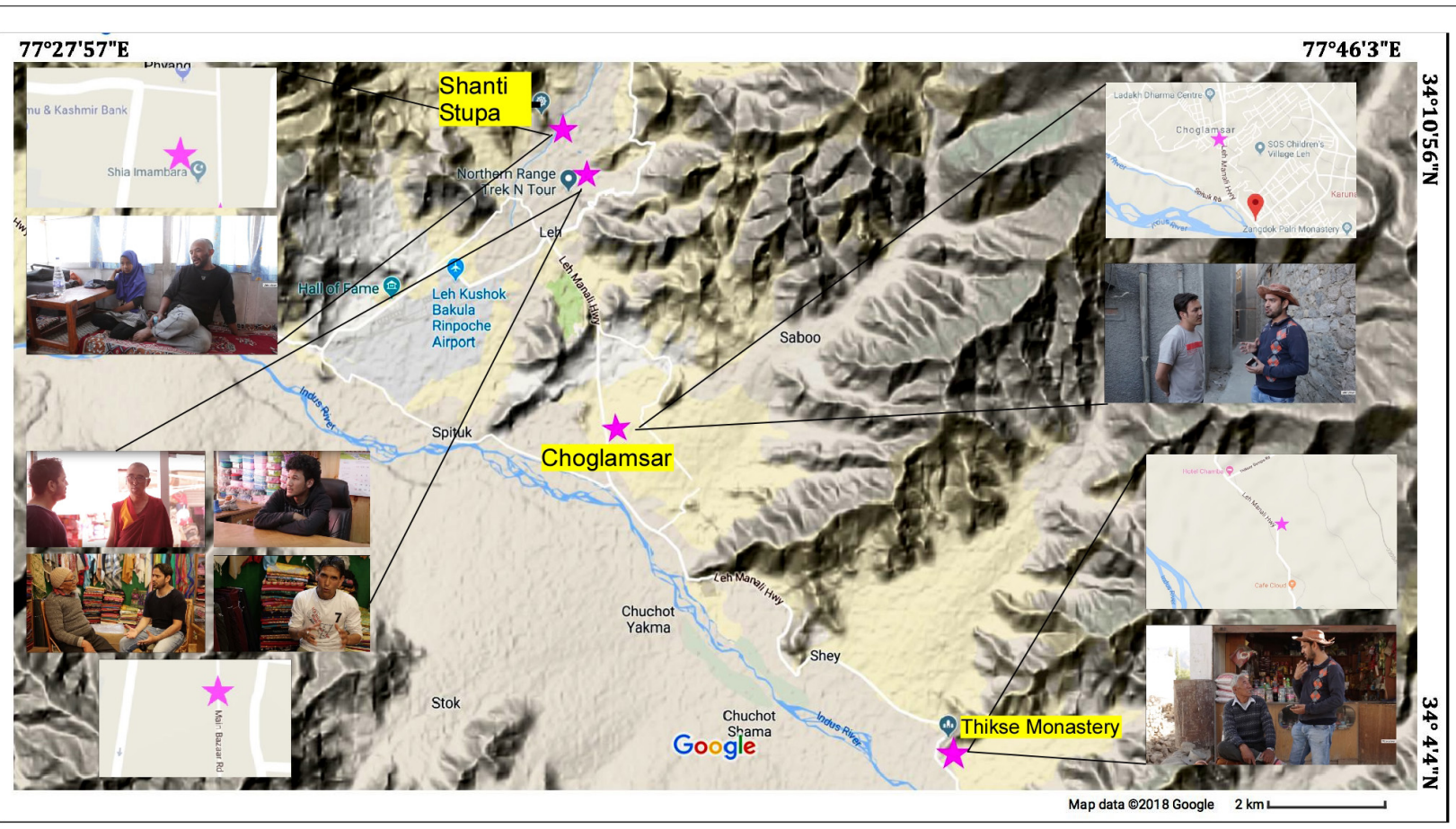

FIGURE 2 | The Google terrain image shows the location of field interaction with locals in Leh. The satellite image is retrieved from Google maps on 20 th July 2018. A written consent form is signed by each participant that is interviewed during the fieldwork in Jammu and Kashmir (a few examples are shown here). 
Transhimalayan Batholith systems, which have intruded at $\sim 47-$ $70 \mathrm{Ma}$ ago in a tectonic arc setting from 7 to $15 \mathrm{~km}$ depth, and the emplacement possibly ended soon after the India-Asia collision at $\sim 50.5 \mathrm{Ma}$ (Najman et al., 2010; St-Onge et al., 2010; Kirstein, 2011). Throughout Leh, these batholiths are exposed mainly on the right bank of the Indus River while as the left bank is delineated by slightly metamorphosed and deformed sequence of limestone, mudstone, and conglomerate. The valley roughly follows the Indus-Tsangpo Suture zone (Figure 1) that demarcates the major boundary of the Indian and Asia plates (Wallis et al., 2016).

Kashmir basin is an example of intermontane basins in NW Himalaya, and it has formed recently at $\sim 4$ Ma ago (Burbank and Johnson, 1982, 1983) at the last stage of India and Asia collision. The presence of the basin within the rising Himalayan mountains ornamented with lush green forests (often with pine trees) makes this basin one of the most beautiful places on the planet Earth. The earthquake and flood disasters have continuously occurred throughout its geological history, and are still posing a significant threat (Lawrence, 1895; Shah, 2013; Meraj et al., 2015). However, while dealing with these hazards we ought to understand a positive aspect of earthquakes that have primarily shaped this region and, therefore, it is crucial that we start to give credit to these events for developing the landscape of Kashmir the way it is now, and we must avoid creating a sense of fear in people to hate earthquakes. It is imperative to sense that earthquakes have primarily contributed to shaping the land that we call home. This becomes obvious when we study rocks, which are mostly marine sedimentary rocks that have formed in an oceanic setting, and are subsequently deformed, and faulted during the collision of India with Asia. These rocks are mostly composed of Triassic limestone units, which have been intruded by Panjal volcanic series. This rock sequence is now overlain by a thick blanket of Holocene to Recent sediments that are mainly formed in fluvial, glacial, and lacustrine environments (Bhatt, 1976; Burbank and Johnson, 1982) and is sourced from the nearby mountains that have risen during the India-Asia collision and are still actively rising. Currently, the Main Himalayan thrust fault is the major earthquake causing fault system onto which the Jammu and Kashmir region is riding (Shah, 2013, 2016). Most of the population in Kashmir reside on these sediments, which are also pierced by one major active fault known as Balapur fault/Kashmir basin fault (Shah, 2013). These sediments are highly prone to liquefaction, which can make monsters out of an ordinary earthquake (Shah et al., 2018). A number of earthquakes are reported to have hit this region in the past (Lawrence, 1895; Bilham et al., 2010; Shah, 2013; Bilham and Bali, 2014), and in the near future a possibility of a major earthquake to hit this region is unavoidable (Shah, 2013). Flood disasters have also devastated the economic condition of this region, and such events have a long history (e.g., Lawrence, 1895; Bilham et al., 2010; Bilham and Bali, 2014). The September 2014 flooding devastated most of the Kashmir valley and turned it into a large pool of water, and the dominant inundation occurred in NE portions of the valley, which are tectonically subsided as the basin rides on fault ramps (Shah, 2016). Flooding mainly occurred along in and around the Jhelum River and some of its tributaries (Meraj et al., 2015).

\section{METHODOLOGY}

The purpose of this work is to map and understand the level of earthquake and flood hazard related scientific awareness in parts of Jammu and Kashmir, NW Himalaya (Figure 1). Therefore, it involves standard pre- and post-fieldwork exercises where initially literature review is used as a guide to make a base of what has been achieved with regards to education and awareness about these hazards. For this study, the geological and historical background of the region is mainly located in the primary and secondary sources. The primary sources comprise the fieldwork via interaction with locals; secondary sources include books, journal articles, and reports. The first step involves making a base map using Google maps data (Figure 1), which is followed by the plotting of possible fieldwork locations on it. The fieldwork is mainly conducted in Leh (Figure 1) where we covered the entire extent of the valley so that it is possible to interact with a range of people distributed across and along the whole stretch of the valley (Figure 2). We targeted people in the age group of 18 years and above so that a variety of subjects are analyzed, and in the end, we recorded interviews of 14 people, who have provided a written and informed consent for this (Figure 2). The typical interaction session followed the questions as listed in Table $\mathbf{1 .}$ The planning to visit the selected places in Kashmir valley did not work because during our field session the region was immersed in violent political conflict-related issues, and therefore, only a few nearby places in Anantnag town are visited (example in Figure 4). No interviews are recorded because of political instability in the region and for security reasons.

\section{RESULTS AND INTERPRETATIONS}

\section{Fieldwork in Leh}

The geological fieldwork in Leh is part of our ongoing scientific mission that involves two lenses of investigation. The first lens mainly focuses on the mapping and understanding of the geological and tectonic origin of Leh basin, which is an intermontane basin similar to Kashmir basin but much smaller in extent (Figure 1). This has significant implication for the occurrence of future earthquakes and floods in the region. The second investigative lens emphasizes the status of scientific outreach activities in the area, and to know the current knowledge of awareness about the earthquake and flood-related hazards in Leh. Below is the summary of our field session:

The fieldwork started in June 2018, and our team surveyed the entire extent of Leh basin (Figure 1), which stretches roughly parallel to the Indus-Tsangpo Suture zone that delineates the major boundary of the India and Asia lithospheric plates (Wallis et al., 2016). The one to one interactive sessions with locals is designed to map and understand the level of scientific knowledge about the earthquake and flood hazards. Therefore, a variety of subjects are approached, that mainly comprise of students, traders, and government officials. The typical questions asked are listed in Table 1. Most of the people that we contacted for our research interactions were very friendly and easy to talk. However, we did find some who were not willing to participate, 
TABLE 1 | The typical questions and answer session with participants.

\begin{tabular}{|c|c|c|}
\hline No. & Typical questions & Typical answers \\
\hline 1. & $\begin{array}{l}\text { What is the most popular story that you know about the formation of Leh } \\
\text { valley. }\end{array}$ & $\begin{array}{l}\text { It was a large lake, and later God/saint reclaimed it by draining off the water } \\
\text { from the lake. }\end{array}$ \\
\hline 2. & Tell us about the earthquake hazards in Leh. & $\begin{array}{l}\text { We don't have earthquake hazards here. However, sometimes small } \\
\text { magnitude quakes do occur. }\end{array}$ \\
\hline 3. & $\begin{array}{l}\text { Have you experienced or heard about any earthquake occurrence in the } \\
\text { Leh region? }\end{array}$ & $\begin{array}{l}\text { No, we heard nothing about past earthquakes from our elders and other } \\
\text { media. }\end{array}$ \\
\hline 4. & What will you do if an earthquake occurs? & $\begin{array}{l}\text { I don't know. We are told there is absolutely no earthquake threat in the } \\
\text { region. Leh is a sacred place. Nothing untoward will happy except by the } \\
\text { permission of God. }\end{array}$ \\
\hline 5. & Have you experienced, in your lifetime, floods in Leh? & $\begin{array}{l}\text { Yes, the memories of } 2010 \text { floods are hard to erase. It is the worst example } \\
\text { of flash flood that we have experienced in Leh during our lifetime. }\end{array}$ \\
\hline 6. & Do you know what to do before, during and after floods? & $\begin{array}{l}\text { We are not specially trained for this; we react instinctively to the situation. In } \\
\text { the } 2010 \text { flood, we rushed from the flood-ridden river area to save life and } \\
\text { property. But this was not a coordinated and well-managed exercise, and } \\
\text { many people lost their lives to the devastating floodwaters. }\end{array}$ \\
\hline 7. & Why people are still building houses in the high flood risk zones. & $\begin{array}{l}\text { Because we do not know where to build. There are no regulations on that, } \\
\text { and often the less flood risk regions are expensive to buy. Relocation is } \\
\text { costly and unaffordable. }\end{array}$ \\
\hline 8. & $\begin{array}{l}\text { Have you read or listened to anything about earthquake and flood hazards } \\
\text { in Leh via books, newspapers, Television, magazines, etc.? }\end{array}$ & $\begin{array}{l}\text { I have heard about floods but not about earthquakes. There are no specific } \\
\text { and scientifically sound programs to train or educate us about these } \\
\text { hazards. }\end{array}$ \\
\hline 9. & $\begin{array}{l}\text { Do you think the government should give more education and research } \\
\text { scholarships to people in Jammu and Kashmir, and especially Leh so that } \\
\text { the people are trained to face these natural hazards? }\end{array}$ & $\begin{array}{l}\text { Yes, the quality of education together with the overall economic condition of } \\
\text { people of Jammu and Kashmir has been dramatically affected by the } \\
\text { political problem here, and therefore, encouraging education and research } \\
\text { through scholarships will be very helpful for us. }\end{array}$ \\
\hline 10. & $\begin{array}{l}\text { Do you think someone responsible should give you training about } \\
\text { earthquake and flood hazards and how to live with such dangers. }\end{array}$ & $\begin{array}{l}\text { Yes, I think this is a great idea, and shall help us to understand the science, } \\
\text { and how to live with hazards. }\end{array}$ \\
\hline
\end{tabular}

and this was particularly witnessed when we informed them that we would like to video record this conversation for our earth science education outreach related documentary movie, which we are planning to make out of the entire field exercise in Leh. This is why we could only record 14 interviews during our 8 days of fieldwork. Before the recording of a formal conversation an informed written consent form is signed by each participant that was interviewed (a few examples are shown in Figure 2). The questions that we asked during the interview sessions were mainly related to the past occurrence of earthquakes and floods in the region, and the scientific information about such events through various sources like books, newspaper articles, local, or international media, etc. (see Table 1 for details).

The majority of the participants are aware of the flood hazards in the region, and we interpret this as a result of devastation that is caused by the 2010 flash flood, which is considered as one of the most devastating floods that the region has witnessed over the decades (Hobley et al., 2012). A significant quality of river discharge accumulated after a convective storm event occurred on August 6, 2010 over the Ladakh Range, which led to an unfortunate loss of $\sim 600$ people and devastated more than 60 villages (Hobley et al., 2012). Several eyewitness accounts confirm that the flooding occurred at about 11 p.m. when most of the people were asleep, and that could be one of the primary reasons for a high number of casualties (Figure 2). However, the locals informed us that the number of casualties are somewhere between 200 and 300 and not 600 as reported earlier (Hobley et al., 2012). Some recent works also indicate the number below 300 (e.g., Thayyen et al., 2013). The Google satellite imagery captured before and after the flood shows the extent of devastation in Choglamsar region, which is considered as one of the most badly affected regions in Leh (Figure 3). Previous studies have shown that the origin of flash flood is Saboo catchment area (Figure 2). This later collected water and debris in the downstream direction and destroyed various property, and resulted in an unfortunate loss of 145 people (Thayyen et al., 2013) in the catchment region, and most of the flood impact is witnessed in the Choglamsar area, which is located at the termination of the catchment. The scare caused by the flood has no effect on the ground because people have started rebuilding houses in the highly vulnerable valleys, which are prone to floods. Some new buildings are erected over the same sites which were previously destroyed in the 2010 flood. This is alarming because such regions are highly vulnerable to the devastating quantity of debris flows, which can wash away such structures easily. And when we asked local people why they rebuild and build houses at these highly risky flood zones, they said they are left with no other choice. They can't move as it entails buying new land in safer places, which is not affordable. And also there is no clear guideline from the authorities on where to build and where not to build. Since Buddhist beliefs mainly dominate the population in Leh, during our interaction most people confessed that it was due to his holiness, Mr. Dalai Lama, the Tibetan spiritual leader that their families were saved during the floods. Mr. Lama has no direct role to control or mitigate floods, but his followers attribute life and death to him. It is essential to understand how religious 

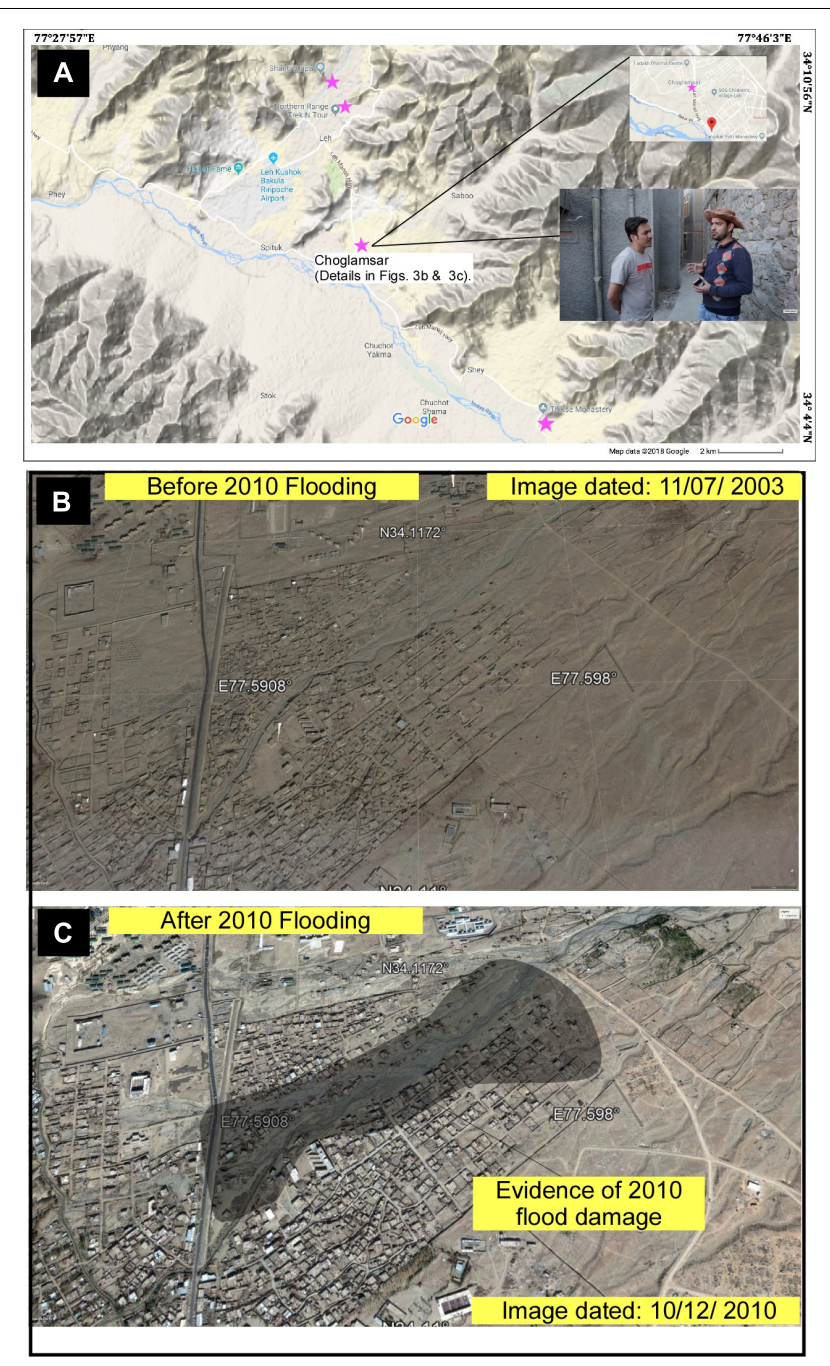

FIGURE 3 | The Google terrain image (A) shows the location of Choglamsar area that was badly impacted by the 2010 flooding. (B) The Google satellite image before 2010 flood and panel (C) is the image after the 2010 flooding. The extent of devastation is visible (highlights in polygon). The first figure (A) is obtained from Google maps on 20th July 2018, and subsequent figures (B,C) are also acquired on the same date from Google Earth that uses images from Digital Globe.

beliefs can influence understanding and how people perceive hazards. A similar story is witnessed in Kashmir (see the Kashmir section below).

Another important information about community vulnerability came to light when we were told by one of the Tibetan refugees who lost his home in the 2010 flood that most of his community members live in Choglamsar area (Figure 3), which was severely hit during the flood. The Indian government gives the land to Tibetan refugees, and they cannot move to another place because they are not the citizens of India! This needs further work as the subject has highlighted administrative failure to safeguard refugees.

People in Leh are not worried about earthquake hazards and are mostly unaware of the science of earthquakes, and if the region is at risk or not. The locals informed us that they do not know about any past earthquake disaster in the area and have not heard any such stories from elders either. The tremors of small magnitudes do occur in the region, and one such tremor occurred while we were interviewing people in June-2018.

\section{Fieldwork in Kashmir Basin}

Kashmir basin, which is an intermontane basin, rides on active fault systems (Burbank and Johnson, 1982; Shah, 2013), and therefore, highly prone to earthquake hazards. And since the basin is carved out of rising Himalayans during the collision orogeny of India and Asia, consequently, the basin is also highly vulnerable to fluvial floods (Meraj et al., 2015; Shah, 2016), and one of the worst such flooding episodes occurred in 2014 (Figure 4) when most of the basin was underwater. Therefore, our motivation to do fieldwork in Kashmir is to highlight the significant issues related to earthquake and flood hazards that people are facing on the ground, and how to deal with it. However, and unfortunately, the current political condition in Kashmir valley has remained turbulent, extremely disturbed, and not suitable for fieldwork. The roots of the decades-old political unrest in Kashmir goes back to at least pre and post 1947 partition of the Indian sub-continent. British India was divided along religious lines into Hindu dominated India and Muslim dominated Pakistan (see section "Discussion" for details), and this division was based on the two nation theory that demarcated separate statehood for Hindus and Muslims of greater India (Gilmartin, 1998). Therefore, during the tenure of our project we were unable to do extensive fieldwork in Kashmir valley, and it was equally risky to conduct interview or surveys. The only locations that we visited are in the close vicinity of Anantnag town (Figure 4). Luckily, through some personal contacts, we were able to organize lectures on earthquake hazards in Jammu and Kashmir in two colleges in Anantnag. A large number of students (more than 100) in each college and staff attended the lecture. The most interesting part of this experience was to engage with the audience during the question and answer session. Questions, particularly from students underline a constant desire and deep quest to learn, understand, and plan for the welfare of the planet that we call home. They were very keen to know about the active faults in Kashmir region, and the tectonics that has largely shaped the geological deposits of the basin, and about the causes of earthquakes and floods in the region, and possible remedial measures to minimize the impact of such hazards in future. Unfortunately, the students are not exposed to local geological outcrops and are equally not aware of geomorphology and tectonics of the region. Our initial plan was to organize a few days of fieldwork with local students to partly fill this knowledge gap; however, because of the worsening political conditions in South Kashmir, where our team is based, we could not organize it, which is really unfortunate. The only interactions that we had largely remained confined to the institute premises. We did ask some locals about the earthquake and floods in the region and visited a few nearby sites. The locals are more worried about floods, and this is mainly because of the repetition of disastrous floods in Kashmir. Our interaction with locals clearly show that the large-scale flooding in September 2014 has instilled a strong 

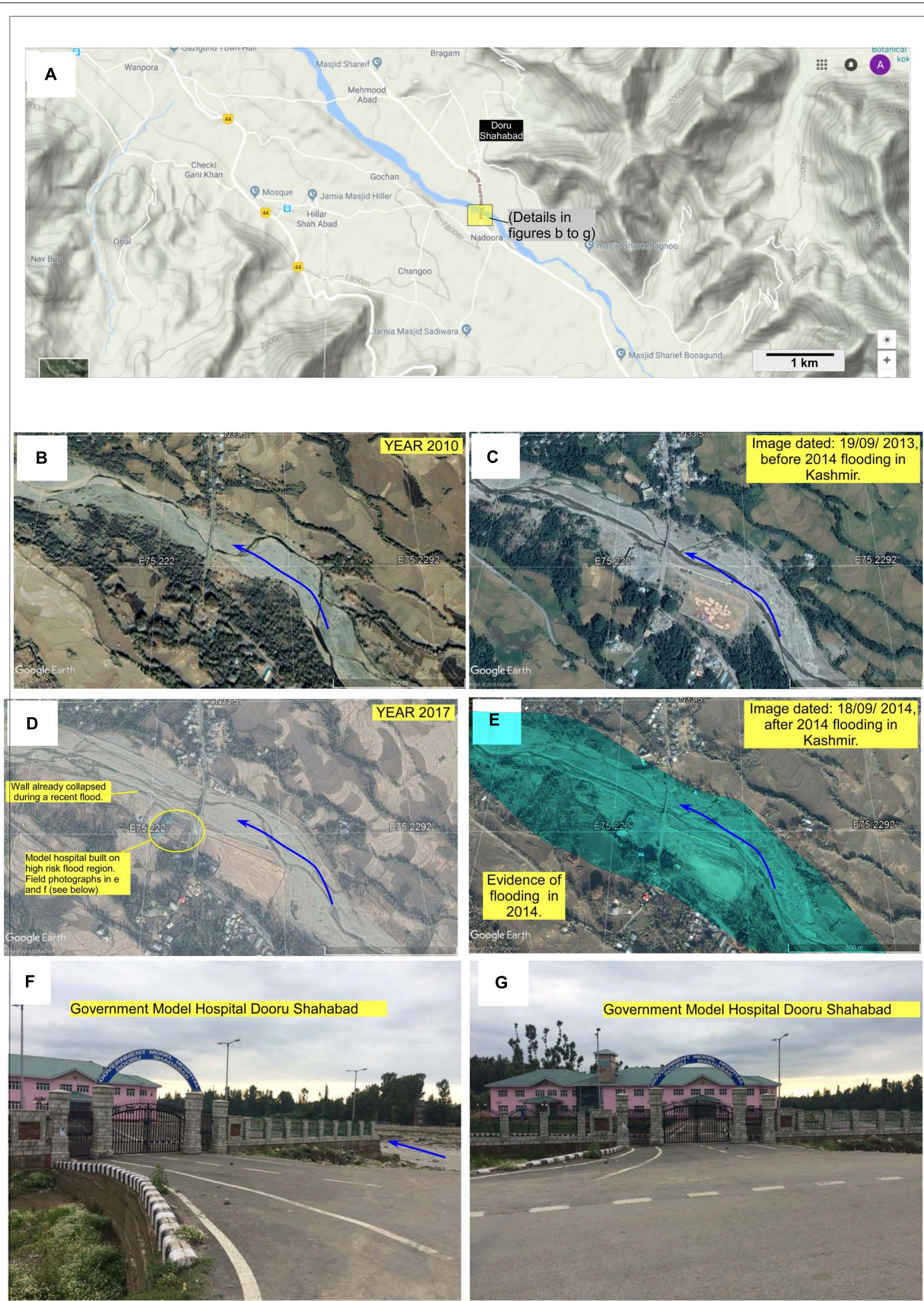

FIGURE 4 | The Google terrain image (A) shows the location of a newly constructed government hospital in Dooru, Anantnag, Kashmir. Subsequent figures (B-E) show the historical satellite images of the area and highlight the reckless attitude of authorities to build a new hospital right on the active flood plain area of the stream that was recently flooded in 2014. The field photographs of the hospital building are also shown (F,G). The first figure (A) is obtained from Google maps on 20th July 2018, and subsequent figures (B-E) are also acquired on the same date from Google Earth that uses images from Digital Globe. 
feeling of fear in people, and whenever it rains for a few days, the locals start to navigate possibilities of rescue and rehabilitation. They remain alert at all the times during rainy seasons, and this has more or less persisted after the 2014 flood. On the ground, there is no roadmap available for the people that would equip them to deal with the potential flood hazards. The urbanization of vulnerable and flood-prone regions has not stopped even after the 2014 flooding. This becomes evident when we look for evidence on the ground and satellite images and come to realize that the regions which were completely submerged during the 2014 flood have been occupied now (Figure 5). This is saddening, as it completely underestimates the safety and security of life and property. However, our interactions with people seem to suggest that there are no better choices to make because of financial hurdles that will not allow one to relocate and buy a new property at safer locations. This is one of the most important reasons that people are not thinking to relocate. They feel the worst nightmare is over, and such a disaster will only recur in a long time or possibly never. This is an example of wishful thinking, but scientifically incorrect or impractical. What amazes one is the fact that even a government model hospital has been recently built on a total flood risk region in Dooru, Anantnag (Figure 4). It is located on a highly vulnerable floodplain area that often gets eroded during high discharge volume in the river. The evidence of a recent such erosional downcutting is even visible from the satellite image (Figure 4D). Similarly, one religious structure is built on a small stream that flows through the town of Laizbal, Anantnag, Kashmir, and whenever it rains heavily for a day or two, the structure becomes inaccessible due to waterlogging. Such types of unplanned urbanization are frequent in Kashmir, and it contributes to the overall increase in flood-related destruction over the years.

The people of Kashmir are predominantly Muslims, and the popular perception is that Allah (God) is testing the erring people through various kinds of calamities, which includes earthquakes and floods. Therefore, the belief pervades that whatsoever people do to save themselves will not work unless they do not mend their life on religious lines. This is something that needs to be taken very seriously as such perceptions can contribute toward the overall development of mindset to deal with hazards (see section "Discussion" for details). The houses that we have seen and visited have no structural integrity to withstand a moment magnitude of six and above earthquakes.

\section{DISCUSSION}

\section{Earthquake and Flood Hazards in Jammu and Kashmir}

Jammu and Kashmir region rides on active fault systems (Figure 1), and Himalayan frontal fault system is one of the major fault systems that can cause unprecedented destruction (Bilham et al., 2010; Shah, 2013) because the preparations to deal with future earthquake disasters have not started at the ground level (Shah, 2016). This gets even murkier because the $>12$ million population of Jammu and Kashmir mainly resides on the unconsolidated sediments that have filled the two
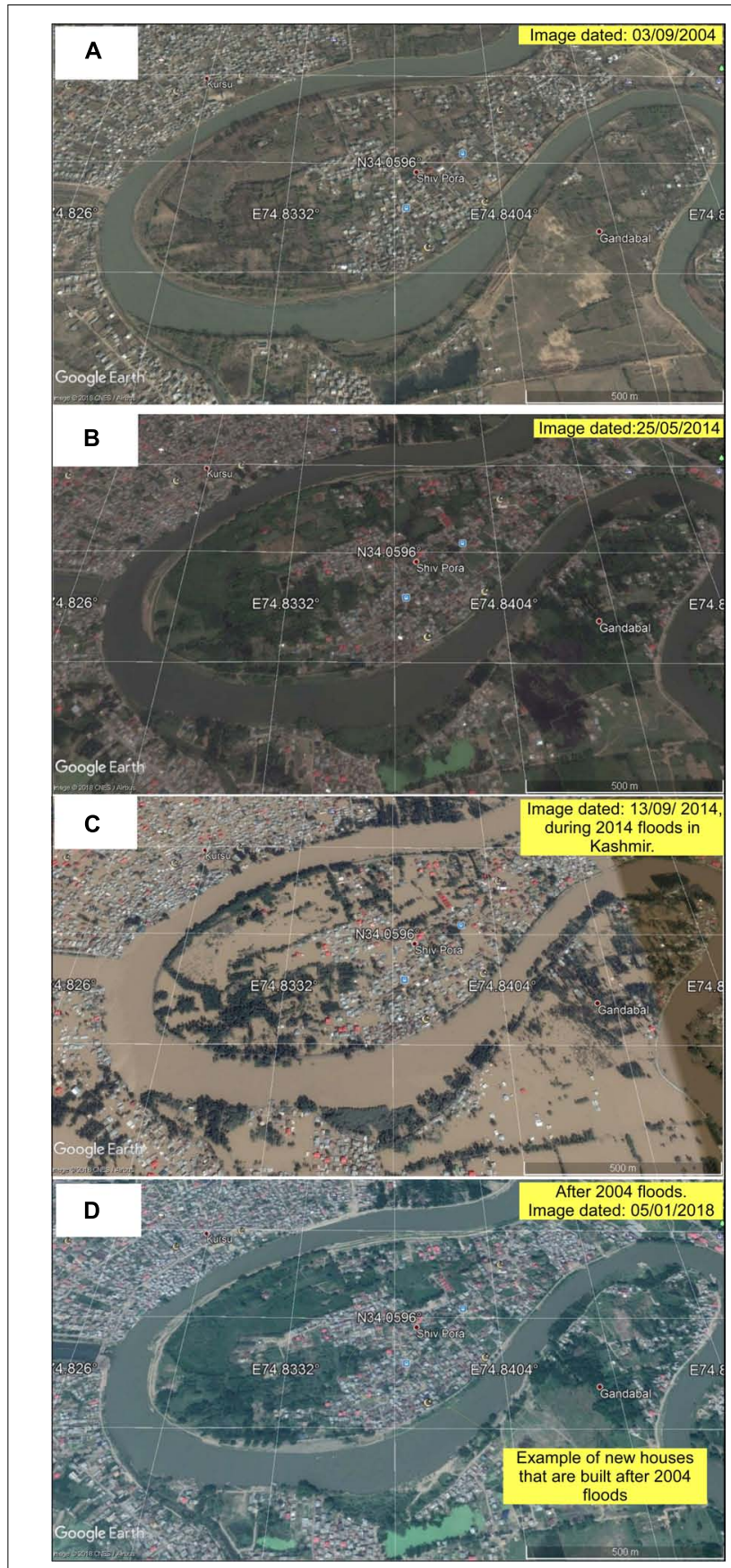

FIGURE 5 | The historical Google satellite images are shown and the urbanization is highlighted (A-D). The region which was completely submerged during the September 2014 floods are now reoccupied (C,D). Such practices are a routine in Jammu and Kashmir. All satellite images are obtained on 20th July 2018 from Google Earth that uses images from CNES/Airbus.

major intermountain basins, the Kashmir and the Leh basins (Figure 1), during the period of India-Asia collision (Burbank and Johnson, 1982). These basins mainly preserve sediments that are deposited in fluvial, glacial, and lacustrine environments. Jammu and Kashmir sits on the tectonically active structural 
ramp of $\mathrm{MHT}$, which can lead to large-scale devastation (Shah, 2013) as a medium to massive magnitude earthquake is expected in the region. This is significantly more devastating for the intermontane basins that are often filled with unconsolidated and water-saturated sediments because medium to large magnitude earthquake can cause intense ground shaking which can lead to the severe problem of liquefaction, and past evidence of earthquakes associated with liquefaction do exist in Kashmir (Ali and Ali, 2018). New Zealand is a developed nation and has grown in the womb of active tectonic plate interactions, which are usually associated with medium to large magnitude earthquakes. Despite all of the past the efforts to improve the infrastructure for safety and security of people the nation witnessed one of the worst earthquakes in history when on February 21, 2011 a medium magnitude earthquake devastated Christchurch and caused 181 deaths. The damage to the buildings was mostly attributed to the widespread occurrence of liquefaction, which considerably worsened the problem and caused significant loss (e.g., Crowley and Elliott, 2012; Shah et al., 2018). This could give us a possible image of the scenario in Jammu and Kashmir, which has not developed any concrete strategy to safeguard people and property.

Our field experience in parts of Leh, and Kashmir basin clearly suggest that on ground the preparations are almost nil, and this is significantly worrying because of the fact that possibility of any future medium to large magnitude earthquake-related damage in this region is very high (Bilham et al., 2001; Shah, 2013). Our field interaction with local people indicates that most of the people are only concerned with the flood hazards, and we interpret this has roots in human psychological attitude toward disasters. When it hits hard, we are concerned, otherwise there seems to be no problem. Since the recurrence interval of a medium to large magnitude earthquake is often longer than a flood recurrence time, therefore, the memory of a devastation event to act often favors flood hazards. Frequent hazards work as a continuous reminder, and often such reminders are needed. Our attitude and experience validate this because routinely whenever a devastating earthquake or flood occurs, we start to research, plan, and implement a solid strategy to counter future potential disasters. We all acknowledge the deadly event of 2004 (Sieh, 2007) that led to the reinvention of tsunami research throughout the world, and in particular within the Asian regions. Similarly, when Pakistan was severely hit in the 2005 earthquake the concerned authorities started to work, but on the ground, it has to go a long, long way (Pathier et al., 2006; Shah et al., 2018). Although the "Republican Day" earthquake of January 2001 that devastated Bhuj (Gujarat) with more than 19000 casualties (Bendick et al., 2001) did awaken the sleeping Indian authorities to act, however, work on the ground is still miles away. And our work in Jammu and Kashmir solidifies such statements.

The scientific information about earthquakes and flood hazards in Jammu and Kashmir region is hugely lacking, and on the ground, most of the people are not concerned about earthquake but floods. However, the continuous construction of residential or government buildings on the high flood risk regions is seriously worrying. Unfortunately, the urbanization has spread into areas, which were submerged entirely and wholly devastated during the 2014 flooding (Figure 5). How can people make such choices? Lack of education and awareness is indeed one of the major contributors to this. But there are other factors, e.g., economic, social, and political conditions, which force one to stay in risky zones. This gets even murkier when earthquake risk is taken into consideration. Currently, people are not following any seismic resistant design to construct houses, etc., and the state government has not given any clearcut direction in this regard. Hopefully, such provisions will be practiced soon. However, merely enforcing a law regarding this may not change much on the ground because the economic condition of people is not healthy, and the decades-old political unrest has dramatically damaged the economic, social, political, and scientific developments in the state. The best option to win the battle with earthquake and flood hazards in Kashmir will be to end the political unrest, which has sabotaged the mental, psychological, political, social, and scientific progress (see below). How can one think of earthquake hazards when daily life is much worst and full of misery and uncertainty?

\section{Contribution of Kashmir Conflict in Understanding and Mitigation of Hazards in Jammu and Kashmir}

Political conflicts have the potential to weaken a nation and make monsters out of ordinary hazards (Shah et al., 2018) and this often hinders any scientific effort to safeguard people. This is evident in Jammu and Kashmir, which is one of the most intense conflicts in Asia. It is very intriguing to note that this region has not developed a robust infrastructure to deal with earthquake and flood hazards when in reality this region has grown in the womb of earthquakes and floods throughout its structural, geological, and tectonic history (Lawrence, 1895; Burbank and Johnson, 1983; Shah, 2013, 2016; Meraj et al., 2015; Kumar and Acharya, 2016). The mighty Himalayas have formed after the India-Asia collision, and that also resulted in the formation of intermontane basins (Burbank and Johnson, 1982), which house most of the population in Jammu and Kashmir. The earthquake and floods have structured the land that we call home. In spite of this intrinsic relationship with hazards, we are still miles away from developing a firm policy to live with these hazards (Shah, 2016). And one of the primary reasons for not achieving this is the role of political conflicts in destroying efforts to win the battle against these natural hazards. The evidence of this is present everywhere in Jammu and Kashmir. During the fieldwork in Leh and Kashmir, we realized that political conflict had overshadowed every sphere. People talk about the resolution of the political dispute as of primary importance, and everything else is secondary (see below). This has a strong reason because it is something which significantly impacts the daily lives of people. Therefore, without addressing the political dispute, it is impossible to improve the standard of living and to deal with natural hazards.

Throughout our fieldwork, in Jammu and Kashmir, we noticed some obvious evidence of political conflict everywhere. This was particularly true and hard to miss in the Kashmir valley which is the center of this political conflict. Graffiti on the public walls 
saying "We Want Freedom," "Go India Go Back," etc., greets visitors everywhere. When we talked to the locals, it became quite apparent that Kashmir conflict has carved deep and painful wounds, which are difficult to ignore. The roots of the Kashmir problem can be traced back to pre and post 1947 partition of the Indian sub-continent (Gilmartin, 1998). The separation of British India into Hindu dominated India and Muslim dominated Pakistan was achieved on the basis of religion, which has its foundation in the two nation theory that differentiates between Muslims and Hindus on the basis of religion. The religiously guided partition of British India into India and Pakistan is one of the most brutal, painful, and agonizing memories in the world because it led to mass migration, dislocation killings, and rapes (Brass, 2003).

India and Pakistan had existed as independent regions for a little over 2 months when they confronted each other in a war over the future of Jammu and Kashmir in October 1947. Before India's partition and Independence Kashmir was a princely state (Subbiah, 2004; Sherman, 2007) ruled from Jammu by the Hindu Dogras, who presided over a mostly Muslim population. It was under the leadership of Sheikh Mohammed Abdullah, who is one of the most important political figures in the modern history of Jammu and Kashmir, and his party the National Conference, that the "freedom movement in Kashmir" was launched in 1931, against the ruling Hindu Dogra monarchy (Wani, 1995). The 1930s was a period when the Kashmiri leadership consolidated this movement and began articulating its agenda in nationalist terms, "one which addressed the issues of the Kashmiri nation as a whole" (Zutshi, 2004). Imbued with socialist ideas and informed by the discourses of Kashmiriyat, the National Conference led by Sheikh Abdullah became "the bearer of the majoritarian nationalist ideology for the people of the state" (Zutshi, 2004). Sheikh Abdullah's close association with Jawaharlal Nehru and, consequently, with the Congress-led Independence movement in India (Fazili, 1980) did not have full support in the valley. As a result, the opposing political force, the Muslim Conference, which was politically close to the Muslim League, regained popularity (Zutshi, 2004). The Muslim League, led by Mohammad Ali Jinnah (Afzal, 1966; Islam, 1981), in turn, did not consider the National Conference as the representative voice of Kashmir. Jinnah is reported to have said that "99 percent of the Muslims who met me are of the opinion that the Muslim Conference alone is the representative organization of the state Muslims" after his visit to Kashmir in 1944 (Fazili, 1980). The Kisan Mazdoor Conference and the Socialist Party in Kashmir were in favor of accession to Pakistan (Fazili, 1980). One can conclude from the different accounts of the 1930s and 1940s that while Abdullah had a towering presence in the valley, other competing political opinions were being expressed during the same period on the future of Kashmir.

The political crisis in Kashmir persisted until the time of India's partition, and the political fate of Kashmir remained undecided even with the creation of India and Pakistan. A revolt against the Maharaja by his own forces was underway in certain parts of the region mainly in Poonch (popularly known as the Poonch Revolt) and Mirpur (Ellis and Khan, 1999; Ding et al., 2005), when a large number of tribesmen from the neighboring areas of NWFP (North West Frontier Province) in Pakistan invaded the Kashmir valley with the help of the Pakistani Army. Many Kashmiri Muslims also looked upon these tribal lashkars (a military force) as liberators fighting the rule of the Dogras (Whitehead, 2007). The National Conference, with its stronghold on the political sentiment in the valley, organized itself into a "militia" to defend Kashmir from this attack. As the fall of Srinagar seemed imminent in October 1947, the Maharaja signed the Instrument of accession to India. The conditions of the accession to India were that the Army would be sent to repel the attack on Kashmir and that the "finality" of the Maharaja's accession would be decided with a "reference to the people" of Jammu and Kashmir (Bose, 1997). Subsequently, the Indian Army was airlifted to Kashmir, and the tribesmen pushed back. Many questions about what happened during those 4 days remain mired in controversy. A ceasefire was announced in 1948 that brought the war to an end. It left "two-thirds" of Jammu and Kashmir under Indian control while parts of "Western Jammu and Poonch as well as Gilgit and Baltistan, fell under Pakistani control" (Bose, 1997). Historically, the 1947-48 Kashmir war is the moment when Kashmir became a "disputed part" of India and Pakistan (Jalal, 1990). Since then Kashmir has become a battleground for three competing nationalism, Indian, Pakistani and the aspirant Kashmiri nationalism. The Indian official position has been that Kashmir is an integral and fair part of India and any opposition, armed or otherwise, against the Indian rule is a handiwork of Pakistan. Pakistan, on the other hand, regards Kashmir as the "the jugular vein of Pakistan" and holds that India has occupied Muslim majority Jammu and Kashmir by pure military might which is against the underlying logic of partition. Kashmiris think that they have historically been deprived of any fair agency over their own political dispensation by two mighty and feuding nations, India and Pakistan (Whitehead, 2007). Seeking their right to self-determination, Kashmiris have tried every possible agency for the past 90 years; ballots, talks, arms, and stones. This struggle for freedom has claimed around 1,00,000 lives, thousands of children have been orphaned, thousands of women raped allegedly by Indian forces, and property worth billions of dollars gutted in anti-terrorist operations by the Indian security forces. The conflict has taken a vicious turn since July 2016 after the famous Hizbul Mujahideen insurgent group commander, Burhan Wani, a local young poster boy was killed by Indian Army. Everyday news of death, torture, injuries, cordons, young boys joining militant groups comes from the Kashmir.

\section{God Testing Us Through Natural Disasters}

The public perception about hazards has evolved over time (Alexander, 2007), and our fieldwork provides further details that cultural practices and beliefs are essential components of scientific knowledge base onto which people usually built castles of misconception, which become barriers to development and progressive approach (Tejwani and Immerman, 2008). This is also suggested by our interaction with locals in Kashmir where 
they firmly believe that God punishes us via earthquake and flood hazards. This is possibly one of the primary reasons that people are not protesting against decades of administrative inaction and failure to secure people from earthquake and flood disasters. Otherwise, any feeble issues related to government failure is routinely contended through public protests in Jammu and Kashmir. Such religious perception is also observed in Leh. The popular cultural tradition in Leh also suggests that in the past the entire Leh valley was a large lake, and God/Saint reclaimed it by removing all the water from the lake. The old lake deposits that surround most of the Leh valley are a testimony to this argument. Interestingly, people of Kashmir have similar views that the valley was a vast lake called Satisar, which was later drained by a saint named Kashyap Rishi (Stein, 1899). The geological studies also agree with lake stories of both these valleys. However, the formation is attributed to the tectonic collision of India with Asia, and not to some supernatural event.

\section{CONCLUSION AND RECOMMENDATIONS}

The fieldwork exercise in parts of Kashmir and Leh is part of our scientific mission to understand the level of earthquake and flood hazard related education and awareness among people. Most of the people are aware of flood hazards, but unfortunately, they continue to rebuild on dangerous flood zones. The concerned authorities in Jammu and Kashmir should thoroughly examine such practices otherwise, if left unchecked, they can lead to devastating flood disasters in the future. The earthquake hazards are less of a concern to people in Leh and Kashmir, and this is possible because of the prolonged recurrence interval of a devastating earthquake event in the recent history of Jammu and Kashmir region. The people are not aware of how to build an earthquake resistant house or any such buildings. The unstable political condition of Kashmir region is one of the primary reasons that people are not really interested in developing earthquake and flood hazard safety measures, which gets gloomy with some religious and cultural perceptions. Undoubtedly, the political dispute is of primary importance to people in Kashmir, and everything else is secondary. Although scientific progress can significantly help one to understand the science and remedy of how to live with hazards, such progress ought to be achieved on the political front as well so that people can feel a sense

\section{REFERENCES}

Afzal, M. R. (ed.) (1966). Speeches and Statements of the Quaid-i-Azam Mohammad Ali Jinnah, 1911-36 and 1947-48. Lahore: Research Society of Pakistan.

Alexander, D. E. (2007). Misconception as a barrier to teaching about disasters. Prehosp. Disaster Med. 22, 95-103. doi: 10.1017/S1049023X00 004441

Ali, U., and Ali, S. A. (2018). Seismically induced soft-sediment deformation structures in an active seismogenic setting: the plio-pleistocene karewa deposits, Kashmir Basin (NW Himalaya). J. Struct. Geol. 115, 28-46. doi: 10.1016/j.jsg. 2018.07.005

Ambraseys, N., and Bilham, R. (2000). A note on the Kangra M s = 7.8 earthquake of 4 April 1905. Curr. Sci. 79, 45-50. of safety and security. There is an urgent need to engage local communities in the building of a resilient community culture to deal with earthquake and flood hazards. International scholarship programs can significantly narrow the knowledge gap by helping local scientists to handle such hazards. International workshop and conferences can also aid in highlighting the scientific and political problems that the region faces and could assist in resolving such issues.

\section{ETHICS STATEMENT}

The Ethics Committee of the Faculty of Arts and Social Sciences, University of Brunei Darussalam in a meeting held on May 1, 2018 reviewed and approved the fieldwork involving subjects in Jammu and Kashmir, India. Under the registration no. 17H0553. The person involved is Sheeba Khwaja, one of the authors of this paper.

\section{AUTHOR CONTRIBUTIONS}

AS and SK coordinated the work and planned the outline of the manuscript. QR and ZJ mainly contributed to field data collection. AS wrote the earthquake and flood-related portions of the manuscript. SK and BS wrote the historical context of the Kashmir problem. BS have contributed significantly to the English language editing of the paper. All authors discussed the results and contributed to the writing of the manuscript.

\section{FUNDING}

Financial support from the National Geographic Society is highly appreciated. Without their support fieldwork would have been impossible.

\section{ACKNOWLEDGMENTS}

We are very grateful to all the people who helped us in data collection in Leh and Kashmir regions. We are especially thankful to Asst. Prof. Firdous and Asst. Prof. Mushtaq from Anantnag Kashmir for their help in the field.

Ambraseys, N., and Bilham, R. (2011). Corruption kills. Nature 469, 153-155. doi: $10.1038 / 469153 a$

Ambraseys, N. N., and Douglas, J. (2004). Magnitude calibration of north Indian earthquakes. Geophy. J. Int. 159, 165-206. doi: 10.1111/j.1365-246X.2004. 02323.x

Avouac, J. P., Meng, L., Wei, S., Wang, T., and Ampuero, J. P. (2015). Lower edge of locked main Himalayan thrust unzipped by the 2015 Gorkha earthquake. Nat. Geosci. 8, 708-711. doi: 10.1038/ngeo2518

Bendick, R., Bilham, R., Fielding, E., Gaur, V. K., Hough, S. E., Kier, G., and Mukul, M. (2001). The 26 January 2001 "Republic Day” earthquake, India. Seismol. Res. Lett. 72, 328-335.

Bhatt, D. K. (1976). Stratigraphical status of karewa group of Kashmir. India Himalayan Geol. 6, 197-208. 
Bilham, R., and Bali, B. S. (2014). A ninth century earthquake-induced landslide and $\mathrm{flood}$ in the Kashmir Valley, and earthquake damage to Kashmir's medieval temples: bull. Earthq. Eng. 12, 79-109. doi: 10.1007/s10518-013-9504-x

Bilham, R., Gaur, V. K., and Molnar, P. (2001). Himalayan seismic hazard. Science 293, 1442-1444. doi: 10.1126/science.1062584

Bilham, R., Singh, B., Bhat, I., and Hough, S. (2010). Historical earthquakes in Srinagar, Kashmir: clues from the shiva temple at pandrethan. Spec. Pap. Geol. Soc. Am. 471, 107-117. doi: 10.1130/2010.2471(10)

Bose, S. (1997). The Challenge in Kashmir. Michigan, IN: University of Michigan Democracy Press.

Brass, P. R. (2003). The partition of India and retributive genocide in the Punjab, 1946-47: means, methods, and purposes. J. Genoc. Res. 5, 71-101. doi: 10.1080/ 14623520305657

Burbank, D. W., and Johnson, G. D. (1982). Intermontane-basin development in the past $4 \mathrm{Myr}$ in the north-west Himalaya. Nature 298, 432-436. doi: 10.1038/ $298432 \mathrm{a} 0$

Burbank, D. W., and Johnson, G. D. (1983). The Late Cenozoic chronologic and stratigraphic development of the Kashmir intermontane basin, northwestern Himalaya. Palaeogeogr. Palaeoclimatol. Palaeoecol. 43, 205-235. doi: 10.1016/ 0031-0182(83)90012-3

Chandra, R., Dar, J. A., Romshoo, S. A., Rashid, I., Parvez, I. A., Mir, S. A., et al. (2018). Seismic hazard and probability assessment of Kashmir valley, northwest Himalaya. India Nat. Hazards 93, 1451-1477. doi: 10.1007/s11069-0183362-4

Ding, L., Kapp, P., and Wan, X. (2005). Paleocene-eocene record of ophiolite obduction and initial India-Asia collision, South central Tibet. Tectonics 24:TC3001. doi: 10.1029/2004TC001729

Copley, A., Avouac, J. P., and Royer, J. Y. (2010). India-Asia collision and the Cenozoic slowdown of the Indian plate: implications for the forces driving plate motions. J. Geophy. Res. 115:B03410. doi: 10.1029/2009JB006634

Crowley, K., and Elliott, J. R. (2012). Earthquake disasters and resilience in the global North: lessons from New Zealand and Japan. Geograph. J. 178, 208-215. doi: 10.1111/j.1475-4959.2011.00453.x

Ellis, P., and Khan, J. (1999). "Kashmir: partition and the diaspora," in Region and Partition: Bengal, Punjab and the Partition of the Subcontinent, ed. G. Singh (New Delhi: Oxford University Press).

Fazili, M. (1980). Socialist Ideas and Movements in Kashmir (1919-1947). New Delhi: Eureka Publications.

Gavillot, Y., Meigs, A., Yule, D., Heermance, R., Rittenour, T., Madugo, C., et al. (2016). Shortening rate and Holocene surface rupture on the Riasi fault system in the Kashmir Himalaya: active thrusting within the Northwest Himalayan orogenic wedge. Geol. Soc. Am. Bull. 128, 1070-1094. doi: 10.1130/B31281.1

Gilmartin, D. (1998). Partition, Pakistan, and South Asian history: in search of a narrative. J. Asian Stud. 57, 1068-1095. doi: 10.2307/2659304

Hobley, D. E., Sinclair, H. D., and Mudd, S. M. (2012). Reconstruction of a major storm event from its geomorphic signature: the Ladakh floods, 6 August 2010. Geology 40, 483-486. doi: 10.1130/G32935.1

Hough, S. E. (2010). Predicting the Unpredictable: The Tumultuous Science of Earthquake Prediction, Vol. 272, Princeton: Princeton University Press. doi: $10.1515 / 9781400883547$

Islam, N. (1981). Islam and national identity: the case of Pakistan and Bangla Desh. Int. J. Middle East Stud. 13, 55-72. doi: 10.1017/S0020743800055070

Jalal, A. (1990). Kashmir Scars: A Terrible Beauty is Torn. New Repub. 17-20.

Kirstein, L. A. (2011). Thermal evolution and exhumation of the Ladakh Batholith, northwest Himalaya. India Tectonophys. 503, 222-233. doi: 10.1016/j.tecto. 2011.03.005

Kumar, R., and Acharya, P. (2016). Flood hazard and risk assessment of 2014 floods in Kashmir valley: a space-based multisensor approach. Nat. Hazards 84, 437-464. doi: 10.1007/s11069-016-2428-4

Kumar, S., Wesnousky, S. G., Rockwell, T. K., Ragona, D., Thakur, V. C., and Seitz, G. G. (2001). Earthquake recurrence and rupture dynamics of Himalayan frontal Thrust. India. Science 294, 2328-2331. doi: 10.1126/science.1066195

Lawrence, W. R. (1895). The Valley of Kashmir. Oxford: Oxford University Press, 205-219.

Le Fort, P. (1975). Himalayas: the collided range. Present knowledge of the continental arc. Am. J. Sci. 275, 1-44.

Meraj, G., Romshoo, S. A., Yousuf, A. R., Altaf, S., and Altaf, F. (2015). Assessing the influence of watershed characteristics on the flood vulnerability of Jhelum basin in Kashmir Himalaya. Nat. Hazards 77, 153-175. doi: 10.1007/s11069015-1605-1

Najman, Y., Appel, E., Boudagher-Fadel, M., Bown, P., Carter, A., Garzanti, E., et al. (2010). Timing of India-Asia collision: geological, biostratigraphic, and palaeomagnetic constraints. J. Geophys. Res. 115:B12416. doi: 10.1029/ 2010JB007673

Nakata, T. (1989). Active faults of the Himalaya of India and Nepal. Geol. Soc. Am. Spec. Pap. 232, 243-264. doi: 10.1130/SPE232p243

Naseer, A., Khan, A. N., Hussain, Z., and Ali, Q. (2010). Observed seismic behavior of buildings in northern Pakistan during the 2005 Kashmir earthquake. Earthq. Spectra 26, 425-449. doi: 10.1193/1.3383119

Paton, D., Bajek, R., Okada, N., and McIvor, D. (2010). Predicting community earthquake preparedness: a cross-cultural comparison of Japan and New Zealand. Nat. Hazards 54, 765-781. doi: 10.1007/s11069-0109500-2

Pathier, E., Fielding, E. J., Wright, T. J., Walker, R., Parsons, B. E., and Hensley, S. (2006). Displacement field and slip distribution of the $2005 \mathrm{Kashmir}$ earthquake from SAR imagery. Geophys. Res. Lett. 33:L20310. doi: 10.1029/2006GL02 7193

Romshoo, S. A., Altaf, S., Rashid, I., and Dar, R. A. (2018). Climatic, geomorphic and anthropogenic drivers of the 2014 extreme flooding in the Jhelum basin of Kashmir. India. Geomat. Nat. Hazards Risk 9, 224-248. doi: 10.1080/19475705. 2017.1417332

Schiffman, C., Singh Bali, B., Szeliga, W., and Bilham, R. (2013). Seismic slip deficit in the Kashmir Himalaya from GPS observations. Geophy. Res. Lett. 40, 5642-5645. doi: 10.1002/2013GL057700

Searle, M., Corfield, R. I., Stephenson, B., and McCarron, J. (1997). Structure of the North Indian continental margin in the Ladakh-Zanskar Himalayas: implications for the timing of obduction of the Spontang ophiolite, India-Asia collision and deformation events in the Himalaya. Geol. Mag. 134, 297-316. doi: 10.1017/S0016756897006857

Shah, A. A. (2013). Earthquake geology of Kashmir Basin and its implications for future large earthquakes. Int. J. Earth Sci. 102, 1957-1966. doi: 10.1007/s00531013-0874-8

Shah, A. A. (2014). Predicting the unpredictable: the tumultuous science of earthquake prediction. Geosci. J. 18, 373-374. doi: 10.1007/s12303-014-0 $002-1$

Shah, A. A. (2015). Assessing the influence of watershed characteristics on the flood vulnerability of Jhelum Basin in Kashmir Himalaya by Gowhar et al., 2015. Nat. Hazards 77, 2139-2143. doi: 10.1007/s11069-0151775-x

Shah, A. A. (2016). The Kashmir Basin fault and its influence on fluvial flooding in the Kashmir Basin, NW Himalaya. Geol. Soc. Am. Spec. Pap. 520, 321-334. doi: 10.1130/2016.2520(28)

Shah, A. A., and Malik, J. N. (2017). Four major unknown active faults identified, using satellite data, in India and Pakistan portions of NW Himalaya. Nat. Hazards 88, 1845-1865. doi: 10.1007/s11069-017-2949-5

Shah, A. A., Qadri, T., and Khwaja, S. (2018). Living with earthquake hazards in South and Southeast Asia. ASEAN J. Commun. Engage. 2, 15-37.

Sherman, T. C. (2007). The integration of the princely state of Hyderabad and the making of the postcolonial state in India, 1948-56. Ind. Econ. Soc. Hist. Rev. 44, 489-516. doi: 10.1177/001946460704400404

Sieh, K. (2007). The Sunda megathrust-past, present and future. J. Earthq. Tsunami 1, 1-19. doi: 10.1142/S179343110700002X

Stein, A. (1899). Memoir on Maps Illustrating the Ancient Geography of Kaśmîr. Kolkata: Baptist Mission Society, 65-66.

St-Onge, M. R., Rayner, N., and Searle, M. P. (2010). Zircon age determinations for the Ladakh batholith at Chumatang (Northwest India): implications for the age of the India-Asia collision in the Ladakh Himalaya. Tectonophysics 495, 171-183. doi: 10.1016/j.tecto.2010.09.010

Subbiah, S. (2004). Security council mediation and the kashmir dispute: reflections on its failures and possibilities for renewal. Boston College Int. Comp. Law Rev. 27, 173-185.

Tejwani, N. C., and Immerman, I. (2008). Myths and legends in orthopaedic practice: are we all guilty? Clin. Orthop. 466, 2861-2872. doi: 10.1007/s11999008-0458-2 
Thayyen, R. J., Dimri, A. P., Kumar, P., and Agnihotri, G. (2013). Study of cloudburst and flash floods around Leh, India, during August 4-6, 2010. Nat. hazards 65, 2175-2204. doi: 10.1007/s11069-012-0464-2

Wallis, D., Carter, A., Phillips, R. J., Parsons, A. J., and Searle, M. P. (2016). Spatial variation in exhumation rates across Ladakh and the Karakoram: new apatite fission track data from the Eastern Karakoram, NW India. Tectonics 35, 704-721. doi: 10.1002/2015TC003943

Wani, G. A. (1995). Kashmir: History and Politics: Annotated Bibliography. Srinagar: G.A.Wani.

Whitehead, A. (2007). A Mission in Kashmir. New Delhi: Penguin Books.

Yin, A. (2006). Cenozoic tectonic evolution of the Himalayan orogen as constrained by along-strike variation of structural geometry, exhumation history, and foreland sedimentation. Earth. Sci. Rev. 76, 1-131. doi: 10.1016/ j.earscirev.2005.05.004
Zutshi, C. (2004). Languages of Belonging: Islam, Regional Identity and the Making of Kashmir. London: C. Hurst \& Co.

Conflict of Interest Statement: The authors declare that the research was conducted in the absence of any commercial or financial relationships that could be construed as a potential conflict of interest.

Copyright (c) 2018 Shah, Khwaja, Shah, Reduan and Jawi. This is an open-access article distributed under the terms of the Creative Commons Attribution License (CC BY). The use, distribution or reproduction in other forums is permitted, provided the original author(s) and the copyright owner(s) are credited and that the original publication in this journal is cited, in accordance with accepted academic practice. No use, distribution or reproduction is permitted which does not comply with these terms. 


\section{OPEN ACCESS}

Edited by:

Jonathan D. Paul,

Imperial College London,

United Kingdom

Reviewed by:

Davide Tiranti,

Agenzia Regionale per la Protezione

Ambientale (ARPA), Italy

Samuele Segoni,

Università degli Studi di Firenze, Italy

*Correspondence:

Victor Marchezin

victor.marchezini@cemaden.gov.br

Specialty section:

This article was submitted to

Geohazards and Georisks,

a section of the journal

Frontiers in Earth Science

Received: 30 August 2018

Accepted: 12 October 2018

Published: 06 November 2018

Citation:

Marchezini V, Horita FEA,

Matsuo PM, Trajber R,

Trejo-Rangel MA and Olivato D (2018)

A Review of Studies on Participatory Early Warning Systems (P-EWS):

Pathways to Support Citizen Science Initiatives. Front. Earth Sci. 6:184. doi: 10.3389/feart.2018.00184

\section{A Review of Studies on Participatory Early Warning Systems (P-EWS): Pathways to Support Citizen Science Initiatives}

\author{
Victor Marchezini 1,2*, Flávio Eduardo Aoki Horita ${ }^{3}$, Patricia Mie Matsuo ${ }^{4}$, \\ Rachel Trajber ${ }^{1}$, Miguel Angel Trejo-Range/ ${ }^{2}$ and Débora Olivato ${ }^{1}$ \\ ${ }^{1}$ Centro Nacional de Monitoramento e Alertas de Desastres Naturais, São José dos Campos, Brazil, ${ }^{2}$ Programa de \\ Pós-Graduação em Ciência do Sistema Terrestre, Instituto Nacional de Pesquisas Espaciais, São José dos Campos, Brazil, \\ ${ }^{3}$ Centro de Matemática Computação e Cognição, Universidade Federal do ABC, São Paulo, Brazil, ${ }^{4}$ Programa \\ de Pós-Graduação Interunidades em Ensino de Ciências, Universidade de São Paulo, São Paulo, Brazil
}

Context: Global environmental change and disasters pose several challenges to governments, society and science. These challenges occurred in social contexts were information and communication technologies can be used to share data and information, engaging citizen scientists in multidirectional and decentralized knowledge creation initiatives. Often referenced as participatory (or people-centered) early warning systems, this has been of a great potential to improve decisions taken by both emergency institutions and exposed and/or affected communities. Several methodologies have been proposed, mainly in natural science, redefining traditional ways of transferring knowledge about scientific process to the public.

Gap: However, practice and research still lack studies that investigate how citizens can be involved in citizen science to support early warning systems. From a social science perspective, this is important as these works do not fill the gap between citizen science and disaster prevention. While, on a technological perspective, efforts have been concentrated on developing systems, methodologies, and approaches rather than understanding citizens' requirements or ways of better engaging citizens.

Objective: This paper provides a social science framework to determine the elements of how citizen science and participatory early warning systems can be bridged.

Method: For doing so, we will conduct a systematic mapping for examining the literature on citizen science and disaster management, in particular, those focused on social science and participatory approaches for early warning systems.

Results: This review showed that only 3,43\% (14 of 408) articles were related to citizen science and P-EWS, which indeed indicate that much effort is needed to disseminate what is citizen science and how it can be mainstreamed in DRM field. Furthermore, the proposed framework can contribute by enhancing stakeholders' reflexivity about EWS.

Keywords: community-based disaster risk management, capacity building, resilience, interdisciplinary, transdisciplinary 


\section{INTRODUCTION}

In 2016, the United Nations International Strategy for Disaster Reduction (Unisdr) conducted an international conference to discuss the role of Science and Technology (S\&T) on the implementation of the Sendai Framework for Disaster Risk Reduction 2015-2030 (SFDRR). The 2016 S\&T Conference aimed to find pathways to expand science's impact on disaster risk reduction (DRR) strategies, building networks among practitioners, policymakers and scientists from different fields of knowledge and expertise (Aitsi-Selmi et al., 2016). One of the working groups focused on how to coordinate the agenda of disaster risk science with the requirements of innovation in interdisciplinary methods, robust data collection, tools and better communication systems, especially in early warning system (EWS).

The most updated definition of EWS provided by United Nations International Strategy for Disaster Reduction [UNISDR] (2016) framed it as an integrated system that comprises disaster risk assessment, hazard forecast, prediction and monitoring, risk communication and emergency preparedness activities. As a set of capacities, data, information and knowledge that allow the early action of individuals and communities exposed to hazards to prepare and evacuate in an appropriate manner and in adequate time to reduce the likelihood of loss of life, personal injury, losses and damages (United Nations International Strategy for Disaster Reduction [UNISDR], 2009). EWS then should combine four complementary elements-risk knowledge, monitoring, communication of warnings, and response capability (United Nations International Strategy for Disaster Reduction [UNISDR], 2005, 2006a,b, 2015). The scientific literature has been adopting two main approaches of EWS - the "last mile" (hazard-centered and top down) and "first mile" (people-centered and bottom up) (Basher, 2006; Thomalla and Larsen, 2010; Garcia and Fearnley, 2012; Villagrán de León, 2012; Kelman and Glantz, 2014). This work will lie on the "first mile" approach, focusing on people-centered EWS (United Nations International Strategy for Disaster Reduction [UNISDR], 2005, 2006b), community early warning systems - CEWS (International Federation of the Red Cross and Red Crescent Societies [IFRC], 2012), community-centric EWS (Baudoin et al., 2016), community-based EWS (Macherera and Chimbari, 2016a), participatory EWS (Baudoin et al., 2016; Marchezini et al., 2017).

There is a growing recognition that "last mile" approach is not sufficient to reach the aims of EWS. The EWS' working group of Unisdr S\&T Conference, for instance, stated that despite the improvements in remote sensing technology, space-based satellite systems and computer technology for observing, comprising real-time data collection, modeling capability and dissemination of information, communication still needs to be critical to the success of EWS (AitsiSelmi et al., 2016). Remembering the critics about the EWS' failures during the 2004 Indian Ocean Tsunami (Kelman, 2006) - when around 230,000 people died - researchers stressed the importance of people-centered approaches and the need to identify capacities of different countries for
EWS implementation. Not only the international, regional and national partnerships were stressed as important, but also the local level capacity to ensure involvement and ownership in EWS. More specifically, the need to consider the user voices from across society and engaging them in EWS were highlighted as essential (Aitsi-Selmi et al., 2016). However, as we will discuss in the section 2 of this paper, there are many forms of engagement and participation in these people-centered approaches.

Although previous studies have stated that Unisdr lacks explicit means for implementing people-centered approaches and bottom-up design (Nguyen et al., 2009; Paveglio et al., 2010; Garcia and Fearnley, 2012; Zia and Wagner, 2015), the 2016 S\&T Conference did not mention the need of research to discover how to promote people-centered EWS (AitsiSelmi et al., 2016). Some working groups recognized the need of bottom-up and participatory approaches in disaster risk research, and considered that such collaborations to co-producing knowledge "could include (but are not limited to) the incorporation of indigenous perspectives and knowledge and using a variety of 'citizen science' programs" (Aitsi-Selmi et al., 2016, p. 18). Citizen science refers to the engagement of the public in data collection, data analysis, information sharing, and knowledge co-production (Teschenhausen, 2015). However, there are different forms of participation (informing, consulting, co-creating etc.) and models of cooperation in citizen science (contributive, collaborative, co-created) (Bonney et al., 2009).

On a technological perspective, efforts have been concentrated on developing systems, methodologies, and approaches rather than understanding citizens' requirements or ways of better engaging citizens in EWS (Villagrán de León et al., 2006; Quansah et al., 2010; Kou and Wu, 2014; Horita et al., 2017). In contrast, practice and research still lack studies that investigate how citizens can be involved in citizen science to support early warning systems. This is important because local citizens are the true first responders to mobilize during emergencies and they have a critical role in saving lives and to render assistance to those in need (Glantz and Ramírez, 2018). This paper provides a social science framework to determine the elements of how citizen science and participatory early warning systems can be bridged. For doing so, we conduct a review that examines the existing literature on citizen science and disaster management, in particular, those focused on social science and participatory approaches for early warning systems, complementing previous systematic review of community-based EWS (Garcia and Fearnley, 2012; Macherera and Chimbari, 2016a).

This paper is structured as follows. Section 2 provides the theoretical background about the two main approaches of EWS, forms of engagement and participation, and models of cooperation in citizen science. Section 3 then describes the research methodology, while Section 4 details the study results. Section 5 discusses these results and introduces the social science framework. Finally, Section 6 draws some conclusions and final considerations. 


\section{THEORETICAL BACKGROUND}

\section{Early Warning Systems}

EWSs are a social process with diverse levels of complexity, vulnerabilities and capacities due the varied political and socioeconomic contexts where they work (Garcia and Fearnley, 2012; Michoud et al., 2013; Kelman and Glantz, 2014; Lumbroso et al., 2016). Moreover, there are different characteristics, types and frequencies of hazards (rapid, slow) and variations in spatial scale (local, regional, national, and global), besides the number of stakeholders involved in the EWS (civil authorities, enterprises, scientists, media, communities, practitioners, and technicians).

Gray and scientific literature have some consensus regarding the importance of the four components of the EWS: risk knowledge, monitoring, communication and response capability. However, the different approaches regarding each of the four axes imply diverse definitions. In this paper, we consider risk knowledge as a systematic data collection and analysis of hazards and vulnerabilities - physical, social, economic, and environmental - that merge in risk scenarios subject to changes in the short and long term (Marchezini et al., 2017). Monitoring implies the capacities for collecting dynamic data and information and for analyze them on the basis of prior knowledge to take decisions. Communication is the process of sharing data, information and knowledge about the risks and warning situations. Response capability is the preparedness capacity to know how to act and is often rooted in resources, skills and networks that stakeholders have. Local governments, for instance, can be more capable when hold sufficient personal, clear structure, proper tasks, delegation and division of labor within the organization (Kusumasari and Alam, 2012).

The traditional conception of EWS conceives it as linear chain with emphasis on risk prediction, monitoring and warning issuance (Basher, 2006). In this approach, EWS are frequently operated by regional or national agencies in charge of risk diagnosis and dissemination of alerts to local authorities and stakeholders. This one-way course is named as the "End-to-End" model (Basher, 2006) and does not directly engage with the users of the EWS in the four-interrelated elements. In this one-way chain, the strong links are technological in nature (risk knowledge and monitoring) whereas communication and response capability are the weak links (Garcia and Fearnley, 2012). This approach has also been named as "last mile," because people are the last to be involved in the system. In this top-down approach, people are not at the center of the social process. The technical equipment (for example, radar and rainfall gauges) detects a hazard and issues alerts to vulnerable people, who are not viewed as being supplied with information and knowledge, or endowed with applicable wisdom. This approach assumes that all the relevant data, information, and knowledge are outside the local communities, placing emphasis on technological and scientific factors. For instance, the checklist of United Nations International Strategy for Disaster Reduction [UNISDR] (2006a) about EWS implementation states the monitoring is the core of the system, but did not cite the importance of participation in this component of EWS.
Other conceptions advocate for more participation in each of the four interrelated components of EWS, and are named the "first mile" approach because put people at first in designing and operation of the system. In this "horizontal" model, multiple stakeholders must be in dialog and cooperation at every phase of the process (Gaillard and Mercer, 2012). To make this approach effective, system planners must comprehend the different types and degrees of vulnerability and capability of people. In other words, the EWS must consider who are the people and examine the interconnection of social dimensions such as human mobility and demographic characteristics, occupation, religion, culture, language, gender relations, sexuality, ethnicity, race, age, persons with disabilities, refugees, livelihoods and environmental change over time. Gender, for instance, means "the socio-culturally and politico-economically constructed roles and responsibilities ascribed to men and women, girls, boys and members of sexual and gender minorities, which change over time, are context- and history-specific, and are inseparable from power relations" (Mustafa et al., 2015, p. 2). Gender relations shape differentiated access to rights and resources - healthcare services, education, transportation, access to information -, and will define, for example, our ability to prepare, cope with, and "be resilient or not" in the wake of hazards.

"First mile" approach has been represented by a variety of names such as people-centered EWS (United Nations International Strategy for Disaster Reduction [UNISDR], 2005, 2006a), community early warning systems - CEWS (International Federation of the Red Cross and Red Crescent Societies [IFRC], 2012), citizen-centered EWS (Mustafa et al., 2015), community-centric EWS (Baudoin et al., 2016), community-based EWS (Macherera and Chimbari, 2016a), participatory EWS (Baudoin et al., 2016; Marchezini et al., 2017).

Community-based early warning system (CBEWS) is defined "as one in which the communities participate in hazard identification and the formulation of the warning system, and not merely reacting to a warning at local level" (Macherera and Chimbari, 2016a, p. 3). According to Macherera and Chimbari (2016a, p. 9), for the International Federation of Red Cross and Red Crescent Societies (IFRC), the term "community"-based early warning systems "does not really imply community participation, but may mean a system that is based at community level but implemented by other agencies". International Federation of the Red Cross and Red Crescent Societies [IFRC] (2012, p. 13) states that community early warning systems (CEWS) is better because "is understood to be an effort by or with, but not for, a community to systematically collect, compile and/or analyze information that enables the dissemination of warning messages that when actionable can help the community (or others 'downstream') reduce harm or loss from a hazard (or threat) event (or process)". Inspired by this IFRC's definition, Baudoin et al. (2016, p. 164) proposed the concept of "community-centric" EWS (CCEWS) which is defined as initiatives by a community "to collect information for hazard risk detection, to enable the dissemination of warning messages among at-risk groups, and to facilitate the implementation of emergency plans or responses that can help the community reduce harm or loss from a hazard event". 
For Baudoin et al. (2016), CCEWS is a system initiated and conducted by its beneficiaries, grounded in the local level, and a response to the gaps in the "End-to-End" model. For these authors, the common participatory principles to guide CCEWS are the need "to understand local context, integrate local knowledge, and take account of individual motivations when planning and implementing risk management activities" (Baudoin et al., 2016, p. 166).

Based on a gray and scientific literature review about CBEWS on Google scholar electronic search engine, Macherera and Chimbari (2016a) stated that NGOs have nurture the development of CBEWS. The authors identified several examples of CBEWS, as well as analyzed step-by-step guides elaborated by NGOs. The researchers pointed out several gaps regarding EWS' definitions adopted by organizations, such as the lack of specification about the source of the warning, and misunderstandings of how early a warning should be issue, since it depends not only on the hazard's characteristics, but on the degree of people's capacities to prepare and cope with risks. Moreover, they stated that definitions often emphasized the need of community participation in the EWS' development, but they do not qualify the extent of engagement or types of participation (Macherera and Chimbari, 2016a).

The next section will discuss about types of participation, considering that despite their different names, these peoplecentered initiatives have participation as their basic element. Perhaps these diverse types of participation can be used differently in the four-interrelated elements of EWSs, increasing gradually the involvement of people in their designing, implementation and operation.

\section{Participation}

Currently social participation is a prominent element in the formulation and implementation of public policies, as it generates greater legitimacy to the process and strengthens governance (Olivato, 2013). It is possible to view participation as a means of mobilizing the subjective knowledge of those affected by climate change and disasters potentially overcoming senses of alienation, apathy or powerlessness.

Social participation refers to the appropriation by individuals of their right to democratic construction of their own destiny. The outcomes depend upon collective organization, providing spaces of discussion within and outside the boundaries of the community for developing strategies for action and the dialog with the public authorities (Tenório and Rozenberg, 1997). Moreover, participatory processes involve overcoming consolidated power relations and ensuring the exercise of citizenship, particularly concerning people in a situation of greater socio-environmental vulnerability (Loureiro and Layrargues, 2013).

To guarantee participatory effectiveness, that is, to produce a favorable outcome, it's essential to ensure the representativeness of various groups of stakeholders, within a transparent decision-making process that provides access to knowledge to all groups involved or affected (Jacobi and Franco, 2011). Santos (2004) points out that participation will only be effective if the community involved is not considered as an object but as subject of the process. According to Dyball et al. (2009), social actors' participation can range from coercion (passive participation, as just representing some group) to co-acting (active participation) (see Table 1).

One lesson learned from Hyogo Framework for Action (HFA) is the need to focus on "meaningful participation of relevant stakeholders at appropriate levels" (United Nations International Strategy for Disaster Reduction [UNISDR], 2015, p. 6). Sendai Framework (SFDRR) states that DRR requires an "all - of-society engagement and partnership, empowerment and inclusive, accessible and non-discriminatory participation, paying special attention to people disproportionately affected by disasters, especially the poorest" (United Nations International Strategy for Disaster Reduction [UNISDR], 2015, p. 8).

Concerning specifically community-based disaster risk management (CBDRM), there are several initiatives and forms of participation (Maskrey, 2011), as well as different barriers to citizen engagement, such as gender inequality (Mustafa et al., 2015), lack of transparency, confidence, financing and ownership (Šakić Trogrlić et al., 2017). Preuner et al. (2017), for instance, examines how responsibilities can be shared among the residents, experts, and public authorities during the design and operation of landslide warning systems in Austria. The findings of this case study indicate the need to think carefully about the views, conflicts and different concerns of stakeholders. The authors stated that deliberative planning does not naturally result in sharing responsibilities, once the audience can have different opinions about their own engagement in the control and maintenance of the EWS. However, the deliberative planning was an effective platform for information and for shared ownership in the EWS (Preuner et al., 2017).

TABLE 1 | Types of participation.

\begin{tabular}{|c|c|c|}
\hline Level & Power relationships & $\begin{array}{c}\text { Type of } \\
\text { participation }\end{array}$ \\
\hline \multirow[t]{5}{*}{ Active } & $\begin{array}{l}\text { Participants set their own agendas. Learnings } \\
\text { occur through the negotiation of ways to carry } \\
\text { them out actions in collaboration and power } \\
\text { shifts depending on the negotiations. }\end{array}$ & Co-acting \\
\hline & $\begin{array}{l}\text { Participants use different forms of knowledge to } \\
\text { integrate new understandings. They define } \\
\text { common agendas, share responsibilities within } \\
\text { existing institutional and social setting and } \\
\text { constraints. }\end{array}$ & Co-creating \\
\hline & $\begin{array}{l}\text { One group takes the initiative and power for } \\
\text { enticing other groups to act. They may set } \\
\text { jointly issues such as agenda and priorities. }\end{array}$ & Enticing \\
\hline & $\begin{array}{l}\text { One group (often the government) searches } \\
\text { information from different groups, but decides } \\
\text { on the final project. }\end{array}$ & Consulting \\
\hline & $\begin{array}{l}\text { Information is usually just formal, in a one-way } \\
\text { flow. It uses technical language and people } \\
\text { often feel intimidated to express their views. }\end{array}$ & Informing \\
\hline Passive & $\begin{array}{l}\text { The will of one group is effectively imposed } \\
\text { upon the other. People cannot give opinions } \\
\text { nor defend their interests. }\end{array}$ & Coercing \\
\hline
\end{tabular}

Source: adapted from Dyball et al. (2009). 
Information sharing, crowdsourcing and community disaster mapping can be interesting ways of promoting this deliberative planning in EWS. Indigenous, traditional and science-based knowledge can be connected with technology to contribute to risk detection and monitoring (Baudoin et al., 2016), and to reduce community vulnerability to hazards (Mercer et al., 2010), especially in areas of the world where open source data collection and mobile phone use are increasing (Baudoin et al., 2016). Citizen science approach can a useful way to foster participation in EWS. Next section will discuss models of cooperation in citizen science.

\section{Citizen Science}

The term citizen science is new. It arose in the Oxford English Dictionary in 2014. Defined as the engagement of members of the general public in data collection and analysis, usually as part of a collaborative project with professional scientists (Bonney et al., 2016), citizen science has been used in different ways. Some authors consider that it involves a situation in which people use scientific methods to investigate phenomena without any institutional cooperation of scientists (Heiss and Matthes, 2017). Others understand citizen science as a transdisciplinary collaboration between professional scientists and volunteers who are responsible for collecting data and sometimes analyze it, producing an educational outcome (Bonney et al., 2009). However, not all citizen science initiatives realize these two goals to the same degree (Heiss and Matthes, 2017).

Bonney et al. (2016) stated that Oxford's definition does not capture the richness and diversity of citizen science initiatives. For example, it disregards the fact that citizen science supports projects in which audiences participate in tasks beyond collection and analysis of data; projects in which volunteers work not only in teams but also by themselves, with or without the collaboration of scientists; projects that are human-focused rather than ecologically focused; projects that emphasize issues raised not by scientists but by communities; and certainly more types of participatory science that are yet to be imagined. The involvement of social science research projects in this topic, for instance, are still hard to find (Heiss and Matthes, 2017).

The methods and conditions under which citizen science projects can effectively engaging public participants in research remains a key challenge in the field (Bonney et al., 2016). There are at least three models of cooperation in citizen science initiatives (Bonney et al., 2009):

- contributive model: volunteers contribute to data collection only;

- collaborative model: volunteers get engaged in data collection, analysis and interpretation;

- co-created projects: volunteers define the research question and design and are also involved in all phases of the scientific process, including collection, analysis and interpretation of data and information.

These three models of cooperation in citizen science (Bonney et al., 2009) are very similar to three approaches identified by Giordano et al. (2010) regarding the using of local audiences for environmental monitoring, namely: volunteer monitoring (citizen involvement in data collection), collaborative monitoring (data collection and analysis to help decision making), and community-based monitoring (active involvement in the design and operation of the monitoring program) (Giordano et al., 2013). Once EWSs comprise at least other three interrelated axes - risk knowledge, communication and response capability -, it is important to identify and design citizen science initiatives considering contributive, collaborative and/or co-created models, different types of hazards, vulnerabilities and capacities, as well as types of participation according to the variety of audiences.

Disaster risk reduction projects based on citizen science are a challenging area for researching and policymaking. Stone et al. (2014), for example, reported interesting findings about community-based volcano monitoring in Ecuador and showed how observational data provided by volunteers were used by scientists and essential for EWS. This citizen science project around volcano Tungurahua was based on a collaborative model where volunteers contribute to data collection, analysis and interpretation. The volunteers "were given basic training from the scientists about what to observe, how to describe phenomena and how to communicate with OVT [Tungurahua Volcano Observatory]" (Stone et al., 2014, p. 7). The identification and analysis of other citizen science initiatives on EWS are an important step to put in place the Unisdr's recommendation of building people-centered EWS (United Nations International Strategy for Disaster Reduction [UNISDR], 2005, 2015). Next section details the methods used in this research.

\section{RESEARCH METHODOLOGY}

The objective of this article is to determine elements that bridge citizen science and participatory early warning systems. For doing so, we conducted a literature review that was routed on principles of systematic literature reviews (SLR) and systematic mapping studies (SMS). The former is a means of evaluating and interpreting all the studies available in the literature about research questions, field area, or phenomenon of interest (Kitchenham and Charters, 2007). While, SMS analyzes relevant studies in order to get an overview of an area or theme (Petersen et al., 2008). Reviews that employ this method often aim to answer broader research questions than SLR that is more delimited and bounded. Both methods have their individual and specific set of characteristics and principles that may be not suitable for all types of literature review. That is why we adopted a combination of them, i.e., the rigor and well-defined methodological steps of SLR with the comprehensiveness of SMS. All elements that guided the literature review were established in a previously predetermined protocol, which was defined after three sessions of discussions among the authors. These elements are presented in the next sections.

\section{Research Goal}

One of the most important elements when conducting a literature review is the establishment of the research goal. This should comprise not only the description of goal, but also the research 
scope, as well as the reasons of why the review is relevant and for whom. We thus adopted the goal definition template for supporting "the definition of measurements goals by specifying purpose (what object and why), perspective (what aspect and who), and context characteristics" (Basili, 1994). Table 2 details the goal of this work using the template.

In regarding the research scope, we also aimed at obtaining only existing primary studies from 2005 to 2018 (Jun) due to the issued date of world-wide disaster risk reduction frameworks; Hyogo in 2005 and Sendai in 2015. Further reason here is to examine the how and if these frameworks motivated and impacted research work in the field. On the basis of these definitions, we establish the following main research questions that this work envisions to answer:

1. RQ1. What are the areas of study?

2. RQ2. What are the types of hazard?

3. RQ3. What are the participatory approaches adopted for supporting EWS?

4. RQ4. What are the models of cooperation in citizen science (Bonney et al., 2009)?

5. RQ5. How existing works cover citizen science projects in EWS?

\section{Search Strategy}

On the basis of the research goal, we delineated the search strategy that comprised the selection of sources for obtaining the primary studies, the establishment of inclusion and exclusion criteria and search string, and the definition of the search procedure.

\section{Source Selection}

We decided to conduct the literature review on well-known journals in the area of disaster risk management as many venues are not yet indexed in automated digital libraries. Furthermore, we aimed at not only identifying studies that cover the whole extent of the context defined for the research goal, but also to obtaining high-quality articles. The criteria adopted in this work were manifold: (i) the frequency of publications (i.e., the number of publications per period); (ii) research themes covered by the venue (i.e., the themes of interest were those related to the research goal); and (iii) availability of publications (i.e., the article should be available to download). We focused only on journals that published research works in English. Table 3 shows the selected journals for this literature review.

Most of the selected journals are only focused on themes of interest to this work, such as policies for disaster prevention and mitigation, as well as education efforts for disaster risk reduction. Although some venues motivate a debate on technical areas

TABLE 2 | Goal definition for the literature review.

Analyze

For the aim of

With respect to

From the perspective of

In the context of existing literature of disaster risk management

identifying the current state-of-the-art

existing efforts that employ participatory information for EWS

scientists and practitioners

disaster risk management of disaster analysis like environmental modeling and physical aspects of disaster events, they have been also publishing works that are of particular interest to our work.

The selection of sources was carried out by a sociologist with expertise in disaster prevention and EWS. His work was developed in collaboration with a computer scientist with experience in conducting systematic literature reviews focused on information systems and collaborative systems for DRM.

\section{Inclusion and Exclusion Criteria}

Having selected the sources for analysis, we mapped all situations in which a primary study would be selected to our literature review. The study selection was then summarized in a set of filtering criteria, i.e., inclusion and exclusion criteria. The primary study is included if: (1) it proposes approaches to use citizen data in the context of EWS; or (2) it reports both scientific and practical experiences of participatory early warning systems. In contrast, a study is excluded in the following situations: (1) it is not written in English; (2) it is not available online; (3) it is duplicated; (4) it is not related to early warning systems; (5) it is not related to citizen science, or participatory data; (6) it is a previous version of a more complete study about the same research; (7) it is an editorial, position paper, keynote, opinion paper, tutorial, poster or panel; (8) it is a secondary study (e.g., reviews, surveys, and SLRs). The first two authors of this work were responsible for establishing and defining these criteria.

\section{Search String}

Since this article aims at investigating the linking of citizen science and participatory early warning systems, we selected four main keywords, "citizen science," "early warning systems," "natural hazard" and "social science." These were then associated with their related synonyms. The final search string is: ("participatory" OR "citizen science" OR "people-centered" OR “community-based”) AND ("early warning system”) AND ("natural hazard” OR “disaster management" OR “disaster risk reduction") AND ("social science").

For evaluating and refining the defined elements, the first two authors conducted a pilot study that was focused on analyzing the title, abstract, and keywords of articles returned in the first page of a search in the Scopus. This search was carried out utilizing the search string, while the selection of studies employed the inclusion and exclusion criteria. After the pilot study, both authors have agreed that no additional modifications would be necessary in the established criteria or in the search string.

\section{Data Extraction}

With the aim of answering the research questions proposed in this work, a set of items were defined to be extracted from the selected primary studies. Table 4 presents the extracted items.

For extracting data, each selected study was read in full by one of the authors, which was also responsible for identifying and extracting the data. Only items I10 and I11 had predetermined alternatives to selecting, i.e., "co-created projects, collaborative model, contributive model, no, or others" for I10 and "Co-acting, co-creating, coercing, consulting, enticing, or informing" for I11. The remaining items were all open-text fields. The I10 
TABLE 3 | Selected journals for this literature review.

\begin{tabular}{|c|c|c|c|}
\hline Journal & Link & $\begin{array}{l}\text { Creation } \\
\text { Year }\end{array}$ & $\begin{array}{l}2017 \text { JCR } \\
\text { Impact Factor }\end{array}$ \\
\hline Disasters & https://onlinelibrary.wiley.com/journal/14677717 & 1977 & 1.596 \\
\hline Natural Hazards & https://link.springer.com/journal/11069 & 1989 & 1.901 \\
\hline Disaster Prevention and Management & https://www.emeraldinsight.com/journal/dpm & 1992 & 1.060 \\
\hline Environmental Hazards & https://www.tandfonline.com/toc/tenh20/ & 1999 & 1,220 \\
\hline Natural Hazards and Earth System Science & https://www.natural-hazards-and-earth-system-sciences.net/ & 2001 & 2.281 \\
\hline Journal of Disaster Risk Studies (Jamba) & https://jamba.org.za/index.php/jamba & 2006 & Not ranked \\
\hline International Journal of Disaster Risk Science & $\begin{array}{l}\text { https://www.springer.com/earth+sciences+and+geography/ } \\
\text { natural+hazards/journal/13753 }\end{array}$ & 2010 & 2.225 \\
\hline International Journal of Disaster Risk Reduction & $\begin{array}{l}\text { https://www.sciencedirect.com/journal/international-journal-of- } \\
\text { disaster-risk-reduction }\end{array}$ & 2012 & 1.968 \\
\hline Resilience & https://www.tandfonline.com/loi/resi20 & 2013 & Not ranked \\
\hline
\end{tabular}

TABLE 4 | Extracted items.

\begin{tabular}{ll}
\hline Item & Title \\
\hline 11 & Title \\
12 & Author (s) \\
13 & Year \\
14 & Journal \\
15 & Abstract \\
16 & Affiliation (s) \\
17 & Study area \\
18 & Type of hazard (s) \\
19 & Citizen science \\
110 & Models of cooperation \\
111 & Type of participation \\
\hline
\end{tabular}

predetermined alternatives were based on classification proposed by Bonney et al. (2009), detailed previously in theoretical background. The I11 alternatives were also explained in the same section and were based on Dyball et al. (2009).

\section{Search Procedure}

Based on the inclusion and exclusion criteria, search string, and data extraction, we defined a search procedure for selecting primary studies and later answering the research questions. This procedure comprises three sequential phases: (a) searching studies on selected journals (Phase 1); (b) selecting studies based on inclusion and exclusion criteria (Phase 2); (c) analyzing and extracting relevant information of selected studies (Phase 3).

To start with, the search string was applied in each of the selected source listed in Table 3, searching the keywords and their synonyms in the title, abstract and keywords of primary studies. As mentioned previously, we considered only those studies published between 2005 and 2018 (June). Furthermore, in only one case, we had to customize the string before applying it. Environmental Hazard journal requires the inclusion of specific metadata ${ }^{1}$. All primary studies returned by the searching process

${ }^{1}$ [[All: "participatory"] OR [All: "citizen]] AND [[All: science"] OR [All: "people-centered"] OR [All: "community-based"]] AND [All: "early warning were downloaded and imported into the SLR management tool. This work adopted as a tool, the Parsifal ${ }^{2}$, which supports the conducting of SLR.

During the second phase, the set of imported studies was analyzed taking as a basis the inclusion and exclusion criteria. Here, we still rely only on the title, abstract and keywords of the studies. When necessary, the introduction and conclusion of a study were also read and analyzed. As a result, a list containing only those studies considered potentially relevant would be generated.

Finally, all studies selected in the previous phase were read in full-text and still analyzed based on the inclusion and exclusion criteria. This analysis was important as the title and abstract of some studies may not reflect clearly the developed work so they should not be considered for data extraction. This phase also included the extraction of all data relevant to answer the proposed research questions. Figure 1 depicts the search procedure with a number of studies per phase.

From an initial set of 408 studies, a total of 125 were selected for data extraction; this represents almost $1 / 3$ of studies, or $30,64 \%$. During data extraction, other 32 articles were excluded. At the end, 93 studies (22,79\%) were selected for our final analysis. It is also worthwhile to mention that we did not have duplicated studies as we conducted the review on individual journal instead of indexed/automated databases.

\section{RESULTS}

This section first details the characterization of the selected studies that comprises the number of studies per year, per selected source, and per country of affiliations. Following, it presents the study results of this literature review focusing on those relevant to answer the research questions. The list of selected studies is available as a Supplementary Material.

system"] AND [All: "natural] AND [[All: hazard"] OR [All: "disaster]] AND [[All: management"] OR [All: "disaster]] AND [All: risk reduction"] AND [All: "social science"] AND [in Journal: Environmental Hazards] AND [Publication Date: (01/01/2005 TO 06/30/2018)].

${ }^{2}$ https://parsif.al/about/ 


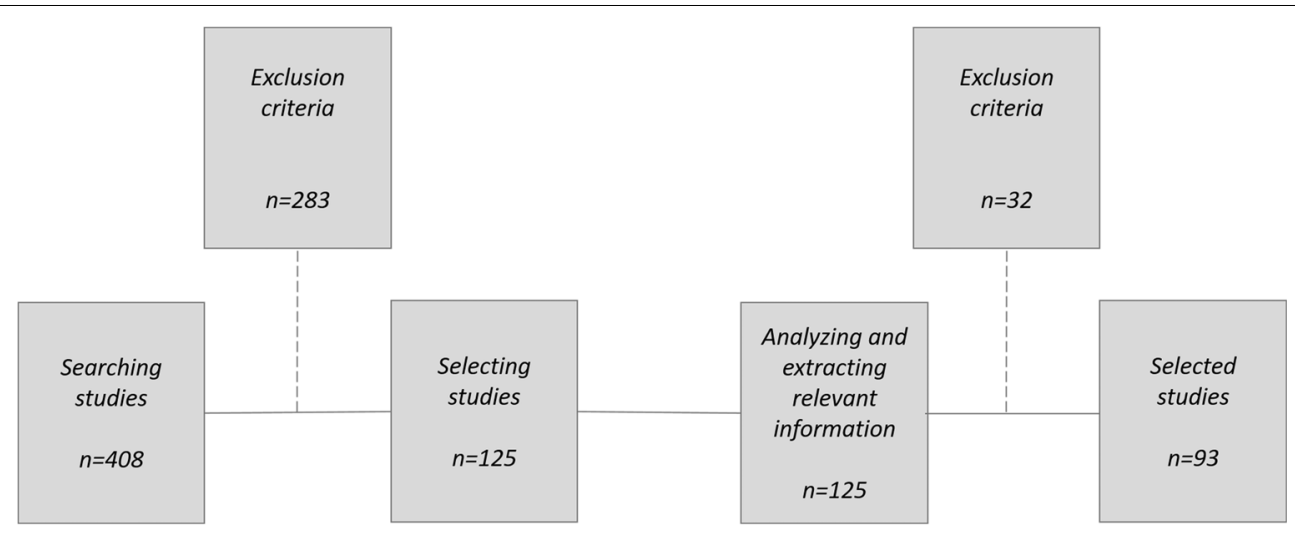

FIGURE 1 | Search procedure.

\section{Studies Characterization}

Our research reveals an increasing tendency of published articles about EWS during 2005-2018 (Figure 2). Interestingly, the two tipping points in this whole period occurred in 2010 ( 9 articles) and in 2016 (15 articles). Maybe the Hyogo Framework for Action (HFA), published in 2005, and the Sendai Framework for DRR (SFDRR), adopted in 2015, have influenced research agenda, since Unisdr provided substantial recommendations regarding EWS $(2005 ; 2006 ; 2009 ; 2015)$. Even the creation of new journals covering disaster risk management issues would have influenced these numbers.

Four of the nine journals analyzed in this study (Table 3) were created after HFA and have important percentage of the selected publications (Figure 3), as well as are ranked with high JRC Impact Factor. For instance, International Journal of Disaster Risk Reduction- IJDRR (created in 2012 and JCR Impact Factor $=1.968)$ has similar percentage of selected studies $(5,38 \%)$ when compared to Disaster Prevention and Management-DPM (created in 1992 and JCR Impact Factor = 1.060), which has 7,53\% of selected studies in this paper (Figure 3). International Journal of Disaster Risk Science-IJDRS (created in 2010 and JCR Impact Factor $=2.225$ ) has $12,9 \%$ of selected studies. Three journals created before HFA represent $67,74 \%$ of selected publications (Natural Hazards $=29,03 \%$; Environmental Hazards $=21,51 \%$; and Disasters $=17,2 \%$ ) (Figure 3). This paper does not want to explain the reasons of these differences - which can be diverse, such as open access policy, aims and scope of each journal etc. Our purpose is to show briefly the landscape of this field to understand how citizen science can be inserted in participatory early warning initiatives.

Other important aspect for planning the expansion of research networks and capacity building of human resources in EWS agenda is the author's affiliation per country (Figure 4). Of the selected articles, there are authors and co-authors affiliated in organizations of 29 countries (Europe: 12; Asia: 9; Africa: 4; Americas: 2; Oceania: 2). 49,46\% (46) have authors and

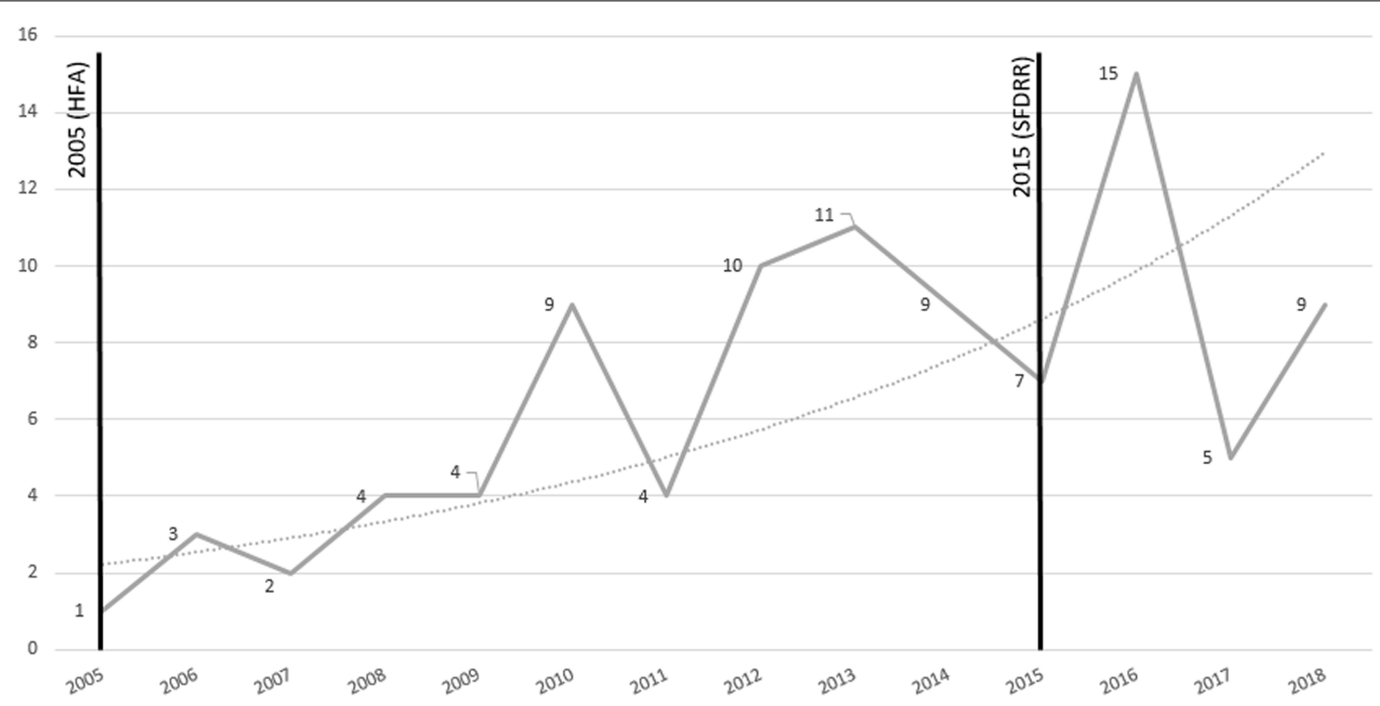

FIGURE 2 | Number of selected studies per year. 


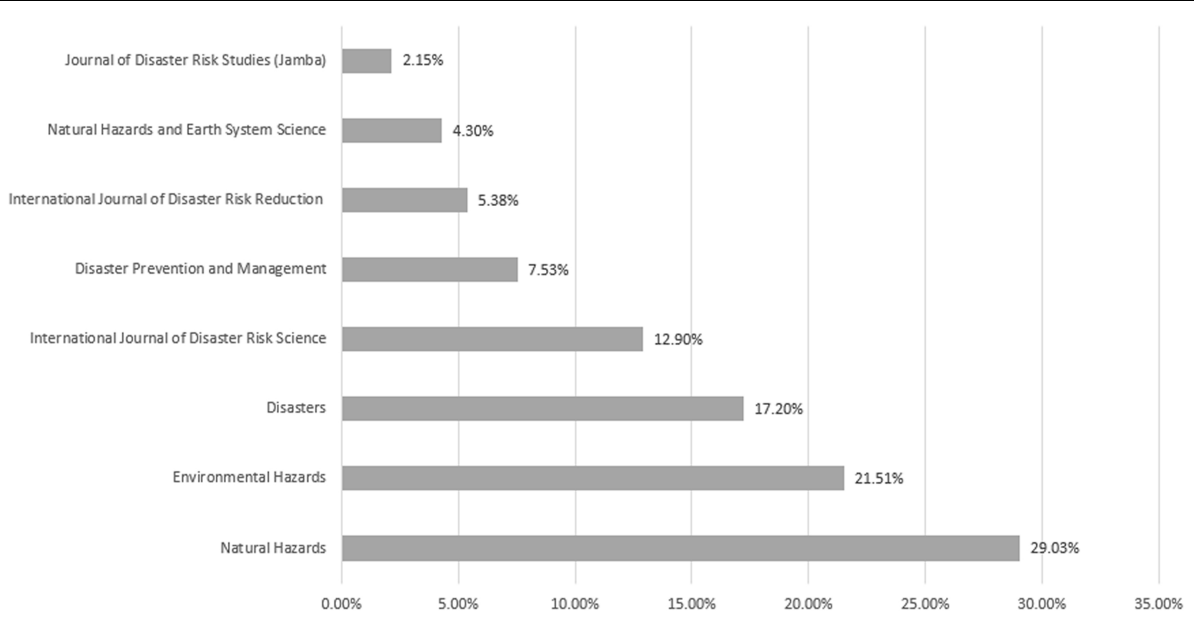

FIGURE 3 | Percentage of selected studies per source.

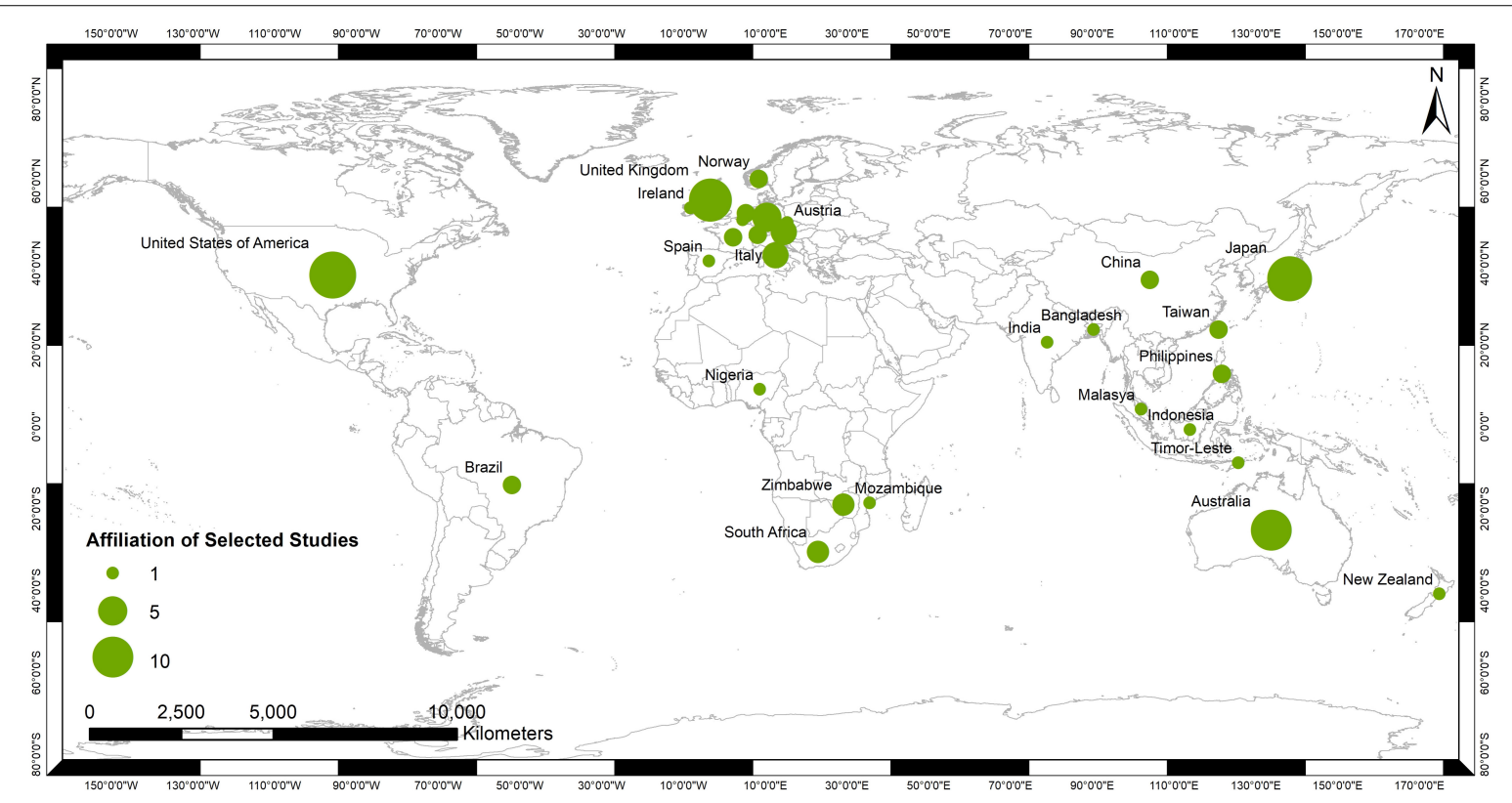

FIGURE 4 | Selected studies per country of affiliation.

co-authors affiliated in organizations from United States (13 articles), Japan (12 articles), United Kingdom (11 articles) and Australia (10 articles). Organizations from Europe are represented in $38,7 \%$ (36) of the 93 papers selected, while organizations from African countries are in 8,6\% (8) of them. It is important to highlight that there are researchers and/or practitioners affiliated in more than one organization, and this multi-affiliation was not excluded. We also consider Taiwan as a country to respect the author's opinion.

\section{Characterization per Areas of Study and Types of Hazards}

In regarding to the first research question (RQ1) proposed in this paper - about the studied areas - 43 countries were analyzed in the 93 selected papers (Figure 5) -only in 5 papers $(5,37 \%)$ were not possible to identify the country that was studied, because articles focused on regional scope, and/or prioritized consultations with stakeholders from different countries around the world, and/or gathered data and information through participatory workshops during international conference on DRR. This represents a high diversity of study areas in which the research works have been developed. It is also important to point out that many studies did comparative analysis involving two or more countries. Asian countries, for instance, were studied in 55,91\% (52) of these 93 studies. By no surprise, the first five study areas were all countries affected by hazardous events in the last years, 2009 Earthquake in Indonesia, 2012 Typhoon in the United States, 2011 Tsunami 


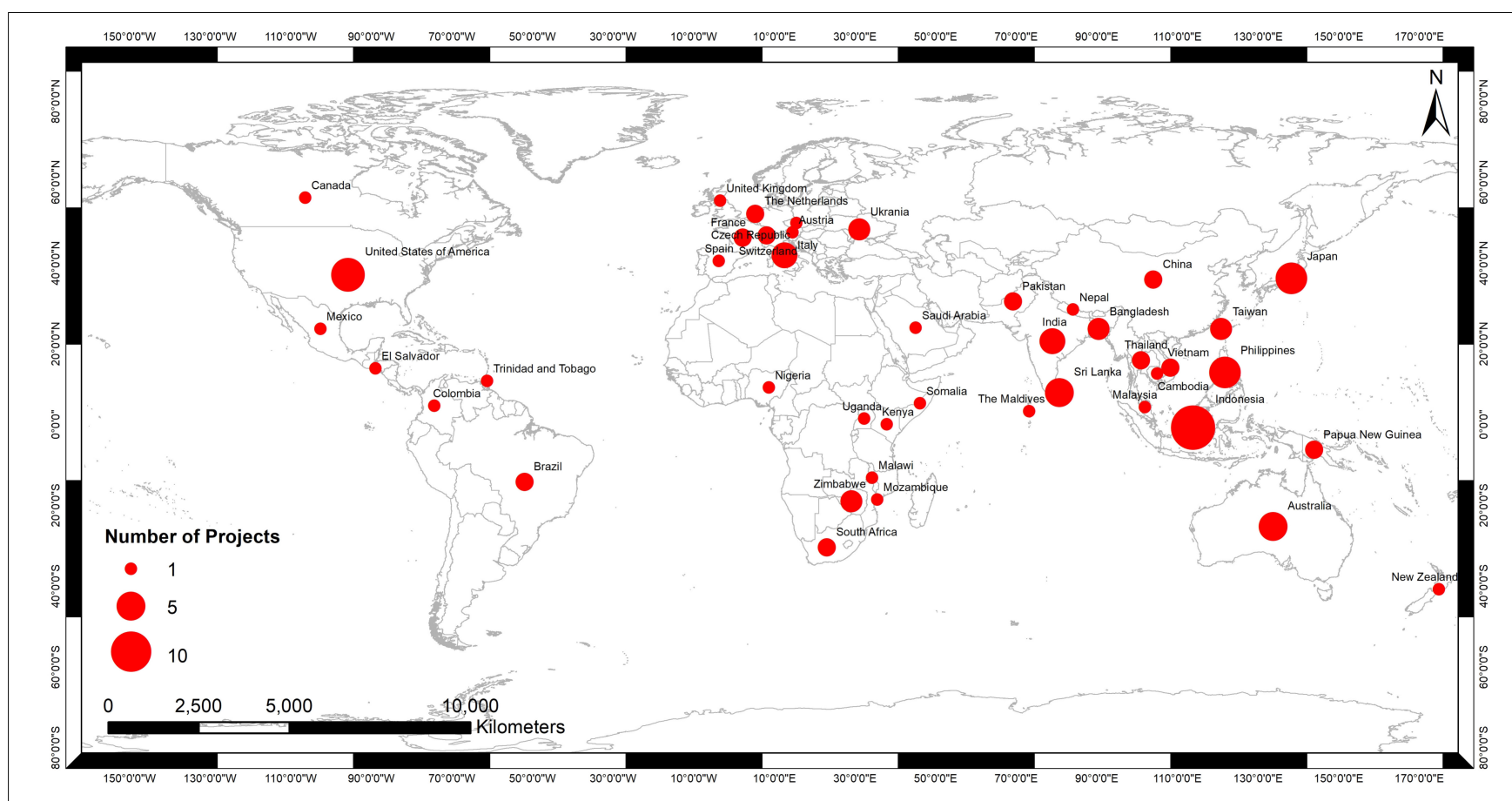

FIGURE 5 | Distribution of selected studies per study area.

in Japan, 2013 Typhoon in the Philippines and 2015 Floods in Sri Lanka.

Other important element of this characterization is the type of hazard in the selected publications. Floods represent the more frequent hazard studied during the period 2005-2018 (Figure 6) and the higher percentage (29\%) of the selected studies, followed by tsunamis (13\%) and droughts (9\%) and tornadoes (9\%) (Figure 7). Other interesting finding is the diversity of hazards discussed, from landslide to public health threats. In 2016, there were selected articles discussing EWS for different types of hazards (multihazard, floods, tornado, tsunami, earthquake, wildfire, drought, malaria, and landslide) (Figure 6).

\section{Characterization per Types of Participatory Approaches and Models of Cooperation in Citizen Science}

In regarding to the types of participation, it is important to point out that during the searching studies we identified 408 results. 283 studies $(69,36 \%)$ were excluded because they were not related with early warning system or participatory data (Phase 1, Figure 8). 125 papers were evaluated during data extraction and analysis (Phase 3, Figure 8) and another 32 studies were excluded, mainly because they were not related with participatory data $(56,25 \%)$. In general, these excluded studies used data to compose indexes of vulnerability, exposure, resilience, but this data is not collected with people.

Of 93 studies selected, the majority (84,95\%) reported participatory experiences in a consultative way, i.e., through surveys, interviews, questionnaires. These studies evaluated opinions of different stakeholders regarding EWS, evacuation behavior, risk perception about warning information etc. The findings indicate that $15,05 \%$ (14) of selected studies (93) dealt with citizen science (Figure 9), through data collection and analysis. The model of cooperation (Bonney et al., 2009) most used was collaborative (11 articles), followed by contributive (2) and co-created (1).

\section{DISCUSSION}

In the days following the Tsunami of 26 December 2004, the Secretary-General of United Nations, Mr. Kofi A. Annan (in memoriam), called for the development of a global EWS for all natural hazards and communities, and a global survey was launched to assess the capacities, gaps and opportunities (United Nations International Strategy for Disaster Reduction [UNISDR], 2006b). One of the most important issue highlighted by the Secretary-General was the need of participatory approaches in EWS and, almost 15 years later, this paper provides evidence that further investigation is still necessary. From an initial set of 408 studies published in well-known journals in the area of disaster risk management (DRM), only $14(3,43 \%)$ articles were related to citizen science and P-EWS, which indeed indicate that much effort is needed to disseminate what is citizen science and how it can be mainstreamed in DRM field.

Hence, this paper contributes to this debate on P-EWS by (1) linking it to citizen science models of cooperation (Bonney et al., 2009), as well as by (2) identifying 


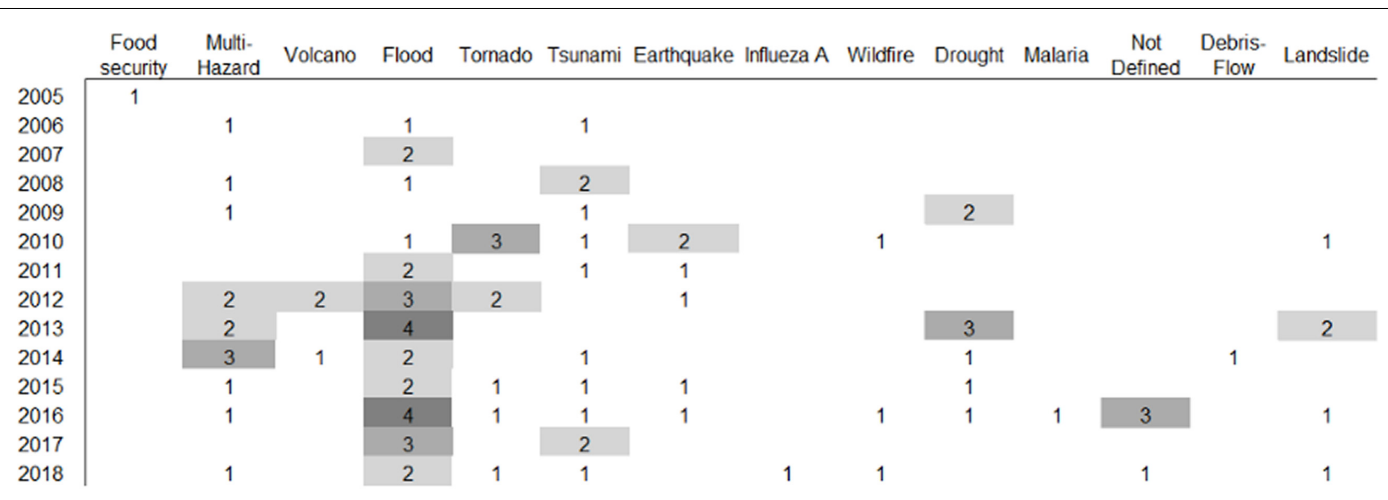

FIGURE 6 | Distribution of selected studies per type of hazard, per year.

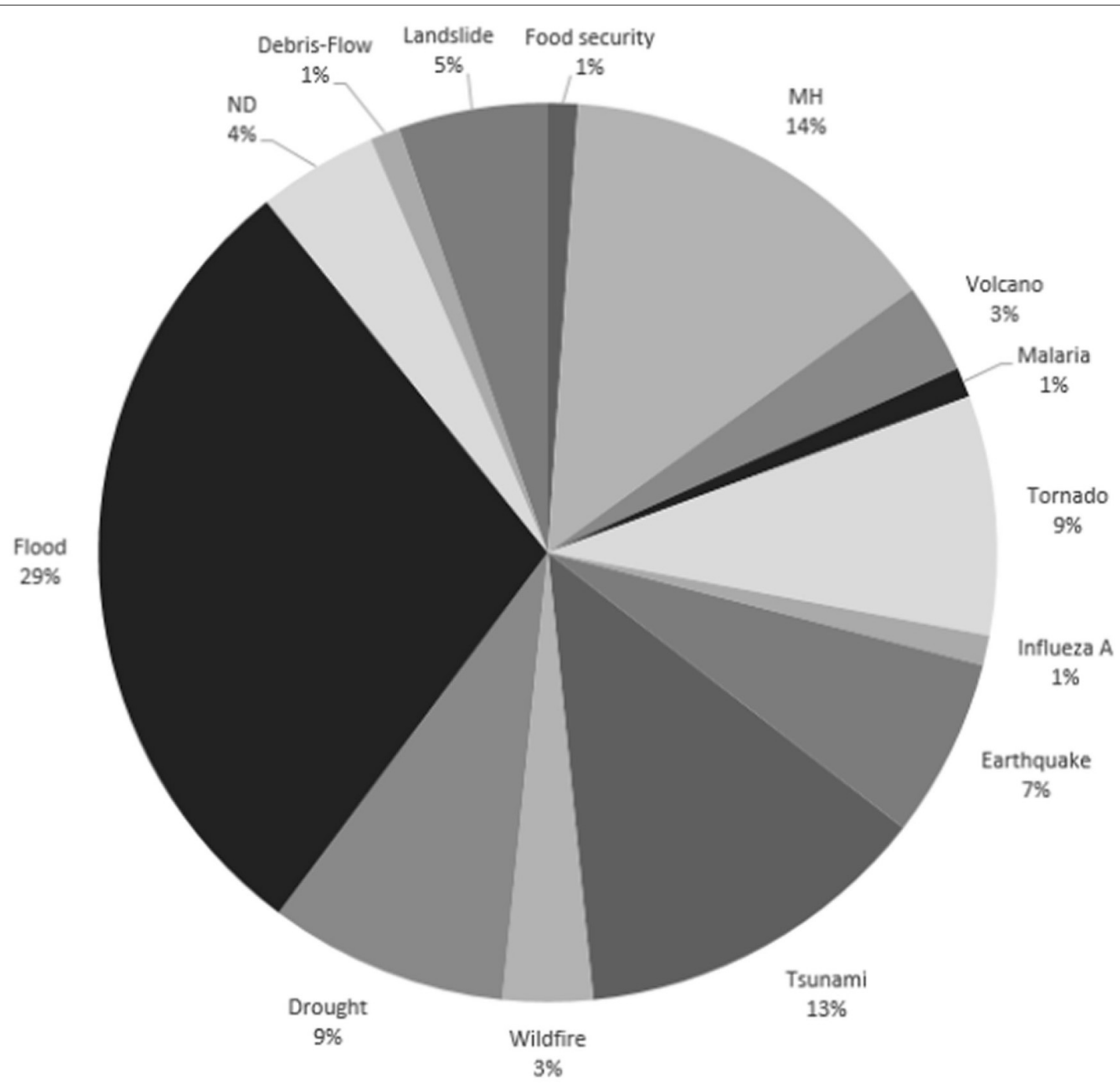

FIGURE 7 | Distribution of selected studies per type of hazard.

how existing works cover citizen science projects and P-EWS. These contributions have been done through the identification of three key issues that were raised from the literature review and then the establishment of a framework for enhancing reflexivity about P-EWS and citizen science. 


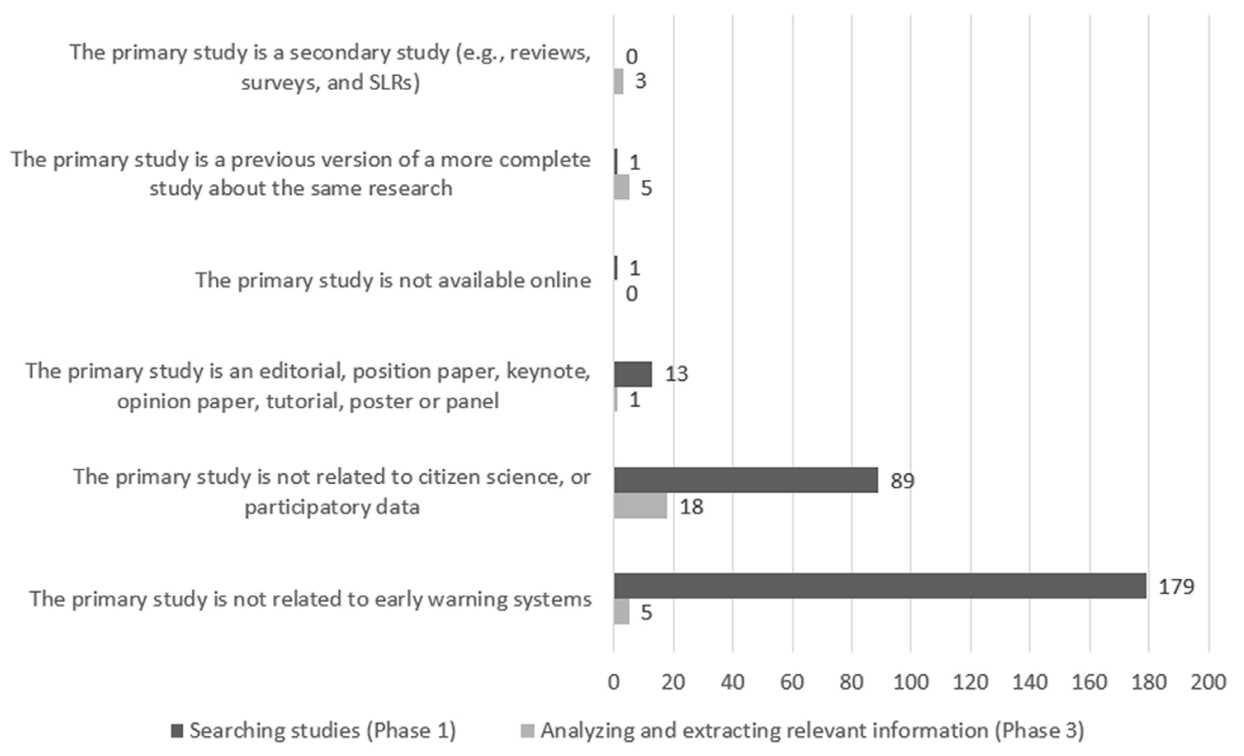

FIGURE $\mathbf{8}$ | Number of excluded studies per criteria, per phase.

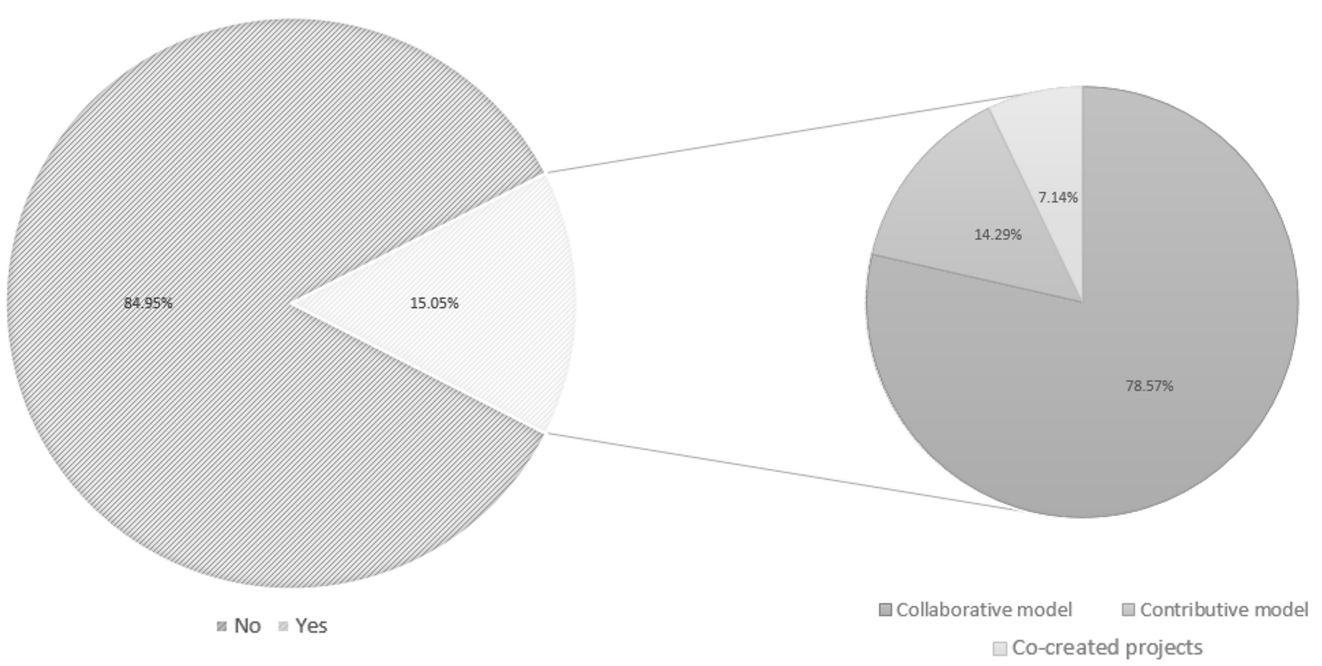

FIGURE 9 | Distribution of selected studies on citizen science projects and per model of cooperation.

\section{DRM Actions Should Recognize the Importance and Usefulness of Citizen Data}

Analyzing the case of Pakistan, Mustafa et al. (2015) stated that there is little room in the data-acquisition protocols of the Pakistan Meteorological Department (PMD) to include citizen or non-governmental based data collection. This is interesting as many meteorological services around the world have been educating the public about meteorological data collection. The authors stated that "the very basic principle of involving citizens in meteorological data collection and processing would be one important step toward not only expanding the data network but also improving public awareness and risk knowledge" (Mustafa et al., 2015, p. 15).

Another interesting case was reported in Malawi. Šakić Trogrlić et al. (2017) noted the installation of water level and rainfall gauges as a part of community-based EWS, where communities are trained to operate equipment, communicate warning messages, and also act in extensive reafforestation programs. According to the authors, there are practical EWS participatory experiences reporting that rainfall data collected by communities are not being stored by the Meteorological Services (Šakić Trogrlić et al., 2017). In the same manner, Horita et al. (2018), through a qualitative analysis of decision-making in monitoring control room, showed the importance of data from the communities as a supplementary source of information. 
This is more relevant and important when official data sources are insufficient, non-existent, or not well calibrated, which thus may lead to “operators deciding 'in the dark' without knowing the 'real' situation in the area; this occasionally may lead to devastating consequences due to a wrong decision" (Horita et al., 2018, p. 29).

Not only policymakers, scientists and practitioners can be unaware of what is citizen science, but sometimes citizens do not know that an EWS exists or even they do not consider why they should participate in EWS. Through participatory rural appraisal techniques that combined focused group discussions, Nguyen et al. (2009) stated that $86 \%$ of community members of Svay Rieng province, Cambodia, believed that they personally had no role to play in the dissemination of early warning for droughts. In another pilot study, but at Lake Trasimeno, Italy, Giordano et al. (2013) stated that local residents perceived institutional monitoring and management actors as having a central role and have not considered themselves as potential sources of knowledge to develop a community-based strategy to monitoring droughts.

But there are places where formal EWS are absent or largely malfunctioning, and citizen engagement is not a matter of choice. During Typhoon Morakot in Taiwan, several residents of mountainous villages in Kaohsiung city had to rely on their own capacities to evacuate from debris-flow prone areas. Only $13.8 \%$ of the residents received institutional (official) alerts, whereas $86.2 \%$ of households had to be confident of their knowledge and impressions to identify the onset of debris-flows - $73 \%$ had no experience in disaster education or previous disaster (Luo et al., 2014). Beyond the EWS failures due to damaged communication infrastructures, many village mayors re-assessed alerts from higher authorities and did not forward warnings and evacuation orders to the people. According to Luo et al. (2014), the crucial point is that the current EWS system in Taiwan does not permit the engagement of people, especially in CBDRM initiatives.

\section{DRM Should Be More Grounded in Citizen Science, Interdisciplinary and Transdisciplinary Works}

We identified that $84.95 \%$ of selected articles reported EWS experiences in a consultative way (Figure 9), searching occasional information from different groups through surveys, interviews etc. New strategies are necessary to promote the use of participatory methodologies of co-producing of data, information and knowledge that matter for citizens and practitioners. There is a richness of participatory methods and tools to enhance the development of CBDRM (Maskrey, 2011). Interdisciplinary methods, such as developed by social volcanology (Donovan et al., 2012), permit to understanding how different cultures influence the local community actions during eruptions. Using ethnography to analyze the EWS functioning during 2006 eruption at Mt Merapi, Indonesia, Donovan et al. (2012) stated that local people refused to evacuate because they had not received the traditional warnings which include forest animals descending from the summit regions into the villages, an increase in rock falls, a change in plume direction, dreams or premonitions. The authors mapped these and other information and included them in GIS platform to subsidize EWS activities. Diverse types of indigenous EWS were reported in Philippines (Hilhorst et al., 2015), India (Panda, 2016), Zimbabwe (Macherera and Chimbari, 2016b). There are important actions to bridge indigenous EWS and citizen science, such as the inclusion of social scientists in interdisciplinary and transdisciplinary EWS' teams, the promotion of researches about cultural norms and traditional forms of knowledge, and the identification of types of scientific and traditional data that can facilitate communication and capacity building according to types of hazards and vulnerabilities. For instance, hydrology and water management have been dialoguing about methods, technologies, experiences and types of data (precipitation, water quality, water use etc.) that can be collected, analyzed and shared in different levels of engagement in citizen science projects (Buytaert et al., 2014).

In Zimbabwe, an interesting community-based malaria EWS framework was developed to integrate indigenous knowledge and the conventional health system (Macherera and Chimbari, 2016b). Using participatory rural appraisals and workshops, communities made a trend analysis of malaria from 1970 to 2011 and that of temperature and rainfall from 1960 to 2011. To foster their risk knowledge and monitoring capacity, they were asked to construct malaria calendars with its causes and the season of occurrence. During focus group discussions (FGDs), the indicators used by the community to predict the occurrence of malaria were documented. FGDs indicated that the behavior of lions and elephant can be used as indicators for malaria. Communities stated that whether elephants or lions pass through the villages at night during the month of September, it means that the coming malaria season is going to be bad (Macherera and Chimbari, 2016b). After documenting this and other indicators (wind patterns, direction and variation etc.), participants agreed who would be the volunteers willing to carry out observations and monitoring. The group of observers also included women and caregivers at the household level. These FGDs also planned the third axis of EWS - risk communication. They determined that communication of the indicators should be two directional - from the observers to the general population and also from population to the observers. The warning should be communicated to the people through the village health workers, the observers and the health workers. This example of citizen science initiative fits into the collaborative model of cooperation because volunteers get engaged in data collection, analysis and interpretation (Bonney et al., 2009).

Other interesting case about landslide P-EWS was reported in Sri Lanka. The pilot project in the Matale district started in 2009 and engaged residents of landslide-prone areas in educational programs, training and evacuation drills. They were trained to daily monitoring of rainfall data in portable fiberglass rain gauges and educated on how to communicate data to their neighborhood (Baudoin et al., 2016). The rainfall thresholds were marked in the rain gauges and colors (green, yellow, and red) were used to differentiate important measures and actions to be taken. For instance, the red threshold implies evacuation. 
This P-EWS experienced an emergency situation in October and November 2010, and " 121 families used this method to evacuate to safer places during landslides" (Baudoin et al., 2016, p. 169).

\section{Heterogeneous Aspects of Citizenship and Science Will Demand Supplementary Actions in DRM}

One crucial element that needs further research is how the different groups can be involved in P-EWS and citizen science initiatives according to the diverse cultures, political contexts and risk scenarios they face. Some of the selected studies pointed out the importance of taking into account gender issues. As stated previously in theoretical background, gender is related to the political, economic, social and cultural constructed roles and responsibilities imputed to women and men, girls, boys and members of sexual and gender minorities, which are inseparable from power relations, change over time, are context- and history-specific, determining social spaces and (non)availability of opportunities - influencing the vulnerability and ability to prepare, respond and recover (Mustafa et al., 2015).

Discussing how to gendering flood EWS in Pakistan, Mustafa et al. (2015) shared important findings about citizen engagement. The authors stated that culturally appropriate and gender-specific EWSs need to go beyond blaring out a siren and tailoring risk messages. Afghan Abadi is home to around 5000 families, including ethnic Pashtuns from different provinces in Pakistan and refugees from Afghanistan settled for the last 30 years. While men are employed in the local market or as daily wage laborers, women's mobility is excessively limited due to a stricter understanding of purdah. As put by one respondent interviewed by Mustafa et al. (2015, p. 12-13): "We are not allowed to go outside of our houses. We know about flood hazard from our men. There are announcements in the mosques but loud speakers do not work due to absence of electricity, we could not hear that warning (...) Even during floods women are not allowed to go outside the homes without the permission of the males. We find safe places inside the home to save ourselves. We cannot move anywhere without the permission of our husbands and for the fear of punishment". The impact of gendered norms on decision-making in EWS needs to be considered in the design of citizen initiatives. Important findings about EWS performance were reported during floods in Indonesia (Mulyasari and Shaw, 2013), wildfire in Australia (Tyler and Fairbrother, 2018) and landslides in Colombia (Coles and Quintero-Angel, 2018).

In Bandung, Indonesia, Women Welfare Associations (WWAs) have been mobilizing the community to engage in EWS. During the 2009-2010 floods, WWA was involved in monitoring water levels, disseminating risk information to communities through FM radio stations and newspapers, coordinating relief efforts etc (Mulyasari and Shaw, 2013). Another participatory EWS experience involving women was reported in Manizales, Colombia. The program "Guardians of the Slope" hires female heads of household to communicate landslide risk to the residents and to maintain landslide-prevention infrastructure. The women guardians are also responsible for conducting door-to-door educational activities and also to share their knowledge with children and youth in school meetings (Coles and Quintero-Angel, 2018).

Other crucial bridging point is considering age groups and intergenerational capacities in tailoring participatory EWS, including children (Muzenda-Mudavanhu et al., 2016), youth (Fernandez and Shaw, 2013; Cumiskey et al., 2015; Marchezini et al., 2017) and elderly (Paveglio et al., 2010). Some studies have produced a series of recommendations for enhancing youth participation (Fernandez and Shaw, 2013; Cumiskey et al., 2015), as well as participatory methodologies to work with citizen science in the four elements of EWS with the help of school curricula (Marchezini et al., 2017). Despite of taking into account the vulnerabilities of these groups and developing pathways for including them in EWS, further research is necessary to consider other groups, such as migrants and refugees, because migrants represent $14 \%$ of global population and almost 200 million people were forced to move as consequence of disaster from 2009 to 2015 (Internal Displacement Monitoring Centre [IDMC], 2015; Guadagno, 2016). Human mobility refers to the population movements - voluntary or forced, assisted or spontaneous, long- or short-distance, long- or short-term (Guadagno, 2016). According to Guadagno (2016), it is important to include migrants in EWS, fostering appropriate structures and procedures, as well as collecting data disaggregated by mobility status and other characteristics (gender, age, ethnicity etc.). For instance, Stokoe (2016) highlighted the importance of putting people at the center of United States's tornado warnings and asked how to include the 11.2 million illegal immigrants in the EWS.

\section{Framework for Enhancing Reflexivity About PEWS and Citizen Science}

Based on the literature review on participatory EWS and citizen science, we provide a framework for enhancing stakeholders' reflexivity about EWS (Figure 10). Reflexivity means the constantly monitoring, reexamination and reformation of social practices in the light of incoming information about them, altering their character (Giddens, 1990). For Giddens (1990, p. 83), "the nature of modern institutions is deeply bound up with the mechanisms of trust in abstract systems, especially trust in expert systems." EWSs are abstract systems that deal with uncertainties and fail, as exemplified in 2004 tsunami in Asia and Africa (Kelman, 2006). To recover trust in EWS is essential to think about the types of participation (co-acting, co-creating, enticing, consulting, coercing, and informing) (Figure 10). Co-acting and co-creation permit that participants share their knowledge, set their agendas and negotiate ways, defining roles and responsibilities. Participatory approaches, such as Views from the Frontline methods (Global Network of Civil Society Organizations for Disaster Reduction, 2013; Gibson and Wisner, 2016) give voice to people and can offer important insights for designing EWS for multiple hazards and vulnerabilities. These types of participation open opportunities for models of cooperation in citizen science, such as contributive, collaborative or co-created projects (Figure 10). These types of cooperation can involve different stakeholders, 


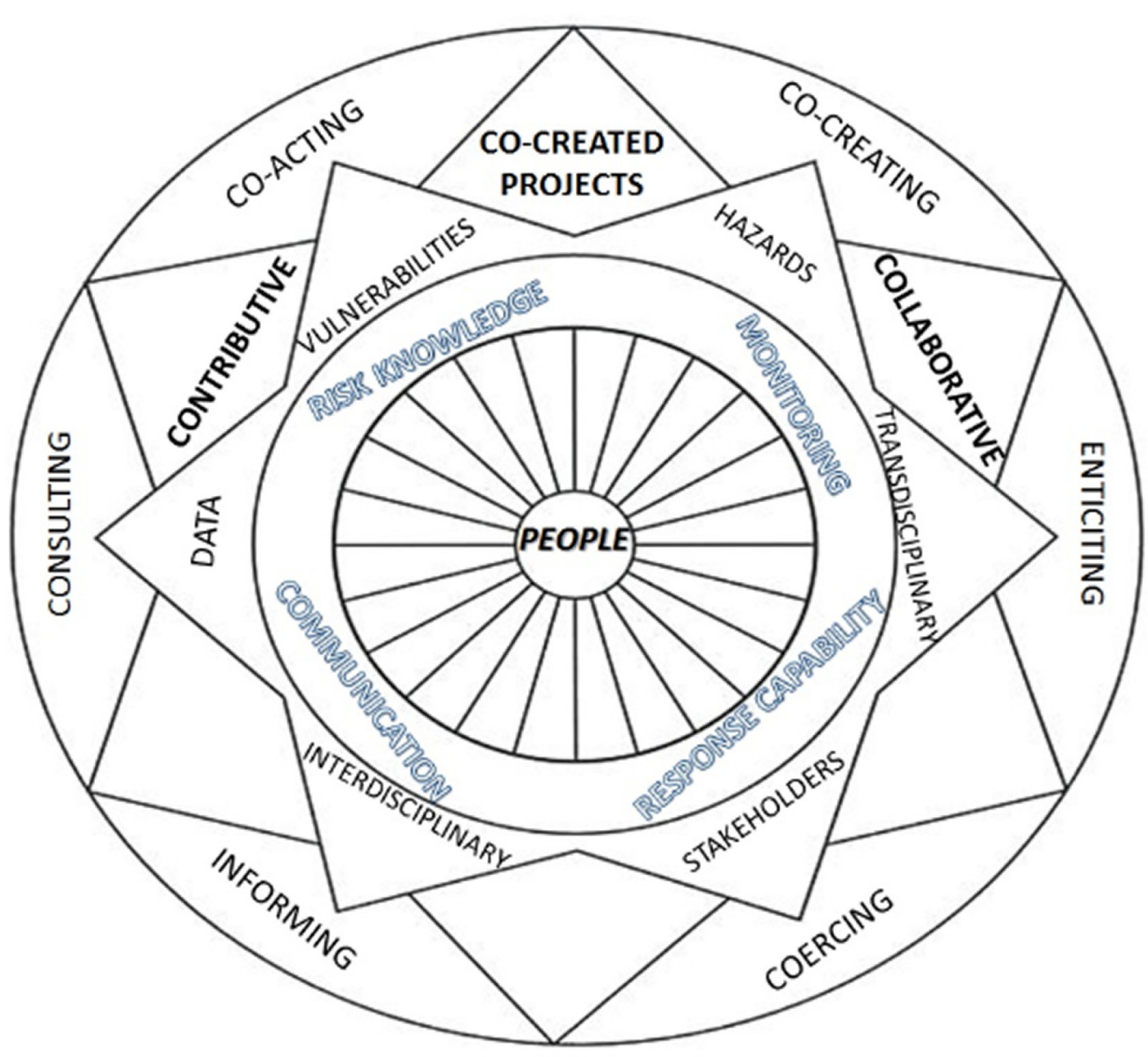

FIGURE 10 | Framework for enhancing reflexivity about PEWS and citizen science. Source: the authors.

fostering transdisciplinary dialogs among experts, practitioners, communities, policymakers, as well as interdisciplinary methods for data collection and analysis, building integrated research, such as provided by Forensic Investigations of Disasters' method (Oliver-Smith et al., 2016). These approaches and methods can involve each of four interconnected elements of EWS - risk knowledge, monitoring, communication and response capability. This reflexivity process should be people-centered, taking into account gender, age, ethnic, minorities and other important aspects of social life (Kelman and Glantz, 2014; Mustafa et al., 2015). Mainstreaming EWS to consider different groups and sectors (Zia and Wagner, 2015) is a challenge that DRR community will face, and maybe citizen science can offer pathways to implement new initiatives among citizenspractitioners-scientists.

\section{Limitations}

Although this work provided a valuable framework for bridging citizen science and P-EWS, some limitations should be acknowledged. To start with, articles published in further journals should be reviewed in order to cover the whole extent of the literature in the theme. The review conducted on well-known journals in DRM aimed at raising the most valuable articles, but some other efforts may be left out. In the same manner, these reviews should also cover conferences in the themes; for example, International Conference on Disaster Response and Management (ICDRM), and Early Warning Conference promoted by Unisdr. Another potential limitation of this work might be that inclusion and exclusion criteria left relevant studies out of the final set of primary studies. The activities to mitigate this issue were the following: (1) a pilot study has been conducted in order to refine both these criteria and search string and (2) as several phases of the research methodology have been conducted by different researchers, a discussion session was conducted with the aim of aligning the elements of methodology (e.g., search strategy, inclusion and exclusion criteria, and data extraction form). The later was also particularly valuable and relevant to reduce the subjectivity of the analysis.

\section{CONCLUSION}

This paper has carried out a literature review of 93 selected articles which findings can support future actions related to 
P-EWS and citizen science. Study findings showed that there is a concentration of studies on Asian countries (55,9\% of the selected studies), as well as the concentration of scientific production in organizations in developed countries $(49,46 \%$ of selected articles have authors and co-authors affiliated in organizations from United States, Japan, United Kingdom, and Australia). Furthermore, results of this literature review provided evidence of the predominance of floods as the main hazard (29\% of selected studies), and the low popularity of citizen science in well-known journals in the field of DRM. Based on these findings, it is important to enhance scientific meetings, capacity building and funding to foster research in less represented countries, building local and national capacity in research, policy-making and citizen engagement in P-EWS.

Moreover, it is essential to promote the use of participatory methodologies and to create mechanisms to monitor the implementation of P-EWS, taking into account the long-term effort involved in this type of initiative. The promotion of new agreements between donors and funding agencies to redesign the duration of the EWS projects and the types of scientific deliverables - less articles, more connection with local demands could drive more implementation of P-EWS. Citizen science research programs on this issue can create new opportunities to connect people to think about disaster risk reduction and global environmental change.

\section{AUTHOR CONTRIBUTIONS}

$\mathrm{VM}$ and $\mathrm{FH}$ led the conception and design of the paper. VM selected the studies. VM, FH, PM, RT, MT-R, and DO

\section{REFERENCES}

Aitsi-Selmi, A., Murray, V., Wannous, C., Dickinson, C., Johnston, D., Kawasaki, A., et al. (2016). Reflections on a science and technology agenda for 21 st century disaster risk reduction. Int. J. Disast. Risk Sci. 7, 1-29. doi: 10.1007/s13753-016-0081-x

Basher, R. (2006). Global early warning systems for natural hazards: systematic and people-centred. Philos. Trans. A Math. Phys. Eng. Sci. 364, 2167-2182. doi: $10.1098 /$ rsta.2006.1819

Basili, V. (1994). GQM approach has evolved to include models. IEEE Softw. $11,1-8$.

Baudoin, M. A., Henly-Shepard, S., Fernando, N., Sitati, A., and Zommers, Z. (2016). From top-down to community-centric approaches to early warning systems: exploring pathways to improve disaster risk reduction through community participation. Int. J. Disast. Risk Sci. 7, 163-174. doi: 10.1007/ s13753-016-0085-6

Bonney, R., Ballard, H., Jordan, R., McCallie, E., Phillips, T., Shirk, J., et al. (2009). A CAISE Inquiry Group Report. Available at: http://files.eric.ed.gov/fulltext/ ED519688.pdf [accessed May 2, 2018].

Bonney, R., Cooper, C. B., and Ballard, H. (2016). The theory and practice of citizen science: launching a new journal. Citizen Sci. Theory Pract. 1:1. doi: $10.5334 /$ cstp. 65

Buytaert, W., Zulkafli, Z., Grainger, S., Acosta, L., Alemie, T. C., Bastiaensen, J., et al. (2014). Citizen science in hydrology and water resources: opportunities for knowledge generation, ecosystem service management, and sustainable development. Front. Earth Sci. 2:26. doi: 10.3389/feart.2014. 00026

Coles, A. R., and Quintero-Angel, M. (2018). From silence to resilience: prospects and limitations for incorporating non-expert knowledge into hazard analyzed and extracted relevant information from the selected studies. VM led the description and discussion of the case studies. VM, FH, PM, RT, MT-R, and DO contributed to the development of ideas and to the interdisciplinary reflection process.

\section{FUNDING}

RT, PM, and DO acknowledge the Brazilian Council for Scientific and Technological Development (CNPq) for their research scholarships. MT-R acknowledges support from the Coordination for the Improvement of Higher Education Personnel (CAPES) for his Ph.D. scholarship. FH would like to express thanks for the financial support provided by CAPES (Grant No. 88887.091744/2014-01).

\section{ACKNOWLEDGMENTS}

The authors are grateful to the Editors, Dr. Jonathan D. Paul, Dr. David M. Hannah and Dr. Wei Lu, and the reviewers for their helpful suggestions.

\section{SUPPLEMENTARY MATERIAL}

The Supplementary Material for this article can be found online at: https://www.frontiersin.org/articles/10.3389/feart. 2018.00184/full\#supplementary-material

management. Environ. Hazards 17, 128-145. doi: 10.1080/17477891.2017. 1382319

Cumiskey, L., Hoang, T., Suzuki, S., Pettigrew, C., and Herrgard, M. M. (2015). Youth participation at the third UN world conference on disaster risk reduction. Int. J. Disast. Risk Sci. 6, 150-163. doi: 10.1007/s13753-0150054-5

Donovan, K., Suryanto, A., and Utami, P. (2012). Mapping cultural vulnerability in volcanic regions: the practical application of social volcanology at Mt Merapi. Indonesia. Environ. Hazards 11, 303-323. doi: 10.1080/17477891.2012.689252

Dyball, R., Brown, V. A., and Keen, M. (2009). “Towards sustainability: five strands of social learning," in Social Learning Towards a Sustainable World. Principles, Perspectives, and Praxis, ed. A. E. J. WALS (Dordrecht: Wageningen Academic Publishers), 181-194.

Fernandez, G., and Shaw, R. (2013). Youth council participation in disaster risk reduction in the philippines. Int. J. Disast. Risk Sci. 4, 126-136. doi: 10.1007/ s13753-013-0014- $x$

Gaillard, J. C., and Mercer, J. (2012). From knowledge to action: bridging gaps in disaster risk reduction. Prog. Hum. Geogr. 37, 93-114. doi: 10.1177/ 0309132512446717

Garcia, C., and Fearnley, C. J. (2012). Evaluating critical links in early warning systems for natural hazards. Environ. Hazards 11, 123-137. doi: 10.1080/ 17477891.2011.609877

Gibson, T., and Wisner, B. (2016). "Let's talk about you": opening space for local experience, action and learning in disaster risk reduction. Disast. Prev. Manag. 25, 664-684. doi: 10.1108/DPM-06-2016-0119

Giddens, A. (1990). The Consequences of Modernity. London: Polity Press.

Giordano, R., Liersch, S., Vurro, M., and Hirsch, D. (2010). Integrating local and technical knowledge to support soil salinity monitoring in the Amudarya river basin. J. Environ. Manag. 91, 1718-1729. doi: 10.1016/j.jenvman.2010.03.010 
Giordano, R., Preziosi, E., and Romano, E. (2013). Integration of local and scientific knowledge to support drought impact monitoring: some hints from an Italian case study. Nat. Hazards 69, 523-544. doi: 10.1007/s11069-0130724-9

Glantz, M. H., and Ramírez, I. J. (2018). Improvisation in the time of disaster. Environment 60, 4-17. doi: 10.1080/00139157.2018.1495496

Global Network of Civil Society Organizations for Disaster Reduction (2013). Views From the Frontline: Beyond 2015. Available at: https://www.gndr.org/ programmes/vfl/itemlist/category/168.html

Guadagno, L. (2016). Human mobility in the Sendai framework for disaster risk reduction. Int. J. Disast. Risk Sci. 7, 30-40. doi: 10.1007/s13753-016-0077-6

Heiss, R., and Matthes, J. (2017). Citizen science in the social sciences: a call for more evidence. GAIA 26, 22-26. doi: 10.14512/gaia.26.1.7

Hilhorst, D., Baart, J., van der Haar, G., and Leeftink, F. M. (2015). Is disaster "normal" for indigenous people? Indigenous knowledge and coping practices. Disast. Prev. Manag. 24, 506-522. doi: 10.1108/DPM-02-2015-0027

Horita, F. E. A., Albuquerque, J. P., and Marchezini, V. (2018). Understanding the decision-making process in disaster risk monitoring and early-warning: a case study within a control room in Brazil. Int. J. Disaster Risk Reduct. 28, 22-31. doi: 10.1016/j.ijdrr.2018.01.034

Horita, F. E. A., Albuquerque, J. P., Marchezini, V., and Mendiondo, E. M. (2017). Bridging the gap between decision-making and emerging big data sources: an application of a model-based framework to disaster management in Brazil. Decis. Support Syst. 97, 12-22. doi: 10.1016/j.dss.2017.03.001

Internal Displacement Monitoring Centre [IDMC] (2015). Global Estimates 2015: People Displaced by Disasters. Geneva: Internal Displacement Monitoring Centre.

International Federation of the Red Cross and Red Crescent Societies [IFRC] (2012). Community Early Warning Systems: Guiding Principles. Geneva: IFRC.

Jacobi, P. R., and Franco, M. I. G. C. (2011). "Sustentabilidade, participação, aprendizagem social [sustainability, participation and social learning]," in Aprendizagem Social- Diálogos e Ferramentas Participativas: Aprender Juntos para Cuidar da Água [Social Learning: Participatory Dialogues and Tools: Learning Together to Take Care of Water], ed. P. R. Jacobi (Brazil: IEE/PROCAM), 11-19.

Kelman, I. (2006). Warning for the 26 december 2004 Tsunamis. Disast. Prev. Manag. 15, 178-189. doi: 10.1108/09653560610654329

Kelman, I., and Glantz, M. H. (2014). "Early warning systems defined," in Reducing Disaster: Early Warning Systems for Climate Change, eds Z. Zommers and A. Singh (Dordrecht: Springer), 89-108. doi: 10.1007/978-94-017-8598-3_5

Kitchenham, B., and Charters, S. (2007). Guidelines for Performing Systematic Literature Reviews in Software Engineering. Goyang: Technical report EBSE.

Kou, G., and Wu, W. (2014). Multi-criteria decision analysis for emergency medical service assessment. Ann. Oper. Res. 223, 239-254. doi: 10.1007/s10479014-1630-6

Kusumasari, B., and Alam, Q. (2012). Bridging the gaps: the role of local government capability and the management of a natural disaster in Bantul. Indonesia. Nat. Hazards 60, 761-779. doi: 10.1007/s11069-0110016-1

Loureiro, C. F., and Layrargues, P. P. (2013). Ecologia política, justiça e educação ambiental crítica: perspectivas de aliança contra-hegemônica [Political ecology, justice, and critical environmental education: perspectives of a counterhegemonic aliance]. Trab. Educ. Saúde 11, 53-71. doi: 10.1590/S198177462013000100004

Lumbroso, D., Brown, E., and Ranger, N. (2016). Stakeholders' perceptions of the overall effectiveness of early warning systems and risk assessments for weatherrelated hazards in Africa, the Caribbean and South Asia. Nat. Hazards 84, 2121-2144. doi: 10.1007/s11069-016-2537-0

Luo, Y., Shaw, R., Lin, H., and Joerin, J. (2014). Assessing response behaviour of debris-flows affected communities in Kaohsiung. Taiwan. Nat. Hazards 74, 1429-1448. doi: 10.1007/s11069-014-1258-5

Macherera, M., and Chimbari, M. J. (2016a). A review of studies on community based early warning systems. Jàmbá 8:206. doi: 10.4102/jamba.v8i1.206

Macherera, M., and Chimbari, M. J. (2016b). Developing a community-centred malaria early warning system based on indigenous knowledge: Gwanda district, Zimbabwe. Jamba 8:289. doi: 10.4102/jamba.v8i1.289
Marchezini, V., Trajber, R., Olivato, D., Muñoz, V. A., de Oliveira Pereira, F., and Oliveira Luz, A. E. (2017). Participatory early warning systems: youth, citizen science, and intergenerational dialogues on disaster risk reduction in Brazil. Int. J. Disast. Risk Sci. 8, 390-401. doi: 10.1007/s13753-017-0150-9

Maskrey, A. (2011). Revisiting community-based disaster risk management revisiting community-based disaster risk management. Environ. Hazards 10, 42-52. doi: 10.3763/ehaz.2011.0005

Mercer, J., Kelman, I., Taranis, L., and Suchet-Pearson, S. (2010). Framework for integrating indigenous and scientific knowledge for disaster risk reduction. Disasters 34, 214-239. doi: 10.1111/j.1467-7717.2009.01126.x

Michoud, C., Bazin, S., Blikra, L. H., Derron, M. H., and Jaboyedoff, M. (2013). Experiences from site-specific landslide early warning systems. Nat. Hazards Earth Syst. Sci. 13, 2659-2673. doi: 10.5194/nhess-13-2659-2013

Mulyasari, F., and Shaw, R. (2013). Role of women as risk communicators to enhance disaster resilience of Bandung, Indonesia. Nat. Hazards 69, 2137-2160. doi: 10.1007/s11069-013-0798-4

Mustafa, D., Gioli, G., Qazi, S., Waraich, R., Rehman, A., and Zahoor, R. (2015). Gendering flood early warning systems: the case of Pakistan. Environ. Hazards 14, 312-328. doi: 10.1080/17477891.2015.1075859

Muzenda-Mudavanhu, C., Manyena, B., and Collins, A. E. (2016). Disaster risk reduction knowledge among children in Muzarabani district, Zimbabwe. Nat. Hazards 84, 911-931. doi: 10.1007/s11069-016-2465-z

Nguyen, H., Prabhakar, S. V. R. K., and Shaw, R. (2009). Adaptive drought risk reduction in cambodia: reality, perceptions and strategies. Environ. Hazards 8, 245-262. doi: 10.3763/ehaz.2009.0005

Olivato, D. (2013). Análise da Participação Social no Context de Gestão de Riscos Ambientais na Bacia Hidrográfica do rio Indaiá, Ubatuba-SP-Brasil [Analysis of Social Participation in the Context of Risk Management in the Basin of the Indaia River - Ubatuba - SP - Brazil]. Ph.D. thesis, University of São Paulo, São Paulo. Oliver-Smith, A., Alcántara-Ayala, I., Burton, I., and Lavell, A. (2016). Forensic Investigations of Disasters (FORIN): A Conceptual Framework and Guide to Research. Beijing: Integrated Research on Disaster Risk. doi: 10.14350/ sc. 02

Panda, A. (2016). Exploring climate change perceptions, rainfall trends and perceived barriers to adaptation in a drought affected region in India. Nat. Hazards 84, 777-796. doi: 10.1007/s11069-016-2456-0

Paveglio, T. B., Carroll, M. S., and Jakes, P. J. (2010). Alternatives to evacuation during wildland fire: exploring adaptive capacity in one Idaho community. Environ. Hazards 9, 379-394. doi: 10.3763/ehaz.2010.0060

Petersen, K., Feldt, R., Mujtaba, S., and Mattsson, M. (2008). Systematic mapping studies in software engineering. EASE 8, 68-77.

Preuner, P., Scolobig, A., Linnerooth Bayer, J., Ottowitz, D., Hoyer, S., and Jochum, B. (2017). A participatory process to develop a landslide warning system: paradoxes of responsibility sharing in a case study in upper Austria. Resources 6:54. doi: 10.3390/resources6040054

Quansah, J. E., Engel, B., and Rochon, G. L. (2010). Early warning systems: a review. J. Terr. Obs. 2, 24-44.

Šakić Trogrlić, R., Wright, G. B., Adeloye, A. J., Duncan, M. J., and Mwale, F. (2017). Taking stock of community-based flood risk management in Malawi: different stakeholders, different perspectives. Environ. Hazards 17, 107-127. doi: 10.1080/17477891.2017.1381582

Santos, R. F. (2004). Planejamento Ambiental: Teoria e Prática [Environmental Planning: Theory and Practice]. Brazil: Editora Oficina dos textos.

Stokoe, R. M. (2016). Putting people at the centre of tornado warnings: how perception analysis can cut fatalities. Int. J. Disast. Risk Reduct. 17, 137-153. doi: 10.1016/j.ijdrr.2016.04.004

Stone, J., Barclay, J., Simmons, P., Cole, P. D., Loughlin, S. C., Ramón, P., et al. (2014). Risk reduction through community-based monitoring: the vigías of Tungurahua, Ecuador. J. Appl. Volc. 3:11. doi: 10.1186/s13617-0140011-9

Tenório, F. G., and Rozenberg, J. E. (1997). Gestão pública e cidadania: metodologias participativas em ação [public management and citizenship: participatory methodologies in practice]. Revista da Administração Pública 1, $1-37$.

Teschenhausen, A. R. R. V. (2015). In the Crowd we Trust: Role and Challenges of Crowdsourcing and Citizen Science in the Context of the Data Revolution - A Transdisciplinary Approach. Ph.D. thesis, Universities of Leipzig, Vienna 
Thomalla, F., and Larsen, R. K. (2010). Resilience in the context of tsunami early warning systems and community disaster preparedness in the Indian Ocean Region. Environ. Hazards 9, 249-265. doi: 10.3763/ehaz. 2010.0051

Tyler, M., and Fairbrother, P. (2018). Gender, households, and decision-making for wildfire safety. Disasters 42, 697-718. doi: 10.1111/disa.12285

United Nations International Strategy for Disaster Reduction [UNISDR] (2005). Hyogo Framework for Action 2005-2015: Building the Resilience of Nations and Communities to Disasters. Geneva: UNISDR.

United Nations International Strategy for Disaster Reduction [UNISDR] (2006a). Developing Early Warning Systems: A Checklist. Bonn: UNISDR.

United Nations International Strategy for Disaster Reduction [UNISDR] (2006b). Global Survey of Early Warning Systems: An Assessment of Capacities, Gaps and Opportunities Towards Building a Comprehensive Global Early Warning System for all Natural Hazards. Geneva: UNISDR.

United Nations International Strategy for Disaster Reduction [UNISDR] (2009). Terminology: Basic Terms of Disaster Risk Reduction. Available at: https://www.unisdr.org/we/inform/publications/7817 [accessed March 1, 2018].

United Nations International Strategy for Disaster Reduction [UNISDR] (2015). Sendai Framework for Disaster Risk Reduction 2015 - 2030. Available at: http://www.wcdrr.org/uploads/Sendai_Framework_for_Disaster_ Risk_Reduction_2015-2030.pdf [Accessed Aug 2018].

United Nations International Strategy for Disaster Reduction [UNISDR] (2016). Report of the Open-Ended Intergovernmental Expert Working Group on
Indicators and Terminology Relating to Disaster Risk Reduction. Available at: https://www.preventionweb.net/files/50683_oiewgreportenglish.pdf [accessed May 1, 2018].

Villagrán de León, J. C. (2012). "Early warning principles and practices," in Handbook of Hazards and Disaster Risk Reduction and Management, eds B. Wisner, J. C. Gaillard, and I. Kelman (Abingdon: Routledge), 481-492.

Villagrán de León, J. C., Bogardi, J., Dannenmann, S., and Basher, R. (2006). Early warning systems in the context of disaster risk management Entwickl. Ländlicher Raum. 2, 23-25.

Zia, A., and Wagner, C. H. (2015). Mainstreaming early warning systems in development and planning processes: multilevel implementation of sendai framework in Indus and Sahel. Int. J. Disast. Risk Sci. 6, 189-199. doi: 10.1007/ s13753-015-0048-3

Conflict of Interest Statement: The authors declare that the research was conducted in the absence of any commercial or financial relationships that could be construed as a potential conflict of interest.

Copyright (C) 2018 Marchezini, Horita, Matsuo, Trajber, Trejo-Rangel and Olivato. This is an open-access article distributed under the terms of the Creative Commons Attribution License (CC BY). The use, distribution or reproduction in other forums is permitted, provided the original author(s) and the copyright owner(s) are credited and that the original publication in this journal is cited, in accordance with accepted academic practice. No use, distribution or reproduction is permitted which does not comply with these terms. 


\section{OPEN ACCESS}

Edited by:

Jonathan D. Paul,

Imperial College London,

United Kingdom

Reviewed by:

Sara Kelly McBride,

Earthquake Science Center, United States Geological Survey,

United States

Remy Bossu,

European-Mediterranean

Seismological Centre, France

${ }^{*}$ Correspondence:

Jennifer A. Strauss

jastrauss@berkeley.edu

Specialty section

This article was submitted to

Geohazards and Georisks,

a section of the journal

Frontiers in Earth Science

Received: 31 August 2018 Accepted: 06 December 2018 Published: 19 December 2018

Citation:

Rochford K, Strauss JA, Kong Q and

Allen RM (2018) MyShake: Using

Human-Centered Design Methods to

Promote Engagement in a

Smartphone-Based Global Seismic

Network. Front. Earth Sci. 6:237.

doi: 10.3389/feart.2018.00237

\section{MyShake: Using Human-Centered Design Methods to Promote Engagement in a Smartphone-Based Global Seismic Network}

\author{
Kaylin Rochford, Jennifer A. Strauss*, Qingkai Kong and Richard M. Allen \\ Berkeley Seismology Laboratory, University of California, Berkeley, Berkeley, CA, United States
}

MyShake is a global seismic platform that uses private citizens' smartphones to detect earthquakes and record both ground shaking and users' experiences. The goal is to reduce earthquake risk and provide users with a resource for earthquake science and information. It is powered by the participation of users, therefore, its success as a global network and its utility for the users themselves is reliant on their engagement and continued involvement. This paper discusses the citizen scientist participation that enables MyShake, with specific attention to the human-centered design process that was used to overhaul the mobile application's user interface. After the successful initial launch of the application in February of 2016, we had the opportunity to revisit the user interface based on user feedback and needs. The process began with an assessment of the user and geographic distribution of the original user base through surveys and Google Play Store analytics. Subsequently, through systematic examination of the motivations and needs of community members in the San Francisco Bay Area and iterative evaluations of design decisions, MyShake was redesigned to appeal as a resource to a wider range of users in earthquake-prone regions. The new user interface was then evaluated through interviews, surveys, and meetups with potential users. We highlight the human-centered methodology we employed, as well as the roadblocks we faced, in the hopes that our experience will be valuable to other citizen science projects in the future.

Keywords: human-centered design, citizen science, seismology, global, smartphone

\section{INTRODUCTION}

While there are thousands of seismic sensors around the world, and thousands of earthquakes each year, seismology remains a data-limited field. The global seismic networks typically consist of a few hundred instruments and are able to detect all earthquakes globally with magnitudes $>5$. However, detailed study of the earthquake source, and the impacts of that earthquake of the human-built environment require sensors in the near-field, i.e., within a few tens of kilometers of the earthquake epicenter. Few countries around the world have seismic networks that are dense enough to provide many seismic records in the near-field for any given earthquake. Therefore, the research community has relied on synthetic datasets to complement what recordings are available (Maechling et al., 2014; Ruhl et al., 2017).

In response to this challenge, multiple groups have explored the use of low-cost MEMS accelerometers in a variety of devices and with varying degrees of citizen participation and science. 
The Quake Catcher Network used private/personal laptops with accelerometers in them or USB-attached sensors (Elizabeth et al., 2009; Yildirim et al., 2015). The Community Seismic Network consisted of similar MEMS sensors attached to a PC in a dedicated "box" that could be deployed in homes and offices (Clayton et al., 2012). Others, have explored using the accelerometers in smartphones both as dedicated devices (D'Alessandro and D'Anna, 2013; Naito et al., 2013; D'Alessandro et al., 2018), or via apps like iShake (Dashti et al., 2012). MyShake is a global network of private/personal smartphones with the goal of furthering seismological research by providing data, and reducing the impacts of earthquakes by providing training/education and alerts. The MyShake app uses the onboard accelerometer to detect earthquakes, record the ground shaking observed by the smartphones, archive the data in a central repository for future research, deliver earthquake information and preparedness information to users, and to provide rapid notifications or "alert" of earthquakes underway. Central to its success is the engagement of a large number of citizens who download the app onto their phone. Therefore, it is critical that an evaluation of what "citizens" want and need be central to the design of the app.

Citizen science is not a new trend. Projects like the Cooperative Observer Program (National Weather Service) began in 1890 to provide more widespread daily measurement of temperature and precipitation to define US climate.SETI@Home began in 1999 and uses citizen scientist's idle computers to search for weak signals and certain classes of signals from astronomical data. MyShake has many parallels with the SETI project in that it uses the idle time on consumer electronics to search for signals. The United States Geological Survey has its own earthquake related citizen science project: Did You Feel It?, which allows users in the epicentral region to report their experience of shaking after the event (Atkinson and Wald, 2007). LastQuake is an app developed by the Euro-Mediterranean Seismic Center, which provides earthquake notifications crowdsourced by the reports of shaking from users themselves over social media and the internet (Bossu et al., 2018). Finally, the Earthquake Network app is designed to detect earthquakes using smartphone accelerometers (Finazzi, 2016, Finazzi and Fassò, 2017). It is different to MyShake in that it does not record and archive the ground shaking for future research.

Here we focus on a question directly relevant to the citizen science aspect of the MyShake project which determines the scale of MyShake's network-how to improve the application's user retention rate and grow its user base so that we can build and sustain this global platform. This paper outlines the human-centered design approach that was used to address these questions. Human-centered design is commonly used in product development to understand consumer needs so that products can be built to meet those needs, with the ultimate goal of creating value for the product in the eyes of users and thus increasing the number of consumers who engage with the product. We hope that by applying the same techniques to this citizen science project, MyShake will be able to provide more utility and value to users, promoting their participation. The approaches we took to address this problem will be introduced below. Using user interviews as the basis of potential solutions, a redesigned application and its evaluation will be presented in the hopes of providing useful information to other citizen science projects.

This paper does not cover technical details about MyShake. Details of the network structure and app architecture are presented by Kong et al. (2016b), and a summary of data quality and observables from the existing network can be found in Kong et al. (2016a). Application of the data to building monitoring is covered in Kong et al. (2018a) and an overview of the machine learning components of the entire MyShake system are in Kong et al. (2018c).

\section{CITIZEN SCIENCE DATA AND HARDWARE}

The acceleration data that MyShake can provide has research value for the seismological and civil engineering communities. Recordings from cell phones can be used to build a scalable earthquake early warning system around the world, which is a key goal of the MyShake global network. Kong et al. (2016a) report on initial observations from MyShake recorded waveforms and compare them with the nearby seismic stations. The Peak Ground Acceleration (PGA) values show the expected attenuation trend with distance from an earthquake, though the amplitude of MyShake recordings are on average twice the observations of traditional seismic stations. This is in part due to the higher amplitude shaking of buildings compared to free surface sites. With careful calibration of building response contributions to the amplitude, MyShake could provide higher resolution ground motion observations. The waveforms recorded by MyShake could also be used to determine basic earthquake event parameters, such as magnitude, location, and origin time, that is comparable to traditional seismic networks in areas where phone density is high and well-covered azimuthally. MyShake also shows the potential of detecting smaller earthquakes using a dense array approach, which could potentially improve the catalog completeness for small events. Research into the feasibility of these techniques is ongoing. Kong et al. (2018a) reports the potential of using personal smartphones to extract building fundamental frequencies, which opens the door to monitoring building state of health. Kong et al. (2018b) shows the challenges and possibilities of using MyShake for earthquake early warning.

Analysis of what causes an earthquake to grow large or remain small is a continuing area of research (Aki, 1987; Meier et al., 2016). A denser global network, such as that provided by MyShake, could record more local earthquakes in areas with sparse seismic instrumentation before and after large earthquakes to mine any characteristic differences that are present and more fully complete the seismic event catalog. The events detected by MyShake could also be used to improve our understanding of local fault zones. New research on local path effects (Aki, 1993) could be stimulated by collecting data with higher spatial resolution. Moreover, it could help us generate microzonation maps that characterize the ground motions at finer scale. Recording more aftershocks, especially in the near-field, could 
augment aftershock probability forecasting (Wetzler et al., 2016; van der Elst and Page, 2017) which requires large data sets that capture wide ranges of locations and magnitudes.

Smartphone market penetration is what makes the MyShake platform possible. The number of smartphone subscriptions worldwide was 4.3 billion in 2017 , and is projected to grow to more than 7.2 billion by 2023 (Jonsson, 2018). The global median of smartphone penetration was 59\% in 2017 and, while this rate is lower in many emerging economies that are susceptible to earthquakes, their smartphone ownership continues to grow. In Indonesia for example, where several destructive earthquakes have occurred this year, the smartphone ownership increased from 21 to 27\% between 2015 and 2017 (Poushter et al., 2018). MyShake could transform this pervasive technology into a global seismic network to serve communities that are vulnerable to earthquakes but lack high-quality traditional seismic networks. The archive of dense seismic data generated by MyShake can also be used by the scientific community to tailor hazard reduction strategies to these underserved areas.

Just as smartphone market penetration has increased globally over the past few years, so has the functionality of the hardware inside those phones. The phones' accelerometers, which the MyShake application uses to detect motion, are not as sophisticated as traditional seismic instruments, but collectively across several nearby devices, they can readily discern the complex signature of earth's movement. MyShake also employs the GPS to accurately pinpoint location. An on-board patented artificial neural network (ANN) created by the researchers at the Berkeley Seismology Lab determines whether or not recorded motions are produced by an earthquake or by normal human activity (Kong et al., 2016a). The ANN remains in a quiescent phase until the accelerometer indicates the phone has been stationary for a defined period of time. Once in this "steady state," the ANN classifies subsequent motion into earthquakelike or human-like types and any earthquake-type parameters are sent to the backend cloud server for aggregation with readings from other nearby devices using spatial and clustering algorithm (Kong et al., 2018c,d). In addition, MyShake uploads 5 min of acceleration time-series data from phones in the area of a detected quake, which are archived for research purposes (Kong et al., 2015).

\section{CURRENT STATUS OF THE MYSHAKE NETWORK}

As of July 2018, MyShake has been downloaded to more than 296,000 devices with about 40,000 active users and 10,000 users on any given week whose devices actively contribute data. Figure la shows the distribution of all the users who have downloaded MyShake, and Figure 1b shows the distribution of the 10,000 users that contributed data during the week of 201807-16. Between February 12th, 2016 and February 12th, 2018, 757 earthquakes were recorded by the system spanning events on almost every continent, as shown in Figure 2. The histogram in the figure shows that there are more events detected during night when most of the phones are steady. Many of these recorded events represent only one or two local users and devices, so for MyShake to truly reach its goal of creating a global dense seismic network and significantly increasing the available nearfield waveforms for the global catalog, a much larger user base is necessary. Moreover, MyShake can only detect earthquakes and record ground motion on a device when it is stationary and has reached steady state. This is because human motions often are of much higher amplitude than earthquake motions, so they can easily get lost in the noise of human activities. Among our current active users, we have observed that between 1 and 6 a.m. local time, about $90 \%$ of the phones running MyShake reach steady state and therefore start monitoring for earthquakes. Between 10 a.m. and 6 p.m., however, only about $20 \%$ of phones are able to monitor for earthquakes and, thus, able to contribute data. A large user base in any given region is required to consistently monitor seismic activity given that many users are often moving and interacting with their devices.

Thus, evaluating the effectiveness of MyShake as a research project and global data archive goes hand in hand with measuring the value it provides to current users and new segments of users who can act as seismic sensors. For this reason, in seeking to grow the MyShake project, we treated the MyShake application as a product and undertook a redesign of the application with the goal of increasing participation in the project and retaining participants for longer periods of time. During the redesign, we employed Human-Centered Design, a philosophy whereby products and services are cultivated based on human needs and goals (Goodwin, 2009).

\section{DEFINING THE USER RETENTION PROBLEM}

We began our efforts to increase the MyShake downloads and retention rates in August 2017 by examining user install and uninstall behaviors to inform effective changes that could be employed to acquire new users. Of the users who have downloaded MyShake since its release on February 12th, 2016, $38 \%$ of users uninstalled the application within a day, $69 \%$ uninstalled within a month, and $95 \%$ uninstalled within a year (Figure 3). This data suggested that while MyShake was able to attract users, especially after our initial global media push and as large earthquake events continued to be mentioned in the news media alongside MyShake, as shown in Figure 4, keeping all of these users in the long-term proved challenging. The application is currently only available in English and Japanese, so lack of local language support could also made it a less useful tool to global user groups.

MyShake requires only passive participation from its citizen scientists-to contribute to the project, a user must simply download (and keep) MyShake on their phone. However, according to the Hooked model of product adoption, people are most likely to continue using something when they use it frequently and perceive it to have utility (Eyal, 2014). We therefore decided to address MyShake's low user retention by examining how to increase user engagement with the application and increase its overall value for users. Our first 

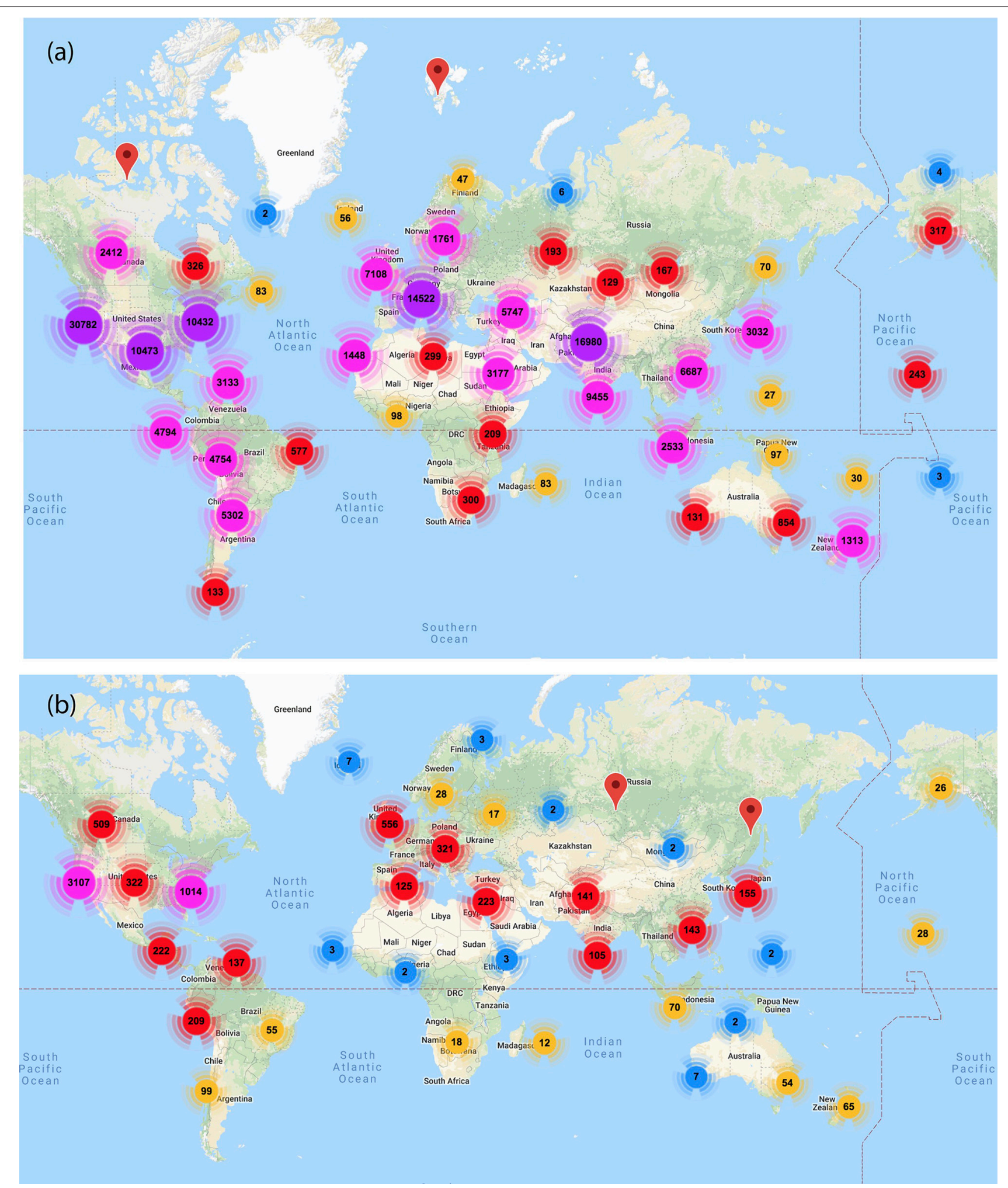

FIGURE 1 | (a) World map of MyShake application downloads, between February 12th, 2016 and July 25th, 2018, clustered by location showing the global reach of the MyShake network. Map data: $\odot 2018$ Google. (b) The active users that contribute data weekly for the week of 2018-07-16. 

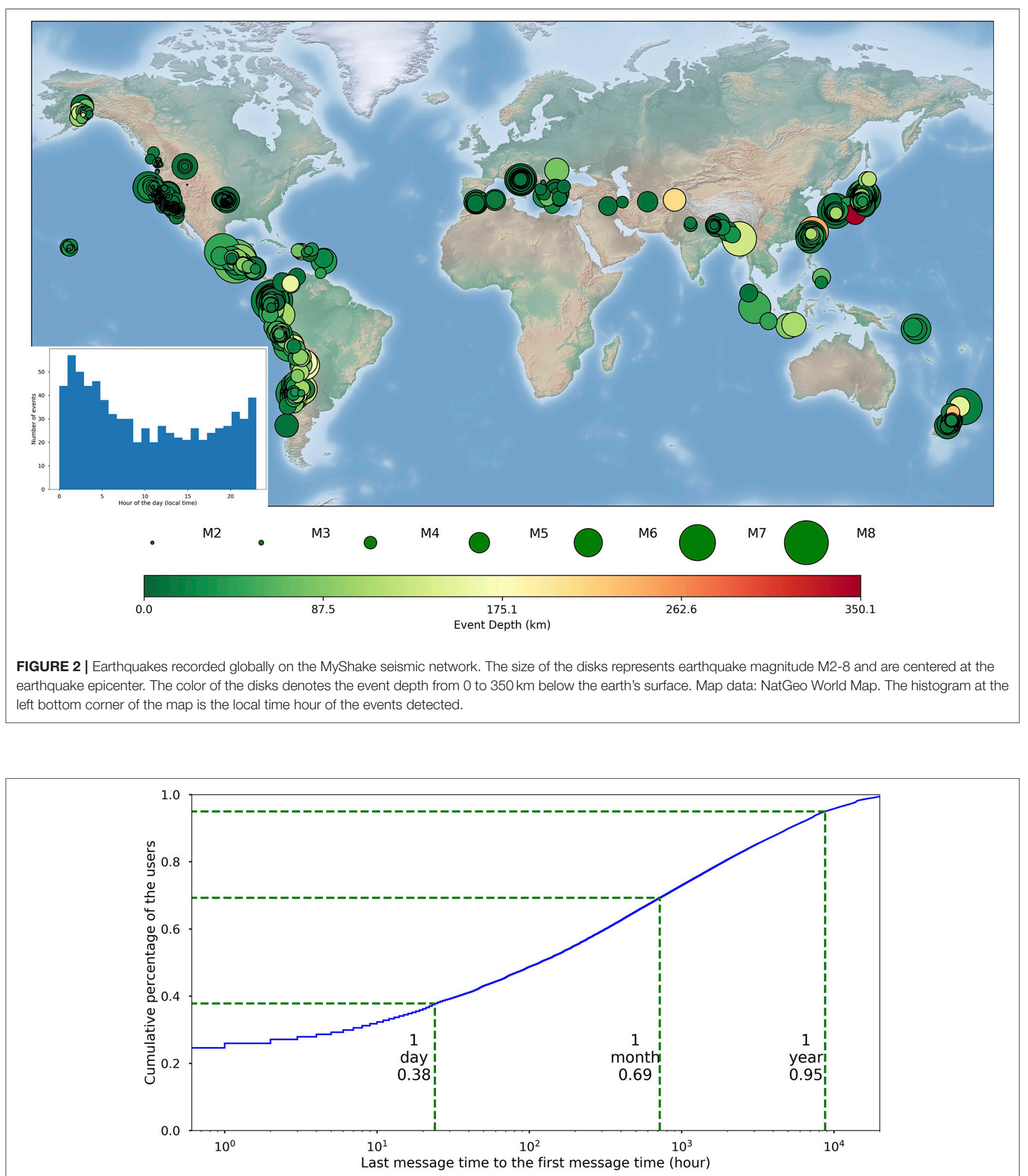

FIGURE 3 | The graph shows the cumulative percentage of users over all time who have kept the app registered on their phone measured as the time difference between the first registration message time and the last heartbeat time measured on that registered device. Thirty-eight percent uninstall within the first day of downloading, $69 \%$ within the first month, and $95 \%$ within the full year. 


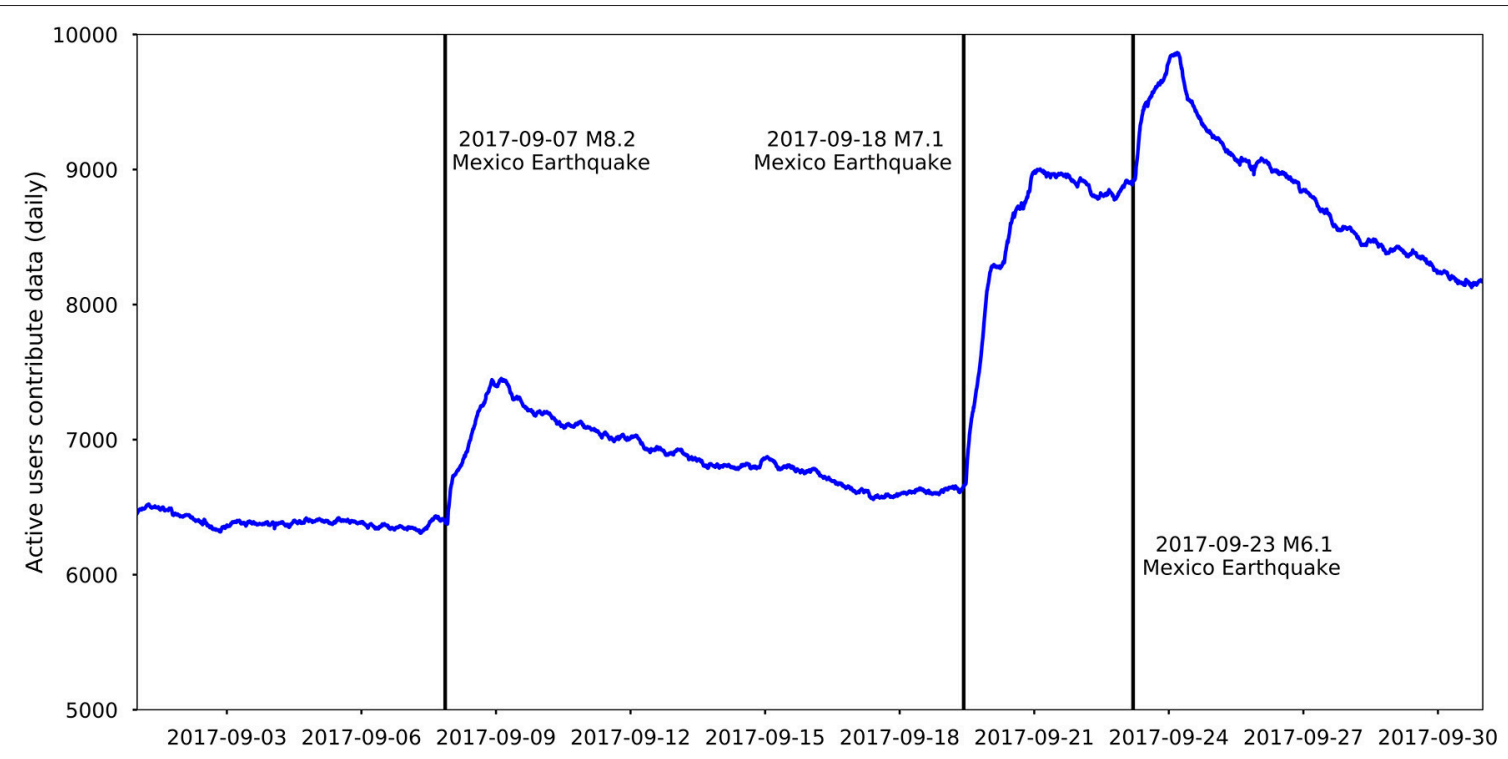

FIGURE 4 | The changes of the active users that contribute data during the Mexico events.

step was to discern in-depth user needs, behaviors, and pain points in relation to earthquakes using Human-Centered Design methods. We first assessed the current state of MyShake's engagement and value by reviewing user feedback on the Google Play store and in email comments. Chief among user complaints was that MyShake consumed too much battery. Users who left comments or sent emails also frequently requested metrics about their contribution to the project and information about the earthquakes they helped detect. We bookmarked these suggestions for our redesign brainstorm later in the process. These insights guided our redesign efforts by allowing us to devise new functionalities and evaluate current features through a lens of usability and utility for our target audience.

\section{USER INTERVIEWS}

Feedback on the content and functionality of the initial application was an important first step, but reaching out into the user community through interviews was essential to discover the needs and interests of these volunteers to encourage their sustained involvement in the project. For this reason, humancentered design was at the core of efforts to grow MyShake's user base. In human-centered design methodologies, human factors including user needs and gaps in meeting those needs are assessed using methods like user interviews and surveys. Based on the results, a design solution is devised and subsequently tested by users in an iterative cycle to ensure usability. Ideally, this results in a product that helps users fulfill unmet needs efficiently and enjoyably, thus conferring value to the product (Goodwin, 2009). By having conversations with potential MyShake participants about their needs, which were unmet by the initial MyShake application offering, we were able to focus all redesign efforts on providing utility to users and in turn persisting their engagement.

The goal of using human-centered methods was to build empathy amongst the MyShake team for the audience of the application. Our information seeking about users was not intended to match the rigor of human subjects research or produce broad findings about the population that we were targeting. After review by the Berkeley Human Research Protection Program, our investigations were exempt from review as they were deemed to be Quality Assurance/Quality Improvement activities which are not considered human research. However, the insights we gained nevertheless helped guide product decisions throughout an iterative application development process. At crossroads in the design and implementation process, we were able to draw on the needs expressed by our desired citizen science user base instead of making uninformed assumptions.

Our analysis of the user retention problem, which looked at the user base as well as install and uninstall trends, showed that MyShake was able to generate organic interest as installs continued over time, even outside of the global media coverage spikes we observed. However, it was unable to sustain interest among a majority of these users, and even those who kept the application on their phones requested additional features to better engage them as citizen scientists. While underserved by the current application, former users and new segments of users had the potential to grow into a large active user base if MyShake could provide them more utility. We chose to identify the audience of MyShake's redesign as: adults of all ages, who own smartphones, and who live in seismically active areas. To understand how MyShake could evolve into a resource for these users, we examined attitudes and behaviors of a subset of this group, with an emphasis on their unmet needs, in relation to earthquakes. 
Our first human-centered design strategy was to conduct qualitative user interviews with residents of the San Francisco Bay Area. Qualitative methods were well-suited as they provided the depth and flexibility of inquiry necessary to better understand user needs in this specific context (Budiu, 2017). Popular quantitative user research methods, like remote surveys, would have been limited in this respect as questions would be standardized making it difficult to ask specific follow up questions based on a participant's response. Additionally, since the goal of these interviews was information seeking for product research, rather than to produce generalizable knowledge about this segment, these interviews allowed us to explore a wide range of different topics with participants producing insights about needs we may not have even known to be looking for. One drawback to this approach is that the freeform answer style does not allow for statistical sampling of responses in the way that a more structured survey with limited response options would.

Residents of the San Francisco Bay area were used as they comprise a portion of our overall target user group and live in earthquake prone region, thus potentially having use for the earthquake resources MyShake could provide them. Given the various ages and time spent living in earthquake country among interviewees, this group allowed us get perspectives across a spectrum of past experiences with earthquakes. We also interviewed a few tourists, to understand points of view of those outside of the area. That being said, because our user research was conducted only with English speakers and in a region of the world whose population is highly technologically fluent, with smartphone adoption rates in the US above $80 \%$ since 2013 (Poushter et al., 2018), it is not representative of every population segment globally we hope MyShake can access and results will be biased toward this type of user.

Our tool was a script of questions designed for in-person interviews lasting roughly $10 \mathrm{~min}$ (see Supplementary Materials). It was developed to collect ethnographic information-about activities and mind-setsfrom our redesign audience (Hall, 2013). The questions focused on attitudes toward earthquakes, reflection on past earthquake experiences and actions that were taken, as well as challenges faced in preparing and responding to earthquakes. We chose to cast a broad net in our information gathering since we were still trying to understand how MyShake could provide utility to users in the multifaceted context of earthquakes. While not all of these inquiries illuminated unmet needs that MyShake could fulfill, information regarding areas where user needs were already satisfied allowed us to save development time attempting to address them. Importantly, most questions we followed up with "Why?" to reveal decision making and emotional responses surrounding behaviors related to earthquakes. The script also included demographic questions to provide more context to each participants' responses, however no personally identifiable information was recorded. While this demographic information did not end up presenting immediate trends in responses, it was important to collect it in case distinct sub groups of users among demographic categories became apparent.
Four members of the MyShake team conducted "man on the street" interviews in Downtown Berkeley, near Frank H Ogawa Plaza in Oakland's City Center, and near the Ferry Building in the Financial District of San Francisco to save on time and costs related to subject recruitment, and to include groups with different relationships with earthquakes, (i.e., homeowners and lifelong residents of earthquake country vs. newcomers). Interviews were conducted on August 15th and 16th of 2017, a Tuesday and Wednesday, respectively, around lunch hours, between roughly 11 a.m. and 2 p.m., when the public spaces were busy. Anyone over 18 who was not otherwise occupied was considered as a potential participant. Team members approached potential participants, asked if they were interested in participating in an anonymous interview for the UC Berkeley Seismology Lab, and, if they consented, were interviewed on the spot. In total, 78 such interviews were conducted. While this is not a statistically significant sample of all residents of earthquake prone regions, it provided us with information about the needs and attitudes of real people, allowing us to make design decisions based on their input rather than our own assumptions about what people wanted from an earthquake application.

In conjunction with user interviews, we also interviewed six experts in fields such as earthquake outreach, emergency management, and emergency behavioral response. We used findings from these interviews, about behavior relating to earthquakes, to begin to draw out meaningful statements and observations from our interviews with users that aligned with expert insights. After discussions and brainstorms among the MyShake team, we organized our takeaways from all interviews through personas and task analysis to draw meaningful insights about the earthquake experience that could be used to shape improvements to MyShake.

\section{HUMAN CENTERED DESIGN RESULTS}

Personas are sample archetypes that represent the distinctive needs and challenges of different user segments, while also highlighting consistent themes in these areas among all users. Our goal with using personas was to produce a snapshot of the needs, habits, and challenges of potential core users that the team could revisit when making product decisions. We began by reviewing all of the interview notes as a team question by question and highlighting interesting insights and commonalities for each question. We used these results to identify interviews from ideal target users. These were people that already showed some engagement with earthquakes, who had pressing needs related to earthquakes that they cared about being fulfilled, or otherwise indicated that an earthquake resource would be valuable to them. For each persona, we kept an especially compelling quote from an interview in its group (Figure 5). We then grouped similar target user responses together and created a persona for each group, pulling demographic information right from an interview. Finally, we identified background information, needs, and challenges for each persona using interview insights. We supplemented these developed personas with findings from the expert interviews and looked for overlaps, especially instances 


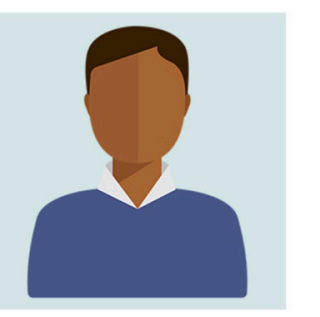

Mark, 24

HR Representative at a startup

"If there's a large earthquake, then nothing I can do will help."

\section{Background}

Mark is a busy professional in the tech industry who wants to make the world a better place. He's fearful of earthquakes but doesn't have much time to think about them and prefers not to. He has experienced some small earthquakes but nothing significant or damaging. When he does feel an earthquake, he uses social media see if others felt it too and share his own experience.

\section{Wants + Needs}

- Needs earthquake information that informs and empowers him to plan for a future event.

- Wants to be a part of project that helps others and needs to understand his contribution to it.

- Needs actionable information after an earthquake to decide what to do next.

Challenges

- Only thinks about earthquakes when they occur near him.

- Limited time/interest for earthquake information and knows little about risk or preparedness

- Fearful and helpless mindset.

- Too busy to contribute to social projects that he is passionate about.

FIGURE 5 | Representative persona that was developed from the user interviews.

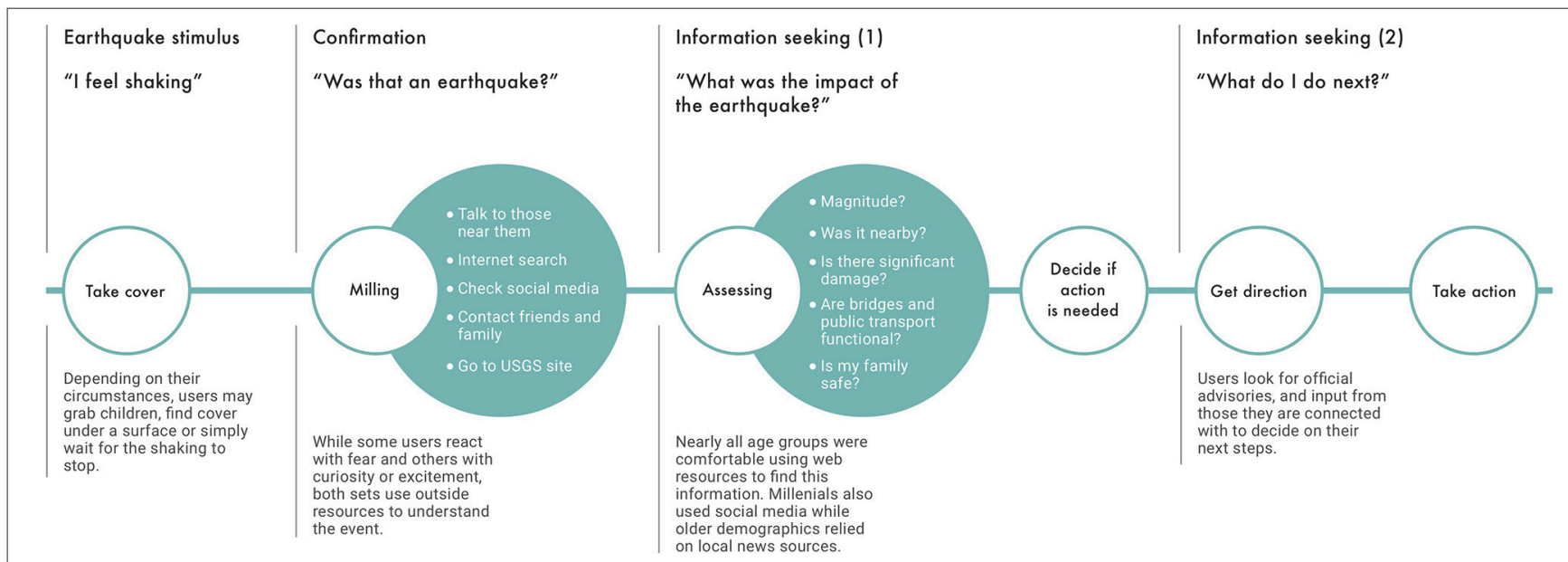

FIGURE 6 | Task analysis infographic depicting the four distinct action types personas engage in after an earthquake event.

when an expert had some insight and a user expanded on the same issue.

Our key insights from creating personas were:

1. Participants expressed feelings of fear toward earthquakes, as well as feeling helpless to prepare themselves for a large event.

2. Participants reported avoiding thoughts of earthquakes, only engaging with earthquake and preparedness information when they either experienced one or saw one in the news.

3. Respondents wanted information about how an earthquake affected the areas where their loved ones and homes were.

4. Respondents relied on several different resources for news after an earthquake, including: social media, local news, search engines, and the United States Geological Survey website.
The responses to the "Experience" section of the user interview were also used to create a task analysis (Figure 6) to build out a broad flow of actions that users described taking, or thought they would take, after experiencing an earthquake The questions were:

- Have you experienced an earthquake? What did you do?

- How do you get information immediately after the earthquake?

- What is the information you are looking for? Did you find it?

A clear pattern of four distinct actions was taken across the identified personas: Recognition, Confirmation, Initial Information Seeking and Secondary Information Seeking.

This mental model for responding to earthquakes matches many overarching themes in the Protective Action Decision Model (PADM) - a model for emergency behavioral response. 
The PADM asserts that individuals decide how to respond to an emergency situation by seeking information from social circles, media outlets, and authorities so that they can confirm environmental and social cues indicating they are at risk. Moreover, as individuals proceed in their decision-making about how to respond once risk has been confirmed, they continually seek new information (Lindell and Perry, 1992, 2012).

After an earthquake, respondents often used conventional news sources to confirm there was an earthquake and get basic information like magnitude and epicentral location. However, when attempting to figure out the impact to different areas of their community and what routes of transport would be accessible to them, respondents reported having trouble finding clear guidance. With this information and guidance from models like PADMin hand, we moved on to brainstorming potential improvements to the MyShake application that could address the identified pain points and align with user mental models surrounding earthquakes.

\section{BRAINSTORM AND REDESIGN}

Our redesign needed to provide more utility to users in order to reach our goal of expanding MyShake's global network to ultimately provide rapid earthquake notifications and data for research. However, we also needed to weigh potential new features that could add utility with their technical feasibility. New feature requests could have impact on data usage, which could adversely incur a cost to a user if they are not connected to Wifi. Extra monitoring features could complicate the battery usage. User privacy considerations are also always at the forefront of design decisions. MyShake does require location information in order to pinpoint the earthquake site, but we do not want to link this to any other personally identifiable information. So personalized registration, interaction, and data viewing features needed to be carefully scrutinized before implementation. We attended to each of these concerns by developing a set of ideal features for users, and then undergoing many cycles of iteration to optimize their usability and technical viability.

Our first step in identifying this set of ideal features was combining our findings from user interviews with expert knowledge and literature in disaster preparedness, emergency behavior, and citizen science in an Affinity diagram. This diagram was assembled by first grouping information with its source (either users, experts, or literature), then rearranging into clusters of shared characteristics, before finally summarizing the common theme expressed by each cluster. Through this process, we identified multiple broader needs, three of which we had the technical ability to address:

1. Need highly local information about surroundings (e.g., road damage and building damage) so users can assess what actions, if any, to take next. This information preferably comes from their community news outlets or social networks.

2. Need to understand their contribution to citizen science projects through metrics and acknowledgment of their participation.
3. Need resources that empower them to learn more about earthquakes and preparedness, without inciting fear and despair.

Through a brainstorming process that included: comparing this set of needs with the limitations of our previous personas, using rapid prototyping techniques to explore different design solutions, and discussions with our technical team about the most efficient and optimal path forward, we created an initial iteration of the MyShake redesign. The main functionality addresses the three identified user needs. The design solution for the first need of hyperlocal information on the state of infrastructure is met through a brief after-earthquake survey that can be filled out by users in the range of an earthquake called an "Experience Report" (Figure 7). Among other questions, the report asks for user input on any visible damage to buildings or roads in their vicinity. For each earthquake, user responses can be visualized graphically or on a map clustered in one kilometer hexbins, which addresses user privacy concerns by protecting individual user locations. Users can both quickly assess the overall impact of an earthquake and zoom into important locations-like their neighborhood, the area around their child's school, as well freeways or bridges they use regularly-to check their condition. Studies into earthquake damage reporting behavior of users of the LastQuake mobile app suggest that reports from users at damaging shaking levels may be more challenging to collect (Bossu et al., 2017). Research on the accuracy of the Did You Feel It crowdsourced shaking intensities also indicate that "reporting and sampling biases can account for historical earthquake intensity biases as high as two intensity units and for the qualitative difference in intensity distance decays for modern vs. historical events" (Hough, 2013). However, crowdsourcing road damage has proven to be useful for traffic apps like Waze and their Connected Citizens Program ${ }^{1}$. We opted to include the feature in the new User Interface design to increase user functionality and meet the need that users would find value in road and building damage reports. To mitigate biases and difficulty in reporting for large shaking levels, we limited the options for response to only four levels: none, light, moderate, and severe. The Modified Mercalli intensity scale ranges from I-X, so having only four levels smooths the responses such that errors even as great as two intensity units would not have large impacts on our user map.

We included pages called My Data (Figure 8) and $M y$ Earthquake Log (Figure 9) to provide users with information about their contribution to the project. My Data shows users' individualized metrics like the number of earthquakes they have been near and the number of Experience Reports they have submitted. It also provides statistics on the network as a whole, such as how many total earthquakes MyShake has successfully detected and how many total Experience Reports have been submitted to the system, to provide them with context for the larger cause that they are helping to support. The My Earthquake Log page provides a timeline of past earthquakes for which users were near the estimated area of felt shaking. For events

${ }^{1}$ Waze. Available online at: https://www.waze.com/ccp (Accessed November 15, 2018). 


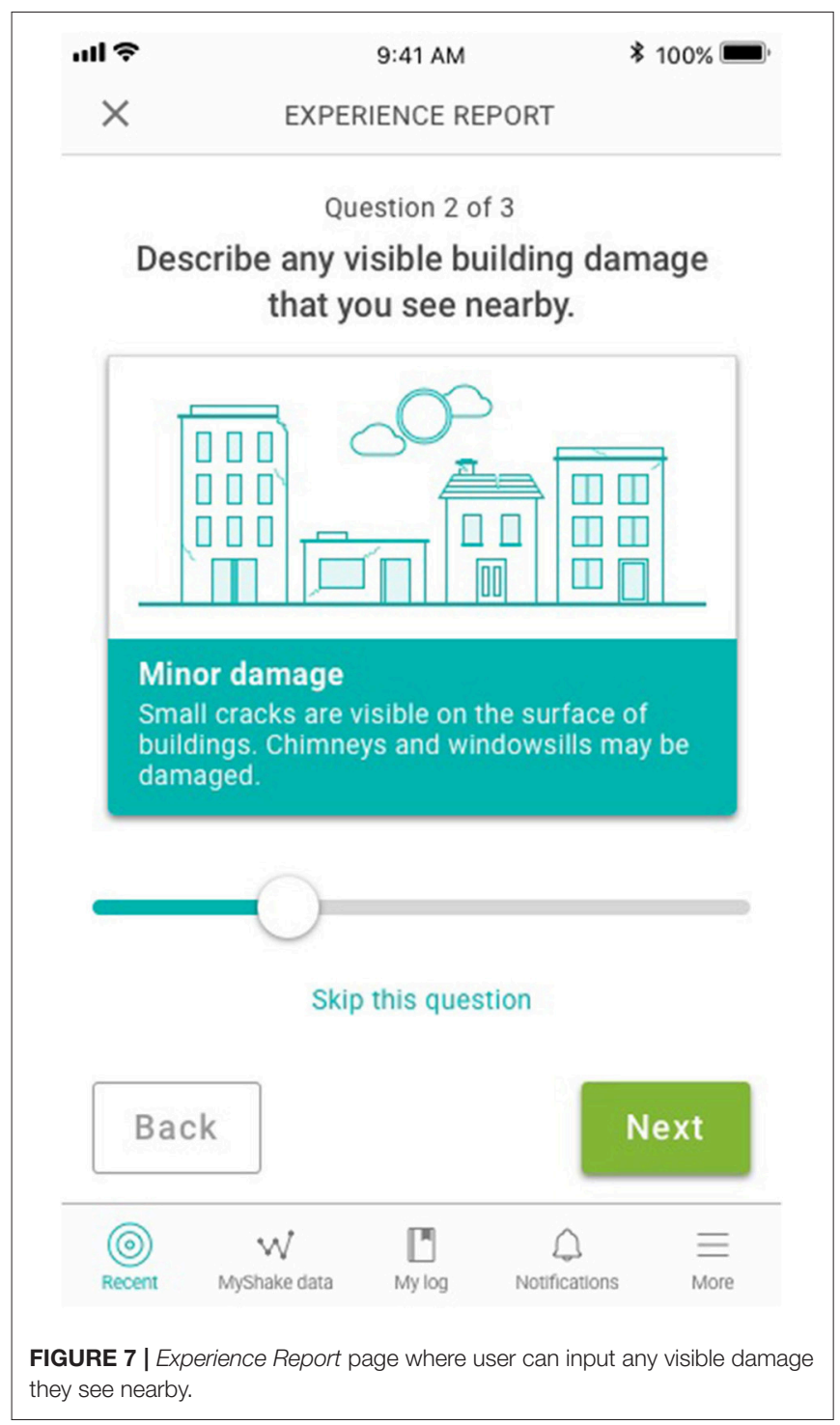

where users have submitted an Experience Report, the timeline also includes a summary of their responses to the survey. This way users can see data that they have contributed as well as, for target users in earthquake prone regions, understand the seismic activity in their community, thus highlighting the import of the MyShake project. Finally, we addressed the need for approachable, empowering earthquake information throughout the application. The Earthquake Details pages (Figure 10) contain engaging map and graphical visualizations of Experience Reports and allow users to explore seismic activity worldwide represented in a visually interesting and readily understandable format. Additionally, features like My Earthquake Log and My Data empower users by allowing them to track their past earthquake experiences, providing context for their personal earthquake history.

Armed with this list of new user-focused functionalities, we performed an iterative design cycle to translate these new objectives into functional wireframes for hard coding. Starting

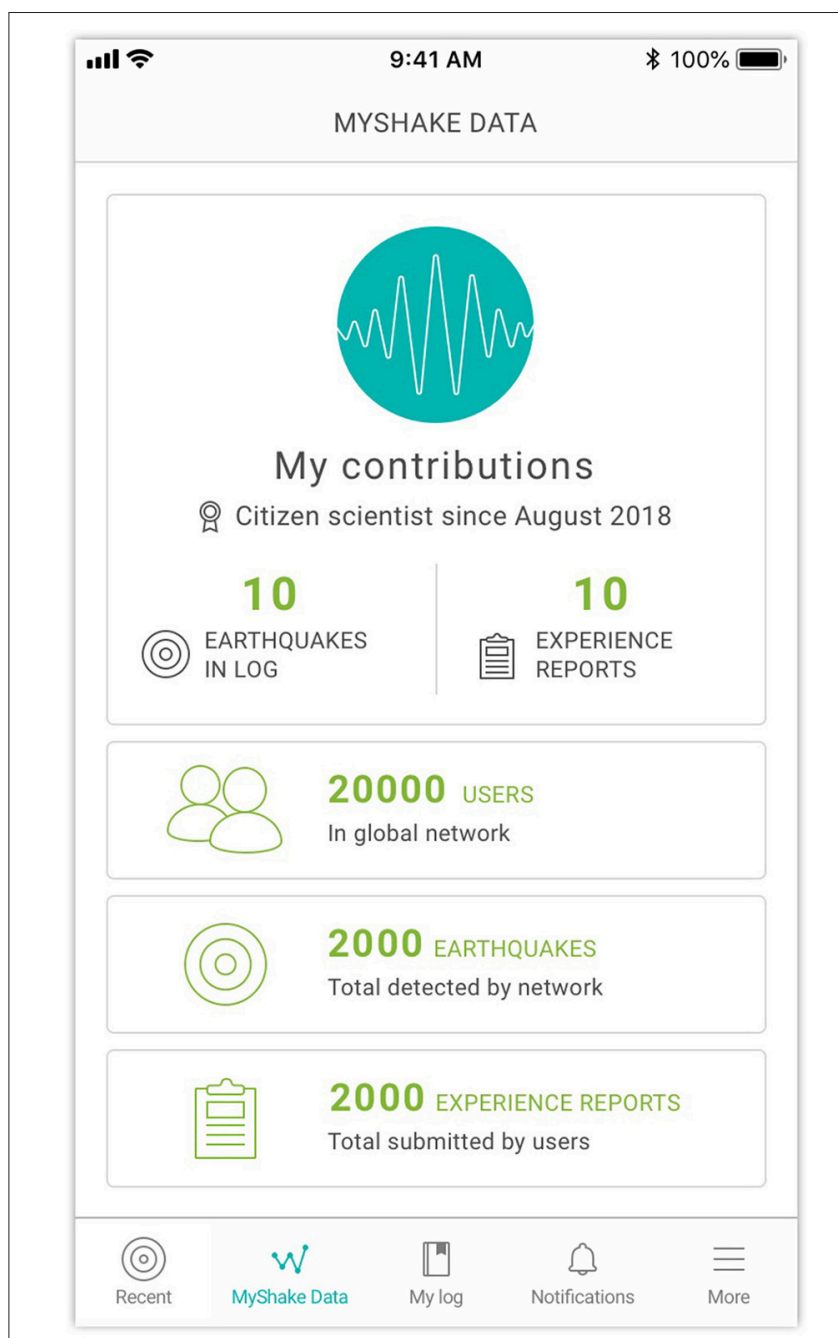

FIGURE 8 | My Data page where users can visualize their contributions to the MyShake project and the reach of the project as a whole.

with rapid pen and paper prototypes, mockups for the application were created, evaluated on the basis of usability and technical feasibility, and edited based on these factors before evolving into a higher fidelity mockup. This process continued through Lo-Fi, Mid-Fi, and Hi-Fi mockups until we had a functioning prototype. Throughout these stages usability was assessed by ensuring the mockups and information architecture of the application complied with the Nielson Norman Group's 10 Heuristics for User Interface Design (Nielson, 1995).

Technical practicality was judged by backend, frontend, and phone-side developers on the MyShake team, who conferred with the UX designer to weigh functionality for users with development time and effort. Several technical challenges required balancing user experience with MyShake's capability as a research tool. Chief among them being the Doze state and App Standby, included in Android 6.0 and subsequent versions, that turn off the background functionality of applications when the 


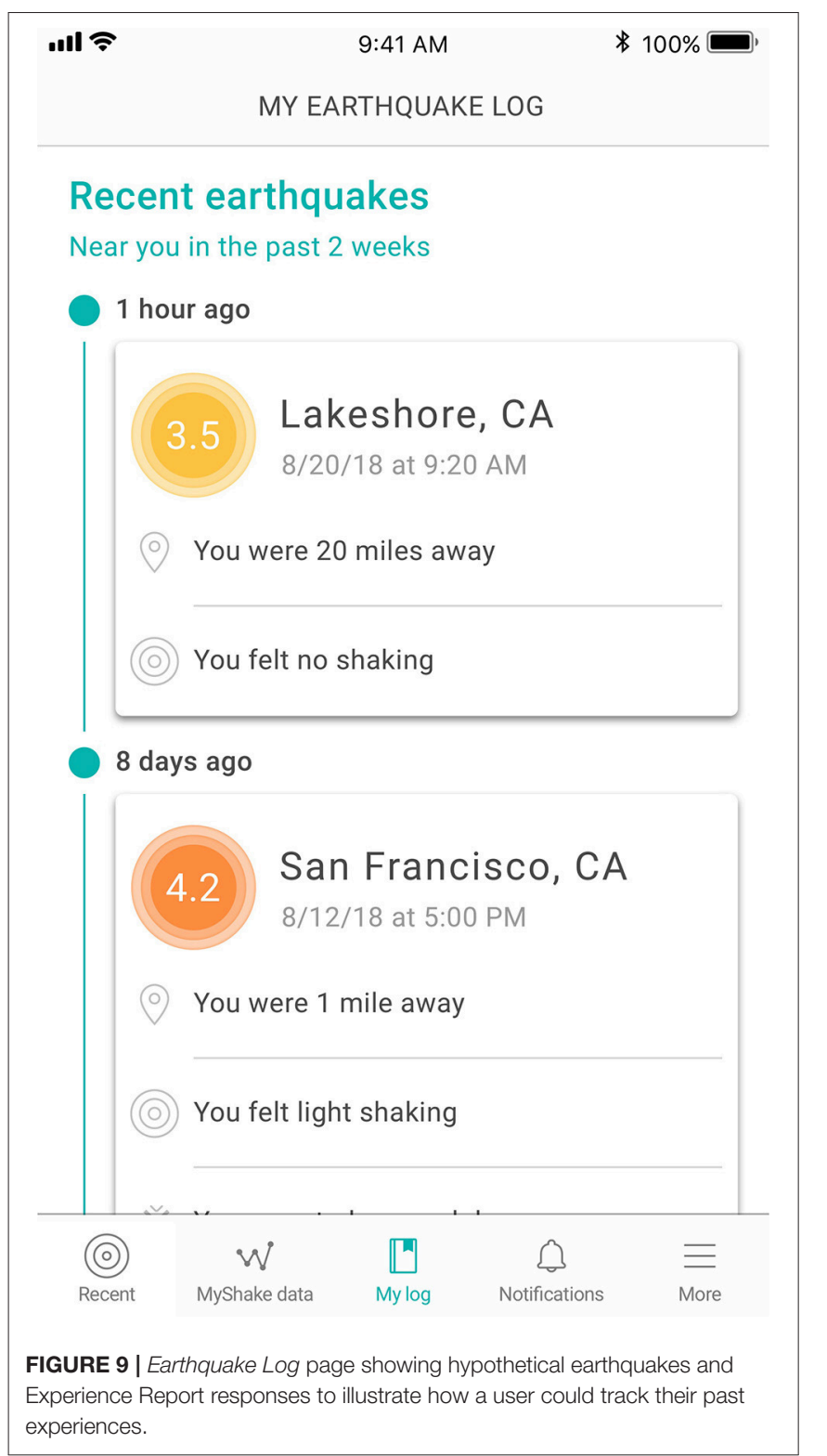

phone is inactive or an application is used infrequently (Optimize for Doze App Standby, n.d.).

Without active background processes, MyShake is unable to monitor sensors in the phone and detect earthquakes. Our developers were able to sustain the application's background function for longer periods of time by sending a persistent notification from the application to the phone, indicating the application is in use. However, this notification results in a fixed icon and message in the user's notification tray. While we had received previous feedback that this lingering message bothered some users, we chose to continue using the scheme to preserve MyShake's ability to monitor phone sensors in non-battery saving mode. Another challenge was MyShake's battery consumption. As noted earlier, this was a major user complaint that arose with the first version of the application. We remained cognizant of this issue during the redesign and in this case chose to prioritize user

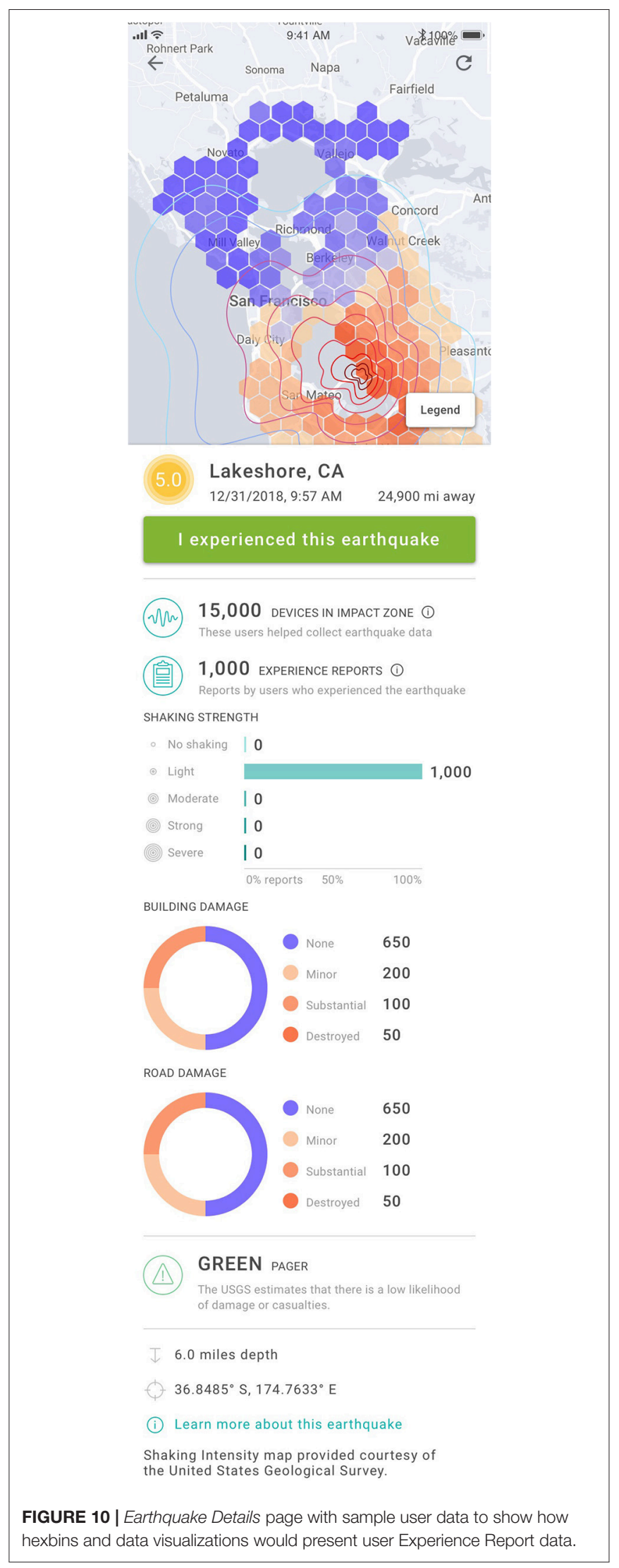


experience over maximum data collection per device. Instead of monitoring all the time, the redesigned MyShake defaults to battery saving mode, that only allows the application to monitor sensors when a device is plugged into power. While it decreases the data that is collected by a single device every day we hope that this change will mean a major improvement in user experience such that more users will continue to keep the application installed on their phone for longer periods of time.

After technical questions were addressed and we reached the stage of creating a functional prototype, we embarked on user testing to ensure our designs were functional and valuable to users.

\section{DESIGN EVALUATION}

We approached user testing by using a methodology similar to that of our initial user needs research. To avoid the expenses and time of recruiting and to get access to users with an array of backgrounds, we approached community members in Downtown Berkeley and near Frank H Ogawa Plaza in Oakland's City Center. Interviews were conducted by four MyShake team members on June 30th and 31st of 2018, a Wednesday and Thursday, respectively, around lunch hours, between roughly 11 a.m. and 2 p.m. Similar to the earlier survey study, any adult who was not otherwise occupied was considered for the interview. Prospective interviewees were asked if they would be willing to be interviewed by the Berkeley Seismology Lab and were able to freely give or refuse consent. No personally identifiable information was collected from the subjects.

Each interview began by asking about the subject's experience with earthquakes and their normal reaction to these events. The users were then asked to pretend that an earthquake had just occurred, and to use the application to find information they would be interested in had such an event occurred. Since the prototype had a fully functioning interface but was not yet supported by a functioning backend or user contributions, a set of data from past earthquakes was used to populate the main earthquake map and placeholder data was used to show hypothetical user responses to the experience reports for each event. Users were asked to complete a few key tasks, but for the most part they were allowed to navigate the application freely while sharing their thoughts and questions about the pages they encountered aloud. At the end of each user testing session, we also asked users: if they found the functionality of the application useful, how they felt about the overall experience of using the application, any features that they'd like to see included or removed from the application, and if the application were available today if they'd want it on their phone.

We organized our findings feature by feature to evaluate their usability and functionality, as well as assessed the application redesign as a whole based on user feedback. Overall the feedback we received about the new prototype was positive. Users were especially interested in the map and data visualizations of user experience responses and expressed many use cases when it could be an important tool in their own lives. We do note that for many earthquake events, there may not be enough responses from users to populate the user generated shaking, road, and building damage portions of the report.
We identified several usability issues that impacted user experience and prevented users from fully utilizing certain features of the application. One such issue was found with the Experience Report map-specifically the map legend. Many users had difficulty finding the legend as the button had no text and a symbol users did not associate readily with a map legend. Before finding the legend, users were confused about what data was being represented on the map, but upon a tester helping them find the legend, users immediately understood what information was being shown and its value to them personally. The map legend was clearly essential to facilitating the overall user experience of the map. We improved this experience by changing to symbolic button to a clearly labeled button simply stating "Legend." Another challenging user experience was found in the My Data page. While users understood that they were being shown metrics about their hypothetical contribution, vague terms like "hours of data collected" and "earthquakes nearby" left them unsure exactly what these metrics meant. Based on this feedback, the page was redesigned with clear phrasing such as "total experience reports submitted" and "total earthquakes in $\log$."

At this point, after revisions were made, final designs were committed for development. Our group expects to release the newly updated version of the MyShake app in Winter of 2018 to select beta testers and to the general public in the Spring of 2019.

\section{CONCLUSION}

The MyShake citizen science project was overhauled from end to end to attract new users and increase user retention. Humancentered design methods were employed to ensure that we were building a global seismic platform which benefited the individual users as well as the research community. A larger, denser user base translates to more data for researchers to tackle unanswered seismological questions, while a user-focused application can also provide great benefit to users at risk of earthquake hazards. While providing rapid earthquake notifications will likely be a key motivator for users in the future, we also hope that the improved functionality of the app will enhance the desire of users to install and keep the app such that more areas reach target density to begin providing these services. Further investigations after the application's release will be required to measure the effectiveness of this redesign process.

\section{ETHICS STATEMENT}

This study was granted Exempt Status from Full Committee review by the UC Berkeley Office for Protection of Human Subjects under Category 2 of the Federal Policy for the Protection of Human Subjects (45 CFR 46) as no identifiable information was collected from subjects. Each potential subject was asked if they were interested in participating in an anonymous interview for the UC Berkeley Seismology Lab with the purpose of improving an earthquake mobile application. The study only proceeded if a subject provided verbal informed consent. 


\section{AUTHOR CONTRIBUTIONS}

KR designed the human-subject research study and executed design methodologies. QK ran data analysis. KR and JS wrote sections of the manuscript. All authors helped collect user feedback and contributed to manuscript editing and revision.

\section{FUNDING}

This project was funded by the Gordon and Betty Moore Foundation through Grant GBMF5230 to UC Berkeley.

\section{REFERENCES}

Aki, K. (1987). Magnitude frequency relation for small earthquakes: a clue to the origin of $f \max$ of large earthquakes. J. Geophys. Res. 92:1349. doi: 10.1029/JB092iB02p01349

Aki, K. (1993). Local site effects on weak and strong ground motion. Tectonophysics 218, 93-111. doi: 10.1016/0040-1951(93)90262-I

Atkinson, G. M., and Wald, D. J. (2007). Did you feel it? Intensity data: a surprisingly good measure of earthquake ground motion. Seismol. Res. Lett. 78, 362-368. doi: 10.1785/gssrl.78.3.362

Bossu, R., Matthieu, L., Frédéric, R., and Robert, S. (2017). Felt reports for rapid mapping of global earthquake damage: the doughnut effect? Seismol. Res. Lett. 89, 138-144. doi: 10.1785/0220170129

Bossu, R., Roussel, F., Fallou, L., Landès, M., Steed, R., and Mazet-Roux, G. (2018). LastQuake: from rapid information to global seismic risk reduction. Int. J. Disaster Risk Reduct. 28, 32-42. doi: 10.1016/j.ijdrr.2018.02.024

Budiu, R. (2017). Quantitative vs. Qualitative Usability Testing. Nielson Norman Group. Available online at: https://www.nngroup.com/articles/quant-vs-qual/

Clayton, R. W., Heaton, T., Chandy, M., Krause, A., Kohler, M., Bunn, J., et al. (2012). Community seismic network. Ann. Geophys. 54. doi: 10.4401/ag-5269

D'Alessandro, A., and D'Anna, G. (2013). Suitability of low-cost threeaxis MEMS accelerometers in strong-motion seismology: tests on the LIS331DLH (iPhone) accelerometer. Bull. Seismol. Soc. Am. 103, 2906-2913. doi: 10.1785/0120120287

D’Alessandro, A., D’Anna, R., Greco, L., Passafiume, G., Scudero, S., Speciale, S., et al. (2018). "Monitoring earthquake through MEMS Sensors (MEMS project) in the town of Acireale (Italy)," 2018 IEEE International Symposium on Inertial Sensors and Systems (INERTIAL) (Moltrasio), 1-4.

Dashti, S., Bray, J. D., Reilly, J., Glaser, S., and Bayen, A. (2012). "IShake: the reliability of phones as seismic sensors," in 15th World Conference on Earthquake Engineering (Lisbon), 1-10.

Elizabeth, S. C., Lawrence, J. F., Christensen, C., Jakka, R. S. (2009). The quakecatcher network: citizen science expanding seismic horizons. Seismol. Res. Lett. 80, 26-30. doi: 10.1785/gssrl.80.1.26

Eyal, N. (2014). Hooked: How to Build Habit-Forming Products. New York, NY: Penguin Group.

Finazzi, F. (2016). The earthquake network project: toward a crowdsourced smartphone-based earthquake early warning system. Bull. Seismol. Soc. Am. 106, 1088-1099. doi: 10.1785/0120150354

Finazzi, F., and Fassò, A. (2017). A statistical approach to crowdsourced smartphone-based earthquake early warning systems. Stochast. Environ. Res. Risk Assessment 31, 1649-1658. doi: 10.1007/s00477-016-1240-8

Goodwin, K. (2009). Designing for the Digital Age: How to Create Human-Centered Products and Services. Indianapolis, IN: Wiley Publishing.

Hall, E. (2013). Just Enough Research. New York, NY: A Book Apart.

Hough, S. E. (2013). Spatial variability of “did you feel it?" intensity data: insights into sampling biases in historical earthquake intensity distributions. Bull. Seismol. Soc. Am. 103. 2767-2781. doi: 10.1785/0120120285

Jonsson, P. (2018). Ericsson Mobility Report. Available online at: https:// www.ericsson.com/assets/local/mobility-report/documents/2018/ericssonmobility-report-november-2018.pdf

\section{ACKNOWLEDGMENTS}

Human Subjects Research testing was approved by the University of California at Berkeley Internal Review Board as a Social Behavioral Exempt protocol 2018-03-10922.

\section{SUPPLEMENTARY MATERIAL}

The Supplementary Material for this article can be found online at: https://www.frontiersin.org/articles/10.3389/feart. 2018.00237/full\#supplementary-material

Kong, Q., Allen, R. M., Bunn, J., Kohler, M., and Heaton, T. (2018a). Structural health monitoring of buildings using crowdsourced smartphones. Seismol. Res. Lett. 89, 594-602. doi: 10.1785/0220170111

Kong, Q., Allen, R. M., and Schreier, L. (2016a). MyShake: initial observations from a global smartphone seismic network. Geophys. Res. Lett. 43, 9588-9594. doi: 10.1002/2016GL070955

Kong, Q., Allen, R. M., Schreier, L., and Kwon, Y.-W. (2016b). MyShake: a smartphone seismic network for earthquake early warning and beyond. Sci. Adv. 2, e1501055-e1501055. doi: 10.1126/sciadv.1501055

Kong, Q., Inbal, A., Allen, R. M., Lv, Q., and Puder, A. (2018c). Machine learning aspects in myshake global smartphone seismic network. Seismol. Res. Lett. doi: 10.1785/0220180309

Kong, Q., Inbal, A., Allen, R. M., and Strauss, J. (2018b). "MyShake: building a global smartphone earthquake early warning system," in SEG Technical Program Expanded Abstracts, Technical Program Chairperson(s), eds A. David and D. Bevc (Society of Exploration Geophysicists), 5520.

Kong, Q., Kwon, Y.-W., Schreierz, L., Allen, S., Allen, R., and Strauss, J. (2015). "Smartphone-based networks for earthquake detection," in 2015 15th International Conference on Innovations for Community Services (I4CS) (Nuremberg). doi: 10.1109/I4CS.2015.7294490

Kong, Q., Trugman, D., Ross, Z. E., Bianco, M., Meade, B., and Gerstoft, P. (2018d). Machine learning in seismology: turning data into insights. Seismol. Res. Lett. doi: 10.1785/0220180259

Lindell, M. K., and Perry, R. W. (1992). Behavioral Foundations of Community Emergency Planning. Washington, DC: Hemisphere Publishing Corp.

Lindell, M. K., and Perry, R. W. (2012). The protective action decision model: theoretical modifications and additional evidence. Risk Anal. 32, 616-632. doi: 10.1111/j.1539-6924.2011.01647.x

Maechling, P. J., Silva, F., Callaghan, S., and Jordan, T. H. (2014). Broadband platform: system architecture and software implementation. Seismol. Res. Lett. 86, 27-38. doi: 10.1785/0220140125

Meier, M.-A., Heaton, T., and Clinton, J. (2016). Evidence for universal earthquake rupture initiation behavior. Geophys. Res. Lett. 43, 7991-7996. doi: 10.1002/2016GL070081

Naito, S., Azuma, H., Senna, S., Yoshizawa, M., Nakamura, H., Hao, K., et al. (2013). Development and testing of a mobile application for recording and analyzing seismic data. J. Disaster Res. 8, 990-1000. doi: 10.20965/jdr.2013.p0990

Nielson, J. (1995). 10 Usability Heuristics for User Interface Design. Nielson Norman Group. Avaialble online at: https://www.nngroup.com/articles/tenusability-heuristics/

Optimize for Doze and App Standby (n.d.). Documentation for App Developers. Available online at: https://developer.android.com/training/monitoringdevice-state/doze-standby

Poushter, J., Caldwell, B., and Hanyu, C. (2018). Social Media Use Continues To Rise In Developing Countries But Plateaus Across Developed Ones. Avaialble online at: http://www.pewglobal.org/2018/06/19/social-media-use-continuesto-rise-in-developing-countries-but-plateaus-across-developed-ones/

Ruhl, C. J., Melgar, D., Grapenthin, R., and Allen, R. M. (2017). The value of realtime GNSS to earthquake early warning. Geophys. Res. Lett. 44, 8311-8319. doi: 10.1002/2017GL074502 
van der Elst, N. J., and Page, M. T. (2017). Nonparametric aftershock forecasts based on similar sequences in the past. Seismol. Res. Lett. 89, 145-152. doi: 10.1785/0220170155

Wetzler, N., Brodsky, E. E., and Lay, T. (2016). Regional and stress drop effects on aftershock productivity of large megathrust earthquakes. Geophys. Res. Lett. 43, 12012-12020. doi: 10.1002/2016GL0 71104

Yildirim, B., Cochran, E. S., Chung, A. I., Christensen, C. M., and Lawrence, J. F. (2015). On the reliability of Quake Catcher Network earthquake detections, Seis. Res. Lett. 86, 856-869. doi: 10.1785/02201 40218
Conflict of Interest Statement: The authors declare that the research was conducted in the absence of any commercial or financial relationships that could be construed as a potential conflict of interest.

Copyright (c) 2018 Rochford, Strauss, Kong and Allen. This is an open-access article distributed under the terms of the Creative Commons Attribution License (CC BY). The use, distribution or reproduction in other forums is permitted, provided the original author(s) and the copyright owner(s) are credited and that the original publication in this journal is cited, in accordance with accepted academic practice. No use, distribution or reproduction is permitted which does not comply with these terms. 


\title{
The Leadership Void for Climate
} Adaptation Planning: Case Study of the Port of Providence (Rhode Island, United States)

\author{
Austin Becker* and Eric Kretsch \\ Department of Marine Affairs, University of Rhode Island, Kingston, RI, United States
}

Climate adaptation requires leadership from a diverse group of stakeholders to shift investment priorities and generate political will for long-term planning. This is especially true for seaport stakeholders. Ports serve as access points to goods and services from around the world, promoting a higher and more robust quality of life. However, with the increased likelihood of intense storms, rising sea levels, and resource scarcity facing coastal communities, stakeholders will need to adapt coastal infrastructure to ensure long-term viability. Solving such problems requires leadership and participation from government across jurisdictional boundaries and/or the private sector. Using the

\section{OPEN ACCESS}

Edited by:

Jonathan D. Paul,

Imperial College London,

United Kingdom

Reviewed by:

Nick Obradovich,

Massachusetts Institute of Technology, United States Julia A. Ekstrom, California Natural Resources Agency, United States

*Correspondence: Austin Becker abecker@uri.edu

Specialty section: This article was submitted to Geohazards and Georisks, a section of the journal

Frontiers in Earth Science

Received: 07 September 2018 Accepted: 05 February 2019

Published: 22 February 2019

Citation:

Becker A and Kretsch E (2019) The Leadership Void for Climate Adaptation Planning: Case Study of the Port of Providence (Rhode

Island, United States).

Front. Earth Sci. 7:29.

doi: 10.3389/feart.2019.00029 case of Port of Providence (Rhode Island, United States), this study finds stakeholder perceptions of leadership responsibility contribute to an institutional void, in which it is unclear who is responsible and who should pay for resilience investment.

\section{HIGHLIGHTS}

- "Leadership" is defined within the context of coastal resilience planning for seaports.

- Empirical results suggest leadership voids serves as barrier to resilience planning.

- Respondents value dialog that engages stakeholders in transformational planning as a first step to developing leadership.

Keywords: leadership, stakeholder systems, seaport systems, climate change adaptation, barriers, resilience planning

\section{INTRODUCTION}

Actions taken today to support climate change adaptation and natural disaster resilience can have far-reaching and positive long-term effects on society and the environment (Allison et al., 2009). Inaction, on the other hand, can set a dangerous and potentially irreversible course affecting many aspects of human life. Society relies on the continued operation and resilience of seaports (Mansouri et al., 2010) for international trade (Hanson and Nicholls, 2012) and transportation (Becker et al., 2018); they are essential for society and the economy. Climaterelated disruptions have proved to be disastrous for society and the economy not only on local levels but also on regional, national, and international scales (United States Department of Transportation [USDOT], 2014; Xiao et al., 2015; Ng et al., 2016). Coastal infrastructure is especially vulnerable to climate impacts due to its exposed location. Adaptation and resilience is thus critical in the face of a changing climate (Becker et al., 2013) and increased occurrence and intensity of natural disasters (Intergovernmental Panel on Climate Change [IPCC], 2012). Adapting seaports systems to increase their resilience to climate impacts and weather events requires 
long-term planning and significant investments (Hallegatte, 2009; Mansouri et al., 2010). To prepare port systems for climate change and natural disasters, many stakeholders can play a role (Becker and Caldwell, 2015), but one (or more) must take up the baton to organize and lead the system forward. The question remains: What mechanisms can drive leadership in this area, despite misalignment between costs (now) and benefits (much later)?

This paper contributes to the growing body of literature in climate change policy in two ways. First, we propose a definition of leadership within the context of coastal adaptation and resilience. Second, we provide empirical data supporting the notion that, at least in the case of the Port of Providence (Rhode Island, United States), a void in leadership serves as a significant barrier to resilience planning. Stakeholders from the Port of Providence participated in previous planning and research efforts of which this paper is a part (Becker, 2017; Becker et al., 2017). In August 2015, port stakeholders participated in a hurricane resilience workshop that used tools and visualizations to introduce concepts of hurricane vulnerability and adaptation strategies. Workshop results concluded that stakeholders though aware of climate change risks to their businesses reached no consensus as to who is responsible for adaptation implementation, who would pay for it, and in what time frame. We thus initiated a second phase to the project and invited 31 stakeholders from the private and government sectors to participate in an online survey and in-person interviews in order to determine where leadership for climate adaptation should lie, as perceived by this group. This study took place between February and May of 2016.

This work also builds on previous research conducted on the impacts of storms on ports and the range of strategies that a wide variety of stakeholders could implement. The earlier work used ports as a lens to explore climate impacts and resilience strategies, since ports rely on exposed coastal locations and serve a critical function to a wide variety of stakeholders (Becker et al., 2014; Becker and Caldwell, 2015). In that research, Becker et al. (2014) and Becker and Caldwell (2015) collected empirical data through interviews of almost 60 port stakeholders from two case studies (Providence, RI and Gulfport, MS) and identified a wide variety of direct impacts, indirect costs, and intangible consequences of hurricanes hitting ports. Port stakeholders from Providence and Gulfport identified 128 unique strategies that could enhance port resilience in the event of a major storm. Responsibility for implementation of those strategies spanned across all stakeholders that made of the port system, including private business, government, community groups, and nongovernmental organizations. However, many of those strategies had not (and have not) been implemented. Interviewees indicated that some strategies would be cost prohibitive, while others fell outside of the jurisdiction or mandate of the key decision makers, and still others simply did not rank highly enough when compared to other priorities. Further, interviews from this earlier study suggested that proper incentives were not in place to drive organizations to take the lead on making longterm resilience investments. For example, individual stakeholders pointed to other stakeholders to provide the necessary funding.
These revelations suggest that there is a lack of cohesion concerning adaptation and resilience planning where resources and leadership are concerned. The research presented in this paper builds on the previous research and the 2015 workshop through additional interviews of key stakeholders in the Port of Providence around their notions of responsibility for resilience investment and action.

\section{Concepts of Adaptation and Resilience}

Herein, we adopt the 2014 National Climate Assessment's definition of resilience: "A capability to anticipate, prepare for, respond to, and recover from significant multi-hazard threats with minimum damage to social well-being, the economy, and the environment" (Melillo et al., 2014), and their definition of adaptation: "Adjustment in natural or human systems to a new or changing environment that exploits beneficial opportunities or moderates negative effects" (Melillo et al., 2014) Adaptation policies have limited exogenous incentives of action (Anguelovski and Carmin, 2011) and, in many instances mandates, laws, and job descriptions fail to address adaptation planning (Moser and Ekstrom, 2010). Adaptation's novelty and lack of policy guidance, along with the major investments and long lead times necessary, stand as key barriers to implementing resilience strategies.

\section{Concepts of Leadership}

Much of the adaptation and resilience process is complex and will require stakeholders to take early action in a process that will have long-term payoffs, but fewer clear short-term returns. Those who pay to adapt may not be the primary beneficiaries of the adaptation benefits. McEvoy et al. (2008) suggest that the disparity between "who pays" and "who ultimately benefits" makes adaptation a difficult sell to some stakeholders. This may be particularly true in the case of seaports, as often port infrastructure have long lifespans (Becker, 2013). Complicating adaptation in this area even more, a seaport is a complex nexus of human and organization factors that interacts with physical infrastructure and equipment (Mansouri et al., 2010). Stakeholders will have different values, concerns, and objectives in the climate adaptation process (Nelson et al., 2007; Adger et al., 2009; Moser and Ekstrom, 2010); and therefore, stakeholders will have different reasons for stepping up as leaders for climate adaptation and resilience. However, leadership is critical in the adaptation process (Moser, 2010) to help overcome some of the difficulties surrounding the process. In fact, leadership is often cited more for its absence (Wilbanks, 2007), which can be a significant barrier to adaptation Moser and Ekstrom (2010) and Ekstrom and Moser (2014).

The Oxford Dictionary defines leadership as "the action of leading a group of people or an organization" (Oxford English Dictionary [OED], 2013), but neither the leadership literature nor the climate literature offer a consensus regarding the definition of "leadership." Table 1 provides examples of other leadership definitions and demonstrates that the leadership concept generally includes a process, an influence, a group, and a common goal.

Given the importance of the seaport system, complexity of stakeholder groups, and increased climate and weather related 
TABLE 1 | Examples of what "leaders" do.

What "leaders" do

Influence followers to achieve group/organizational goals (Maak and Pless, 2006)

The action of one or more people who selects, equips, trains, and influences one or more follower(s) who have diverse gifts, abilities, and skills and focuses the

follower(s) to the organization's mission and objectives (Winston and Patterson, 2006)

The ability to influence individuals and mobilize organizations to realize a vision (Egri and Herman, 2000)

Move people in a direction that is genuinely in their real long- term best interests (Barker, 2001)

Arranging a situation so that various members of a group... can achieve common goals (Bellows, 1959; Bass and Bass, 2009)

Influencing the activities of an organized group in its efforts toward goal setting and goal achievement (Stogdill, 1974; Bass and Bass, 2009)

Influencing people to cooperate toward some goal which they come to find desirable (Tead, 1935; Bass and Bass, 2009)

threats (Becker, 2014), a clear, concise definition of adaptation leadership would benefit the adaptation and resilience process to inform decision makers on how to best create the proper incentives. We constructed the following definition of leadership based on those established components (process, influence, group, common goal), as follows:

Leadership for adaptation of seaport systems initiates actions through guidance, directive, mandate, self- or altruistic-interest that make the system, or components thereof, more resilient to climate change and natural disasters.

Adapting infrastructure to be resilient to climate change will require a variety of individual stakeholder initiatives, as well as collaborations and large investment of money and other resources (Tompkins et al., 2008). Leaders will be necessary to initiate (Moser and Ekstrom, 2010; Anguelovski and Carmin, 2011) and advance the adaptation process (Ekstrom and Moser, 2014), a process that will involve conflicting stakeholder groups (Nelson et al., 2007; Parola and Maugeri, 2013) from which leaders will, hopefully, emerge. For example, some coastal communities may be well-served by the construction of a new storm barrier, such as the Maeslantkering Barrier in Rotterdam. This type of project costs billions of dollars to construct and would be fraught with confounding implications for social justice and the environment. Many stakeholders would play a role in the choice of design, the location, the research studies, and the raising of both capital and political will, but one or more leaders from amongst the interested stakeholders would need to champion the project to push it forward.

To date, there lacks research focused specifically on leadership as a barrier to adaptation and resilience. Further, few researchers have focused on strategies for overcoming lack of leadership as a barrier to coastal infrastructure and seaport adaptation activities, leaving this vital sector largely unaddressed in the conversation. This study focuses on the stakeholders of the Port of Providence (RI) to explore issues of leadership, and the lack thereof, for resilience planning.

\section{Case Study - The Port of Providence (RI)}

The Port of Providence is located south of downtown Providence (Rhode Island, United States) at the mouth of Providence River and the head of Narragansett Bay (Figure 1). The study area for this project encompasses waterfront industrial business on both the Providence and East Providence sides of the river. The port is critical to the Rhode Island economy and the Rhode Island,
Connecticut, and Massachusetts region (Providence Working Waterfront Alliance [PWWA], 2010) and its location is exposed to climate impacts including sea level rise and storm surge from hurricanes (Rubinoff, 2007). The governance structure of the port is complex. Notably, there is no operating port authority. Overlapping local and state zoning laws and regulations govern the port and approximately 30 independent businesses operate within the study area.

As for many ports, enhancing port resilience to climate change will likely be beyond the resource capacity of port operators acting alone (Becker and Caldwell, 2015) and leadership by other stakeholder groups will be necessary to prepare seaport systems for climate change and natural disasters. Adaptation to a changing climate involves a complex group of stakeholders (Tompkins et al., 2008; Becker and Caldwell, 2015) from both the public and private sector (McEvoy et al., 2010). In the seaport context, the stakeholder list may include port authorities, shipping owners, importers, exporters, local environmental groups, local residents, regional governments, national governments, transport firms, and manufacturing industries (de Langen, 2006; Hall et al., 2013). Twenty-five stakeholders responded, representing 13 businesses or nongovernmental organizations (i.e., private) and 12 government agencies (at local, state, and federal level).

\section{Conceptual Framework for Leadership Responsibility}

To structure the interview analysis, we adapted a framework (Stiller and Meijerink, 2016) for organizational responsibility around our definition of leadership (Figure 2). We rely on a simple model of the policy process comprised of three major phases that are necessary for adaptation (Moser and Ekstrom, 2010):

1. Understanding includes identifying problems and measuring their potential impact on a system.

2. Planning includes identifying potential resilience options; assessing the feasibility, costs, and benefits; and selecting the optimal option.

3. Managing entails installing, monitoring, and evaluating the selected resilience option.

Throughout the adaptation process, leaders provide five functions (Stiller and Meijerink, 2016) to initiate action (through 


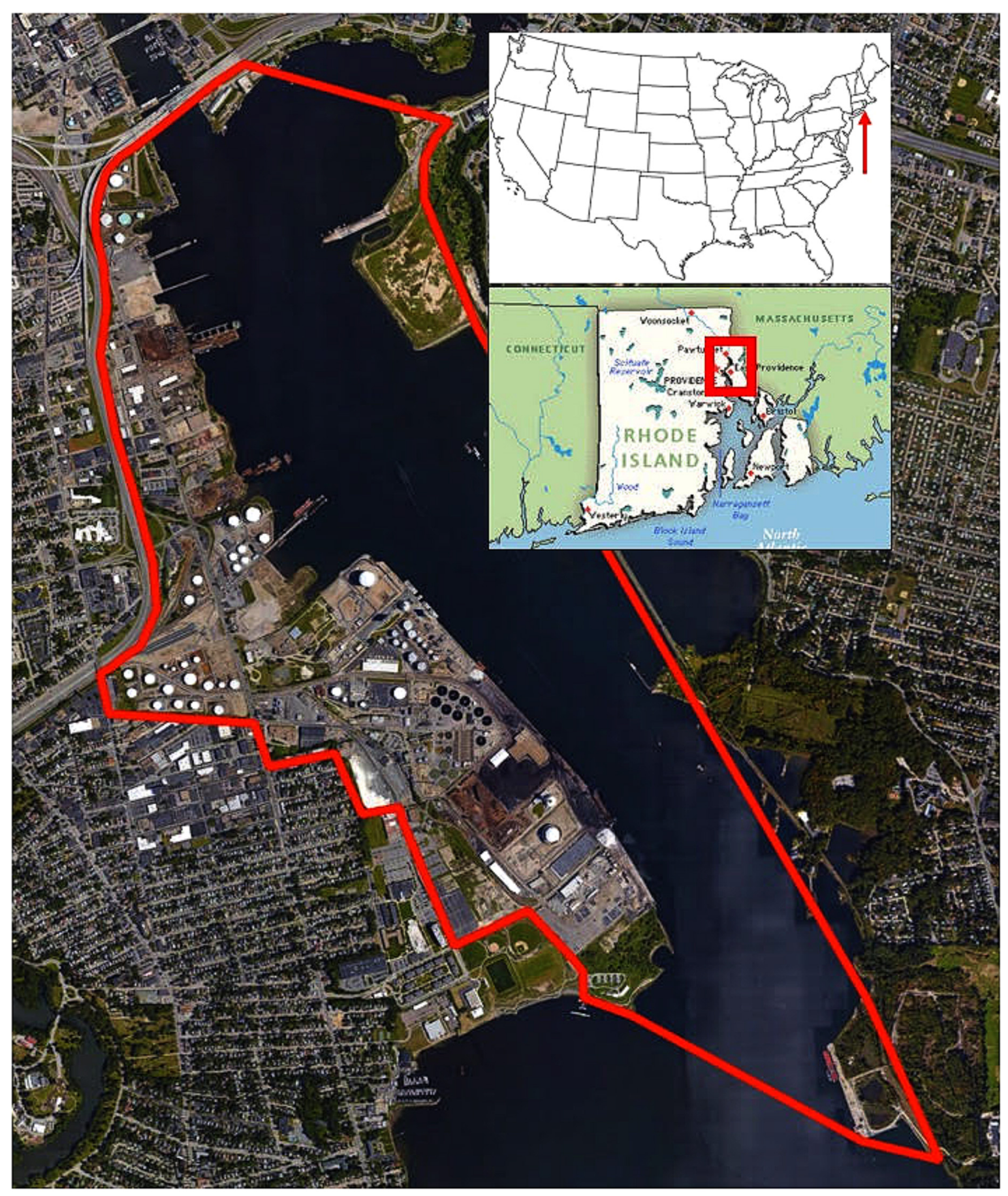

FIGURE 1 | Map of Port of Providence, RI (Becker, 2017).

guidance, directive, mandate, self- or altruistic-interest) to make the system, or components thereof, more resilient to climate change and natural disasters. These five functions are briefly defined as follows:

a Political administrative function - consists of "every day" actions to facilitate the management of the policy processes, such as making decisions on strategy options and designating funding sources for selected strategies.

b Enabling function - motivates progress by instilling a sense of urgency, through initiating discussions and setting deadlines.

c Adaptive function - creates new ideas and process, as well as solutions to exposed barriers. This function allows 


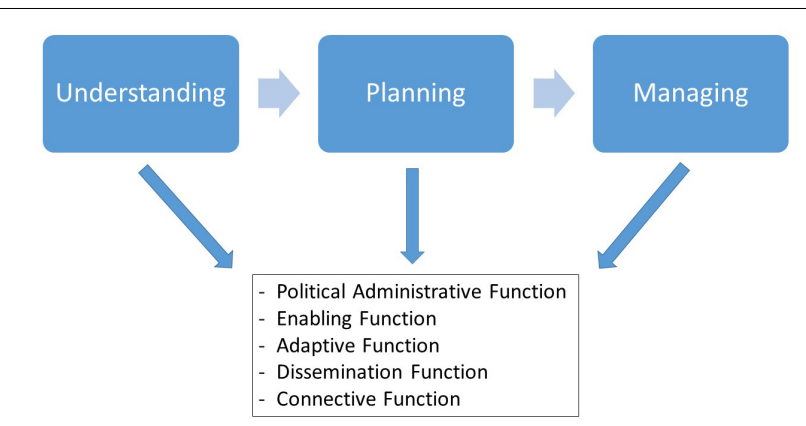

FIGURE 2 | Leadership functions throughout the three phases of the policy process - the political administrative function, enabling function, adaptive function, dissemination function, and connective function are facilitated by leadership.

the organization to change structurally to meet external changes and forces.

d Dissemination function - provides information on new ideas, problems, and solutions to resilience partners and collects information from partners and incorporates them into decision-making.

e Connective Function - incorporates stakeholders into a collective group. It provides connections between stakeholders by initiating meetings and work sessions and by engaging new stakeholders.

\section{DATA COLLECTION METHODS}

This study consisted of two components: First, we conducted an online survey to compare stakeholders' perceptions of leadership responsibility. We sent to the 31 stakeholders who participated in the workshop described above, with 25 respondents completing it. Thirteen respondents selfidentified as representing the public sector (e.g., local, state, federal government) and 12 identified as representing the private sector. In the results section, we use these two broad groups to make some comparisons in attitudes for leadership responsibility. Second, we conducted interviews with representatives of the organizations identified by the 25 respondents as having leadership responsibility for the planning and implementation of three long-term transformational adaptation strategies developed in the earlier workshop (Figure 3).

\section{Part I - Survey of Port of Providence Stakeholders}

In Part 1, an online survey, conducted in February 2016, identified which actors or organizations respondents perceive as responsible for taking the lead and what they considered as the ideal organizational structures for pursuing the three strategies of protect, relocate, and accommodate. These were used to frame the concepts of resilience and emphasize the large-scale strategies, rather than focusing on measures more typically associated with emergency response activities.
For each of these three broad approaches, we asked respondents to identify the appropriate leadership structure for planning and implementing adaptation projects (Table 2). Options included: private businesses independently, private businesses in collaboration (no government), informal publicprivate collaboration, formal public-private collaboration (e.g., state mandated special committee), local lead (City of Providence and East Providence), state lead, and federal lead. Respondents answered on a 1-5 scale that included: (1) not responsible at all, (2) less responsible than others, (3) just as responsible as others, (4) more responsible than others, and (5) entirely responsible.

For each strategy, we also asked which specific actors (i.e., specific agencies, organizations, or persons) respondents perceived as holding responsibility for implementing the strategy. We totaled the number of mentions and identified the nine top organizations perceived as potential leaders of adaptation, as follows:

1. City Government of Providence (planning department),

2. City Government of East Providence,

3. Rhode Island Department of Transportation,

4. Rhode Island Department of Environmental Management,

5. Rhode Island Coastal Resources Management Council,

6. Rhode Island Statewide Planning (part of the RI Department of Administration),

7. CommerceRI,

8. United States Army Corps of Engineers,

9. Providence Working Waterfront Alliance (an organization that represents much of the Port of Providence business community).

We targeted these nine organizations for detailed semistructured interviews, as described in Part II below.

\section{Part II - Interview of Stakeholder Perceived Leaders}

In the second step conducted in May 2016, we interviewed seven of the nine "respondent-identified actors" (two were unable or unwilling to be interviewed) and asked them to selfevaluate their organization's responsibility to facilitate the five "leadership functions" in planning and implementing resilience strategies at the Port of Providence. We conducted in-person interviews with a representative of the organization who survey respondents identified as having the most knowledge about Port of Providence resilience issues. Interviews lasted between $30 \mathrm{~min}$ and an hour. We asked interviewees to evaluate their own organization's leadership responsibility and about the barriers they feel prevent them from taking a more active leadership role.

\section{FINDINGS}

This section first discusses survey results and then interview results, then implications and gaps revealed by these findings. 
Protect - This concept uses infrastructure like a storm barrier located seaward of the port. It requires the construction of a barrier to protect from hurricane surge impact. The concept, unless including a lock system, does not accommodate for impacts from sea level rise, as this rise is passive, and the barrier will remain open to allow for navigation of commerce.

Relocate - This concept moves some non-essential infrastructure away from vulnerable locations. Examples are moving chemical storage (e.g., oil tanks), office space, and equipment storage to higher ground. This would require the purchase of off-port locations.

Accommodate - This concept develops coordinated micro-strategies throughout the port to improve, which cumulatively creates transformational change to the port. Examples of this are elevating properties, elevating utilities and structures, utilizing floodable spaces and breakthrough walls, and waterproofing structures. This strategy potentially can accommodate for sea level rise.

FIGURE 3 | Definitions of long-term adaptation approaches developed for the Port of Providence Resilience workshop (see also www.portofprovidenceresilience.org).

TABLE 2 | Organizational leadership structures for climate adaptation.

\begin{tabular}{|c|c|}
\hline Form of leadership & Description \\
\hline Businesses independently & Private businesses independently have sole responsibility for the implementation of resilience. \\
\hline Business in collaboration & Private business collaborates to improve resilience collectively with no/little government support. \\
\hline Public-private informal collaboration & $\begin{array}{l}\text { Business and government working cooperatively to improve resilience. An example of this is a Special Area } \\
\text { Management Plan process. }\end{array}$ \\
\hline Public-private formal collaboration & $\begin{array}{l}\text { Public and private organizations work cooperatively in a Rhode Island legislature authorized/mandated body. An } \\
\text { example of this is the Governor's Commission of Dredging, formed by governor Lincoln Almond in Rhode Island in } 1996 .\end{array}$ \\
\hline $\begin{array}{l}\text { Local lead (City of Providence and East } \\
\text { Providence) }\end{array}$ & City governments take a lead role in facilitating implementation of resilience in the study area. \\
\hline State lead (Rhode Island) & The state of Rhode Island takes a lead role in facilitating implementation of resilience in the study area. \\
\hline Federal lead (United States) & The U.S. federal government takes a lead role in facilitating implementation of resilience in the study area. \\
\hline
\end{tabular}

\section{Survey Finding 1: Stakeholders See a Collaborative Effort as Responsible to Implement Resilience Strategies and Believe Planning Should Begin Now}

The results of the survey suggest the group's perception of the most appropriate leadership structures for resilience planning, as well as the specific actors who should take the lead (Figure 4).

Overall, respondents most supported a public-private informal collaboration structure, with the average respondent ranking it as more responsible to entirely responsible. State lead leadership scored as the second-choice leadership structure. On the other hand, port stakeholders did not see private business independently or private businesses in collaboration as responsible. Thus, most stakeholders see the government as playing a significant role in adaptation planning, with preference for either a completely topdown (state-lead) approach or a collaboration between state and private entities.

However, respondents from different sectors (public vs. private) showed different preferences about which specific organization should be responsible for leading in different resilience approaches. For example, private sector respondents felt that the Accommodate approach required a more public (government) leadership approach. On the other hand, public sector respondents felt that the business side should take a stronger leadership role for Accommodate approaches. This example illustrates the finger-pointing nature of the resilience challenge, with government pointing to the business community to take the lead and vice-versa.

With respect to timing, 22 of the 24 respondents answering the question felt that planning for resilience should begin either immediately or within the next 2 years. Thus, while there was currently no organization in place to spearhead resilience planning for the port, the stakeholders felt that this should be a priority.

\section{Survey Finding 2 - No Clear Specific Leader}

In the open-ended survey questions asking stakeholders who, specifically, is responsible for leading the implementation adaptation approaches, stakeholders named 25 entities, with various organizations rising to the top depending on the resilience approach specified (Figure 5). Though the survey questions was worded to elicit specific organizations or agencies, many respondents provided broader responses (e.g., RI Government or Courts). The private sector respondents listed the Rhode Island Department of Environmental Management as being responsible for accommodate; city government and CommerceRI as responsible for relocate; and the United States Army Corps of Engineers and the State of Rhode Island 


\section{Public sector respondents $(\mathrm{n}=\mathbf{1 2}$ )}

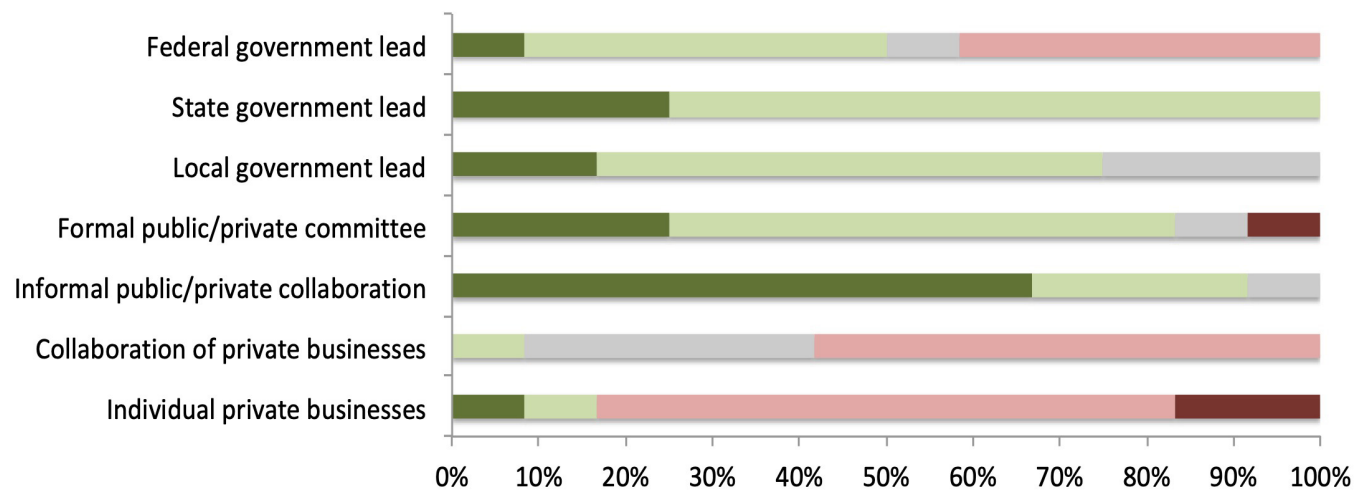

Private sector respondents $(n=13)$

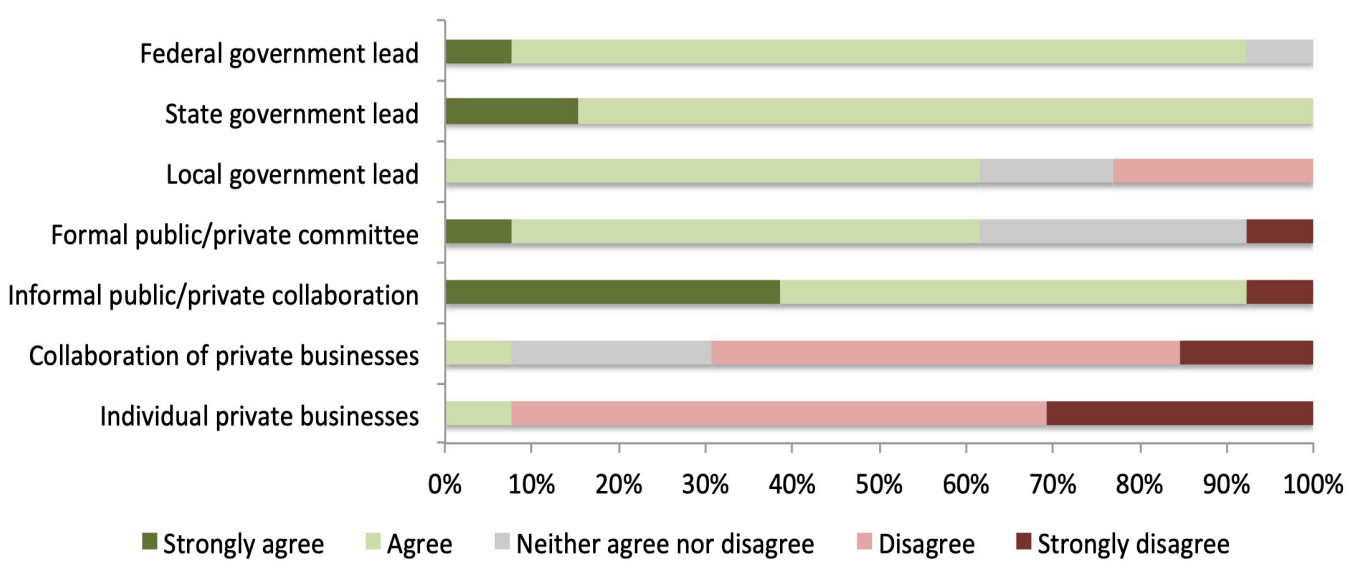

FIGURE 4 | Respondents' opinions of what structural organization should take the lead on planning and implementing resilience strategies.

responsible for protect. Given the numerous organizations listed, we can deduce that survey respondents perceived many organizations as partially responsible for adaptation leadership. The results do not show a consensus around which organization is responsible.

However, by aggregating the individual named organizations into broader categories, it becomes clear that this group of respondents feels that the state and federal government agencies need to play a lead role in developing resilience for the port (Figure 6), with 94 of the 131 total mentions naming government organizations and only 14 naming private firms.

\section{Survey Finding 3 - Private and Public Stakeholders Disagreed on Who Should Pay for Resilience}

When asked which types of entities should be responsible for funding long-scale resilience projects (e.g., protect, accommodate, relocate), survey respondents from the private sector were more likely to put the burden on governments (Figure 7). Over $50 \%$ of the private sector respondents felt that they had little or even no financial responsibility for resilience investments and the majority felt that state and federal governments were the most responsible. This finding points to the complexity of resilience investments, in which individual businesses may benefit, but the costs fall on shoulders of the taxpayer. Public sector respondents, on the other hand, tended to favor more of a shared approach. This might take the form of public/private partnerships, for example, or other strategies that involve private sector funding for resilience.

\section{Interview Finding 1 - Identified Leaders Agreed That They Have Some Leadership Responsibilities, but Only in Part and Never for All Five Functions of the Policy Process Phases}

In Part II of this study, we conducted interviews with seven of the nine organizations most frequently mentioned as having leadership responsibility in the online survey. Interview results showed that six of the seven interviewees stated that their organization is (or should be) a leader in resilience 


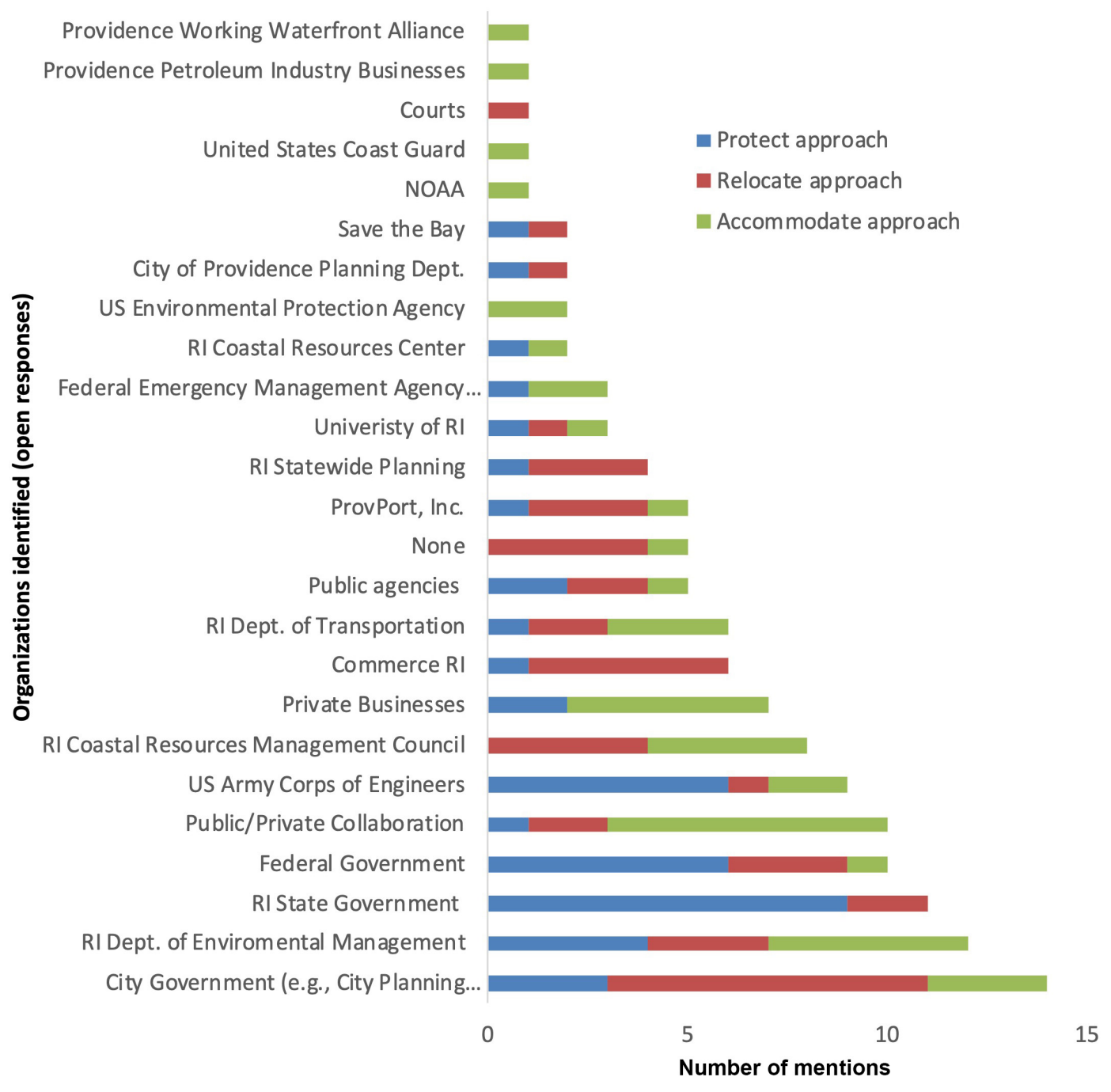

FIGURE 5 | Survey respondents from the public sector $(n=12)$ and private sector $(n=13)$ identified 25 organizations that they felt should take a leadership role for planning and investing in the three broad resilience approaches. A total of 131 responses to the open-ended question were received from the 25 survey respondents.

implementation. With respect to their role in building resilience for the Port of Providence, the representatives characterized their leadership in two ways: First they perceived themselves as leaders, but cited limits in their ability to implement resilience planning at the Port of Providence. As stated by one respondent, "I think we have a leadership role in all these [functions of leadership], what I am curious about ... is the magnitude of our role." Second, they perceive themselves in a leadership role, but as a participant, partner or supporter, rather than as the "main" leader. As stated by one respondent "We do have a direct role. I see us as a direct participant.”

No representative felt his/her organization could fulfill all five of the functions of leadership throughout the various phases of the adaptation policy process. For example, two organizations felt they were responsible for fulfilling the dissemination, adaptation, and connective function during the planning phase; however, they felt they had no role in the implementation phase and that the responsibility would be passed to someone else.

Similarly, another stated that for protect strategies, in particular, they held responsibility for the implementation of that project but not necessarily responsible for the planning phases of that project. Another organization representative stated that it focused on the dissemination of information and helping port businesses understand their risk, indicating that this organization saw themselves as fulfilling the dissemination function during the understanding phase of the policy process. As stated by one respondent, "We are trying to assist where we can, by providing data and support" and "[We are] working to make custom analyses, to look at which pieces of transportation are at risk." One interviewee indicated that their organization held responsibility for all five leadership functions, but primarily in the planning phase: "We are already initiating the planning process by assessing risk, we do coordinate stakeholders, we are 


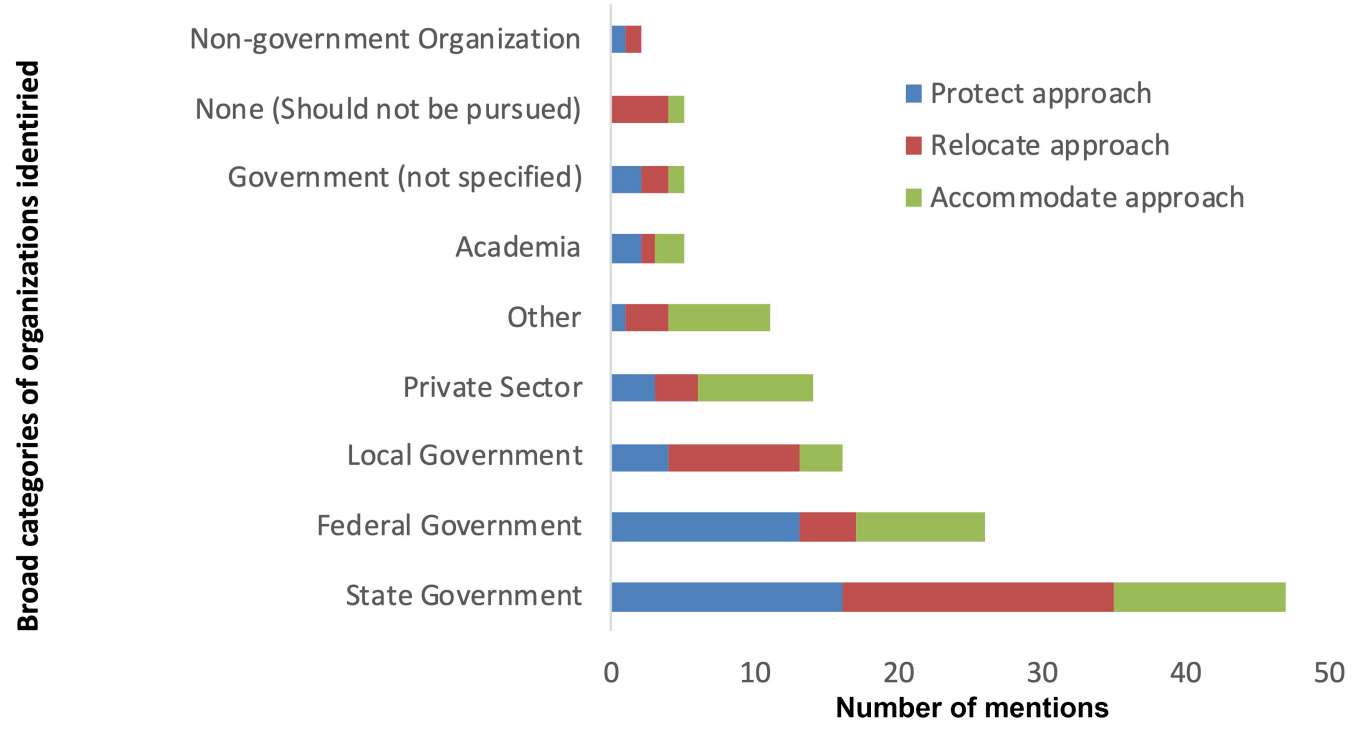

FIGURE 6 | Broad categories of organizations mentioned by respondents ( $n=25$ respondents and 131 total mentions).

developing, selecting, and assessing potential resiliency options" but in regards to implementation, "Managing successful change, we are somewhat responsible for that."

The results show that there is no one organization that holds a leadership role for resilience from conception to management, to construction, implementation and monitoring. Thus, numerous agencies and actors would need to share responsibility, requiring some overarching collaboration and management.

\section{Interview Finding 2 - Actors Face Three Key Barriers That Affect Their Leadership Ability}

Interviewees identified four specific barriers to leadership: (1) lack of expertise, (2) lack of jurisdiction/mandate, and (3) lack of resources. These barriers left interviewees with the sense that they, even if they wanted to devote resources to resilience planning, they felt hindered and/or not wholly responsible.

\section{Lack of Expertise}

Interviewees cited a lack of skills or expertise to fulfill one or more of the leadership functions. For example, one organization found that they could not complete the connective function because their organization had no history of bringing together collaboration, stating, "A limitation is our [lack of] understanding of all of the players." The organization could not fulfill the connective function because they did not know who should be involved in the process. Limited planning horizons also factored into perceptions that they lacked expertise. Only one organization stated they could plan for 50-100 years ahead, a period in which many of the major impacts of climate change are likely to occur.

\section{Lack of Jurisdiction/Mandate}

Some interviewees felt limited by their jurisdiction, while others felt limited by the scope of their mandate. For example, one organization stated, "Yes we take a lead role [but only] within [our City lines]." This representative said that within their city they had the ability to take the lead; however, they would need to be part of a larger collaborative effort if a given resilience approach impacted multiple municipalities.

Others felt that planning at the port scale was too small of a unit to work: "We have taken [a leadership role]... for the entire coastline, including in Providence Harbor." Another organization stated, "Yes, [we have] taken a high-level leadership role in Providence Harbor as well as in other locations." In the latter quote, the representative was discussing the fact that the organization focused on disseminating climate risk information at the local level throughout the state. This organization was currently working with the city and towns of the state in long-term resilience planning. He/she stated that if port business stakeholders reached out to them, they would be able to input information into the planning process. This organization followed up by saying at the current moment resources were also a limiting factor to their participation at the Port of Providence.

Two interviewees, one state (Rhode Island) and one federal, stated that though their involvement was within their jurisdiction, a lack of authorization from legislative organizations inhibited their leadership at the Port of Providence. An interviewee stated, "If we are going to impose change... it would take specific authority to require that." Other interviewees stated that though not totally in their jurisdiction but if mandated by law, their organization would take a lead role in resilience implementation at the port, particularly if grant funding was provided to conduct the work. Another interviewee stated, "We only get involved when someone says, 'Hey, we think there is a problem here [and your organization] should take a look at and has the authority to solve." 


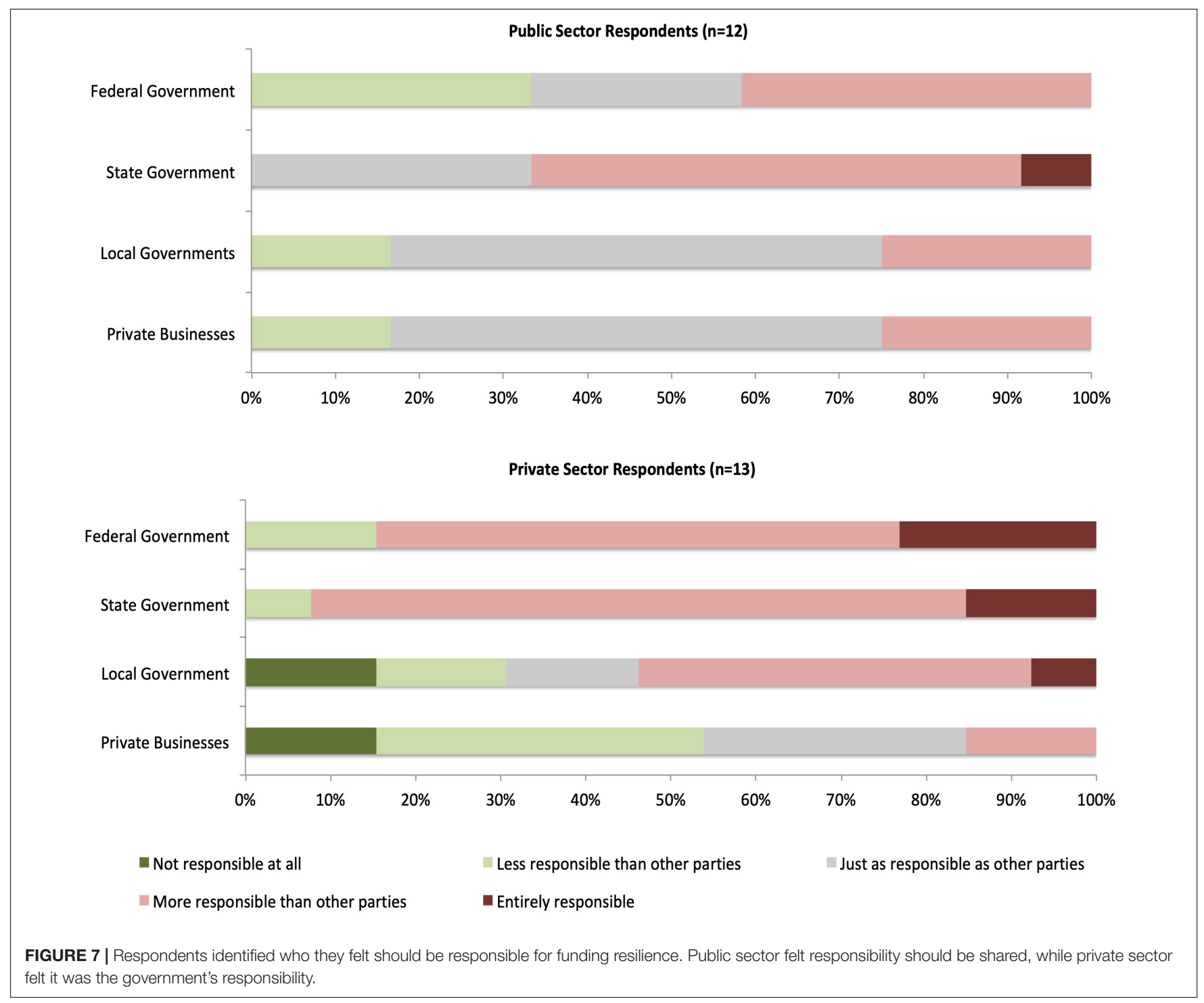

\section{Lack of Resources}

Every interviewee stated that a lack of staff and financial resources limited their ability to lead in adaptation planning and implantation at the Port of Providence, as evidenced in the following quotes:

"Funding is always an issue; if we don't have the resources to complete the job correctly, then that is a barrier."

"Funding, authority, and appropriation barriers - we can't just go out and do anything we want."

"Resources are always an issue, [we] are always spread everywhere thin-personnel and financial."

All interviewees expressed the need for more money and more personnel if resilience measures were to be planned for and implemented. One organization expressed the importance of federal resilience grants to incentivize the participation of businesses, government, and non-governmental organizations (including universities).

\section{Interview Finding 3 - Interviewees See Opportunities to Collaborate as Motivation and a Chance to Clarify Roles}

Interviewees underscored the need for dialog to help motivate their organization into a leadership role for resilience planning. As one stated, "Resiliency is not something that is going to be addressed by one organization." Interviewees cited the benefits of opportunities to cooperate and of groups that drive discussion. One interviewee mentioned the Port of Providence workshop conducted prior to this research as a valuable motivating force, stating, "It is helpful to have things like the workshop to help remind [us of potential risks] and give ideas." Another raised the value of workshops, "to see what other people do." This was the same interviewee previously mentioned that they did not know "all the players." 


\section{DISCUSSION}

Climate change and natural disaster resilience have long-term effects with decisions made today having an impact for many decades (United States, 2008; Hallegatte, 2009; Savonis et al., 2014). Investing resources in making seaports resilient now is one way to avoid serious infrastructure costs and improve business over the long-term (Hallegatte, 2009; Mansouri et al., 2010). However, adapting and making seaports resilient to climate impacts will require stakeholders to take on leadership responsibility in the process. While much research and literature is devoted to stakeholder identification, engagement, and collaboration, less attention is paid to whom within a stakeholder group is best positioned to take the lead on making coastal infrastructure ready for the changing climate and oncoming natural disasters and what may motivate them to do so.

In a complex decision-making system such as the Port of Providence, organizations will need to fulfill each of the five functions of leadership for each of the three phases of resilience planning. Interviews and surveys showed that those identified by the stakeholder community as being "leaders," agreed that their organizations had some level of responsibility. Further, the actors interviewed pointed to significant barriers, such as lack of expertise, jurisdiction, and financial resources, that stand in the way of prioritizing and implementing resilience planning. However, at the time of this project, the system, as a whole, was far too fragmented to determine a clear vision for which actors could (or should) serve as the catalyst for resilience planning. Though individual actors recognized their responsibility pieces of the process, none self-identified as a champion for resilience planning.

Results suggest that this is due in part to a lack of cohesion around the type of organizing body that would be most appropriate. Most participants favored the creation of stakeholder group, made up of both public and private sector representatives, to plan for and implement resilience. At the time of this project, no such group existed and, naturally, the formation of such a group requires one or more organizations to take a leadership role. This presents somewhat of a conundrum, given the various attitudes of the stakeholders themselves. The private sector, as seen in survey results, puts the leadership burden on the public sector. The public sector puts the burden, at least in part, on the private sector. In any case, most agreed that the state needs to play a large role in leading the process and thus resilience is not likely to occur in a bottom-up fashion from the business community of the Port of Providence.

This problem is not unique to Providence, as for most United States ports local land use and urban development powers rest with the municipality, while coastal and environmental regulations are reserved for the state, and the navigable water of the channel itself is under federal jurisdiction. However, Providence does have a history of overcoming this fragmentation. The $\$ 63$ million dredging of the shipping channel completed in 2005 serves as an example of how this stakeholder community can join together for a common goal. That project was championed by then Senator Claiborne Pell, with strong support from the RI Marine Trades Association and the Marine Pilots
Association. In this case, though, stakeholders realized immediate benefits after the $40^{\prime}$ dredging project finished, as deeper-draft ships began using the channel.

Pre-planning and other forums for dialog could allow stakeholders to begin identifying first steps. Since resilience planning is in relatively uncharted waters, such activities allow stakeholders to better understand their roles and their risks. Dialog amongst stakeholders can provide clarification of the feasible and favored resilience options (Becker, 2017). Such dialogs further instill a sense of ownership in the process, as well as increased trust and participation (Douglas et al., 2012). The convening of workshops and focus groups is a natural fit for academics and other boundary organizations that can bridge the public and private sectors. These activities require little upfront funding and can be conducted in a low-risk, nonthreatening, manner that engages stakeholders. The workshop that preceded this study (Becker, 2017) serves as an example of such a process and can be explored in more detail at www.portofprovidenceresilience.org.

Finally, we must also note that leadership is not purely a function of jurisdiction, mandate, and resource availability. Leaders must have the appropriate position within the system, but they must also have the personality and character necessary to bring the right actors together. Leadership for major infrastructure projects, especially in a federalist system such as the United States, must connect and integrate within a system designed to separate and distribute powers across scales and sectors. The major challenge in transformational adaptation for ports is finding the right actor(s), with the right personality, and the appropriate level of responsibility and mandate, in order to take the lead on major projects with big long-term gains (but less clear short-term benefits). Success often results from identifying and championing the short-term gains and making long-term resilience a "co-benefit" (Kates et al., 2012). Examples include the "Make Room for the Rivers" project in The Netherlands, which created new river parks and space to accommodate flooding. For Providence, a new storm barrier (such as the "Protect" strategy described herein) could serve the short term need of protecting the harbor from its current flood risk, create new public space on a protective berm, and serve to reduce the long-term risk from more intense storms of the future.

As a case study, this research has the advantage of describing a rich picture of one such port system, but also several limitations with respect to generalizability. As Yin (2008) well states in his seminal work on case study research, "The distinctive need for a case-study approach arises out of the desire to understand complex social phenomena." This work is exploratory in nature, as no previous work on leadership for climate adaptation and resilience could be identified by the research team. This lays a foundation for future studies that can strengthen the conclusions or point to contrasts with other port (or other infrastructure) systems. The findings describe the unique case of a small port that does not have a public port authority, thus there is no direct government oversight of port planning activities. However, even ports that do have a state (or national) port authority likely face similar leadership voids. Since ports consist of numerous stakeholders and organizations beyond just the 
port authority, each with its own priorities and authorities, responsibility for long term resilience planning may fall by the wayside as illuminated by the findings of this study.

\section{CONCLUSION}

Protecting port infrastructure systems has long-term benefits (Mansouri et al., 2010), but also requires long lead times (Hallegatte, 2009; Ford et al., 2011). In 80 years, sea level rise could mean that water levels in some areas are 11 feet higher than they are today (Sweet et al., 2017). Likewise, hurricanes may be more intense, resulting in higher levels of storm surge. Although many stakeholders recognize the likelihood of climate change and the increased occurrence of major storm events affecting their port (Becker et al., 2014), many times threats are not perceived as imminent and little is done to prepare. However, since large-scale projects can take decades to plan, fund, and construct, the process should begin today (Karassin, 2009). Whether a community like Providence wishes to construct new storm barriers or move infrastructure or enhance structures in place, numerous stakeholders will need to play a role. Today, the incentives for making such investments are still not clear. But specific leaders from the private and/or public sectors will need to step forward to initiate actions - through guidance, directive, mandate, self- or altruistic-interest - that make the system, or components thereof, more resilient to climate change and natural disasters. The empirical research conducted in this project demonstrates that the 25 stakeholders surveyed in the Port of Providence remain fragmented about which organizations can or should take up the charge. While the climate risks distribute across the system, there (as yet) appears to be no one "champion" to push a climate adaptation agenda forward for the port. The organizations identified by this group as having the highest responsibility for leading the effort agree that they

\section{REFERENCES}

Adger, W. N., Dessai, S., Goulden, M., Hulme, M., Lorenzoni, I., Nelson, D. R., et al. (2009). Are there social limits to adaptation to climate change? Clim. Change 93, 335-354. doi: 10.1007/s10584-008-9520-z

Allison, E. H., Perry, A. L., Badjeck, M.-C., Adger, W. N., Brown, K., Conway, D., et al. (2009). Vulnerability of national economies to the impacts of climate change on fisheries. Fish Fish. 10, 173-196. doi: 10.1111/j.1467-2979.2008. 00310.x

Anguelovski, I., and Carmin, J. (2011). Something borrowed, everything new: innovation and institutionalization in urban climate governance. Curr. Opin. Environ. Sustain. 3, 169-175. doi: 10.1016/j.cosust.2010.12.017

Barker, R. A. (2001). The nature of leadership. Hum. Relat. 54, 469-494. doi: $10.1177 / 0018726701544004$

Bass, B. M., and Bass, R. (2009). The Bass Handbook of Leadership: Theory, Research, and Managerial Applications. New York, NY: Simon and Schuster.

Becker, A. (2013). Building Seaport Resilience for Climate Change Adaptation: Stakeholder Perceptions of the Problems, Impacts, and Strategies. Stanford, CA: Stanford University.

Becker, A. (2014). "Maritime transportation and ports," in Encyclopedia of Natural Resources, ed. Y. Wang (Abingdon: Taylor \& Francis). do have some responsibility or mandate, but only for limited aspects of the adaptation planning and investment process. The research suggests that more robust dialog would help create the momentum and differentiate roles amongst this community.

\section{ETHICS STATEMENT}

This study was carried out in accordance with the recommendations of the University of Rhode Island Institutional Review Board with written informed consent from all subjects. All subjects gave written informed consent in accordance with the Declaration of Helsinki. The protocol was approved by the "University of Rhode Island Institutional Review Board."

\section{AUTHOR CONTRIBUTIONS}

$\mathrm{AB}$ was the principal investigator and project lead. EK conducted the interviews and surveys. Both authors contributed to drafting and revision of the manuscript.

\section{FUNDING}

This study received funding support from the Rhode Island Department of Transportation and Federal Highway Administration Grant Number - FHWA-RIDOT-RTD-17-3.

\section{ACKNOWLEDGMENTS}

Thanks to the participants who generously gave their time to assist with this research and to Prof. Richard Burroughs in the Department of Marine Affairs. Thanks also to Dr. Ken Payne for feedback and ideas.

Becker, A. (2017). Using boundary objects to stimulate transformational thinking: storm resilience for the port of Providence, Rhode Island (USA). Sustain. Sci. 12, 477-501. doi: 10.1007/s11625-016-0416-y

Becker, A., Acciaro, M., Asariotis, R., Cabrera, E., Cretegny, L., Crist, P., et al. (2013). A note on climate change adaptation for seaports: a challenge for global ports, a challenge for global society. Clim. Change 120, 683-695. doi: 10.1007/ s10584-013-0843-z

Becker, A., Burroughs, R., Kretch, E., McIntosh, R. D., and Haymaker, J. (2017). Stakeholder Vulnerability and Resilience Strategy Assessment for Maritme Infrastructure: Pilot Project for the Port of Providence. Providence, RI: Rhode Island Department of Transportation.

Becker, A., and Caldwell, M. R. (2015). Stakeholder perceptions of seaport resilience strategies: a case study of Gulfport (Mississippi) and Providence (Rhode Island). Coast. Manag. 43, 1-34. doi: 10.1080/08920753.2014.983422

Becker, A., Matson, P., Fischer, M., and Mastrandrea, M. D. (2014). Towards seaport resilience for climate change adaptation: stakeholder perceptions of hurricane impacts in Gulfport (MS) and Providence (RI). Progr. Plann. 99, 1-49. doi: 10.1016/j.progress.2013.11.002

Becker, A., Ng, A. K. Y., McEvoy, D., and Mullett, J. (2018). "Implications of climate change for shipping: ports and supply chains," in Wiley Interdisciplinary Reviews: Climate Change, ed. M. Hulme (Hoboken, NJ: John Wiley \& Sons Ltd). Bellows, R. (1959). Creative Leadership. Oxford: Prentice-Hall. 
de Langen, P. W. (2006). Stakeholders, conflicting interests and governance in port clusters. Res. Transp. Econ. 17, 457-477. doi: 10.1016/S0739-8859(06)17020-1

Douglas, E. M., Kirshen, P. H., Paolisso, M., Watson, C., Wiggin, J., Enrici, A., et al. (2012). Coastal flooding, climate change and environmental justice: identifying obstacles and incentives for adaptation in two metropolitan Boston Massachusetts communities. Mitig. Adapt. Strateg. Glob. Chang. 17, 537-562. doi: 10.1007/s11027-011-9340-8

Egri, C. P., and Herman, S. (2000). Leadership in the North American environmental sector: values, leadership styles, and contexts of environmental leaders and their organizations. Acad. Manag. J. 43, 571-604.

Ekstrom, J. A., and Moser, S. C. (2014). Identifying and overcoming barriers in urban climate adaptation: case study findings from the San Francisco Bay Area, California, USA. Urban Clim. 9, 54-74. doi: 10.1016/j.uclim.2014.06.002

Ford, J. D., Berrang-Ford, L., and Paterson, J. (2011). A systematic review of observed climate change adaptation in developed nations. Clim. Change 106, 327-336. doi: 10.1007/s10584-011-0045-5

Hall, P. V., O'Brien, T., and Woudsma, C. (2013). Environmental innovation and the role of stakeholder collaboration in West Coast port gateways. Res. Transp. Econ. 42, 87-96. doi: 10.1016/j.retrec.2012.11.004

Hallegatte, S. (2009). Strategies to adapt to an uncertain climate change. Glob. Environ. Chang. 19, 240-247. doi: 10.1016/j.gloenvcha.2008.12.003

Hanson, S., and Nicholls, R. J. (2012). "Extreme flood events and port cities through the twenty-first century," in Maritime Transport and the Climate Change Challenge, eds R. Asariotis and H. Benemara (New York, NY: Routledge), 243.

Intergovernmental Panel on Climate Change [IPCC] (2012). in Managing the Risks of Extreme Events and Disasters to Advance Climate Change Adaptation. Special Report of the Intergovernmental Panel on Climate Change, eds C. B. Field, V. Barros, T. F. Stocker, and Q. Dahe (Cambridge: Cambridge University Press). doi: $10.1017 /$ CBO 9781139177245

Karassin, O. (2009). Mind the gap: knowledge and need in regulating adaptation to climate change. Georget. Int. Environ. Law Rev. 22:383.

Kates, R. W., Travis, W. R., and Wilbanks, T. J. (2012). Transformational adaptation when incremental adaptations to climate change are insufficient. Proc. Natl. Acad. Sci. U.S.A. 109, 7156-7161. doi: 10.1073/pnas.1115521109

Maak, T., and Pless, N. M. (2006). Responsible leadership in a stakeholder societya relational perspective. J. Bus. Ethics 66, 99-115. doi: 10.1007/s10551-006-9 $047-\mathrm{z}$

Mansouri, M., Nilchiani, R., and Mostashari, A. (2010). A policy making framework for resilient port infrastructure systems. Mar. Pol. 34, 1125-1134. doi: 10.1016/j.marpol.2010.03.012

McEvoy, D., Lonsdale, K., and Matczak, P. (2008). Adaptation and mainstreaming of EU climate change policy: an actor-based perspective. CEPS Policy Brief 1-15. Available at: http://aei.pitt.edu/7541/1/149.pdf

McEvoy, D., Matczak, P., Banaszak, I., and Chorynski, A. (2010). Framing adaptation to climate-related extreme events. Mitig. Adapt. Strateg. Glob. Chang. 15, 779-795. doi: 10.1007/s11027-010-9233-2

Melillo, J. M., Richmond, T. T. C., and Yohe, G. W. (eds) (2014). Climate Change Impacts in the United States: The Third National Climate Assessment. Global Change Research Program. Washington, DC: U.S. Government Printing Office.

Moser, S. C. (2010). Now more than ever: the need for more societally relevant research on vulnerability and adaptation to climate change. Appl. Geogr. 30, 464-474. doi: 10.1016/j.apgeog.2009.09.003

Moser, S. C., and Ekstrom, J. A. (2010). A framework to diagnose barriers to climate change adaptation. Proc. Natl. Acad. Sci. U.S.A. 107, 22026-22031. doi: 10.1073/pnas.1007887107

Nelson, D. R., Adger, W. N., and Brown, K. (2007). Adaptation to environmental change: contributions of a resilience framework. Ann. Rev. Environ. Resour. 32, 395-419. doi: 10.1146/annurev.energy.32.051807.090348

Ng, A. K. Y., Becker, A., Cahoon, S., Chen, S.-L., Earl, P., and Yang, Z. (2016). Climate Change and Adaptation Planning for Ports. New York, NY: Routledge.
Oxford English Dictionary [OED]. (2013). Oxford English Dictionary. Oxford: Oxford University Press.

Parola, F., and Maugeri, S. (2013). Origin and taxonomy of conflicts in seaports: towards a research agenda. Res. Transp. Bus. Manag. 8, 114-122. doi: 10.1016/j. rtbm.2013.07.005

Providence Working Waterfront Alliance [PWWA]. (2010). Economic Impact - Providence Working Waterfront Alliance. Available at: http://providenceworkingwaterfront.org/index.php/providences-workingwaterfront/economic-impact/

Rubinoff, P. (2007). Increasing Resilience Along Rhode Island's Coast. Narragansett, RI: URI Coastal Resources Center.

Savonis, M. J., Potter, J. R., and Snow, C. B. (2014). Continuing challenges in transportation adaptation. Curr. Sustain. Renew. Energy Rep. 1, 27-34. doi: 10.1111/j.1365-2648.2011.05699.x

Stiller, S., and Meijerink, S. (2016). Leadership within regional climate change adaptation networks: the case of climate adaptation officers in Northern Hesse, Germany. Reg. Environ. Chang. 16, 1543-1555. doi: 10.1007/s10113-015-0 886-y

Stogdill, R. M. (1974). Handbook of Leadership: A Survey of Theory and Research. New York, NY: Free Press.

Sweet, W., Kopp, R. E., Weaver, C. P., Obeysekera, J., Horton, R. M., Thieler, E. R., et al. (2017). Global and Regional Sea Level Rise Scenarios for the United States, in NOAA Technical Report NOS CO-OPS 083. Silver Spring, MD: NOAA.

Tead, O. (1935). The Art of Leadership. New York, NY: Mcgraw-Hill Book Company.

Tompkins, E., Few, R., and Brown, K. (2008). Scenario-based stakeholder engagement: incorporating stakeholders preferences into coastal planning for climate change. J. Environ. Manage. 88, 1580-1592. doi: 10.1016/j.jenvman. 2007.07.025

United States Climate Change Science Program [USCCSP]. (2008). "Impacts of climate change and variability on transportation systems and infrastructure: gulf coast study, phase I," in A Report by the U.S. Climate Change Science Program and the Subcommittee on Global Change Research, eds M. Savonis, V. R. Burkett, and J. Potter (Washington, DC: U.S. Environmental Protection Agency).

United States Department of Transportation [USDOT]. (2014). Impacts of Climate Change and Variability on Transportation Systems and Infrastructure The Gulf Coast Study, Phase 2 Screening for Vulnerability Final Report, Task 3.1. Washington, DC: ICF International.

Wilbanks, T. J. (2007). Scale and sustainability. Clim. Pol. 7, 278-287. doi: 10.3763/ cpol.2007.0713

Winston, B. E., and Patterson, K. (2006). An integrative definition of leadership. Int. J. Leadersh. Stud. 1, 6-66.

Xiao, Y.-B., Fu, X., Ng, A. K. Y., and Zhang, Y. (2015). Port investments on coastal and marine disasters prevention: economic modeling and implications. Transp. Res. Part B Methodol. 78, 202-221. doi: 10.1016/j.trb.2015. 04.009

Yin, R. (2008). Case Study Research: Design and Methods. Thousand Oaks, CA: Sage Publications, Inc.

Conflict of Interest Statement: The authors declare that the research was conducted in the absence of any commercial or financial relationships that could be construed as a potential conflict of interest.

Copyright (c) 2019 Becker and Kretsch. This is an open-access article distributed under the terms of the Creative Commons Attribution License (CC BY). The use, distribution or reproduction in other forums is permitted, provided the original author(s) and the copyright owner(s) are credited and that the original publication in this journal is cited, in accordance with accepted academic practice. No use, distribution or reproduction is permitted which does not comply with these terms. 


\title{
A Review of Citizen Science and Crowdsourcing in Applications of Pluvial Flooding
}

\author{
Linda See* \\ Ecosystems Services and Management Program, International Institute for Applied Systems Analysis, Laxenburg, Austria
}

Pluvial flooding can have devastating effects, both in terms of loss of life and damage. Predicting pluvial floods is difficult and many cities do not have a hydrodynamic model or an early warning system in place. Citizen science and crowdsourcing have the potential for contributing to early warning systems (EWS) and can also provide data for validating flood forecasting models. Although there are increasing applications of citizen science and crowdsourcing in fluvial hydrology, less is known about activities related to pluvial flooding. Hence the aim of this paper is to review current activities in citizen science and crowdsourcing with respect to applications of pluvial flooding. Based on a search in Scopus, the papers were first filtered for relevant content and then classified into four main themes. The first two themes were divided into (i) applications relevant during a

OPEN ACCESS

Edited by:

Jonathan D. Paul, Imperial College London, United Kingdom

Reviewed by:

Joern Lauterjung,

Helmholtz Centre Potsdam, Germany

Carmen De Jong,

Université de Strasbourg, France

*Correspondence:

Linda See see@iiasa.ac.at

Specialty section: This article was submitted to Geohazards and Georisks, a section of the journal

Frontiers in Earth Science

Received: 01 November 2018

Accepted: 22 February 2019

Published: 07 March 2019

Citation:

See L (2019) A Review of Citizen

Science and Crowdsourcing

in Applications of Pluvial Flooding.

Front. Earth Sci. 7:44.

doi: 10.3389/feart.2019.00044 flood event, which includes automated street flooding detection using crowdsourced photographs and sensors, analysis of social media, and online and mobile applications for flood reporting; and (ii) applications related to post-flood events. The use of citizen science and crowdsourcing for model development and validation is the third theme while the development of integrated systems is theme four. All four main areas of research have the potential to contribute to EWS and build community resilience. Moreover, developments in one will benefit others, e.g., further developments in flood reporting applications and automated flood detection systems will yield data useful for model validation.

Keywords: pluvial flooding, urban flooding, citizen science, crowdsourcing, mobile apps, sensors

\section{INTRODUCTION}

Over the period 1995-2015, 90\% of disasters globally have been weather-related, e.g., due to floods, storms, and extreme temperatures (CRED and UNISDR, 2015). Of these events, 47\% were due to flooding, which affected 2.3 billion people globally. Flooding can be caused by different factors (Doornkamp, 1998; Falconer et al., 2009; Hammond et al., 2015). Fluvial flooding occurs when river levels rise to due to heavy rainfall, snowmelt, rain on snow, dam collapse or sudden ice melting due to volcanic activity or ice dam breaching in a partially frozen river in winter. When water levels exceed the river banks, the surrounding areas are flooded. Groundwater flooding can occur due to groundwater rise, which can cause large-scale flooding. Coastal flooding is caused by storm surges due to large storm events, e.g., hurricanes or cyclones, rising sea levels due to climate change or from tsunamis. Pluvial flooding occurs when overland flow and ponding are generated by rainfall before it enters a drainage or sewer system, or a water course, or because the capacity of the network is 
full, flooding streets and nearby structures. Pluvial flooding is often only a few centimeters in depth but can cause considerable damage to houses and other assets. It occurs more frequently in urban areas because of higher concentration of impervious surfaces (Maddox, 2014). This is in contrast to surface water flooding, which refers to combined pluvial and fluvial flooding in urban areas, and flash flooding, which is generally associated with high-intensity rainfall arising from a watercourse (Falconer et al., 2009), both of which can lead to asset damage and loss of life.

With climate change, the frequency and severity of extreme events and hence weather-related natural disasters will most likely increase (IPCC, 2014), affecting greater numbers of people through flooding. Early warning systems (EWS) are one area of response where more efforts could be deployed, particularly in areas with vulnerable populations (CRED and UNISDR, 2015). Cools et al. (2016) recommend the need to engage local communities, both in the design of EWS but also in data collection, where the information can be used to calibrate and validate flood forecasting models or to refine the thresholds of the early warning alerts issued. The involvement of citizens in data collection for environmental monitoring or scientific research is becoming increasingly common, and is often referred to as citizen science or crowdsourcing. Citizen science is the involvement of citizens in the scientific process, where the degree of involvement can range from tasks such as data collection to full involvement in research design (Bonney et al., 2009). Crowdsourcing is the outsourcing of tasks to a crowd that would otherwise be too large to accomplish by a single organization (Howe, 2006). However, crowdsourcing can also be used in the context of tasks undertaken by citizens for any purpose including data collection. Citizen science has a strong tradition in the fields of conservation and biodiversity (See et al., 2016) yet more recently, citizen science and crowdsourcing are being used within many different domains in the geosciences (Zheng et al., 2018). Many of the citizen science and crowdsourcing applications in hydrology are focused on water quality (Jollymore et al., 2017) or river flooding (Assumpção et al., 2018). Yet an area where citizen science and crowdsourcing might be very helpful is in applications related to pluvial flooding, where citizens could report the occurrence of flooding in real-time, improving the spatial and temporal availability of information for disaster response and management. The aim of this paper is to establish the current situation with regard to citizen science, crowdsourcing and pluvial flooding, and to reflect on future directions in this field.

\section{THE LITERATURE REVIEW PROCESS}

In the literature, pluvial flooding is not always explicitly referred to using this terminology. Hence to find an initial set of papers, the Scopus facility was searched using the following expression:

\section{("citizen science" OR crowdsourc*) AND flood*}

Although this will not include every paper written on this topic or the non-English literature, these results should represent an adequate sample for determining the latest trends in this field. The search yielded 129 papers, of which 31 were removed due to irrelevance, e.g., papers with sentences such as "the flood of data" or a topic that mentions flooding but is not directly related.

The papers were then classified based on the type of flooding addressed, i.e., pluvial, fluvial, groundwater or coastal flooding, multiple flood types (e.g., surface water flooding) or unspecified, to isolate those papers dealing primarily with pluvial flooding or those applicable to any type of flooding. These remaining papers (around 50) were then categorized into a set of main themes. It was clear that some papers presented applications during flood events while others were related to post-flood event analysis. Another set was related to the validation of models or providing information to forecasting models. The remaining papers fell into a group called integrated systems, which dealt with bringing information together from different sources. These became the four themes. Within the main themes, further subthemes were extracted based on the methodologies employed and the data used.

\section{RESULTS}

Table 1 summarizes the themes and sub-themes with indicative references; more detail is provided below.

\section{During Flood Events Automated Flood Detection}

One clear area of research is in automated flood detection from two sources. Crowdsourced photographs are the first source, where Witherow et al. $(2018 \mathrm{a}, \mathrm{b})$ present a workflow for determining if streets are flooded from pairs of crowdsourced photographs that show flooded and non-flooded scenes. Despite problems related to differences in resolution, lighting and the presence of unwanted vehicles in the photographs, the results are promising. Overall accuracies in detecting the area of inundation ranged from 72 to $95 \%$ depending on the location. A second area of research is in the use of sensors that automatically detect flooded roads. Wu and Wang (2014) describe how sensors installed on the side of roads in Oregon trigger alerts when they become submerged and reach a threshold, sending messages to a central system and to drivers in the area. Automatic detection systems have also been developed in the Philippines. De Guzman et al. (2016) designed and tested a flood detection system that uses Arduinos and ultrasonic sensors to automatically detect floods on road surfaces along with cameras for monitoring the situation. A similar system has been developed by Amagsila et al. (2018), but it additionally includes a mobile app for drivers to receive flood warnings and make flood reports in places where Arduino sensors are not located. Although promising, the system does not yet appear to be operational.

\section{Social Media}

Another prominent area of research is in the analysis of data from social media, primarily Twitter. Twitter is a passive source of crowdsourced information and has been analyzed to 
TABLE 1 | The main themes in the literature regarding citizen science, crowdsourcing and pluvial flooding (or with potential for application to pluvial flooding), with indicative references.

\begin{tabular}{|c|c|c|c|}
\hline Theme & Sub-theme & Description & Indicative references \\
\hline \multirow[t]{5}{*}{ During flood events } & $\begin{array}{l}\text { Automated flood } \\
\text { detection }\end{array}$ & $\begin{array}{l}\text { Use of crowdsourced photographs to detect } \\
\text { flooding }\end{array}$ & Witherow et al., 2018a,b \\
\hline & & Use of sensors in vehicles to detect flooding & $\begin{array}{l}\text { Wu and Wang, 2014; De Guzman et al., 2016; } \\
\text { Amagsila et al., } 2018\end{array}$ \\
\hline & $\begin{array}{l}\text { Social media such } \\
\text { as Twitter }\end{array}$ & $\begin{array}{l}\text { Analysis of data from Twitter or similar social } \\
\text { media data to detect flood events or map flood } \\
\text { extent }\end{array}$ & $\begin{array}{l}\text { Holderness and Turpin, 2015; Kiatpanont et al., } \\
\text { 2016; Pandey and Natarajan, 2016; Yadav and } \\
\text { Rahman, 2016; Albahari and Schultz, 2017; } \\
\text { Arthur et al., 2018; Feng and Sester, 2018; Lin } \\
\text { et al., 2018; Ogie and Forehead, 2018; Ogie } \\
\text { et al., 2018; Yang et al., 2018; Bhuvaneswari } \\
\text { and Valliyammai, } 2019\end{array}$ \\
\hline & Online reporting & $\begin{array}{l}\text { Use of online applications such as Ushahidi or } \\
\text { bespoke applications to report flooding }\end{array}$ & $\begin{array}{l}\text { Koswatte et al., 2015, 2016, 2018; Ludwig } \\
\text { et al., 2015; Naik, 2016; Victorino et al., 2016; } \\
\text { Pánek et al., } 2017\end{array}$ \\
\hline & Mobile apps & Use of mobile apps to report flooding & $\begin{array}{l}\text { Liu et al., 2011; Victorino and Estuar, 2014; Le } \\
\text { Coz et al., 2016; Victorino et al., 2016; } \\
\text { Middelhoff et al., 2017; Minn et al., 2017; } \\
\text { Sahay et al., 2017; Hendricks et al., 2018; } \\
\text { Wang et al., 2018; Yabut et al., } 2018\end{array}$ \\
\hline Post-flood event & $\begin{array}{l}\text { Damage } \\
\text { assessment }\end{array}$ & $\begin{array}{l}\text { Applications for reporting damage after a flood } \\
\text { event }\end{array}$ & $\begin{array}{l}\text { Molinari et al., 2014; Schnebele et al., 2014; } \\
\text { Kim et al., } 2015\end{array}$ \\
\hline \multirow[t]{2}{*}{ Modeling } & Development & $\begin{array}{l}\text { Use of crowdsourced data to understand how } \\
\text { pluvial floods develop }\end{array}$ & Smith and Rodriguez, 2017 \\
\hline & Validation & $\begin{array}{l}\text { Use of crowdsourced data to validate models } \\
\text { relevant to pluvial flooding }\end{array}$ & $\begin{array}{l}\text { Kutija et al., 2014; Blumberg et al., 2015; Yu } \\
\text { et al., 2016; Lewis and Silkstone, 2017; Loftis } \\
\text { et al., } 2017\end{array}$ \\
\hline Integrated systems & - & $\begin{array}{l}\text { Systems for integrating sensors, authoritative } \\
\text { data and crowdsourced data for flood } \\
\text { management and early warning }\end{array}$ & $\begin{array}{l}\text { Wan et al., 2014; de Assis et al., 2018; Leyh, } \\
2018\end{array}$ \\
\hline
\end{tabular}

create flood maps in real-time (Arthur et al., 2018), to detect, cluster and map flood events or to categorize different types of flood-related information (Kiatpanont et al., 2016; Pandey and Natarajan, 2016; Albahari and Schultz, 2017; Feng and Sester, 2018; Lin et al., 2018; Bhuvaneswari and Valliyammai, 2019). Twitter has also been used in a more active manner in the PetaJakarta application (Holderness and Turpin, 2015; Ogie and Forehead, 2018; Ogie et al., 2018; Yang et al., 2018). Citizens in Jakarta are very active on Twitter, e.g., $2.4 \%$ of global tweets in 2012 originated from Jakarta (Holderness and Turpin, 2015). Hence a system was set up to identify tweets related to flooding ('unconfirmed reports), where the system then contacted the same individuals via Twitter for more information in order to become "confirmed" reports of flooding. One type of tweet sent to the system was about flood conditions, which could include the height of the water, either in $\mathrm{cm}$ or $\mathrm{m}$, or as a description, e.g., knee height, with a photograph. From this, maps of affected areas have been produced in real-time. However, there are uncertainties in the accuracy of the tweet locations in relation to the actual flooding as well as the need to better align the outputs with the needs of the local authorities. Similarly, during the 2015 rains in Chennai, Twitter and Facebook were used to disseminate information to the public and as a source of communication for those stranded or trying to locate missing family and friends (Yadav and Rahman, 2016).

\section{Online Reporting and Mobile Apps}

The development of applications that allow for online reporting or reporting of floods using a mobile application is another area of active research. Ushahidi was developed in Kenya as a website for crowdsourcing and sharing of information (Okolloh, 2009); in this context it has been used to report floods in Australia (Koswatte et al., 2015, 2016, 2018) and to develop a crisis map of the Czechia during the 2013 floods (Pánek et al., 2017). Other online reporting systems include the Flooded Streets application for reporting street flooding in Chennai during the 2015 floods (Naik, 2016), the CrowdMonitor application, which assigns data gathering tasks to citizens during an emergency of different kinds, including any kind of flooding (Ludwig et al., 2015) and flood reporting via the Philippines Flood Hazard Maps application (Victorino et al., 2016). The latter application is also supported by the Flood Patrol mobile app (Victorino and Estuar, 2014). In addition to online reporting, a number of papers outline different mobile apps for flood reporting (Liu et al., 2011; Le Coz et al., 2016; Middelhoff et al., 2017; Minn et al., 2017; Sahay et al., 2017; Hendricks et al., 2018; Wang et al., 2018; Yabut et al., 2018). Le Coz et al. (2016) provide an overview of different mobile apps developed in Argentina, France, and New Zealand while the other papers outline individual apps. Most of the papers deal with the development of a bespoke app for flood reporting, e.g., in the Philippines, India, United States, and Vietnam. However, some 
of the apps presented were more generic, i.e., for reporting different types of disaster (Liu et al., 2011), for tasking the crowd with specific data collection activities in the context of a flood emergency (Middelhoff et al., 2017) or an app for infrastructure surveying of ditches, culverts, and drains (Hendricks et al., 2018), i.e., for flood preparedness.

\section{Post-flood Event}

Three papers specifically addressed data collection by citizens after a large event to aid in the assessment of damage. For a large hurricane event in 2014, Kim et al. (2015) used Ushahidi to crowdsource damage due to fallen trees and from storm surge or flooding in Hawaii. Molinari et al. (2014) developed their own system called Poli-RISPOSTA to collect flood damage information following flood events in Italy in support of the EU Floods Directive. Schnebele et al. (2014) developed a methodology to generate a road damage map for New York City after Hurricane Sandy. Authoritative data were merged with videos from YouTube and Twitter data to fill in gaps in information, both spatially and temporally, demonstrating the effectiveness of such an approach.

\section{Modeling}

Early warning systems need a sensor network or a model in order to issue alerts. Crowdsourcing can provide a source of validation for these models. Four studies have used crowdsourcing to validate hydrodynamic models in Shanghai (Yu et al., 2016), two in the United States in New Jersey (Blumberg et al., 2015) and Virginia (Loftis et al., 2017) and one in the city of Newcastle in the United Kingdom (Kutija et al., 2014). However, the source of crowdsourced information differed in the studies. In Yu et al. (2016), flood reports from citizens were collected using an emergency reporting portal while crowdsourced flood extents were captured using a mobile app in Loftis et al. (2017). In both the studies by Blumberg et al. (2015) and Kutija et al. (2014), the public was approached for the information postevent, i.e., for photographs and flood reports through an email and questionnaire, respectively. The results showed satisfactory performance in all four models. For example, in Yu et al. (2016), the results showed that the model is capable of predicting the broad pattern of flooded areas across the city as well as the flood timing while the results by Blumberg et al. (2015) were satisfactory when comparing watermarks, inundation depths and overall flood extent from the two sources.

In addition to flood models, improved nowcasting, which uses multiple sources of data including reports from social media and data from amateur weather stations, can also provide much needed inputs to pluvial EWS. Lewis and Silkstone (2017) analyzed three severe thunderstorms in northern England and used social media, photographs and video to verify impacts such as surface water flooding and hail in real-time. Data from amateur weather stations allowed United Kingdom Met Office staff to track the progression of a storm that was not possible using the official observing network alone. A final study in this area of research is by Smith and Rodriguez (2017), who examined how crowdsourced data from call centers could be used in combination with radar and rainfall data to help understand the characteristics of flooding (flash, pluvial, and coastal surge) in New York city. Such data could potentially be used to build data-driven models for early warning purposes.

\section{Integrated Systems}

The final area in which research is taking place is in the development of systems that can integrate data from different sources, including crowdsourced data, for flood risk management. The first is an example from Brazil where de Assis et al. (2018) present a middleware architecture that can integrate any type of sensor using open standards with unstructured crowdsourced data from citizen reports, demonstrated on four flood events. Although there may be other national or regional examples, these were not found in the literature search.

The other examples are more global in nature. For example, Leyh (2018) presented the design of an interface to the OpenStreetMap (OSM) application to provide a standardized data collection system for surface water features, which can cover different types of flooding. This could encourage volunteers to use OSM as a platform for flood reporting that could be accessed by any city in the world for early warning purposes. The cloudbased system developed by Wan et al. (2014) has similarities to the previous application, i.e., building an infrastructure (called CyberFlood) around an existing database, in this case the Global Flood Inventory, to access the data for visualization, model validation, management of flood risks and awareness raising. The interface also has an online reporting module where users can upload flood observations, thereby enhancing the data from the Global Flood Inventory.

\section{DISCUSSION AND CONCLUSION}

This paper has summarized the state-of-the-art in citizen science, crowdsourcing and pluvial flooding based on a review of the academic literature. Most papers are from 2014 and later, indicating a relatively new and emerging area of research. The topic with the largest number of papers was on the use of Twitter and other social media for flooding applications. These are not necessarily related to pluvial flooding alone but can be used to detect flood events of any nature and even create flood maps in real-time. An example is PetaJakarta, which has taken advantage of the willingness of Jakarta residents to use Twitter and turned it into an active source of flood reports. Applications such as these will be much more effective than passive data mining of Twitter, and should see transference to other cities in the future.

Despite the fact that the use of sensors for automatic flood detection was only described in a small number of papers, this is clearly an area of future growth. As sensors become cheaper and with new open standards for sensor networks now available, more cities plagued by frequent pluvial flooding may adopt this type of technological solution in the development of EWS, once it becomes more developed. Moreover, with advances in computer vision, applications of automatic flood detection from photographs is an area where there is much potential. Yet automation alone is not the answer and the role of citizens is still critical. For example, they can provide verification of 
flooding when alerts are received or make flood reports where sensors are not available, increasing both the spatial and temporal resolution of the information. Examples can be found in the EUfunded WeSenseIt, Scent, Ground Truth 2.0, and FloodCitiSense projects, which have or are providing information to EWS with information about flooding conditions, either in real-time or in post-flood analysis. Numerous developments in online platforms and mobile applications for flood reporting clearly indicate the value of citizens in flood risk management and building of resilience, particularly in terms of awareness raising and engagement in a larger observation network. More examples of these types of applications will, undoubtedly, appear in the future.

There is clearly great potential for using data collected by citizens for model development and validation as evidenced by the papers on this topic. The amount of data collected in the different modeling examples was actually not that large yet can still provide an effective form of validation. As more web- and mobile-based flood reporting systems are developed, more data will become available for this task. The development of more integrated systems may also facilitate this process as citizen observations become one data stream of many in a flood forecasting and EWS. Moreover, building interfaces to existing systems such as OSM and the Global Flood Inventory are promising developments. OSM already has a vast number of contributors and could provide standardized flood reporting that could be accessed by any city or used for model validation. However, the quality of data from citizen

\section{REFERENCES}

Albahari, A., and Schultz, C. H. (2017). A qualitative analysis of the spontaneous volunteer response to the 2013 Sudan floods: changing the paradigm. Prehosp. Disaster Med. 32, 240-248. doi: 10.1017/S1049023X17000164

Amagsila, G. A., Cabuhat, M. E., Tigbayan, J. E., Uy, E., and Ramirez, E. (2018). “A framework for mobile application of flood alert monitoring system for vehicle users using Arduino device," in Proceedings of the 9th International Conference on Humanoid, Nanotechnology, Information Technology, Communication and Control, Environment and Management HNICEM 2017 (Manila: IEEE), 1-6. doi: 10.1109/HNICEM.2017.8269431

Arthur, R., Boulton, C. A., Shotton, H., and Williams, H. T. P. (2018). Social sensing of floods in the UK. PLoS One 13:e0189327. doi: 10.1371/journal.pone.0189327

Assumpção, T. H., Popescu, I., Jonoski, A., and Solomatine, D. P. (2018). Citizen observations contributing to flood modelling: Opportunities and challenges. Hydrol. Earth Syst. Sci. 22, 1473-1489. doi: 10.5194/hess-22-1473-2018

Bhuvaneswari, A., and Valliyammai, C. (2019). Social IoT-enabled emergency event detection framework using geo-tagged microblogs and crowdsourced photographs. Adv. Intell. Syst. Comput. 814, 151-162. doi: 10.1007/978-981-131501-5_13

Blumberg, A. F., Georgas, N., Yin, L., Herrington, T. O., and Orton, P. M. (2015). Street-scale modeling of storm surge inundation along the New Jersey Hudson river waterfront. J. Atmos. Ocean. Technol. 32, 1486-1497. doi: 10.1175/JTECHD-14-00213.1

Bonney, R., Cooper, C. B., Dickinson, J., Kelling, S., Phillips, T., Rosenberg, K. V., et al. (2009). Citizen science: a developing tool for expanding science knowledge and scientific literacy. Bioscience 59, 977-984. doi: 10.1525/bio.2009. 59.11 .9

Cools, J., Innocenti, D., and O’Brien, S. (2016). Lessons from flood early warning systems. Environ. Sci. Policy 58, 117-122. doi: 10.1016/j.envsci.2016.01.006

CRED and UNISDR (2015). The Human Cost of Weather Related Disasters 1995-2015. Available at: https://www.preventionweb.net/files/46796_ cop21weatherdisastersreport2015.pdf science and crowdsourcing has been raised as an issue of concern more generally; see e.g., Flanagin and Metzger (2008) and Lukyanenko et al. (2016). These concerns are being addressed through numerous methods now available for ensuring quality (Goodchild and Li, 2012; Kosmala et al., 2016; Fonte et al., 2017) while training and regular feedback have been shown to improve data quality and volunteer retention (Kosmala et al., 2016).

Teasing out pluvial flooding from the papers was difficult in some instances as some papers could include surface water flooding or other flooding types. In other cases, applications were more generic but could be applied to pluvial flooding. Despite these limitations, the four main themes were clearly in evidence, all of which should see continued research and development in the future.

\section{AUTHOR CONTRIBUTIONS}

LS did the literature search, classified the papers by theme, and wrote the manuscript.

\section{FUNDING}

This paper has been supported by the ENSUF FloodCitiSense project (\#860918), funded in Austria by the Austrian Agency for the Promotion of Science (FFG).

de Assis, L. F. F. G., Horita, F. E. A., de Freitas, E. P., Ueyama, J., and de Albuquerque, J. P. (2018). A service-oriented middleware for integrated management of crowdsourced and sensor data streams in disaster management. Sensors 18:1689. doi: 10.3390/s18061689

De Guzman, E., Cuadra, V. S., Grace de Luna, A., and Villanueva, C. (2016). "Flood detector system using Arduino," in Proceedings of the 37th IRES International Conference, Bangkok.

Doornkamp, J. C. (1998). Coastal flooding, global warming and environmental management. J. Environ. Manag. 52, 327-333. doi: 10.1006/jema. 1998.0188

Falconer, R. H., Cobby, D., Smyth, P., Astle, G., Dent, J., and Golding, B. (2009). Pluvial flooding: new approaches in flood warning, mapping and risk management. J. Flood Risk Manag. 2, 198-208. doi: 10.1111/j.1753-318X.2009. 01034.x

Feng, Y., and Sester, M. (2018). Extraction of pluvial flood relevant volunteered geographic information (VGI) by deep learning from user generated texts and photos. ISPRS Int. J. Geo Inf. 7:39. doi: 10.3390/ijgi7020039

Flanagin, A., and Metzger, M. (2008). The credibility of volunteered geographic information. Geo J. 72, 137-148. doi: 10.1007/s10708-008-9188-y

Fonte, C. C., Antoniou, V., Bastin, L., Estima, J., Arsanjani, J. J., Laso-Bayas, J.C., et al. (2017). "Assessing VGI data quality," in Mapping and the Citizen Sensor, eds G. M. Foody, L. See, S. Fritz, C. C. Fonte, P. Mooney, A.-M. Olteanu-Raimond, et al. (London: Ubiquity Press), 137-164.

Goodchild, M. F., and Li, L. (2012). Assuring the quality of volunteered geographic information. Spat. Stat. 1, 110-120. doi: 10.1016/j.spasta.2012.03.002

Hammond, M. J., Chen, A. S., Djordjević, S., Butler, D., and Mark, O. (2015). Urban flood impact assessment: a state-of-the-art review. Urban Water J. 12, 14-29. doi: 10.1080/1573062X.2013.857421

Hendricks, M. D., Meyer, M. A., Gharaibeh, N. G., Van Zandt, S., Masterson, J., Cooper, J., et al. (2018). The development of a participatory assessment technique for infrastructure: neighborhood-level monitoring towards sustainable infrastructure systems. Sustain. Cities Soc. 38, 265-274. doi: $10.1016 /$ j.scs.2017.12.039 
Holderness, T., and Turpin, E. (2015). "From social media to geosocial intelligence: crowdsourcing civic co-management for flood response in Jakarta, Inddonesia," in Social Media for Government Services, eds S. Nepal, C. Paris, and D. Georgakopoulos (Cham: Springer), 115-133. doi: 10.1007/978-3-31927237-5_6

Howe, J. (2006). The rise of crowdsourcing. Wired Mag. 14, 1-4.

IPCC (2014). "Climate Change 2014: impacts, Adaptation, and Vulnerability. Part A: global and Sectoral Aspects," in Proceedings of the Contribution of Working Group II to the Fifth Assessment Report of the Intergovernmental Panel on Climate Change, eds C. B. Field, V. R. Barros, D. J. Dokken, K. J. Mach, M. D. Mastrandrea, T. E. Bilir, et al. (Cambridge: Cambridge University Press), 1132.

Jollymore, A., Haines, M. J., Satterfield, T., and Johnson, M. S. (2017). Citizen science for water quality monitoring: data implications of citizen perspectives. J. Environ. Manag. 200, 456-467. doi: 10.1016/j.jenvman.2017.05.083

Kiatpanont, R., Tanlamai, U., and Chongstitvatana, P. (2016). Extraction of actionable information from crowdsourced disaster data. J. Emerg. Manag. 14, 377-390. doi: $10.5055 /$ jem.2016.0302

Kim, K., Pant, P., and Yamashita, E. (2015). "Disasters, drones, and crowdsourced damage assessment," in Proceedings of the 14th International Conference on Computers in Urban Planning and Urban Management CUPUM 2015 (Cambridge, MA: MIT Press).

Kosmala, M., Wiggins, A., Swanson, A., and Simmons, B. (2016). Assessing data quality in citizen science. Front. Ecol. Environ. 14, 551-560. doi: 10.1002/fee. 1436

Koswatte, S., McDougall, K., and Liu, X. (2015). SDI and crowdsourced spatial information management automation for disaster management. Survey Rev. 47, 307-315. doi: 10.1179/1752270615Y.0000000008

Koswatte, S., Mcdougall, K., and Liu, X. (2016). "Semantic location extraction from crowdsourced data," in Proceedings of the International Archives of the Photogrammetry, Remote Sensing and Spatial Information Sciences - ISPRS Archives, Prague, 543-547. doi: 10.5194/isprsarchives-XLI-B2-543-2016

Koswatte, S., McDougall, K., and Liu, X. (2018). VGI and crowdsourced data credibility analysis using spam email detection techniques. Int. J. Dig. Earth 11, 520-532. doi: 10.1080/17538947.2017.1341558

Kutija, V., Bertsch, R., Glenis, V., Alderson, D., Parkin, G., Walsh, C. L., et al. (2014). "Model valiation using crowd-sourced data from a large pluvial flood," in Proceedings of the 11th International Conference on Hydroinformatics (HIC 2014), (New York, NY: Curran Associates, Inc.).

Le Coz, J., Patalano, A., Collins, D., Guillén, N. F., García, C. M., Smart, G. M., et al. (2016). Crowdsourced data for flood hydrology: feedback from recent citizen science projects in Argentina, France and New Zealand. J. Hydrol. 541, 766-777. doi: $10.1016 /$ j.jhydrol.2016.07.036

Lewis, M. W., and Silkstone, N. (2017). Improvements in nowcasting capability: analysis of three structurally distinct severe thunderstorms across northern England on 1 July 2015. Weather 72, 91-98. doi: 10.1002/wea.2837

Leyh, W. (2018). A conceptual building-block and practical openstreetmapinterface for sharing references to hydrologic features. Adv. Intell. Syst. Comput. 600, 137-148. doi: 10.1007/978-3-319-60450-3_14

Lin, W.-Y., Wu, T.-H., Tsai, M.-H., Hsu, W.-C., Chou, Y.-T., and Kang, S.-C. (2018). Filtering disaster responses using crowdsourcing. Autom. Constr. 91, 182-192. doi: 10.1016/j.autcon.2018.03.016

Liu, Y., Piyawongwisal, P., Handa, S., Yu, L., Xu, Y., and Samuel, A. (2011). "Going beyond citizen data collection with mapster: a mobile++cloud realtime citizen science experiment," in Proceedings - 7th IEEE International Conference on e-Science Workshops, eScienceW (Stockholm: IEEE), 1-6. doi: 10.1109/eScienceW.2011.23

Loftis, J. D., Wang, H., Forrest, D., Rhee, S., and Nguyen, C. (2017). "Emerging flood model validation frameworks for street-level inundation modeling with storm sense," in Proceedings - 2017 2nd International Workshop on Science of Smart City Operations and Platforms Engineering, in partnership with Global City Teams Challenge. SCOPE, Pittsburg, PA, 13-18. doi: 10.1145/3063386. 3063764

Ludwig, T., Siebigteroth, T., and Pipek, V. (2015). Crowdmonitor: monitoring physical and digital activities of citizens during emergencies. Lecture Notes Comput. Sci. 8852, 421-428. doi: 10.1007/978-3-319-15168-7_51

Lukyanenko, R., Parsons, J., and Wiersma, Y. F. (2016). Emerging problems of data quality in citizen science: editorial. Conserv. Biol. 30, 447-449. doi: 10.1111/ cobi.12706
Maddox, I. (2014). The Risks of Hazard. Three Common Types of Flood Explained. Available at: https://www.intermap.com/risks-of-hazard-blog/three-commontypes-of-flood-explained

Middelhoff, M., Widera, A., Van Den Berg, R. P., Hellingrath, B., Anferbauer, D., Havlik, D., et al. (2017). "Crowdsourcing and crowdtasking in crisis management lessons learned from a field experiment simulating a flooding in the city of the hague," in Proceedings of the 2016 3rd International Conference on Information and Communication Technologies for Disaster Management, ICT-DM 2016 (Vienna: IEEE). doi: 10.1109/ICT-DM.2016.7857212

Minn, Q. T., Chi, T. N., and Toulouse, M. (2017). “Toward a crowdsourcingbased urban flood mitigation platform," in Proceedings of the ACM International Conference Proceeding Series, Nha Trang City, 301-308. doi: 10.1145/3155133. 3155153

Molinari, D., Mazuran, M., Arias, C., Minucci, G., Atun, F., and Ardagna, D. (2014). Implementing tools to meet the Floods Directive requirements: a "procedure" to collect, store and manage damage data in the aftermath of flood events. WIT Trans. Ecol. Environ. 184, 215-226. doi: 10.2495/FRIAR 140181

Naik, N. (2016). "Flooded streets-A crowdsourced sensing system for disaster response: a case study," in Proceedings of the ISSE 2016 - 2016 International Symposium on Systems Engineering (Edinburgh: IEEE). doi: 10.1109/SysEng. 2016.7753186

Ogie, R. I., Clarke, R. J., Forehead, H., and Perez, P. (2018). Crowdsourced social media data for disaster management: lessons from the PetaJakarta.org project. Comput. Environ. Urban Syst. 73, 108-117. doi: 10.1016/j.compenvurbsys.2018. 09.002

Ogie, R. I., and Forehead, H. (2018). "Investigating the accuracy of georeferenced social media data for flood mapping: the PetaJakarta.org case study," in Proceedings of the 2017 4th International Conference on Information and Communication Technologies for Disaster Management. ICT-DM (Piscataway, NJ: IEEE), 1-6. doi: 10.1109/ICT-DM.2017.8275672

Okolloh, O. (2009). "Ushahidi, or 'testimony': Web 2.0 tools for crowdsourcing crisis information," in Change at hand: Web 2.0 for development Participatory learning and action, ed. H. Ashley (London: International Institute for Environment and Development), 65-70.

Pandey, N., and Natarajan, S. (2016). "How social media can contribute during disaster events? Case study of Chennai floods 2015," in Proceedings of the International Conference on Advances in Computing, Communications and Informatics, ICACCI 2016 (Jaipur: IEEE), 1352-1356. doi: 10.1109/ICACCI. 2016.7732236

Pánek, J., Marek, L., Pászto, V., and Valůch, J. (2017). The Crisis Map of the Czech Republic: the nationwide deployment of an Ushahidi application for disasters. Disasters 41, 649-671. doi: 10.1111/disa.12221

Sahay, A., Kumar, A. A., Pongpaichet, S., and Jain, R. (2017). "Multimedia rescue systems for floods," in Proceedings of the 9th International Conference on Management of Digital EcoSystems, Bangkok, 210-215. doi: 10.1145/3167020. 3167052

Schnebele, E., Cervone, G., and Waters, N. (2014). Road assessment after flood events using non-authoritative data. Nat. Hazards Earth Syst. Sci. 14, 10071015. doi: 10.5194/nhess-14-1007-2014

See, L., Mooney, P., Foody, G., Bastin, L., Comber, A., Estima, J., et al. (2016). Crowdsourcing, citizen science or Volunteered Geographic Information? The current state of crowdsourced geographic information. ISPRS Int. J. Geo Inf. 5:55. doi: 10.3390/ijgi5050055

Smith, B., and Rodriguez, S. (2017). Spatial analysis of high-resolution radar rainfall and citizen-reported flash flood data in ultra-urban New York City. Water 9:736. doi: 10.3390/w9100736

Victorino, J. N. C., and Estuar, M. R. J. E. (2014). "Profiling flood risk through crowdsourced flood level reports," in Proceedings of the 2014 International Conference on IT Convergence and Security, ICITCS 2014 (Beijing: IEEE). doi: 10.1109/ICITCS.2014.7021800

Victorino, J. N. C., Estuar, M. R. J. E., and Lagmay, A. M. F. A. (2016). "Validating the voice of the crowd during disasters," in Lecture Notes in Computer Science (including subseries Lecture Notes in Artificial Intelligence and Lecture Notes in Bioinformatics) 9708 LNCS, eds K. Xu, D. Reitter, D. Lee, and N. Osgood, (Cham: Springer), 301-310. doi: 10.1007/978-3-319-39931-7_29

Wan, Z., Hong, Y., Khan, S., Gourley, J., Flamig, Z., Kirschbaum, D., et al. (2014). A cloud-based global flood disaster community cyber-infrastructure: 
development and demonstration. Environ. Modell. Softw. 58, 86-94. doi: 10. 1016/j.envsoft.2014.04.007

Wang, R.-Q., Mao, H., Wang, Y., Rae, C., and Shaw, W. (2018). Hyper-resolution monitoring of urban flooding with social media and crowdsourcing data. Comput. Geosci. 111, 139-147. doi: 10.1016/j.cageo.2017.11.008

Witherow, M. A., Elbakary, M. I., Iftekharuddin, K. M., and Cetin, M. (2018a). "Analysis of crowdsourced images for flooding detection," in Lecture Notes in Computational Vision and Biomechanics, Vol. 27, eds J. Avares and R. Natal Jorge, (Cham: Springer), 140-149. doi: 10.1007/978-3-31968195-5_15

Witherow, M. A., Sazara, C., Winter-Arboleda, I. M., Elbakary, M. I., Cetin, M., and Iftekharuddin, K. M. (2018b). Floodwater detection on roadways from crowdsourced images. Comput. Methods Biomech. Biomed. Eng. doi: 10.1080/ 21681163.2018.1488223

Wu, Y., and Wang, Y. (2014). "A portable flood detection system using heterogeneous sensor networks," in Proceeding of the 2014 IEEE $33 r d$ International Performance Computing and Communications Conference (IPCCC), (Austin, TX: IEEE), 1-2. doi: 10.1109/PCCC.2014. 7017026

Yabut, E. R., Balceda, C. D., Juan, R. E. Q. S., Tumamak, J. R., Velasquez, R. E., Jamis, M. N., et al. (2018). "e-wasBaha: A mobile application framework for flood monitoring in Metro Manila using crowdsourcing," in Proceedings of the 9th International Conference on Humanoid, Nanotechnology, Information Technology, Communication and Control, Environment and Management HNICEM 2017 (Manila: IEEE), 1-6. doi: 10.1109/HNICEM.2017.8269533
Yadav, M., and Rahman, Z. (2016). The social role of social media: the case of Chennai rains-2015. Soc. Netw. Anal. Min. 6:101. doi: 10.1007/s13278-0160410-5

Yang, K., Michael, K., Abbas, R., and Holderness, T. (2018). "Urban flood modelling using geo-social intelligence," in Proceedings of the International Symposium on Technology and Society, Proceedings (Sydney, NSW: IEEE), 1-9. doi: 10.1109/ ISTAS.2017.8319086

Yu, D., Yin, J., and Liu, M. (2016). Validating city-scale surface water flood modelling using crowd-sourced data. Environ. Res. Lett. 11:124011. doi: 10. 1088/1748-9326/11/12/124011

Zheng, F., Tao, R., Maier, H. R., See, L., Savic, D., Zhang, T., et al. (2018). Crowdsourcing methods for data collection in geophysics: state of the art, issues, and future directions. Rev. Geophys. 56, 698-740. doi: 10.1029/ 2018RG000616

Conflict of Interest Statement: The author declares that the research was conducted in the absence of any commercial or financial relationships that could be construed as a potential conflict of interest.

Copyright (c) 2019 See. This is an open-access article distributed under the terms of the Creative Commons Attribution License (CC BY). The use, distribution or reproduction in other forums is permitted, provided the original author(s) and the copyright owner(s) are credited and that the original publication in this journal is cited, in accordance with accepted academic practice. No use, distribution or reproduction is permitted which does not comply with these terms. 


\title{
Earthquake Education Through the Use of Documentary Movies
}

\author{
Batmanathan Navakanesh ${ }^{1}$, Afroz Ahmad Shah ${ }^{2 *}$ and M. V. Prasanna ${ }^{1}$ \\ ${ }^{1}$ Department of Applied Geology, Faculty of Engineering and Science, Curtin University Malaysia, Miri, Malaysia, \\ ${ }^{2}$ Department of Physical and Geological Sciences, University of Brunei Darussalam, Bandar Seri Begawan, Brunei
}

\section{OPEN ACCESS}

Edited by:

Jonathan D. Paul,

Imperial College London,

United Kingdom

Reviewed by:

Wen-Tzong Liang,

Academia Sinica, Taiwan

Yasamin O. Izadkhah,

International Institute of Earthquake

Engineering and Seismology, Iran

*Correspondence:

Afroz Ahmad Shah

afroz.shah@ubd.edu.bn;

afroz.shah@gmail.com

Specialty section:

This article was submitted to Geohazards and Georisks,

a section of the journal

Frontiers in Earth Science

Received: 01 October 2018

Accepted: 20 February 2019

Published: 19 March 2019

Citation:

Navakanesh B, Shah AA and Prasanna MV (2019) Earthquake

Education Through the Use

of Documentary Movies.

Front. Earth Sci. 7:42.

doi: 10.3389/feart.2019.00042
Unscientific, false, inaccurate and/or exaggerated reporting about anything in media or other platforms is a serious concern that needs a solution. This is particularly important when reporting about disasters (e.g., earthquakes). The lack of authentic scientific input into about science news reporting may can lead to news disasters, which may can prove to be much more critical and dangerous than say -earthquake disasters. Therefore, this paper explores such a this problem in a portion of NW Borneo and offers solution to improve the existing norms on the earthquake science, education and awareness programs in SE Asia. The explored field location is Sabah, Malaysia, which is targeted to map the level of earthquake science education and awareness of local people, and to examine the co-seismic deformation associated with the 5th June, 2015 earthquake. This event has surprised the local communities because the region is geographically located away from the active tectonic plate boundaries, and has traditionally been considered a low earthquake risk region. This is in contrast to the existence of high earthquake hazard and risk regions in the neighboring Indonesia and the Philippines. Therefore, not surprisingly, the residents of Borneo where puzzled, surprised, and worried when a medium magnitude earthquake occurred and caused significant loss of life and property. The lack of scientific education on the causes, and remedies of earthquake hazards in most of the South and Southeast Asian regions is a reality, which needs a proper solution. Therefore, through this work a small initiative has been started in Sabah, Malaysia where stories from the earthquake victims were recorded after the devastation caused by the June 2015 earthquake. Their real time experiences were blended with the updated scientific data on the occurrence of earthquakes in Borneo, which are mostly gathered from previously published works and the work presented here. The entire work is converted into a small documentary movie that highlights the causes of earthquakes and how it impacts human life.

Keywords: earthquake, Sabah, NW Borneo, education, hazard

\section{INTRODUCTION}

Science education historians have suggested that one of the prime facets of scientific literacy is to understand and examine reporting and discussion on science that appear in the popular media (DeBoer, 2000). And with the advancement of technology to communicate science it has become increasingly difficult to differentiate facts from fiction (Barnett et al., 2006). This is particularly 
true in fictional cinema and television on science that has blurred the distinction between fact and fiction (Frank, 2003). These concerns were also raised by National Science Foundation (2000) by arguing that visual media has corroded the critical thinking of public at large because it lacks credibility, authenticity, and honesty on scientific reporting. It is therefore imperative to communicate authentic science to public, which can be achieved if scientists are actively involved in such endeavors. And since most of the people use various types of technical gadgets to learn about science therefore it will be easy to feed scientifically valid information through the use of modern technological tools. Below we demonstrate through our work in Malaysia and Brunei that valid and updated earthquake science education and awareness campaign is needed to fill the gap that is evident in the region. The earthquake hazards are a great concern to most of South and Southeast Asia countries (Figures 1, 2), which makes communication authentic science to people an urgency.

Our concern about the earthquake hazards and scientific awareness in SE Asia with a special focus on Malaysia started in 2010 with a small contribution published in 2015 (Shah, 2015) where a comprehensive methodology and planning to map all of the seismogenic structures in Malaysia is highlighted. The equally important component of the work was to translate earthquake science education into action on ground via education and awareness campaign. Therefore, keeping in view the importance of earthquake science in Malaysia the second authors of this contribution applied for a research grant in 2013-2014 but unfortunately the grant was rejected by the review committee which argued that since there is no earthquake threat in Malaysia therefore it was not important and necessary to fund such a research proposal. This was $\sim 2$ years before the June 2015 quake that caused significant damage to the life and property (Shah, 2015; Shah et al., 2018c) in Sabah (Figure 1). This motivated us further to raise awareness about the science of earthquake hazards in the region, which has somehow remained elusive even from the responsible scientific community. The Sabah event caused widespread public outrage, and forced researchers to rethink about the traditional interpretation of the earthquake hazards in Borneo (Shah, 2015; Wang et al., 2017; Shah et al., 2018b). And the realization to have a competent earthquake education and outreach program mainly comes from the field interaction with locals in parts of Malaysia and Brunei. The local Malaysian students (undergraduates and graduates) are asked about the earthquake hazards in the country and they have shown complete lack of knowledge about the fault system in their neighborhood, and what lies under their feet (Shah et al., 2018b). Their confident outlook of not knowing about the earthquake hazards, and the potential impact of a future earthquake is a direct outcome of the background education and information that these students are exposed to (e.g., Balendra and Li, 2008; Lam et al., 2016; Loi et al., 2018; Shah et al., 2018b). Therefore, the present work is built on the published literature about the earthquake science education and how that information percolates down in the public domain. Such works are few, because most of the scientific research is usually concerned about the science and very few on how that science is transported into the public spheres and action on ground (e.g., Sandal, 1996; Hall, 2002; Balaguru et al., 2003;
Hesse et al., 2009; Morley, 2009; Cullen, 2010; King et al., 2010a,b; Sapin et al., 2013; Shah, 2013; Mathew et al., 2016a,b; Menier et al., 2017; Tongkul, 2017; Wang et al., 2017; Shah et al., 2018c).

The present work demonstrates a small documentary project, funded by National Geographic Foundation, on the understating of occurrence and causes of earthquakes in Sabah, Malaysia. A medium magnitude earthquake struck Sabah on 5th June 2015 (UTC+8) and caused a great loss to life and property (Wang et al., 2017; Shah et al., 2018c). The earthquake challenged the popular consensus among public that Borneo is seismically stable, and that there was no need to worry about earthquake hazards in the region. This information feeds on the historical seismicity data of the region, which show the lack of occurrence of medium to large magnitude earthquakes, and that is possibly the main reason that earthquake resistant building codes are not a prerequisite for building structures in Borneo. This motivated us to generate updated information on earthquakes occurrences in the region, and communicate this vital information through a less than 10 min long documentary movie on Sabah earthquake. We are deeply encouraged by the work produced by the Earth Observatory of Singapore, which is part of Nanyang Technological University, and the only place in SE Asia where research in Earth Sciences, and particularly on disasters is translated into documentary, animation, and computer games. Some of their famous works are: Mayon: The Volcano Princess, Sudden Nature, Earth Girl and People-Coral-Mentawai. These works offer a perfect blend of science, society, and education, and this motivated us to take a small step toward working on earthquake science education via documentary movies.

\section{BRIEF TECTONIC BACKGROUND OF THE STUDY AREA}

The regional tectonic map (Figure 1) of northwest Borneo shows Sabah is enclosed within a network of active tectonic plate boundaries that include Indo-Australian, Eurasian, and Philippines Sea plates (Figure 1). The distribution and depth of earthquake hypocenters indicate a sack like clustering that surrounds NW Borneo, and it testifies the occurrence of active plate boundaries in the region. Seismicity is scarcely distributed in most of Borneo compared to the NW portions where more earthquakes are observed. And this configuration remain consistent with its location relatively far from the regional plate boundaries (e.g., Hall et al., 2008; Sapin et al., 2011; Wang et al., 2017; Shah et al., 2018c). Such observations are further supported by the lack of significant volcanic activity, coupled with relatively low, and apparently variable presentday geodetic convergence rates relative to Eurasia (Sapin et al., 2013). However, the prominent structural, and topographical expression of mountains and valleys in the region cannot be overlooked (Shah et al., 2018c). The well-developed mountain ranges are carved by channels, and various small valleys occur right in the middle of mountains which are filled with Quaternary to Recent fluvial deposits. This requires understanding. And although the earthquake distribution in NW Borneo is scarce but their occurrence needs to be understood to fully comprehend 


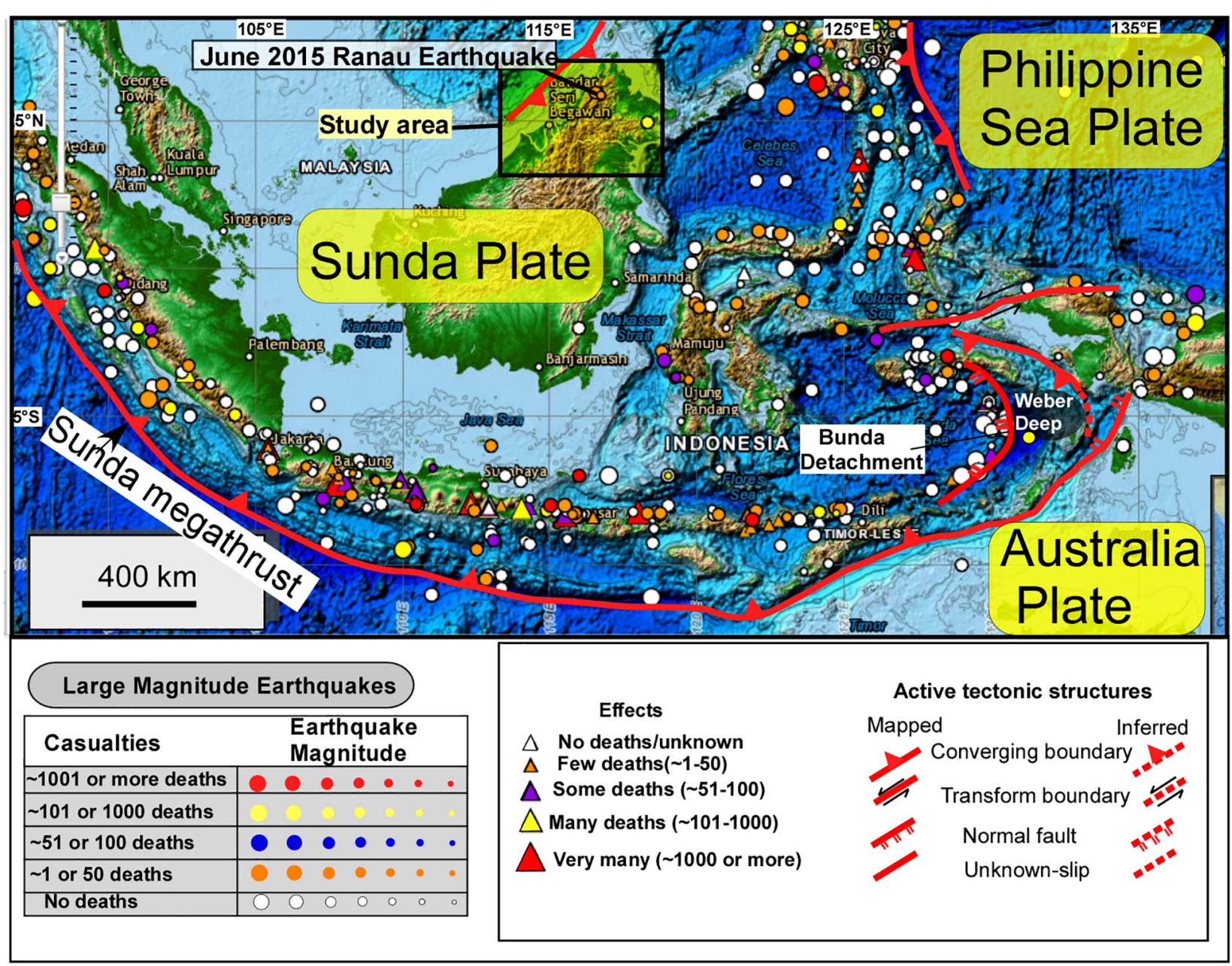

FIGURE 1 | Regional tectonic map of SE Asia (after Shah et al., 2018c) shows the distribution of lithospheric plates and the location of earthquakes, volcanoes, and some of the major active fault systems. The earthquake and plate boundary data (some boundaries are modified herein) are obtained from the National Geophysical Data Center/World Data Service (NGDCMDS): Significant Earthquake Database. National Geophysical Data Center, NOAA. doi: 10.7289/N5TD9V7K.

the earthquake geology of the region. Undoubtedly, the recent earthquake in Sabah (Figure 3) (Shah et al., 2018b) has initiated an interest and unrest in academic, research, and public spheres about the causes and concerns of earthquake occurrences in the region. Historically, the earthquake is regarded as the biggest recorded earthquake in the region, which led to an unfortunate loss of significant life and property (Wang et al., 2017; Shah et al., 2018c). And most of the casualties were of hikers who used to hike the Mount Kinabalu peak which is the highest mountain in Malaysia, and attracts a large number of hikers globally. The loss of life teaches us that even if a region is located away from the active plate boundaries, the impact of intraplate earthquake hazards cannot be overlooked (Shah et al., 2018b).

\section{METHODOLOGY}

The standard methodology adapted here uses geological field investigations as a tool to map the evidence of faulting in parts of Sabah (Figure 4). The freely available Google satellite and GeoMap App. data are used to prepare the basemap (Figures 3, 4) onto which the potential field locations are plotted. These data are aided by the Garmin GPS (Oregon 750). Figure 4 shows the location map of geological outcrops and other field sites visited during the fieldwork. Most of data are collected from the selected sites that were affected by the 2015 earthquake. The typical earthquake related investigation session with locals is shown in Table 1. Some of the interviews with locals were recorded, and before that a formal written and informed consent form was signed by each participant. Lack of funding is the only reason that stopped us to expand the sampling size, and it is anticipated that in future this void can be filled. Therefore, the limited data presented below show the importance of undertaking a large scale sampling in the region. The seismological data shown here are not relocated, and therefore there are error bars associated with both the vertical and horizontal distribution 


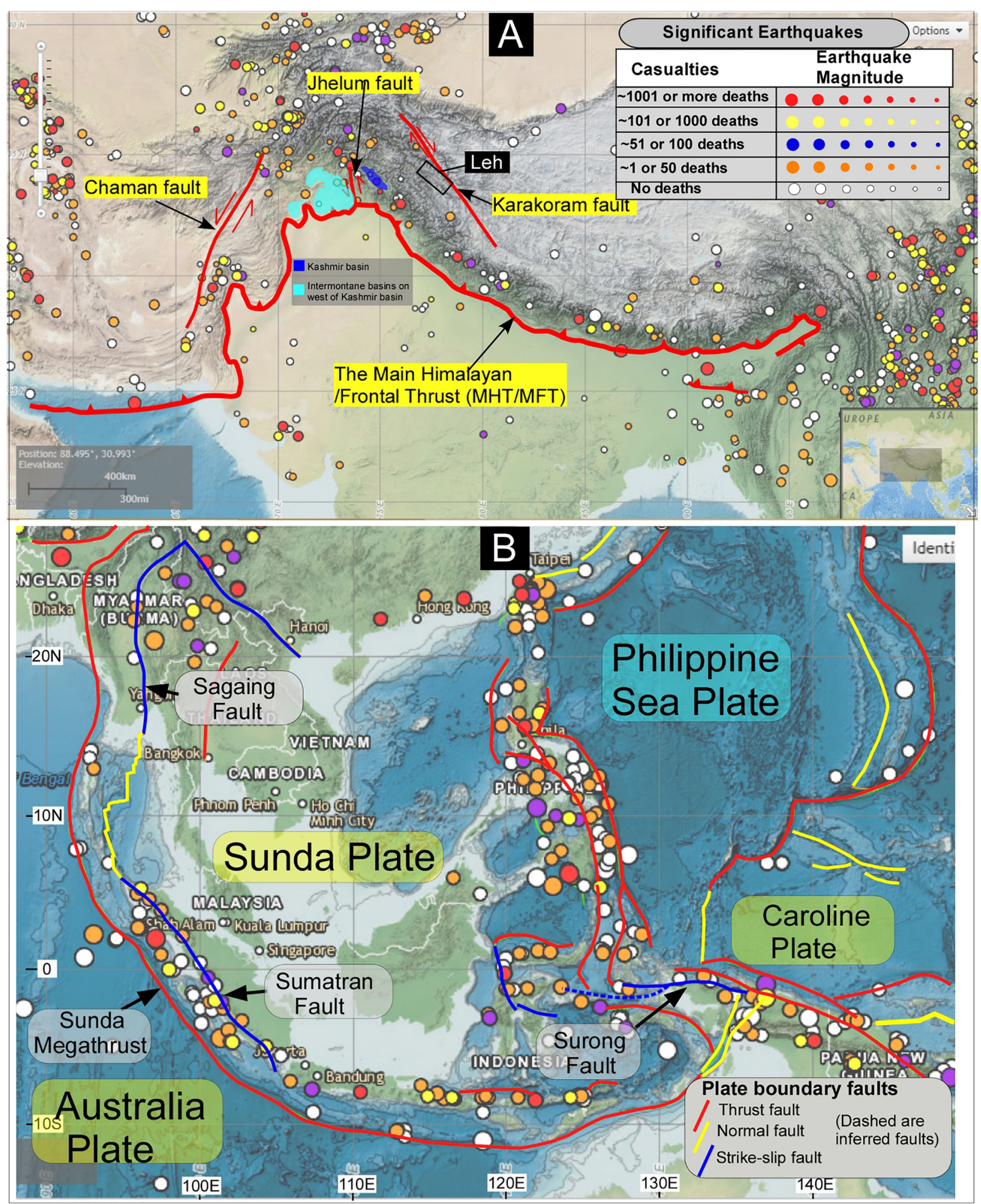

FIGURE 2 | (A) The topographic map shows some of the major faults in South (after Shah et al., 2018a) and Southeast Asia (B). The colored dots are significant earthquakes (Mw 6 and above with a depth of 0-50 km) in the region, which dates back to 2150 B.C. until present. The earthquake and plate boundary data (some boundaries are modified) are obtained from the National Geophysical Data Center/World Data Service (NGDC/WDS): Significant Earthquake Database. National Geophysical Data Center, NOAA. doi: 10.7289/N5TD9V7K. 


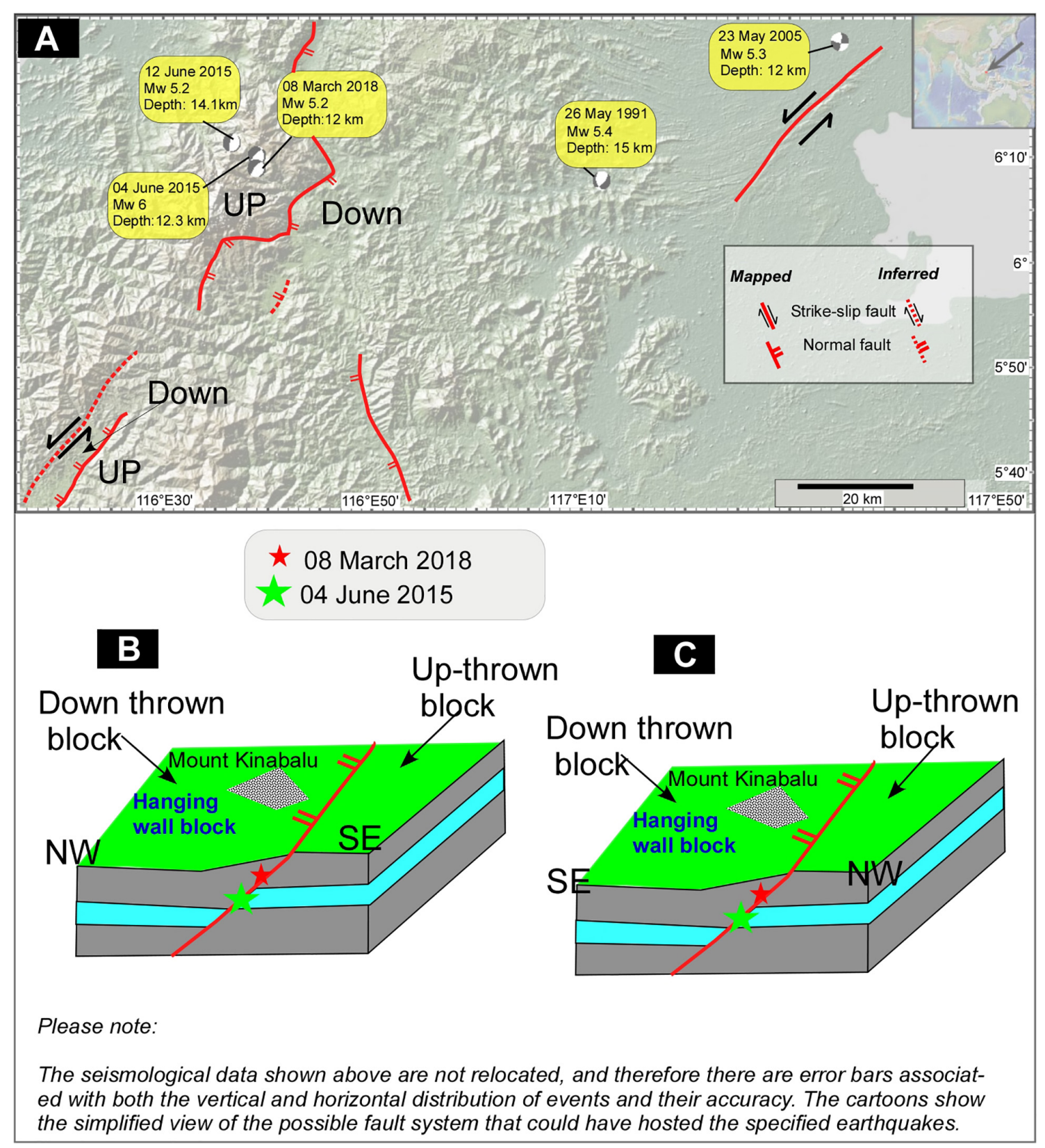

FIGURE 3 | Topographic and structural map of NW Borneo shows the locations of Centroid-Moment-Tensor solutions and the traces of active faults (A). The figure is created using the GeoMap App. software, which uses data from the Global Centroid-Moment-Tensor Project since the year 1976 until now. The most of the mapped active faults are after Shah (2015) and Shah et al. (2018b). The cartoon (B) shows the structurally most feasible fault plane on which the June 2015 and March 2018 earthquake events might have originated. The SE dipping fault plane is not fitting well with the fault parameters and the field data (C).

of events and their accuracy (e.g., Bondár et al., 2004; Bondár and McLaughlin, 2009).

\section{RESULTS AND INTERPRETATION}

\section{Fieldwork in Ranau, Sabah}

The geological field investigations were carried out in February, April and July of year 2017 with an underlying mission to map the evidence of co-seismic deformation related to the June 2015 earthquake, and to interact with locals to know about their knowledge on earthquake hazards in the region. A total of 50 geological outcrops were examined, and most of these sites expose interbedded sandstone and shale lithology of Miocene age. A series of $\sim \mathrm{NW}$ and SE dipping normal faults are mapped at a number of sites (e.g., Figure 5). These faults have vertically displaced some marker beds and the displacement varies from a few centimeters to meters (Figure 5). The normal faults 


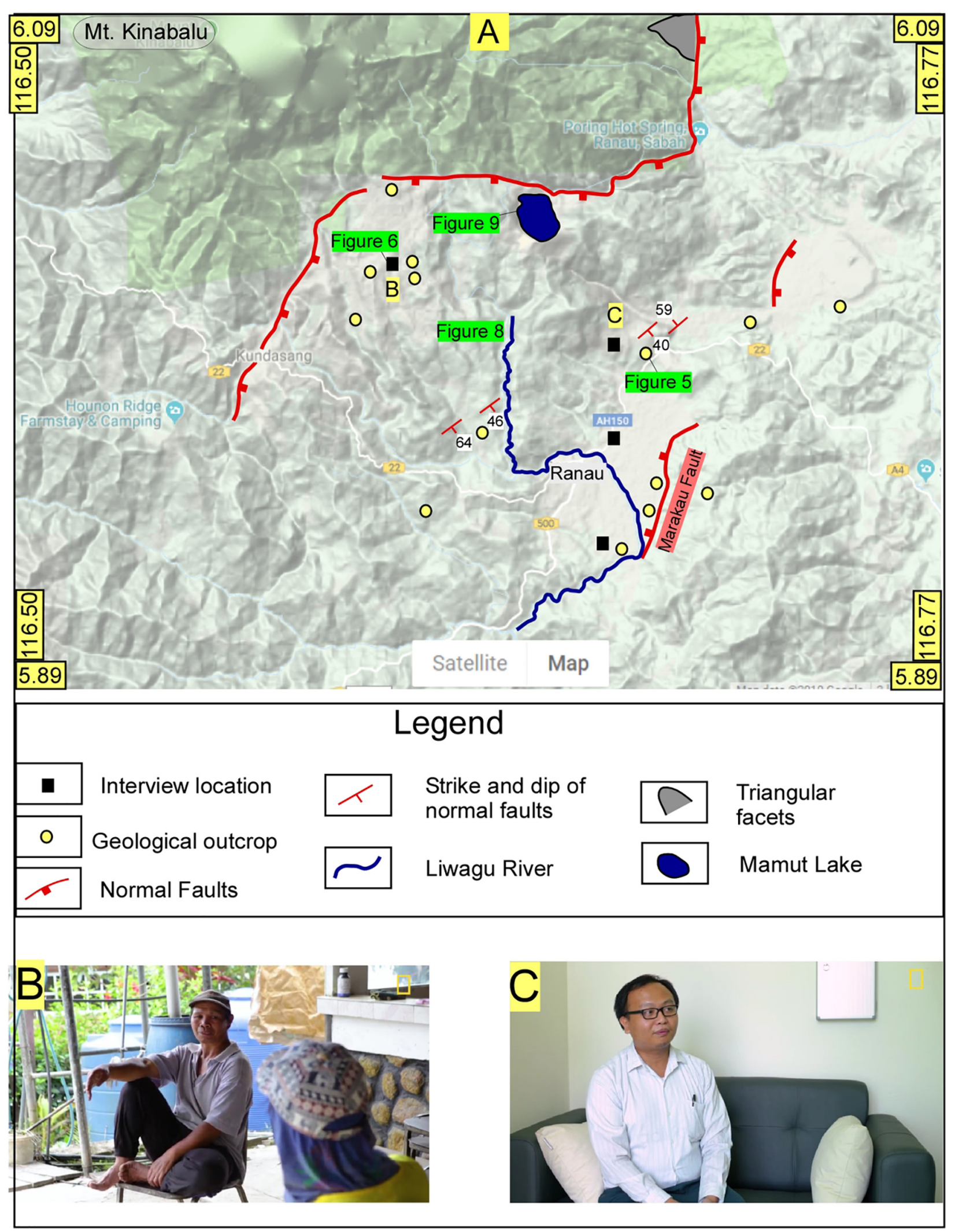

FIGURE 4 | Google terrain map shows the geological field investigation sites (A) and the location of oral interviews (B,C). Some of the active faults and geological bedrock data are also shown. 
TABLE 1 | A typical questionnaire that was used to map the earthquake damage, education and awareness during the field interaction sessions with locals in Sabah, Malaysia.

\begin{tabular}{|c|c|c|}
\hline No. & Typical questions & Typical answers \\
\hline 1 & $\begin{array}{l}\text { Briefly explain your experience during the 5th June } 2015 \text { earthquake } \\
\text { that occurred in Ranau, Sabah. }\end{array}$ & We were totally surprised and scared. \\
\hline 2 & Can you give an approximate time and duration of the main quake? & $\begin{array}{l}\text { The earthquake occurred between } 6 \text { and } 7 \text { a.m., it lasted for about } 7 \mathrm{~s} \text { in } \\
\text { Ranau, and about } 10 \mathrm{~s} \text { in Kota Kinabalu. }\end{array}$ \\
\hline 3 & Did you observe any damages due to the earthquake? & $\begin{array}{l}\text { Yes, the Liwagu lodge was closed for a week due to flooding that occurred after } \\
\text { the earthquake. The water tank had burst, and there was no electricity and } \\
\text { phone signal. Some windows were also shattered. One fishing pool moved } \\
\text { sideways and cracks developed. }\end{array}$ \\
\hline 4 & Have you felt trauma after the earthquake? & $\begin{array}{l}\text { Yes. We were traumatized because we never felt an earthquake before. It was a } \\
\text { total surprise. }\end{array}$ \\
\hline 5 & $\begin{array}{l}\text { Was such an earthquake expected in the region. Earthquakes in the } \\
\text { region? }\end{array}$ & No, we were told that Malaysia is not an earthquake prone region. \\
\hline 6 & $\begin{array}{l}\text { What is your knowledge about earthquake hazards in the Sabah } \\
\text { region? }\end{array}$ & $\begin{array}{l}\text { We know that earthquakes are not a problem for Sabah. We are safe as we } \\
\text { belong to the stable part of the Borneo Island. }\end{array}$ \\
\hline 7 & Has your perspective changed after the 2015 quake? & $\begin{array}{l}\text { It has definitely changed. We have experienced aftershocks for more than } 30 \\
\text { times since then. }\end{array}$ \\
\hline 8. & Do you know what to do before, during and after an earthquake? & No, we are not aware about it. \\
\hline 9. & $\begin{array}{l}\text { Do you think the government should provide resources for earthquake } \\
\text { education? }\end{array}$ & $\begin{array}{l}\text { Yes, we want to know why earthquakes occur, and what will happen in future, } \\
\text { and how to live with such hazards. }\end{array}$ \\
\hline
\end{tabular}

displace older lithology, and none is observed to cut through a younger stratigraphy, which suggests that active faults have not ruptured the surface here. However, the strike and dip direction of the active faults that are mapped on the satellite images (Shah, 2015) match with the structural details of the faults that are mapped in the field (Figure 3). The structural details of the June 2015 and March 2018 earthquakes suggest that these quakes have occurred on $\sim \mathrm{NW}$ dipping fault plane (Figure 3) and not on $\sim \mathrm{SE}$ dipping fault plane (Figure 3C). The clear geomorphic evidence of the past fault rupture (Shah, 2015; Wang et al., 2017) indicates that the Kota Kinabalu pluton sits on the foot-wall portion of the fault (Figure 3B), which is the up-thrown block. The down-thrown block is on the SE portion of the region, and this configuration suggests that $\sim \mathrm{NW}$ dipping plane is the best possible fault plane solution for the above mentioned earthquakes. This further suggests that both of these quakes have either reactivated an older normal fault system or have occurred on a similar but new fault system. The proximity of the quakes closer to the existing fault system makes it more feasible to suggest that earthquakes have originated on the older fault system. The lack of evidence of recent fault ruptures associated with the co-seismic deformation of the earthquakes indicate that the quakes have occurred on a blind fault. And this seems consistent with the structural configuration of the older faults (Shah, 2015; Wang et al., 2017). The earthquakes have ruptured a portion of a large fault system that runs $\sim \mathrm{NE}-$ SW through the Borneo Island (Wang et al., 2017; Shah et al., 2018c). The occurrence of active normal faults in the region indicate $\sim \mathrm{NW}-\mathrm{SE}$ extension, which could be related to the tectonic stress associated with the regional oblique compression (Shah et al., 2018c). This interpretation argues that the region is slowly accumulating tectonic strain and can host medium to large magnitude earthquakes in the future. It will be further tested in future as more scientific investigations on Borneo become available. However, the earthquake hazard in the region cannot be ignored because evidence of active deformation is visible, and therefore people have to be updated on the available scientific wisdom (for more information, please go to section "Interaction With Locals About June 2015 Earthquake") about the region, and must be educated, trained, and equipped with the latest information on the earthquake hazards.

\section{Interaction With Locals About June 2015 Earthquake}

The post-June 2015 earthquake awareness related field session with locals in Ranau (Figure 4) suggests severe lack of earthquake science education in the region, and that is one of the major reasons why the earthquake took them by total surprise. People are still in shock, and some of them believe in myths and all of the unscientific information that was available. For example the Kadazan-Dusun community of people, which is the largest ethnic group in Sabah (Lasimbang, 2004; Halim et al., 2013), believe that the dead spirits settle at Mt. Kinabalu, which is regarded as a sacred place. The natives have performed "Monogit ceremony" or animal sacrifice over centuries to please the mountain god "Aki Nabalu" (Halim et al., 2013). Such rituals are performed annually to avoid any catastrophic event. The periodicity of such a ritual suggests that in the distant past damaging earthquakes might have occurred in the region. This needs a thorough investigation, and historical archival data can be useful resource to uncover such evidence.

Some of the people, who believe in myths, were not happy when on 30th May 2015 a group of 10 tourists stripped near Mt. Kinabalu. They believe that the God will be angry and will take revenge for such cultural insensitivity by some tourists. And unfortunately, just a week after this incident the infamous Mw 6 earthquake occurred in the region. Thus reinforcing their belief 

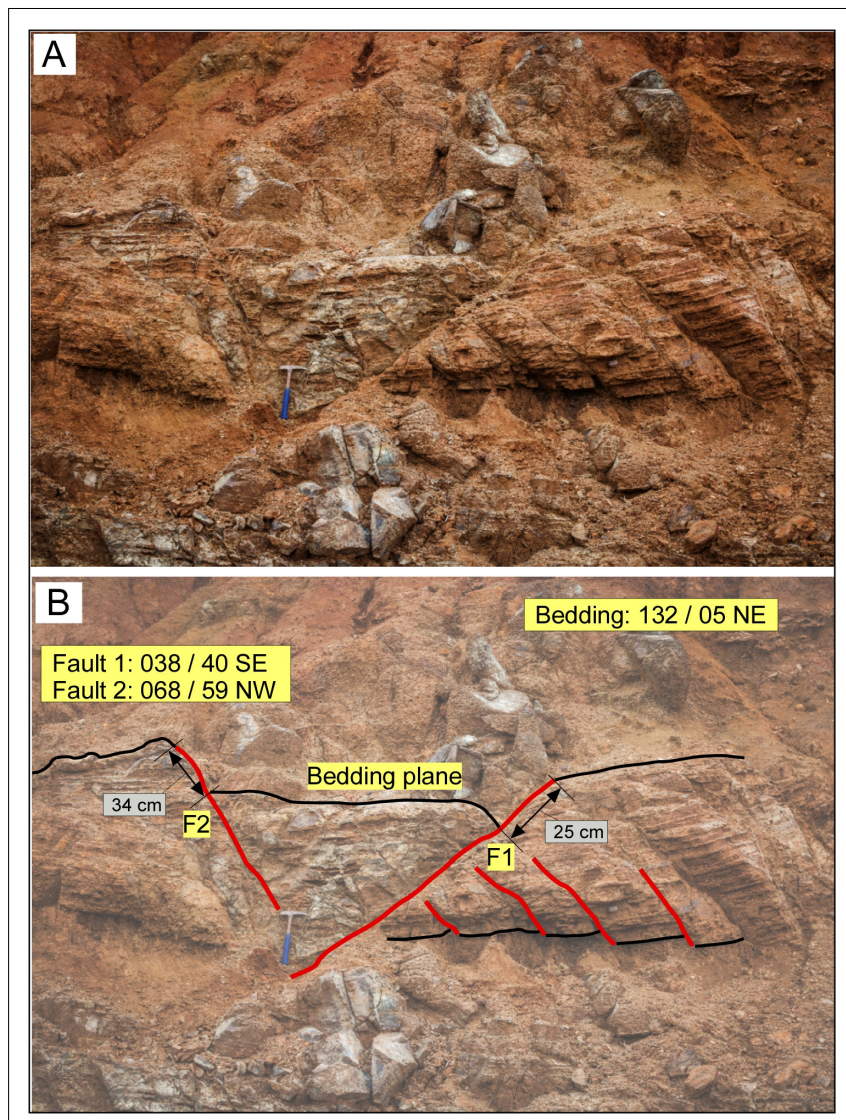

FIGURE 5 | The field photograph shows evidence of normal faulting in Ranau region, Sabah. The un-interpreted $(\mathbf{A})$ field photograph is interpreted below (B) and shows the rock sequence is cut through by the two prominent NW and SE dipping normal fault systems. The faults are older, and have not pierced through younger lithology.

in such super natural powers. A significant number of religious people also believe that this kind of obscenity by tourists led to the catastrophic event in Ranau, Sabah.

Several eyewitnesses' accounts have confirmed that the earthquake shaking lasted for $\sim 7 \mathrm{~s}$ and that the quake occurred between 6 and 7 a.m. The shaking was scary, and it was hard to understand what was happening, said the participants. The electricity and phone signals were disrupted, and subsequently restored in a few hours. Several cracks appeared on the ground (Figure 6), buildings, and roads but luckily no building collapsed due to earthquake or landslides in the region. Three students from Universiti Malaysia Sabah (UMS), Kota Kinabalu, claimed that the seismic shaking lasted for $\sim 10 \mathrm{~s}$ in Kota Kinabalu region. They were equally puzzled, surprised and were not aware that earthquakes can jolt this region as well. Their hostel was damaged, windows shattered, and the impact partially broke the swimming pool. A number of buildings at several places developed extensional cracks after the quake (Figure 3). Such structural damage must be repaired immediately to avoid any subsequent structural failure and damage in a future earthquake event.

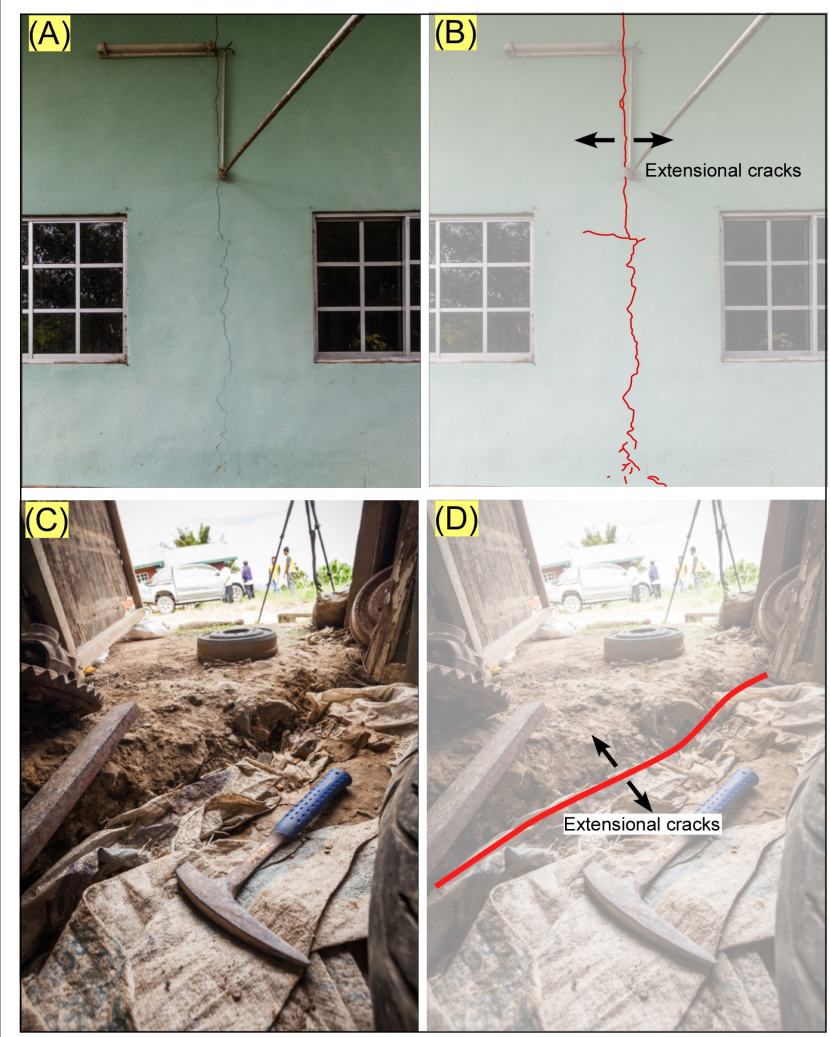

FIGURE 6 | The field photographs show evidence of co-seismic cracks that have developed during the June 2015 earthquake. The un-interpreted images are on the left $(\mathbf{A}, \mathbf{C})$ and interpreted images are on the right $(\mathbf{B}, \mathbf{D})$ of the observer.

Importantly, the curiosity of the people to know about the scientific background of the earthquake events in Sabah is a persistent quest for its inhabitants that we realized throughout our work in Sabah. Although, some people truly believe in various rituals, a large section of educated people are now asking pertinent questions about the science of the occurrence of earthquake in the region. We were told that the earthquake administration has installed seismic monitoring stations at various places in Sabah. This is a welcome initiative and could help in the understanding the crustal deformation in the region. Hopefully, more such stations will be installed throughout the country.

\section{Landslides Associated With June 2015 Earthquake}

The co-seismic effects in the forms of landslides have perhaps intensified in the recent past, and routinely some of the major earthquakes were reported to have caused co-seismic landslides. For example: the Mw 8.0 earthquake that struck Wenchuan region of China in 2008; the Mw 7.6 earthquake of Chi-Chi, Taiwan in 1999; the Mw 9.0 earthquake of 2011 in Tohoku, Japan, and the Mw 7.6 earthquake of Kashmir in 2005 (e.g., Wistuba et al., 2018). Similarly, extensive landslides were initiated just after the June 2015 earthquake that shattered the famous Mount 

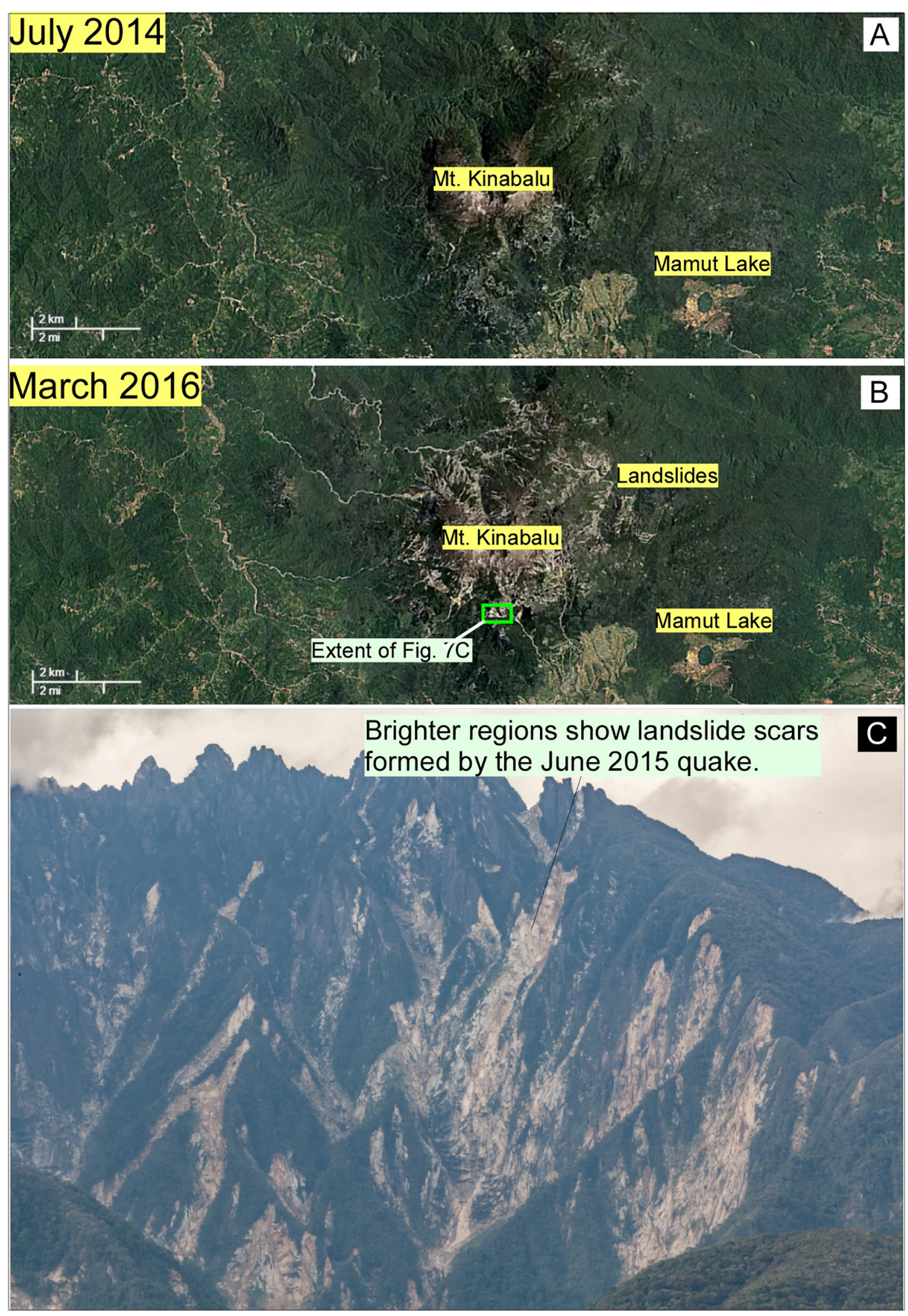

FIGURE 7 | Google satellite images show the Mount Kinabalu region before (A), and after the June 2015 earthquake (B). The extent of landslide occurrence on the steep slopes on the mountain is clearly visible. Field evidence of this is shown at the bottom (C). 
Kinabalu region, and this is said to be the main reason for the unfortunate loss of 18 hikers (Wang et al., 2017; Shah et al., 2018c). The Mount Kinabalu is a 4,100 m mountain of granitic composition that has formed in Late Miocene (Cottam et al., 2013). It is one of the highest mountain peaks in SE Asia, and therefore a favorite tourist attraction for hikers, which is why the earthquake caused considerable casualties. The satellite image captured before and after the landslide shows the widespread damage associated with co-seismic deformation (Figure 7). Most of the landslides occurred on the Mount Kinabalu, which could have occurred because of shaking of the hanging wall block (Figure 3B), as would be predicted normal faults that dip $\sim$ NW (Figure 3), and the presence of steep slopes could also contribute to it. The earthquake hypocentral depth ranges from $\sim 10$ to $13 \mathrm{~km}$, which has not been relocated, and therefore errors exist in both the depth and location of the recorded earthquake events. However, Wang et al. (2017) have relocated the main shock and eight aftershocks, which are distributed in a narrow zone of $\sim 15 \mathrm{~km} \times 5 \mathrm{~km}$, and are consistent with the previous mapped fault system (Shah, 2015). The coseismic slip of $<50 \mathrm{~cm}$ has occurred at a depth of 13-14 km (Wang et al., 2017), which is similar to the hypocenter depths that are used herein.

\section{Flooding After Landslides}

Earthquakes often cause landslides (Wistuba et al., 2018) and floods (Shah and Malik, 2017; Shah et al., 2018a), and this systemic chronological order of such disasters remains one of the most difficult tasks to accomplish, particularly during the post-disaster operations. Previous studies have demonstrated several such cases, for example a large number of landslides and associated floods were triggered by the Mw $7.6 \mathrm{Kashmir}$ earthquake that devastated the eastern portion of Pakistan and most of the Muzaffarabad area in 2005 (e.g., Kamp et al., 2008). Several eyewitness accounts suggest that a large quantity of debris associated with the 5th June 2015 landslide has accumulated in some of the rivers. This is notable in Liwagu River, which is located downslope of the Mount Kinabalu (Figures 4, 8). This is the reason why a large quantity of landslide derived debris has been accumulated in it. This caused choking of streams as sediment load builds up, which is particularly observed at bridges or narrow passages where flow of the material is restricted. Local reports also suggest that it rained for a few days after the earthquake, and since the Liwagu River was filled with debris therefore it caused floods with usual precipitation. A lot of residential areas, which are closer to the river (Figure 8) had to be evacuated. This opened up multiple disaster fronts, which are usually not expected.

This also confirms the recent works where the relation between the earthquakes, landslides, and floods is now fairly well established, and therefore to make most of what such disasters can entail one must work on strengthening of the scientific knowledge database, and sharing and coordination between various sectors (e.g., engineers, scientists, disaster management, etc.). Such efforts can greatly help in the overall reduction of the risk associated with a potential hazard that could become a future disaster.

\section{Artificial Lake, the Mamut Lake}

Locals informed us that they are worried about an artificial lake (Figures 4, 9) that formed from an abandoned mine known as Mamut Copper Mine (MCM), which is a porphyry type $\mathrm{Cu}$ $\mathrm{Au}$ deposit and it is related to quartz monzonite ("adamellite") that has formed from the upper Miocene Mount Kinabalu plutonism (Akira, 2000). The mine is located very close to the active fault system (Figure 4), and people are concerned that the situation may turn chaotic and disastrous if any future earthquake damaged the lake. Since the lake contains a large quantity of water therefore it can pose serious threat to people living in the downstream direction. This mine also poses a threat to the pristine environment of tropical rainforests because it produces a large volume of sulfidic mineral waste (van der Ent and Edraki, 2018), which is often mobilized by the high amount of precipitation in the tropics of Sabah. The polluted mine pit derived with water often percolates into the fresh river and groundwater reserves. Therefore, the lake poses a great risk to life and environment, and ought to be properly managed.

\section{Short Documentary Movie}

The interview session with victims of the Sabah Earthquake of June 2015, and the various interactions with locals during our field exercises in Malaysia and Brunei inspired us to make a short movie on the science of earthquake disasters in Borneo. The movie is less than $10 \mathrm{~min}$ and blends the science of earthquakes in NW Borneo with the real stories of locals who were affected by the earthquake. It is freely available on YouTube and can be accessed here: https://www.youtube.com/watch?v= BtgsgTLI8Ck.

The interaction and interview session was an eye opener as it clearly shows that people are not aware about the earthquake hazards in the region, and are equally not aware about the existence of regional seismogenic fault systems. This information is vital for any future planning of science education in the region, and particularly about earthquake hazards. The movie shows the current scientific discourse on the understanding of the earthquake geology of the region, which is mainly the contributions from the second author of this paper. It presented a very brief snapshot of what type of earthquakes occur in NW Borneo, and what it means on the tectonic scale. The local interviews are placed in the context to make the documentary impactful, and scientifically sound. The movie highlights how scientists gather evidence about active faults through the study of satellite imagery, and how that information is used to target field sites where the usage of various instruments is required to study details about faults, etc. Therefore, the documentary movie is made with an underlying motivation to improve the scientific knowledge about earthquake hazards in SE Asia, and particularly in Sabah. It highlights the need for making scientifically sound documentary movies on earthquake science and how such efforts can help us in dissemination of authentic scientific information to public, students, and others. This simple effort demonstrates that a scientific documentary movie can translate a geologically difficult and complicated region into a simple and meaningful cinema, which can be 


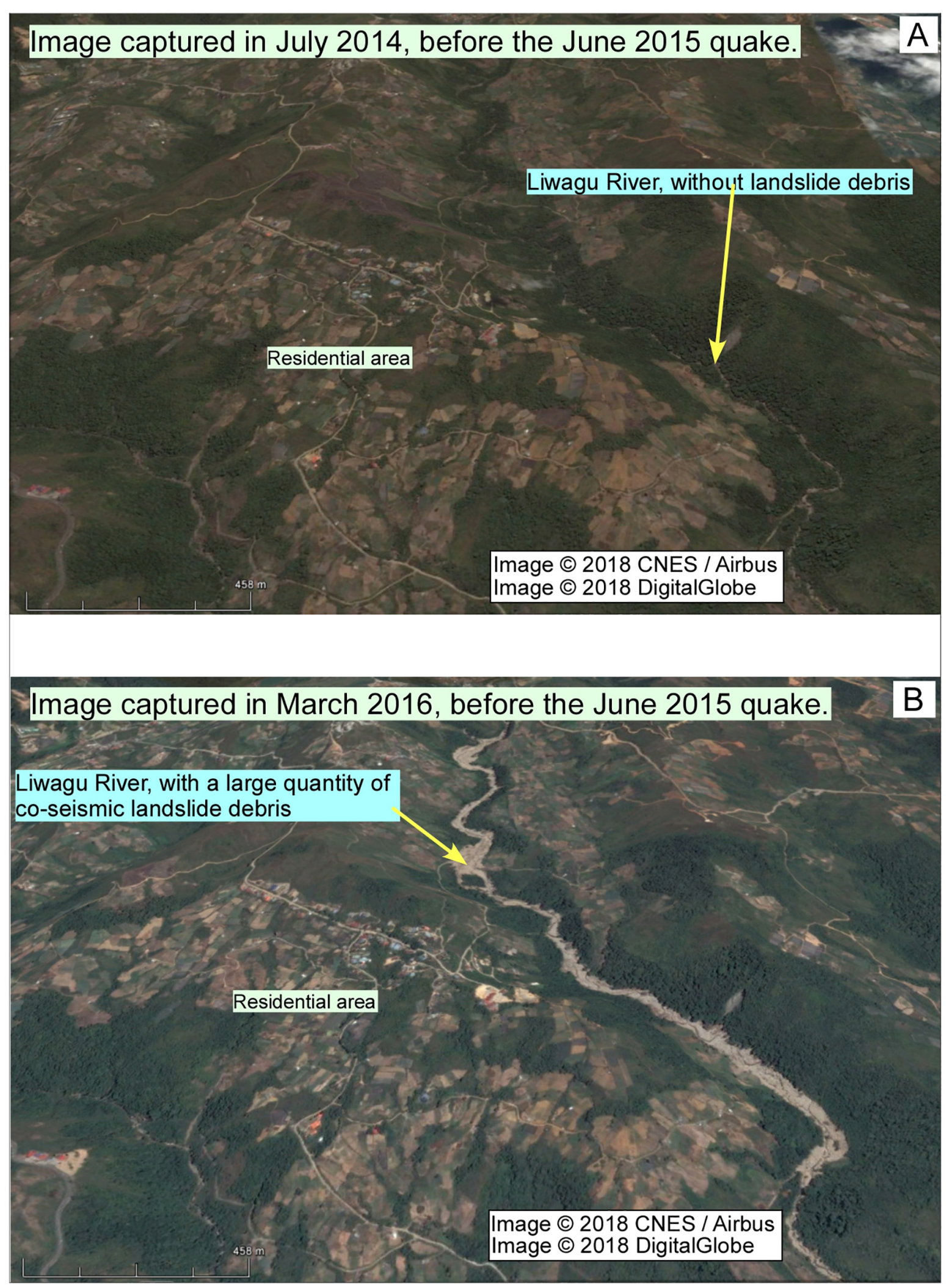

FIGURE 8 | Google satellite images show the scenes captured before (A) and after (B) the June 2015 quake in Sabah. The changes in Liwagu River are highlighted. The filling on the river bed are the remains of the debris that was derived from the earthquake induced landslides in the Mt. Kinabalu region. The debris filled river makes it vulnerable to future fluvial flooding. 


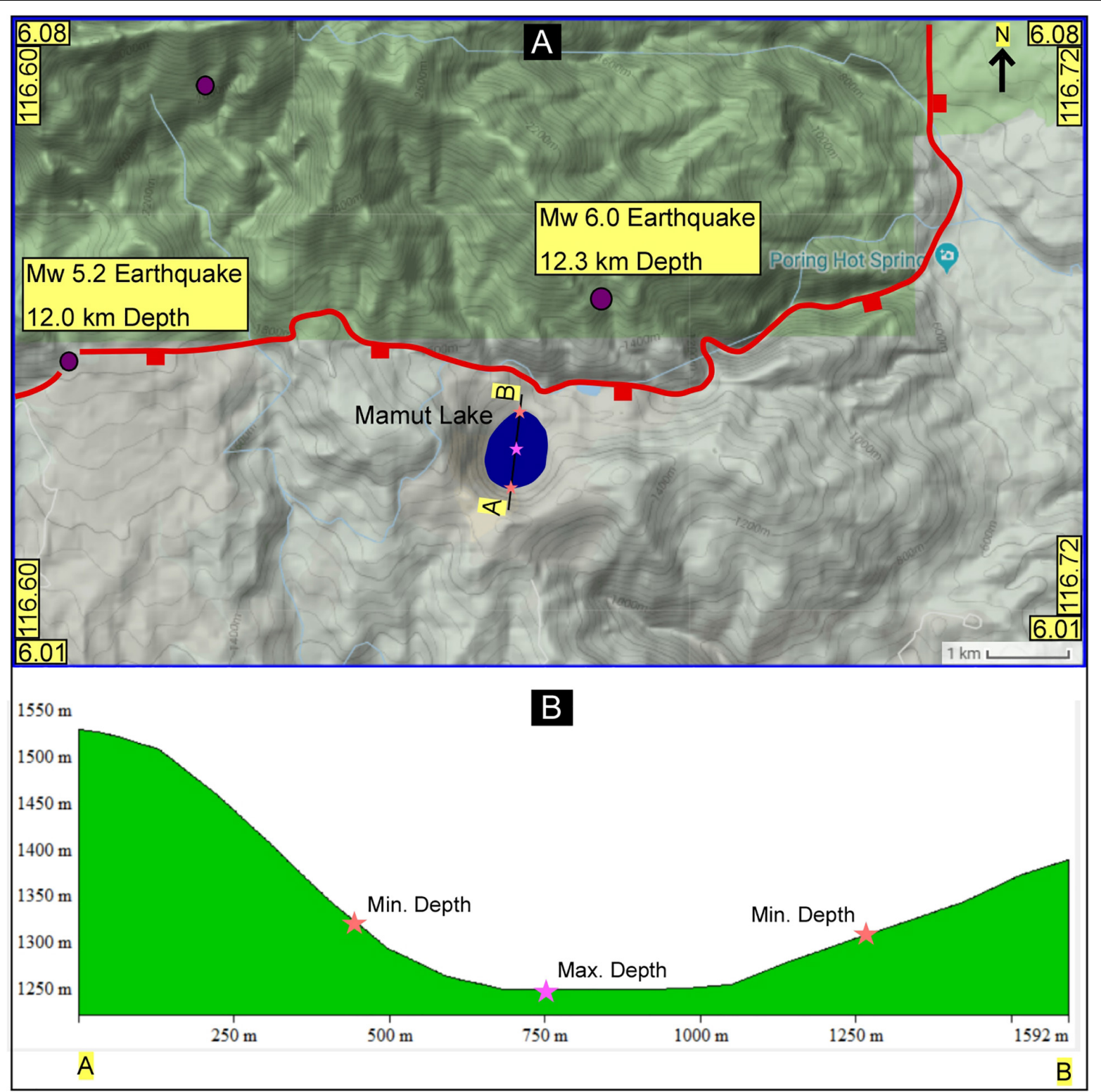

FIGURE 9 | Location and topographic map of the Mamut Lake in Ranau, which is an abandoned mine pit, and poses environmental and flood hazards. The topographic profile across the mine pit is shown in panels $\mathbf{( A , B )}$.

understood by ordinary people. However, such efforts can become more meaningful if more members of the scientific community get involved in such endeavors. Special grants are required to support such efforts and the scientists working on outreach programs.

\section{DISCUSSION}

\section{Why Earthquake Science Education Is Important in SE Asia}

A major earthquake of $\mathrm{Mw} 7.5$ struck Minahasa, Sulawesi, Indonesia on 28th September 2018 and it also caused the formation of tsunami waves, which could quickly reach the coastal regions. The tsunami is reported to have occurred because of the collapse of a volcano. The earthquake shaking together with the deadly tsunami waves resulted in extensive damage to life and property with a loss of more than 2,000 lives. Importantly, the earthquake ruptured a previously mapped active left-lateral strike-slip fault system, the Palu-Koro fault (Figure 2B), at a shallower depth of $10.0 \mathrm{~km}$ (Hui et al., 2018; Sassa and Takagawa, 2018). The unfortunate loss of life and property is mainly related to tsunami, liquefaction, and earthquake shaking, which clearly suggests that poor infrastructure and lack of earthquake disaster preparedness are the unpleasant realities that continue to challenge us. This has happened in a region which is well 
known for being one of the most tectonically active regions in Asia (e.g., Indonesia and the Philippines). Although the previous geological wisdom has exclusively demonstrated that a number of major active fault systems that encircle South and Southeast Asia (e.g., Sunda Megathrust) are capable of producing some of the most destructive earthquakes (e.g. Bilham, 2019) on the planet (Figure 2) yet our efforts are not making any decent progress on ground. This is a major challenge that stares us in our face, and we must take it head-on. Loss of life on known active fault zones is avoidable provided we work toward the solution.

Similarly, the nature and extent of destruction caused by the past earthquakes on the Sunda megathrust fault offers more lessons of wisdom (Shearer and Bürgmann, 2010; Shah et al., 2018b). It marks the location of the Sumatra subduction zone along which the Indo-Australia oceanic plate subducts under Sunda plate (Sieh, 2007; Shearer and Bürgmann, 2010), and this shall continue to pose major risk to millions of people (Figure 2). In December 2004 a portion of the fault broke, and caused one of the most devastating earthquakes in the region, which was followed by an equally devastating tsunami. Both these disasters resulted in the unfortunate loss of $\sim 156,000$ to 178,000 people across more than 11 nations (Liu et al., 2005; Geist et al., 2006; Shah et al., 2018b). Such enormous scale of devastation happened even after spending billions of dollars on understanding the causes of earthquakes since the inception of the earthquake sciences, which started more than 250 years ago. This clearly suggests that progress that is needed to secure life has not been achieved yet, and one of the major causes of such failure is the wide gulf between science its applicability on ground (Shah et al., 2018b). The earthquake studies in SE Asia have grown since the 2004 Indian Ocean earthquake event, and great efforts have been made in understanding the causes of earthquakes in the region. The newly compiled regional probabilistic seismic hazard map of SE Asia (Chan et al., 2017) is one such example where reliable seismic hazard maps are produced with a motivation to save life and property. Although this map is not complete, yet it highlights the major seismogenic sources in the region. It highlights areas with high seismic risk, and these are usually associated with high slip rates on major fault systems in the region (Figure 2). However, our understanding of faulting suggests that low slipping faults can also pose significant damage, as witnessed during the recent medium magnitude earthquake that occurred on a normal fault in Sabah (Malaysia) on 5th June and caused unfortunate loss of 18 people (Wang et al., 2017; Shah et al., 2018c). It is important therefore to know the sources of earthquake occurrences in the region and to map and understand the extent of seismic risk.

Further, our knowledge about the science of earthquakes has grown manifold throughout the historical past, and now we are at a stage where we do understand to a large extent the various causes of faulting. However, we are still unable to predict the exact timing of earthquake events, and that is the reason why earthquake forecasting is now more popular in scientific community (Hough, 2010). This also means that we have to put in more efforts in place to educate public about the potential of earthquake disasters, and how to live with one (Shah, 2014). This is particularly important in places that are highly prone to earthquake risk, and SE Asia is one such example where serious scientific awareness campaign is highly required to educate public about the science and remedy of earthquake disasters (Shah et al., 2018b). This is significant because a large number of people live on or close to active faults, and are at a greater risk (Figure 2). Generally, earthquake related education material is distributed in communities to help them understand the science of faulting, what to do when an earthquake strikes, and how to live with them (Sieh, 2007; Cummins, 2017). Here, we extend this approach by educating public through the use of documentary movies, which can be made freely available to benefit large number of people globally.

Our field session with students and public at large in Borneo clearly suggests lack of awareness about the science of earthquake hazards in the region. Throughout our project (which is ongoing) on the science of earthquakes in NW Borneo we realized that earthquake related education is needed and such efforts will make a major difference in changing the attitude of people toward earthquake hazards. Since Borneo was not in the radar of seismic resilient building planners therefore infrastructure to withstand earthquake shaking has not been planned in the past (Shah et al., 2018b). The first step toward making of an earthquake hazard and risk resilient society is to produce reliable fault mapping data (Chan et al., 2017; Shah et al., 2018b) that can be used to educate authorities about the level of risk, and what to build, how and where. Such information is largely absent in Borneo, although, some progress has been made recently about the science of earthquake and outreach activities (Shah, 2015; Mathew et al., 2016a,b; Tongkul, 2017; Wang et al., 2017; Shah et al., 2018b).

\section{Earthquake Science Education Program: Role of Scientists}

Earthquake science has grown in various directions from microscopic to megascopic levels (details in Shah et al., 2018b), however, we are still unable to save life because the prediction has not gone far, and a large portion of the population still lacks education and infrastructure to deal with such hazards (Shah et al., 2018a,b). People look forward to hearing from the scientists about the science of earthquake disasters but unfortunately not many local or international experts have participated in any such interactive sessions with locals. One of the major reasons for this is the lack of funding, which hinders any such program and progress. Therefore, it is required to allocate a portion of annual scientific budget for earthquake science education, outreach, and awareness exercises. All efforts should be made to make such programs more meaningful, successful and rewarding. Scientists should be motivated to participate in such programs through incentives, rewards, and other similar encouragements. Educating people about hazards will help in removing the ambiguity related to false reporting, propaganda, and exaggerated exigencies surrounding science, and in particular earthquakes (Brumbaugh, 1999; Paton et al., 2010). 


\section{Earthquake Science in School Curriculum}

Scientific education has progressed greatly with time but awareness around it has not been able to match it. A cursory look at it reinforces that the scientific community has mainly remained focused in progression of science but not on how science can be transposed into action on ground. The huge void that exists is now being filled with unscientific discourse and has reinforced the old belief system of going away from the scientific wisdom. This also comes from schools where teachers are not well equipped to teach students about science and the latest critical developments in sciences, therefore such education system will not be useful or engaging for students. This is one of the foremost reasons why many students do not continue in science (Holton, 1992). The answer to this is to fully train teachers first so they can disseminate updated, authentic, and rigorously researched science to students from a very early stage. The existing school curriculum must be thoroughly reviewed with the help of local and international science experts, and accordingly upgraded to the scale of latest developments. The local scientific community can enormously help any nation to accomplish this goal by coordinating with schools and other institutions. It is an important step toward the development of a scientifically aware and responsible society.

\section{Training Adults and Children}

Global data on disasters suggest that children are more vulnerable and account for about $30-50 \%$ of deaths (Wistuba et al., 2018). They require protection from adults, but even this may change little on ground because most of the casualties occur because of lack of training, education and skills to protect one self and to be protected during a disaster (Mitchell et al., 2008; Haynes and Tanner, 2015; Amri et al., 2018). It makes it imperative for children and youth to play an active and important role in disaster risk reduction programs, and this has been recognized in the global commitment for disaster risk reduction, the Sendai Framework for Disaster Risk Reduction 2015-2030 (UNISDR 2015). This can be achieved if proper scientific and administrative framework is established to educate, train, and equip the younger generations with the skills they need to understand hazards and the associated risk, and how to fight a disaster. Children are often curious to know and learn new things and a good grooming can greatly improve their skills, which can dramatically change our perception about how young minds can actively contribute toward the reduction of disaster related casualties (Tom et al., 2008). Adults who have traditionally taken a leading role in various disaster risk reduction activities need to realize that it is time to fully prepare the younger generations to work with adults. The culture of living with disasters has to be internalized, accepted and acted upon. The adults have a special role to play in this exercise because they are experienced, and can significantly improve the standard of such activities world over.

\section{Religion and Earthquake Hazards}

There are many myths surrounding earthquake disasters. One such widely held myth is that earthquakes are evidence of God's wrath against people who have disobeyed (Marianna et al., 2016). When Sabah earthquake occurred a number of newspapers also reported similar stories. The religious and cultural view on the occurrence of natural disasters has thrived throughout the history as people wanted to know more about the unexplainable and destructive face of the Earth. Such views have consolidated around different myths because of lack of scientific explanation for the same. The logical explanation that might help is to ask people if God is testing you through disasters, how about disease or ailments? Why one has to visit a doctor to cure a disease, if that is also a test from God. The earthquake hazards demand a cure not a mythological unreasoning. This can be effectively achieved by working with religious leaders and various other community helpers to equip and train them about the science of disasters and how to live with them. It is equally important to understand that earthquakes have thrived on the planet Earth before the emergence of humans! Faults are much older than any of the known human remains or civilizations.

\section{Documentary Movies on the Major Fault Systems in South and Southeast Asia}

Field interaction with locals in Borneo clearly suggests that people are aware about the whereabouts of the San Andreas Fault, a major dextral strike-slip fault system (Forand et al., 2018) in United States but they do not know about the existence of similar fault systems in their neighborhood in South and Southeast Asia (e.g., Sunda Megathrust) (Shah et al., 2018b). This is a challenge that requires attention and an action oriented strategic planning on ground. And one of the best possible solutions will be to make scientifically realistic educational documentary movies on the major fault systems. Figure 2 shows such fault systems in South and Southeast Asia, which include the Chaman fault, the Main Himalayan/Frontal thrust, the Sagaing fault, the Sunda megathrust fault, the Sumatran fault, and the Sorong fault. Such efforts will definitely improve our relationship with the landscape, faulting, earthquakes, and how to live in harmony with earthquake hazards. This has perhaps never been as important in the historical past as it is today because of the urbanization, and population growth that has exploded post-industrial periods. Therefore, it is our duty, as responsible scientists, to train, educate and inform people that seismogenic faults are here to stay and there is no existing technique or technology to stop faults from slipping, which makes living with such hazards a reality.

\section{CONCLUSION}

This paper briefly touches on a string of topics that are important to win the centuries old battle with earthquake hazards. Such concerns demand much detailed explanation, which is beyond the scale of this work. And the biggest challenge in achieving all of the above is to build a strategy around the most useful process on how to stop hazards from becoming disasters. This is particularly important for earthquake hazards, which pose consistent threat to most of the world inhabitants who live in the vicinity of active fault systems. South and Southeast Asia is home to some of major active faults (e.g., Sunda megathrust) 
on Earth, and the possibility of major earthquakes on these fault systems is unavoidable, and therefore there is a great concern for the loss of life and property. Since earthquakes are unpredictable it means that we have to work on equipping people to be prepared for any such eventuality. One of the first steps to achieve this is to educate, train, and engage local communities that live on or near active faults. Faults have structured the brittle parts of the planet on which we live and build our homes, and remember there is no mechanism to stop fractures from becoming faults. This means we must learn how to live with faults, and that we can do so by earthquake education and awareness, and sharing of such information with family, friends, and colleagues. In the present times, most of the people use gadgets to learn and communicate. This medium can be a highly useful platform for the dissemination of earthquake science education and at a much larger scale. Another useful tool is to make documentary movies on the science of disasters. Perhaps the only talk available on YouTube on earthquakes that has attained some viewership is by Prof. Ross Stein, who is a well-known geophysicist with the United States Geological Survey in California. It can be viewed here: https://www.youtube. com/watch? $\mathrm{v}=\mathrm{Bg} 4 \mathrm{kSIgn} 67 \mathrm{I}$. The total views are $\sim 43 \mathrm{k}$ (accessed on 31st January 2019) and when it is compared with the normal viewership of songs from any famous artist it becomes evident that science is not what attracts people! However, the good news is that a number of universities are making scientific talks freely available on the net. Many scientists are also making effort to reach out to people with the most authentic information, but these efforts could be made mainstream by making serious cinema that entertains people via science. The small step (shown above) of making an earthquake documentary movie on Sabah demonstrates that it is possible and doable, but a strong workforce is needed to make science easily available to people. The documentary intends to motivate scientists to get involved with such documentary projects with a mission to reduce the propagation and consumption of adulterated scientific

\section{REFERENCES}

Akira, I. (2000). Genesis of the Mamut porphyry copper deposit, Sabah, East Malaysia. Resour. Geol. 50, 1-23. doi: 10.1111/j.1751-3928.2000.tb00052.x

Amri, A., Haynes, K., Bird, D. K., and Ronan, K. (2018). Bridging the divide between studies on disaster risk reduction education and child-centered disaster risk reduction: a critical review. Childrens Geogr. 16, 239-251. doi: 10.1080/ 14733285.2017.1358448

Balaguru, A., Nichols, G., and Hall, R. (2003). The origin of the 'circular basins' of Sabah, Malaysia. Geol. Soc. Malaysia 46, 335-351.

Balendra, T., and Li, Z. (2008). Seismic hazard of Singapore and Malaysia. Electron. J. Struct. Eng. 8, 57-63.

Barnett, M., Wagner, H., Gatling, A., Anderson, J., Houle, M., and Kafka, A. (2006). The impact of science fiction film on student understanding of science. J. Sci. Educ. Technol. 15, 179-191. doi: 10.1007/s10956-006-9001-y

Bilham, R., (2019). Himalayan Earthquakes: A Review of Historical Seismicity and Early 21st Century Slip Potential. London: Geological Society of London, 483.

Bondár, I., Stephen, C. M., Robert, E., and Eric, A. B. (2004). Epicentre accuracy based on seismic network criteria. Geophys. J. Int. 156, 483-496. doi: 10.1111/j. 1365-246X.2004.02070.x

Bondár, L., and McLaughlin, K. (2009). A new ground truth data set for seismic studies. Seismol. Res. Lett. 80, 465-472. doi: 10.1785/gssrl.80.3.465

Brumbaugh, D. S. (1999). Earthquakes: Science and Society. New Jersey: Prentice Hall. information that is routinely fed to public. The target is to reach out to the unprepared populations in Asia and elsewhere who live in earthquake hazard zones and to help them to become an earthquake resilient community.

\section{ETHICS STATEMENT}

Curtin Sarawak Ethical Committee has kindly granted the permission to conduct fieldwork in Sabah. Before the formal interviews of the subjects were recorded a prior written informed consent was signed by each participant.

\section{AUTHOR CONTRIBUTIONS}

$\mathrm{BN}$ and AS coordinated the work and planned the outline of the manuscript. BN mainly contributed in the collection of field data, figures, and writing. AS conceptualized the paper and contributed in writing of the manuscript. MP managed the field related activities, contributed in the methodology, and results sections.

\section{FUNDING}

This work was funded by the National Geographic Society, United States.

\section{ACKNOWLEDGMENTS}

The authors are very grateful to all the people who helped us in data collection in Sabah. Special thanks to Dr. Sheeba Khwaja for her work on English corrections. Financial support from the National Geographic Society is highly appreciated. Without their support fieldwork would have been impossible.

Chan, C., Wang, Y., Shi, X., Ornthammarath, T., Warnitchai, P., Kosuwan, S., et al. (2017). Toward Uniform Probabilistic Seismic Hazard Assessments For Southeast Asia. Washington, DC: American Geophysical Union.

Cottam, M. A., Hall, R., Sperber, C., Kohn, B. P., Forster, M. A., and Batt, G. E. (2013). Neogene rock uplift and erosion in northern Borneo: evidence from the Kinabalu granite, Mount Kinabalu. J. Geol. Soc. 170, 805-816. doi: 10.1144/ jgs2011-130

Cullen, A. (2010). Transverse segmentation of the Baram - Balabac Basin, NW Borneo: refining the model of Borneo's tectonic evolution. Petrol. Geosci. 16, 3-19. doi: 10.1144/1354-079309-828

Cummins, P. R. (2017). Geohazards in Indonesia: earth science for disaster risk reduction-introduction. Geol. Soc. 441, 1-7. doi: 10.1144/SP441.11

DeBoer, G. E. (2000). Scientific literacy: another look at its historical and contemporary meanings and its relationship to science education reform. J. Res. Sci. Teach. 37, 582-601. doi: 10.1002/1098-2736(200008)37:6<582::AIDTEA5>3.0.CO;2-L

Forand, D., Evans, J. P., Janecke, S. U., and Jacobs, J. (2018). Insights into fault processes and the geometry of the San Andreas fault system: analysis of core from the deep drill hole at Cajon Pass, California. Geol. Soc. Am. Bull. 130, 64-92. doi: 10.1130/B31681.1

Frank, S. (2003). Reel reality: science consultants in hollywood. Sci. Cult. 12, 427-443. doi: 10.1080/0950543032000150319

Geist, E. L., Titov, V. V., and Synolakis, C. E. (2006). Tsunami: wave of change. Sci. Am. 294, 56-63. doi: 10.1038/scientificamerican0106-56 
Halim, A. A., Jawan, J. A., Ismail, S. R., Othman, N., and Masnin, M. H. (2013). Traditional knowledge and environmental conservation among indigenous people in Ranau, Sabah. Glob. J. Hum. Soc. Sci. Geogr. Geo Sci. Environ. Disaster Manag. 13, 5-12.

Hall, R. (2002). Cenozoic geological and plate tectonic evolution of SE Asia and the SW Pacific: computer-based reconstructions, model and animations. J. Asian Earth Sci. 20, 353-431. doi: 10.1016/S1367-9120(01)00069-4

Hall, R., van Hattum, M. W., and Spakman, W. (2008). Impact of India-Asia collision on SE Asia: the record in Borneo. Tectonophysics 451, 366-389. doi: $10.1016 /$ j.tecto.2007.11.058

Haynes, K., and Tanner, T. (2015). Empowering Young People and strengthening resilience: youthcentred participatory video as a tool for climate change adaptation and disaster risk reduction. Childrens Geogr. 13, 357-371. doi: 10. 1080/14733285.2013.848599

Hesse, S., Back, S., and Franke, D. (2009). The deep-water fold-and-thrust belt offshore NW Borneo: gravity-driven versus basement-driven shortening. Geol. Soc. Am. Bull. 121, 939-953. doi: 10.1130/B26411.1

Holton, G. (1992). How to think about the 'anti-science' phenomenon. Public Underst. Sci. 1, 103-128. doi: 10.1088/0963-6625/1/1/012

Hough, S. E. (2010). Predicting the Unpredictable: The Tumultuous Science of Earthquake Prediction. Princeton, NJ: Princeton University Press, 272. doi: 10.1515/9781400883547

Hui, G., Li, S., Wang, P., Suo, Y., Wang, Q., and Somerville, I. D. (2018). Linkage between reactivation of the sinistral strike - slip faults and 28 September 2018 Mw 7.5 Palu Earthquake, Indonesia. Sci. Bull. 64, 26-35. doi: 10.1016/j.scib. 2018.11.021

Kamp, U., Growley, B. J., Khattak, G. A., and Owen, L. A. (2008). GIS-based landslide susceptibility mapping for the 2005 Kashmir earthquake region. Geomorphology 101, 631-642. doi: 10.1016/j.geomorph.2008.03.003

King, R. C., Backe, G., Morley, C. K., Hillis, R. R., and Tingay, M. R. P. (2010a). Balancing deformation in NW Borneo: quantifying plate-scale vs. gravitational tectonics in a delta and deepwater fold-thrust belt system. Mar. Petrol. Geol. 27, 238-249. doi: 10.1016/j.marpetgeo.2009.07.008

King, R. C., Hillis, R. R., Tingay, M. R. P., and Damit, A. R. (2010b). Present day stress and neotectonic provinces of the Baram Delta and deep-water fold-thrust belt. J. Geol. Soc. 166, 197-200. doi: 10.1144/0016-76492008-062R

Lam, N., Tsang, H. H., Looi, D., Lumantarna, E., and Wilson, J. (2016). "Seismic hazard modelling for Malaysia," in Proceeding of the Australian Earthquake Engineering Society 2016 Conference, Melbourne, VIC, 1-12.

Lasimbang, R. (2004). To promote the kadazandusun languages of Sabah. Austr. Bus. Deans 34, 10-12.

Liu, P. L. F., Lynett, P., Fernando, H., Jaffe, B. E., Fritz, H., Higman, B., et al. (2005). Observations by the international tsunami survey team in Sri Lanka. Science 308, 1595-1595. doi: 10.1126/science. 1110730

Loi, D. W., Raghunandan, M. E., and Swamy, V. (2018). Revisiting seismic hazard assessment for peninsular malaysia using deterministic and probabilistic approaches. Nat. Hazards Earth Syst. Sci. 18, 2387-2408. doi: 10.5194/nhess-182387-2018

Marianna, B., Francesco, D., and Roberto, G. (2016). Earthquakes, religion, and transition to self-government in Italian cities. Q. J. Econ. 131, 1875-1926. doi: 10.1093/qje/qjw020

Mathew, M. J., Menier, D., Siddiqui, N., Kumar, S. G., and Authemayou, C. (2016a). Active tectonic deformation along rejuvenated faults in tropical Borneo: inferences obtained from tectono-geomorphic evaluation. Geomorphology 267, 1-15. doi: 10.1016/j.geomorph.2016.05.016

Mathew, M. J., Menier, D., Siddiqui, N., Ramkumar, M., Santosh, M., Kumar, S., et al. (2016b). Drainage basin and topographic analysis of a tropical landscape: insights intosurface and tectonic processes in northern Borneo. J. Asian Earth Sci. 124, 14-27. doi: 10.1016/j.jseaes.2016.04.016

Menier, D., Mathew, M., Pubellier, M., Sapin, F., Delcaillau, B., Siddiqui, N., et al. (2017). Landscape response to progressive tectonic and climatic forcing in NW Borneo: implications for geological and geomorphic controls on flood hazard. Sci. Rep. 7:457. doi: 10.1038/s41598-017-00620-y

Mitchell, T., Haynes, K., Hall, N., Choong, W., and Oven, K. (2008). The roles of children and youth in communicating disaster risk. Child. Youth Environ. 18, 254-279.

Morley, C. K. (2009). Growth of folds in deep-water setting. Geopshere 5, 59-89. doi: $10.1130 /$ GES00186.1
National Science Foundation (2000). Indicators: Science and Engineering 2000. Washington, DC: National Science Foundation.

Paton, D., Bajek, R., Okada, N., and McIvor, D. (2010). Predicting community earthquake preparedness: a cross-cultural comparison of Japan and New Zealand. Nat. Hazards 54, 765-781. doi: 10.1007/s11069-010-9500-2

Sandal, S. T. (1996). The Geology and Hydrocarbon Resources of Negara Brunei Darussalam. Petaling: Syabas.

Sapin, F., Hermawan, I., Pubellier, M., Vigny, C., and Ringenbach, J. C. (2013). The recent convergence on the NW Borneo Wedge-a crustal-scale gravity gliding evidenced from GPS. Geophys. J. Int. 2, 549-556. doi: 10.1093/gji/ggt054

Sapin, F., Pubellier, M., Lahfid, A., Janots, D., Aubourg, C., and Ringenbach, J. C. (2011). Onshore record of the subduction of a crustal salient: example of the NW Borneo Wedge. Terra Nova 23, 232-240. doi: 10.1111/j.1365-3121.2011. 01004.x

Sassa, S., and Takagawa, T. (2018). Liquefied gravity flow - induced tsunami: first evidence and comparison from the 2018 Indonesia Sulawesi earthquake and tsunami disasters. Landslides 16, 195-200. doi: 10.1007/s10346-018-1114-x

Shah, A. A. (2013). Megathrust earthquakes and the associated volcanic subsidence. Curr. Sci. 105, 567-567.

Shah, A. A. (2014). "Book review," in Predicting the Unpredictable: The Tumultuous Science of Earthquake Prediction, Vol. 18, ed. S. Hough (Princeton, NJ: Princeton University Press), 373-374.

Shah, A. A. (2015). Understanding the recent Sabah Earthquake, and other seismogenic sources in North West Borneo. Sci. Malaysia 11, 7-10.

Shah, A. A., and Malik, J. N. (2017). Four major unknown active faults identified, using satellite data, in India and Pakistan portions of NW Himalaya. Nat. Hazards 88, 1845-1865. doi: 10.1007/s11069-017-2949-5

Shah, A. A., Khwaja, S., Shah, B. A., Reduan, Q., and Jawi, Z. (2018a). Living with earthquake and flood hazards in Jammu and Kashmir, NW Himalaya. Front. Earth Sci. 6, 179. doi: 10.3389/feart.2018.00179

Shah, A. A., Qadri, T., and Khwaja, S. (2018b). Living with earthquake hazards in South and Southeast Asia. ASEAN J. Commun. Engag. 2, 15-37. doi: 10.7454/ ajce.v2i1.105

Shah, A. A., Zhafri, M. N., Delson, J., and Navakanesh, B. (2018c). Major strikeslip faults identified using satellite data in central Borneo, SE Asia. Geosciences 8:156. doi: $10.3390 /$ geosciences 8050156

Shearer, P., and Bürgmann, R. (2010). Lessons learned from the 2004 SumatraAndaman megathrust rupture. Annu. Rev. Earth Planet. Sci. 38, 103-131. doi: 10.1146/annurev-earth-040809-152537

Sieh, K. (2007). The Sunda megathrust-past, present and future. J. Earthquake Tsunami 1, 1-19. doi: 10.1142/S179343110700002X

Tom, M., Haynes, K., Hall, N., Choong, W., and Oven, K. (2008). The roles of children and youth in communicating disaster risk. Children Youth Environ. 18, 254-279. doi: 10.1007/s11920-018-0942-7

Tongkul, F. (2017). Active tectonics in Sabah - seismicity and active faults. Bull. Geol. Soc. Malaysia 64, 27-36. doi: 10.7186/bgsm64201703

van der Ent, A., and Edraki, M. (2018). Environmental geochemistry of the abandoned Mamut Copper Mine (Sabah) Malaysia. Environ. Geochem. Health 40, 189-207. doi: 10.1007/s10653-016-9892-3

Wang, Y., Wei, S., Wang, X., Lindsey, E. O., Tongkul, F., Tapponnier, P., et al. (2017). The $2015 \mathrm{M}$ w $6.0 \mathrm{Mt}$. Kinabalu earthquake: an infrequent fault rupture within the Crocker fault system of East Malaysia. Geosci. Lett. 4:6. doi: 10.1186/ s40562-017-0072-9

Wistuba, M., Malik, I., Krzemień, K., Gorczyca, E., Sobucki, M., WrońskaWałach, D., et al. (2018). Can low-magnitude earthquakes act as a triggering factor for landslide activity? Examples from the Western Carpathian Mts, Poland. CATENA 171, 359-375. doi: 10.1016/j.catena.2018.07.028

Conflict of Interest Statement: The authors declare that the research was conducted in the absence of any commercial or financial relationships that could be construed as a potential conflict of interest.

Copyright (c) 2019 Navakanesh, Shah and Prasanna. This is an open-access article distributed under the terms of the Creative Commons Attribution License (CC BY). The use, distribution or reproduction in other forums is permitted, provided the original author(s) and the copyright owner(s) are credited and that the original publication in this journal is cited, in accordance with accepted academic practice. No use, distribution or reproduction is permitted which does not comply with these terms. 


\section{OPEN ACCESS}

Edited by:

Jonathan D. Paul,

Imperial College London,

United Kingdom

Reviewed by:

Wouter Buytaert,

Imperial College London,

United Kingdom

Tim van Emmerik,

Delft University of Technology,

Netherlands

Jon Olav Skøien

European Commission - Joint

Research Center, Belgium

${ }^{*}$ Correspondence:

Jan Seibert

jan.seiber@ggeo.uzh.ch

Specialty section:

This article was submitted to Hydrosphere,

a section of the journal

Frontiers in Earth Science

Received: 07 September 2018

Accepted: 19 March 2019

Published: 12 April 2019

Citation:

Seibert J, Strob/ B, Etter S, Hummer $P$ and van Meerveld $H J$

(2019) Virtual Staff Gauges

for Crowd-Based Stream Level

Observations. Front. Earth Sci. 7:70.

doi: 10.3389/feart.2019.00070

\section{Virtual Staff Gauges for Crowd-Based Stream Level Observations}

\author{
Jan Seibert ${ }^{1,2 *}$, Barbara Strobl' ${ }^{1}$, Simon Etter ${ }^{1}$, Philipp Hummer ${ }^{3}$ and \\ H. J. (Ilja) van Meerveld ${ }^{1}$
}

'Department of Geography, University of Zurich, Zurich, Switzerland, ${ }^{2}$ Department of Aquatic Sciences and Assessment, Swedish University of Agricultural Sciences, Uppsala, Sweden, ${ }^{3}$ SPOTTERON GmbH, Vienna, Austria

Hydrological observations are crucial for decision making for a wide range of water resource challenges. Citizen science is a potentially useful approach to complement existing observation networks to obtain this data. Previous projects, such as CrowdHydrology, have demonstrated that it is possible to engage the public in contributing hydrological observations. However, hydrological citizen science projects related to streamflow have, so far, been based on the use of different kinds of instruments or installations; in the case of stream level observations, this is usually a staff gauge. While it may be relatively easy to install a staff gauge at a few river sites, the need for a physical installation makes it difficult to scale this type of citizen science approach to a larger number of sites because these gauges cannot be installed everywhere or by everyone. Here, we present a smartphone app that allows collection of stream level information at any place without any physical installation as an alternative approach. The approach is similar to geocaching, with the difference that instead of finding treasurehunting sites, hydrological measurement sites can be generated by anyone and at any location and these sites can be found by the initiator or other citizen scientists to add another observation at another time. The app is based on a virtual staff gauge approach, where a picture of a staff gauge is digitally inserted into a photo of a stream bank or a bridge pillar, and the stream level during a subsequent field visit to that site is compared to the staff gauge on the first picture. The first experiences with the use of the app by citizen scientists were largely encouraging but also highlight a few challenges and possible improvements.

\section{Keywords: citizen science, smartphone app, water level class, crowdsourcing, data collection}

\section{INTRODUCTION}

Data on the quantity and quality of water are needed for appropriate water management decisions. However, hydrology and water resources management are frequently restricted by limited data availability, particularly in data-scarce regions with urgent water management issues (Mulligan, 2013). The decline of national hydrological and meteorological observation networks (Vörösmarty et al., 2001; Fekete et al., 2012; Ruhi et al., 2018) is frustrating, especially in light of the current local and global water-related challenges, and those ahead, such as adaptation to extreme events 
and securing water resources for a growing population. Although new observation techniques, including remote sensing, geophysical methods, and wireless sensor networks, provide exciting opportunities for new data collection, central hydrological variables, such as soil moisture or streamflow remain difficult to observe with a sufficient spatiotemporal resolution. Therefore, crowd-based data collection might be a valuable complementary approach to collect data and overcome data limitations (Buytaert et al., 2014).

The idea to include the public in hydrological and meteorological data collection is by no means new. The Swedish meteorologist Tor Bergeron asked the public through appeals over radio and phone calls to measure snow depth (Bergeron, 1949) and rainfall (Bergeron, 1960) and to mail their observations on postcards. This resulted in much more detailed maps than would have been possible with official station data alone. It allowed the creation of a snow depth map for an area of one degree square covering Uppland, Sweden based on 98 observations by volunteers rather than data from only 12 official stations (Bergeron, 1949). For the rainfall observations, Bergeron and his co-workers developed the Pluvius rain gauge as an inexpensive alternative to existing, official gauges. While later there were $\sim 800$ of these gauges in other parts in Sweden, for the initial surveys during 1953 about 150 gauges were distributed in a $\sim 30 \mathrm{~km}$ by $\sim 30 \mathrm{~km}$ area around Uppsala, Sweden (Bergeron, 1960). Both of these projects led to a better understanding of the influence of topography and vegetation on precipitation formation. Even though these early studies were very successful, similar approaches remained rare due to the logistical challenge to transmit and enter the collected data in a common database. However, recent developments in information and communication technology provide exciting new opportunities for citizen-science based approaches using text messages (Lowry and Fienen, 2013; Weeser et al., 2018), websites (e.g., Stream Tracker ${ }^{1}$ ), apps (e.g., Teacher et al., 2013; Davids et al., 2018; Kampf et al., 2018; Photrack ${ }^{2}$ ), data mining (Smith et al., 2015; Li et al., 2018) or custom-designed wearable sensors (e.g., Hut et al., 2016; smartfin ${ }^{3}$ ). However, as stated by Jerad Bales, the Chief scientist for hydrology at the U.S. Geological Survey, "Crowdsourcing water-information is in its infancy [...], and there remain major issues of data quality and sustainability (Lowry and Fienen, 2013). Nevertheless, the use of crowdsourcing to report routine water data, as well as information on floods and droughts, needs to be creatively explored" (Bales, 2014).

With a large number of contributions from citizens, the CrowdHydrology project ${ }^{4}$ (Lowry and Fienen, 2013) has (and still does) successfully demonstrated that it is possible to engage the public in hydrological measurements by asking them to submit stream level observations via text messages. A similar system was implemented in Cithyd ${ }^{5}$. However, these approaches using staff gauges (scaled measurement sticks in the water) restrict the

\footnotetext{
${ }^{1}$ http://www.streamtracker.org

${ }^{2}$ http://www.photrack.ch/mobile.html

${ }^{3}$ https://smartfin.org/

${ }^{4}$ http://www.crowdhydrology.com

${ }^{5}$ http://www.cithyd.com/it/
}

number of places where stream levels can be observed because staff gauges cannot be installed everywhere and by everyone. In mountainous streams, a stable installation is challenging even for hydrologists, and often permits are required before a staff gauge can be installed. Furthermore, if a physical installation is possible, one might consider installing a stream level logger instead of a staff gauge as these loggers have become less expensive and more reliable in recent years. Instead, we propose an approach where anyone can start a measurement location and the observations can be taken anywhere and by anyone. Our approach is similar to geocaching ${ }^{6}$, with the difference that instead of treasure hunting sites, stream level observation sites are established and can be revisited by other citizen scientists. In this paper, we describe the virtual staff gauge approach, highlight several design considerations, and discuss whether people understand the concept. In another study (Strobl et al., 2019), we found that most people can classify the water level correctly by comparing it to a reference picture with a virtual staff gauge. Here the focus was on how well people are able to "install" a virtual staff gauge in the app, i.e., taking the reference picture and placing the staff gauge in this picture.

\section{VIRTUAL STAFF GAUGE}

\section{General Approach}

The advantage of the virtual staff gauge approach is that it avoids physical installations and makes the setup of new observation sites fast and easy. The basic idea behind our approach for stream level observations is that it is usually possible to identify a number of features in a stream or on the streambank, such as rocks, that allow ranking of the stream levels (i.e., "below this tree but above that rock"). While such stream level class observations are not as precise as continuous stream level observations from a staff gauge (i.e., no millimeter resolution) and provide more qualitative information such as "the water level is very low" or "there is a flood event," they can be quite informative for hydrological modeling (van Meerveld et al., 2017). The challenge is to allow easy identification of the different stream level classes, without the need for lengthy verbal descriptions. A picture is helpful in this respect but needs to be amended by a scale. For this, we use the virtual staff gauge approach (see also Figure 1):

- The user chooses a suitable site along a stream and identifies the location on a map in the smartphone app.

- The user takes a picture of the streambank (perpendicular to the flow direction and as level as possible, to minimize contortion of the view). There should be some reference in the picture, such as a bridge or stones and ideally, the picture is taken during low flow conditions.

- An image of a yardstick with a number of classes is digitally inserted into the picture as a virtual staff gauge. The user can move the inserted staff gauge in the image and scale it so that it covers the expected stream level variations.

\footnotetext{
${ }^{6}$ https://www.geocaching.com/
} 

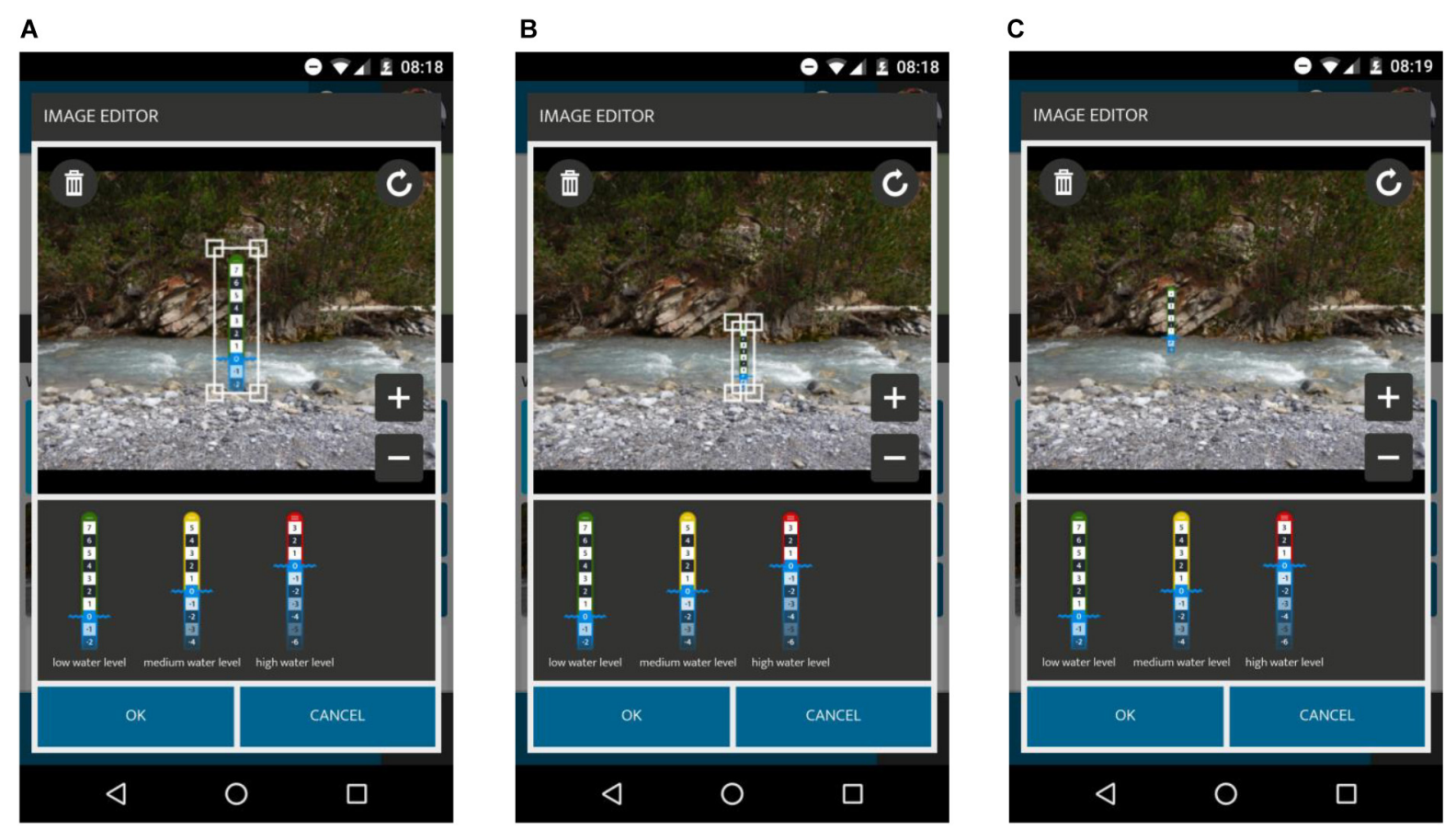

FIGURE 1 | Series of screenshots showing the insertion of the virtual staff gauge in the reference picture: $(\mathbf{A})$ insert the image of the staff gauge in the reference picture, (B) scale the inserted image, and (C) move the image so that the blue line matches the stream level in the picture.

\section{ORIGINAL IMAGE}

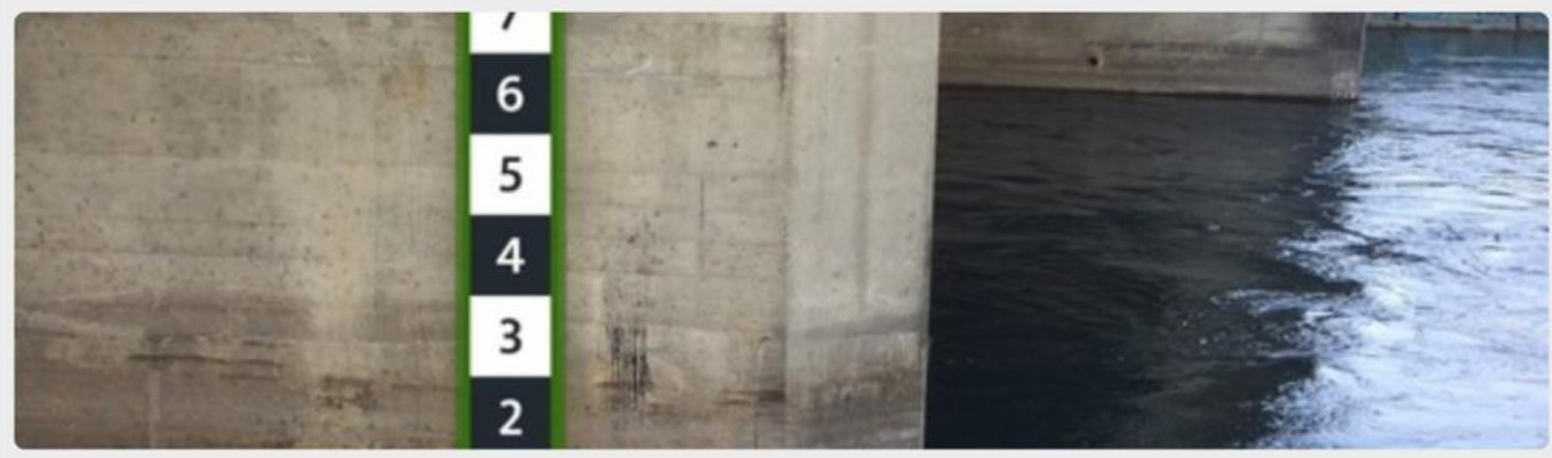

\section{HOW HAS THE WATER LEVEL CHANGED?}

Enter the new water level on the staff gauge:

$\begin{array}{llllllllllllllll}-6 & -5 & -4 & -3 & -2 & -1 & 0 & +1 & +2 & +3 & +4 & +5 & +6 & +7\end{array}$

FIGURE 2 | The horizontal version of the staff gauge at the "Update Spot" interface as selectable buttons to report the new water level class observation. Design/author: Philipp Hummer, SPOTTERON Citizen Science, www.spotteron.net.

This reference picture with the virtual staff gauge allows anyone who visits the site at a later time to estimate the stream level class by relating the current stream level to the features on the photo and the virtual staff gauge (e.g., the stream level has changed and is now above a certain rock). For this update, a simplified horizontal staff gauge design is used in the "Update 

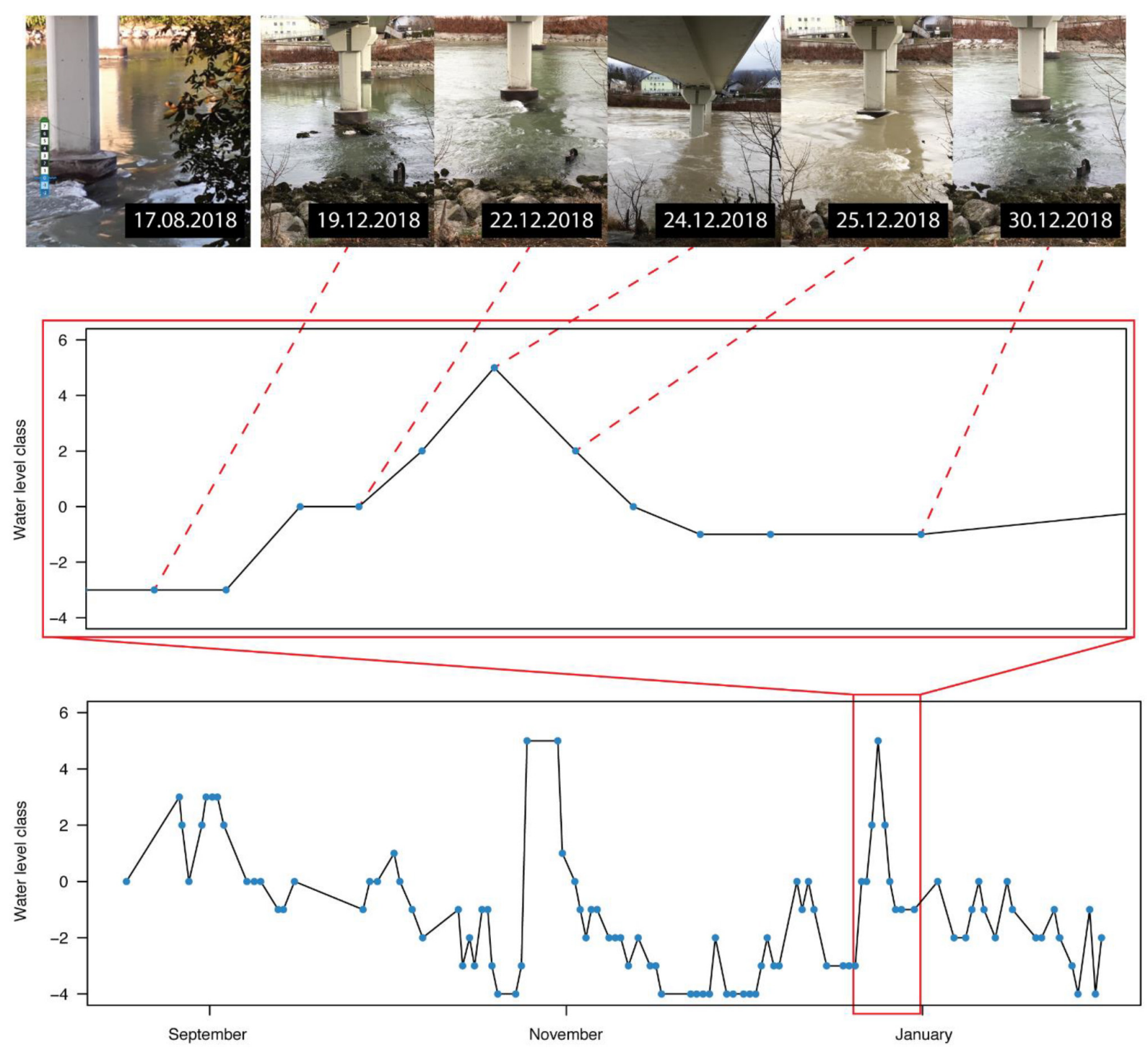

FIGURE 3 | Example of a water level time series obtained using the CrowdWater app (River Salzach, Austria). The pictures for one runoff event (and the reference picture) are shown as an example in the top row.

Spot" interface of the app (Figure 2) that shows the full range of class bars for input. To update a spot and provide a new observation of the stream level, the user compares the current stream level with the reference picture with the staff gauge in the app, takes a new picture of the stream, clicks on the current stream level class on the horizontal staff gauge and submits the new observation to the data servers. Over time, this results in a time series of water level observations (Figure 3). It is important to note, that the user observes and enters the water level; the new picture is only used for documentation. While automated image recognition could be valuable, at this point we rather rely on human eyes and interpretation and avoid issues such as the exact location and angle when the picture is taken. The pictures, however, allow data quality control. We have recently developed the CrowdWater game as an approach to use these pictures for crowdbased quality control of the water level class data (see "Game").

\section{Design Considerations and Initial Tests}

Several decisions on the design of the virtual staff gauge had to be taken before implementation in the smartphone app. Early on it was decided to use relative stream level classes instead of numeric values in, for instance, centimeters, as there is an obvious limitation in the resolution of streamlevel observations that can be achieved with a virtual staff gauge. Translating the virtual staff gauge levels to absolute levels would also make the "virtual installation" much more time consuming as it would require observations of different heights.

${ }^{7}$ https://www.crowdwater.ch 


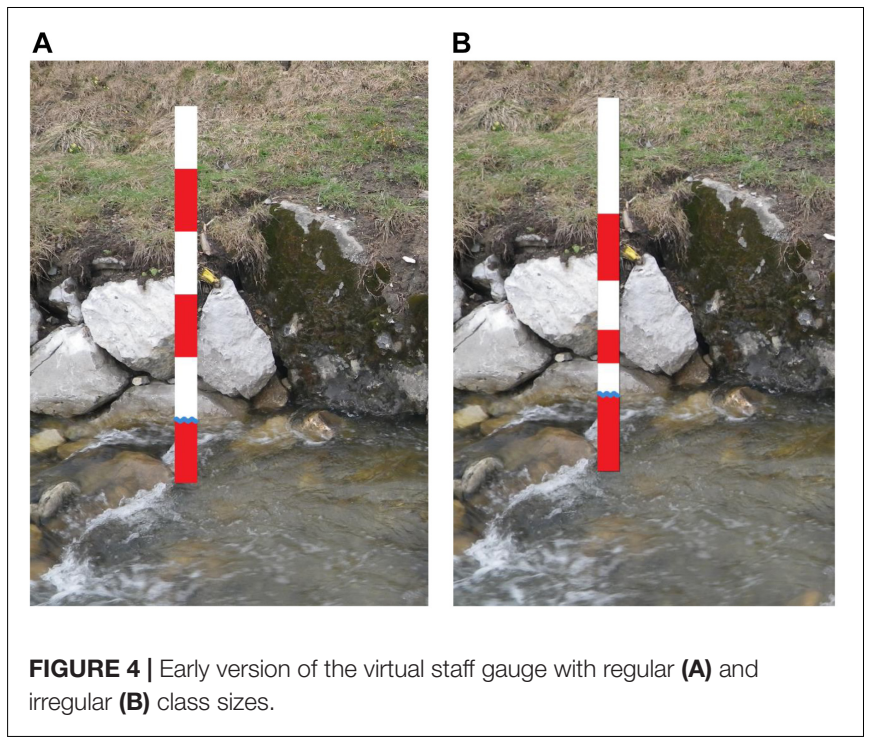

Absolute levels would also be site-specific, i.e., the offset would vary largely from place to place. Fortunately, absolute levels are not needed for the potential use in hydrological modeling because the relative values provide important information on the timing of streamflow responses (Seibert and Vis, 2016; van Meerveld et al., 2017).

In an early test with university students, two different types of staff gauges were tested. In addition to regular class sizes (as ultimately implemented in the app), we also tested irregular class sizes (Figure 4), but this idea was discarded because some users found it confusing and because it did not allow for as much flexibility as we had hoped.

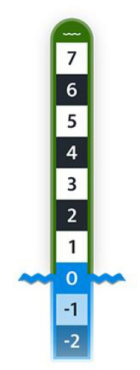

low water level

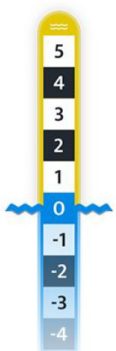

medium water level

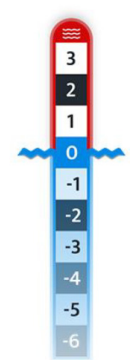

high water level
FIGURE 6 | The three staff gauges available in the app. Their ideal application depends on the flow condition of the river at the time that the reference picture is taken. Design/author: Philipp Hummer, SPOTTERON Citizen Science, www.spotteron.net.

Once we had decided to have a non-metric virtual staff gauge with regular class sizes, we started to discuss the implementation with SPOTTERON, which is the app company hired to develop the CrowdWater app. During these discussions, the focus was largely on how to make the app intuitive to use. A clearly visible blue wave on the virtual staff gauge was chosen to indicate the stream level at the time that the reference picture was taken (Figure 5). During placement, the citizen scientists will highlight the stream level in the photo with the water line in the staff gauge (Figure 1). We decided to use ten classes on the virtual staff gauge; this was a compromise between simplicity, resolution, and usability. Through the use of a negative and positive scale, we tried to make the image even more intuitive, as a negative value
A

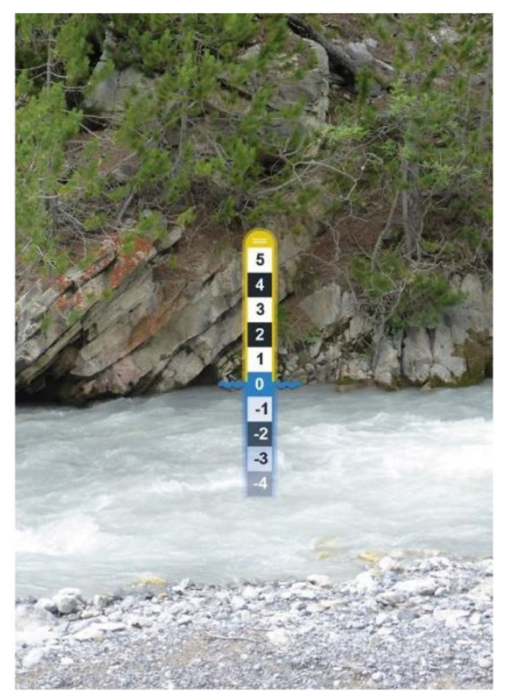

B

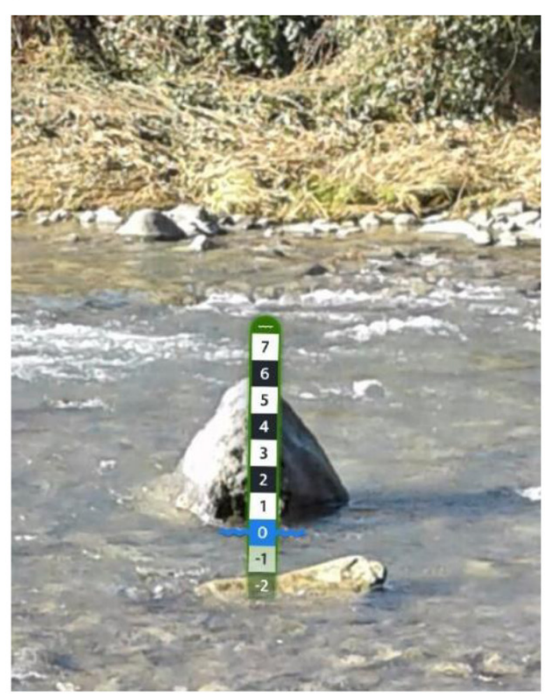

C

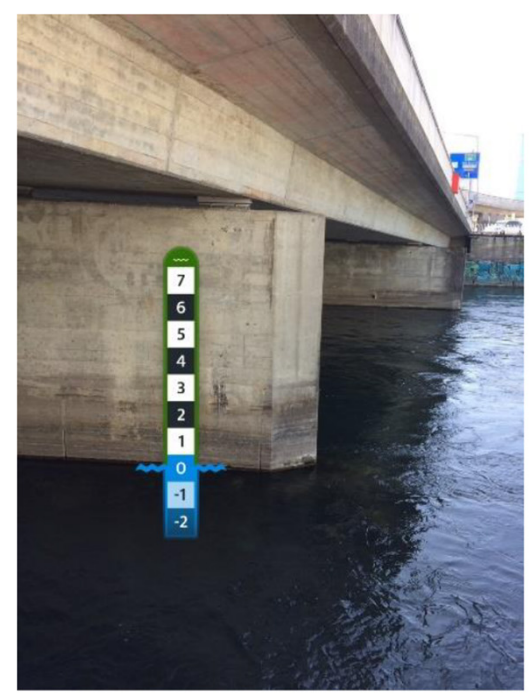

FIGURE 5 | Examples of well-placed virtual staff gauges on (A) the opposite stream bank, (B) a rock in the stream, and (C) a bridge pillar, showing the blue wave at the stream level when the site was established and the positive and negative scale above and below the current stream level, respectively. 


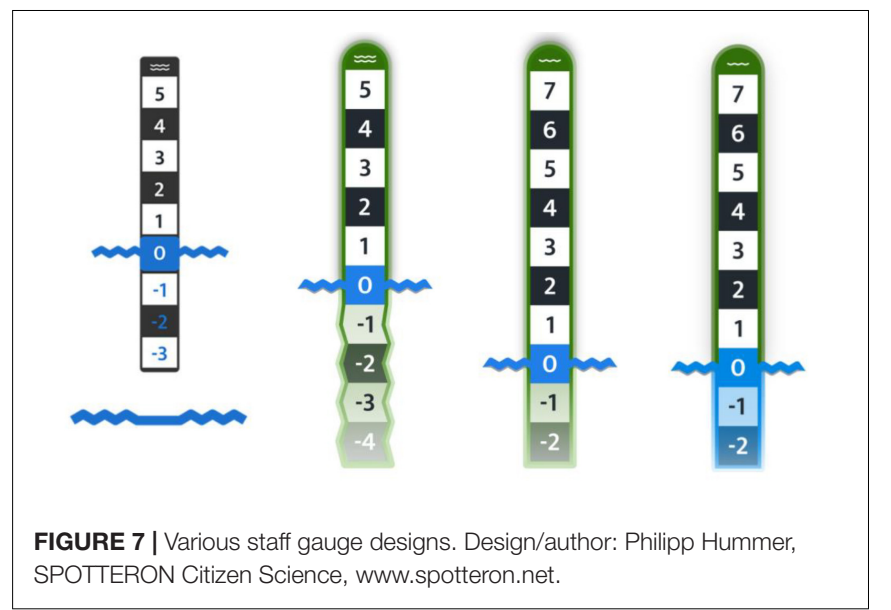

would indicate a stream level below the level in the reference picture and a positive value above it (Figure 6). The stream level numbers and class bars follow a neutral black/white scheme to utilize contrast between the sections but also maintain secondary visual weight.

We recommend that citizen scientists initiate a new measurement site during low flow conditions because the reference points are better visible during low flow conditions and this enables future users to better assess the situation for an update. However, this might be a strong restriction in practice and we, therefore, decided to allow insertion of virtual staff gauges also in photos taken during situations with high stream levels. To use suitable staff gauges for all flow conditions, we decided to offer three different staff gauges to the user (Figure 6). The green staff gauge is best suited for rivers with a low water level at the time that the reference picture is taken, as it still has many positive classes (i.e., above the blue wave) to record stream levels for higher flow conditions. The yellow staff gauge is well suited for when the reference picture is taken at average flow conditions, and the red staff gauge is ideal for high flow conditions. The red, yellow and green staff gauges were chosen because strong, vibrant colors visually communicate not only a difference but also a development over time, e.g., traffic lights signal different states of movement.

\section{Virtual Staff Gauge Implementation}

The virtual staff gauge was implemented as a so-called "sticker". Stickers are a common practice in app design; they use image- or vector-based content as overlays in photos that are taken on a smartphone. They are mainly used in messenger tools, such as WhatsApp or Facebook Messenger to add additional information or emotions to images. Positioning and transformation are usually done by multitouch gestures for scaling, placement, and rotation. In this case the sticker has to be moved so that the staff gauge is aligned with the streambank or bridge pillar and the blue line is located at the water level (Figure 1). By adopting such a rather well-known input method, the use of the app is more intuitive and, thus, optimizes usability. Obviously, using an established technique also had technical advantages for the implementation.

In practice, the placement of the staff gauge can happen on bright or dark, blurry or clear, high- or low-saturation pictures, taken by the users on all kinds of smartphone models and cameras. Therefore, various designs for the virtual staff gauges were tested on different backdrop images and directly on smartphone screens (Figures 7,8 ). To ensure that the staff gauge is visible in various conditions, we used additional soft shadows to enhance the edge contrast, but still let the staff gauge immerse itself into the picture as part of the scenery. We furthermore decided to strengthen the visual representation of the areas above and below the stream level by using a blue hue for all class bars below the water level and making them slightly transparent (Figures 6-8).

\section{TEST OF THE APP IN PRACTICE}

\section{CrowdWater App}

The virtual staff gauge was implemented in the CrowdWater smartphone app. The app was first launched for iOS and

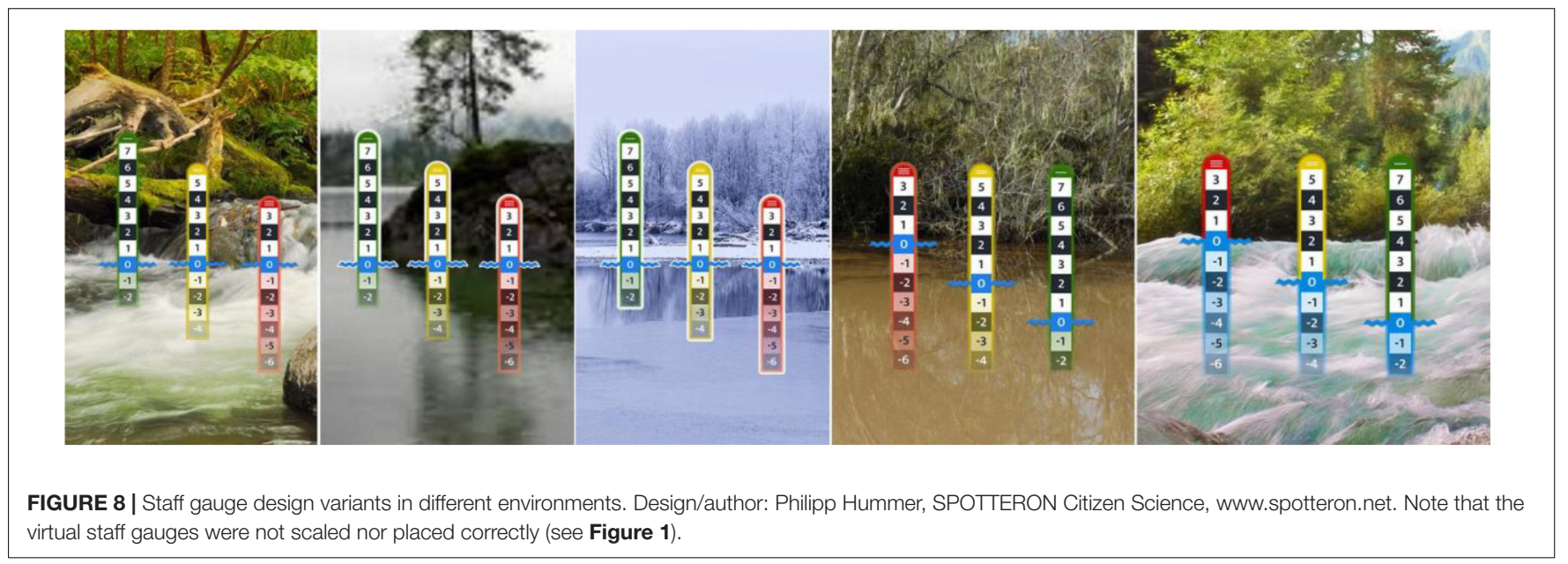




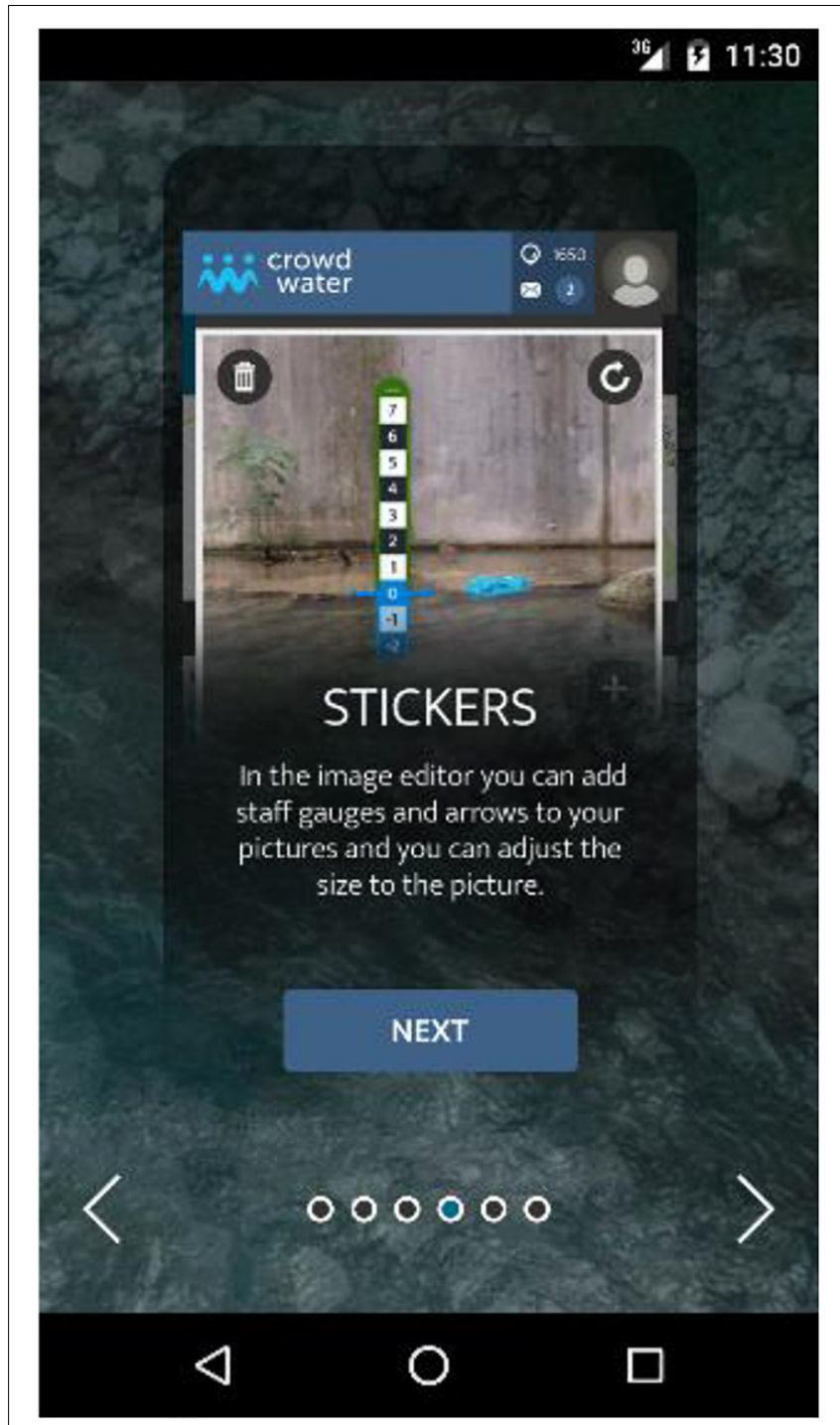

FIGURE 9 | Screenshot of an intro slide that appears when the app is opened for the first time. These can be re-watched anytime. The goal is to quickly provide the most important information on the basic functionalities of the app.

Android in March 2017; there have been several updates of the app since its initial launch. The app was promoted on the CrowdWater homepage (see Footnote 7), through Facebook, Twitter, Instagram, LinkedIn, and ResearchGate posts, as well as on the CrowdWater YouTube channel and at several conferences.

When starting the app, the user has to browse through a number of intro-slides that explain the basic functionalities and the interface of the app. Among them is the sticker function of the virtual staff gauge (Figure 9). Additional guidance on how to use the app in the form of texts, pictures and videos are provided on the project homepage and in an explanatory YouTube video ${ }^{8}$.

\footnotetext{
${ }^{8}$ https://www.youtube.com/watch?v=3ag4sHWf0yg
}

TABLE 1 | Collection of errors made by app-users grouped into broader error categories and frequency of occurrence.

\begin{tabular}{|c|c|c|}
\hline Error type & & $\begin{array}{c}\text { Frequency of } \\
\text { occurrence }\end{array}$ \\
\hline \multirow{2}{*}{$\begin{array}{l}\text { Staff gauge size } \\
\text { problem }\end{array}$} & Staff gauge too big & +++ \\
\hline & Staff gauge too small & + \\
\hline \multirow{2}{*}{$\begin{array}{l}\text { Staff gauge placement } \\
\text { problem }\end{array}$} & Wrong angle & +++ \\
\hline & Staff gauge not on the water surface & +++ \\
\hline \multirow[t]{10}{*}{ Unsuitable location } & $\begin{array}{l}\text { Lack of reference structure for stream } \\
\text { level identification }\end{array}$ & ++ \\
\hline & Structure hidden by vegetation or snow & + \\
\hline & Unclear which structure to use & + \\
\hline & River bank too far away & ++ \\
\hline & Poor image quality & + \\
\hline & Site not easily accessible & . \\
\hline & $\begin{array}{l}\text { No suitable site for staff gauge } \\
\text { placement available }\end{array}$ & . \\
\hline & Changes in the rating curve & + \\
\hline & $\begin{array}{l}\text { Multiple measurement sites at (almost) } \\
\text { the same location }\end{array}$ & + \\
\hline & $\begin{array}{l}\text { Testing (e.g., beer glasses, not a river, } \\
\text { out of a train, etc.) }\end{array}$ & ++ \\
\hline
\end{tabular}

+++ : occasional $=$ more than 10 times; ++ : seldom $=5-10$ times; + : rare: less than 5 times; . : not quantifiable.

\section{Typical Mistakes}

While users seem to understand the approach used in the CrowdWater app in general, there were also a number of recurrent mistakes related to the staff gauge placement or size. These mistakes affect about $10 \%$ of the more than 500 reference pictures (Table 1). Staff gauge placement or size problems could be due to users not having read the available instruction material or not fully understanding the concept. Some other issues are not directly related to setting up a virtual staff gauge site but still affect the results, e.g., it is less useful if users create new measurement sites in, or close to, a location where another spot already exists than when they update the existing spot or start a new site on a different river.

\section{Staff Gauge Placement Problem}

The most common mistake was related to the placement of the virtual staff gauge. Some users took pictures in the direction of the flow (instead of perpendicular to the flow, see example in Figure 10). This makes it almost impossible to place a virtual staff gauge that allows subsequent level observations because clear reference features are usually missing on these pictures. Another placement related issue occurs when the blue wave of the staff gauge is not located at the water surface in the reference picture. This means that the stream level of the reference picture is not at zero, which could lead to confusion for other users when updating the spot later on.

\section{Staff Gauge Size Problems}

In a number of cases, the size of the staff gauge was suboptimal. This may be either because people do not realize that they 
A

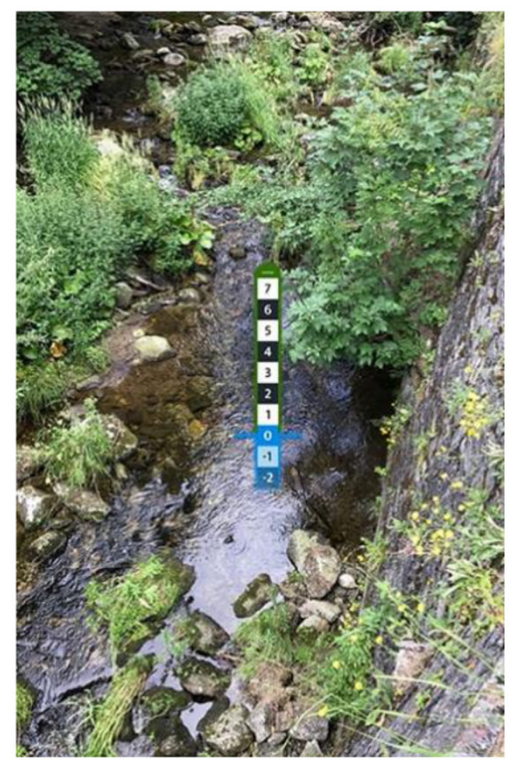

B

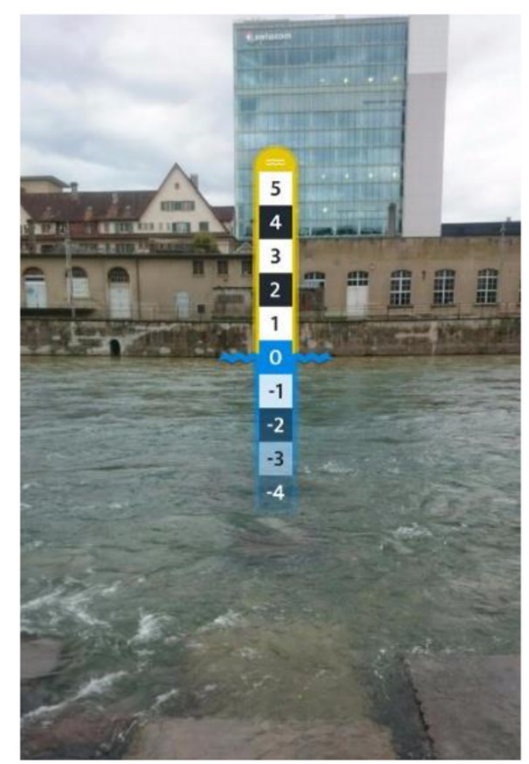

C

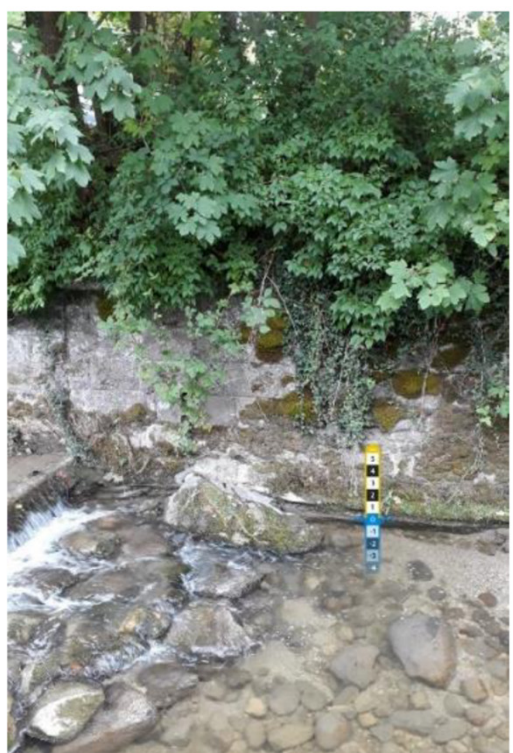

FIGURE 10 | Examples of misplaced virtual staff gauges: (A) The picture was taken in the upstream direction instead of perpendicular to the flow direction, which makes it impossible to estimate subsequent stream level changes, (B) The virtual staff gauge is so large that it is unlikely that the water level will reach different classes and is therefore improbable to obtain an approximate representation of the stream hydrograph, (C) The small virtual staff gauge can show small changes in the stream level, but cannot represent very high flows as anything above a medium flow falls into the highest class.

can resize the size of the staff gauge or do not understand why it is useful to rescale the staff gauge. The perfect staff gauge size is however, somewhat subjective and might to some degree depend on the specific research question and data needs for a site.

In our instruction material, we show the optimal case where the highest class of the staff gauge reaches up to the level of the highest in-bank flow. This may, however, be hard to imagine for citizen scientists and is probably also not considered when users place their first virtual staff gauge. Staff gauges that are too large are not only unrealistic (i.e., the stream level is very unlikely to rise into the highest classes) but this also reduces the variation in future observations because it is less likely that a change in stream level is large enough to reach the next class. There were also a few cases where the staff gauge was too small. A small staff gauge can make it hard to determine the class of the current stream level because the differences between the classes are too small. It also makes it hard to document very high or very low flows. Furthermore, finding the location of the measurement site can be challenging when users take a very detailed (zoomed-in) picture of the reference structure. This issue was more common for small staff gauges and could probably be solved by implementing an option to add an overview photo that shows the general location of the reference structure.

\section{Unsuitable Location}

An obvious problem are pictures that lack references for level identification or pictures where a staff gauge was not inserted in the picture. Optimal conditions to place a virtual staff gauge, such as a vertical wall on the opposite river bank or a vertical structure like a rock or bridge pillar in the river, are sometimes hard to find. At least in some cases, the reason for problematic pictures could also be that the rivers were not easily accessible or had no suitable reference features but people still wanted to take a picture to establish a measurement site. Another problem is that in some locations the vegetation growth obscures features on the river bank that were visible when the reference picture was taken (e.g., in winter when there was no vegetation). This makes it nearly impossible to compare stream levels properly. Reference pictures with snow can also make it difficult to assess the stream level later on.

On wide rivers, it is difficult to place a reasonably sized staff gauge at the opposite river bank and still observe changes in stream levels. Furthermore, in these cases, the quality of the pictures is often low due to zooming. This problem can be solved at locations with an instream structure (such as a bridge pillar) and placing the staff gauge along a pillar.

Changes due to erosion or sedimentation are another issue. In these cases stream levels are not a reliable indicator of streamflow. Our dataset contains one site where the riverbed changed quite drastically due to deposited sediment. Because the reference structure (a concrete wall next to a bridge) stayed in place, approximately the same flow meant a different stream level class compared to the situation in the reference picture taken before the sediment was deposited. The solution 
to this problem would be to archive the reference picture and create a new one.

\section{CONCLUDING REMARKS}

In this paper, we presented a new citizen science approach based on virtual staff gauges that allow crowd-based stream level observations along any stream. The advantage of this approach is that no physical installations are needed, which makes the approach fully scalable, as it is easy and quick for anyone to set up a new measurement site or contribute an observation to an existing site. As discussed in this paper, during development and testing of the virtual staff gauge approach, we identified several issues that required modifications in the original design. Further app developments and better guidance for app users on how to set up a virtual staff gauge site will reduce the number of incorrect sites in the future. Despite these challenges, the first experiences from using the virtual staff gauge approach are encouraging and show that this approach can be useful to collect stream level data at many locations by citizen scientists.

In the first year since launching the smartphone app, numerous measurement sites have been set up. On 3. September 2018, 2431 observations had been submitted by 218 users. For 79 of the 675 sites, more than five updates on the stream level class had been submitted. The collected data have a limited resolution due to the use of stream level classes and are sometimes spotty in time. However, previous work using synthetic data indicates that such data are still informative to constrain hydrological models. Time series of precipitation and temperature are more likely to be available than those of streamflow. The observed stream level class data can, thus, be used in combination with these time series to generate modeled streamflow time series. The potential value of such data has been evaluated based on subsets of existing data. These studies have indicated the value of water level class data for model calibration (van Meerveld et al., 2017);

\section{REFERENCES}

Bales, J. D. (2014). Progress in data collection and dissemination in water resources - 1974-2014. Water Resour. Impact 16, 18-23.

Bergeron, T. (1949). The problem of artificial control of rainfall on the globe. Part II: the coastal orographic maxima of precipitation in autumn and winter. Tellus 1, 15-32. doi: 10.1111/j.2153-3490.1949.tb0 1264.x

Bergeron, T. (1960). Operation and Results of "Project Pluvius". Washington, DC: American Geophysical Union, 152-157. doi: 10.1029/GM005p0152

Buytaert, W., Zulkafli, Z., Grainger, S., Acosta, L., Alemie, T. C., Bastiaensen, J., et al. (2014). Citizen science in hydrology and water resources: opportunities for knowledge generation, ecosystem service management, and sustainable development. Front. Earth Sci. 2:26. doi: 10.3389/feart.2014. 00026

Davids, J. C., Rutten, M. M., Shah, R. D. T., Shah, D. N., Devkota, N., Izeboud, P., et al. (2018). Quantifying the connections-linkages between land-use and water in the Kathmandu Valley. Nepal. Environ. Monit. Assess. 190:17. doi: 10.1007/s10661-018-6687-2

Etter, S., Strobl, B., Seibert, J., and van Meerveld, I. (2018). Value of uncertain streamflow observations for hydrological modelling. Hydrol. Earth Syst. Sci. 22, 5243-5257. doi: 10.5194/hess-2018-355 uncertain streamflow estimates were less informative (Etter et al., 2018). The water level data collected in the CrowdWater project are publicly available, and we expect them also to be used for other uses, be it for research, flood protection or leisure activities.

While our current focus is on measurement sites in Switzerland, the app can be, and is already, used worldwide. For developing and evaluating the value of the data obtained with the virtual staff gauge approach countries with a relative wealth of stream data, such as Switzerland, are favorable, but we anticipate that, once developed and tested, the approach will be most beneficial in regions where data are scarce.

\section{AUTHOR CONTRIBUTIONS}

JS and HvM developed the first idea of the virtual staff gauge while hiking along a Swiss creek. BS and SE were responsible for the tests and the evaluation of the user experience of the app and contributed by specifying the requirements for the app, which were then discussed among all authors and further developed with $\mathrm{PH}$. PH was responsible for most of the graphical design and the implementation of the smartphone app. JS wrote the manuscript with input from all authors.

\section{FUNDING}

The CrowdWater project is funded by the Swiss National Science Foundation (Project Number 163008).

\section{ACKNOWLEDGMENTS}

We thank all participants of the CrowdWater project for contributing their observations.

Fekete, B. M., Looser, U., Pietroniro, A., and Robarts, R. D. (2012). Rationale for monitoring discharge on the ground. J. Hydrometeorol. 13, 1977-1986. doi: 10.1175/JHM-D-11-0126.1

Hut, R., Tyler, S., and Van Emmerik, T. (2016). Proof of concept: temperaturesensing waders for environmental sciences. Geosci. Instrum. Methods Data Syst. 5, 45-51. doi: 10.5194/gi-5-45-2016

Kampf, S., Strobl, B., Hammond, J., Annenberg, A., Etter, S., Martin, C., et al. (2018). Testing the waters: mobile apps for crowdsourced streamflow data. EOS 99, 30-34. doi: 10.1029/2018EO096355

Li, Z., Wang, C., Emrich, C. T., and Guo, D. (2018). A novel approach to leveraging social media for rapid flood mapping: a case study of the 2015 South Carolina floods. Cartogr. Geogr. Inf. Sci. 45, 97-110. doi: 10.1080/15230406.2016. 1271356

Lowry, C. S., and Fienen, M. N. (2013). CrowdHydrology: crowdsourcing hydrologic data and engaging citizen scientists. Ground Water 51, 151-156. doi: 10.1111/j.1745-6584.2012.00956.x

Mulligan, M. (2013). WaterWorld: a self-parameterising, physically based model for application in data-poor but problem-rich environments globally. Hydrol. Res. 44:748. doi: 10.2166/nh.2012.217

Ruhi, A., Messager, M. L., and Olden, J. D. (2018). Tracking the pulse of the Earth's fresh waters. Nat. Sustain. 1, 198-203. doi: 10.1038/s41893-0180047-7 
Seibert, J., and Vis, M. J. P. (2016). How informative are stream level observations in different geographic regions? Hydrol. Process. 30, 2498-2508. doi: 10.1002/ hyp. 10887

Smith, L., Liang, Q., James, P., and Lin, W. (2015). Assessing the utility of social media as a data source for flood risk management using a real-time modelling framework. J. Flood Risk Manag. 10, 370-380. doi: 10.1111/jfr3.12154

Strobl, B., Etter, S., van Meerveld, I., and Seibert, J. (2019). Accuracy of crowdsourced streamflow and stream level class estimates. Hydrol. Sci. J. (in press). doi: 10.1080/02626667.2019.1578966

Teacher, A. G. F., Griffiths, D. J., Hodgson, D. J., and Inger, R. (2013). Smartphones in ecology and evolution: a guide for the app-rehensive. Ecol. Evol. 3, 52685278. doi: 10.1002/ece3.888

van Meerveld, H. J., Vis, M. J. P., and Seibert, J. (2017). Information content of stream level class data for hydrological model calibration. Hydrol. Earth Syst. Sci. 21, 4895-4905. doi: 10.5194/hess-21-48952017

Vörösmarty, C. J., Askew, A., Grabs, W., Barry, R. G., Birkett, C., Döll, P., et al. (2001). Global water data: a newly endangered species. Eos Trans. Am. Geophys. Union 82, 1999-2001. doi: 10.1029/01EO00031
Weeser, B., Stenfert Kroese, J., Jacobs, S. R., Njue, N., Kemboi, Z., Ran, A., et al. (2018). Citizen science pioneers in Kenya - A crowdsourced approach for hydrological monitoring. Sci. Total Environ. 631-632, 1590-1599. doi: 10.1016/ j.scitotenv.2018.03.130

Conflict of Interest Statement: $\mathrm{PH}$ is founder and co-owner of the company SPOTTERON GmbH.

The remaining authors declare that the research was conducted in the absence of any commercial or financial relationships that could be construed as a potential conflict of interest.

Copyright (c) 2019 Seibert, Strobl, Etter, Hummer and van Meerveld. This is an open-access article distributed under the terms of the Creative Commons Attribution License (CC BY). The use, distribution or reproduction in other forums is permitted, provided the original author(s) and the copyright owner(s) are credited and that the original publication in this journal is cited, in accordance with accepted academic practice. No use, distribution or reproduction is permitted which does not comply with these terms. 


\section{OPEN ACCESS}

Edited by:

Jonathan D. Paul,

Imperial College London,

United Kingdom

Reviewed by:

Qingkai Kong,

University of California, Berkeley,

United States

Kiran Kumar Singh Thingbaijam, Institute of Seismological Research,

India

*Correspondence:

Wen-Tzong Liang

wt@earth.sinica.edu.tw

Specialty section:

This article was submitted to

Geohazards and Georisks,

a section of the journal

Frontiers in Earth Science

Received: 27 November 2018

Accepted: 27 March 2019

Published: 17 April 2019

Citation:

Liang W-T, Lee J-C and

Hsiao N-C (2019) Crowdsourcing

Platform Toward Seismic Disaster

Reduction: The Taiwan Scientific

Earthquake Reporting (TSER) System.

Front. Earth Sci. 7:79.

doi: 10.3389/feart.2019.00079

\section{Crowdsourcing Platform Toward Seismic Disaster Reduction: The Taiwan Scientific Earthquake Reporting (TSER) System}

\author{
Wen-Tzong Liang ${ }^{1 *}$, Jian-Cheng Lee ${ }^{1}$ and Nai-Chi Hsiao ${ }^{2}$ \\ ${ }^{1}$ Institute of Earth Sciences, Academia Sinica, Taipei, Taiwan, ${ }^{2}$ Seismological Center, Central Weather Bureau, Taipei, Taiwan
}

We initiated an earthquake reporting project in 2016 to collect field observations of ground damages caused by large earthquakes from trained volunteers and interested citizens. After a potentially damaging earthquake occurs in the Taiwan area, our system, the Taiwan scientific earthquake reporting system (TSER), would send a notice to the participants, who are encouraged to visit the epicentral area to survey and describe in as much detail as possible the variations of the ground damages using a Usahidibased mapping platform. They may also upload relevant images in the field when the condition permitted (i.e., good mobile signal). This collective information will be shared with the public after a quick check by the on-duty scientists. Statistically, in Taiwan damaging inland earthquakes, e.g., magnitude greater than 6 , occurred every 2-3 years. During the intermittent time, the platform serves to share educational materials such as pictures of geological structures and landscapes, which are beneficial to many of the volunteers, who are high school science teachers. This experimental, science-oriented crowdsourcing system was first tested during the February 6, 2018 Mw 6.4 offshore Hualien, Taiwan earthquake. We received 19 field reports in the first 3 days after the earthquake. Most of these reports provided surface damage details along the Milun fault, which also ruptured during the $1951 \mathrm{ML}$ 7.1 Longitudinal Valley earthquake sequence. The crowdsourcing approach of TSER has proven to be effective in enhancing public awareness and the potential for scientific advancement in hazard mitigation.

Keywords: crowdsourcing, earthquake triggered geohazards, Taiwan seismicity, citizen seismology, seismic disaster reduction

\section{INTRODUCTION}

Being located at the tectonically active boundary between Eurasian and Philippine Sea plates, earthquakes occur frequently, and the associated surface deformation is significant in the vicinity of the island of Taiwan (Figure 1). According to the newly published probabilistic seismic hazard analysis (PSHA) results (Wang et al., 2016), the probabilities of occurrence of the earthquakes larger than moment magnitude $(\mathrm{Mw}) 6.0$ are higher than $20 \%$ in the next 30 years for multiple seismogenic structures (i.e., active faults) in Taiwan. Historically in September 20 of 1999, the Mw 7.6 Chi-Chi Earthquake hit central western Taiwan and the surface rupture extended for 
about $90-\mathrm{km}$ long along the Chelungpu fault. The co-seismic surface offsets on the fault increased from 1 to $2 \mathrm{~m}$ in the south to 6-8 $\mathrm{m}$ in the north, as revealed by fault scarp measurements (Central Geological Survey [CGS], 1999; Lee et al., 2002; Lee and Chan, 2007). The severe ground shaking caused by this disastrous earthquake also triggered several fatal landslides (e.g., Chang et al., 2006; Tang et al., 2009), one of which formed a dam lake in the Tsaoling area (e.g., Chen et al., 2006). In addition, soil liquefaction had been widely observed in the coastal plain (National Center for Research on Earthquake Engineering [NCREE], 1999), where the surface is covered by immense late Quaternary soft deposits. The landscape shaped by the 1999 Chi-Chi Earthquake had a great impact on both society and research community of Taiwan.

Although dense instrumental seismic and geodetic networks have been implemented in Taiwan in the past decades (e.g., Institute of Earth Sciences, Academia Sinica, Taiwan, 1996; Hsiao et al., 2009), some earthquake induced ground damages, such as surface rupture, landslide, rock fall, liquefaction, and landslide-triggered dam lake, etc., may not easily be identified by seismic instruments right after the earthquake. In order to rapidly collect field observations on earthquake triggered surface damages which could possibly be hazardous, immediate or longterm, to public, we have launched an experimental program in 2016. In this project, we incorporate (1) computer-aided volunteer management system (VMS), (2) educational training course and (3) online report and mapping platform. The success of this program replies on not only the quantity and completeness of collected witness reports, but also their quality and reliability. Therefore, encouraging people, in particular trained volunteers, to participate in reporting the earthquake damages during seismic events is crucial. In the past few decades, some crowdsourcing projects either spread questionnaires (e.g., Ward et al., 1999) and/or relevant cartoons (Bossu et al., 2018), so that volunteers can report their experiences during or after a felt earthquake. These platforms or Apps allow all volunteers to submit their earthquake experiences without, however, providing associated educational trainings for necessary scientific knowledge or skills.

Since we are aiming to collect scientific information in terms of earthquake induced surface damages, it might require necessary scientific knowledge or skills to carry out this kind of field observations and investigations. It is, thus, important to build up knowledge capacity for volunteers to meet this goal. As a result, we designed a series of training courses with relevant topics, including regional and local geology, historical earthquake, geohazards and so on. Meanwhile, we have been constructing the Taiwan scientific earthquake reporting (TSER) system. We adopted the pre-existing Ushahidi mapping platform ${ }^{1}$, which has been widely used on crowdsourcing and had some success in different purposes. Participants may add an APPlike icon of the website on their mobile devices ${ }^{2}$. When a potential damaging earthquake occurred in the Taiwan area, trained volunteers will be notified within one or two days. The email

${ }^{1}$ http://www.ushahidi.com

${ }^{2}$ http://tesis.earth.sinica.edu.tw/TSER/ notification would guide the participants to the epicentral area to carry out field surveys. The participants are then required to submit their reports, including description of surface damages and on-site photography, through this real-time report system. The collected information will be shared with all public after a quick check by the on-duty scientists.

In order to attract volunteers as well as letting them be familiar with the TSER platform, we added an additional function on TSER for people, particularly the trained volunteers of school teachers, to post and share landscape pictures (and encouraging with geological explanations) in Taiwan. This is not only to help volunteers get acquainted with this reporting system but also to share any teachable material (see section "Geological Landscape Sharing Mechanism" for more details) on this platform, since a large portion of our trained volunteers are high school or junior high school teachers in natural sciences.

This experimental, seismic damages crowdsourcing system was tested during the $2018 \mathrm{Mw} 6.4$ Hualien earthquake. The earthquake produced surface ruptures 8-10 kilometers long through the city of Hualien and caused a few casualties due to building collapses near the surface fault. We received 19 field reports from volunteers, including two anonymous, interested citizens, in the first 3 days following the earthquake. 17 out of the 19 reports were given on different sites along the Milun fault, which was apparently triggered by the earthquake. It is also worth noting that historically the fault ruptured during the 1951 ML 7.1 earthquake (Hsu, 1962; Figure 1). Although similar observations have been provided by other scientists in the following days and weeks, the accounts from the local volunteers obviously have given a reliable rapid report and surface evidence in a scientific way. In short, for the case of the Hualien earthquake, the TSER platform provided not only the distribution of the surface ruptures, but also rupture orientation, type of faulting, and offset dimension (see section "2018 Mw 6.4 Hualien Earthquake: a Test of Real Case").

However, the experiences from this earthquake show that we were still short of trained volunteers in the Hualien area, partly because eastern Taiwan is not populated as western Taiwan (only a few high schools in the area). Nevertheless, we have shown that this TSER system, relying on enthusiastic participation from trained volunteers and general public, is workable during damaging earthquakes. Some technical issues were found during the 2018 earthquake, such as real-time GPS location, image (photograph) size limitation, and menu options, giving us indications to improve. Also, additional knowledge regarding the impacts imposed by historic earthquakes and robust earthquake preparedness should be included in our future training courses. The ultimate goals are to enhance the public awareness of earthquake hazards and to promote citizen seismology in Taiwan.

\section{RATIONALE OF THE TAIWAN SCIENTIFIC EARTHQUAKE REPORTING (TSER) SYSTEM}

Taiwan scientific earthquake reporting is a crowdsourcing system designed for collecting quantitative descriptions from 


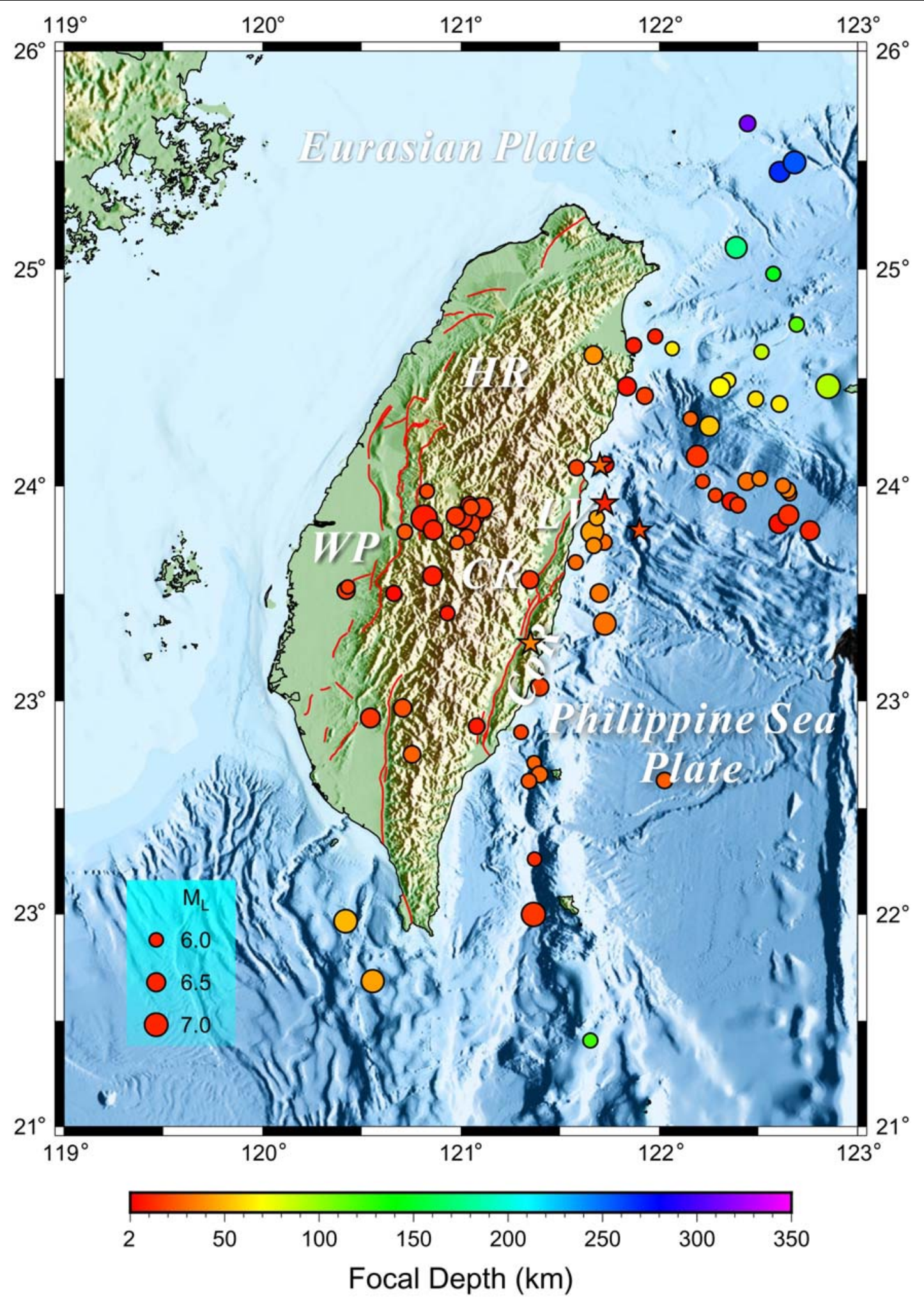

FIGURE 1 | Distribution of the large earthquakes greater than ML 6.0 which occurred in the Taiwan area in the past 28 years (1991-2018). Symbol size represents the magnitude, whereas the color indicates the earthquake focal depth. Although more than a half of the earthquakes occurred in the offshore area, there were still 26 damaging large earthquakes ruptured underneath the inland Taiwan. Epicenters with ML > 7.0 in the 1951 Longitudinal Valley Sequence are shown in red starts. Red lines mark the surface traces of 33 active faults, which were announced by the Central Geological Survey of Taiwan. Geological terranes: WP, western coastal plain and foothills, HR, hsuehshan range, CR, central range, LV, longitudinal valley, CoR, coastal range. 
trained volunteers and general public for earthquake triggered surface damages. We incorporated this system to work together with other well-developed pre-existing facilities at earthquake science community in Taiwan (Liang et al., 2016, 2017). We intend to build a framework to promote public involvement in better understanding earthquake science and improving hazard mitigation. According to the earthquake catalog from the Taiwan Central Weather Bureau (CWB), 101 earthquakes with a local magnitude larger than 6 occurred in the vicinity of Taiwan in the past 28 years (i.e., 1991-2018) (Figure 1). Among them, 26 shallow crustal events (i.e., focal depth $<30 \mathrm{~km}$ ) ruptured underneath inland Taiwan. Although not every event ruptured to the surface, the island of Taiwan was hit by a severe earthquake $(M>6)$ almost every $2-3$ years in average (Liang et al., 2017). The newly published seismic hazard maps in the Taiwan area (Wang et al., 2016) indicate the highest hazard probability is evaluated to be in two areas: (a) Southwestern Taiwan and (b) the Longitudinal Valley of Eastern Taiwan, which is comparable to the distribution of historic large earthquakes as shown in Figure 1. Most of the identified seismogenic structures or active faults (Wang et al., 2016) are located close to the populated area (Figure 1). As a result, nearby, well-trained, educated volunteers could play an important role in collecting key features caused by any damaging earthquakes to complement the real-time instrumental data. One major concern is that the safety of volunteers must be secured first. To achieve so, we provide a security guide for volunteers to take necessary actions before and during conducting field investigations. The principle is to keep our volunteers away from any places at high aftershock risks and stay safe. As geoscientists, we need to combine the field observations with those from the real-time instruments (e.g., seismometer, GPS, etc., Lee et al., 2013; Wu et al., 2013, 2016, 2018; Jian et al., 2018b), in order to determine the responsible structure(s) and the impact of the possible related hazards. These firsthand rapid eyewitness reports will enable appropriate site selection for further sophisticated geological field investigations and also enrich our knowledge database. The question is: how to proceed to make sure the field damage information will be fulfilled in TSER system during disastrous earthquake event?

The key points include (1) to encourage public involvement in this program and (2) to build up the knowledge capacity of volunteers. Also (3) we need to establish an online web platform so that trained volunteers and general public are able to report field observations without difficulties. In order to do so, we designed a computer-aided VMS, a series of training courses, and a Web GIS-based crowdsourcing platform for this particular need. Figure 2 is a workflow diagram illustrating the rationale of this TSER system. Table $\mathbf{1}$ is the summary of main working items that were involved in this program. We believe the enthusiasm, willingness and reliability are critical to the success of this crowdsourcing system. For future perspective, to keep our volunteers engaged and inspired, we think some recognition mechanisms, such as contribution acknowledgment, success stories sharing and regular communication, are rather important; thus, the associated functions in TSER are now under construction (we shall discuss this in more details in Section "Current Status and Future Perspective").

\section{TRAINING COURSES}

As mentioned above, in order to collect rapid scientific information for earthquake triggered or induced natural surface damages, it is important to build up the knowledge capacity for volunteers. As a consequence, we have designed a series of training courses with relevant topics, including (1) an overview of Taiwan tectonics and geology, (2) historic earthquakes and associated surface damages, (3) geohazards of Taiwan, (4) introduction of TSER and volunteer reporting system, (5) citizen seismology, and (6) field geology excursion with on-site reporting practices. We invited dedicated 6-8 scientists including university professors to contribute lectures for these courses.

We organized this kind of training course in three consecutive years of 2016, 2017, and 2018, although the one in 2018 was postponed last minute due to typhoon. The first training course was held at Taipei in 2016. A total of 72 participants, mostly high school teachers, joined a 3-day workshop, including a 1-day field trip. We found that the majority of participants came from northern Taiwan. As a result, the 2nd training course was held in the city of Tainan in southwestern Taiwan in 2017. Indeed, this workshop received 30 participants, among whom 27 came from southwestern Taiwan. We followed this strategy for moving the location of the training course. In 2018, the 3rd training course was set to be held in the city of Hualien in eastern Taiwan. As mentioned above, the workshop unfortunately was forced to be postponed due to typhoon Maria.

Here, we show an example of the training course at Tainan in 2017 in more detail ${ }^{3}$ in Chinese. In this workshop, we focused on earthquake science education (i.e., topic \#5) in Day 1 and presented topics \#1, 2, 3, and 4 in Day 2. In Day 3, we organized a geological field excursion in the nearby foothills area of Southwestern Taiwan, where a young, active fold-and-thrust belt is still developing. It is also near the epicentral area of the $2016 \mathrm{Mw} 6.4$ Meinong earthquake, which caused significant surface damages in several places. Related handouts are accessible in the links listed inside the agenda table. Figure 3 shows the photographs that were taken during this training workshop. In Figure $\mathbf{3 A}$, participants were playing with a board game designed for learning knowledge about local earthquakes as well as the ways to mitigate the associated hazards. Basic seismological observations and local active faults were introduced by experts as shown in Figures 3B,C. Figure 3D presents a photograph taken in the Tsao Shan Moon World, a tract of barren land (badland) formed within the mudstone region during the field excursion. We also let the participants practice the TSER damages reporting system during the field trip. Participants were requested to submit their observations with their mobile phone in the field. Some examples can be found at http://tesis.earth.sinica.edu.tw/ TSER/. This package of teaching material has been archived in our database and continues to be updated and integrated in the platform.

\footnotetext{
${ }^{3}$ http://tec.earth.sinica.edu.tw/new_web/news_con.php?id=190
} 


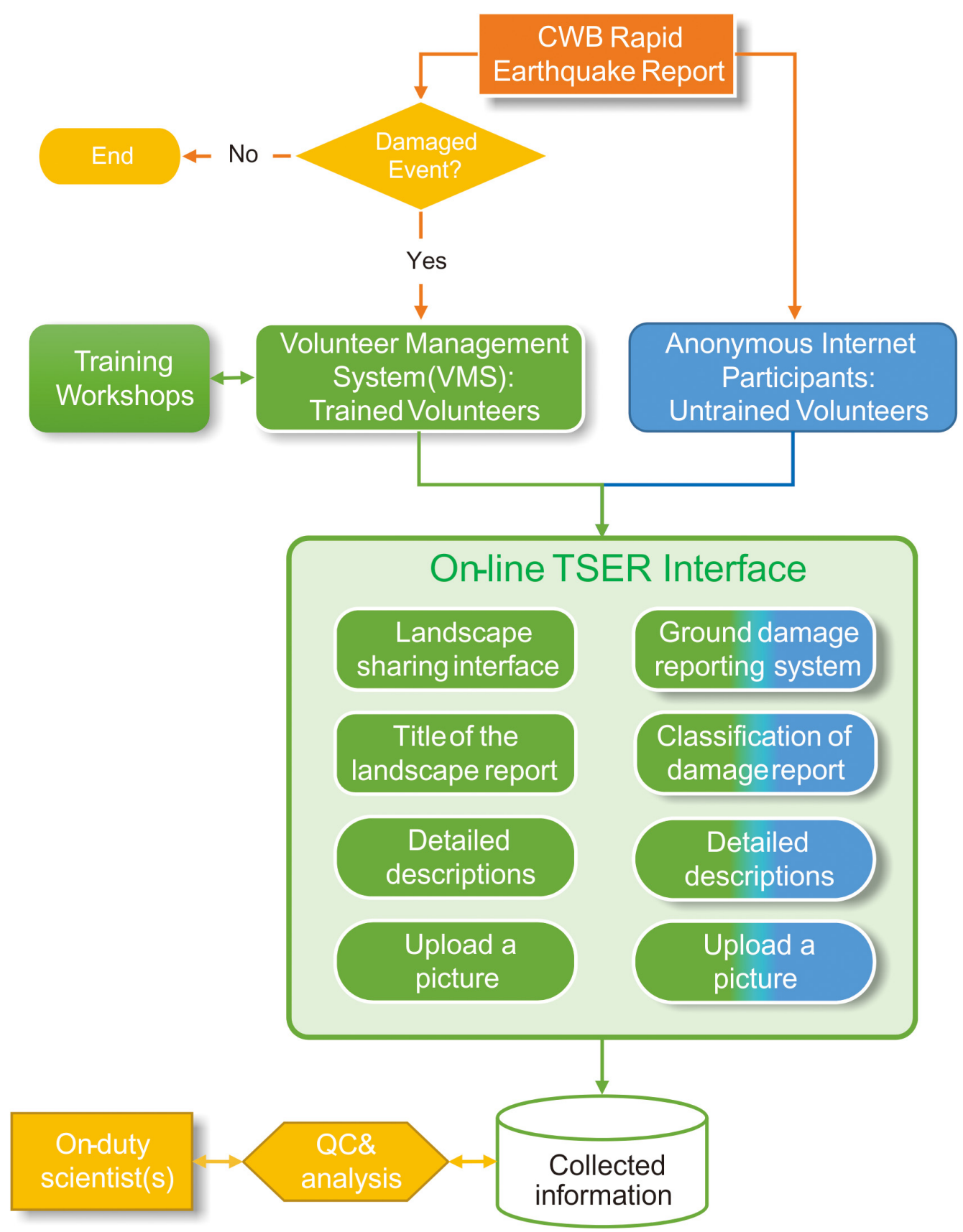

FIGURE 2 | A workflow diagram illustrating the rationale of the Taiwan earthquake scientific reporting (TSER) system. Yellow boxes indicate those actions taken by scientists involved in this project. Green boxes show three major components (see main text) developed in this project. Blue boxes represent the way that untrained volunteers may contribute to this project.

\section{COMPUTER-AIDED VOLUNTEER MANAGEMENT SYSTEM}

We have been working together with the researchers and technicians of computer sciences at the Institute of Information Science, Academia Sinica to develop a VMS. TSER is one of the projects at Academia Sinica which intend to use crowdsourcing data for disaster risk reduction. This VMS archives contact information of volunteers and allows them to participate in multiple projects.

When the potentially hazardous earthquake occurred, our VMS will send an alert or notification to volunteers who have expressed their willingness to help collect field observations in the epicentral area of the target earthquake. This notification reminds volunteers to stay safe in any case. A security guide is provided for volunteers to take necessary actions before and 
TABLE 1 | Summary of the working items for Taiwan scientific earthquake reporting system.

\begin{tabular}{lll}
\hline Training courses & \multicolumn{1}{c}{$\begin{array}{c}\text { Volunteer } \\
\text { management } \\
\text { system }\end{array}$} & $\begin{array}{l}\text { Taiwan scientific } \\
\text { earthquake reporting } \\
\text { (TSER) system }\end{array}$ \\
\hline - Overview of Taiwan & - Volunteer management & - Surface rupture \\
tectonics and geology & - Alert notification & - Landslide \\
- Historic earthquakes & - Volunteer dispatch & - Rock fall \\
and their impacts & - Volunteer recognition & - Liquefaction \\
- Geohazards of Taiwan & & - Landslide dam \\
- Citizen seismology & & - Other ground \\
- Field excursion & & damages \\
\hline
\end{tabular}

during conducting field investigations. If possible (e.g., they are close to the affected region), they are encouraged to help conduct field observations at their convenience. In order to protect the privacy of volunteers, we do not actively collect their location coordinates unless they took our request and recorded their eyewitness reports. The reliability weighting of individual volunteers depends on the frequency he/she has participated in the training workshops organized by the TSER program.

To attract more qualified, educated volunteers, we were targeting mostly on high school teachers in natural sciences. We collaborated with the Fundamental Earth Science Education
Resource Center, an official association of high school teachers in Taiwan, to co-organize the aforementioned training workshops for high school teachers. We also encourage them to play as seed volunteers in their schools. In the future, we have a plan to broaden the participation from high school teachers to university students through multiple events, such as annual openhouse activities of Academia Sinica, educational conferences and related school activities. As revealed in our previous work (Liang et al., 2016), to continue to keep their interest in participating the TSER program for individual volunteers is a challenge, which needs to be further addressed. Based on our experience by interviewing workshop participants, we understand that providing effective recognition might be a valuable reward to volunteers. We shall put related functions in TSER or organize activities on our next working list, such as a credit ranking, top gorgeous pictures award in the year, geological field excursion routes design, and so on. We may also provide certificates to dedicated volunteers in a formal way to express our appreciation and encouragement.

\section{THE ONLINE TSER INTERFACE}

Here we illustrate the current design of TSER portal page (Figure 4). The leftmost column listed basic functions, including
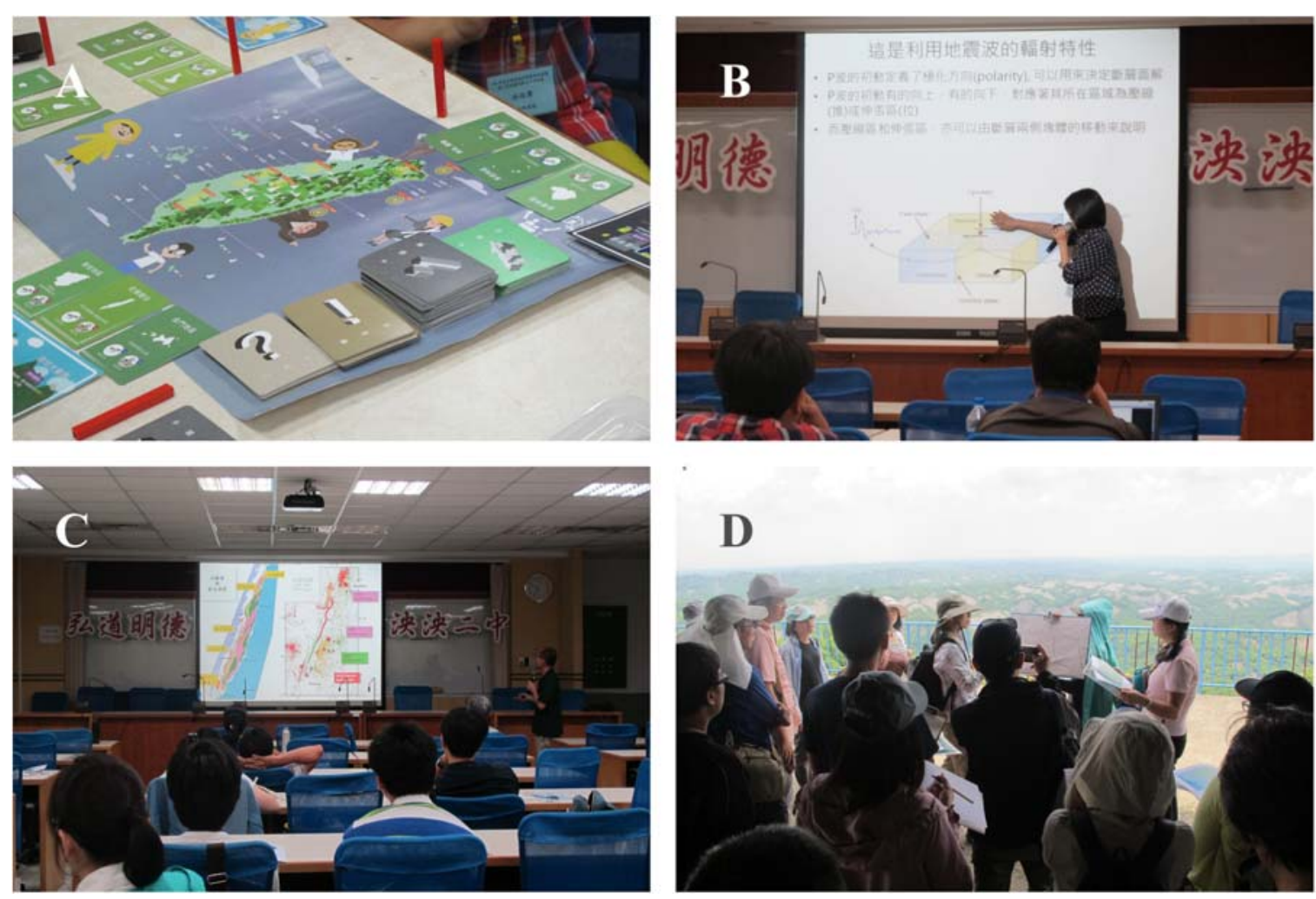

FIGURE 3 | Photographs illustrating activities and highlights of the 2017 training workshop. (A) A board game designed for learning knowledge and hazard mitigation for earthquakes and extreme weather in Taiwan. (B) Lecture introducing basic knowledge of seismology. (C) Lecture explaining active faults and earthquake triggered geohazards. (D) photograph taken in the field excursion around area of badland mudstone, where different earthquake-triggered damages could potentially occur. (Written informed consent were obtained from participants that may be identifiable in this figure). 


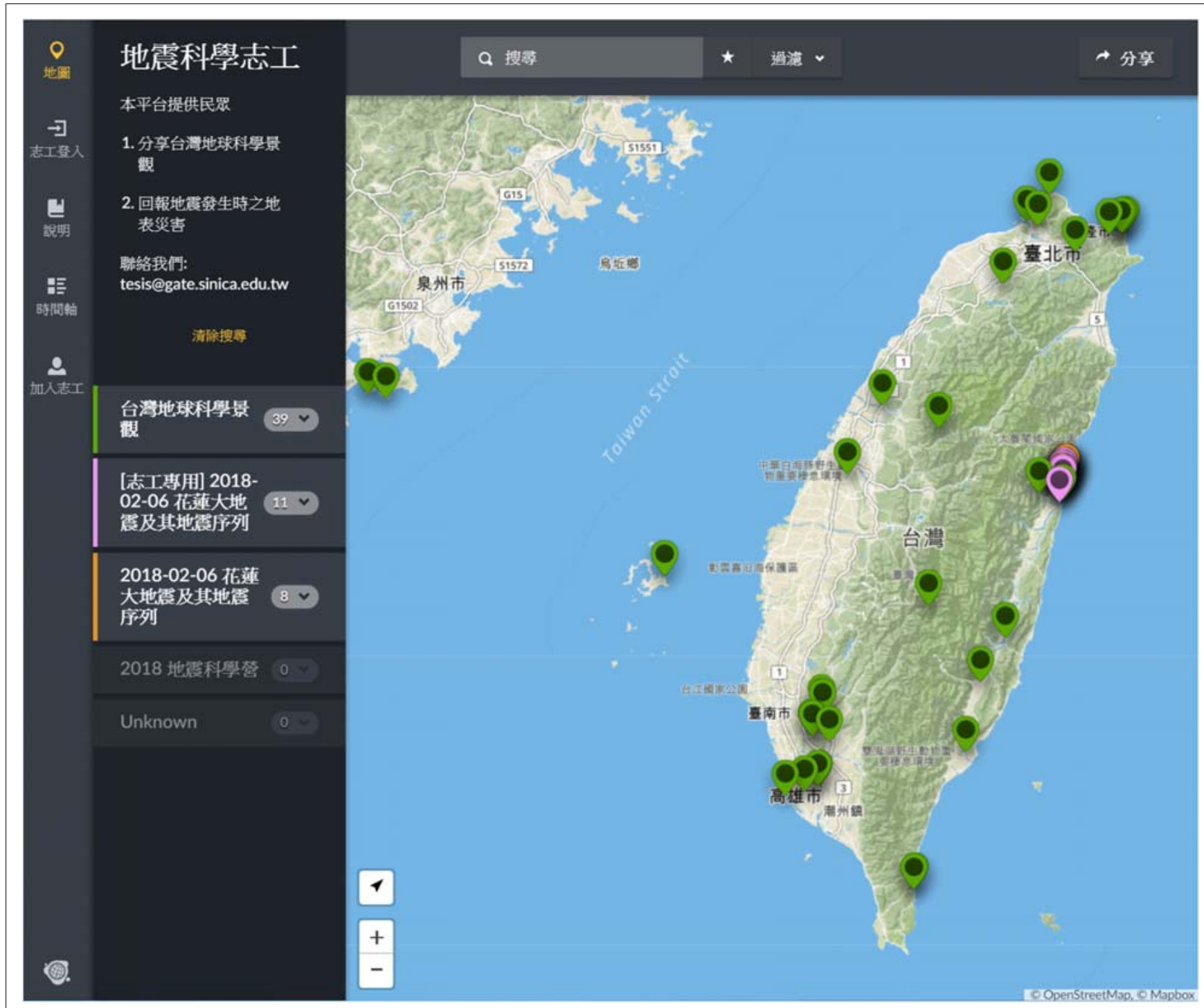

FIGURE 4 | The home page of the TSER portal page. Each small balloon represents geographical site of individual reports for either earthquake-triggered surface natural damages (pink color) or geological landscape (green color).

Map, Login, Instruction, Time line and Registration, from top to bottom. Adjacent to its right, the brief contact information is presented on the top, followed by on-going project names. In this example, on-going projects include (1) Geological Landscape in Taiwan and around the world, (2) Volunteer Reports for the 2018-02-06 Hualien Earthquake, (3) Public Reports for the 2018-02-06 Hualien Earthquake, and (4) The 2018 volunteer training workshop, which are labeled with green, purple, orange and red colors, respectively, from top to bottom. Once the user clicks on any of the projects, "the sites of interest" will appear in the map of the main frame.

For instance, we received 19 reports in total from Projects (2) and (3) for the $2018 \mathrm{Mw} 6.4$ Hualien Earthquake. For project of geological landscape, so far there are 39 worldwide pictures of landscapes post on this platform. All the locations of these landscape photos are presented on the map in the main frame. Only registered volunteers are able to login to submit their landscape images in order to prevent malicious attacks on the Internet. On-duty scientist(s) would then examine submitted materials and modify them if necessary. Clicking on each project will enable or disable the corresponding views on the map.

To record eyewitness reports for a particular project, registered volunteers have to log into the TSER platform either on a mobile device or on computer. For reporting earthquakeinduced surface damages, they are required to fill or select items during their surveys, including (1) identify the ground damage category from a menu (among surface rupture, mudflow/debris flow, landslide, liquefaction, mud volcano eruption, and others), (2) briefly describe this natural ground damage (e.g., length, width, orientation, etc.), (3) locate this damage by clicking the observation point on the map, and (4) upload a picture taken 
from their phone/camera and indicate the corresponding viewing orientation (i.e., azimuth). Volunteers are allowed to modify their reports to correct typos or unintentional mistakes. The platform also registers every step (movements) volunteers have made, so we can back track the records.

\section{GEOLOGICAL LANDSCAPE SHARING MECHANISM}

As mentioned above, in average a damaging earthquake (e.g., magnitude greater than 6 with shallow focal depth) has occurred within inland Taiwan every 2-3 years during the past three decades (e.g., Cheng and Yeh, 1989; Liang et al., 2017). To help volunteers to be accustomed to the online reporting system, we designed a geoscientific landscape sharing interface for users to view and upload images with short descriptions. Whenever the volunteers (e.g., as school teachers) find a spectacular or remarkable natural landscape, the system encourages them to post the photography (with some descriptions). The procedure of using this interface is very similar to the one for reporting earthquake triggered ground damages, with four simple steps: (1) identify the category of this landscape, (2) describe the geological/geographical characteristics of the feature, (3) locate this landscape by clicking the observation point on the map, and (4) upload an image associated with this witness report. These pictures and corresponding reports will be examined by on-duty scientist(s) before open to the public.

We expect that these kinds of information will be beneficial to teachers and students for educational purpose. For example, one can design a suitable field trip itinerary for learning local geological features based on the reported landscape sites. To expand our database, we are planning to collaborate with universities in which the geological field training and short courses are provided for students. This is not only to enrich the archived geoscience landscape images, but also to promote the public involvement in this citizen science activity. For example, volunteers from school teachers are able to find local, teachable material, such as images, locations and descriptions for a specific geological structure with the help of searching keywords through this system. Figure $\mathbf{5}$ is an example demonstrating an image of a normal fault taken in northern Taiwan. A sub-vertical normal fault plane offsetting the sedimentary strata of Miocene-Pliocene Tapu formation is well illustrated in this example. One can learn the characteristic geological features in Taiwan from accumulated information shared in this platform. Eventually a customized geology field trip route with explained highlighted sites can be planned based on TSER's archive.

\section{Mw 6.4 HUALIEN EARTHQUAKE: A TEST OF REAL CASE}

A shallow earthquake with Mw 6.4 and focal depth of $15-18 \mathrm{~km}$ hit eastern Taiwan at 23:50 (UTC+8) on February 6th, 2018 and caused the collapse of several buildings in the City of Hualien, in which 17 people were killed and 285 injured $^{4}$. The location of the hypocenter estimated by CWB was about $18-20 \mathrm{~km}$ to the north of Hualien City in the offshore area. The maximum Taiwan ground seismic intensity was seven, which is relevant to MMI scale of VIII (severe). The aftershock activities spread out toward south in the first few days after the main shock, whereas a large "foreshock" with ML 5.8 occurred near the main shock 2 days before (Kuo-Chen et al., 2018). The latest research results argued that there might be multiple faults ruptured following the main shock. Meanwhile, the rupture initiated at the north off the coast of Hualien and propagated southward into the Hualien City (e.g., Lee et al., 2018; Jian et al., 2018a). The Milun fault in Hualien is either part of the main faulting plane or dynamically triggered by the main shock faulting (Lee et al., 2018). The observations of the significant surface deformation along the Milun fault were revealed by field geological investigations (Central Geological Survey [CGS], 2018; TSER platform), InSAR satellite imagery (Yen et al., 2018), and GPS measurements (e.g., Kuo et al., 2018). The collected rapid observation of surface rupture traces did provide a constraint that is comparable to the inferred source model of the triggered Milun fault by Lee et al. (2018).

Significant surface ruptures along the Milun Fault were documented by scientists during the field investigations following the earthquake. Soil liquefaction and ground settlements during this earthquake sequence have also been reported based on field surveys (Ko et al., 2018). Rockfalls were reported at the SuaoHualien Highway No. 9 and Highway No. 8 in the Taroko National Park (two were killed), north of Hualien city.

Although these researches present detailed scientific information related to the 2018 offshore Hualien earthquake sequence, the impact is not as strong as the rapid results carried out from some real-time operating systems, such as the Taiwan earthquake scientific information system (TESIS, Liang et al., 2017). This TESIS webpage collects the rapid earthquake report issued by CWB and many other near real-time scientific results from various organizations in Taiwan. These pieces of near real-time information are all derived from sensor data, such as intensity maps, focal mechanisms, and associated seismic waveforms. In addition, some background geospatial data, including geological maps, active faults and inter-seismic GPS vectors are accessible. These allow correlation between responsible seismogenic structures, and the earthquakes, and evaluation of the impacts that the earthquake might cause.

Coming back from the TSER reporting system, we received 19 reports in the first 3 days after the main shock. The interesting thing is that all these reports were submitted at locations along the Milun fault, which was previously ruptured in 1951 magnitude 7.1 earthquake in the Hualien area (Figure 1; Hsu, 1962). Figure 6A shows the location distribution of these 19 witness reports and two other landscape reports at the southern edge of the map. The surface trace of Milun fault roughly follows the marks of the arc-shape location of submitted reports (Figure 6B). It shows that the reported locations of the surface ruptures agree rather well with the

\footnotetext{
${ }^{4}$ https://www.cna.com.tw/news/firstnews/201802110113.aspx
} 


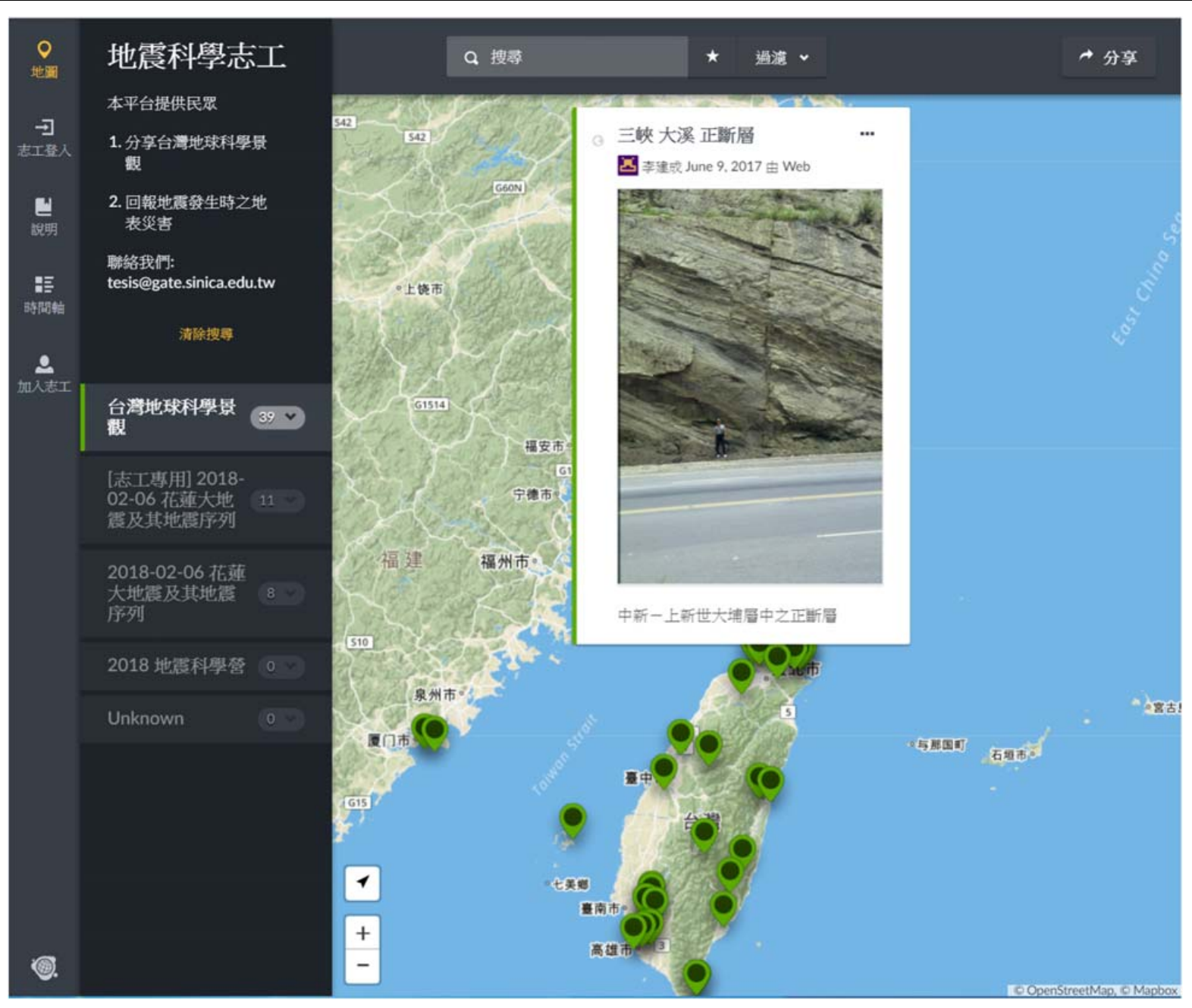

FIGURE 5 | An example illustrating a geological landscape reported in the TSER system. The information includes name of the landscape feature (normal fault), location, post by whom and date, the associated photography or image, and descriptions of the key features in landscape.

previously mapped Milun fault, and are thus closely associated with the dislocated fault plane of the earthquake. Several of these field observation reports described both the fault type (left- or right-lateral) and offset amounts (a few centimeters to tens of centimeters) across the observed surface ruptures on human structures. According to the information from these rapid reports, it appeared that the Milun fault was obviously triggered, either dynamically or statically, by this offshore earthquake. As a result, it left significant surface ruptures and damages along the Milun fault (e.g., Lee et al., 2018). Our collected eyewitness reports cover a variety of structural features on the surface ruptures, including pressure ridge of road pavement, offset of bridge floor, dislocation in en-echelon array in the sports ground, building collapses, etc. Prior to the earthquake in 2016, the Central Geological Survey (CGS) had officially announced the Milun fault as the Category I active fault. The CGS also released an avoidance zone within $200 \mathrm{~m}$ of the Milun fault (Central Geological Survey [CGS], 2016), in which any new constructions should be prohibited. Whether this governmental enforcement had helped to reduce the earthquake risks during the 2018 earthquake remained to be investigated.

\section{CURRENT STATUS AND FUTURE PERSPECTIVE}

Since 2016, we have provided two training workshops, which had helped a combined number of 102 participants to build up their capacity for reporting appropriate earthquake-induced damages field observations. The third workshop planned in July 2018 was postponed due to typhoon Maria, and will probably be re-scheduled in 2019. So far, 60 of 102 participants applied as volunteers in our management system. Most of these volunteers are from urban areas in western Taiwan. As mentioned above in Section "Rationale of the Taiwan Scientific Earthquake Reporting (TSER) System", to keep volunteers engaged and inspired, we are now working on designs of (1) online training courses, (2) contribution acknowledgment, (3) social interaction, 

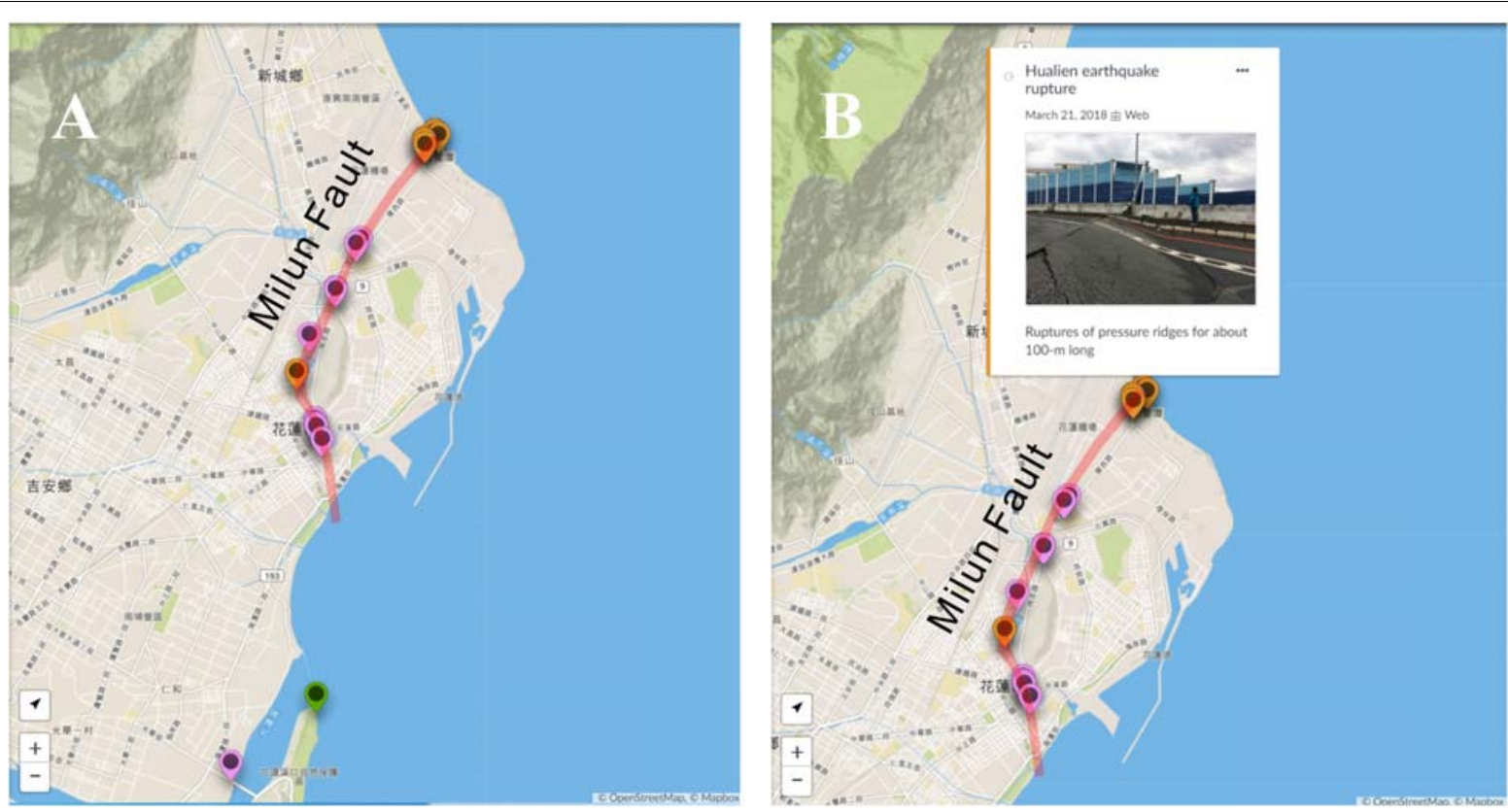

FIGURE 6 | A case study of eyewitness reports during the 2018 Mw 6.4 offshore Hualien earthquake sequence. (A) Among 19 reports, a large portion of the damages collectively marked an arc-shape surface trace, which agrees with the previously identified and mapped Milun fault. We can also find two reports located farther south, indicating other damages existed outside of the Milun fault. (B) A report revealing collapse and offset of the Qixingtan bridge floor close to the northern end of Milun fault.

(4) sharing of success stories, and (5) friendlier TSER interface. In addition, we are planning to regularly highlight nice examples of named eyewitness reports on a blog page. A Q\&A page is also considered, which is likely helpful to improve the system, either on a web-based blog or on social media.

The reliability of an upload report might depend on the poster's capacity, which is why we put great efforts on educational training workshops. However, the general public with basic scientific knowledge may help as well. As a result, in practice we also open this TSER reporting system to the general public who are interested in sharing their eyewitness reports during damaging earthquakes. The scientist(s) on-duty are responsible for validating these reports as quickly as possible. In the first phase of this project, only registered volunteers have been dispatched by a notice sent out through the VMS. In the next phase, this notice will be disseminated through all available channels. We welcome anonymous volunteers to join in with this project. Meanwhile, not only will the ground damage be reported, induced damages of the built environment are considered to be included as well. In fact, these damages usually account for most of the social impact from a disastrous earthquake, rather than the ground damage. In the 2018 Hualien earthquake case, we received two reports with pictures of building collapse, where major injuries and fatalities occurred.

\section{CONCLUSION}

We initiated a citizen seismology program (TSER platform project), incorporating training courses and VMS with the web
GIS-based platform, to crowdsource scientific eyewitness reports for earthquake triggered surface natural damages. By collecting the on-site field reports, we intend to complement the field ground observations with the real-time instrumental data and results, to better understand the surface damages and geohazards caused by large earthquakes. We feel it might be of great potential to help rescue and better assess the social impacts.

In order to keep the volunteers familiar with the reporting system and its procedure, we designed a geological landscape posting/reporting mechanism for volunteers. This is also beneficial to the volunteers, since most of them are high school science teachers. Volunteers who have participated in our training workshops may have a higher weighting on the reliability of their reports. The VMS will automatically notify and dispatch registered volunteers when a significant earthquake happened underneath inland Taiwan.

This still-developing TSER system was tested in the real case of the $2018 \mathrm{Mw}$ 6.4 Hualien Earthquake. The crowdsourced eyewitness reports, although not abundant, indeed showed a heavily damaged zone along the Milun fault, which had been historically ruptured during the 1951 earthquake sequence.

We are continuing to take care of the recognition for volunteers in order to promote broader future public involvement in this program.

\section{ETHICS STATEMENT}

This work will collect only eyewitness reports from scientific volunteers. The privacy protection and information security 
policy of Academia Sinica is strictly followed. No individual information will be collected from the developed platform. In this case, a formal approval from an ethics committee is not required as per the local legislation. Written informed consent were obtained from participants that may be identifiable in Figure 3.

\section{AUTHOR CONTRIBUTIONS}

W-TL and J-CL conceived the system development. N-CH assisted with the real-time earthquake alert from the Central Weather Bureau. W-TL drafted the manuscript. J-CL supervised the findings of this work and oversaw the revisions.

\section{FUNDING}

This work was supported in part by the "Disaster Resiliency through Big Open Data and Smart Things, DRBoast" project (Grant No.: AS-105-SS-A03) (Funding Agency: Academia

\section{REFERENCES}

Bossu, R., Roussel, F., Fallou, L., Landes, M., Steed, R., Mazet-Roux, G., et al. (2018). LastQuake: from rapid information to global seismic risk reduction. Inter. J. Disaster Risk Red. 28, 32-42. doi: 10.1016/j.ijdrr.2018. 02.024

Central Geological Survey [CGS] (1999). Report of the Geological Survey of the 1999 Chi-Chi Earthquake (in Chinese). Taipei: CGS.

Central Geological Survey [CGS] (2016). Central Geological Survey. Available at: https://www.moeacgs.gov.tw/newlaw/downloads/announcement/1051221/ F0011/F0011\%E7\%B1\%B3\%E5\%B4\%99\%E6\%96\%B7\%E5\%B1\%A4\%E5\%8A\% 83\%E5\%AE\%9A\%E8\%A8\%88\%E7\%95\%AB\%E6\%9B\%B8.pdf (accessed April 5, 2019).

Central Geological Survey [CGS] (2018). Report of the Geological Survey of the 20180206 Hualien Earthquake (in Chinese). Taipei: CGS.

Chang, K.-J., Taboada, A., Chan, Y.-C., and Dominguez, S. (2006). Post-seismic surface processes in the Jiufengershan landslide area, 1999 Chi-Chi earthquake epicentral zone, Taiwan. Eng. Geol. 86, 102-117. doi: 10.1016/j.enggeo.2006. 02.014

Chen, R.-F., Chang, K.-J., Angelier, J., Chan, Y.-C., Deffontaines, B., Lee, C.-T., et al. (2006). Topographical changes revealed by high-resolution airborne LiDAR data: the 1999 Tsaoling landslide induced by the ChiChi earthquake. Eng. Geol. 88, 160-172. doi: 10.1016/j.enggeo.2006. 09.008

Cheng, S. N., and Yeh, Y. T. (1989). Catalog of the Earthquakes in Taiwan From 1604 to 1988. Taipei: Academia Sinica, 255.

Hsiao, N.-C., Wu, Y.-M., Shin, T.-C., Zhao, L., and Teng, T. L. (2009). Development of earthquake early warning in Taiwan. Geophys. Res. Lett. 36:L00B02. doi: 10.1029/2008GL036596

Hsu, T.-L. (1962). Recent faulting in the longitudinal valley of eastern Taiwan. Memoir Geol. Soc. China 1, 95-102.

Institute of Earth Sciences, Academia Sinica, Taiwan (1996). Broadband Array in Taiwan for Seismology. Taipei: Academia Sinica.

Jian, P.-R., Hung, S.-H., and Meng, L. (2018a). Rupture behavior and interaction of the 2018 hualien earthquake sequence and its tectonic implication. Seismo. Res. Lett. 90, 68-77. doi: 10.1785/0220180241

Jian, P.-R., Tseng, T.-L., Liang, W.-T., and Huang, P.-H. (2018b). A new automatic full-waveform regional moment tensor inversion algorithm and its applications in the Taiwan area. Bull. Seismo. Soc. Am. 108, 573-587. doi: 10.1785/ 0120170231

Ko, Y.-Y., Hsu, S.-Y., Yang, H.-C., Lu, C.-C., Hwang, Y.-W., Liu, C.-H., et al. (2018). Soil liquefaction and ground settlements in 6 February 2018
Sinica), as well as the Taiwan Earthquake Research Center program (TEC) (Grant Nos.: MOST 106-2119-M-001-021 and 107-2116-M-001-023; TEC Contribution Number for this article is 00148) (Funding Agency: Ministry of Science and Technology of Taiwan, MOST). This is a contribution of Institute of Earth Sciences Academia Sinica, IESAS-2372.

\section{ACKNOWLEDGMENTS}

We are grateful for many constructive comments and suggestions of the two reviewers, Dr. Ban-Yuan Kuo and the editor, which substantially improved this manuscript. We thank Ms. Chi-Fang Lee for her great support on the technical development of the Ushahidi interface. We are also grateful to have the TEC office staff offered tremendous help for training workshop assistance and for testing numerous times on the reporting system of this platform.

Hualien, Taiwan, earthquake. Seismo. Res. Lett. 90, 51-59. doi: 10.1785/022018 0196

Kuo, Y.-T., Wang, Y., Hollingsworth, J., Huang, S.-Y., Chuang, R.-Y., Lu, C.-H., et al. (2018). Shallow fault rupture of the milun fault in the $2018 \mathrm{Mw} 6.4$ Hualien earthquake: a high-resolution approach from optical correlation of pléiades satellite imagery. Seismo. Res. Lett. 90, 97-107. doi: 10.1785/0220180227

Kuo-Chen, H., Guan, Z.-K., Sun, W.-F., Jhong, P.-Y., and Brown, D. (2018). Aftershock sequence of the $2018 \mathrm{Mw} 6.4$ hualien earthquake in eastern taiwan from a dense seismic array data set. Seismo. Res. Lett. 90, 60-67. doi: 10.1785/ 0220180233

Lee, J.-C., and Chan, Y.-C. (2007). Structure of the 1999 Chi-Chi earthquake rupture and interaction of thrust faults in the active fold belt of western Taiwan. J. Asia Earth Sci. 31, 226-239. doi: 10.1016/j.jseaes.2006. 07.024

Lee, J.-C., Chu, H.-T., Angelier, J., Chan, Y.-C., Hu, J.-C., Lu, C.-Y., et al. (2002). Geometry and structure of northern surface rupture of the $1999 \mathrm{Mw}=7.6 \mathrm{Chi}-$ Chi, Taiwan earthquake: influence from inherited fold belt structures. J. Struct. Geol. 24, 173-192. doi: 10.1016/S0191-8141(01)00056-6

Lee, S.-J., Liang, W.-T., Cheng, H.-W., Tu, F.-S., Ma, K.-F., Tsuruoka, H., et al. (2013). Toward real-time regional earthquake simulation I: real-time Moment Tensor monitoring (RMT) for regional events in Taiwan. Geophy. J. Int. 196, 432-446. doi: 10.1093/gji/ggt371

Lee, S.-J., Lin, T.-C., Liu, T.-Y., and Wong, T.-P. (2018). Fault-to-fault jumping rupture of the $2018 \mathrm{Mw} 6.4$ Hualien earthquake in eastern Taiwan. Seismo. Res. Lett. 90, 30-39. doi: 10.1785/0220180182

Liang, W.-T., Chen, K. H., Wu, Y.-F., Yen, E., and Chang, C. Y. (2016). Earthquake school in the cloud: citizen seismologists in Taiwan. Seismo. Res. Lett. 87, 177-185. doi: 10.1785/0220150061

Liang, W.-T., Lee, J.-C., Chen, K. H., and Hsiao, N.-C. (2017). Citizen earthquake science in Taiwan: from science to hazard mitigation. J. Disaster Res. 12, 1174-1181. doi: 10.20965/jdr.2017.p1174

National Center for Research on Earthquake Engineering [NCREE] (1999). Geotechnical Reconnaissance Report of the 9/21 Chi-Chi Earthquake. Taiwan (in Chinese), NCREE-99-053. Taipei: National Center for Research on Earthquake Engineering.

Tang, C.-L., Hu, J.-C., Lin, M.-L., Angelier, J., Lu, C.-Y., Chan, Y.-C., et al. (2009). The Tsaoling landslide triggered by the Chi-Chi earthquake, Taiwan: insights from a discrete element simulation. Eng. Geol. 106, 1-29. doi: 10.1016/j.enggeo. 2009.02.011

Wang, Y.-J., Chan, C.-H., Lee, Y.-T., Ma, K.-F., Shyu, J. B. H., Rau, R.-J., et al. (2016). Probabilistic seismic hazard assessments for Taiwan. Terr. Atmos. Ocean Sci. 27, 325-340. doi: 10.3319/TAO.2016.05.03.01(TEM) 
Ward, D. J., Quitoriano, V., Dengler, L. A., and Dewey, J. W. (1999). Utilization of the internet for rapid community intensity maps. Seism. Res. Lett. 70, 680-697. doi: $10.1785 /$ gssrl.70.6.680

Wu, Y.-M., Chen, D.-Y., Lin, T.-L., Hsieh, C.-Y., Chin, T.-L., Chang, W.-Y., et al. (2013). A high density seismic network for earthquake early warning in Taiwan based on low cost sensors. Seismo. Res. Lett. 84, 1048-1054. doi: 10.1785/0220130085

Wu, Y.-M., Liang, W.-T., Mittal, H., Chao, W.-A., Lin, C.-H., Huang, B.-S., et al. (2016). Performance of a low-cost earthquake early warning system (P-alert) during the 2016 ML 6.4 Meinong (Taiwan) earthquake. Seismo. Res. Lett. 87, 1050-1059. doi: 10.1785/0220160058

Wu, Y.-M., Mittal, H., Huang, T.-C., Yang, B.-M., Jan, J.-C., and Chen, S.-K. (2018). Performance of a low-cost earthquake early warning system (P-Alert) and shake map production during the $2018 \mathrm{Mw} 6.4$ Hualien (Taiwan) Earthquake. Seismo. Res. Lett. 87, 1050-1059. doi: 10.1785/0220180170
Yen, J.-Y., Lu, C.-H., Dorsey, R. J., Kuo-Chen, H., Chang, C.-P., Wang, C.-C., et al. (2018). Insights into seismogenic deformation during the 2018 hualien, Taiwan, earthquake sequence from InSAR, GPS, and modeling. Seismo. Res. Lett. 90, 78-87. doi: 10.1785/0220180228

Conflict of Interest Statement: The authors declare that the research was conducted in the absence of any commercial or financial relationships that could be construed as a potential conflict of interest.

Copyright (C) 2019 Liang, Lee and Hsiao. This is an open-access article distributed under the terms of the Creative Commons Attribution License (CC BY). The use, distribution or reproduction in other forums is permitted, provided the original author(s) and the copyright owner(s) are credited and that the original publication in this journal is cited, in accordance with accepted academic practice. No use, distribution or reproduction is permitted which does not comply with these terms. 


\title{
Growing Pains of Crowdsourced Stream Stage Monitoring Using Mobile Phones: The Development of CrowdHydrology
}

\author{
Christopher S. Lowry ${ }^{1 *}$, Michael N. Fienen ${ }^{2}$, Damon M. Hall ${ }^{3}$ and Kristine F. Stepenuck ${ }^{4}$ \\ 1 Department of Geology, University at Buffalo, Buffalo, NY, United States, ${ }^{2}$ Upper Midwest Water Science Center, \\ United States Geological Survey, Middleton, WI, United States, ${ }^{3}$ School of Natural Resources, Department of Biomedical, \\ Biological and Chemical Engineering, University of Missouri, Columbia, MO, United States, ${ }^{4}$ Rubenstein School \\ of Environment and Natural Resources, University of Vermont, Burlington, VT, United States
}

OPEN ACCESS

Edited by:

Jonathan D. Paul,

Imperial College London,

United Kingdom

Reviewed by:

Joern Lauterjung,

GFZ German Research Centre for Geosciences, Germany

Stefano Martellos,

University of Trieste, Italy

*Correspondence:

Christopher S. Lowry

cslowry@buffalo.edu

Specialty section: This article was submitted to Geohazards and Georisks, a section of the journal Frontiers in Earth Science

Received: 30 October 2018 Accepted: 13 May 2019

Published: 28 May 2019

Citation:

Lowry CS, Fienen MN, Hall DM and Stepenuck KF (2019) Growing Pains of Crowdsourced Stream Stage Monitoring Using Mobile Phones: The Development

of CrowdHydrology.

Front. Earth Sci. 7:128.

doi: 10.3389/feart.2019.00128
Citizen science-based approaches to monitor the natural environment tend to be bimodal in maturity. Older and established programs such as the Audubon's Christmas bird count and Community Collaborative Rain, Hail, and Snow Network (CoCoRaHS) have thousands of participants across decades of observations, while less mature citizen science projects have shorter lifespans often focused on local or regional observations with tens or hundreds of participants. For the latter, it can be difficult to transition into a more mature and sustainable citizen science-based research program. This paper focuses on this transition by evaluating CrowdHydrology (ca. 2010), a citizen science project that has transitioned from a regional to national network. It evaluates the data accuracy, citizen participation, and station popularity. The CrowdHydrology network asks citizens to send in text messages of water levels in streams and lakes, which has resulted in 16,294 observations submitted by over 8,000 unique participants at 120 unique locations. Using water level data and participation records from CrowdHydrology, we analyze the expansion and citizen participation from a regional to national citizen science network. We identify barriers to participation and evaluate why some citizen science observation stations are popular while others are not. We explore our chosen contributory program model for CrowdHydrology and the influence this model has had on long-term participation. Results demonstrate a highly variable rate of contributions of citizen scientists. This paper proposes hypotheses on why many of our observations are from one-time participants and why some monitoring stations are more popular than others. Finally, we address the future expansion of the CrowdHydrology network by evaluating successful monitoring locations and growing interest of watershed groups to expand the network of gauges.

Keywords: citizen science, CrowdHydrology, crowdsourcing, hydrology, public participation, stream stage, water resources 


\section{INTRODUCTION}

In developing new methods for analyzing and monitoring natural hazards, citizen science can be a powerful tool to collect critical environmental observations for both research and long-term monitoring. While, citizen science may lack technical rigor, which can cause professional scientists to use caution in adopting these methods, the time has come to reevaluate our current scientific paradigm. Under a changing climate we expect rising sea levels and higher intensity storm events in addition to longer droughts, which pose increased risk to humans and directs us as professional scientists to look to new methods for monitoring environmental change. Among scientific revolutions, technology is a consistent driver in paradigm shifts (Kuhn, 1962). With the advancements in computing and seamless flow of information between professional scientists, the scientific field has benefited by exponential growth (Szalay and Gray, 2006). It can be argued this growth further increases the gap between professional scientists and some sectors of the general public (Gauchat, 2012). Yet, the underlying driver of advancements in technology is not exclusive to professional science. Over 77 percent of the general public now hold high powered computer processors and advanced telemetry systems in the palm of their hands in the form of smartphones, with 95 percent of the population in the United States owning some form of mobile phone (Pew Research Center, 2018). Professional scientists have an opportunity to embrace the power of technologically advanced citizen sciencebased observers. While opportunities in citizen science-based observation networks are not new, it is time scientists recognize and learn how to tap into the potential.

As a methodology for collecting environmental data, citizen science spans the continuum from qualitative to quantitative measurement techniques. One of the most successful research projects using qualitative measurements by citizen scientists involves ground verification of precipitation using the mobile phone applications mPing (Elmore et al., 2014). This class of techniques termed "qualitative guided" measurements, uses phone-based applications that ask participants to describe the current atmospheric conditions and submit these observations, which are georeferenced and time stamped, to a central database. A related use of citizen observations is termed "qualitative binary," where participants are asked to identify binary phenomenon such as if a stream is flowing or dry (i.e., Kampf et al., 2018) ${ }^{1}$. These qualitative guided and binary techniques are used primarily as tools for data validation. In contrast to these, CoCoRaHS is one of the most successful citizen science projects engaging over 7,000 observers daily to measure precipitation across the United States (Cifelli et al., 2005). Citizens use standardized rain gauge and snow platforms to report precipitation totals. This method can be classified as "quantitative guided" because it requires some sort of training (e.g., videos) and active participation by citizen scientists. Other quantitative guided projects include measures of stream nutrient or pesticide concentrations (Breuer et al., 2015), and water clarity (Lottig et al., 2014, Canfield et al., 2016). There is

${ }^{1}$ StreamTracker.org also a classification termed "quantitative passive," where citizen scientists may not initially realize they are collecting quantitative data. These projects include data mining of social media channels such as YouTube to collect observations of streamflow (Le Coz et al., 2016) or water levels (Michelsen et al., 2016). Quantitative passive data collection can also include citizen scientists who agree to have instruments installed on their phones or property that passively collect scientific data. Quantitative passive collection can include private wells owners installing water level sensors (Little et al., 2016) or internet enabled weather stations (Bell et al., 2013), which can then be shared in real-time with the scientific community.

Given the context to the range of methods available in citizen science-based data collection, the objectives of this research are to assess what factors support the growth and sustainability of a citizen science program. Our primary hypothesis is that a strong citizen science network is maintained by a core group of engaged citizen scientists who are brought together by a locally relevant scientific question. Our secondary hypothesis proposes that a critical mass of observations and/or measurement stations are needed to build sufficient public interest to maintain a sustainable network. We test these hypotheses by reviewing participation in the CrowdHydrology program (Lowry and Fienen, 2013), to determine what allows a citizen science-based observation network to grow from a small set of observation stations to a national or international network. While it is easy to start a citizen science research program, it is difficult to develop a network of interested participants that is sustainable and has scientific reach beyond a single research project. While there are a few successful large-scale programs such as the Audubon Christmas Bird Count (Butcher et al., 1990), CoCoRaHS (Cifelli et al., 2005), and PhenoCam (Richardson et al., 2018), these programs seem to be the exception to the thousands of smaller projects cataloged on citizen science databases such as SciStarter.com. This paper evaluates participation in CrowdHydrology, a hydrology-based citizen science program that has successfully made it past the initial network development phase and is now reaching maturity. It explores the rates of participation and the successful and not so successful methods in collecting hydrologic data. We quantitatively evaluate participation rates of citizen scientists and qualitatively explore reasons behind these figures such as why some observation locations seem to be popular while other are not. The aim is to support other citizen science-based observation networks by detailing what we believe are the key components to long-term engagement with citizen scientists for successfully transitioning from local to national-scale projects.

\section{The CrowdHydrology Program}

Throughout the United States, there are approximately 7,600 United States Geological Survey gauges placed in rivers and streams gathering a variety of water resources data (stream height, flow, water temperature, and sometimes water quality metrics) for a variety of uses such as forecasting floods, characterizing water quality conditions, monitoring quantity of power production, recreation, culvert design, and wildlife habitat, among others. As Earth's systems change, these long-term data are critically important to understand, predict, and manage the 
health of our watersheds for all who depend upon these resources. However, maintaining the quality of long-term data has its costs. One stream gauge station requires about $\$ 18,000$ to install and $\$ 16,000$ to $\$ 21,000$ annually for the United States Geological Survey to service the physical system, perform quality assurance, maintain rating curves converting stage to discharge, and to serve and display these data. Such costs prohibit many streams from being monitored. Data from these-often smaller-streams are essential for hydrologists, fisheries biologists, indigenous tribes, water recreationalists, anglers, natural resources management agencies, and all of the related industries.

To augment formally collected data, could we solicit citizen scientists to collect at least water-level data? While not a replacement for official data, maybe citizen scientists could provide a valuable supplement. To test this, a class A staff gauge was installed at the Buffalo Audubon Society nature center in North Java, NY, United States in 2010 and with a sign that asked passers-by to use their phones to text message the readings (data) to the researchers (Lowry and Fienen, 2013). It worked. These data were then used to model the hydrology of a stream and wetland system using MODFLOW (Feiner and Lowry, 2015). These citizens provided valuable stream-height information where there was none (Seibert and Vis, 2016; van Meerveld et al., 2017). Additional gauges were installed and the network was dubbed CrowdHydrology. Through this monitoring network, crowd-sourced data were presented on a website ${ }^{2}$. Below, we describe how this one gauge grew into a network of gauges and we assess this growth.

\section{MATERIALS AND METHODS}

To participate in CrowdHydrology, citizen scientists read the water level in streams and ponds on a staff gauge and send in text messages reporting their observed water levels (Lowry and Fienen, 2013). At each physical gauge there are two signs, one on the shore that informs the participant on how they can contribute (Figure 1B) to the project and a second sign at the top of the staff gauge (Figure 1A). The participant is asked to send in a text message of the water level and the station ID to a specific phone number. Once a citizen scientist chooses to participate, their text message is sent via their mobile phone to a central computer server. The central server then runs the Social.Water python code (Fienen and Lowry, 2012), which is open-source and freely available to the public ${ }^{3}$, that reads and parses each text message. The Social.Water code extracts the time stamp of the observation, water level, and creates a unique identifier (obscuring name and phone number) for each participant based on the participant's phone number. These data are added to the associated station database. Within a maximum of $5 \mathrm{~min}$ of a citizen scientist texting in a water level, their reported water level is published on the web (see text footnote 2) and is available for distribution.

${ }^{2}$ www.CrowdHydrology.com

${ }^{3}$ https://github.com/mnfienen-usgs/Social.Water
The placement of these gauges is critical to citizen science engagement. Popular stream access locations for placing gauges do not always align with professional scientists' research questions. Often, the placement of one of these gauges depends upon the support of a watershed group or nature center staff to commit to maintaining the station. Early in the project, we spent a significant amount of time trying to get permission to place these stations in streams, but after 8 years in operation most new stations are initiated by partner watershed and environmental groups. Due to the physical location of the original project team, most stations are within the Great Lakes region with limited expansion in the western and eastern United States (Figure 2).

The methodology of hydrology data collection via this program has been described elsewhere (Fienen and Lowry, 2012; Lowry and Fienen, 2013), and this research focuses on analyzing when and where citizen scientists chose to participate and what conditions are most conducive to their participation. The results presented here are based on citizen observations from approximately 8,000 unique participants over 8 years. These data allow us to identify how often and where a given citizen scientist has chosen to provide an observation, the seasonality of observations, the popularity of given observation stations, and the mobility of participants who send in observations across multiple locations.

\section{RESULTS}

From July 2011 to July 2018, the cumulative growth of CrowdHydrology reached 120 stations in 13 states (Figure 3). The first 2 years of the project showed small growth while the network was still a regional network in New York State. The transition to a multi-state network is shown by the state abbreviations on Figure 3, which represent the time when the first new stations in a given state joined the network. Rapid growth in the summer of 2013 likely corresponded with personal networking with several watershed groups in Michigan and a National Public Radio story on Weekend Edition (see NPR marker, Figure 3). Other step increases, such as during the summer of 2016, are attributed to expansion of the network within existing states.

\section{Participants}

For the study period, the CrowdHydrology system received 16,294 observations from 8,255 unique participants. The majority (86\%) of participants submitted only a single observation (Figure 4). The distribution of the number of observations per participant decreased with increased observations per participant. Eleven people or $0.1 \%$ of the citizen scientists sent in over 100 observations. Participants with over 100 observations are classified here as "champions." While this group of champions was small, they contributed $19 \%$ of all observations. Most champions sent in observations for a single site, while only four champions sent in observations at more than one site. The greatest number of sites a single champion contributed to was six, while the largest number of champions at a single 
A

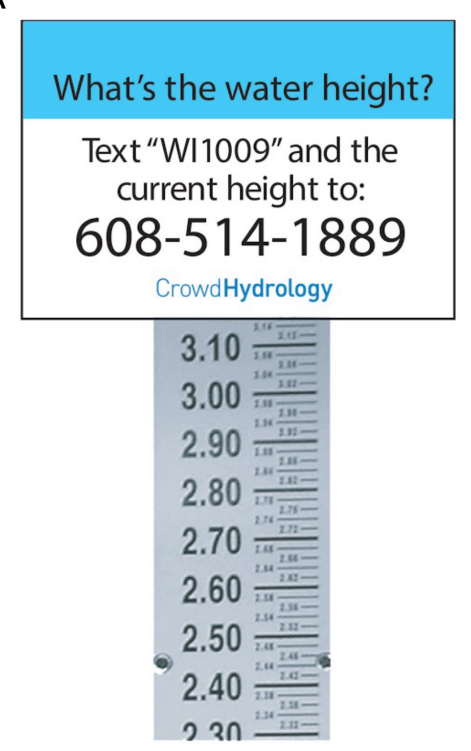

B

\section{What's the water height today? Text us.}

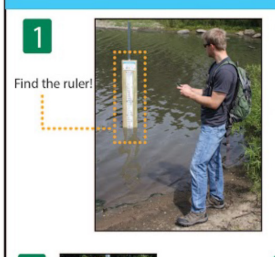

What to do:

1. Look around for a ruler mounted in the water.

2. Read the measurement at the water's surface.

3. Text that number and "WI1009" to 608-514-1889.

Visit www.crowdhydrology.com to see your measurement (It will take a few minutes to load your point.)

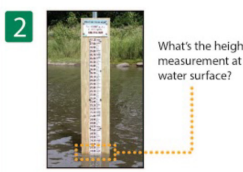

CrowdHydrology collects water data using social media and citizen science. When you text us today's water height, we use your measurement to create a historical record of this lake or stream. If enough people send data, we can help predict floods and droughts.

State and local agencies can't put scientific monitoring equipment on every water body, but CrowdHydrology provides a way for local communities to track any lake or stream that's important to them. Help support CrowdHydrology by

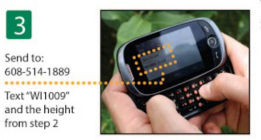
ding a measurement every time you visit this area.

CrowdHydrology | PARTNERS

POWERED BY: social water ‡USGS

FIGURE 1 | CrowdHydrology informational signage in (A) stream and (B) on shore asking citizen scientists to send in observations of water levels.

gauge was two. Three sites had two champions each (MI1033, NY1008, and OR1000).

\section{Station Popularity}

The ten most popular stations in the network represent $62 \%$ of the total network observations (Table 1). The locations of these stations are grouped into three categories: nature centers, hiking trails, and city parks. Of the three categories of locations, only the nature centers have personnel on site who may encourage citizen scientists to contribute observations. The top three stations, on average, received almost one observation a day without having any educator or staff on site to promote participation in the program. Three of the top 10 stations had two champions at each station and two of the top 10 stations has a single champion (NY1000, NY1009). The percentage of total observations from champions at these stations varies from $79 \%$ (MI1033) to $27 \%$ (NY1009) with an average of $45 \%$ of the observations coming from champions and no trend in location type.

\section{DISCUSSION}

\section{Lessons Learned Data Accuracy}

There is always the question of accuracy of the participants' data. Numerous comparison studies of volunteer vs. professional water resources data suggest that volunteer data are generally comparable to professional data for chemical (Obrecht et al., 1998; Loperfido et al., 2010), physical (Rodrigues and Castro, 2008), and biological (Fore et al., 2001; Vail et al., 2003; Gowan et al., 2007; Stepenuck et al., 2011) monitoring. Notably, in all of these studies, volunteers were trained to carry out the monitoring in which they were engaged. Alternatively, untrained volunteers have been observed to produce less accurate data when sorting and identifying macroinvertebrates (Nerbonne and Vondracek, 2003). Arguably that was a more challenging type of monitoring than is employed in the CrowdHydrology network. One concern is that one-time participants may submit inaccurate observations due to a lack of familiarity with the methods. Nonetheless, to ensure accurate observations are made over time, developing a short training video that participants can view on their phones at the field sites may help ensure accuracy of the submitted data across participants. Limited validation in the CrowdHydrology project, using a co-located pressure transducer (Lowry and Fienen, 2013), revealed root mean square error of participant data versus researcher data of about 0.02 feet - roughly the resolution of a class A staff gauge.

\section{Citizen Participation}

The CrowdHydrology network is dominated by one-time participants who submitted just under half of all observations received into the system. Fewer than three percent of the total participants $(8,255)$ sent in more than five observations. This may be due to the program design, which engages volunteers in data collection to address scientist-defined questions, and provides limited communications between scientists and volunteers. Such programs, sometimes termed contributory, are predicted to be effective in adding to large scale data collection efforts (Shirk et al., 2012), as has been demonstrated with the CrowdHydrology network. However, because contributory programs are scientistled, the likelihood that the monitoring efforts address public interests is minimized (Shirk et al., 2012). This has been suggested to limit participant ownership of these data (Cornwall and Jewkes, 1995). As such, it may limit volunteer motivation to contribute data over time (Rotman et al., 2014). Further, in contributory programs, limited communications between 


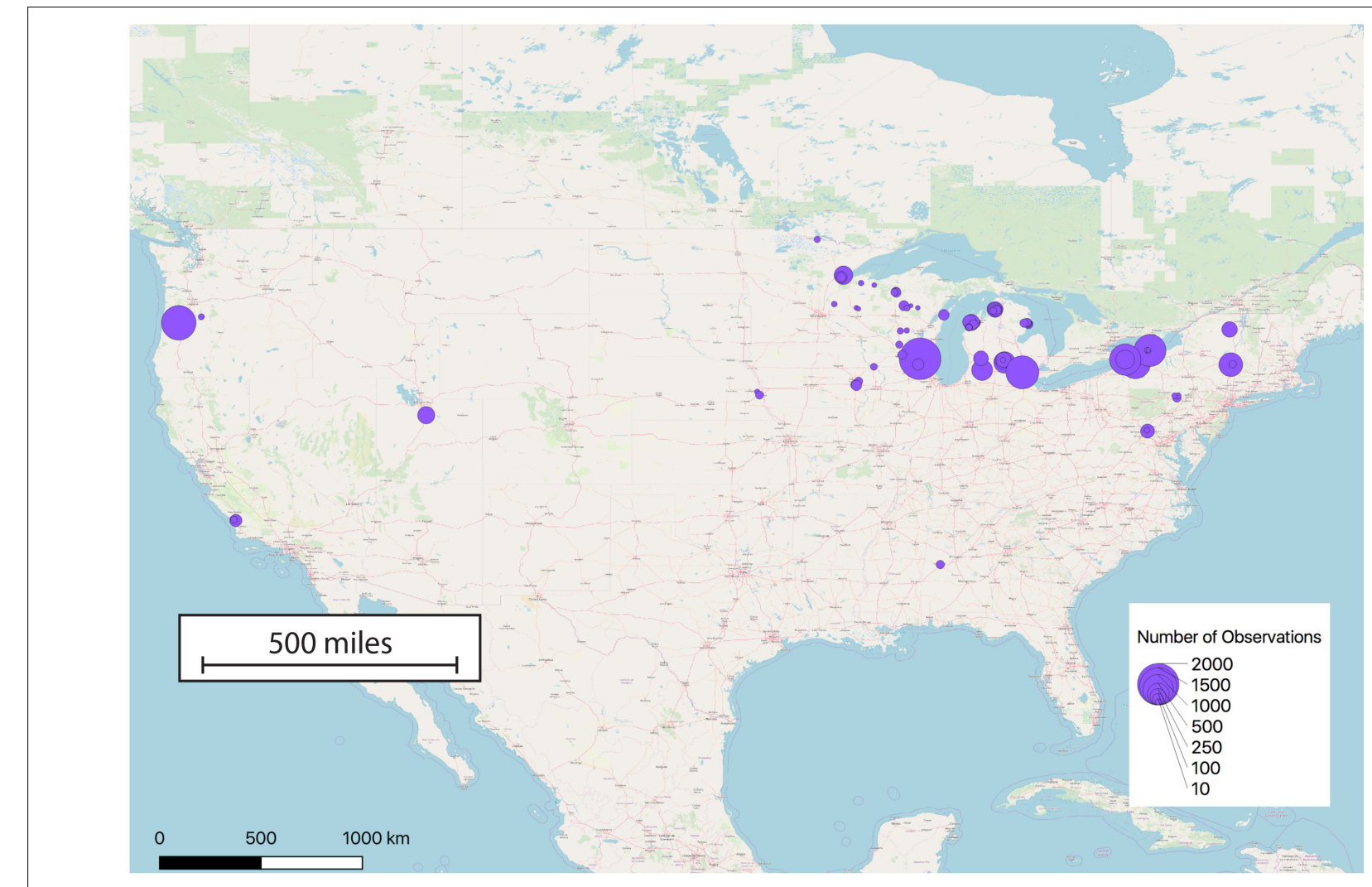

FIGURE 2 | Locations of CrowdHydrology gauges as of July 2018 with the size of the marker indicating the number of citizen science observations.

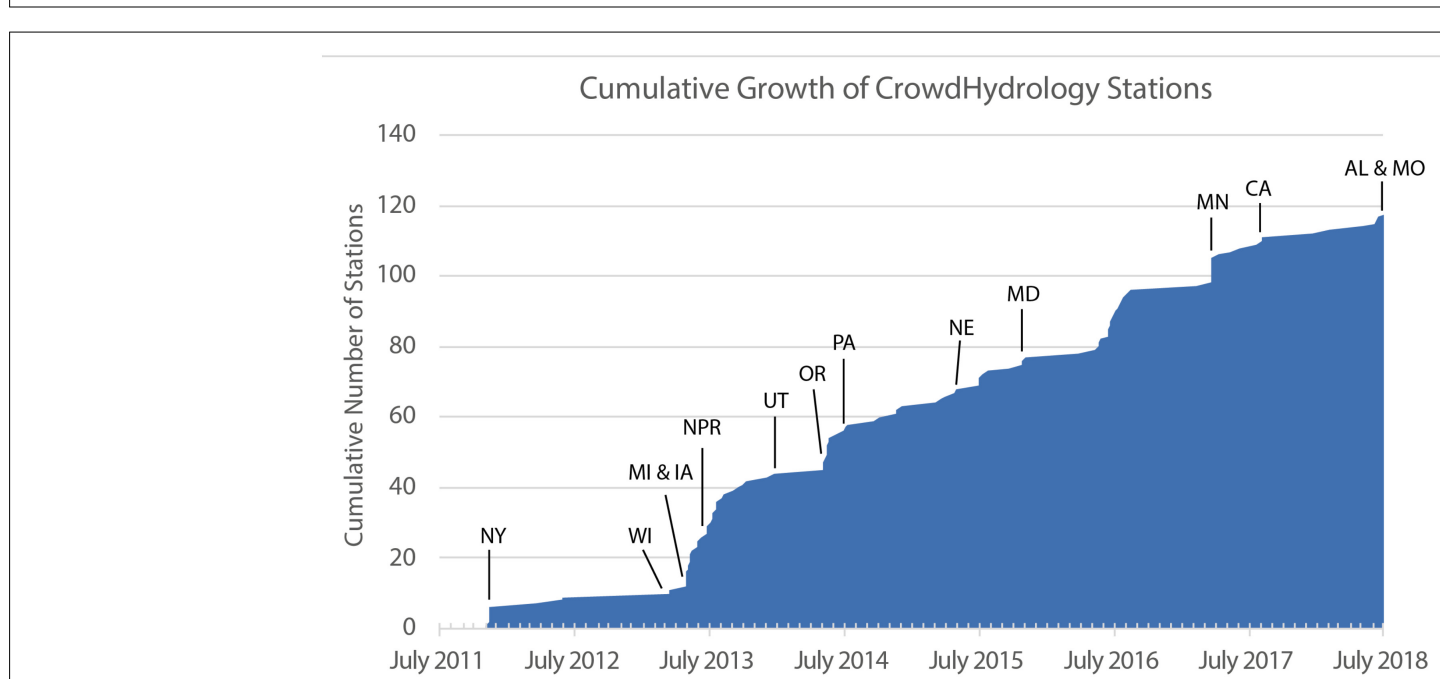

FIGURE 3 | Growth of the CrowdHydrology network. State initials designates the time the first CrowdHydrology station became active. NPR represents date of national radio coverage.

program leaders and participants reduces opportunity for relationship building and trust development (Shirk et al., 2012). Ongoing communications to share program goals, outcomes, and status, are critical to ensure long-term participation (Rotman et al., 2014) and to sustain volunteer commitment over time (Devlin et al., 2001). CoCoRaHS, for instance, maintains a message blog, sharing educational information relevant to the program, and summarizing data submissions at least weekly, and often every few days ${ }^{4}$. In the CrowdHydrology network, the lead scientists have communicated very little with participants over

${ }^{4}$ http://cocorahs.blogspot.com 
Number of observations per Citizen Scientist

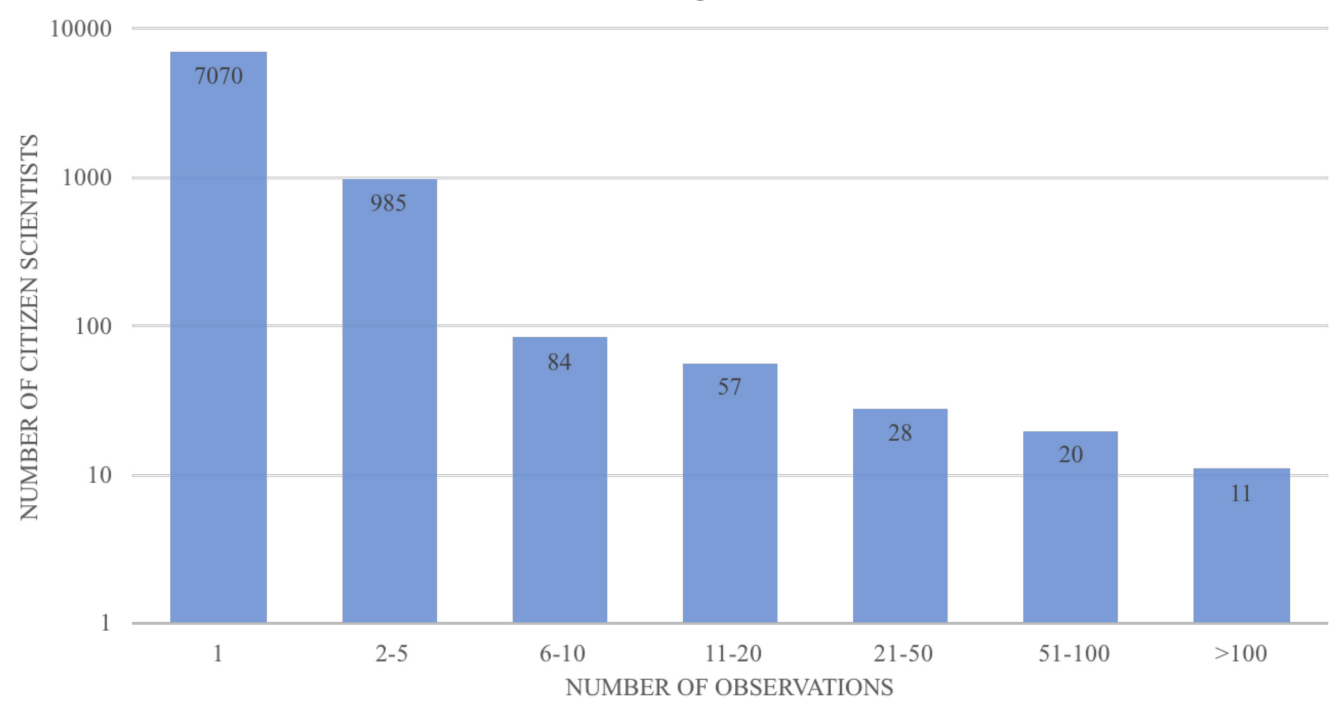

FIGURE 4 | Number of observations submitted per citizen scientist.

time, including not acknowledging data contributions with a reply text message after measurements are submitted. Modifying the methodology in these two ways could fix perceived issues of lack of information, interest, and feedback among onetime participants.

One-time participants are helpful and may be all that are needed in the case of monitoring a specific event in real-time. However, for developing historical trends at a site for monitoring long-term change (Hayhoe et al., 2007), requires transitioning one-time participants into champions. Currently, we have four hypotheses as to why a participant may only send in one observation. The first hypothesis is due to lack of information provided by the professional scientists, causing participants to think it may be only necessary to send in one measurement. This hypothesis is based on anecdotal evidence from talking to one-time participants while performing maintenance on several of the gauges. The onshore signage points out the need for repeated measurements but it is unclear whether participants read and internalize the information from that signage. The second hypothesis is that those who participate have a lack of interest in long-term participation. The onetime participants may find it a novelty to send in a single observation without any true interest in participating in the future. The third hypothesis is that lack of feedback causes participants to become disengaged (or never to become engaged); we have chosen not to send text messages back to citizen scientists thanking them for their observations, or summarizing station results over time. Citizen scientists who have used our system in the past have recently requested feedback to make sure their observation was recorded and to provide further information on why their data are important. This hypothesis is supported by existing research that suggests that without communications, participants have no ownership of the results and do not feel like partners working toward a common scientific mission (Rotman et al., 2014). The fourth hypothesis is that the sparsity of station locations results in limited awareness of the program and ability to contribute over time. This is particularly true when a given citizen scientist does not live near any of the existing gauges and may have submitted their only observation via text message, say, while on vacation. While the fourth hypothesis is not easily addressed, the first three potential hypotheses of one-time participants can be tested, with the hope that we can transition one-time participants into champions.

Champions, who are those participants who send in more than 100 observations, represent a small fraction of the citizen scientist that participate, yet they produce $19 \%$ of the network observations. Five of the top ten CrowdHydrology sites are sustained by champions. These champions tend to have a single station to which they contribute. There is only one champion that has contributed to more than two stations, their contributions are limited to the State of Michigan but cover stations that are spread across the state. As a result of not collecting personal information, it is unclear what motivates this participant but they seem to be an outlier.

\section{Station Popularity}

Our classification of popular stations is based on the total number of observations not on the total number of citizen scientists sending in observations. For professional scientists, the number of observations outweigh the number of participants. Using this classification, the three most common locations - nature centers, hiking trails, and city parks - all represent locations where the general public is commonly present, and likely recreating, which affords them the time and opportunity to participate. Volunteer motivation to participate in citizen science projects relates to participants' interests in helping the environment and contributing to science (Domroese and Johnson, 2017). 
TABLE 1 | Top ten CrowdHydrology stations based on total number of observations.

\begin{tabular}{|c|c|c|c|c|c|}
\hline Station ID & Number of observations & $\%$ of total observations & Location & Initial observation date & Average observations per year \\
\hline Wl1001 & 1854 & $11 \%$ & Hiking Trail & $3 / 27 / 13$ & 347 \\
\hline OR1000* & 1287 & $8 \%$ & City Park & $5 / 17 / 14$ & 306 \\
\hline Ml1033* & 1173 & $7 \%$ & City Park & $4 / 15 / 15$ & 356 \\
\hline NY1008* & 1102 & $7 \%$ & Hiking Trail & $11 / 25 / 11$ & 165 \\
\hline NY1009* & 1060 & $7 \%$ & Nature Center & $5 / 25 / 13$ & 204 \\
\hline NY1000* & 1007 & $6 \%$ & Nature Center & $11 / 15 / 11$ & 150 \\
\hline WI1000 & 929 & $6 \%$ & Hiking Trail & $3 / 27 / 13$ & 174 \\
\hline NY1010 & 597 & $4 \%$ & Nature Center & $10 / 2 / 13$ & 124 \\
\hline Ml1000 & 481 & $3 \%$ & Nature Center & $5 / 14 / 13$ & 92 \\
\hline Ml1004 & 453 & $3 \%$ & Nature Center & $5 / 14 / 13$ & 87 \\
\hline
\end{tabular}

*Designates station with one or more champion.

Stations that proved unpopular included those at boat ramps, near major roads, and at popular fly-fishing holes. In part, the lack of popularity may be the access to a participant's phone at these locations as the participant is in or very near the water. Boat ramps can also be stressful locations as they are shared access points and people tend to be in a rush to move boats in and out of the water. At stations near major roads, it appears that participants do not want to stop or are moving quickly to get away from the road and onto more desirable amenities. Finally, in talking with fly fishermen we have found that many do not carry their phones because they simply want to fish and do not want to be reached. While some of these locations may be scientifically important for a particular study, they lack in citizen engagement.

\section{Future Directions Changes to Our Methodology}

While the growth of the CrowdHydrology network over the last 8 years has been consistent, modification to our methodology is necessary to preserve and expand the network. Based on our historical data we have a hypothesis of why one station location may be more popular than other stations but we need to communicate with the participants at these sites to determine their true motivations. Based on opportunistic conversations with participants we have learned that citizen scientists would like feedback that their message has been received. This is consistent with others' findings as well (Devlin et al., 2001; Rotman et al., 2014). We are currently modifying our methodology to confirm a participant's message was received and respond when an observation is perceived to be incorrect based a preset range of water levels at a given station. This should increase engagement. A mistake in our first 2 years of network operation was not actively engaging with citizens in the local area around CrowdHydrology stations. We have seen rapid growth in the network after engaging several large watershed groups in Michigan and getting some good national level press coverage. There is also a great need to quantify the accuracy of onetime participants as compared to champions. In the application of citizen science for natural hazards, real-time data will likely come from one-time participants. As professional scientists, we need to know what types of data we can count on these citizen scientists to report and we need to know the accuracy of those data. All of these require close examination and reflection on our communications with participants to assess how we can more meaningfully engage citizens based on their interests, concerns, and data needs (Hall et al., 2016). Finally, we have no data on non-participation-individuals who may visit one of the CrowdHydrology stations and choose not to make an observation. Non-participation is likely extremely high, but in understanding the motivation of potential citizen scientists we have an opportunity for further engagement and thus expansion.

Several CrowdHydrology network modifications, if implemented, may aid in nurturing some of the one-time volunteers to submit additional observations. First, to address possible participant confusion over their role as data contributors, we could update signage at sites to more prominently ask people to visit and report data on multiple occasions. To address the potential that people are only participating as a novelty or are not engaging or becoming disengaged due to lack of feedback, as noted previously, we are generating automated text messages to be sent in response to those who submit observations as confirmation that there is a purpose and reason for their actions. When we initiated the project, we were concerned that a response message might trigger privacy concerns among participants, but subsequent literature has suggested that the value to participation would likely eclipse such privacy concerns, and in our response, we can include an opt-out option. We could also develop partnerships with local emergency management agencies or weather forecasters, educating them about the available water level data, and thereby creating a meaningful, altruistic reason for people to continue to submit results - as their observations may inform flood forecasting or be a first indicator, or a unique indicator, of an extreme event. The Cooperative Observer and CoCoRaHS networks both share data with the National Weather Service and other weather forecasting agencies, with individual observers occasionally being credited publicly (e.g., Jankoski, 2016). Notably, the Cooperative Observer Network is one of the oldest citizen science networks in the United States, beginning in 1890 (Kunkel et al., 2005). Further, gamification, such as recording the number of observations per volunteer or a providing a forum platform where participants can share 
anecdotes from their sites to the network website may help people to build a personal connection among participants, and encourage gentle competition among them to help them to engage repeatedly over time. Such an approach was recently adopted by a similar program, CrowdWater (Seibert et al., 2019), which operates primarily in Europe ${ }^{5}$. While altruistic reasons have been observed to be a motivation for volunteers early in a program, we know that building personal networks is cited as a valued outcome and motivator for continued participation over time (Ryan et al., 2001; Gooch, 2005). This deserves future attention.

Champions are key to developing a robust network fueled by consistent observations at specific locations. However, champions seem to contribute to a single station, even when multiple stations are located near each other. Future work should focus on understanding motivations of current champions, and using that information, identifying potential champions at a given station and then encouraging them to become champions. We have no evidence to suggest that champions are motivated to visit a site explicitly to send in a measurement, but with some gamification or reward mechanism, they might be motivated. Surveying current champions to assess their motivations will help hone our actions. Developing strategic partnerships with organizations with existing volunteer bases and communications networks could result in expanded environmental data collection and the ability to identify long-term trends (Imperial, 2005). Further, such partnerships with local watershed organizations, state agencies or non-profits could enable CrowdHydrology gauges to be installed in targeted areas where there have been or are predicted to be flooding or other critical events. A recent study suggests that volunteer water monitoring groups that focus their efforts to address environmental crises report more impacts for natural resource policy and management (Stepenuck and Genskow, 2019).

\section{Network Expansion}

Results show an initially slow expansion of the CrowdHydrology network with 2 years of limited growth. This was followed by a marked increase in stations as methodologies were validated, new partnerships were formed, and national media attention was gained. This record does not include the initial method development starting in 2010 where data processing procedures were developed and tested at a single site. Starting at the end of 2012, we presented the methodology used for data processing at scientific conferences, and demonstrated the accuracy of the method (Fienen and Lowry, 2012; Lowry and Fienen, 2013). Publishing our first two papers convinced professional scientists that these methods could be useful. This validation contributed to the expansion of the network into three new states. Additionally, in the spring of 2013, the National Public Radio show Weekend Edition ${ }^{6}$ reported a story on the CrowdHydrology network. This publicity resulted in doubling the number of stations in the network and connected

\footnotetext{
${ }^{5}$ https://www.crowdwater.ch/en/welcome-to-crowdwater/

${ }^{6}$ https://www.npr.org/templates/story/story.php?storyId=203890657? storyId= 203890657
}

us with other professional scientists across the country. As a result, the network has experienced steady growth over the last 5 years.

There also appears to be a critical mass effect where watersheds with one or two stations (i.e., CA, OR, UT) do not seem to promote additional stations, however, having 10 or more stations (i.e., MI) in a watershed promotes rapid growth of additional stations. The promotion of additional stations may also be impacted by the type of organization that installed the gauge. The gauges installed in OR and UT are maintained by academic institutions, which may not have a vested interest beyond a specific stream location, or capacity to promote participation in or expansion of the network. Conversely, the MI sites are maintained by a variety of watershed groups that likely promote the growth of the network. Many watershed groups benefit from having a network of members with a shared interest in protecting a waterbody, and are motivated to engage in monitoring as part of their membership (Middleton, 2001).

\section{CONCLUSION}

Analysis of the results over an 8-year data collection period partially support our primary hypothesis that a strong citizen science network is maintained by a core group of engaged individuals. Almost $20 \%$ of the CrowdHydrology observations were reported by just $0.1 \%$ of the total number of participants; these "champions" submitted greater than 100 observation per person. An opportunity exists to engage in future research to understand motivations of these individuals and to use that information to encourage more extensive participation by others. Our results also suggest missed opportunities to engage with one-time users to promote further participation. This is a lesson not only to us, but to other citizen science programs globally. We intend to shift our recruitment methodologies to promote participation through active requests for data collection (e.g., by updating signage at monitoring sites), and our ongoing communications to provide feedback to participants to encourage great participation.

Citizen science projects take time to build a robust and sustainable network. The expansion of the CrowdHydrology network took almost 3 years to grow beyond a small regional network. The network expansion corresponded with the validation of the methodology, development of connections with watershed groups, and some good publicity. These factors are credited with expansion of the network into the larger Great Lakes region and midwestern region of the United States. Continued network expansion seems to be most successful where there is a critical mass of stations, which partially supports our secondary hypothesis. The growth of the network seems to do best when there are more than 10 stations in a given watershed causing potential participants in neighboring watersheds to set up stations. One or two stations in a small watershed seem to do little to promote the growth of the network, which does not support our secondary hypothesis. Even with a set of champions 
at a given station (i.e., OR1000) resulting in a robust time series, the lack of a critical mass of stations seems to prevent expansion within a watershed. This leads to the idea that quantity of stations not quality of data at a single station may be the driving factor in network expansion in a region.

The popularity of a station seems to be highly dependent on its physical location. Locations at nature centers, hiking trails, and city parks represent stations with the largest participation. The commonality of these stations seems to be locations where the public are physically moving slowly and in locations that predispose participants to observe nature. Areas near roadways and recreational water locations (boat ramps and fishing spots) were found to be poor locations based on our observation record. These locations, with low observational counts, represent locations where the potential citizen scientists are focused on specific tasks other than measuring water levels. When considering the placement of future observational stations these patterns may be helpful. However, these locations may not align with fundamental research questions posed by professional scientists.

Citizen science programs can generate extensive data sets that can aid researchers in addressing locally specific and broad scale questions. However, to generate the most comprehensive and useful datasets, professional scientists must take care to not only formulate specific questions, but to communicate required data needs to intended citizen participants. Without such information, many participants may contribute only limited data, thus hindering the ability of the researcher to understand systems or to draw conclusions. Recommendations for ensuring complete datasets include providing feedback to participants about the data submitted, data needs, and scientific purpose and importance of the data being collected.

\section{REFERENCES}

Bell, S., Cornford, D., and Bastin, L. (2013). The state of automated amateur weather observations. Weather 68, 36-41. doi: 10.1002/wea.1980

Breuer, L., Hiery, N., Kraft, P., Bach, M., Aubert, A. H., and Frede, H.-G. (2015). HydroCrowd: a citizen science snapshot to assess the spatial control of nitrogen solutes in surface waters. Sci. Rep. 5:16503. doi: 10.1038/srep16503

Butcher, G., Fuller, M., McAllister, L., and Geissler, P. (1990). An Evaluation of the christmas bird count for monitoring population trends of selected species. Wildlife Soc. Bull. 18, 129-134.

Canfield, D. E. Jr., Bachmann, R. W., Stephens, D. B., Hoyer, M. V., Bacon, L., Williams, S., et al. (2016). Monitoring by citizen scientists demonstrates water clarity of Maine (USA) lakes is stable, not declining, due to cultural eutrophication. Inland Waters 6, 11-27. doi: 10.5268/iw-6.1.864

Cifelli, R., Doesken, N., Kennedy, P., Carey, L. D., Rutledge, S. A., Gimmestad, C., et al. (2005). The community collaborative rain, hail, and snow network: informal education for scientists and citizens. Bull. Am. Meteorol. Soc. 86, 1069-1077.

Cornwall, A., and Jewkes, R. (1995). What is participatory research? Soc. Sci. Med. 41, 1667-1676.

Devlin, M., Waterhouse, J., and Brodie, J. (2001). Community and connectivity: summary of a community based monitoring program set up to assess the movement of nutrients and sediments into the great barrier reef during high flow events. Water Sci. Technol. 43:121. doi: 10.2166/wst.2001.0522

\section{ETHICS STATEMENT}

As a citizen science project, this study uses observations from humans of water levels in streams and lakes in the form of text messages. Our methodology converts all incoming text messaged to a universally unique identifier (UUID) using our Social.Water code resulting in no identifiable information collected from subjects. We contacted the IRB office at the University at Buffalo and were told this study does not require approval as no personal identifiable data is collected.

\section{AUTHOR CONTRIBUTIONS}

CL and MF developed the CrowdHydrology network. MF wrote the Social.Water code used to compile observations and identify unique participants. CL analyzed and processed these data. DH and $\mathrm{KS}$ analyzed the trends in citizen science observations. CL, $\mathrm{MF}, \mathrm{DH}$, and KS contributed to the writing of the manuscript.

\section{FUNDING}

This research was supported by the National Science Foundation under grants ABI-1661324 and SCC-1831475.

\section{ACKNOWLEDGMENTS}

This work would not be possible without the support of thousands of citizen scientists and watershed organizations that took the time to install CrowdHydrology gauges and send in water level measurements. Any use of trade, firm, or product names is for descriptive purposes only and does not imply endorsement by the U.S. Government.

Domroese, M. C., and Johnson, E. A. (2017). Why watch bees? Motivations of citizen science volunteers in the great pollinator project. Biol. Conserv. 208, 40-47. doi: 10.1016/j.biocon.2016.08.020

Elmore, K. L., Flamig, Z. L., Lakshmanan, V., Kaney, B. T., Farmer, V., Reeves, H. D., et al. (2014). MPING: crowd-sourcing weather reports for research. Bull. Am. Meteorol. Soc. 95, 1335-1342. doi: 10.1175/bams-d-13-00014.1

Feiner, K., and Lowry, C. S. (2015). Simulating the effects of a beaver dam on regional groundwater flow through a wetland. J. Hydrogeol. Reg. Stud. 4, 675-685. doi: 10.1016/j.ejrh.2015.10.001

Fienen, M. N., and Lowry, C. S. (2012). Social. water-A crowdsourcing tool for environmental data acquisition. Comp. Geosci. 49, 164-169. doi: 10.1016/j. cageo.2012.06.015

Fore, S. L., Paulsen, K., and O'laughlin, K. (2001). Assessing the performance of volunteers in monitoring streams. Freshwater Biol. 46, 109-123. doi: 10.1046/j. 1365-2427.2001.00640.x

Gauchat, G. (2012). Politicization of science in the public sphere: a study of public trust in the United States, 1974 to 2010. Am. Sociol. Rev. 77, 167-187. doi: $10.1177 / 0003122412438225$

Gooch, M. (2005). Voices of the volunteers: an exploration of the experiences of catchment volunteers in coastal Queensland, Australia. Local Environ. 10:5. doi: 10.1080/1354983042000309289

Gowan, C., Ruby, M., Knisley, R., and Grimmer, L. (2007). Stream monitoring methods suitable for citizen volunteers working in the coastal plain and lower piedmont regions of virginia. Am. Entomol. 53, 48-57. doi: 10.1093/ae/53.1.48 
Hall, D. M., Gilbertz, S. J., Anderson, M., and Ward, L. (2016). Beyond "buy-in": designing citizen participation in water planning as research. J. Cleaner Prod. 133, 725-734. doi: 10.1016/j.jclepro.2016.05.170

Hayhoe, K., Wake, C. P., Huntington, T. G., Luo, L., Schwartz, M. D., Sheffield, J., et al. (2007). Past and future changes in climate and hydrological indicators in the US Northeast. Clim. Dyn. 28:381. doi: 10.1007/s00382-006-0187-8

Imperial, M. T. (2005). Using collaboration as a governance strategy: Lessons from six watershed management programs. Administr. Soc. 37, 281-320. doi: $10.1177 / 0095399705276111$

Jankoski, T. (2016). Become a CoCoRaHS Weather Observer! NBC Connecticut. Available at: https://www.nbcconnecticut.com/weather/stories/CoCoRahsMarch-Madness-Become-a-Weather-Observer-370945001.html (accessed October 23, 2018).

Kampf, S., Strobl, B., Hammond, J., Anenberg, A., Etter, S., Martin, C., et al. (2018). Testing the Waters: Mobile Apps for Crowd Sourced Stream Flow Data. Seattle: EOS.

Kuhn, T. S. (1962). The Structure of Scientific Revolutions. Chicago: University of Chicago Press, 264.

Kunkel, K. E., Easterling, D. R., Hubbard, K., Redmond, K., Andsager, K., Kruk, M. C., et al. (2005). Quality control of pre-1948 cooperative observer network data. J. Atmos. Ocean. Technol. 22, 1691-1705. doi: 10.1175/JTECH1816.1

Le Coz, J., Patalano, A., Collins, D., Guillén, N. F., García, C. M., Smart, G. M., et al. (2016). Crowdsourced data for flood hydrology: feedback from recent citizen science projects in Argentina, France and New Zealand. J. Hydrol. 541, 766-777. doi: 10.1016/j.jhydrol.2016.07.036

Little, K. E., Hayashi, M., and Liang, S. (2016). Community-based groundwater monitoring network using a citizen-science approach. Groundwater 54, 317 324. doi: 10.1111/gwat.12336

Loperfido, J. V., Beyer, P., Just, C. L., and Schnoor, J. L. (2010). Uses and biases of volunteer water quality data. Environ. Sci. Technol. 44, 7193-7199. doi: 10.1021/ es100164c

Lottig, N. R., Wagner, T., Norton Henry, E., Spence Cheruvelil, K., Webster, K. E., Downing, J. A., et al. (2014). Long-term citizen-collected data reveal geographical patterns and temporal trends in lake water clarity. PLoS One 9:e95769. doi: 10.1371/journal.pone.0095769

Lowry, C. S., and Fienen, M. N. (2013). CrowdHydrology: crowdsourcing hydrologic data and engaging citizen scientists. Ground Water 51, 151-156. doi: 10.1111/j.1745-6584.2012.00956.x

Michelsen, N., Dirks, H., Schulz, S., Kempe, S., Al-Saud, M., and Schüth, C. (2016). YouTube as a crowd-generated water level archive. Sci. Total Environ. 568, 189-195. doi: 10.1016/j.scitotenv.2016. 05.211

Middleton, J. V. (2001). The stream doctor project: community-driven stream restoration: through the sos program, the izaak walton league is working to increase public awareness of water pollution issues and to build an active network of watershed stewards to monitor and restore community streams and rivers. AIBS Bull. 51, 293-296.

Nerbonne, J. F., and Vondracek, B. (2003). Volunteer macroinvertebrate monitoring: assessing training needs through examining error and bias in untrained volunteers. J. North Am. Benthol. Soc. 22, 152-163. doi: 10.2307/ 1467984

Obrecht, D. V., Milanick, M., Perkins, B. D., Ready, D., and Jones, J. R. (1998). Evaluation of data generated from lake samples collected by volunteers. Lake Reserv. Manag. 14, 21-27. doi: 10.1080/07438149809354106
Pew Research Center (2018). Internet and Technology Mobile Fact Sheet. Available at: http://www.pewinternet.org/fact-sheet/mobile/ (accessed October 23, 2018).

Richardson, A. D., Hufkens, K., Milliman, T., Aubrecht, D. M., Chen, M., Gray, J. M., et al. (2018). Tracking vegetation phenology across diverse North American biomes using PhenoCam imagery. Sci. Data 5:180028. doi: 10.1038/ sdata.2018.28

Rodrigues, A. S. L., and Castro, P. T. A. (2008). Adaptation of a rapid assessment protocol for rivers on rocky meadows. [Adaptacao de um protocolo de avaliacao rapida para rios em campos rupestres]. Acta Limnol. Brasil. 20, 291-303.

Rotman, D., Hammock, J., Preece, J., Hansen, D., Boston, C., Bowser, A., et al. (2014). "Motivations Affecting Initial and Long-Term Participation in Citizen Science Projects in Three Countries," in Proceedings of the iConference 2014, (London: ACM), 110-124.

Ryan, R. L., Kaplan, R., and Grese, R. E. (2001). Predicting volunteer commitment in environmental stewardship programmes. J. Environ. Plan. Manag. 44, 629648. doi: 10.1080/09640560120079948

Seibert, J., Strobl, B., Etter, S., Hummer, P., and van Meerveld, H. J. (2019). Virtual staff gauges for crowd-based stream level observations. Front. Earth Sci. 7:70. doi: 10.3389/feart.2019.00070

Seibert, J., and Vis, M. J. P. (2016). How informative are stream level observations in different geographic regions? Hydrol. Process. 30, 2498-2508. doi: 10.1002/ hyp. 10887

Shirk, J. L., Ballard, H. L., Wilderman, C. C., Phillips, T., Wiggins, A., Jordan, R., et al. (2012). Public participation in scientific research: a framework for deliberate design. Ecol. Soci. 17:29.

Stepenuck, K. F., and Genskow, K. D. (2019). Understanding key traits of volunteer water monitoring programs that report natural resource management and policy outcomes. Soc. Nat. Resour. 32, 275-291. doi: 10.1080/08941920.2018. 1511022

Stepenuck, K. F., Wolfson, L. G., Liukkonen, B. W., Iles, J. M., and Grant, T. S. (2011). Volunteer monitoring of E. coli in streams of the upper Midwestern United States: a comparison of methods. Environ. Monitor. Assess. 174, 625633. doi: 10.1007/s10661-010-1483-7

Szalay, A., and Gray, J. (2006). 2020 computing: science in an exponential world. Nature 440, 413-414. doi: 10.1038/44 $0413 \mathrm{a}$

Vail, J. H., Morgan, R., Merino, C. R., Gonzales, F., Miller, R., and Ram, J. L. (2003). Enumeration of waterborne escherichia coli with petrifilm plates: comparison to standard methods. J. Environ. Qual. 32, 368-373.

van Meerveld, H. J., Vis, M. J. P., and Seibert, J. (2017). Information content of stream level class data for hydrological model calibration. Hydrol. Earth Syst. Sci. 21, 4895-4905. doi: 10.5194/hess-21-48952017

Conflict of Interest Statement: The authors declare that the research was conducted in the absence of any commercial or financial relationships that could be construed as a potential conflict of interest.

Copyright (c) 2019 Lowry, Fienen, Hall and Stepenuck. This is an open-access article distributed under the terms of the Creative Commons Attribution License (CC BY). The use, distribution or reproduction in other forums is permitted, provided the original author(s) and the copyright owner(s) are credited and that the original publication in this journal is cited, in accordance with accepted academic practice. No use, distribution or reproduction is permitted which does not comply with these terms. 
OPEN ACCESS

Edited by:

Jonathan D. Paul,

Imperial College London,

United Kingdom

Reviewed by:

José Pedro Matos,

Independent Researcher, Switzerland

Hyoungsu Park,

Oregon State University,

United States

*Correspondence: Robert Witkop

robert_witkop@my.uri.edu

Specialty section:

This article was submitted to

Geohazards and Georisks,

a section of the journal

Frontiers in Earth Science

Received: 10 September 2018

Accepted: 14 May 2019

Published: 12 June 2019

Citation:

Witkop R, Becker A, Stempel P

and Ginis I (2019) Developing

Consequence Thresholds for Storm

Models Through Participatory

Processes: Case Study of Westerly

Rhode Island. Front. Earth Sci. 7:133.

doi: 10.3389/feart.2019.00133

\section{Developing Consequence Thresholds for Storm Models Through Participatory Processes: Case Study of Westerly Rhode Island}

\author{
Robert Witkop ${ }^{1 *}$, Austin Becker ${ }^{1}$, Peter Stempel ${ }^{1}$ and Isaac Ginis ${ }^{2}$ \\ ${ }^{1}$ Department of Marine Affairs, University of Rhode Island, South Kingstown, RI, United States, ${ }^{2}$ Graduate School \\ of Oceanography, University of Rhode Island, Narragansett, Rl, United States
}

Emergency managers face challenges in understanding and communicating potential hurricane hazards. Preparedness typically emphasizes the last event encountered, the potential implications of future hazards may thus be underestimated. Risk assessment models (e.g., basic HAZUS) that emphasize accumulated damages in economic terms do not provide actionable data regarding specific local concerns, such as access by emergency vehicles and potential communications disruptions. Qualitative methods conventionally used to identify these concerns, however, lack the specificity necessary to incorporate the managers' knowledge into hazard models (e.g., highly exact geographic location of the vulnerability or cascading consequences). This research develops a method to collect rich, actionable, qualitative data from critical facility managers that can be utilized in combination with hydrodynamic, wind, and precipitation models to assess potential hazard consequences. A pilot study was conducted with critical facility managers in Westerly, RI, United States, using semi-structured interviews and participatory mapping. Interview methods were based on existing practices for vulnerability assessments, and further augmented to obtain data based on hurricane modeling requirements. This research identifies challenges and recommendations when collecting critical facility manager's knowledge for incorporation into storm simulations. The method described enables local experts to contribute actionable knowledge to natural hazard models and augment more traditional engineering-based approaches to risk assessment.

Keywords: consequence, threshold, hazard, hurricane, facility, interview, manager

\section{INTRODUCTION}

Emergency and infrastructure facility managers face challenges in understanding and communicating hurricane hazards (Morrow et al., 2015). Robust emergency management and resiliency planning starts with identifying the problem, which includes understanding impacts, risks, opportunities, and associated vulnerabilities (Moser and Ekstrom, 2010; Preston et al., 2010; Bierbaum et al., 2013). However, preparedness typically emphasizes the last event encountered, which often leads to the underestimation of the risks of future hazards (Adger et al., 2013; Kellens et al., 2013). Traditional risk assessment models (e.g., basic HAZUS) that emphasize accumulated 
damages in economic terms or use generic damage functions do not provide actionable data regarding specific local concerns, such as potential damage to a given facility's emergency generator (Paul et al., 2018). Qualitative methods typically used to identify managers local concerns, however, lack the specificity necessary to incorporate such local concerns into hazard models (e.g., exact geographic coordinates of the vulnerability or cascading consequences), resulting in concerns that can be described, but not modeled. The modeling of hazard impacts for individual pieces of infrastructure and facilities requires data at a resolution that is both specific to the facility and provides specific actionable outputs that are relevant to emergency and facility managers.

Existing data points and damage curves that may be sufficient for generalized or aggregate analysis (e.g., "basic" loss estimation with HAZUS) are often not applicable at granular scales to serve the needs of facility and emergency response managers. While "direct damages" are relatively easy to quantify and "indirect impacts" can be quantified through a variety of economic modeling techniques, the "intangible consequences" that decision makers and society face after a storm are best suited to qualitative data-collection approaches (Becker et al., 2015). This project developed a method to gather rich, actionable, qualitative data from critical facility managers that can be utilized for risk assessment and emergency response. These data provide additional granular detail regarding impacts to enhance Disaster Risk Reduction (DRR) and other participatory risk assessment processes.

Disaster Risk Reduction is the systematic practice of evaluating and reducing risks posed by natural hazards such as storm surge associated with hurricanes (Thomalla et al., 2006). A "context first" DRR approach encourages decision makers to start with the adaptation problem itself (e.g., the need to maintain communications) and then appraises adaptation strategies through hazard impact models (Reeder and Ranger, 2011). DRR assessments also employ risk-based approaches, which take the climate hazard as the starting point of analysis and introduce impact models to an assessment through experts that provide the likelihood and consequence of a particular climate-related event [see for example (Holper et al., 2007; Port of Dover, 2015; Port of Felixstowe, 2015)]. These kinds of DRR assessments most commonly rely on models that predict the impacts of a simulated climate event through engineering approaches based on characteristics of exposed assets (e.g., elevations of coastal homes) and storm hazards (e.g., wave height). Some DRR assessments use vulnerability curves to evaluate physical damage and degree of loss estimations based on flood depth or wind speed at a structure's location (Aerts et al., 2018) while others use fragility curves to predict the probability of similar storm forces causing a specific damage level on an asset (Porter, 2015).

Fragility and vulnerability curves are based on expert opinions, empirical methods, analytical methods or a hybrid of these approaches (Schultz et al., 2010). They may be developed for a particular structure or used to make generalized predictions. Empirical curves use observational data from natural or scientific experiments to predict impacts of hazards while analytical curves use engineering principals of assets and hazards to predict impacts. Methods chosen to build a vulnerability curve depends on the information available and the requirement for a precise output (Schultz et al., 2010). Hybrid curves combine multiple data types to compensate for shortcomings of individual approaches (Porter, 2015). However, in many cases, fragility and vulnerability curves do not account for more detailed qualitative or quantitative storm concerns that may be raised by stakeholders of interconnected systems, such as facility managers in a particular region (Schneider and Schauer, 2006).

Further, many human responses to disasters cannot be reliably output by fragility and vulnerability curves due to the unpredictability of human behavior even though these responses significantly impact damage to and recovery of a system (Aerts et al., 2018). Thus, decision makers are calling for the development of new methods to understand how their concerns may be triggered by storms so that they may find ways to reduce vulnerability and increase resilience (United States Environmental Protection Agency [USEPA], 2008; Becker et al., 2013).

Emergency and facility managers face unique challenges in this regard, as the infrastructure that is relied on to recover from major storm events may itself be vulnerable to storms. Incorporating their concerns (e.g., the short-circuiting of a hospital's generator) into scenario plans through participatory processes such as workshops can improve the accuracy (White et al., 2010) and usefulness of storm models (Messner and Meyer, 2006), and is an essential component of hazard management (Eakin and Luers, 2006). Many DRR methods, including HAZUS, specifically recommend accounting for expert's local concerns when developing detailed storm impact models (Vickery et al., 2006). However, most flood risk assessments use single average fragility and vulnerability curves, ignoring the qualitative concerns of many decision makers. Incorporating these concerns into quantitative DRR assessments can increase their relevance at a finer geographic scale (Brecht, 2007).

Using critical facility managers (FMs) in Westerly Rhode Island in a case study approach, this research addresses the following questions:

RQ1. How can existing methods for eliciting vulnerability data be adapted to collect FMs' intra-facility level storm concerns for inclusion in storm impact models?

RQ2. What challenges exist as researchers collect FM's concerns for incorporation into storm impact models?

$R Q 3$. How can storm impact models be improved by collecting stakeholders' concerns for inclusion in the model?

After establishing the basis for this study's approach through a review of existing assessment methodologies, this methodology is subsequently evaluated based on interviews with $13 \mathrm{FMs}$ in Westerly Rhode Island. The manuscript identifies challenges that exist when collecting interviewee's concerns for incorporation into storm impact models and how storm impact models can be improved by including stakeholders in storm impact modeling through participatory assessments.

Methods for collecting qualitative concerns for incorporation into storm impact models at the intra-facility scale have not 
been elaborated (Palmer and Smith, 2014; Hendricks et al., 2018). There is a framework to incorporate citizen scientists into hydrological models, including for flood risk management (Buytaert et al., 2014), these methods, however, do not specify how to collect stakeholders concerns for incorporation into storm impact models such as HAZUS. This study reviewed 16 vulnerability assessments to establish a basis for collecting stakeholders concerns for incorporation into hazard models. The 16 assessments were chosen because each identified components required for incorporating stakeholder concerns into hazard impact models (Table 1). 15 of the 16 assessments are meant to identify a community's or facility's vulnerabilities by working with local stakeholders.

Preliminary storm impact models created by the authors, and review of literature that will be subsequently described, demonstrated that integrating qualitative concerns into storm impact models requires five components, as follows:

(1) The concern - An asset the stakeholder perceives can be directly impacted by a storm force. For example, a generator that can be short circuited by flooding.

(2) The specific location of concern - The latitude and longitude of the asset the stakeholder believes can be directly

TABLE 1 | Methodologies reviewed for "consequence thresholds" approach.

\begin{tabular}{|c|c|c|c|c|c|}
\hline Vulnerability Assessment Study & $\begin{array}{l}\text { Defines } \\
\text { stakeholder's } \\
\text { local concern }\end{array}$ & $\begin{array}{l}\text { Identifies } \\
\text { specific } \\
\text { Iocation of } \\
\text { concern }\end{array}$ & $\begin{array}{l}\text { Identifies } \\
\text { modellable } \\
\text { hazard }\end{array}$ & $\begin{array}{l}\text { Identifies } \\
\text { threshold(s) }\end{array}$ & $\begin{array}{l}\text { Defines } \\
\text { consequence }\end{array}$ \\
\hline $\begin{array}{l}\text { Climate Risks and Business Port Terminal Marítimo Muelles } \\
\text { el Bosque Cartagena, Colombia (Stenek et al., 2011) }\end{array}$ & $x$ & $x$ & $x$ & $x$ & $x$ \\
\hline $\begin{array}{l}\text { Coping strategies and risk manageability: using } \\
\text { participatory geographical information systems to represent } \\
\text { local knowledge (Peters-Guarin et al., 2012) }\end{array}$ & $x$ & & $x$ & $x$ & $x$ \\
\hline $\begin{array}{l}\text { Development of GIS-based flood-simulation software and } \\
\text { application to flood-risk assessment (Yamaguchi et al., } \\
\text { 2007) }\end{array}$ & & & $x$ & $x$ & $x$ \\
\hline $\begin{array}{l}\text { Climate change impacts on critical international } \\
\text { transportation assets of Caribbean Small Island Developing } \\
\text { States (SIDS): The case of Jamaica and Saint Lucia } \\
\text { (Monioudi et al., 2018) }\end{array}$ & $x$ & & $x$ & $x$ & $x$ \\
\hline $\begin{array}{l}\text { How do you adapt in an uncertain world?: lessons from the } \\
\text { Thames Estuary } 2100 \text { project (Reeder and Ranger, 2011) }\end{array}$ & $x$ & & $x$ & $x$ & $x$ \\
\hline $\begin{array}{l}\text { Climate Risk Assessment for Avatiu Port and Connected } \\
\text { Infrastructure (Cox et al., 2013) }\end{array}$ & $x$ & & $x$ & $x$ & $x$ \\
\hline Preparing for the rising tide (Douglas et al., 2013) & $x$ & & $x$ & & $x$ \\
\hline $\begin{array}{l}\text { Integrating knowledge and actions in disaster risk } \\
\text { reduction: the contribution of participatory mapping (Cadag } \\
\text { and Gaillard, 2012) }\end{array}$ & $x$ & $x$ & $x$ & & $x$ \\
\hline $\begin{array}{l}\text { Hurricane Sandy in New Jersey and New York-Building } \\
\text { Performance Observations, Recommendations, and } \\
\text { Technical Guidance (Federal Emergency Management } \\
\text { Agency [FEMA], 2013) }\end{array}$ & $x$ & & $x$ & & $x$ \\
\hline $\begin{array}{l}\text { The Development of a Participatory Assessment Technique } \\
\text { for Infrastructure: Neighborhood-level Monitoring toward } \\
\text { Sustainable Infrastructure Systems (Hendricks et al., 2018) }\end{array}$ & $x$ & $x$ & & & \\
\hline $\begin{array}{l}\text { Stakeholder vulnerability and resilience strategy assessment } \\
\text { for maritime infrastructure: Pilot project for the Port of } \\
\text { Providence, Rl (Becker et al., 2017) }\end{array}$ & $x$ & & $x$ & & $x$ \\
\hline $\begin{array}{l}\text { Multidisciplinary assessment of critical facility response to } \\
\text { natural disasters: the case of Hurricane Katrina (Hapij, 2011) }\end{array}$ & $x$ & & & & $x$ \\
\hline $\begin{array}{l}\text { The UKCIP Adaption Wizard v } 4.0 \text { (United Kingdom Climate } \\
\text { Impacts Programme [UKCIP], 2013) }\end{array}$ & $x$ & & $x$ & $x$ & $x$ \\
\hline $\begin{array}{l}\text { Climate Risk and Vulnerability Assessment Framework for } \\
\text { Caribbean Coastal Transport Infrastructure (United Nations } \\
\text { Conference on Trade and Development [UNCTAD], 2017) }\end{array}$ & $x$ & & $x$ & $x$ & $x$ \\
\hline $\begin{array}{l}\text { Threat and Hazard Identification and Risk Assessment } \\
\text { Guide Comprehensive Preparedness Guide 201, Second } \\
\text { Edition (Department of Homeland Security [DHS], 2013) }\end{array}$ & $x$ & & $x$ & & $x$ \\
\hline $\begin{array}{l}\text { Adaptation planning in the Lower Mekong Basin: Merging } \\
\text { scientific data with local perspective to improve community }\end{array}$ & $x$ & & $x$ & $x$ & $x$ \\
\hline
\end{tabular}
scientific data with local perspective to improve community resilience to climate change (Gustafson et al., 2018) 
impacted by a storm force. For example, a generator's location at $41.12345 \mathrm{~N}$ and $-71.12345 \mathrm{~W}$.

(3) A modellable hazard - A storm force (or range of forces) that the stakeholder perceives as a risk to the asset, can be quantified such as inundation depth or wind velocity, and is modeled by the underlying storm simulation.

(4) The threshold(s) - The storm force threshold that when exceeded at the location of concern triggers a consequence according to the stakeholder. For example, winds above $100 \mathrm{mph}$ or flooding above one foot.

(5) The consequence - The outcome if the storm force exceeds the threshold at the location of concern according to the stakeholder. For example, the generator would short-circuit.

We define these combined five components as a "Consequence Threshold" (CT), to distinguish this method from other methods of calculating damage and loss (e.g., damage curves).

Some vulnerability assessments have identified all the above CT components and incorporated them into intra-facility level hydrodynamic simulations (Stenek et al., 2011), but none have detailed the nuanced challenges of gathering this information (Table 1). To address this, this research adopts principals from the vulnerability assessment (United Kingdom Climate Impacts Programme [UKCIP], 2013) and participatory mapping methodologies (Cadag and Gaillard, 2012) represented in Table 1 to gather the five CT components since the UKCIP method has been used to explore stakeholder storm concerns and thresholds (Port of Felixstowe, 2015) and Cadag and Gaillard have used participatory mapping techniques to identify locations of stakeholders concerns.

\section{MATERIALS AND METHODS}

\section{Sampling Approach}

Developing meaningful qualitative data regarding critical facilities presents several challenges, such as the sensitivity and security of the information, and the parameters of its use (Rinaldi, 2004). This work was thus conceived in collaboration with the Rhode Island Emergency Management Agency (RIEMA) as part of a larger effort to evaluate and improve preparedness in Rhode Island. Clarity regarding the purposes, scope, and auspices of the work was essential to the perceived legitimacy of the inquiry. This allowed investigators to gain access to FMs within the case study that might otherwise be hesitant to participate because of security threat concerns (Rinaldi, 2004).

Westerly Rhode Island was chosen as the pilot community because of its relatively small number of critical facilities and high level of hazard exposure. Westerly is a coastal community on Rhode Island's southern coast with a population of about 18,000 as of 2010 (United States Census Bureau, 2018). The Hurricane of 1938, 1954, and the "Floods of 2010" (a series of rain events that impacted Westerly during March of 2010) all impacted the town and it lost many buildings during Hurricane Sandy due to storm surge and winds that reached $86 \mathrm{mph}$ (sustained at $64.4 \mathrm{mph}$ ) in Westerly (Manning et al., 2014). The combination of hazard exposure and limited number of facilities allowed for investigation of interdependencies and cascading consequences which are of particular concern to RIEMA.

Gaining access to infrastructure vulnerability information is challenging because it is normally proprietary in nature (Rinaldi, 2004). Partnership with RIEMA and clarity regarding the use of outputs facilitated introductions to local emergency managers (EMs). By the nature of their work, local EMs are highly informed about how a storm affects their community (Newkirk, 2001) and are well connected to the FMs in their community. EMs played an essential role in selecting FMs to interview since FMs are highly informed about their facility (Mendonça and Wallace, 2006) and external resources their facilities rely on (Rinaldi, 2004). Critical facilities were defined in collaboration with EMs based on FEMA's definition as facilities that, "if severely damaged, would reduce the availability of essential community services necessary to cope with an emergency" and facilities "associated with utilities that are required to protect the health and safety of a community" according to the local EM (Federal Emergency Management Agency [FEMA], 2012). These critical facilities include fire departments, police stations, hospitals, and waste water treatment plants among others.

Selected FMs were invited to participate via email and telephone. Investigators explained the overall goal of the research while scheduling interviews (Paul et al., 2018). Additional FMs were interviewed as opportunities presented themselves (Patton and Appelbaum, 2003). In total, 13 FMs from 11 of 30 critical facilities in Westerly were interviewed. This included four fire departments, the police station, the dispatch center, the ambulance corps, the waste water treatment plant, the water department, the largest electrical distribution substation and the department of public works (Figure 1). FMs from Westerly's hospital, school system, telephone networks, and natural gas facilities declined to participate, in most cases due the perceived security threat posed by sharing sensitive information. As this method has been developed, tested and demonstrated in Westerly, interest in participation in subsequent processes across the state has increased. Demonstrating the utility of outputs and trustbuilding through iterative processes is thus essential to building effective databases.

\section{Interview Instrument Design}

An open-ended interview instrument was designed to collect a wide range of FM's storm concerns. Questions were adapted from the Department of Homeland Security's Critical Infrastructure vulnerability assessment (Department of Homeland Security [DHS], 2013), the UKCIP's threshold identification methods (United Kingdom Climate Impacts Programme [UKCIP], 2013), the global consulting firm ICF's climate vulnerability assessment (ICF International, 2017), and results from the Sandy Mitigation Assessment Team for critical facilities (Federal Emergency Management Agency [FEMA], 2013) (see Appendix I). Three members of RIEMA's Critical Infrastructure 


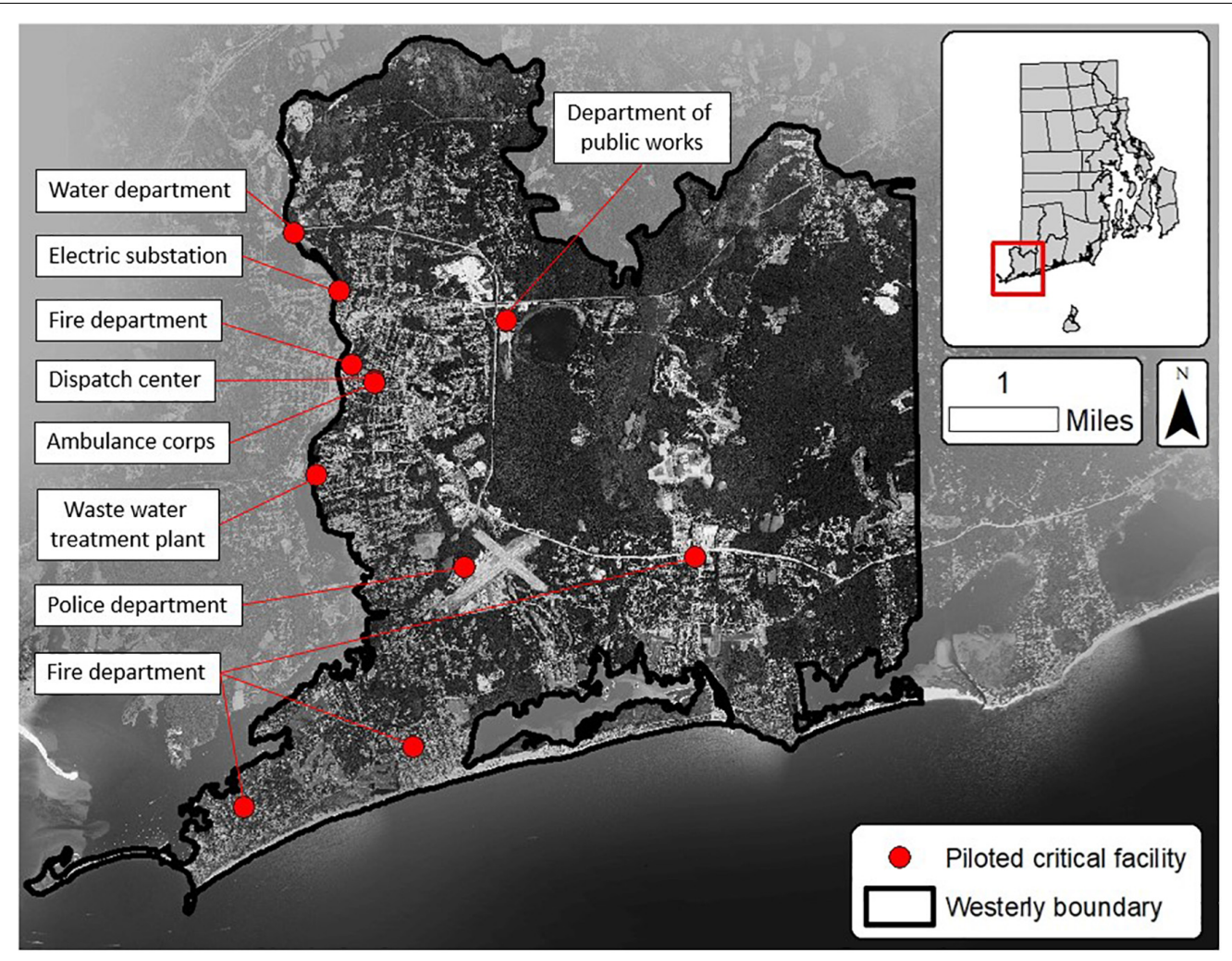

FIGURE 1 | Westerly, RI critical facilities included in pilot study (Image: authors, data from RIGIS).

Program reviewed the survey instrument along with two members of URI Marine Affairs Department, and one ex-FM from Rhode Island.

\section{Interview Process}

In three cases, an interviewee's colleagues joined the interviews, which helped interviewees feel more comfortable and is a recommended practice for risk communication meetings (Chess et al., 1988). To begin, we explained that the purpose of the interview was to collect interviewee's storm concerns for incorporation into storm impact models (Chess et al., 1988). We used an illustration of a fictional CT for a petroleum facility triggered by storm surge from Hurricane Carol at 4:30 pm on August 5th, 1954 overlaid on a modern day map at the Port of Providence as a thought prompt to show the interviewee how the information could ultimately be used (Figure 2; White et al., 2010). We explained to interviewees that their names would be kept confidential and quotes from their responses would not be identified or attributed to them individually but might be discovered due to the limited number of critical facilities in Westerly.

We then asked for the interviewee's immediate concerns to a storm and encouraged them to consider storm consequences on other parts of the community (e.g., roads) that could affect their facility. We listened to interviewee's concerns (Chess et al., 1988), and then worked to identify remaining CT components for each concern interviewees identified (Figure 3).
We asked the interviewee to identify the location of his/her concern on a navigable Google Map satellite (15 m to $15 \mathrm{~cm}$ resolution) and/or street view using a laptop computer (Figure 4). We also asked the interviewee to identify the concern threshold using an open response threshold-identification method similar to the ICF and United Kingdom Climate Impacts Programme (UKCIP) methods (United Kingdom Climate Impacts Programme [UKCIP], 2013; Monioudi et al., 2018). For example, we asked, "What inundation level would cause the consequence you mentioned?" Although interviewees were encouraged to identify the storm forces that the underlying storm models used (rain, wind, storm surge, standing inundation, and wave height), interviewees also identified other weather and geological concerns, for example lightning strikes, soil moisture content, and microbursts.

Interviewee's usually began by identifying storm consequences they had previously experienced. Once the interviewee exhausted these historical reference, asking the interviewee about unprecedented storms enabled the collection of more consequences. If interviewees had trouble identifying concerns, follow-up prompts were used to stimulate the conversation (see Appendix I). For example, questions like, "What are the consequences of one foot of flooding where we are standing now?" or "What concerns do you have if a storm with $150 \mathrm{mph}$ winds passed over this facility?" both prompted additional consequences. The precise wording and order in which the questions came up were not 


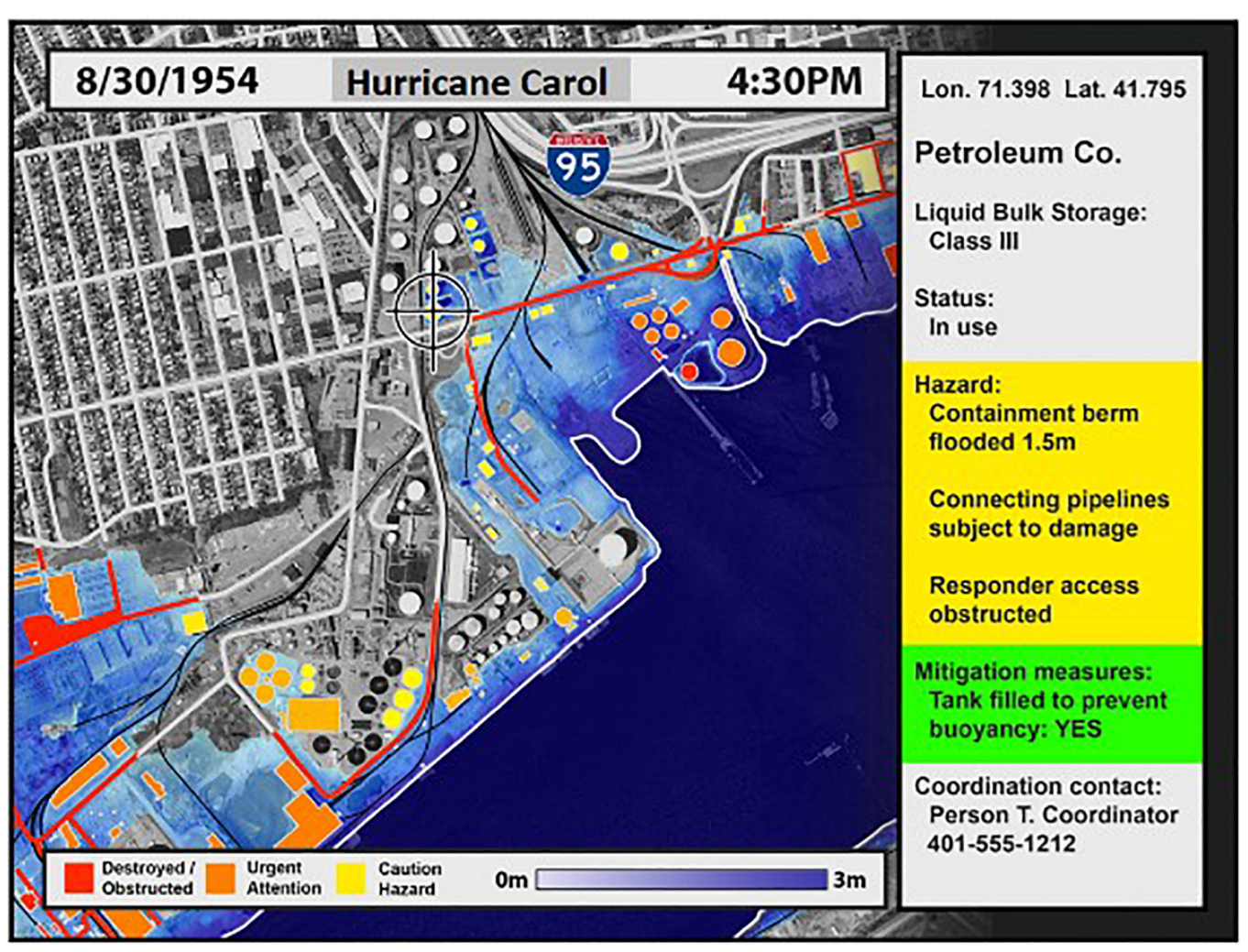

FIGURE 2 | Image used to explain potential of storm models during interviews (Image: authors, data from RIGIS).

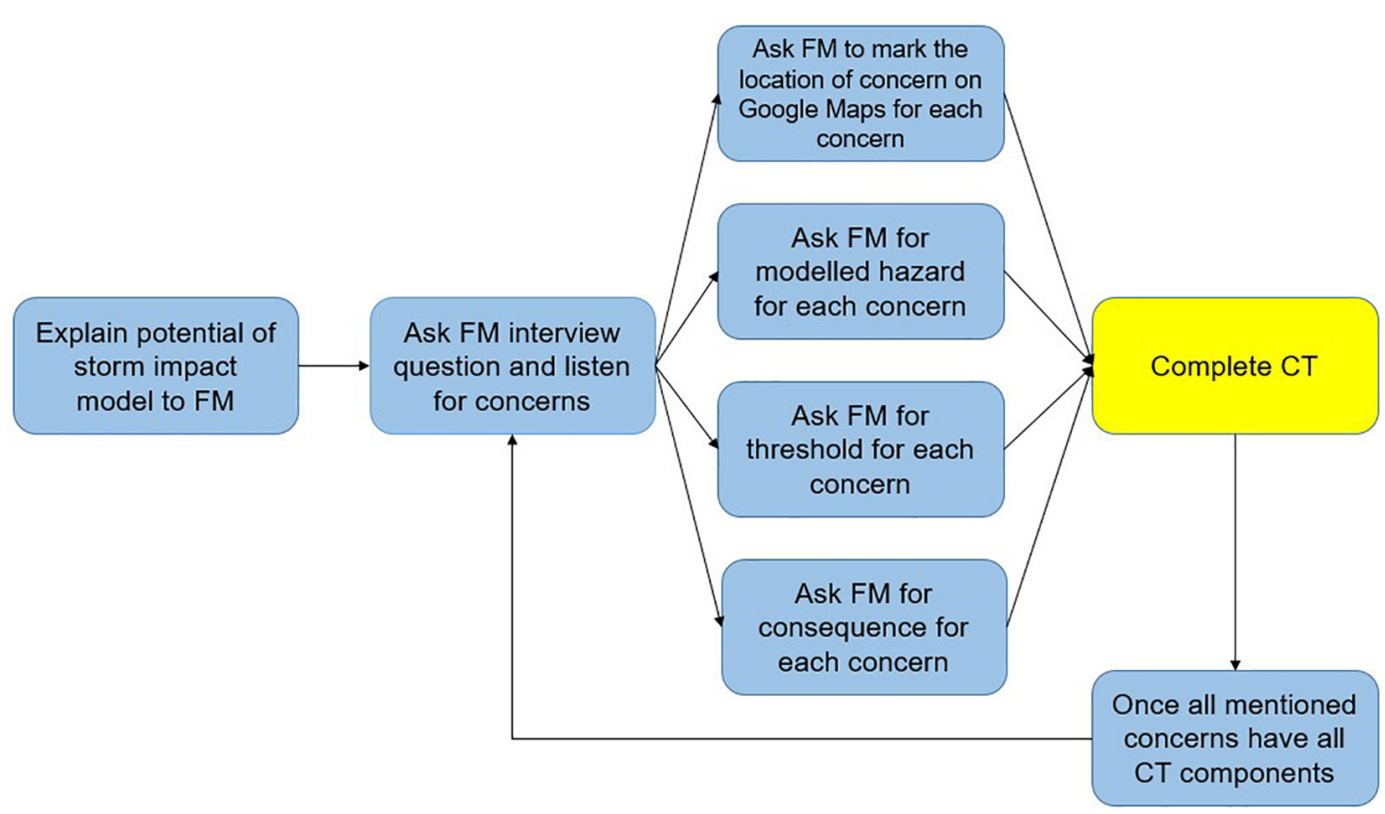

FIGURE 3 | Consequence Threshold (CT) data collection process with facility manager (FM) interviewees (Image: authors).

constrained (Merriam, 1988), since interviews were focused on subjects that matched the interviewee's knowledge and points that the interviewee brought up (Lewis and Sheppard,
2006). Interviewees identified the location of the concern using the navigable Google Maps satellite or street view during the interview. 


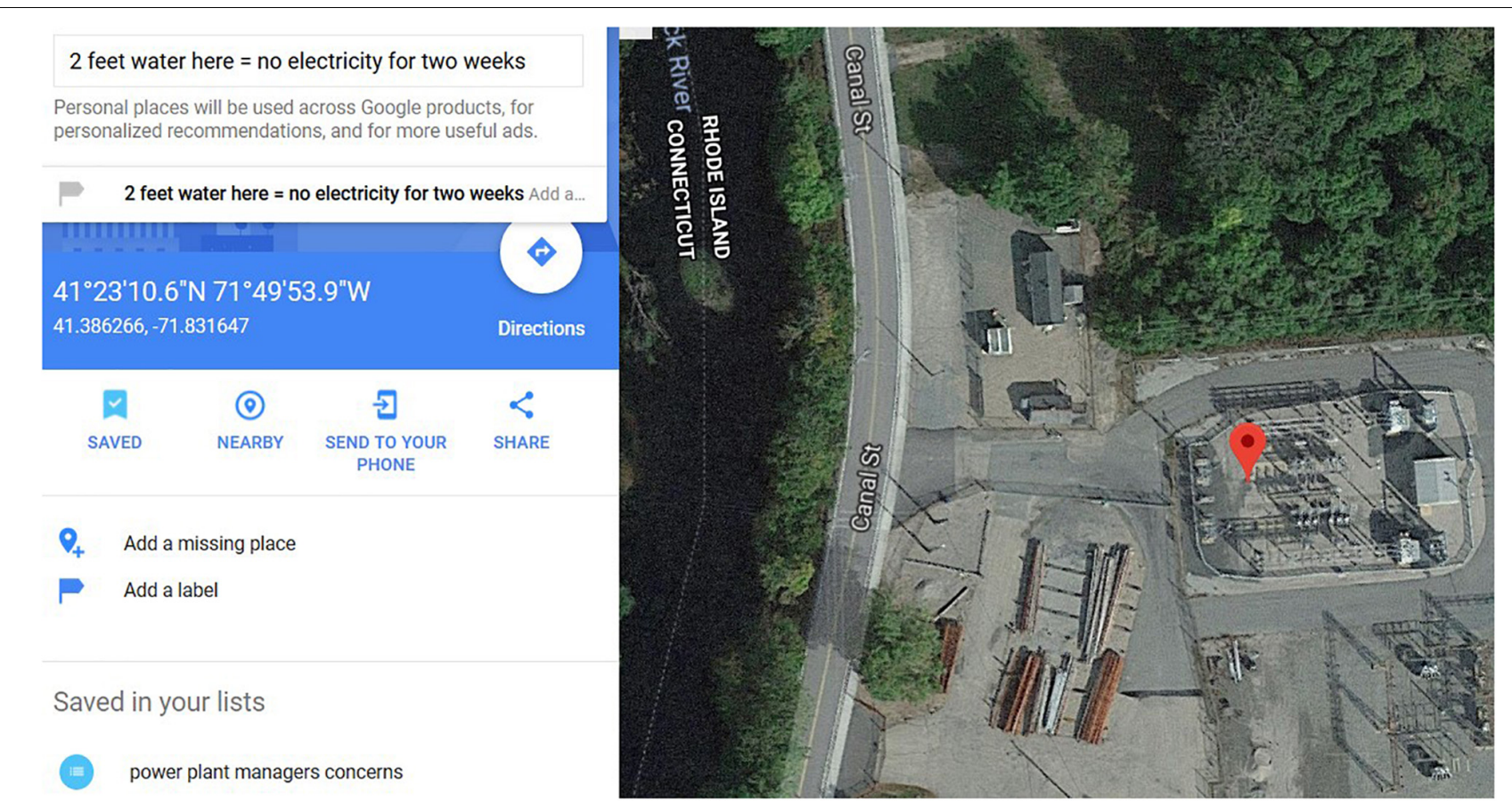

FIGURE 4 | Interviewee's used Google maps satellite views to identify and label locations of concern (Image: authors, data Google Maps).

Respondents also described their career experience and responsibilities at the facility. Interviews lasted between 1 and $2 \mathrm{~h}$ each.

\section{Coding for Incorporation Into Storm Impact Model}

We digitally recorded and transcribed the interviews in full with the help of a hired transcription service (200 pages). In order to answer our three research questions, we identified and analyzed all CT components mentioned by interviewees using Microsoft Excel. We also coded interviews line by line and identified themes in the data through an analytic induction method using NVivo, a form of grounded theory described by Ratcliff (1994) as an iterative process. We standardized CT components before incorporating them into a storm impact model (Table 2).

The storm impact model employed high-resolution physics-based simulations of surface winds during hurricane landfall using the track, intensity and size parameters of historic or hypothetical storm events. This model adapts Gao and Ginis (2016) model for open ocean hurricanes to account for changes in surface roughness at landfall in order to better simulate landfalling storms (Gao and Ginis, 2016). This model was developed as part of a larger project for the Department of Homeland Security Coastal Resilience Center. Storm surge response to the wind model was computed using the ADvanced CIRCulation (ADCIRC) model (Luettich et al., 1992), coupled with the Simulating Waves Nearshore (SWAN) model (Booij et al., 1999). An all numerical storm impact model combining outputs from the wind and hydrodynamic models was programmed to test the collected CTs.
The hazards available for testing CTs included:

- Wind velocity and direction at $15 \mathrm{~min}$ increments

- Water velocity and direction at $15 \mathrm{~min}$ increments

- Inundation depth based on sea surface elevation (maximum envelope of water) at $15 \mathrm{~min}$ increments.

- Significant wave height at $15 \mathrm{~min}$ increments.

- Total rainfall and hourly rate.

The use of the storm impact models allowed investigators to test the effectiveness of the whole process, and to verify whether the five components identified (the concern, the location, the modeled hazard, the threshold, and the consequence) were sufficient for modeling. Testing the gathered CTs also allowed investigators to provide feedback regarding specific CTs to participating FMs and RIEMA. The use of the full range of

TABLE 2 | Standardization of interviewee's threshold component responses.

\begin{tabular}{|c|c|c|c|}
\hline $\begin{array}{l}\text { Language used } \\
\text { by interviewee }\end{array}$ & Example & $\begin{array}{l}\text { Threshold } \\
\text { chosen }\end{array}$ & Rationale \\
\hline Threshold range & $\begin{array}{l}\text { "The consequence } \\
\text { would occur when } \\
\text { the water reached } \\
1 \text { to } 2 \text { feet here } \\
\text { [indicating a point } \\
\text { on the map]" }\end{array}$ & 1 foot & $\begin{array}{l}\text { Choosing the } \\
\text { lowest value in } \\
\text { range makes the } \\
\text { storm impact } \\
\text { model output more } \\
\text { conservative. }\end{array}$ \\
\hline Hurricane category & $\begin{array}{l}\text { "The consequence } \\
\text { would occur when } \\
\text { winds reached } \\
\text { category 1." }\end{array}$ & 74 mph & $\begin{array}{l}\text { This is the } \\
\text { sustained wind } \\
\text { speed required to } \\
\text { be considered a } \\
\text { category } 1 .\end{array}$ \\
\hline
\end{tabular}


available time increments allowed for the order of events to be investigated (e.g., when radio communications would be likely to fail or when a particular road would be blocked).

\section{RESULTS}

The results section is ordered according to the five CT components. We discuss themes for each component that emerged from analysis of interview transcripts.

\section{Concerns}

The CT collection method resulted in identification of 201 concerns from 13 interviewees representing 11 critical facilities (see Supplementary Table 1). Many concerns and associated consequences were based on the interviewee's experiences with the Floods of 2010 and Hurricane Sandy.

\section{The Accurate Location of Concerns}

Since geographical coordinates are necessary to integrate CTs into storm models, the accurate location of each concern was noted by the respondent. Most concerns could be tied to one location, but the interviewees explained that 40 of the 201 concerns had multiple locations in Westerly that were difficult to geospatially locate. For example, one interviewee was concerned that a storm would flood fire hydrants and prevent his firemen from reaching them. However, the interviewee did not know the locations of the fire hydrants that were at risk to flooding and therefore the concern was not incorporated into the storm impact model. Though a GIS database of fire hydrants for Westerly probably exists, bringing those additional datasets in was beyond the scope of this project. In other examples, the interviewee could identify several locations, but was not aware of which in particular would be vulnerable to a storm impact. Other concerns interviewees were not able to immediately geospatially identify included:

(1) Roads

(2) Telephone lines

(3) Power lines

(4) Sewage/rain man hole covers

(5) Residential oil tanks

(6) Residential propane tanks

(7) Residential basements

(8) Fire hydrants

(9) Personnel

(10) Vehicles

\section{Modeled Hazards}

One Hundred-Ninety three FM consequences could be triggered by either a hydrodynamic, wind, or precipitation model. FMs explained that 90 CTs were at risk to standing inundation, 74 to wind, 13 to rain, seven to storm surge, and five to wave height (Table 3). However, the clearest challenge in gathering modelable CTs from FMs was the incompatibility of terms from the wind and ocean models which are based on physical simulations and the observations of FMs. Whereas water velocity and direction can be modeled in meters per second, these forces are seldom measured or discussed in those terms. For example, one fire chief was concerned that storm surge could cause a bridge his crew relied on to collapse, but could only estimate that a "Category 5 hurricane" would cause this to happen. Without a quantifiable water velocity or direction that would cause the collapse, we could not include this consequence into the models. Validation of modeled surge velocities often relies upon forensic studies of damage (Pistrika and Jonkman, 2010). As will be subsequently discussed, the incompatibility of terms makes it difficult for FMs

TABLE 3 | Total number of concerns, description of concern for each modeled hazard and coding classification of corresponding threshold component for 13 Westerly FMs of 11 critical facilities.

\begin{tabular}{|c|c|c|c|c|c|}
\hline \multirow[b]{2}{*}{$\begin{array}{l}\text { The } \\
\text { modeled } \\
\text { hazard }\end{array}$} & \multirow[b]{2}{*}{$\begin{array}{l}\text { Concern most } \\
\text { commonly impacted } \\
\text { by modeled hazard }\end{array}$} & \multicolumn{4}{|c|}{ Threshold classification } \\
\hline & & $\begin{array}{c}\text { Threshold } \\
\text { was } \\
\text { modelable }\end{array}$ & $\begin{array}{c}\text { Threshold } \\
\text { was } \\
\text { unknown }\end{array}$ & $\begin{array}{l}\text { Threshold was } \\
\text { given in } \\
\text { unmodelable unit }\end{array}$ & $\begin{array}{l}\text { Threshold was } \\
\text { not explicitly } \\
\text { asked for after } \\
\text { concern was } \\
\text { discussed by } \\
\text { interviewee }\end{array}$ \\
\hline $\begin{array}{l}\text { Inundation } \\
\text { (90) }\end{array}$ & $\begin{array}{l}\text { cars, roads, generators, } \\
\text { electrical panels, facility } \\
\text { specific equipment } \\
\text { (wells, clarifiers) }\end{array}$ & 56 & 5 & 9 & 13 \\
\hline Wind (74) & $\begin{array}{l}\text { cars, power/telephone } \\
\text { lines, roofs, personnel }\end{array}$ & 44 & 19 & 2 & 9 \\
\hline Rain (13) & $\begin{array}{l}\text { power/telephone lines, } \\
\text { generators, electrical } \\
\text { panels }\end{array}$ & 1 & 14 & 2 & 1 \\
\hline $\begin{array}{l}\text { Wave } \\
\text { height (5) }\end{array}$ & boats, roads & 1 & 2 & 0 & 2 \\
\hline $\begin{array}{l}\text { Storm } \\
\text { surge (7) }\end{array}$ & $\begin{array}{l}\text { home gas, water and } \\
\text { electrical systems, } \\
\text { bridges }\end{array}$ & 0 & 1 & 3 & 4 \\
\hline
\end{tabular}


to identify thresholds. Even those who have witnessed events have no practical way to estimate forces.

Several consequences could be triggered by "hazards" that were not part of the underlying storm simulation. For example, ten consequences could be triggered by hurricane forecasts. If the National Weather Service (NWS) warned that a category 2 hurricane was going to hit Rhode Island, an ambulance corpsman would station an ambulance on the other side of the Pawcatuck River to maintain access to certain neighborhoods. Also, when combined with other storm forces, time was mentioned as a hazard for a few CTs. For example, an ambulance corpsman explained that if roads were blocked by fallen trees for 9 days, his facility would run out of fuel because fuel deliveries could not arrive. Both of these hazards would be challenging to model because they rely on the behaviors of individuals (Aerts et al., 2018).

Highly specific thresholds combined with time incremented events provided valuable feedback to EMs and made it possible to discuss the order consequences from the modeled storm would occur (the unfolding of these events can be seen in Figure 5).

\section{Thresholds at Which a Consequence Is Triggered}

Interviewees most commonly gave thresholds for flooding in feet and wind speed in miles per hour. 86 of the 201 CTs could not be incorporated into storm impact models because the interviewee did not know the threshold, it was not explicitly asked for, or the interviewee gave the threshold in unmodelable units (Table 3). Almost every threshold given by interviewees was coded as uncertain, which means the interviewee was willing estimate the threshold, but was unsure of its accuracy. 41 of the thresholds were coded as "unknown," which means the interviewee was not willing to estimate the threshold. One interviewee illustrated this dilemma when he said, "for an antenna to break, each one has a rated wind speed velocity- and you have to look up each and every antenna because there's multiple types of antennas, different manufacturers." Only one threshold was modelable for rainfall and no threshold was modelable for storm surge because interviewee's do not know numerical values of rainfall rates or storm surge velocities (Table 3). One interviewee illustrated this when he said, "When it rains, it rains hard! That's all I know." Similarly, for storm surge, another interviewee explained that he would not drive his fire truck through water, "If you could see a decent current with any type of like a ripple to it."

When asked for the threshold that would cause the impact, interviewees asked the researcher for wind speed/storm surge levels of Hurricane Sandy and the rainfall amounts of the Floods of 2010. Interviewees also tried to look up these thresholds online during the interview. One interviewee illustrated a commonly given un-modelable threshold with the quote, "Whatever the 2010 floods were, how much rain we got."

\section{Consequences}

This method collected a range of FM's storm concerns. 195 consequences were immediate, e.g., when water reaches one foot at a generator, the generator short-circuits. Eight consequences were long term, e.g., sand deposits prevent fire trucks from accessing certain areas after a storm. 50 of the consequences were related to mobility (roads/vehicles), 41 of the consequences were related to power (power lines/electrical panels/generators), 40 were related to communications (telephone lines/antennas), 34 were related to specific equipment operated by waste water and water purification plants (pump stations/wells), 22 were structural (windows/roofs) and five were related to personnel. 26 of the consequence components included an interviewee's immediate response to the consequence and 34 included an interviewee's long-term response to the consequence. For example, the water department's wells need to be shut down immediately if water reaches them and then they require a long-term chemical treatment process once the floods recede. Most consequences mentioned by emergency response FMs (firemen, policemen, and ambulance corpsmen) were related to mobility and communications.

\section{DISCUSSION}

This research collected interviewee's intra-facility level storm consequences for incorporation into storm impact models and identifies challenges and opportunities posed by the process. This work contributes to answering the call for applied research that links geographic information to practitioners concerns (Moser, 2010) and for the development of multi-criteria tools in order to include non-monetary intangible damage into the assessment framework of flood damage analysis (Messner et al., 2013). The following section discusses findings based on the three guiding research questions.

\section{RQ1 - How Can Existing Methods for Eliciting Vulnerability Data Be Adapted to Collect FM's Intra-Facility Level Storm Concerns for Inclusion in Storm Impact Models?}

Participatory mapping using Google Maps and a set of exploratory open-ended questions was an effective way to collect interviewee's storm concerns. Many of the concerns mentioned at the beginning of interviews had been impacted during Rhode Island's Floods of 2010 and Hurricane Sandy. Also, beginning interviews with storm consequences that have already occurred may have made the research more relevant and realistic to FMs, which likely made it easier for interviewees to identify CT components. Interviewees readily identified location of concerns on the navigable Google Map satellite view during the interview. When the satellite view was limited, Google Map's Street View, which includes a 3D visualization, helped identify location of concerns. Identifying the location of concern on a Google map made it easier to record interviewee's concerns and identify remaining CT components. For example, identifying locations of concern helped identify thresholds because we could explain to the interviewee that thresholds should be for the location the interviewee identified on the map. This was useful because interviewees tended to identify inundation thresholds 

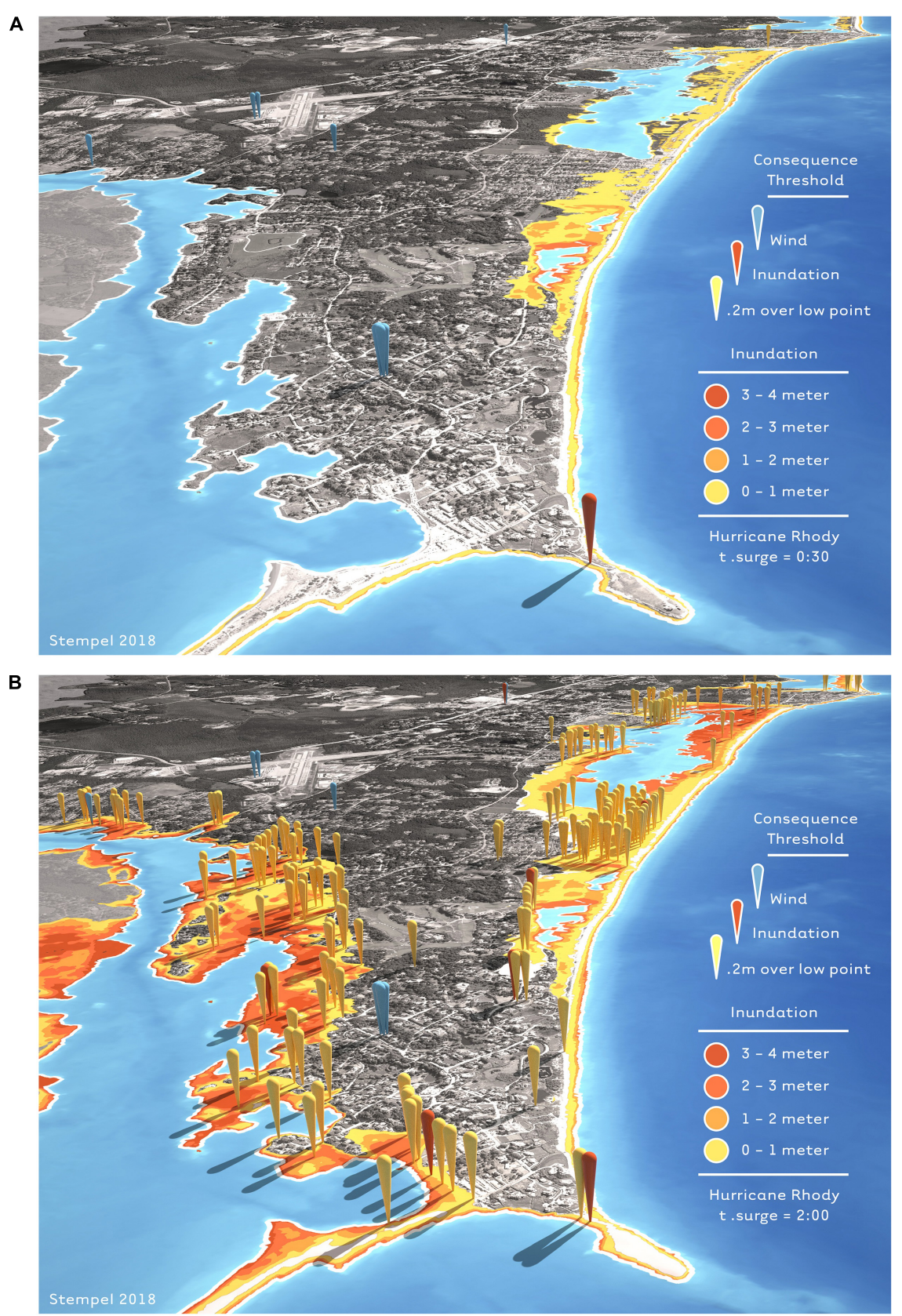

FIGURE 5 | Storm impact model for Westerly's critical facilities showing wind and inundation CTs triggered by hypothetical Hurricane Rhody 30 min (A) and 2 h (B) after Rhody's landfall. The red pin in front is a CT triggered by one foot of flooding and represents a fire chief's concern that, "When it floods above a foot here, we can't reach the homes around the lighthouse." Yellow pins show where inundation blocks roads (Image: authors).

in feet above sea level instead of feet above ground level at the location of the concern.

Consequence Thresholds can be integrated with static and dynamic models. This is a key feature of the CT approach, as it allows the audience to understand how consequences of storms unfold over time. Once the CTs are integrated with a storm model, the parameters of the model (e.g., surge, wind speed, and flooding) trigger concern thresholds upon running the model. To illustrate, we incorporated the CTs from this project into a storm impact model for a hypothetical storm, called Hurricane Rhody (Ginis et al., 2017). Hurricane Rhody is a plausible hurricane scenario created to simulate the effects of a high-impact storm on the Rhode Island coast in order to provide state and local agencies with better understanding of the hazards associated with extreme hurricanes. The characteristics of the hurricane are not arbitrarily chosen, but are based on those of several historical storms that have impacted the region. In this example, 23 of the CTs identified in interviews were triggered by wind and $21 \mathrm{CTs}$ were triggered 
by storm inundation. Text Box 1 describes some of the 44 CTs triggered by Rhody in chronological order.

\section{RQ2 - What Challenges Exist When Collecting FM's Concerns for Incorporation Into Storm Impact Models?}

The most common challenges when collecting interviewee's concerns for incorporation into storm impact models are identifying modelable thresholds and identifying accurate locations of concern.

\section{Challenge 1 - The Modelable Threshold Identification}

Researchers conducting climate change vulnerability assessments have found that determining the quantified weather force that would cause a particular consequence on a community was, "considerably more challenging than [determining] qualitative descriptors like hotter, drier and rainier" (Gustafson et al., 2018, p. 155). Shackley and Deanwood (2003) found stakeholders were reluctant to quantify climate forces and associated consequences because quantification precisely defines the model scenario and is less likely to be correct than less accurate qualitative statements. This research found that stakeholder's uncertainty extends to storm force thresholds.

To help future researchers collect FM's concerns for incorporation into storm impact models we recommend researchers ask a set of standardized questions with consistent anchors after an interviewee mentions a concern. For example, the researcher should ask, "Would the concern be impacted when water reached between 0 and 1 foot (anchor 1), 1 to 2 feet (anchor 2), or above 2 feet (anchor 3 ) at the location of concern?" Since many interviewees referenced previous storms that impacted their facility to identify the threshold, we recommend researchers use the thresholds of the biggest and most recent storms to affect the interviewee's area as the anchors. Another way to standardize the threshold identification process could be by showing a set of photographs, videos or realistic visualizations of the storm forces. For example, a researcher could show photographs or videos of 60,100 , and $140 \mathrm{mph}$ winds in another area or realistic visualizations for the interviewee's facility under various inundation levels. Finally, if interviewees are not comfortable giving a threshold, or even a threshold range, researchers should ask for the concern's make and model so the researcher can look up the threshold after the interview. To promote effective policy through model building, iterative processes like this are key (White et al., 2010).

\section{Challenge 2 - Unknown Locations of Concerns}

Twenty percentage of interviewee's concerns could be impacted at many locations. For example, interviewees were concerned about power lines, roads and fire hydrants. Without identifying the exact latitude and longitudes of these concerns, it is not possible to incorporate them into storm impact models. To incorporate CTs with multiple, currently unknown locations into storm impact models we recommend the creation of datasets of these locations. Determining the locations of concern for sewage manhole covers, fire hydrants, telephone/power lines and the remaining concerns with multiple unknown locations was outside of the scope of this work. However, we were able to use existing e911 road data to conduct a roadway low point analysis for Westerly to account for interviewee's road inundation concerns. When water reached above $8^{\prime \prime}$ at the low point on the road, the road was flagged as impassable since that is the depth some Westerly FMs are blocked (Box 1). Similar analyses can be done for remaining CTs that have vague locations of concern once locations of concerns are collected for those CTs.

\section{RQ3 - How Are Storm Impact Models Improved by Collecting FM's Concerns Through a Participatory Process?}

Incorporating qualitative consequences of storms can improve storm impact models by increasing their accuracy and relevance to participants. Traditional DRR assessment outputs struggle to provide actionable data regarding relevant, specific local concerns for communities to use to prepare for disasters (Paul et al., 2018). For example, caution needs to be used when analyzing HAZUS hurricane damage outputs for a community's facilities because results are based on average damages to similar facilities under similar circumstances (Vickery et al., 2006). Traditional DRR outputs like HAZUS also do not take into account intangible consequences of storms like losses of cultural assets (Messner and Meyer, 2006) even though these types of losses are what people normally mourn the most after a flood (Becker et al., 2015). Therefore, including FMs concerns using a participatory process allows storm impact models to output more specific local concerns than relying on generalized damage curves and may make the models more credible, actionable and relevant to participating FMs. However, additional research is needed to quantify how developing CTs through participatory processes influences a storm impact model's credibility, actionability and relevance for participating FMs.

As storm simulations increase in accuracy (Aerts et al., 2018), on-the-ground vulnerability information will need to be collected with increasing precision using a participatory method to use these models most effectively. Incorporating CTs into many

\footnotetext{
Box 1 | CTs triggered by hypothetical "Hurricane Rhody" storm simulation. Day 1

0000h - Hurricane Rhody's winds knock out Westerly's power and no emergency responder has communications, aside from cell phones and hand-held radios (CT 10061).

Day 2

0000h - Hurricane Rhody makes landfall.

0030h Storm surge blocks a fire department from reaching sections of homes (CT 10203).

0100h Westerly's water distribution pipes may be broken and the water supply of the town may be contaminated (CT 10022).

$\mathbf{0 2 0 0 h}$ - the storm pushes water further inland and floods the WWTP, which requires the plant to operate as a primary facility for 10 to 21 days (CT 10192) and receive essential materials from another WWTP (CT 10193). 0230h Westerly's main power station is flooded and requires a mobile substation (CT 10072). The water department requires two wells to shut down and be chemically treated for 72 hours (CTs 10175-10176).
} 
storm impact models through a Montecarlo analysis may help decision makers more objectively prioritize storm adaptations (see for example (Bosma et al., 2015). The use of these methods goes some distance to addressing concerns about uncertainty. Storm impact models may also assist FMs prepare for real storms in the days and hours leading up to landfall (Stempel et al., 2018).

\section{Broader Implications}

That investigators had to make consequential decisions in implementing the data that was collected (e.g., choosing the most conservative estimate) points to the need for consistency and standardization in processes. Anchoring and other methods previously elaborated will help that process. There is a larger question regarding the utility and perceived legitimacy of CTs if they are utilized outside of local processes in which thresholds are gathered, tested, and reflected to participants. Participation not only enhances the perceived legitimacy of the outputs (White et al., 2010), there are real questions as to the validity of the gathered thresholds where individual judgments on the part of FMs are applied outside of the particular facilities and situations with which they are familiar. If CTs are to function as more than boundary objects - points of common communication between FMs, EMs, and scientists-attention must be paid to standardizing procedures for gathering data. This may include, for instance, standardizing anchor points and prompts among different researchers and agreeing that the conservative estimate will be utilized. If sufficient data can be gathered for common types of facilities using consistent methods, it may be possible to aggregate and generalize CTs once enough have been collected to situations for which no new data is gathered.

\section{Limitations of This Approach}

This methodology was piloted with some of the FMs of one community and should be repeated with other FMs in other regions in order to both validate the utility of the approach and refine it based on the findings described in this paper. Modeling storm surge impacts involves compounding uncertainties. In addition to, the uncertainty of the scenario itself (probability of occurrence), there are uncertainties regarding the interaction between the landfalling hurricane, landform, and physical infrastructure that are not accounted for in numerical simulations (Kostelnick et al., 2013). Uncertainty on the part of interviewees regarding the thresholds are compounded on top of those existing uncertainties, and thus not accounted for.

Precisely quantifying the storm force at which a consequence occurs makes the output appear more certain than it is (Shackley and Deanwood, 2003). When experts identify a point at which a certain piece of infrastructure will fail, it is likely that the point has a good deal of uncertainty, which is not easily shown by the point (Cooke and Goossens, 2004). Adding an additional query regarding uncertainty may address some of these concerns, however, many of these interactions are fundamentally unknowable (Couclelis, 2003). Until sufficient external validation takes place, in part through engineering based structural analyses that address newly identified concerns, the utility of CTs is thus best understood as a tool for DRR used with participating EMs and FMs (Schroth et al., 2011). Also, selecting appropriate FMs is an important additional step if the method presented here is to be used to prepare communities for storms.

An essential next step in developing and assessing the utility of CTs is a comparison between CTs and fragility curves for impacts that are conducive to such an analysis. This comparison can underscore the complimentary nature of the approaches.

\section{CONCLUSION}

As storm impact models and the underlying storm simulations increase in accuracy and applicability, researchers will need to develop standardized methods to collect on-the-ground vulnerability information in a participatory manner to increase the relevance and credibility of storm impact models. This paper presents an exploration of a methodology that collects FM's rich concerns at the intra-facility level for incorporation into storm impact models. Using semi-structured interviews and participatory mapping, results show CTs triggered by a hydrodynamic model (Stempel et al., 2018; Witkop et al., 2019). 96 CTs were collected and incorporated into storm impact models using principals from participatory mapping and vulnerability assessment literature. Interview methods were based on existing practices for vulnerability assessments (e.g., Stenek et al., 2011; Peters-Guarin et al., 2012; Cox et al., 2013), and further augmented to obtain data based on impact modeling methods (Stempel et al., 2018). After incorporating these concerns into storm impact models, we found the chronological order a hypothetical storm would impact those concerns. The basis for the method tested is drawn from and expands current approaches to vulnerability assessment that address aspects of disaster risk and citizen science related to DRR.

This work reveals distinct challenges, specifically in the mismatch between the nomenclature of model simulations (e.g., velocity measured in meters per second) and the observed experiences of FMs. Given the possible identified role of anchor points, and the importance of decisions made by researchers such as using the most conservative estimate of a threshold, standardization becomes more than a matter of best practices. Standardization of interview and data handling procedures becomes an essential part of ensuring the validity of collected data in a local process. It further supports the possibility that CTs could be used more broadly, especially where common infrastructure types, vehicle types, or insurance standards are utilized. If the qualitative data held by FMs can be leveraged to create qualitative thresholds that can be more broadly applied, EMs, FMs, and scientists may gain an important new tool to aid in planning disaster response and DRR more broadly.

\section{ETHICS STATEMENT}

University of Rhode Island's Internal Review Board was the ethics committee that approved this study. Researchers obtained written consent from interviewees for the interview and recording prior to the start of interviews. 


\section{AUTHOR CONTRIBUTIONS}

$\mathrm{PS}, \mathrm{AB}$, and RW conceptualized the research questions. RW conducted interviews and interpreted the data. IG provided the underlying storm models. All authors drafted the manuscript, read and approved the final version of the manuscript.

\section{FUNDING}

This material is based upon work supported by the United States. Department of Homeland Security under Grant Award Number 2015-ST-061-ND0001-01 and by the USDA National Institute of Food and Agriculture, Hatch project 1014166.

\section{REFERENCES}

Adger, W. N., Quinn, T., Lorenzoni, I., Murphy, C., and Sweeney, J. (2013). Changing social contracts in climate-change adaptation. Nat. Clim. Change 3:330. doi: 10.1038/nclimate 1751

Aerts, J. C. J. H., Botzen, W. J., Clarke, K. C., Cutter, S. L., Hall, J. W., Merz, B., et al. (2018). Integrating human behaviour dynamics into flood disaster risk assessment. Nat. Clim. Change 8, 193-199. doi: 10.1038/s41558-018-0085-1

Becker, A., Burroughs, R., Kretsch, E., Mcintosh, R., and Haymaker, J. (2017). Stakeholder Vulnerability And Resilience Strategy Assessment for Maritme Infrastructure: Pilot Project for the Port of Providence. Rhode Island RI: Rhode Island Dept. of Transportation.

Becker, A. H., Acciaro, M., Asariotis, R., Cabrera, E., Cretegny, L., Crist, P., et al. (2013). A note on climate change adaptation for seaports: a challenge for global ports, a challenge for global society. Clim. Change 120, 683-695. doi: 10.1007/ s10584-013-0843-z

Becker, A. H., Matson, P., Fischer, M., and Mastrandrea, M. D. (2015). Towards seaport resilience for climate change adaptation: stakeholder perceptions of hurricane impacts in gulfport (MS) and providence (RI). Progr. Plann. 99, 1-49. doi: 10.1016/j.progress.2013.11.002

Bierbaum, R., Smith, J. B., Lee, A., Blair, M., Carter, L., Chapin Iii, F. S., et al. (2013). A comprehensive review of climate adaptation in the United States: more than before, but less than needed. Mitigat. Adap. Strategies Global Change 18, 361-406. doi: 10.1007/s11027-012-9423-1

Booij, N., Ris, R. C., and Holthuijsen, L. H. (1999). A third-generation wave model for coastal regions: 1. Model description and validation. J. Geophys. Res. Oceans 104, 7649-7666. doi: 10.1029/98jc02622

Bosma, K., Douglas, E., Kirshen, P., Mcarthur, K., Miller, S., and Watson, C. (2015). MassDOT-FHWA Pilot Project Report: Climate Change and Extreme Weather Vulnerability Assessments and Adaptation Options for the Central Artery. Boston: Massachusetts Department of Transportation.

Brecht, H. (2007). Geo-technologies in hurricane research. Cartogr. Geogr. Information Science 34, 153-154. doi: 10.1559/152304007781002181

Buytaert, W., Zulkafli, Z., Grainger, S., Acosta, L., Alemie, T. C., Bastiaensen, J., et al. (2014). Citizen science in hydrology and water resources: opportunities for knowledge generation, ecosystem service management, and sustainable development. Front. Earth Sci. 2:26.

Cadag, J. R. D., and Gaillard, J. (2012). Integrating knowledge and actions in disaster risk reduction: the contribution of participatory mapping. Area 44, 100-109. doi: 10.1111/j.1475-4762.2011.01065.x

Chess, C., Hance, B. J., and Sandman, P. M. (1988). Improving Dialogue With Communities: A Short Guide For Government Risk Communication Division of Science and Research. New Jersey, NJ: Department of Environmental Protection.

Cooke, R. M., and Goossens, L. H. J. (2004). Expert judgement elicitation for risk assessments of critical infrastructures. J. Risk Res. 7, 643-656. doi: 10.1080/ 1366987042000192237

Couclelis, H. (2003). The Certainty of uncertainty: GIS and the limits of geographic knowledge. Trans. GIS 7, 165-175. doi: 10.1111/1467-9671.00138

\section{ACKNOWLEDGMENTS}

We thank Mark Bennett from the Rhode Island Emergency Management Agency for connecting us to the local emergency and facility managers of Westerly. Pam Rubinoff and the Coastal Resources Center and RI Sea Grant also assisted by providing contacts and input to the project.

\section{SUPPLEMENTARY MATERIAL}

The Supplementary Material for this article can be found online at: https://www.frontiersin.org/articles/10.3389/feart. 2019.00133/full\#supplementary-material

Cox, R. J., Panayotou, K., and Cornwell, R. M. (2013). Climate Risk Assessment for Avatiu Port and Connected Infrastructure. Water Research Lab. Australia: University of New South Wales.

Department of Homeland Security [DHS]. (2013). Threat and Hazard Identification and Risk Assessment Guide Comprehensive Preparedness Guide 201, 2nd Edn. Washington, D.C: Department of Homeland Security.

Douglas, E., Kirshen, P., Li, V., Watson, C., and Wormser, J. (2013). Preparing for the Rising Tide. Boston, MA: The Boston Harbor Association.

Eakin, H., and Luers, A. L. (2006). Assessing the vulnerability of socialenvironmental systems. Ann. Rev. Environ. Res. 31, 365-394. doi: 10.1146/ annurev.energy.30.050504.144352

United States Environmental Protection Agency [USEPA]. (2008). Planning for Climate Change Impacts at U.S. Ports White Paper Prepared by ICF International for the USEPA. Washington, DC: USEPA.

Federal Emergency Management Agency [FEMA]. (2012). Definitions of Critical Facilities and Risk Categories", in: Mitigation Assessment Team Report Hurricane Sandy in New Jersey and New York. Washington, DC: Federal Emergency Management Agency.

Federal Emergency Management Agency [FEMA]. (2013). Hurricane Sandy in New Jersey and New York-Building Performance Observations, Recommendations, and Technical Guidance. Washington, DC: Federal Emergency Management Agency.

Gao, K., and Ginis, I. (2016). On the equilibrium-state roll vortices and their effects in the hurricane boundary layer. J. Atmos. Sci. 73, 1205-1222. doi: 10.1175/jas-d-15-0089.1

Ginis, I., Kincaid, C., Hara, T., Rothstein, L., Ullman, D. S., Chawla, H. A., et al. (2017). Modeling the combined coastal and inland hazards from high-impact hypothetical hurricanes. Annual project performance report prepared for the DHS Coastal Resilience Center. Chapel Hill: The University of North Carolina at Chapel Hill.

Gustafson, S., Cadena, A. J., and Hartman, P. (2018). Adaptation planning in the lower mekong basin: merging scientific data with local perspective to improve community resilience to climate change. Clim. Dev. 10, 152-166. doi: 10.1080/ 17565529.2016.1223593

Hapij, A. W. (2011). Multidisciplinary Assessment of Critical Facility Response to Natural Disasters: The Case of Hurricane Katrina. Reston: American Society of Civil Engineers.

Hendricks, M. D., Meyer, M. A., Gharaibeh, N. G., Van Zandt, S., Masterson, J., Cooper, J. T., et al. (2018). The development of a participatory assessment technique for infrastructure: Neighborhood-level monitoring towards sustainable infrastructure systems. Sustain Cities Soc. 38, 265-274. doi: 10.1016/j.scs.2017.12.039

Holper, P., Lucy, S., Nolan, M., Senese, C., and Hennessy, K. (2007). ). Infrastructure and Climate Change Risk Assessment for Victoria. Consultancy Report to the Victorian Government prepared by CSIRO, Maunsell Australia, and Phillips Fox. Aspendale, VIC: CSIRO.

ICF International (2017). Climate Risk and Vulnerability Assessment Framework for Caribbean Coastal Transport Infrastructure. Geneva: ICF. 
Kellens, W., Terpstra, T., and De Maeyer, P. (2013). Perception and communication of flood risks: a systematic review of empirical research. Risk Anal. 33, 24-49. doi: 10.1111/j.1539-6924.2012. 01844.x

Kostelnick, J. C., Mcdermott, D., Rowley, R. J., and Bunnyfield, N. (2013). A Cartographic Framework for Visualizing Risk. Cartographica. Int. J. Geogr. Inform. Geovisual. 48, 200-224. doi: 10.3138/carto.48.3.1531

Lewis, J. L., and Sheppard, S. R. J. (2006). Culture and communication: Can landscape visualization improve forest management consultation with indigenous communities? Lands. Urban Plann. 77, 291-313. doi: 10.1016/j. landurbplan.2005.04.004

Luettich, R. A. Jr., Westerink, J. J., and Scheffner, N. W. (1992). ADCIRC: an advanced three-dimensional circulation model for shelves, coasts, and estuaries". in Theory and Methodology of ADCIRC-2DDI and ADCIRC-3DL. eds A. L.Richard, J. W.Joannes, W. S.Norman (Springfield: National Technical Information Service).

Manning, H., Carnevale, M., and Rubinoff, P. (2014). "Rhode Island Coastal Property Guide. Rhode Island RI: University of Rhode Island's Coastal Resources Center.

Mendonça, D., and Wallace, W. A. (2006). Impacts of the 2001 world trade center attack on New York city critical infrastructures. J. Infra. Systems 12, 260-270. doi: 10.1061/(asce)1076-0342(2006)12\%3A4(260)

Merriam, S. B. (1988). Case Study Research in Education: A Qualitative Approach. San Francisco. CA: Jossey-Bass.

Messner, F., and Meyer, V. (2006). "Flood damage, vulnerability and risk perception-challenges for flood damage research," in Flood risk management: hazards, vulnerability and mitigation measures, eds J. Schanze, E. Zeman, and J. Marsalek (Berlin: Springer), 149-167. doi: 10.1007/978-1-4020-45981 13

Messner, S., Moran, L., Reub, G., and Campbell, J. (2013). Climate change and sea level rise impacts at ports and a consistent methodology to evaluate vulnerability and risk. WIT Trans. Ecol. Environ. $169,13$.

Monioudi, I. N, Asariotis, R., Becker, A., Bhat, C., Gooden, D. D., Esteban, M., et al. (2018). Climate change impacts on critical international transportation assets of Caribbean Small Island developing states (SIDS): the case of Jamaica and Saint Lucia. Reg. Environ. Change 18, 2211. doi: 10.1007/s10113-018-13 60-4

Morrow, B. H., Lazo, J. K., Rhome, J., and Feyen, J. (2015). Improving storm surge risk communication: stakeholder perspectives. Bull. Am. Meteorol. Soc. 96, 35-48. doi: 10.1175/bams-d-13-00197.1

Moser, S. C. (2010). Now more than ever: The need for more societally relevant research on vulnerability and adaptation to climate change. Appl. Geogr. 30, 464-474. doi: 10.1016/j.apgeog.2009.09.003

Moser, S. C., and Ekstrom, J. A. (2010). A framework to diagnose barriers to climate change adaptation. Proc. Natl. Acad. Sci. U.S.A 107, 22026-22031. doi: 10.1073/pnas.1007887107

Newkirk, R. T. (2001). The increasing cost of disasters in developed countries: a challenge to local planning and government. J. Contingen. Crisis Manag. 9, 159-170. doi: 10.1111/1468-5973.00165

Palmer, P. I., and Smith, M. J. (2014). Model human adaptation to climate change. Nature 512:365.

Patton, E., and Appelbaum, S. H. (2003). The case for case studies in management research. Manag. Res. News 26, 60-71. doi: 10.1108/0140917031078 3484

Paul, J. D., Buytaert, W., Allen, S., Ballesteros-Cánovas, J. A., Bhusal, J., Cieslik, K., et al. (2018). Citizen science for hydrological risk reduction and resilience building. Wiley Interdis. Rev. Water. 5, $1-15$.

Peters-Guarin, G., Mccall, M. K., and Van Westen, C. (2012). Coping strategies and risk manageability: using participatory geographical information systems to represent local knowledge. Disasters 36, 1-27. doi: 10.1111/j.1467-7717.2011. 01247.x

Pistrika, A. K., and Jonkman, S. N. (2010). Damage to residential buildings due to flooding of New Orleans after hurricane Katrina. Nat. Hazards 54, 413-434. doi: 10.1007/s11069-009-9476-y

Port of Dover (2015). Port of Dover Climate Adaptation Report. Available at: https://assets.publishing.service.gov.uk/government/uploads/system/uploads/ attachment_data/file/488087/climate-adrep-dover-port.pdf
Port of Felixstowe (2015). Climate Change Adaption Report for the Felixstowe Dock and Railway Company. Available at: https://www.gov.uk/government/up loads/system/uploads/attachment_data/file/530910/climate-adrep-port-felixs towe.pdf

Porter, K. (2015). Beginner's guide to fragility, vulnerability, and risk. Encyclopedia Earthquake Eng. 235-260. doi: 10.1007/978-3-642-353444_256

Preston, B. L., Westaway, R. M., and Yuen, E. J. (2010). Climate adaptation planning in practice: an evaluation of adaptation plans from three developed nations. Mitig. Adapt. Strat. Global Change 16, 407-438. doi: 10.1007/s11027010-9270-x

Ratcliff, D. E. (1994). Analytic induction as a qualitative research method of analysis. Univ. Georgia. 1:2010.

Rinaldi, S. M. (2004). "Modeling and simulating critical infrastructures and their interdependencies", in: System sciences, 2004," in Proceedings of the 37th annual Hawaii international conference on: IEEE, (Big Island: IEEE), 8.

Schneider, P. J., and Schauer, B. A. (2006). HAZUS-its development and its future. Nat. Hazards Rev. 7, 40-44. doi: 10.1061/(asce)1527-6988(2006)7\% $3 \mathrm{~A} 2(40)$

Schroth, O., Pond, E., and Sheppard, S. R. (2011). "Integration of Spatial Outputs from Mathematical Models in Climate Change Visioning Tools for Community-Decision Making on the Landscape Scale," in Teaching Landscape Architecture, eds E. Buhmann, S. Ervin, D. Tomlin, and M. Pietsch (Bernburg: Anhalt University of Applied Sciences), 246-255.

Schultz, M. T., Gouldby, B. P., Simm, J. D., and Wibowo, J. L. (2010). Beyond the Factor of Safety: Developing Fragility Curves to Characterize System Reliability. Vicksburg: Engineer research and development Center.

Shackley, S., and Deanwood, R. (2003). Constructing social futures for climatechange impacts and response studies: building qualitative and quantitative scenarios with the participation of stakeholders. Clim. Res. 24, 71-90. doi: $10.3354 / \mathrm{cr} 024071$

Stempel, P., and Becker, A. (2016). "Data driven visualization". in Proceedings of the Estuarine and Coastal Modeling Conference, South Kingstown, RI.

Stempel, P., Ginis, I., Ullman, D., Becker, A., and Witkop, R. (2018). Real-Time Chronological Hazard Impact Modeling. J. Mar. Sci. Eng. 6:134. doi: 10.3390/ jmse6040134

Stenek, V., Amado, J.-C., Connell, R., Palin, O., Wright, S., Pope, B., et al. (2011). Climate Risk and Business: Ports: Terminal Marítimo Muelles el Bosque Cartagena, Colombia. Climate Risk Case Study. Washington, D.C: World Bank Group.

Reeder, T., and Ranger, N. (2011). How do you Adapt in an Uncertain World? Lessons from the Thames Estuary 2100 project. Washington, DC: World Resources Report.

Thomalla, F., Downing, T., Spanger-Siegfried, E., Han, G., and Rockström, J. (2006). Reducing hazard vulnerability: towards a common approach between disaster risk reduction and climate adaptation. Disasters 30, 39-48. doi: 10. $1111 / j .1467-9523.2006 .00305 . x$

United Kingdom Climate Impacts Programme [UKCIP] (2013). The UKCIP Adaption Wizard v 4.0 [Online]. Oxford: United Kingdom Climate Impacts Programme. Available at: http://www.ukcip.org.uk/wizard/ (accesed May 26, 2017).

United Nations Conference on Trade and Development [UNCTAD] (2017). Climate Risk and Vulnerability Assessment Framework for Caribbean Coastal Transport Infrastructure: Final Report Climate Change Impacts on Coastal Transport Infrastructure in the Caribbean: Enhancing the Adaptive Capacity of Small Island Developing States (SIDS) UNDA Project 14150. Geneva: UNCTAD

United States Census Bureau (2018). QuickFacts Westerly CDP, Rhode Island. Available at: https://www.census.gov/quickfacts/fact/table/ westerlycdprhodeisland/POP010210\#viewtop

Vickery, P. J., Skerlj, P. F., Lin, J., Twisdale, L. A. Jr., Young, M. A., and Lavelle, F. M. (2006). HAZUS-MH hurricane model methodology. II: Damage and loss estimation. Nat. Hazards Rev. 7, 94-103. doi: 10.1061/(asce)1527-6988(2006) 7\%3A2(94)

White, D. D., Wutich, A., Larson, K. L., Gober, P., Lant, T., and Senneville, C. (2010). Credibility, salience, and legitimacy of boundary objects: water managers' assessment of a simulation model in an immersive decision 
theater. Sci. Public Policy 37, 219-232. doi: 10.3152/030234210x49 7726

Witkop, R., Stempel, P., and Becker, A. (2019). Developing Consequence Thresholds for Storm Models through Participatory Processes: Case Study of Westerly Rhode Island. Open Access Master's Theses. Rhode Island, RI: University of Rhode Island.

Yamaguchi, S., Ikeda, T., Iwamura, K., Naono, K., Ninomiya, A., Tanaka, K., et al. (2007). "Development of GIS-based flood-simulation software and application to flood-risk assessment," in proceedings of the 2nd IMA International Conference on Flood Risk Assessment, (Plymouth, UK).
Conflict of Interest Statement: The authors declare that the research was conducted in the absence of any commercial or financial relationships that could be construed as a potential conflict of interest.

Copyright $(2019$ Witkop, Becker, Stempel and Ginis. This is an open-access article distributed under the terms of the Creative Commons Attribution License (CC BY). The use, distribution or reproduction in other forums is permitted, provided the original author(s) and the copyright owner(s) are credited and that the original publication in this journal is cited, in accordance with accepted academic practice. No use, distribution or reproduction is permitted which does not comply with these terms. 


\section{OPEN ACCESS}

Edited by:

Jonathan D. Paul,

Imperial College London,

United Kingdom

Reviewed by:

Victor Marchezini,

Centro Nacional de Monitoramento e

Alertas de Desastres Naturais

(CEMADEN), Brazil

Yo Fukutani,

Kanto Gakuin University, Japan

*Correspondence:

Anna Hicks

ahicks@bgs.ac.uk

Specialty section:

This article was submitted to

Geohazards and Georisks,

a section of the journal

Frontiers in Earth Science

Received: 27 May 2019

Accepted: 19 August 2019

Published: 18 September 2019

Citation:

Hicks A, Barclay J, Chilvers J, Armijos MT, Oven K, Simmons $P$ and

Haklay M (2019) Global Mapping

of Citizen Science Projects

for Disaster Risk Reduction.

Front. Earth Sci. 7:226.

doi: $10.3389 /$ feart.2019.00226

\section{Global Mapping of Citizen Science Projects for Disaster Risk Reduction}

\author{
Anna Hicks ${ }^{1 *}$, Jenni Barclay², Jason Chilvers², M. Teresa Armijos ${ }^{3}$, Katie Oven ${ }^{4}$, \\ Peter Simmons ${ }^{2}$ and Muki Haklay ${ }^{5}$ \\ ${ }^{1}$ British Geological Survey, Lyell Centre, Edinburgh, United Kingdom, ${ }^{2}$ School of Environmental Sciences, University of East \\ Anglia, Norwich, United Kingdom, ${ }^{3}$ School of International Development, University of East Anglia, Norwich, \\ United Kingdom, ${ }^{4}$ Department of Geography, Durham University, Durham, United Kingdom, ${ }^{5}$ Department of Geography, \\ University College London, London, United Kingdom
}

Citizen science for disaster risk reduction (DRR) holds huge promise and has demonstrated success in advancing scientific knowledge, providing early warning of hazards, and contributed to the assessment and management of impacts. While many existing studies focus on the performance of specific citizen science examples, this paper goes beyond this approach to present a systematic global mapping of citizen science used for DRR in order to draw out broader insights across diverse methods, initiatives, hazards and country contexts. The systematic mapping analyzed a total of 106 cases of citizen science applied to DRR across all continents. Unlike many existing reviews of citizen science initiatives, relevance to the disaster risk context led us to 'open up' our mapping to a broader definition of what might constitute citizen science, including participatory research and narrative-based approaches. By taking a wider view of citizen science and opening up to other disciplinary practices as valid ways of knowing risks and hazards, we also capture these alternative examples and discuss their relevance for aiding effective decision-making around risk reduction. Based on this analysis we draw out lessons for future research and practice of citizen science for DRR including the need to: build interconnections between disparate citizen science methods and practitioners; address multi-dimensionality within and across hazard cycles; and develop principles and frameworks for evaluating citizen science initiatives that not only ensure scientific competence but also attend to questions of equity, responsibility and the empowerment of those most vulnerable to disaster risk.

Keywords: citizen science (CS), participation, narrative, disaster risk reduction, knowledge

\section{INTRODUCTION}

Citizen science, or the participation of people from outside professional organizations in the gathering or analysis of scientific data, is now a well-established field of research and an important trend in scientific practice (Bonney et al., 2009b; Haklay, 2013). From its origin, citizen science has included participatory practices in shaping and guiding scientific and social scientific research to local needs (Irwin, 1995), as well as the provision of 'amateur' observational data to facilitate scientific understanding and create improved public understanding of science (Bonney, 1996). A large evidence base exists of the positive contribution of people from all walks of life to diverse scientific fields from, for example, improving understanding of avian biological patterns 
(e.g., Sullivan et al., 2009) to galaxy classification (e.g., Fortson et al., 2013). Consequently, Strasser et al. (2018) contend that current practices and expectations of citizen science most closely resemble those which follow the norms and values of institutional scientific approaches. However, while citizen science applied in this way is a useful tool for collection and analysis of large datasets, it also has a potentially valuable role in the rapid generation and sharing of information. This needs to draw not only on its origins and subsequent development as a tool for opening up discourse, and scientific data-gathering, but also to include experiential knowledge and knowledge situated in the socio-cultural context in which it is gathered (Irwin, 1995). Perhaps none more so than in hazard-prone settings where people can provide authorities with 'ground truth' of the occurrence and impact of hazardous natural events such as landslides, floods and severe weather. Not only can this information act as an early warning, which may help to save lives and livelihoods, it also has the potential to generate shared understandings of hazardous phenomena, improve communication and help communities at risk take actions to build their resilience during, after, and in preparation for future hazardous events.

To understand where practice and advances in citizen science might be most effective in this context it is necessary to consider the context of the disaster risk reduction (DRR) agenda. DRR broadly aims to anticipate and reduce the damage caused by natural hazards (for definitions please refer to a glossary in the Appendix). This is typically achieved through disaster risk management (DRM) which is the implementation of measures that create an ethic of prevention, and can involve systematic efforts to analyze and reduce the causal factors of disaster risk. More recently, these risks are understood to be social and culturally constructed in hazard-prone areas (e.g., Desai and Lavell, 2015). Disasters disproportionately impact those in developing world settings, and often the most vulnerable sectors of society in those settings (UNISDR, 2015) and currently there is growing recognition that successful DRM should be integrated within sustainable development by offering a contribution to social well-being and positive development of individuals and communities. This is most clearly conceptualized through three avenues: the prospective avoidance of further risk creation, the corrective mitigation of existing risk, and strengthening measures that can support the absorptive capacities of individuals and societies against the shocks generated by hazardous events. There is therefore strong potential for the contribution of citizen science in resource-constrained settings to support these goals, but particularly where it draws on citizen science traditions that encourage the integration of scientific-technological knowledge with experiential and contextual knowledge. In particular it should be aligned with the seven global targets ${ }^{1}$ of the

\footnotetext{
${ }^{1}$ The seven global targets are to: (a) Substantially reduce global disaster mortality by 2030 , aiming to lower average per 100,000 global mortality rate in the decade 2020-2030 compared to the period 2005-2015; (b) Substantially reduce the number of affected people globally by 2030, aiming to lower average global figure per 100,000 in the decade 2020-2030 compared to the period 2005-2015; (c)
}

Sendai Framework for Disaster Risk Reduction (UNISDR, 2015) and should clearly consider how it intersects or complement participatory methodologies associated with inclusive action on disaster risk. However, this alignment and the emphasis on the social and cultural construction of risks as well as the occurrence of the associated hazards suggests approaches in citizen science that engage with these multiple dimensions to risk may be more effective.

Hazard-centered, technology-led citizen science for DRR (e.g., utilizing sensors to collect data about hazards) are the most conventional initiatives and have been very effective in many disaster contexts. Yet, the use of Information and Communication Technologies (ICT) does not always guarantee high data quality and participant engagement (Wiggins, 2013). There has been appeal for citizen science scholars and practitioners to embrace tools used in other disciplines, such as social sciences (Hecker et al., 2018).

Although not currently aligned with or related to citizen science, DRR scholars and practitioners (e.g., Wisner et al., 2004; Kelman et al., 2011; Maskrey, 2011; Mercer et al., 2012; Scolobig et al., 2015a), as a consequence of the emphasis on the social construction of risk, advocate approaches that put those at risk at the center of risk reducing initiatives. These approaches are sometimes referred to as 'people-centered' DRR and are often focused at the community scale and emphasize the empowerment of individuals within a community to 'own their risk' in the longer term and, where appropriate, act to reduce it. In comparison to projects that overtly label themselves as citizen science, participatory approaches to DRR typically focus more squarely on empowering people to foster longer-term preparedness development of their own mitigation strategies, and influence on decision-making processes at multiple scales. Nonetheless there is clearly strong potential for intersection and learning between these two knowledge traditions. There are examples of 'people-centered' DRR where communities threatened by hazards have successfully mapped their risk environment to articulate and generate knowledge of long-term impacts (Cronin et al., 2004a; Cadag et al., 2018), or where communities have influenced decision-making processes (e.g., Stone et al., 2014). There are, however, fewer that deal with immediate hazard threat or that work across multiple scales. The argument for considering these different epistemologies in parallel is clear: it is already recognized that the integration of 'local' peoplecentered DRR with risk management plans and processes at other scales could lead to a 'sustainable reduction in disaster risks over time' (Maskrey, 2011). This would be further reinforced

Reduce direct disaster economic loss in relation to global gross domestic product (GDP) by 2030; (d) Substantially reduce disaster damage to critical infrastructure and disruption of basic services, among them health and educational facilities, including through developing their resilience by 2030; (e) Substantially increase the number of countries with national and local disaster risk reduction strategies by 2020; (f) Substantially enhance international cooperation to developing countries through adequate and sustainable support to complement their national actions for implementation of this Framework by 2030; (g) Substantially increase the availability of and access to multi-hazard early warning systems and disaster risk information and assessments to the people by 2030. UNISDR 2015. Sendai Framework for Disaster Risk Reduction 2015-2030. 
by deepening collaboration between citizens at risk and those responsible for scientific information gathering or emergency response. This could benefit both participants and scientists, which should generate sustained involvement in communitybased risk reduction projects. Further, by considering the intersection of more traditional citizen science projects with participatory processes associated with DRR there is also the potential to more explicitly work to equalize access to scientific data and knowledge regardless of wealth, status or gender, consistent with the Global Goals for Sustainable Development (UNISDR, 2015).

If there is potential benefit from looking beyond hazardfocused citizen science and integrating tools from participatory research for DRR, there may also be advantage in crossfertilization of techniques more commonly used in the arts and humanities. Such interdisciplinary approaches are often applied in DRR research, and examples also exist from citizen science (frequently under the header of 'Digital Humanities'). We know that scientific, socio-scientific, cultural and political knowledge can all contribute to the reduction of disaster risk but are often considered in isolation, or underutilized in practice. We have also established that successful DRM demands improved experiential and situational knowledge and means to empower the citizens at risk, both of which can be offered by drawing on methods and techniques from the humanities. Attempts to understand the crucial ingredients for success in citizen science should also draw on these knowledge traditions.

In this paper, which attempts to understand how citizen science is and could be applied to DRR, we extend our characterization and analysis of citizen science from purely science and technology-led initiatives to include projects which adopt participatory methods and explore the role of vernacular and narratives for DRR. As more interdisciplinary fields are emerging applied to the prevention of disastrous outcomes from natural hazards, we consider it timely to map out the range of activities across a broader suite of citizen science techniques and consider lessons and synergies across diverse fields. This is already in line with some interpretations of citizen science (Irwin, 1995; People's Knowledge Editorial Collective, 2016). We argue that the field of practice (or epistemology) from which the technique draws is of secondary importance to identifying how and when positive outcomes occur for communities at risk. We review citizen science initiatives for DRR by mapping $>10$ years trends across disciplines, hazard and location in an attempt to understand the components of citizen science projects that determine success, and as a corollary, what citizen science initiatives have to offer DRR.

We begin by providing some context to our suite of citizen science techniques followed by a description of the approach to our global mapping, and the interdisciplinary workshop that informed it. We then present our global mapping results and analysis followed by a discussion of the challenges that DRR poses to citizen science and the benefits of taking a broader approach by 'opening up' citizen science initiatives to diverse disciplines.

\section{CITIZEN SCIENCE SUITE OF TECHNIQUES: CONTEXT}

\section{Traditional Scientific Technological Approaches to Citizen Science}

Technological developments have facilitated a rapid rise in citizen science initiatives, often labeled as crowdsourcing - a voluntary activity by a large, unsolicited group of people (the crowd) who contribute information, ideas or services, usually via the internet. In citizen science initiatives applied to DRR, this type of information is sometimes referred to as Volunteered Geographic Information. The 'crowd' can use their digital devices to capture photos and record real-time observations of hazardous events or damage, and/or analyze images post hoc. This information can support emergency responders at the time, as well as relieve pressure on disaster analysts post-event. Smartphone accelerometers and Global Positioning Systems can detect earthquakes and potentially provide warnings (Ervasti et al., 2011; Minson et al., 2015; Kong et al., 2016), for example, the proof-of-concept MyShake smartphone seismic network harnesses smartphone sensors to detect magnitude five earthquakes and above at distances of $10 \mathrm{~km}$ or less. This information could be used to support early warning systems in regions with traditional seismic and geodetic networks by helping to confirm earthquake detection, and in regions without traditional seismic networks (which often have high smartphone ownership), and could be used to deliver alerts (Kong et al., 2016). Games, apps and online activities such as mapping (e.g., via OpenStreetMap) are becoming more popular with the public and researchers to be able to record observations, monitor hazards and provide early warning (Palen et al., 2007, 2015; Mani et al., 2016; Mossoux et al., 2016). Web-enabled databases are used for the public to submit observations directly about hazards, such as volcanic ash distribution (Wallace et al., 2015) and about hazard impacts on, for example, infrastructure (Baum et al., 2014). This information is useful for monitoring agencies to assess the characteristics of, for example, a volcanic eruption plume, which can be used to update ashfall advisories for aviation. Social media data can be leveraged and transformed into useful and useable information for both the public at risk, emergency responders and decision makers. This was the central hypothesis of the PetaJakarta.org project which collected verified reports of flooding from residents of Jakarta via Twitter. The geolocated tweets provided a valuable real-time 'knowledge network' of flood events of unparalleled spatial and temporal resolution (Holderness and Turpin, 2015).

\section{Participatory Approaches in DRR and Their Intersection With Citizen Science}

While traditional citizen science approaches are likely to stem from science and technology, by definition the involvement of the wider public makes citizen science initiatives a participatory activity. Indeed, one of the terms that can be used for this field is Public Participation in Scientific Research (Bonney et al., 2009a). Within the context of DRR, participatory activities are typically classified via their framing or originator from 'bottom 
up' or 'grassroots, i.e., conceived, planned and driven by citizens, through to 'top down', i.e., organized campaigns usually driven by non-governmental organizations, local political actors or researchers, framings familiar to citizen science. Depending on the research goal, approaches across the spectrum can achieve success, but most participatory activities do not have new information about hazards or hazard impacts as their core goal and so would not usually be regarded as closely aligned with citizen science. In DRR, participation is usually a core principle or perceived as a key dimension of success. For example, the guiding principles of the Sendai Framework for Disaster Risk Reduction requires "all-of-society engagement and partnership," for participation to be empowering, inclusive, accessible and non-discriminatory, and that "special attention should be paid to the improvement of organized voluntary work of citizens" (UNISDR, 2015, p. 13). There are, however, increasing numbers of 'participatory DRR' projects that take a more mid-ground, co-creative approach where both scientists and citizens use and generate different forms of knowledge to integrate new understandings and create a shared agenda. Numerous examples of participatory initiatives exist that align with these guiding principles and the wider aims of citizen science, from the development and evolution of a communitybased volcano monitoring network at Tungurahua volcano in Ecuador (Stone et al., 2014; Armijos et al., 2017), to the initiation of 'slope watchwomen' to inspect the landslide-prone slopes in the city of Manizales, Colombia (Mejía Prieto et al., 2006; Hermelin and Bedoya, 2008).

\section{Use of Narratives in Citizen Science for Disaster Risk Reduction}

Developing the idea that citizen science in the context of DRR is the generation of any relevant new knowledge, there is mounting evidence that narrative (social and/or historical) has a role to play in preparedness and recovery. For example, on Simeulue Island in Indonesia, thousands of lives were saved from the impacts of the 26 December 2004 tsunami by people shouting Smong (meaning 'tsunami in'). This is a story told in lullabies, poems and songs, inherited and shared over generations. On hearing the word following an earthquake, people move to higher ground (Syafwina, 2014). The 'Strengthening Resilience in Volcanic Areas' (STREVA) project created oral history films to capture community experience of volcanic eruptions in Colombia and St. Vincent and the Grenadines, which proved not only to be a cathartic act for survivors sharing their experiences on film, but also motivated audiences to consider ownership of risk and potential actions to reduce it (Hicks et al., 2017). Similarly in New Zealand, the production of a dance performance assisted the recovery of those that had been affected by the Christchurch earthquake (Egan and Quigley, 2015).

Beyond these examples, narrative could have a number of functions in relation to citizen science more broadly, and not only for DRR: (1) as a data source from which information can be extracted (Stone et al., 2014); (2) as a data object, e.g., for bonding and social connection (social capital) (ChamleeWright, 2017); (3) as a tool for communication e.g., storytelling (Hicks et al., 2017); (4) as a resource to challenge dominant narratives; and (5) as a tool to evaluate a project or intervention (Constant and Roberts, 2017).

\section{RESEARCH METHODOLOGY}

\section{Context and Framing}

This paper stems from a $14-$ month $^{2}$ research project called "Harnessing 'citizen science' to reinforce resilience to environmental disasters: creating an evidence base and community of practice." The aim of our project was to understand how citizen science is currently applied to DRR objectives in the face of natural hazards, and how it might be more effectively applied in the future. We also aimed to create an outward facing network of researchers interested in evidence-based approaches to applying a broad suite of citizen science techniques to environmental hazards. In this context, and drawing on the different knowledge traditions outlined above, our definition of citizen science is as follows: "Citizen science places citizens at the center of a process that generates new knowledge for disaster risk reduction ${ }^{3}$." In a recent review of citizen science terminology, Eitzel et al. (2017) concluded that no single term is appropriate for all contexts and in trying to develop a new epistemic framework for citizen science (Strasser et al., 2018) argue that opening up definitions of knowledge and participation in citizen science could 'result in a different kind of science and a different kind of knowledge' that has the potential to transform understandings of the natural world. In parallel, we conclude that the application of citizen science to DRR needs to be appropriate to that context, so we deliberately gathered evidence widely across disciplines and epistemologies. Our definition uses the word 'knowledge' instead of 'science' to acknowledge this widening from scientific norms to define the landscape of DRR-focused citizen science projects across the world.

\section{Initial Project Workshop}

In April 2017, our first project workshop was held with 27 researchers ${ }^{4}$ and international project partners ${ }^{5}$ working across the physical and social sciences, arts and humanities, many of whom had been or were actively involved in citizen science projects, or came from knowledge traditions of relevance to citizen science in DRR contexts or the improvement of DRR outcomes. The aims of the workshop pertinent to this paper were: (a) discuss the synthesis of citizen science literature to date, particularly asking, "are there conceptual crossovers between the

\footnotetext{
${ }^{2}$ Project duration: January 2017 - March 2018.

${ }^{3}$ The United Nations Office for Disaster Risk Reduction (UNISDR) defines disaster risk as the potential loss of life, injury, or destroyed or damaged assets which could occur to a system, society or a community in a specific period of time as a function of hazard, exposure, vulnerability and capacity. So, disaster risk reduction is aimed at preventing new and reducing existing disaster risk and managing residual risk. ${ }^{4}$ Researchers (United Kingdom-based) were from University of East Anglia (representation from five schools), British Geological Survey, University of Bristol, University of Durham (representation from two schools), University College London (representation from two departments), University of Oxford, University of Essex, Kings College London and the University of Leeds.

${ }^{5}$ International partners were from Trinidad and Tobago, Nepal and Ecuador.
} 
wider [as we are defining it] suite of citizen science projects?"; and (b) discuss the questions, "what lessons can we learn from existing initiatives?" and "how can the design of future initiatives be improved?" Key findings from region-specific analyses were introduced and we used breakout groups and plenary discussion to think about the development of our mapping framework and what makes an 'effective' citizen science project. After producing an initial list, we used a 'fantasy' citizen science project exercise based in St. Vincent and the Grenadines, to test and converge on key principles for successful citizen science that conforms to the wider goals of DRR (see section Discussion).

\section{Global Citizen Science for DRR Project Mapping}

Following the workshop, a literature mapping scoping note was sent to the project team for suggestions of potential cases to be included in our expanded review corpus. We requested that each case must involve some kind of citizen engagement with natural hazards (e.g., recording observations or participatory mapping), but could be from any disciplinary area. However, our deliberately broad definition of citizen science, differing epistemologies within the multi-disciplinary team and the breadth and number of studies made it challenging to bound our literature mapping. As a result we drew on a systematic mapping method which has been developed to map across diverse forms and systems of public participation in science and environmental issues (Chilvers et al., 2018). This method involves the following steps: (i) scoping the literature, framework for analysis and search terms; (ii) expert panel feedback, in this case from workshop participants; (iii) searching and screening through systematic searches of academic literatures based on key terms and synonyms relating to the 'how' (i.e., method), 'who' (i.e., who participates) and the object (e.g., hazard or problem) of citizen science initiatives; and (iv) document and case study analysis of cases screened into the literature corpus to identify key patterns and trends in citizen science for DRR.

Drawing on this approach we developed a list of search terms which were synonyms of 'how', i.e., the model of citizen science or the means through which citizens engage (the process), to be searched alongside synonyms of 'who', i.e., who are the participants, synonyms of 'what,' i.e., what is the object of citizen science or what problem is it addressing, and synonyms of outcomes or products of citizen science. Originally a project-wide collaborative exercise, it resulted in a long list of synonyms that generated 1.26 million results from peer reviewed sources alone. Acknowledging that it would be beyond the scope of the project to review this many sources, the authors' final selected search terms were: "citizen science," crowdsource*, particip*, narrative, story $^{*}$, disaster and hazard. Restricting the search terms was necessary to make the global scope of the mapping workable, although it will have restricted attention to particular meanings of citizen science to some degree and led to the exclusion of some studies from our searches. However, this allowed us to sample representative projects that might demonstrate effective approaches in achieving broad goals aligned with current challenges in DRR and management. It is also important to note that we restricted the search to the academic peer-reviewed literature. Firstly, in this literature, there was more likely to be descriptions of framing rationalization, measures of success and analysis of the outcomes from the project. Secondly, although there are many more cases within the gray literature, for example in World Bank reports (GFDRR, 2018), the scale of this initial mapping made their inclusion difficult. While this means that some cases will therefore have been excluded, it does signify the need to explore diverse forms of citizen science and obtain evidence for citizen science projects that push beyond codified documentation of practice. We completed our searches through the academic search engines Web of Knowledge and Scopus ${ }^{6}$ and filtered by subject in order to reduce the number of irrelevant cases. There was no restriction imposed on date of publication as our preliminary searches established that most citizen science projects related to hazards were conducted, or at least published, in the last 10 years. Duplicates generated from the two search engines were filtered, conference proceedings were omitted and then the results were manually screened to identify relevant cases. A total of 305 studies were identified at the first screening stage.

We then categorized the corpus of cases in order to map the diversities and patterns of projects across a set of variables (Table 1). The initial set of variables for our first iteration of coding were: (1) project country focus (division into developing or developed countries); (2) whether it was a 'new' citizen science project, as compared to a review of a project or set of projects, and (3) whether it was in fact a citizen science project for DRR, as per our agreed definition. Coding against variables 2 and 3 condensed the number of relevant publications considerably, making a final corpus of 106 in total. Once the relevant publications had been screened we conducted a second round of coding to explore the projects in more depth. These variables broadly addressed the who, what, why, where, when and how and were chosen to help us identify geographical and hazard focus (and potentially patterns) of projects, the broad methodological approach and the proportion of projects initiated at particular times along the disaster continuum (i.e., before, during and after). Along with other data such as project aims, specific methodologies, project participants and funding bodies (gathered in case interesting patterns emerged), we collected this information to help us understand the trends and landscape of citizen science projects and how they aligned with current challenges or best practice in DRM, and the ingredients for and barriers to success. It is important to understand this was not to critique any individual study (which may have only serendipitously included goals associated with DRM as a result of another chief aim) but to use them to collectively understand current practice and knowledge and project framing.

Where available, we also coded information about the nature of the association between scientist and participants (Table 2), i.e., were both scientists and citizens outside of the region/country where the hazard occurred? Were scientists outside and participants experiencing the hazard? Were both inside the country? Were they collective movements (grassroots)? Related to this, we documented the type of interaction between the two (collaborative, collaborative but with strong direction

${ }^{6}$ Web searches were conducted between the 25-27th February 2018. 
TABLE 1 | Inclusion criteria and variables for global mapping of citizen science for DRR projects.

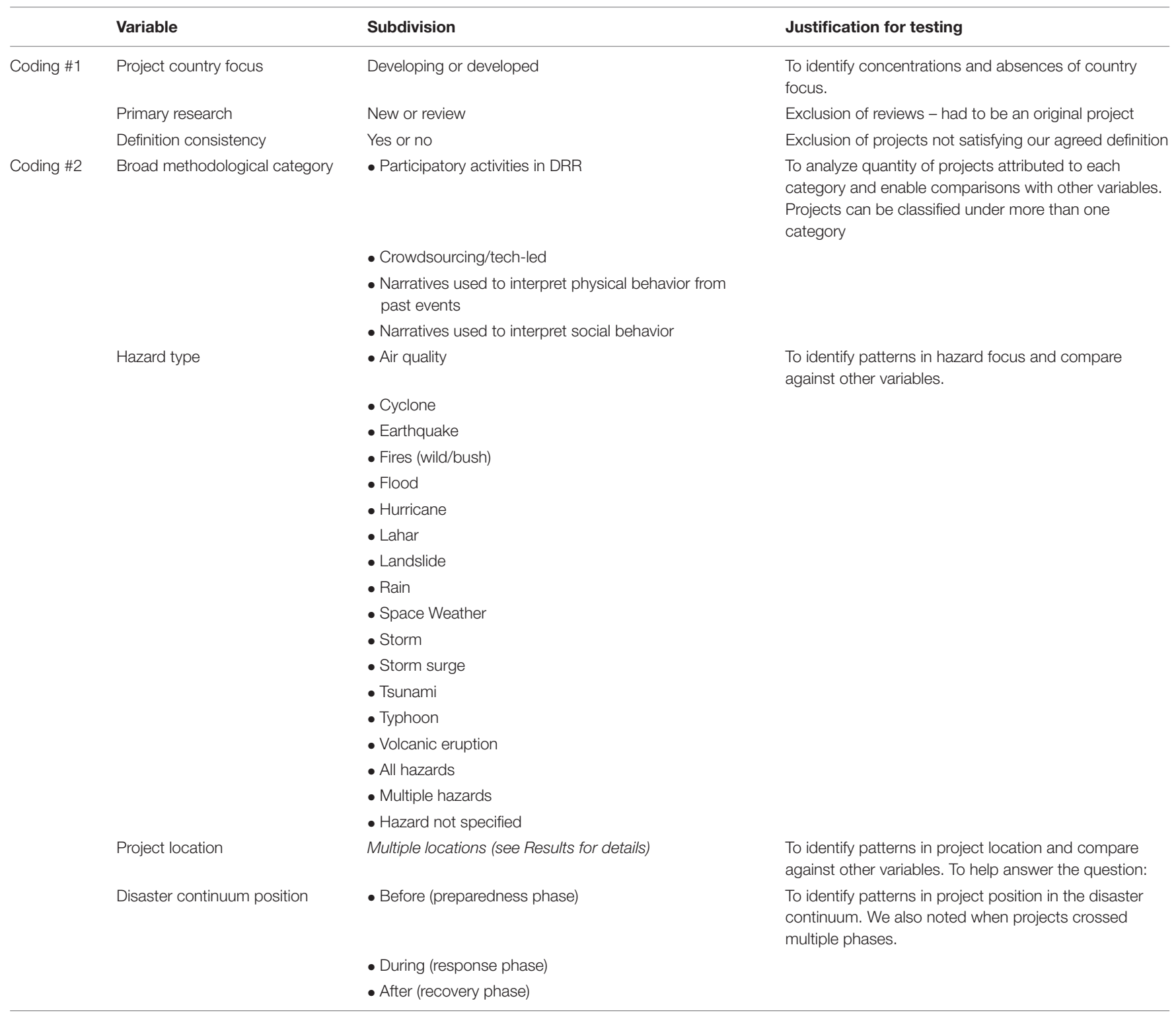

from scientists, extractive, and analytical). These variables relate closely to the 'contributive,' 'collaborative' and 'co-created' models of cooperation in citizen science projects (Bonney et al., 2009b; Shirk et al., 2012) and acknowledge the power relationships between participants, an important dimension of participatory methodologies in DRR. They also allow us to reflect on the extent to which apparently different knowledge traditions have potential to intersect or learn from one another. The variables 'extractive' and 'analytical' refer to instances where participants are data subjects (with no direct benefits to them for participation) and where the participants explore and interpret information they, or others, have gathered, respectively. If documented, we recorded measures of success, acknowledged pitfalls of the project(s) and whether the project(s) met or expressed parallel principles to those that we had synthesized as a consequence of the first workshop (see section Discussion for details on the principles). The details of our corpus of cases are in a spreadsheet in the Supplementary Materials, and on the project website citizensciencedrr.com.

\section{RESULTS AND ANALYSIS}

This section details the characterization of our cases by country focus, by hazard focus, by stage along the disaster continuum and by model of cooperation between scientist and citizen. As stated above, we take our global mapping beyond existing reviews of the citizen science literature (e.g., Conrad and Hilchey, 2011) by opening up our mapping to include projects using methodologies more commonly associated with social sciences, arts and humanities (i.e., participatory research and narrative based approaches). These cases are also characterized. 


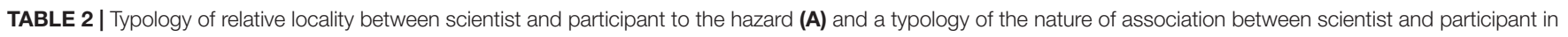
citizen science projects/initiatives for DRR (B).

\begin{tabular}{|c|c|}
\hline \multicolumn{2}{|l|}{ (A) } \\
\hline Relative locality between scientist and participant to the hazard & Definition \\
\hline 'In-In' & $\begin{array}{l}\text { Both scientist and participant were located in the same region/country experiencing the } \\
\text { hazard }\end{array}$ \\
\hline 'Out-In’' & Scientists were outside the region/country and participants were inside \\
\hline 'Out-Out' & $\begin{array}{l}\text { Both scientist and participant were outside of the region/country experiencing the } \\
\text { hazard }\end{array}$ \\
\hline Grassroots & $\begin{array}{l}\text { Collective movements devised and driven completely by participants experiencing the } \\
\text { hazard }\end{array}$ \\
\hline \multicolumn{2}{|l|}{ (B) } \\
\hline Nature of scientist/participant association & Definition \\
\hline $\begin{array}{l}\text { Collaborative (also known as co-created with reference to Shirk et al., } \\
\text { 2012) }\end{array}$ & $\begin{array}{l}\text { Participants and scientists equally share and own the research question(s), project } \\
\text { design, data gathering, analysis, and interpretation. }\end{array}$ \\
\hline $\begin{array}{l}\text { Collaborative but with strong direction from scientists (collaborative, } \\
\text { with reference to Shirk et al., 2012) }\end{array}$ & $\begin{array}{l}\text { Participants contribute to data collection, analysis and interpretation but do not direct } \\
\text { research questions. }\end{array}$ \\
\hline Extractive & Participants are data subjects with no direct benefit from participating. \\
\hline Analytical & Participants explore and interpret information either they, or others, have gathered. \\
\hline
\end{tabular}

\section{Characterization of Cases per Country}

Of our corpus of cases (\#106) there were relatively equal numbers of citizen science for DRR projects based in both developed and developing countries. Figure 1 shows a global map of country focus for the projects we identified in our analysis. While there is a relatively high diversity of study areas in which citizen science for DRR projects were focused - with a notable exception of the African continent - there are no examples of follow-on or iterative projects in any one location. There is one example where the lead author used a participatory approach in one location, developed and applied it in another (Cronin et al., 2004a,b). Three out of four publications from Ecuador also have a single citizen science 'case' as the focus (Stone et al., 2014; Mothes et al., 2015; Armijos et al., 2017). It is also important to note that some projects did comparative studies involving two or more countries, which have all been included in the characterization.

For most developing countries, there were projects that addressed one or more of the top three hazards contributing to average annual reported losses (EM-DAT). For the United States, which had the highest number of projects, this was storms (including hurricanes), flood and wildfire. The suite of projects also included examples from each stage along the disaster continuum and each of our four 'method' categories (Table 1). The hazard focus of Australia-based projects were fires and flooding, despite storm surge being their second largest contributor. New Zealand-based projects were focused on flood, storms and volcanic eruptions, and projects were almost always initiated after a disaster. Of developing country examples, the Philippines had relatively high numbers of projects focusing on wind, storm surge, and earthquakes, as did the Caribbean, albeit with a dominance of projects based in Haiti. For Indonesia, projects focused on volcanic eruptions, floods, and earthquakes. While India has one of the highest occurrence of disasters in Asia - with flooding making up $76 \%$ of the hazard contribution to the average annual losses - there was only one project example from our mapping. Our mapping also only highlighted only two examples from Africa (note that the Aalst et al., 2008 study adopted the same approach in two African countries). This could be due to differences in the historical and social relationship with what constitutes 'science' and 'knowledge' (Leach and Fairhead, 2002), although arguably given our 'opened up' approach to the literature search, examples rooted in indigenous knowledge theory and practice, rather than citizen science, should have been captured.

\section{Methodological Characterization of Cases}

Against our four 'method' categories (Table 1), 52 projects used participatory approaches as the core methodology, 59 were related to crowdsourcing and/or science/technology-led, 14 projects used narratives to interpret physical behavior from past events, and 12 used narratives to interpret and understand social behavior and response to past events. Note that several projects were coded against more than one category. For example, the study by Armijos et al. (2017) was coded against all four categories. Seven of the 36 publications that reviewed citizen science projects for DRR were additionally a discrete study adopting one or more of these methodological categories, so were included in the dataset.

\section{Characterization of Cases by Hazard}

Hazard characterization of the projects reveals that flooding and earthquakes are the most frequent focus of citizen science for DRR projects, with more than double the number of earthquake and flood projects based in developed countries than developing. For earthquakes particularly, this is likely because of the prevalence of crowdsourcing-related projects for earthquake reporting (e.g., Wald et al., 2012; Kong et al., 2016; 


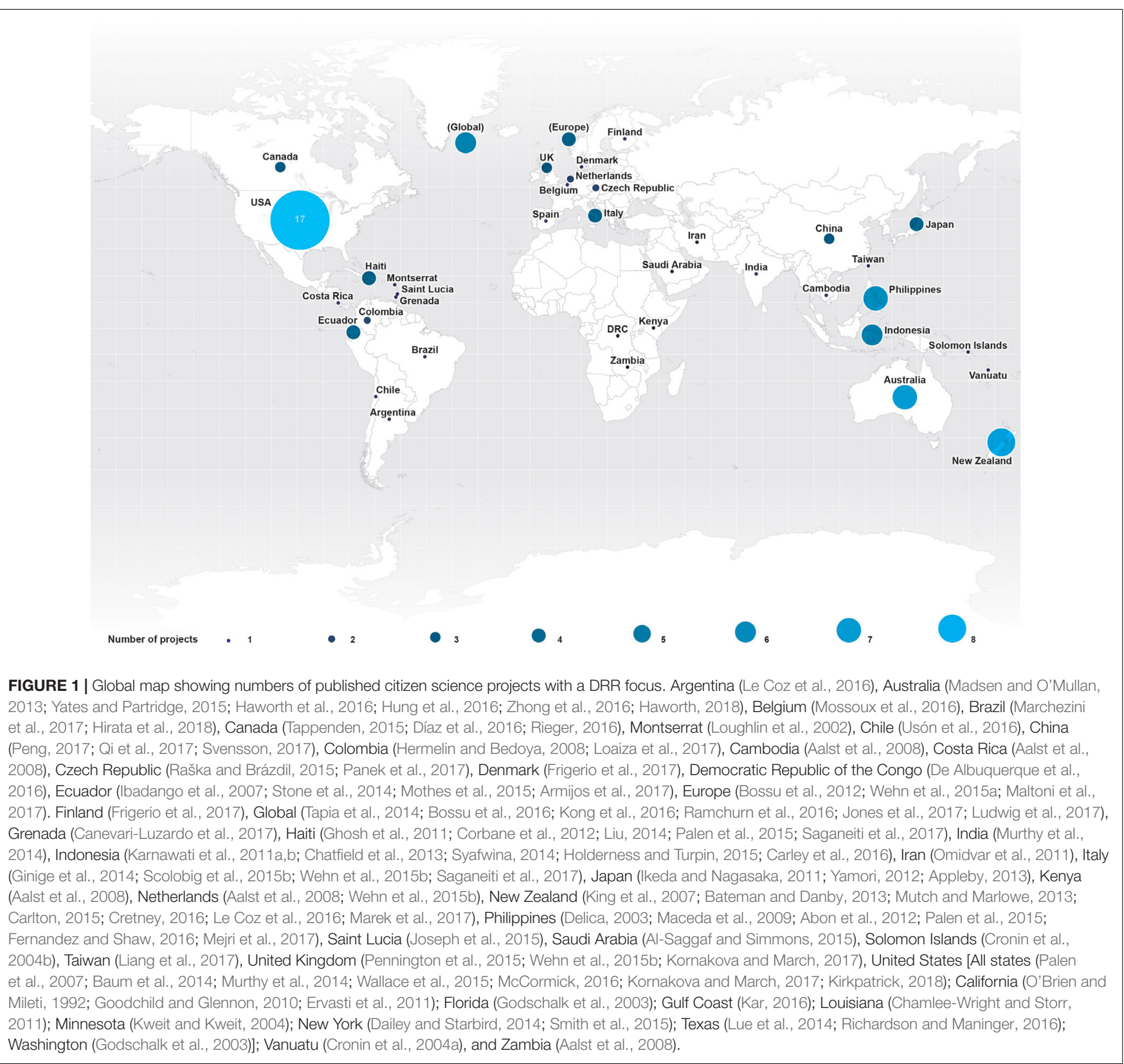

Liang et al., 2017; Peng, 2017), which usually (though not always) rely on a broad user group with access to a smartphone and the internet. There are more projects on landslides and volcanic eruptions in developing countries, likely to be due to the disproportionately severe impact of these events in developing countries (Dowling and Santi, 2014) resulting from a number of contributing factors such as development patterns, access to health care and emergency services and lack of early warning.

\section{Characterization of Cases by Stage of the Disaster Continuum}

A third of projects take place in the aftermath of disaster, likely attributable to the focus of financial and societal support for disaster response (e.g., Aldrich, 2012). The Sendai Framework for Action advises proactive planning and investment in DRR (UNISDR, 2015), but this is often challenging due to a lack of political commitment to resource DRR efforts for prioritization of other development problems (Lassa et al., 2019). Our mapping shows that most citizen science projects initiated before an event are participatory and collaborative in nature and in general tend to be focused around community-centered activities such as hazard mapping, monitoring or mitigation. Those projects concurrent with disaster are almost all associated with more traditional technology-driven citizen science, mostly using crowdsourcing via online mapping to support humanitarian efforts. Citizen science projects conducted after an event are a mixture of traditional citizen science using 'sci-tech' and participatory activities. Interestingly almost all of the projects 
that applied methods from the arts and humanities (particularly narratives) to generate new knowledge and understanding occurred after the event.

\section{Characterization of Cases by Model of Cooperation Between Scientist and Participant}

In terms of the relationship between scientist and participant, approximately 50 projects (47\% of total) were classified as inin' (i.e., both scientist and participant were located in the same region/country experiencing the hazard). Approximately $18(17 \%)$ were coded as 'out-in' (i.e., scientists were outside the region/country and participants were inside), one as 'outout' (i.e., both were outside of the region/country), and six as grassroots (i.e., collective movements devised and driven completely by participants experiencing the hazard). For some projects, it was not possible to determine the model of cooperation between scientist and participant. The majority of 'in-in' projects were either extractive in nature (i.e., where participants are data subjects) or collaborative, but with strong direction from scientists. The majority of 'out-in' projects were also collaborative but with strong direction from scientists. Of the grassroots initiatives we identified, there were relatively equal numbers of projects that were collaborative (none with strong direction from scientists), analytical or extractive.

\section{DISCUSSION}

Our global mapping shows that citizen science for DRR initiatives are being conducted across the world to help address some of the global challenges associated with disasters. While short-term success and sustainability of projects is variable, nonetheless, the discrete nature of the methods and cases is limiting opportunities for methodological innovation, active and broader networking of participants, and flexibility to adapt initiatives as conditions change. A key outcome from our mapping is that we can do much more to move beyond discrete methods and cases of citizen science for DRR to build linkages, connections and relationships more broadly. This would more closely align projects with DRR and help to address some live challenges (e.g., Desai and Lavell, 2015) in using DRM s as a tool to afford positive development trajectories. This finding is concurrent with evidence from other citizen science reviews in related fields (e.g., Hecker et al., 2018; Marchezini et al., 2018). For the remainder of this paper, we reflect on three key issues raised from our global mapping exercise.

\section{Citizen Science for DRR Needs to Be Multi-Dimensional}

Examining DRR-focused citizen science projects in a more holistic manner along the disaster continuum shows the significance of the temporal aspect of the initiatives, and how this affects success. During a disaster (or the response phase) is, generally speaking, the only part of the cycle that is relatively temporally constrained. Our mapping shows that most initiatives concurrent with disaster are technology-led citizen science designed to support humanitarian efforts. Whether this is volunteer mapping of hazards and impacts by altruistic 'outsiders' motivated to help people, or crowdsourced 'ground-truthing' by affected citizens themselves, volunteering to add to a dataset and generate new knowledge is often a passing interest during the time of crisis. This is not necessarily a detriment to any one particular initiative, and there are few examples of opportunities to nurture long-term loyalty to an initiative once the disaster has passed (Turk, 2017). Our mapping shows that there is a need to consider the application of citizen science for DRR in a more multi-dimensional way, particularly the connections and interrelations of methods throughout the disaster continuum.

Our mapping also shows that most citizen science initiatives are compartmentalized around specific hazards (Figure 2). Taking a multi-hazards approach to observing the world around us to account for differing rates of hazard occurrence and documenting the cumulative or even cascading impacts of most relevance to the communities at risk may help to foster continued citizen engagement in observing and monitoring environmental change, whether that be driven by rational egoism and/or collectivism (Baruch et al., 2016; Tipaldo and Allamano, 2016). This would align more clearly with prospective approaches to DRM that could anticipate and reduce the creation of new risks, or identify means to adapt to ongoing hazards. Our analysis shows that current initiatives tend to be bi-modal. Those underway before disasters occur tend to be participatory and collaborative in nature, and focused around communitycentered activities such as hazard mapping, monitoring or mitigation. Those initiated afterward are more extractive or technology-led citizen science. Projects that apply methods from the arts and humanities tend to be associated with the recovery phases, or with the generation of knowledge of the impacts of past events. In both preparatory and recovery phases, there is often - but not always - more time for participants and designers of citizen science projects (it is noted that these can be the same) to develop initiatives that have more subtle, yet important, ingredients for ongoing success, for example, a longer project lifespan to help foster sustainable preparedness, or the flexibility to evolve and adapt to changing environmental and/or socio-economic conditions, which may include scaling up initiatives.

In a DRR context, the value of spatial and temporally focused citizen science initiatives could be strengthened by being part of a multi-method approach (Pelling, 2007) addressing all phases along the disaster continuum. A blending of citizen science initiatives applying successful, evidence-based methods across disciplines that are contextually appropriate before, during and after a disaster may help to influence decision-making processes at multiple scales although this is a challenging task that requires appropriate resources.

\section{Cross-Fertilization of Communities Will Bring Innovation}

We identified that similar numbers of projects took either a technology-led approach or a participatory approach 


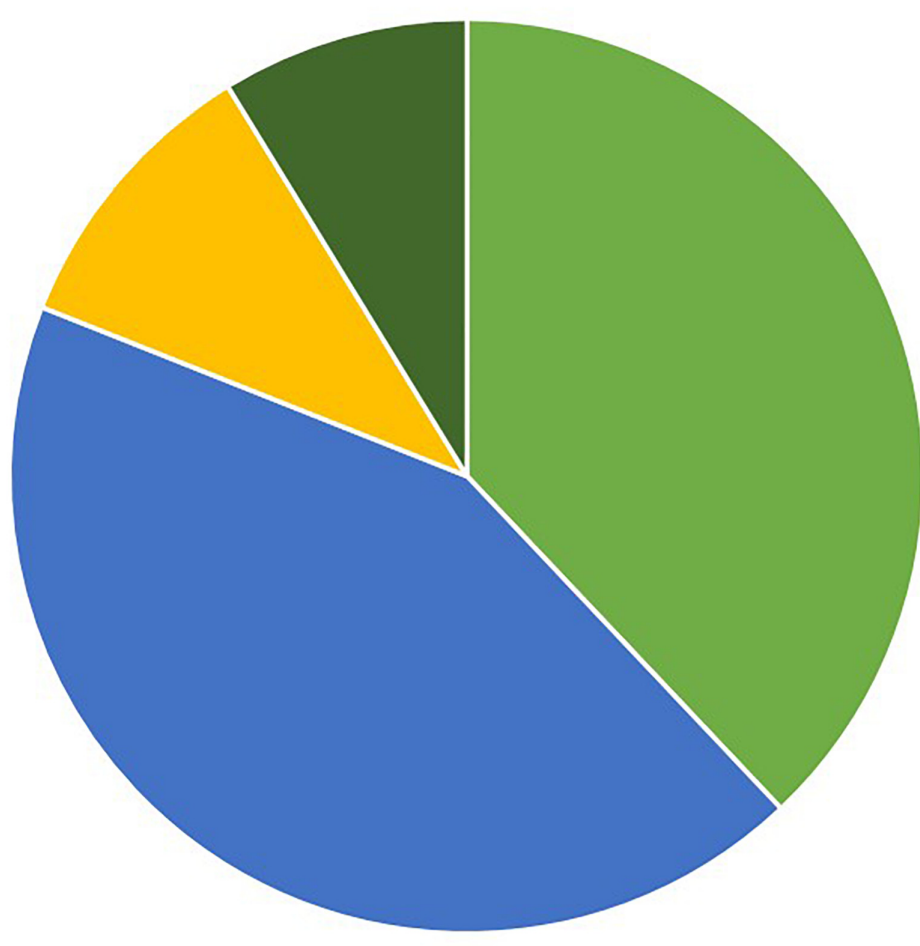

- Projects applying participatory activities for DRR

- Projects applying crowdsourcing and/or informations and communication technology

- Examples of the use of narrative to interpret physical behavior from past events

- Examples of the use of narrative used to interpret social behavior

FIGURE 2 | Methodological characterization of cases.

to their initiatives (some projects took both). Where we could identify the relationships between the participants and the researchers there was a rough equivalency between projects that were largely extractive (where participants were data subjects or providing data with no direct benefits to them beyond altruism) or collaborative. Comparatively few projects explored the role of narrative in knowing hazard and risk, and the majority of those were extractive in nature. Relatively few projects had been initiated and mobilized by the communities themselves [referred to as 'grassroots' in our analysis (Supplementary Materials)]. This reflects the broader pattern of research in both citizen science research more generally, which has been dominantly science-centered (largely driven by scientists and of benefit to scientists), and DRR research which is dominantly people-centered (although this is not to say that DRR research is not scientific). Bridging these two parallel fields of research specifically for citizen science for DRR requires consideration about the crossover between them. Citizen science requires the participation of citizens in the scientific process, and while participatory approaches also requires the participation of citizens, it need not necessarily involve science or scientists. This is why, for this study, we use the word 'knowledge' in place of 'science.' If we consider citizen science as knowledge making, and we know knowledge is relevant if it reduces disaster risk (promoting an ethic of prevention), then citizen science is a subset of all development participation, but one with a troublesome relationship with equitable partnerships and empowerment. At the moment, citizen science initiatives more clearly reflect the experience and documentation of individual hazards rather than understanding the creation of disaster risk. There is compartmentalization into initiatives focused on individual hazards (Figure 3), or designed for specific 'moments' in the disaster continuum (Figure 4). This compartmentalization clearly reflects the specific goals of any one study, and it is important to recognize that the strong compartmentalization of our review papers is also a reflection of the academic audience intended for the peerreviewed literature, but it signals the more focused immediate goals of citizen science in hazard settings. We contend that bringing together the core principles of citizen science with those of participatory DRR could create opportunities to address current challenges in DRR where future 'success' is defined against the reduction of future societal damages 


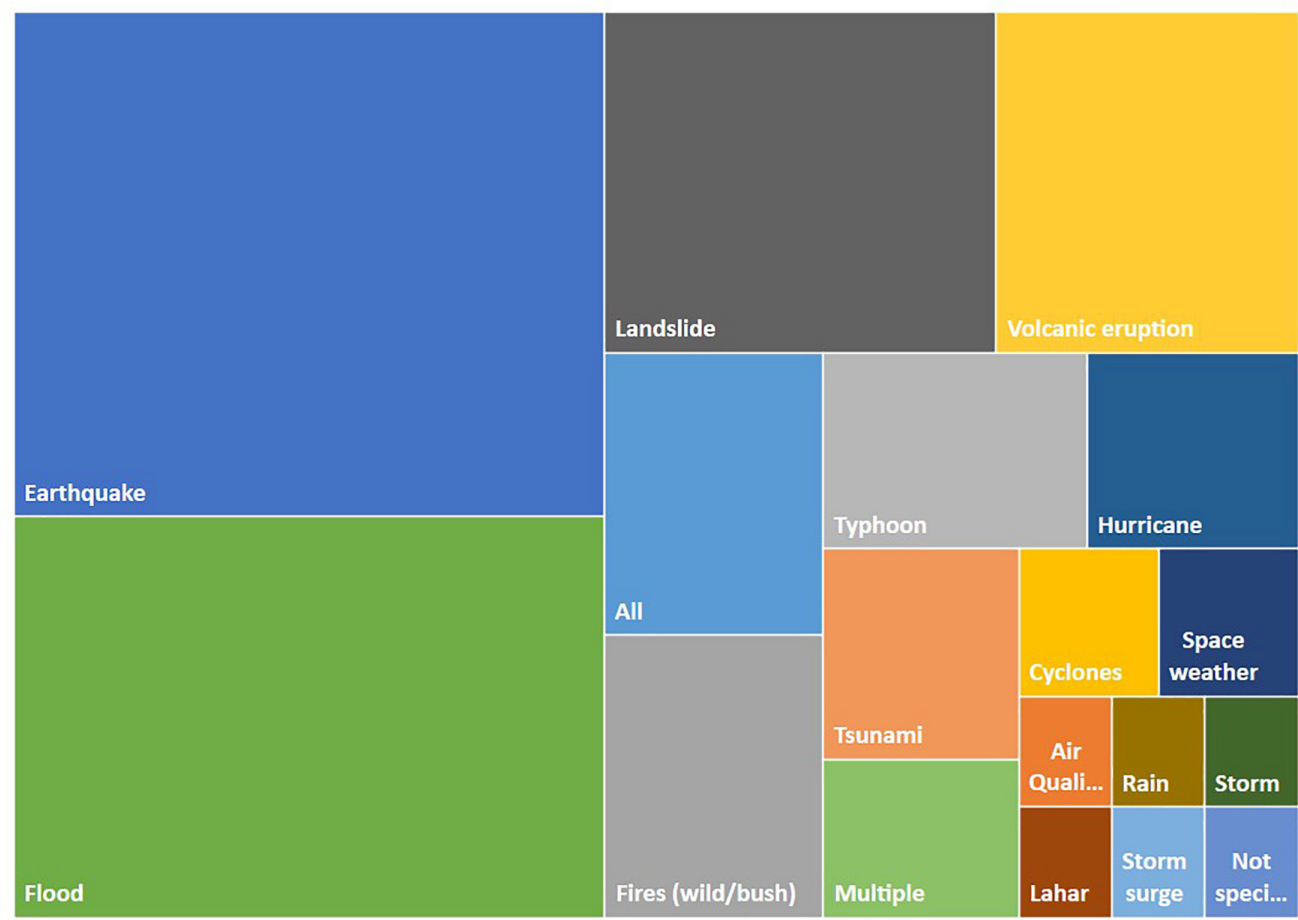

FIGURE 3 | Treemap of hazard focus for citizen science for DRR projects.

associated with natural hazard. So, for example, with this framing it then becomes important to reconcile knowledge generated by multiple human perspectives (not strictly scientific knowledge) or inherent vulnerabilities as it is to describe single hazardous events. However, important conversations are needed about the comparative importance of empowerment and involvement measured against the value of the data generated toward reducing future risk, whether this is the politicization of citizen science, or encouraging the creation of scientific activism. The creation of these communities of practice requires space, time and, perhaps crucially, the curiosity of researchers themselves. The measure of success we develop below need not necessarily have been the primary goal of the studies reviewed here, but should some DRR benefit always be clear and transparent when working on and with communities at risk? It is not easy to bring different communities of practice together but the common goal or aim framed around the reduction of disaster risk could provide the momentum to generate these conversations and this analysis points to some of the gaps in evidence.

\section{Stimulating Cross-Community Collaboration via an Evidence-Based Framework?}

To further explore how a multi-dimensional framework centered around DRR might look in practice, we now consider the agreed principles from our project workshop. Participants here represented those with direct experience of citizen science initiatives, particularly in developing world and multihazard contexts, those from the knowledge tradition of participatory DRR, experts in technological citizen science (sensor design and remote sensing), hazard scientists and those with experience of narratives, nature writing and literary criticism. Our aim was to make these principles as simple but as comprehensive as possible.

The key argument that emerged was that through connecting and linking citizen science for DRR contexts, communities, methods and practices, we can improve our initiatives and also broaden the principles for effectiveness to include criteria of equity, justice, and empowerment.

Our project team developed six common key principles that determine a multi-dimensional citizen science project for DRR:

(1) Active benefits for all participants

(2) Clear attempts to ensure legacy and longevity

(3) Responsible engagement in both quiet times and during active hazard moments

(4) Framed around DRR goals

(5) Careful definition of partners (to ensure equitable outcomes)

(6) Equitable and empowering

These principles, which draw on a variety of knowledge traditions pertinent to DRR, are not designed to supersede the ten principles of citizen science developed by the European Citizen 


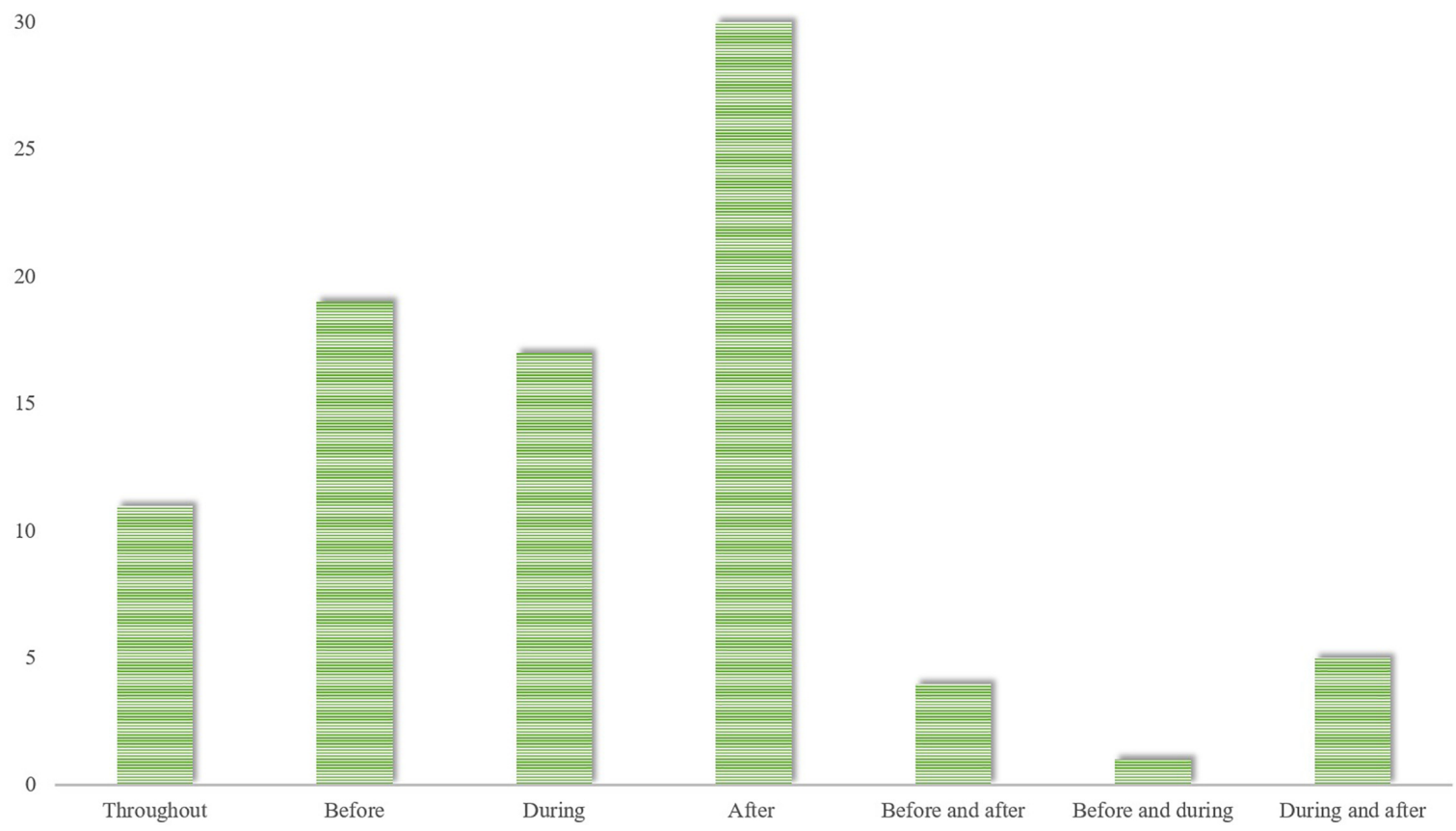

FIGURE 4 | Characterization of cases by stage of the disaster continuum.

Science Association (Robinson et al., 2018) but rather as exercise of consensus building around the particular case of citizen science for DRR. The addition of principles that speak to inclusion and empowerment was seen as important in contexts where data gathering might directly affect those who had experienced the trauma of the impacts of natural hazard. Nonetheless, some of the principles here are also more squarely aimed at generating success in the project and drew on direct experience, for example principle one is almost identical to ECSA's principle 3 (Robinson et al., 2018), and is borne of experience that without benefits for the scientists too, then projects can falter, while also speaking to a more normative rationale. Thus they include some of the broader aims associated with participatory DRR and broader participatory methodologies, and draw on knowledge of what drives success and good practice in broader citizen science initiatives. Where our principles diverge most clearly from the ECSA principles are around the use and definition of 'science outcomes.' Our broader definition of 'science outcomes' as 'new knowledge for DRR' enables a wider variety of research to be incorporated into this type of work. We also did not incorporate the ethical and legal dimensions of the work in our principles or explicitly consider good practice in evaluating and learning from citizen science (ECSA Principles 9 and 10, Robinson et al., 2018). However, our goal in converging on our principles was partly to create a framework against which we could understand how current practice measured against these principles and whether success was measured relative to the reduction of disaster risk either directly or tangentially (via, for example, improved knowledge of hazards). Is there an emerging evidence base for how to be successful? Where some principles were used, we wanted to evaluate the extent to which these helped to drive the success of the project in terms of tangibly reducing disaster risk. Thus, for each case study analysis we investigated who was conducting the citizen science project and how the interaction and data were gathered (see Methods and Supplementary Materials) and whether benefits to participants or equitable partnerships ensued. We also tried to understand the extent to which a citizen science project was deemed successful and how this success aligned with the reduction of disaster risk. None of the projects analyzed provided evidence for using all of the principles in any one project. Principles that were most frequently articulated were those around ensuring active benefits for participants and the careful definition of partners.

These results suggest that there is considerable opportunity to improve outcomes of citizen science in the context of DRR but a clearer framing of projects around these principles is necessary. Another striking feature is the extent to which studies in the literature report on the implementation and design phase of the research with rather less emphasis on the longevity or reflecting on the success of the project against original objectives. Thus, there is evidence that the principles of mutual benefits and empowerment are important but at the moment the evidence for how this ultimately creates success needs more work. 


\section{CONCLUSION}

Citizen science, or the participation of 'non-specialists' in the gathering or analysis of scientific data, is playing an increasingly important role in scientific research. In the context of disasters, it is an excellent way for citizens to contribute to the forecasting and warning of hazards that impact them, and has great potential to be particularly helpful in low and middle income countries. In these regions, citizen science also has the potential to generate shared understanding of hazardous phenomena, improve communication and help communities at risk take actions to improve their resilience during and after hazardous events.

We conducted a global systematic mapping of citizen science for DRR projects in the academic literature, but 'opened up' our review to include projects that apply ideas and techniques that might more normally be associated with the social sciences and humanities as well as the traditional sciences. Our definition of citizen science in this context uses the word 'knowledge' instead of 'science' to define the landscape of DRR-focused citizen science projects across the world. This is because scientific, socioscientific, cultural and political knowledge can all contribute to the reduction of disaster risk. Attempts to understand the crucial ingredients for success in citizen science also needs to draw on these knowledge traditions. It was beyond the scope of our research to include gray literature in our mapping and we recognize that further research is needed to truly 'open up' a review of citizen science for DRR to capture learning from projects published outside of peer-reviewed literature.

Our mapping identified 106 articles reporting on citizen science for DRR projects across the world. We identified: (a) geographic clusters (e.g., United States) and gaps (e.g., Africa), (b) a global predominance of earthquake and floodingfocused projects, (c) similar numbers of projects applying either crowdsourcing or participatory approaches and rather less applying methodologies from the arts and humanities, and (d) a post-event project majority. We also gathered information on the model of cooperation between scientist and citizen, and evidence for success in relation to our principles of citizen science. Based on our analysis, we conclude that interconnections between citizen science methods and practitioners are needed to strengthen and advance the field of citizen science, researchers and practitioners need to address the multi-dimensional nature of disasters and develop initiatives across the disaster continuum and, lastly, that principles and frameworks for evaluating citizen science initiatives are developed to tackle the challenges of ensuring equity, responsibility and empowerment of those most vulnerable to disaster risk. We identify scope for an international, transdisciplinary community of practice in citizen science for DRR to share lessons and inform grounded and relevant research in this field.

\section{DATA AVAILABILITY}

All datasets generated for this study are included in the manuscript and/or the Supplementary Files.

\section{ETHICS STATEMENT}

The research that produced this article was conducted in compliance with the University of East Anglia's Ethical Guidelines. The process included an expert workshop to which academics and practitioners with expertise relevant to the study were invited. Participants from outside the project consortium were informed of the aims of the research, including its publication goals, prior to consenting to take part and these aims were reiterated at the start of the workshop, this is in compliance with University of East Anglia's Ethical Guidelines, separate consent beyond consent obtained during the workshop was not necessary.

\section{AUTHOR CONTRIBUTIONS}

$\mathrm{AH}$ and JB led the conception and design of the manuscript, with input from JC and $\mathrm{MH}$ in the final stages. $\mathrm{AH}$ conducted the mapping and selected the studies, and with support from JB, JC, MA, PS, and KO, analyzed and extracted relevant information from the selected studies.

\section{FUNDING}

This project was funded by the UK's Global Challenges Research Fund: Building Resilience call. Small grants were made available for the design of foundation-building activities with a view to develop inter-disciplinary research communities to address the issue of 'Building Resilience' to both sudden and slow-onset environmental hazards (e.g., land-degradation, deforestation, drought, hurricanes, climate change). This was a joint UK research council call, led by the Natural Environment Research Council (NERC), the Arts and Humanities Research Council (AHRC), and the Economic and Social Research Council (ESRC). JB was PI for this project, grant number: NE/P016014/1.

\section{ACKNOWLEDGMENTS}

We wish to thank the interdisciplinary project team, particularly visiting partners from the University of the West Indies. We also wish to thank the National Emergency Management Organisation of St. Vincent for supporting the project and for facilitating related fieldwork in St Vincent. We are grateful to the editor JP and the reviewers for their helpful suggestions which considerably improved the framing of the review and manuscript.

\section{SUPPLEMENTARY MATERIAL}

The Supplementary Material for this article can be found online at: https://www.frontiersin.org/articles/10.3389/feart. 2019.00226/full\#supplementary-material 


\section{REFERENCES}

Aalst, M., Cannon, T., and Burton, I. (2008). Community level adaptation to climate change: the potential role of participatory community risk assessment. Glob. Environ. Change 18, 165-179. doi: 10.1016/j.gloenvcha.2007. 06.002

Abon, C. C., Primo, C., David, C., and Tabios, G. Q. (2012). Communitybased monitoring for flood early warning system: an example in central Bicol River basin, Philippines. Disaster Prev. Manag. 21, 85-96. doi: 10.1108/ 09653561211202728

Aldrich, D. P. (2012). Building Resilience: Social Capital in Post-Disaster Recovery. Chiago, IL: University of Chicago Press.

Al-Saggaf, Y., and Simmons, P. (2015). Social media in Saudi Arabia: exploring its use during two natural disasters. Technol. Forecast. Soc. Change 95, 3-15. doi: $10.1016 /$ j.techfore.2014.08.013

Appleby, L. (2013). Connecting the Last Mile: Internews Europe Report on the Role of Communications in the Great East Japan Earthquake. London: Internews Europe.

Armijos, M. T., Phillips, J., Wilkinson, E., Barclay, J., Hicks, A., Palacios, P., et al. (2017). Adapting to changes in volcanic behaviour: formal and informal interactions for enhanced risk management at Tungurahua Volcano, Ecuador. Glob. Environ. Change 45, 217-226. doi: 10.1016/j.gloenvcha.2017.06.002

Baruch, A., May, A., and Yu, D. (2016). The motivations, enablers and barriers for voluntary participation in an online crowdsourcing platform. Comput. Hum. Behav. 64, 923-931. doi: 10.1016/j.chb.2016.07.039

Bateman, A., and Danby, S. (2013). Recovering from the earthquake: early childhood teachers and children collaboratively telling stories about their experiences. Disaster Prev. Manag. 22, 467-479. doi: 10.1108/dpm-10-20130177

Baum, R. L., Highland, L. M., Lyttle, P. T., Fee, J. M., Martinez, E. M., and Wald, L. A. (2014). "Report a Landslide" A Website to Engage the Public in Identifying Geologic Hazards. Cham: Springer International Publishing, 95-100.

Bonney, R. (1996). Citizen science: a lab tradition. Living Bird 15, 7-15.

Bonney, R., Ballard, H., Jordan, R., Mccallie, E., Phillips, T., Shirk, J., et al. (2009a). Public Participation in Scientific Research: Defining the Field and Assessing its Potential for Informal Science Education. A CAISE Inquiry Group Report. Washington, DC: Center for Advancement of Informal Science Education (CAISE).

Bonney, R., Cooper, C. B., Dickinson, J., Kelling, S., Phillips, T., Rosenberg, K. V., et al. (2009b). Citizen science: a developing tool for expanding science knowledge and scientific literacy. BioOne 59, 977-984. doi: 10.1525/bio.2009.59.11.9

Bossu, R., Gilles, S., Mazet-Roux, G., Roussel, F., Frobert, L., and Kamb, L. (2012). Flash sourcing, or rapid detection and characterization of earthquake effects through website traffic analysis. Ann. Geophys. 54, 716-727. doi: 10.4401/ag5265

Bossu, R., Steed, R., Mazet-Roux, G., Roussel, F., Etivant, C., Frobert, L., et al. (2016). "The key role of eyewitnesses in rapid impact assessment of global earthquakes," in Earthquakes and Their Impact on Society, ed. S. D'Amico (Cham: Springer).

Cadag, J. R., Driedger, C., Garcia, C., Duncan, M., Gaillard, J. C., Lindsay, J., et al. (2018). "Fostering participation of local actors in volcanic disaster risk reduction," in Observing the Volcano World: Volcano Crisis Communication, eds C. J. Fearnley, D. K. Bird, K. Haynes, W. J. McGuire, and G. Jolly (Cham: Springer International Publishing).

Canevari-Luzardo, L., Bastide, J., Choutet, I., and Liverman, D. (2017). Using partial participatory Gis in vulnerability and disaster risk reduction in Grenada. Clim. Dev. 9, 95-109. doi: 10.1080/17565529.2015.1067593

Carley, K. M., Malik, M., Landwehr, P. M., Pfeffer, J., and Kowalchuck, M. (2016). Crowd sourcing disaster management: the complex nature of Twitter usage in Padang Indonesia. Saf. Sci. 90, 48-61. doi: 10.1016/j.ssci.2016. 04.002 doi: 10.1016/j.ssci.2016.04.002

Carlton, S. (2015). Connecting, belonging: volunteering, wellbeing and leadership among refugee youth. Int. J. Disaster Risk Reduct. 14, 160-167. doi: 10.1016/j. ijdrr.2015.10.010

Chamlee-Wright, E. (2017). The power of narrative in post-disaster entrepreneurial response. Rev. Aust. Econ. 31, 467-472. doi: 10.1007/ s11138-017-0395-y
Chamlee-Wright, E., and Storr, V. H. (2011). Social capital as collective narratives and post-disaster community recovery. Sociol. Rev. 59, 266-282. doi: 10.1111/j.1467-954x.2011.02008.x

Chatfield, A. T., Scholl, H. J., and Brajawidagda, U. (2013). Tsunami early warnings via Twitter in government: net-savvy citizens' co-production of time-critical public information services. Gov. Inform. Q. 30, 377-386. doi: 10.1016/j.giq. 2013.05.021

Chilvers, J., Pallett, H., and Hargreaves, T. (2018). Ecologies of participation in socio-technical change: the case of energy system transitions. Energy Res. Soc. Sci. 42, 199-210. doi: 10.1016/j.erss.2018.03.020

Conrad, C. C., and Hilchey, K. G. (2011). A review of citizen science and community-based environmental monitoring: issues and opportunities. Environ. Monitor. Assess. 176, 273-291. doi: 10.1007/s10661-010-1582-5

Constant, N., and Roberts, L. (2017). Narratives as a mode of research evaluation in citizen science: understanding broader science communication impacts. J. Sci. Commun. 16, 1-18.

Corbane, C., Lemoine, G., and Kauffmann, M. (2012). Relationship between the spatial distribution of SMS messages reporting needs and building damage in 2010 Haiti disaster. Nat. Hazards Earth Syst. Sci. 12, 255-265. doi: 10.5194/ nhess-12-255-2012

Cretney, R. M. (2016). Local responses to disaster: the value of community led post disaster response action in a resilience framework. Disaster Prev. Manag. 25, 27-40. doi: 10.1108/dpm-02-2015-0043

Cronin, S. J., Gaylord, D. R., Charley, D., Alloway, B. V., Wallez, S., and Esau, J. W. (2004a). Participatory methods of incorporating scientific with traditional knowledge for volcanic hazard management on Ambae Island, Vanuatu. Bull. Volcanol. 66, 652-668. doi: 10.1007/s00445-004-0347-9

Cronin, S. J., Petterson, M. G., Taylor, P. W., and Biliki, R. (2004b). Maximising multi-stakeholder participation in government and community volcanic hazard management programs; a case study from Savo, Solomon Islands. Nat. Hazards 33, 105-136. doi: 10.1023/b:nhaz.0000035021.09838.27

Dailey, D., and Starbird, K. (2014). Journalists as crowdsourcerers: responding to crisis by reporting with a crowd. Comput. Support. Coop. Work 23, 445-481. doi: 10.1007/s10606-014-9208-z

De Albuquerque, J. P., Herfort, B., and Eckle, M. (2016). The tasks of the crowd: a typology of tasks in geographic information crowdsourcing and a case study in humanitarian mapping. Remote Sens. 8:859. doi: 10.3390/rs8100859

Delica, Z. G. (2003). "Community mobilisation for early warning in the Philippines," in Early Warning Systems for Natural Disaster Reduction, eds J. Zschau and A. Küppers (Berlin: Springer).

Desai, B., and Lavell, A. (2015). Future Challenges of Disaster Risk Management. Global Assessment Report on Disaster Risk Reduction 2015. Geneva: United Nations Office for Disaster Risk Reduction.

Díaz, P., Carroll, J., and Aedo, I. (2016). Coproduction as an approach to technology-mediated citizen participation in emergency management. Fut. Internet 8:41. doi: 10.3390/fi8030041

Dowling, C. A., and Santi, P. M. (2014). Debris flows and their toll on human life: a global analysis of debris-flow fatalities from 1950 to 2011. Nat. Hazards 71, 203-227. doi: 10.1007/s11069-013-0907-4

Egan, C. J., and Quigley, M. C. (2015). Dancing earthquake science assists recovery from the Christchurch earthquakes. Res. Dance Educ. 16, 161-183. doi: 10. 1080/14647893.2014.930819

Eitzel, M. V., Cappadonna, J. L., Santos-Lang, C., Duerr, R. E., Virapongse, A., West, S. E., et al. (2017). Citizen science terminology matters: exploring key terms. Citiz. Sci. 2:1. doi: 10.5334/cstp.96

EM-DAT, EM-DAT: The OFDA/CRED International Disaster Database -. Brussels. Belgium: Université Catholique de Louvain. doi: 10.5334/cstp.96 (accessed March, 2019).

Ervasti, M., Dashti, S., Reilly, J., Bray, J. D., Bayen, A., and Glaser, S. (2011). "iShake: mobile phones as seismic sensors - user study findings," in Proceedings of the 10th International Conference on Mobile and Ubiquitous Multimedia, (Beijing: ACM). doi: 10.1002/9781118396599.ch1

Fernandez, G., and Shaw, R. (2016). "13 - Urban disasters and risk communication through youth organizations in the Philippines," in Urban Disasters and Resilience in Asia, eds R. Shaw, R. Atta Ur, A. Surjan, and G. A. Parvin (Oxford: Butterworth-Heinemann). doi: 10.1201/b12994-2

Fortson, L. F., Willett, K. W., Raddick, M. J., Schawinski, K., Skibba, R. A., Simmons, B. D., et al. (2013). Galaxy Zoo 2: detailed morphological 
classifications for 304122 galaxies from the Sloan Digital Sky Survey. Mon. Notic. R. Astronom. Soc. 435, 2835-2860. doi: 10.1093/mnras/stt1458

Frigerio, S., Bianchizza, C., Schenato, L., and Del Bianco, D. (2017). A mobile application to engage citizens and volunteers. Crowdsourcing within natural hazard. Rend. Online Soc. Geol. It. 42, 70-72. doi: 10.3301/rol.2017.17

GFDRR (2018). Identifying Success Factors in Crowdsourced Geographic Information Use in Government. Washington, DC: GFDRR.

Ghosh, S., Huyck, C. K., Greene, M., Gill, P. S., Bevington, J., Svekla, W., et al. (2011). Crowdsourcing for rapid damage assessment: the global earth observation catastrophe assessment network (GEO-CAN). Earthq. Spectra 27, S179-S198.

Ginige, A., Paolino, L., Romano, M., Sebillo, M., Tortora, G., and Vitiello, G. (2014). Information sharing among disaster responders - an interactive spreadsheetbased collaboration approach. Comput. Support. Coop. Work 23, 547-583. doi: 10.1007/s10606-014-9207-0

Godschalk, D. R., Brody, S., and Burby, R. (2003). Public participation in natural hazard mitigation policy formation: challenges for comprehensive planning. J. Environ. Plann. Manag. 46, 733-754. doi: 10.1080/0964056032000138463

Goodchild, M. F., and Glennon, J. A. (2010). Crowdsourcing geographic information for disaster response: a research frontier. Int. J. Dig. Earth 3, 231-241. doi: 10.1080/17538941003759255

Haklay, M. (2013). "Citizen science and volunteered geographic information: overview and typology of participation," in Crowdsourcing Geographic Knowledge: Volunteered Geographic Information (VGI) in Theory and Practice, eds D. Sui, S. Elwood, and M. Goodchild (Dordrecht: Springer).

Haworth, B., Whittaker, J., and Bruce, E. (2016). Assessing the application and value of participatory mapping for community bushfire preparation. Appl. Geogr. 76, 115-127. doi: 10.1016/j.apgeog.2016.09.019

Haworth, B. T. (2018). Implications of volunteered geographic information for disaster management and GIScience: a more complex world of volunteered geography. Ann. Am. Assoc. Geogr. 108, 226-240. doi: 10.1080/24694452.2017. 1321979

Hecker, S., Bonney, R., Haklay, M., Hölker, F., Hofer, H., Goebel, C., et al. (2018). Innovation in citizen science - perspectives on science-policy advances. Citiz. Sci. 3, 1-14.

Hermelin, M., and Bedoya, G. (2008). Community participation in natural risk prevention: case histories from Colombia. Geol. Soc. 305, 39-51. doi: 10.1144/ sp305.5

Hicks, A., Armijos, M. T., Barclay, J., Stone, J., Robertson, R., and Cortés, G. P. (2017). Risk communication films: process, product and potential for improving preparedness and behaviour change. Int. J. Disaster Risk Reduct. 23, 138-151. doi: 10.1016/j.ijdrr.2017.04.015

Hirata, E., Giannotti, M. A., Larocca, A. P. C., and Quintanilha, J. A. (2018). Flooding and inundation collaborative mapping - use of the Crowdmap/Ushahidi platform in the city of Sao Paulo, Brazil. J. Flood Risk Manag. 11, S98-S109.

Holderness, T., and Turpin, E. (2015). "From social media to geosocial intelligence: crowdsourcing civic co-management for flood response in Jakarta, Indonesia," in Social Media for Government Services, eds S. Nepal, C. Paris, and D. Georgakopoulos (Cham: Springer International Publishing).

Hung, K.-C., Kalantari, M., and Rajabifard, A. (2016). Methods for assessing the credibility of volunteered geographic information in flood response: a case study in Brisbane, Australia. Appl. Geogr. 68, 37-47. doi: 10.1016/j.apgeog.2016. 01.005

Ibadango, C. E., Escarate, S., Jackson, L., and Sladen, W. (2007). Application Of Landslide Studies for Risk Reduction in the Andean Community of Reinaldo Espinoza, Southern Ecuador. Landslides and Climate Change: Challenges and Solutions. London: Taylor and Franics.

Ikeda, S., and Nagasaka, T. (2011). An emergent framework of disaster risk governance towards innovating coping capability for reducing disaster risks in local communities. Int. J. Disaster Risk Sci. 2, 1-9. doi: 10.1007/s13753-0110006-7

Irwin, A. (1995). Citizen Science: A Study of People, Expertise, and Sustainable Development. Abingdon: Routledge.

Jones, S. R., Barnard, L. A., Scott, C. J., Owens, M. J., and Wilkinson, J. (2017). Tracking CMES using data from the Solar Stormwatch project; observing deflections and other properties. Space Weather 15, 1125-1140. doi: 10.1002/ 2017 sw001640
Joseph, E. P., Beckles, D. M., Cox, L., Jackson, V. B., and Alexander, D. (2015). An evaluation of ambient sulphur dioxide concentrations from passive degassing of the Sulphur Springs, Saint Lucia geothermal system: implications for human health. J. Volcanol. Geotherm. Res. 304, 38-48. doi: 10.1016/j.jvolgeores.2015. 07.036

Kar, B. (2016). Citizen science in risk communication in the era of Ict. Concurr. Comput. 28, 2005-2013. doi: 10.1002/cpe.3705

Karnawati, D., Fathani, T. F., Wilopo, W., Setianto, A., and Andayani, B. (2011b). Promoting the hybrid socio-technical approach for effective disaster risk reduction in developing countries. WIT Trans. Built Environ. 119, 175-182.

Karnawati, D., Fathani, T. F., Ignatius, S., Andayani, B., Legono, D., and Burton, P. W. (2011a). Landslide hazard and community-based risk reduction effort in Karanganyar and the surrounding area, central Java, Indonesia. J. Mt. Sci. 8, 149-153. doi: 10.1007/s11629-011-2107-6

Kelman, I., Lewis, J., Gaillard, J. C., and Mercer, J. (2011). Participatory action research for dealing with disasters on Islands. Island Stud. J. 6, 59-86.

King, D., Goff, J., and Skipper, A. (2007). Mâori environmental knowledge and natural hazards in Aotearoa-New Zealand. J. R. Soc. N. Z. 37, 59-73. doi: 10.1080/03014220709510536

Kirkpatrick, S. J. B. (2018). Pedaling disaster: citizen bicyclists in disaster response-Innovative solution or unnecessary effort? Nat. Hazards 90, 365-389. doi: 10.1007/s11069-017-3048-3

Kong, Q., Allen, R. M., Schreier, L., and Kwon, Y. W. (2016). MyShake: a smartphone seismic network for earthquake early warning and beyond. Sci. Adv. 2:e1501055. doi: 10.1126/sciadv.1501055

Kornakova, M., and March, A. (2017). The role of citizens in DRR planning exercises: when to inform or consult. Int. J. Disaster Resil. Built Environ. 8, 209-222. doi: 10.1108/ijdrbe-12-2014-0077

Kweit, M. G., and Kweit, R. W. (2004). Citizen participation and citizen evaluation in disaster recovery. Am. Rev. Publ. Admin. 34, 354-373. doi: 10.1177/ 0275074004268573

Lassa, J. A., Surjan, A., Caballero-Anthony, M., and Fisher, R. (2019). Measuring political will: an index of commitment to disaster risk reduction. Int. J. Disaster Risk Reduct. 34, 64-74. doi: 10.1016/j.ijdrr.2018.11.006

Le Coz, J., Patalano, A., Collins, D., Guillén, N. F., García, C. M., Smart, G. M., et al. (2016). Crowdsourced data for flood hydrology: feedback from recent citizen science projects in Argentina, France and New Zealand. J. Hydrol. 541, 766-777. doi: 10.1016/j.jhydrol.2016.07.036

Leach, M., and Fairhead, J. (2002). Manners of contestation: "citizen science" and "indigenous knowledge" in West Africa and the Caribbean. Int. Soc. Sci. J. 54, 299-311. doi: 10.1111/1468-2451.00383

Liang, W.-T., Lee, J.-C., Huihsuan Chen, K., and Hsiao, N.-C. (2017). Citizen earthquake science in Taiwan: from science to hazard mitigation. J. Disaster Res. 12, 1174-1181. doi: 10.20965/jdr.2017.p1174

Liu, S. B. (2014). Crisis crowdsourcing framework: designing strategic configurations of crowdsourcing for the emergency management domain. Comp. Support. Coop. Work 23, 389-443. doi: 10.1007/s10606-014-9204-3

Loaiza, V. R., Hernández, L. A. Z., Rodríguez, M. C. G., Díaz, A. C., and Burneo, T. A. (2017). Treinta años después de la erupción del volcán Nevado del Ruiz: memorias, voces, reparación y escenarios de participación. Rev. Colomb. Sociol. 40, 45-64. doi: 10.15446/rcs.v40n1.61948

Loughlin, S. C., Baxter, P. J., Aspinall, W. P., Darroux, B., Harford, C. L., and Miller, A. D. (2002). Eyewitness accounts of the 25 June 1997 pyroclastic flows and surges at Soufrière Hills Volcano, Montserrat, and implications for disaster mitigation. Geol. Soc. Lond. Mem. 21, 211-230. doi: 10.1144/gsl.mem.2002.021. 01.10

Ludwig, T., Kotthaus, C., Reuter, C., Van Dongen, S., and Pipek, V. (2017). Situated crowdsourcing during disasters: managing the tasks of spontaneous volunteers through public displays. Int. J. Hum. Comput. Stud. 102, 103-121. doi: 10.1016/j.ijhcs.2016.09.008

Lue, E., Wilson, J. P., and Curtis, A. (2014). Conducting disaster damage assessments with spatial video, experts, and citizens. Appl. Geogr. 52, 46-54. doi: 10.1016/j.apgeog.2014.04.014

Maceda, E., Gaillard, J.-C., Stasiak, E., Le Masson, V., and Le Berre, I. (2009). Experimental use of participatory 3-dimensional models in island community-based disaster risk management. Int. J. Res. Island Cult. 3, $72-84$. 
Madsen, W., and O'Mullan, C. (2013). Responding to disaster: applying the lens of social memory. Aust. J. Commun. 40, 57-70.

Maltoni, C., Rossi, C., and Sanchez, G. (2017). Improving resilience to emergencies through advanced cyber technologies: the I-REACT project. Geomedia 21, $18-22$.

Mani, L., Cole, P. D., and Stewart, I. (2016). Using video games for volcanic hazard education and communication: an assessment of the method and preliminary results. Nat. Hazards Earth Syst. Sci. 16, 1673-1689. doi: 10.5194/nhess-16-1673-2016

Marchezini, V., Horita, F. E. A., Matsuo, P. M., Trajber, R., Trejo-Rangel, M. A., and Olivato, D. (2018). A review of studies on participatory early warning systems (P-EWS): pathways to support citizen science initiatives. Front. Earth Sci. 6:184. doi: $10.3389 /$ feart.2018.00184

Marchezini, V., Trajber, R., Olivato, D., Muñoz, V. A., De Oliveira Pereira, F., and Oliveira Luz, A. E. (2017). Participatory early warning systems: youth, citizen science, and intergenerational dialogues on disaster risk reduction in Brazil. Int. J. Disaster Risk Sci. 8, 390-401. doi: 10.3390/ijerph1407 0749 doi: $10.1007 /$ s13753-017-0150-9

Marek, L., Campbell, M., and Bui, L. (2017). Shaking for innovation: the (re)building of a (smart) city in a post disaster environment. Cities 63, 41-50. doi: 10.1016/j.cities.2016.12.013

Maskrey, A. (2011). Revisiting community-based disaster risk management. Environ. Hazards 10, 42-52. doi: 10.4324/9781315067261-5

McCormick, S. (2016). New tools for emergency managers: an assessment of obstacles to use and implementation. Disasters 40, 207-225. doi: 10.1111/disa. 12141

Mejía Prieto, B., Giraldo Valencia, G. I. and Trujillo Gálvez, L. M. (2006). Guardianas de la Ladera: un Programa de Cultura Ciudadana en la Prevención del Riesgo, Manizales, Colombia: Taller Internacional Sobre Gestión del Riesgo a Nivel Local: El Caso de Manizales, 28-29.

Mejri, O., Menoni, S., Matias, K., and Aminoltaheri, N. (2017). Crisis information to support spatial planning in post disaster recovery. Int. J. Disaster Risk Reduct. 22, 46-61. doi: 10.1016/j.ijdrr.2017.02.007

Mercer, J., Gaillard, J. C., Crowley, K., Shannon, R., Alexander, B., Day, S., et al. (2012). Culture and disaster risk reduction: lessons and opportunities. Environ. Hazards 11, 74-95. doi: 10.1080/17477891.2011.609876

Minson, S. E., Brooks, B. A., Glennie, C. L., Murray, J. R., Langbein, J. O., Owen, S. E., et al. (2015). Crowdsourced earthquake early warning. Sci. Adv. 1:e1500036. doi: 10.1126/sciadv.1500036

Mossoux, S., Delcamp, A., Poppe, S., Michellier, C., Canters, F., and Kervyn, M. (2016). Hazagora: will you survive the next disaster? - a serious game to raise awareness about geohazards and disaster risk reduction. Nat. Hazards Earth Syst. Sci. 16, 135-147. doi: 10.5194/nhess-16-135-2016

Mothes, P. A., Yepes, H. A., Hall, M. L., Ramón, P. A., Steele, A. L., and Ruiz, M. C. (2015). The scientific-community interface over the fifteen-year eruptive episode of Tungurahua Volcano, Ecuador. J. Appl. Volcanol. 4:9.

Murthy, M. S. R., Bajracharya, B., Pradhan, S., Shrestha, B., Bajracharya, R., Shakya, K., et al. (2014). Adoption of geospatial systems towards evolving sustainable himalayan mountain development. Int. Arch. Photogramm. Remote Sens. Spat. Inform. Sci. 8, 1319-1324. doi: 10.5194/isprsarchives-xl-8-13192014

Mutch, C., and Marlowe, J. (2013). Lessons from disaster: the power and place of story. Disaster Prev. Manag. Int. J. 22, 385-394. doi: 10.1108/dpm-10-20130172

O’Brien, P. W., and Mileti, D. (1992). Citizen participation in emergency response following the Loma Prieta earthquake. Int. J. Mass Emerg. Disasters 10, 71-89.

Omidvar, B., Zafari, H., and Khakpour, M. (2011). Evaluation of public participation in reconstruction of Bam, Iran, after the 2003 earthquake. Nat. Hazards 59, 1397-1412. doi: 10.1007/s11069-011-9842-4

Palen, L., Hiltz, S., and Liu, S. (2007). Online forums supporting grassroots participation in emergency prepardness and response. Commun. ACM 50, 54-58.

Palen, L., Soden, R., Anderson, T. J., and Barrenechea, M. (2015). "Success \& scale in a data-producing organization: the socio-technical evolution of openstreetmap in response to humanitarian events," in Proceedings of the 33rd Annual ACM Conference on Human Factors in Computing Systems, (Seoul: $\mathrm{ACM})$.
Panek, J., Marek, L., Paszto, V., and Valuch, J. (2017). The crisis map of the Czech Republic: the nationwide deployment of an Ushahidi application for disasters. Disasters 41, 649-671. doi: 10.1111/disa.12221

Pelling, M. (2007). Learning from others: the scope and challenges for participatory disaster risk assessment. Disasters 31, 373-385. doi: 10.1111/j.1467-7717.2007. 01014.x

Peng, L. (2017). Crisis crowdsourcing and China's civic participation in disaster response: evidence from earthquake relief. China Inform. 31, 327-348. doi: 10.1177/0920203x17735668

Pennington, C., Freeborough, K., Dashwood, C., Dijkstra, T., and Lawrie, K. (2015). The National landslide database of Great Britain: acquisition, communication and the role of social media. Geomorphology 249, 44-51. doi: 10.1016/j.geomorph.2015.03.013

People's Knowledge Editorial Collective (2016). People's Knowledge and Participatory Action Research: Escaping the White-Walled Labyrinth. Rugby: Practical Action Publishing.

Qi, W. H., Su, G. W., Sun, L., Yang, F., and Wu, Y. (2017). "Internet plus " approach to mapping exposure and seismic vulnerability of buildings in a context of rapid socioeconomic growth: a case study in Tangshan, China. Nat. Hazards 86, 107-139. doi: 10.1007/s11069-016-2581-9

Ramchurn, S. D., Wu, F., Jiang, W., Fischer, J. E., Reece, S., Roberts, S., et al. (2016). Human-agent collaboration for disaster response. Auton. Agents Multi Agent Syst. 30, 82-111. doi: 10.1007/s10458-015-9286-4

Raška, P., and Brázdil, R. (2015). Participatory responses to historical flash floods and their relevance for current risk reduction: a view from a post-communist country. Area 47, 166-178. doi: 10.1111/area.12159

Richardson, B. K., and Maninger, L. (2016). "We were all in the same boat": an exploratory study of communal coping in disaster recovery. South. Commun. J. 81, 107-122. doi: 10.1080/1041794x.2015.1111407

Rieger, C. (2016). Demonstrating the Capacity of Online Citizen Science Mapping Software To Communicate Natural Hazards and Engage Community Participation. Lethbridge, AB: University of Lethbridge.

Robinson, L. D., Cawthray-Syms, J. L., West, S. E., Bonn, A., and Ansine, J. (2018). Ten Principles of Citizen Science. London: UCL Press.

Saganeiti, L., Amato, F., Murgante, B., and Nolè, G. (2017). Vgi and crisis mapping in an emergency situation. Comparison of four case studies: Haiti, Kibera Kathmandu, Centre Italy. GEOmedia 3, 26-29.

Scolobig, A., Prior, T., Schröter, D., Jörin, J., and Patt, A. (2015a). Towards peoplecentred approaches for effective disaster risk management: balancing rhetoric with reality. Int. J. Disaster Risk Reduct. 12, 202-212. doi: 10.1016/j.ijdrr.2015. 01.006

Scolobig, A., Thompson, M., and Linnerooth-Bayer, J. (2015b). Compromise not consensus: designing a participatory process for landslide risk mitigation. Nat. Hazards 81(Suppl. 1), 45-68. doi: 10.1007/s11069-015-2078-y

Shirk, J. L., Ballard, H. L., Wilderman, C. C., Phillips, T., Wiggins, A., Jordan, R., et al. (2012). Public participation in scientific research: a framework for deliberate design. Ecol. Soc. 17:29.

Smith, J., Dubois, B., and Krasny, M. (2015). Framing for resilience through social learning: impacts of environmental stewardship on youth in post-disturbance communities. Sustain. Sci. 11, 441-453. doi: 10.1007/s11625-015-0348-y

Stone, J., Barclay, J., Simmons, P., Cole, P., Loughlin, S., Ramon, P., et al. (2014). Risk reduction through community-based monitoring: the vigias of Tungurahua, Ecuador. J. Appl. Volcanol. 3:11.

Strasser, B., Baudry, J., Mahr, D., Sanchez, G., and Tancoigne, E. (2018). "Citizen Science"? rethinking science and public participation. Sci. Technol. Stud. 32, 52-76. doi: $10.23987 /$ sts. 60425

Sullivan, B. L., Wood, C. L., Iliff, M. J., Bonney, R. E., Fink, D., and Kelling, S. (2009). eBird: a citizen-based bird observation network in the biological sciences. Biol. Conserv. 142, 2282-2292. doi: 10.1016/j.biocon.2009.05.006

Svensson, M. (2017). Digitally enabled engagement and witnessing: the Sichuan earthquake on independent documentary film. Stud. Document. Film 11, 200-216. doi: 10.1080/17503280.2017.1338370

Syafwina, (2014). Recognizing indigenous knowledge for disaster management: smong, early warning system from Simeulue Island, Aceh. Proc. Environ. Sci. 20, 573-582. doi: 10.1016/j.proenv.2014.03.070

Tapia, A. H., LaLone, N., MacDonald, E. A., Hall, M., Case, N. A., and Heavner, fnmM. (2014). "Aurorasaurus: citizen science, early warning systems and space weather," in Proceedings of the Second AAAI Conference on Human Computation 
and Crowdsourcing (Palo Alto, CA: The AAAI Press), 30-32. doi: 10.13140/2.1. 4865.0563

Tappenden, K. (2015). The District of North Vancouver's Landslide Management Strategy: Role of Public Involvement for Determining Tolerable Risk and Increasing Community Resilience. Ph.D Thesis. University of Albertam, Edmonton.

Tipaldo, G., and Allamano, P. (2016). Citizen science and community-based rain monitoring initiatives: an interdisciplinary approach across sociology and water science: citizen science and community-based rain monitoring initiatives. Wires Water 4:e1200. doi: 10.1002/wat2.1200

Turk, C. (2017). Cartographica incognita: 'Dijital Jedis', Satellite Salvation and the Mysteries of the 'Missing Maps'. Cartogr. J. 54, 14-23. doi: 10.1080/00087041. 2016.1244323

UNISDR (2015). Sendai Framework for Disaster Risk Reduction 2015-2030. Geneva: UNISDR.

UNISDR (2018). Open-Ended Intergovernmental Expert Working Group on Indicators and Terminology Relating to Disaster Risk Reduction [Online]. Available at: https://www.preventionweb.net/files/50683_oiewgreportenglish. pdf (accessed August 5, 2019)

Usón, T. J., Klonner, C., and Höfle, B. (2016). Using participatory geographic approaches for urban flood risk in Santiago de Chile: insights from a governance analysis. Environ. Sci. Policy 66, 62-72. doi: 10.1016/j.envsci.2016.08.002

Wald, D. J., Quitoriano, V., Worden, C. B., Hopper, M., and Dewey, J. W. (2012). Usgs “did you feel it?" Internet-based macroseismic intensity maps. Ann. Geophys. 56, 688-707.

Wallace, K., Snedigar, S., and Cameron, C. (2015). 'Is ash falling?', an online ashfall reporting tool in support of improved ashfall warnings and investigations of ashfall processes. J. Appl. Volcanol. 4:8.

Wehn, U., Mccarty, S., Lanfranchi, V., and Tapsell, S. (2015a). Citizen observatories as facilitators of change in water governance? Experiences from three European cases. J. Environ. Eng. Manag. 14, 2073-2086. doi: 10.30638/eemj.2015.222
Wehn, U., Rusca, M., Evers, J., and Lanfranchi, V. (2015b). Participation in flood risk management and the potential of citizen observatories: a governance analysis. Environ. Sci. Policy 48, 225-236. doi: 10.1016/j.envsci.2014. 12.017

Wiggins, A. (2013). "Free as in puppies: compensating for ict constraints in citizen science," in Proceedings of the 2013 Conference on Computer Supported Cooperative Work, (San Antonio, TX: ACM).

Wisner, B., Blaikie, P., Cannon, T., and Davies, I. (2004). At Risk: Natural Hazards, people's Vulnerability and Disasters. 2nd Edn. London: Routledge.

Yamori, K. (2012). Using games in community disaster prevention exercises. Group Decis. Negotiat. 21, 571-583. doi: 10.1007/s10726-0119227-9

Yates, C., and Partridge, H. (2015). Citizens and social media in times of natural disaster: exploring information experience. Inform. Res. 20:659.

Zhong, X., Duckham, M., Chong, D., and Tolhurst, K. (2016). Real-time estimation of wildfire perimeters from curated crowdsourcing. Sci. Rep. 6:24206. doi: 10.1038/srep24206

Conflict of Interest Statement: The authors declare that the research was conducted in the absence of any commercial or financial relationships that could be construed as a potential conflict of interest.

Copyright (C) 2019 Hicks, Barclay, Chilvers, Armijos, Oven, Simmons and Haklay. This is an open-access article distributed under the terms of the Creative Commons Attribution License (CC BY). The use, distribution or reproduction in other forums is permitted, provided the original author(s) and the copyright owner(s) are credited and that the original publication in this journal is cited, in accordance with accepted academic practice. No use, distribution or reproduction is permitted which does not comply with these terms. 


\section{APPENDIX}

\section{Glossary (Based on UNISDR, 2018)}

Disaster: A serious disruption of the functioning of a community or a society at any scale due to hazardous events interacting with conditions of exposure, vulnerability and capacity, leading to one or more of the following: human, material, economic and environmental losses and impacts.

Disaster Risk Management: The application of disaster risk reduction policies and strategies to prevent new disaster risk, reduce existing disaster risk and manage residual risk, contributing to the strengthening of resilience and reduction of disaster losses.

Disaster Risk Reduction: Is aimed at preventing new and reducing existing disaster risk and managing residual risk, all of which contribute to strengthening resilience and therefore to the achievement of sustainable development.

Exposure: The situation of people, infrastructure, housing, production capacities and other tangible human assets located in hazard-prone areas.

Hazard: A process, phenomenon or human activity that may cause loss of life, injury or other health impacts, property damage, social and economic disruption or environmental degradation.
Preparedness: The knowledge and capacities developed by governments, response and recovery organizations, communities and individuals to effectively anticipate, respond to and recover from the impacts of likely, imminent or current disasters.

Recovery: The restoring or improving of livelihoods and health, as well as economic, physical, social, cultural and environmental assets, systems and activities, of a disaster affected community or society, aligning with the principles of sustainable development and "build back better," to avoid or reduce future disaster risk.

Resilience: The ability of a system, community or society exposed to hazards to resist, absorb, accommodate, adapt to, transform and recover from the effects of a hazard in a timely and efficient manner, including through the preservation and restoration of its essential basic structures and functions through risk management.

Response: Actions taken directly before, during or immediately after a disaster in order to save lives, reduce health impacts, ensure public safety and meet the basic subsistence needs of the people affected.

Vulnerability: The conditions determined by physical, social, economic and environmental factors or processes which increase the susceptibility of an individual, a community, assets or systems to the impacts of hazards. 


\title{
Building Resilience to Chronic Landslide Hazard Through Citizen Science
}

\author{
Katarzyna Cieslik ${ }^{1 *}$, Puja Shakya ${ }^{2}$, Madhab Uprety $^{2}$, Art Dewulf $^{1}$, Caroline Russell ${ }^{3}$, \\ Julian Clark ${ }^{3}$, Megh Raj Dhital ${ }^{4}$ and Amrit Dhakal ${ }^{4}$
}

\begin{abstract}
${ }^{1}$ Public Administration and Policy Group, School of Social Science, Wageningen University \& Research, Wageningen, Netherlands, ${ }^{2}$ Practical Action (Nepal), Kathmandu, Nepal, ${ }^{3}$ School of Geography, Earth and Environmental Sciences, University of Birmingham, Birmingham, United Kingdom, ${ }^{4}$ Department of Geology, Tribhuvan University, Kirtipur, Nepal
\end{abstract}

\section{OPEN ACCESS}

Edited by:

Jonathan D. Paul, Imperial College London,

United Kingdom

Reviewed by:

Emanuele Intrieri,

University of Florence, Italy

Davide Tiranti,

Agenzia Regionale per la Protezione Ambientale (ARPA), Italy

*Correspondence: Katarzyna Cieslik kc566@cam.ac.uk

Specialty section:

This article was submitted to Geohazards and Georisks, a section of the journal

Frontiers in Earth Science

Received: 22 January 2019

Accepted: 17 October 2019

Published: 07 November 2019

Citation:

Cieslik K, Shakya P, Uprety M,

Dewulf A, Russell C, Clark J, Dhital MR and Dhakal A (2019)

Building Resilience to Chronic Landslide Hazard Through Citizen Science. Front. Earth Sci. 7:278. doi: 10.3389/feart.2019.00278
Landslides disrupt livelihoods, cause loss of human lives and damages to property and infrastructure. In the case of Nepal, the destructive impact of landslides has been steadily increasing as a result of the rising occupation of marginal land and extreme weather events caused by climate change. In particular, the impacts of seasonal, shallow landslides have been underestimated due to underreporting, and lack appropriate policy response. Within this paper, we argue that citizen science - the practice of incorporating the general public in the process of knowledge co-production - may help address this issue by increasing the knowledge base of stakeholders at different levels. We present the preliminary results from an interdisciplinary scoping study of two landslide sites in Western Nepal, in Bajhang and Bajura, where the Landslide-EVO research project, including a citizen science component, is currently being implemented. The aim of the project is to innovate participatory environmental monitoring and to generate evidence to support resilience. Our exploratory qualitative investigation outlines the strategies currently employed by the local communities that continue living in the landslide affected areas. These include demographic shifts and patterns, land use changes and occupational diversification. We argue that these existing local adaptation and mitigation practices compound a wealth of experiential knowledge. Based on evidence from literature, as well as our first-hand experience of starting citizen science activities in the both landslide sites, we argue that citizen science has the potential to build on local knowledge base and strengthen the adaptive capacities of different level stakeholders. Our theoretical contribution is the proposed typology of citizen-science interventions. We distinguish between community science, participatory environmental monitoring and virtual citizen science, providing examples of how they can benefit stakeholders at different levels and/or different types of research. Finally, we examine the ways in which different types of citizen science could be applied in our case study sites, specifying the conditions under which they can attain maximum usefulness.

Keywords: citizen science, Nepal, local knowledge, participatory science, landslide, chronic hazard 
Interviewer: You said that there are houses here, at the peak of the landslide. What do the people who live here do during the monsoon season? Do they move to a safer place?

Informant: Nah. What can we do? Our houses are there so we cannot just leave everything and go to another place as we do not own land in other place! So even if we have to die, we will live and die in our own house; that is what we think.

/BARBELKA, Bitthadchir, Bajhang/

\section{INTRODUCTION}

In geological terms, "landslide" describes a broad variety of processes that result in the slope-forming materials falling, toppling, sliding, spreading, or flowing down the mountain side (Cruden and Varnes, 1996; Kirschbaum et al., 2010). While big and acute landslides tend to garner public attention due to their immediate destructive nature, smaller seasonal landslides also have lasting detrimental implications for the inhabitants of the risk zones (Sudmeier-Rieux et al., 2012; Sidle et al., 2017). Apart from direct risk to people's lives and health, seasonal landslides result in gradual land and property loss that can seriously threaten the livelihoods and food security of the mountain communities (Tobin et al., 2011; Arouri et al., 2015).

At the same time, the recurrent and unremitting nature of chronically occurring hazards presents an unparalleled opportunity for community-level experimentation and learning (Hermelin and Bedoya, 2008; Lacasse and Nadim, 2009). Contrary to acute landslides which tend to result in largescale resettlement schemes (Vlaeminck et al., 2016), populations exposed to chronic landslide hazard often continue living in the risk zones and applying a range of mitigation and adaptation strategies (Glade and Crozier, 2005; Gentle and Maraseni, 2012; Sudmeier-Rieux et al., 2012; Vaciago, 2013). For this reason, we believe that certain forms of citizen science - the process of knowledge co-generation by societal actors and scientists has the potential to leverage these local capacities, improving community resilience.

This paper shares learning from a citizen-science based project, Landslide-EVO, currently underway in two landslide sites in Western Nepal, in Bajhang and Bajura districts. The aim of the project is to innovate participatory environmental monitoring and to generate evidence to support resilient livelihoods. Basing our analysis on individual and group interviews conducted in the settlements on the landslideprone slopes, we outline the strategies employed by the local communities as means of adapting to living with a chronic landslide hazard. These include demographic shifts and patterns, land use changes and alternative occupational choices as well as experiential, generational knowledge of various mitigation measures. We argue that even though these practices enabled the communities to continue living in the hazard-prone area, presently they have little potential to improve livelihoods in the long run.

In the second part of the paper we propose a set of guidelines for citizen science - based approaches for chronic hazard monitoring. Studies have demonstrated that citizen scientists can both provide good quality data for scientific modeling and forecasting and prompt community sensitization and engagement (Bonney et al., 2009; Buytaert et al., 2014; Stone et al., 2014; Jacobs et al., 2019). At the same time, the very concept of citizen science emerged and gained popularity in Western Europe and North America (Haklay M., 2013). When applied to development contexts - such as rural Nepal its contribution to the existing participatory approaches is unclear (Gaventa and Barrett, 2010). For this reason, in our theoretical model, we distinguish between participatory science (community science), participatory environmental monitoring, and virtual citizen science. We enlist the main attributes of each of these approaches, comparing and contrasting their utility for different research contexts. Finally, we describe the first attempt of introducing citizen-science activities in our case study sites, specifying the conditions under which they can attain maximum usefulness.

The contribution of the paper is twofold. First, we identify, describe and categorize the locally evolved strategies that allow the local communities to continue living on the landslideprone slopes despite the continuously shrinking livelihood options. Second, we discuss the ways in which citizen science approaches may help navigate the daily uncertainties that the local stakeholders face, paving the way for more social impact in science.

\section{CHRONIC LANDSLIDE HAZARD - POLICY CHALLENGES AND THE PROMISE OF CITIZEN SCIENCE}

\section{The Underestimated Hazard: The Destructive Significance of Seasonal Landslides}

In the slope failures classification, deep-seated landslides are those in which the bulk of the slide surface lies below the roots of trees (Barik et al., 2017). The occurrence and velocity of these slides are often linked with the changes in the geologic and hydrologic processes in the area, such as earthquakes and fluctuating ground water levels (Van Den Eeckhaut et al., 2009). On the contrary, shallow landslides are characterized by land mass flows occurring within the forest rooting zone (Cohen and Schwarz, 2017). Shallow landslides are most often seasonal: they are initiated by intense rainfall during monsoon, when the saturation of the ground loosens the soil structure. They tend to be accompanied by a mudflow and/or a debris flow (Guzzetti et al., 2008).

Interestingly, deep-seated landslides have a minimal effect on mountain communities' livelihoods and may stay unheeded for extended periods of time, up until the ecosystem's "tipping point" has been reached and a major catastrophic event occurs (Hilley et al., 2004). In majority of cases, due to the collapse of ecosystem process functions, recovery is not possible (Sidle et al., 2006). Deep-seated landslides are thus considered to be "acute" events (Broothaerts et al., 2012). 
In contrast, in the case of shallow landslides, human settlements are immediately impacted: though smaller in scale and range, these slides cause immediate damage to households and livelihoods: they tear down terraced farmlands, result in livestock loses, knock down houses and disrupt local infrastructure (irrigation, drinking water piping, roads and passageways). In the case of Nepal, these impacts have been gradually increasing over the past years, due to the rising occupation of marginal land and changing weather patterns related to climate change (Petley et al., 2007). The seasonal, unrelenting character of shallow landslides gradually exhausts the adaptive capacity of human settlements: the ever-decreasing amount of agricultural land imposes major structural changes in the livelihood strategies, deeply affecting the social institutions of the mountain communities (Gerrard and Gardner, 2002; Sudmeier-Rieux et al., 2012; Pisano et al., 2017).

From the point of view of disaster management, the distinction between deep-seated landslides resulting in oneoff, large-scale events and shallow, seasonal landslides, has important implications for policy and practice. While very little can be done to stop the deep-seated landslides, the advance of shallow landslides can, in some cases, be mitigated with the right combination of land engineering, draining and reinforcement and large-scale afforestation schemes (Stokes et al., 2014). In particular, changes in land use hold considerable promise to help local communities attenuate the impact of landslides (Glade, 2003; Che et al., 2011; Petrone and Perti, 2013; Persichillo et al., 2017).

While a number of these studies identified the human factors that result in slope instability, little has been done to translate these insights into policy making. This is because of three major problems. First, the seasonally occurring, shallow landslides remain largely underreported (Kervyn et al., 2015; Kirschbaum et al., 2015). The global and national landslide reporting databases suffer from regional bias, and marginal areas (rural provinces, grassland and forest covered localities) remain underrepresented for decades (Sudmeier-Rieux et al., 2013). Guzzetti et al., 2012 estimate that "landslide maps cover less than $1 \%$ of the slopes in the landmasses, and systematic information on the type, abundance, and distribution of landslides is lacking" (2012: 42). Secondly, predominantly non-fatal, shallow landslides are too frequent and commonplace to attract the attention of the local officials and trigger a timely policy response (Guzzetti, 2000). Finally, the extent to which mitigation interventions can be effective varies across contexts and timescales. For example, while afforestation might help lessen the landslide impacts in one area at a given point in time, it might no longer work a couple of years later due to the change in monsoon intensity (Stokes et al., 2014). Similarly, if preventing overgrazing seems to have an effect in one locality, it might not work in others (depending on erosion rates, soil structure, precipitation, etc.). A number of misconceptions and myths exist regarding the extent to which landslides can be managed and the appropriate course of action. As a result, mountain communities are often left to their own devices to adapt to their harsh environments, mitigate the hazard impacts and persevere in their livelihood choices.

\section{Local Knowledge Integration and the Promise of Citizen Science - Evidence From Literature}

Interestingly, studies have shown that the traditional, locally evolved practices can effectively improve disaster preparedness and response (Dekens, 2007; Gardner and Dekens, 2007; Hiwasaki et al., 2014). We define local knowledge as unique, experiential knowledge developed over an extended period of time and held by a group of people in a specific location (Roncoli et al., 2002). Particularly in the case of water-induced hazards like floods and landslides, local knowledge offers invaluable insights about the disaster dynamics and frugal preventive measures (Alcántara-Ayala, 2004; Maes et al., 2019; see also Shaw et al., 2008). Current studies in disaster risk reduction bring evidence that it is in fact the over-reliance on top-down engineering structures and expert solutions that has an adverse effect on community resilience, creating dependencies and incapacitating local-level stakeholders (Wisner, 2006; Munroe et al., 2013).

Studies have shown that local knowledge systems are naturally geared toward coping with and adapting to changing environments (Turner and Clifton, 2009). At the same time, traditional knowledge systems often fail in confrontation with the fast-paced change induced by the Anthropocene (Naess, 2013). Recently, a growing body of research has been documenting cases where the integration of local and expert (scientific) knowledge(s) substantially increased the resilience of the hazard-prone communities (Mercer et al., 2010; Walshe and Nunn, 2012). For this reason, citizen science - a joint co-production of knowledge by the scientists and the concerned populations - has been growing in popularity in both the academe and the development sector (Bonney et al., 2009, 2014; McKinley et al., 2017).

Importantly, including local stakeholders in the processes of knowledge production has a long tradition in development studies, dating back to the groundbreaking work of Robert Chambers and Paul Freire. Credited with strengthening decisionmaking and having an empowering effect on populations, the tradition of participatory research has deeply impacted the way development is conceptualized and managed (Brosius et al., 1998; Campbell and Vainio-Mattila, 2003). Citizen science builds on this tradition but, due to the enabling role of technology (mainly, information and communication technology, ICT4D), allows to bring both participatory monitoring and scientific modeling to scale (Bonney et al., 2009; Haklay M., 2013; Jalbert and Kinchy, 2015).

Just like seasonally occurring shallow landslides, citizen science - based projects are cyclic in nature: annually/seasonally repeated, continuously revising the relevance of the outputs achieved and the usability of the information generated (Leeuwis et al., 2018). As such, citizen science projects go beyond the planned acquisition and processing of data, focusing instead on incremental learning, flexibility and adaptation (Silvertown, 2009). This learning occurs at different scales or levels of the system, including the scientists themselves, but also the 
citizens, knowledge communities, organizations and institutions. By allowing the researchers to better understand the diversity of epistemic viewpoints held by heterogonous stakeholders, citizen science has the potential to boost the existing adaptation and mitigation practices, contributing to long-term resilience building. Table $\mathbf{1}$ provides an overview of citizen science uses in disaster contexts, ranging from oil spills and forest fires to floods, landslides, and earthquakes.

\section{RESILIENCE TO CHRONIC LANDSLIDES}

In recent years, resilience has become the key term in interdisciplinary frameworks used to describe and explain how humans cope with environmental shocks and stressors (Folke et al., 2002; Walker et al., 2004). By directing the attention from vulnerability (deficiencies and incapacities) to the dynamic interaction between ecosystems and their human inhabitants, resilience has come to denote the capacity of systems to absorb change (Folke et al., 2010).

Within disaster studies, the application of the "resilience framework" has been steadily growing over the past decade, slowly becoming the normative standard for researchers and practitioners working with natural hazards. At the same time, Barrios (2016) observes that the definitions of resilience make a number of assumptions about the nature of communities and their preferences pertaining to coping with the disaster's impact. The supposed "bouncing back" to the pre-disaster state implies that the hazardous event was a singular, surprising occurrence and that the pre-disaster state was, in fact, acceptable and desired (Schuller, 2012). Looking at the socio-economic conditions of a number of disaster-prone communities, he argues that the state of extreme poverty, deprivation, vulnerability, dependency and general underdevelopment should not be considered the desired outcome of a "resilient" post-disaster recovery.

This translation of resilience into "bouncing back" has been questioned in terms of which state of affairs is desirable to bounce back to. When the focus is on bouncing back, resilience becomes a conservative concept (Olsson et al., 2015) that does not challenge the status quo, which might be socially unjust, environmentally unsustainable, or overly risky (Béné et al., 2018). Particularly in the field of disaster resilience, criticism has been voiced about the "unquestioned acceptance of recovery and rebuilding policies and activities that re-inscribed pre-existing power structures and gender inequities" (Cox and Perry, 2011: 408). One response to this critique has been to emphasize the possibility and desirability of "bouncing forward," implying a view of resilience in terms of "building adaptive capacity for positive change" (de Milliano et al., 2015: 21). Others have gone further by coupling resilience with transformation (Folke et al., 2010; Pelling and Manuel-Navarrete, 2011; Mao et al., 2017). From an evolutionary resilience view (White and O'Hare, 2014), where there is no assumption of a stable state, "it is not about bouncing back to where we were, but about the capacity for adaptation and, crucially, for transformation. it is about the capacity to break away from undesirable 'normal'." (Davoudi, 2018: 4).

In areas where both development and disaster risk reduction are key concerns, the distinction between humanitarian resilience and development resilience is valuable (Barrett and Constas, 2014). Here, humanitarian resilience in the sense of dealing with disasters is considered necessary but not sufficient in the absence of development resilience. Development resilience is

TABLE 1 | Example of citizen science use in disaster contexts.

\begin{tabular}{|c|c|c|}
\hline Research article & Nature of the hazard and locality & Type of citizen science applied \\
\hline Meier et al., 2012 & Kenya, Haiti, Japan, Libya, and Somalia & Crowdsourced data: CrisisMapping, Ushahidi \\
\hline Cochran et al., 2009; Liang et al., 2017 & Earthquakes in Taiwan & $\begin{array}{l}\text { Crowdsourced data: Quake-Catcher Network (QCN): seismic network } \\
\text { that implements distributed/volunteer computing with the potential to } \\
\text { provide critical earthquake information by filling in the gaps between } \\
\text { traditional seismic stations }\end{array}$ \\
\hline Goodchild and Glennon, 2010 & Wildfires in Santa Barbara & $\begin{array}{l}\text { Crowdsourced data: risk mapping, post-disaster need mapping using } \\
\text { social media }\end{array}$ \\
\hline Hassanzadeh and Nedovic-Budic, 2014 & Earthquake in Bam City (Iran) & $\begin{array}{l}\text { Crowdsourced data paired with remote sensing and predictive } \\
\text { modeling }\end{array}$ \\
\hline McCormick, 2012 & Deepwater Horizon oil spill in the Gulf Coast & $\begin{array}{l}\text { Crowdsourced data: geo-referenced observations and photographs; } \\
\text { organized via grass-roots }\end{array}$ \\
\hline Chu and Chen, 2018 & Landslide hot spots and debris flows & Crowdsourced data of hazard photographs \\
\hline Degrossi et al., 2014 & Flood risk management in Brazil & Crowdsourced data: Flood Citizen Observatory \\
\hline Marchezini et al., 2017 & $\begin{array}{l}\text { Prototyping an early warning system for floods } \\
\text { in Brazil }\end{array}$ & Workshops and participatory mapping with high school students \\
\hline Le Coz et al., 2016 & $\begin{array}{l}\text { Flood risk mapping and visualization in } \\
\text { Argentina, France and New Zealand }\end{array}$ & $\begin{array}{l}\text { Online repository of videos and photos of flash floods: Flood Chasers, } \\
\text { FloodScale RiskScape }\end{array}$ \\
\hline Zook et al., 2010 & Post disaster relief: Haiti earthquake & $\begin{array}{l}\text { Crowdsourced data: CrisisCamp Haiti, OpenStreetMap, Ushahidi, and } \\
\text { GeoCommons }\end{array}$ \\
\hline De Longueville et al., 2010 & Reporting flood events in the United Kingdom & Crowdsourced data: geo-referenced Flickr images \\
\hline Wald et al., 2011 & $\begin{array}{l}\text { Recording Earth shaking intensities for } \\
\text { earthquakes in the United States and around } \\
\text { the globe }\end{array}$ & $\begin{array}{l}\text { Macro-seismic United States Geological Survey's "Did You Feel It" } \\
\text { (DYFI): system has automatically collected shaking and damage reports } \\
\text { from Internet users immediately following earthquakes }\end{array}$ \\
\hline
\end{tabular}


then defined as "the capacity over time of a person, household or other aggregate unit to avoid poverty in the face of various stressors and in the wake of myriad shocks. If and only if that capacity is and remains high over time, then the unit is resilient" (Barrett and Constas, 2014: 14626). This is in line with Barrios's understanding of resilience as the capacity of a system to not just carry on, but also improvise, evolve and transform in response to the overwhelming challenges (Barrios, 2014, 2016).

In the case study presented below, we first analyze the resilience potential of the strategies currently applied by the communities exposed to chronic landslide hazard. Then, we present an overview of citizen-science based activities initiated by the Landslide-EVO project that may, somehow, improve the overall wellbeing of the concerned stakeholders rather than simply allowing them to persist in a given locality.

\section{METHODOLOGY}

Our investigation began with an in-depth analysis of existing secondary sources: these included research papers about landslide susceptibility of the study areas as well as demographic data available from the Nepalese Bureau of Statistics. We also consulted the geological reports to learn about the geomorphology of the sites as well as the general characteristics of acute and chronic landslides to learn about the implications they might have for local livelihoods.

We decided on a qualitative exploratory research approach (Miles and Huberman, 1994). This is because our aim was to get insights into how local inhabitants and stakeholder experience and respond to landslide hazard in their environment, and to learn into the potential of citizen science approaches in this context. Qualitative research methods such as participatory observation and semi-structured interviews allow researchers to capture respondents' views and behaviors while avoiding predetermined categories and possibly biased preconceptions on what is relevant and not to landslide resilience in this particular context. As opposed to structured surveys, qualitative interviewing allows the informants to choose the most relevant content, as well as the mode (flow) in which it is presented.

The field research was conducted in three stages: in November 2017, and then in March and July 2018. As the first stage of the data collection we conducted semi-structured group interviews in 14 settlements in the two study areas (Table 2). We first applied convenience sampling design (interviewing large groups in the center of the settlements, Robinson, 2014), followed by snowball sampling (talking to selected informants, e.g., household heads of the most affected families, Heckathorn, 2011), and finally deliberate sampling (interviewing the local government officials: mayors, deputies and the representatives of the Forestry and Water councils). Non-probability sampling (selecting samples based on the researcher's subjective judgment rather than randomly) is often used for qualitative exploratory studies that aim to discover trends, patterns and mechanisms and relationships between them, rather than generalize. The total of five individual interviews and eleven group interviews were conducted. The results were complemented by observation materials (notes and transcripts) and notes from two group discussion sessions.

We started off with semi-structured interviews, focusing on the following thematic areas: livelihood strategies, perceptions of landslides and their underlying causes, landslide-related problems and ways to amend them (if any). The interviews varied between 20 and $120 \mathrm{~min}$. All of the materials were transcribed and translated. Next, a two-stage analysis was employed: contentfocused, looking for emergent themes, and structural, focused on the coding categories of adaptation, mitigation and resilience) (Riessman, 2008).

\section{THE CASE STUDY: RESEARCH SITES: SUNKUDA (BAJHANG) AND BAJEDI (BAJURA)}

The two research sites chosen for the purpose of this study were Sunkuda (Bajhang) and Bajedi (Bajura). Both sites are located in the West part of Nepal, comprising two catchments in the Karnali basin in the Lesser Himalayas (Figures 1, 2).

In each of the research locations we can observe both the deep-seated and shallow slides. The last major landslide event in Sunkuda took place almost 50 years ago and in Bajedi 6 years ago. At the same time, both locations are continually experiencing seasonal shallow slides: in the case of Sunkuda it is mostly soil slides while in Bajedi it is rockslides. Research shows that the shallow landslides are not only the most common but also they exert the greatest impact on rural livelihoods in the Middle Hills Region (Sudmeier-Rieux et al., 2012). These impacts are expected to deepen considerably as a result of climate change (Petley et al., 2007).

\section{Geological Characteristics}

The district of Bajhang is characterized by extremely rugged topography with altitudes ranging from 915 to $7036 \mathrm{~m}$. The study area is located in the Lesser Himalayan Sequence, and comprises sedimentary and low-grade metamorphic rocks. The whole area of Bajhang is geologically fragile, prone to erosion and subject to rapid deterioration. Climatically, the Bajhang District falls under the alpine and temperate regions, with an annual average rainfall of $2200 \mathrm{~mm}$ and mean monthly temperatures of $5^{\circ} \mathrm{C}(\mathrm{min})$ and $40^{\circ} \mathrm{C}$ ( $\left.\max \right)$. According to the Relief Need Assessment report of District Administration Office, the district suffers from a high landslide risk. Other major hazards are heavy snowfall, flood, drought and fire.

The landslide of Sunkuda lies at the boundary of a thrust sheet of quartzites and schists resting over slates and dolomites (Figure 3). The slide occupies the south limb of a syncline, the axial trace of which passes through the stream valley (Dhital, 2015). It is essentially a single large soil slide (about $1 \mathrm{~km}$ long and $250 \mathrm{~m}$ wide) with a surface area of approximately $3.6 \mathrm{~km}^{2}$. The landslip is currently affecting a road and paddy grounds. It is about $25 \mathrm{~m}$ deep, translational debris slide. A stream is continuously eroding the toe of the slide and contributing to the instability. The slide seems to also exacerbated by road construction, since it interrupted the natural water course. 
TABLE 2 | Respondents: individual and group interviews.

\begin{tabular}{|c|c|}
\hline Data sources/Informants & Village/Municipality \\
\hline Group interview: ward heads/ teachers/political leaders/elders of the village/6-8 & BAJEDI, Budiganga, Bajura \\
\hline Individual interview: Village leader/ community members/8-12 & GUMLA, Chhededaha, Bajura \\
\hline Group interview: community members /random/6-10 & GUIBAN, Chhededaha, Bajura \\
\hline Group interview: community members/ a number of women present and participating/7-9 & THALAMEL TOLE, Budiganga, Bajura \\
\hline Group interview: community members /majority landless/10-50 & DALIT TOLE, Budiganga, Bajura \\
\hline Group interview: community members/7-9 & BASALI KOT, Budiganga, Bajura \\
\hline Individual interview: forestry office, district forest officer (DFO) & MARTADI, Bajura \\
\hline Individual interview: soil conservation office & MARTADI, Bajura \\
\hline Group interview: community members /a number of women present and participating/9-13 & DENSAYEL, Budiganga, Bajura \\
\hline Group interview: community members, school children, women and elderly also present/3-8 & NIMANI, Budiganga, Bajura \\
\hline Individual interview: key informant interview: retired teacher & THUMA, Budiganga, Bajura \\
\hline Group interview: ommunity members, mayor, teachers, social mobiliser/6-8 & SUNKUDA, Bitthadchir, Bajhang \\
\hline Group interview community members, including neighbouring households/12-14 & ADHIKARI TOLE/DALIT TOLE, KADAGAUN, Bitthadchir, Bajhang \\
\hline Individual (key informant) interview: head of household, lost his house twice & DHOKLA, Bitthadchir, Bajhang \\
\hline Group interview: ccommunity members/ women present/3-5 & BARBELKA, Bitthadchir, Bajhang \\
\hline Group interview: community members & KAPHELGAIRA, Bitthadchir, Bajhang \\
\hline Individual interview: district soil conservation officer & CHAINPUR, BHAJANG \\
\hline Individual interview: district forestry officer & CHAINPUR, BHAJANG \\
\hline
\end{tabular}

The district of Bajurais divided into three distinct regions from north to south: the Greater Himalayan Region, the Higher Mountain and the Mid Mountains. Geologically, the Bajedi Landslide of Bajura lies in the Lesser Himalayan Sequence of white quartzites, gray-green schists, gray dolomites and black slates. There are also a few bands of blue-green amphibolite and gray-green garnet schist. A sharp south-dipping active fault lies to the north of the landslide area. The quartzites, schists, and amphibolites of Proterozoic age compose the hanging wall of the thrust, whereas red-purple shales and gray-green sandstones of Miocene age constitute its footwall (Figure 4). Bajura has a cooler, temperate climate with annual rainfall of about $18,000 \mathrm{~mm}$ and temperature varying from 0 to $40^{\circ} \mathrm{C}$. The Bajedi landslide, which was chosen as our research site, is a large, deep-seated rockslide. It has been active for more than 30 years. The rockslide is approximately $3 \mathrm{~km}$ long, more than $500 \mathrm{~m}$ wide, more than $50 \mathrm{~m}$ deep, and covers about $2 \mathrm{~km}^{2}$.

The Bajedi slide of Bajura a number of smaller (less than ten meters) slides are also present within the watershed. The main failure mechanism is related to rock weathering and disintegration. Since the rock is much fractured, during the rainy season, water infiltrates into the ground and percolates to deeper levels (over $50 \mathrm{~m}$ deep). It then forms a continuous column that exerts pore pressure, leading to failure. The most active part of the slide is in the upper slopes, where it is propagating rapidly towards the ridge. The slide has formed multiple scarps and slices, especially in the upper and middle sections. The failed mass moves through gullies and streams into the main channel and generates debris flows in the downstream areas. In the past, this area used to be cultivated. It is highly probable that the combination of irrigation and heavy monsoon precipitation triggered the slope failure.

As mentioned before, both districts are subject to a wide range of natural hazards, in particular, landslides and flooding (including cascading effects). In both study sites, a syncline fold is present in the district and axial trace of syncline fold passes through the stream valley.

\section{Socio-Economic Characteristics}

Bajhang's total population comprises of about $66.54 \%$ Chhetri, $16 \%$ Dalits, $10.20 \%$ Brahmin, $7.33 \%$ Kamis, followed by others, in terms of caste and ethnicity. Caste-based discrimination is still common in many communities in Bajhang. Dalits are the most discriminated caste and are also particularly vulnerable to hazards. Most of the Dalits are confined to traditional professions such as blacksmith work, tailoring, goldsmith and copper work, as well as hired hands. Agriculture, cottage industries and trading are the main economic activities of the district. The major crops grown in the area are rice, wheat, maize, barley, millet, and buckwheat. Overall, the district is considered food-insecure, which can be attributed to both geographic (remote, drought and flood prone) and economic (lack of irrigation facilities, market access and infrastructure, i.e., transportation) factors. About 50\% of the total population of Bajhang lives under the poverty line.

Similarly to Bajhang, Bajura has a multi ethnic composition with Chhetri, Kami, Thakuri, Brahman, Magar, Damai, Sarki, Newar, Sherpa, Rai kirati and Sanyashi (Giri and Puri). The common language is Nepali (96\%) followed by Bhote Sherpa $(0.46 \%)$ and Tamang $(0.42 \%)$. Agriculture (including livestock/poultry) is the main occupation and source of income of the district, with some additions from cottage industries and trading. Wheat, paddy, buckwheat and potatoes are the main agriculture products. Due to low level of agricultural production, the majority of the households face acute food shortages for the large part of the year. The different municipalities of the district are classified as highly and moderately food insecure region ${ }^{1}$.

${ }^{1}$ NeKSAP 2016. Nepal Food Security Monitoring System. Ministry of Agricultural Development (MoAD) and World Food Programme (WFP). 

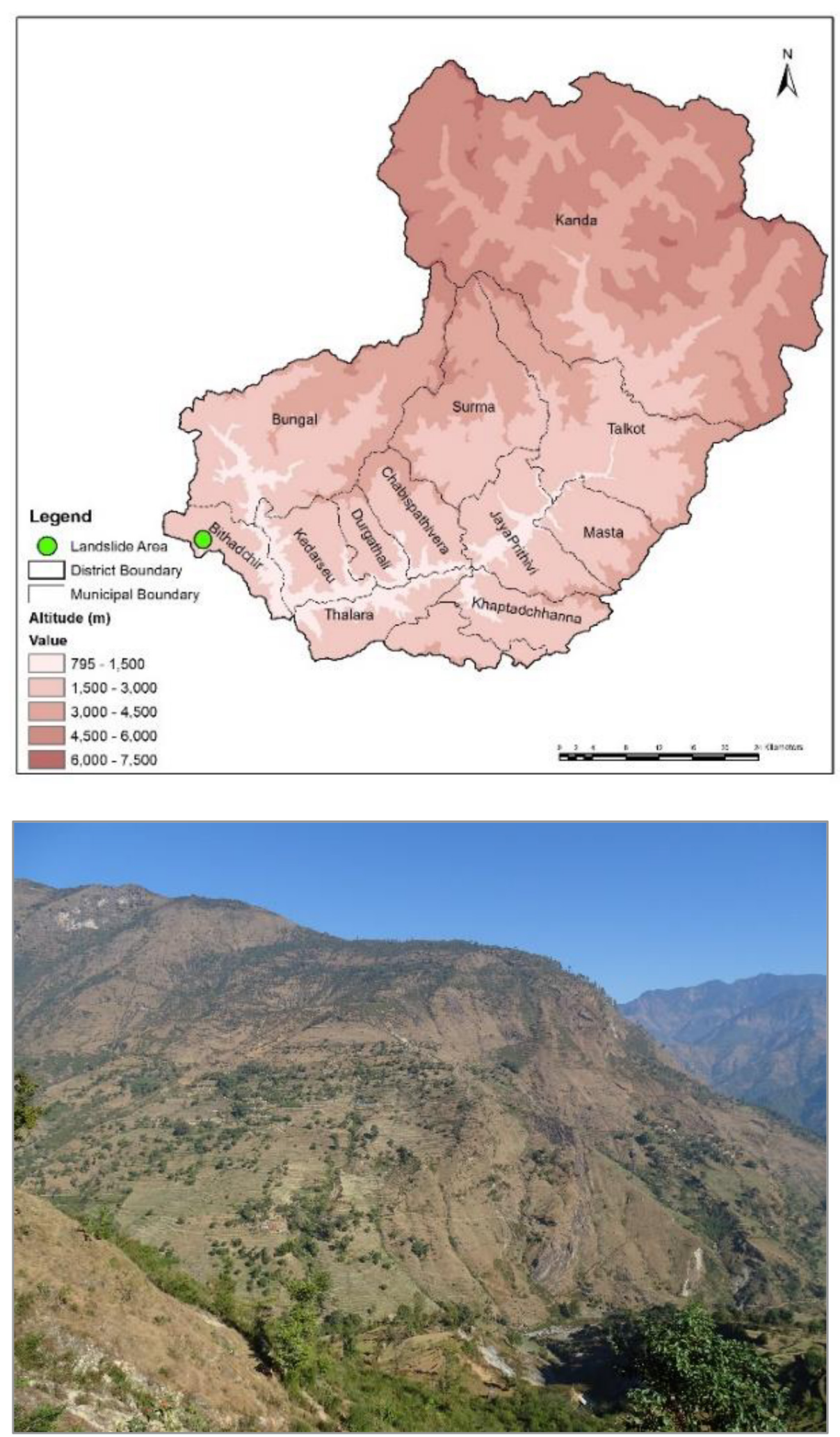

FIGURE 1| The Sunkuda Landslide in Bajhang. 

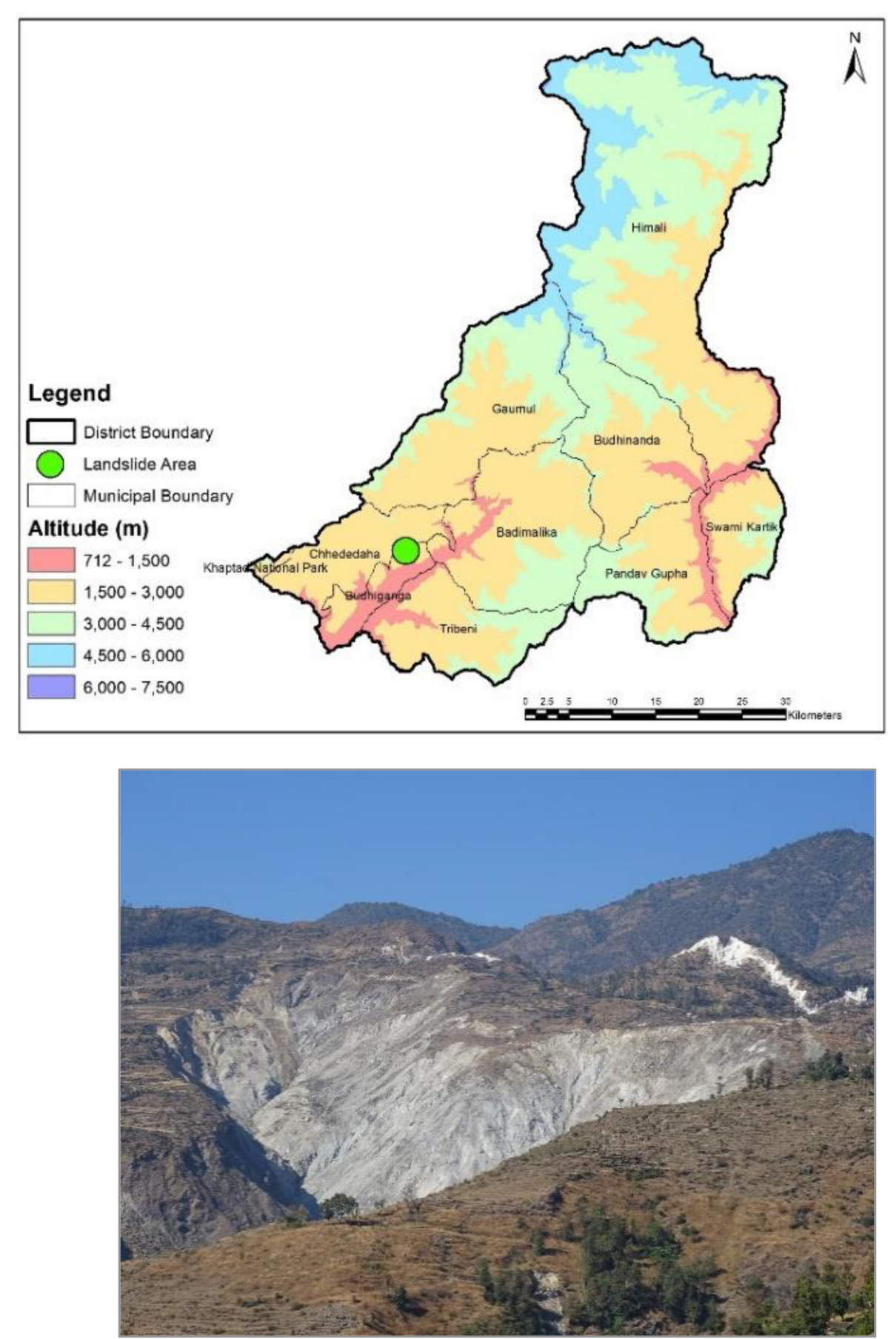

FIGURE 2 | The Bajedi landslide in Bajura.

Overall, the economic condition of the district is poor; with the average income per person is Rs. 3,428 per month ${ }^{2}$. According to the District Disaster Preparedness Plan, this district is highly vulnerable to the natural hazards. The most occurring hazards are floods, landslides, hailstorm, lightening, drought and earthquake.

${ }^{2}$ National Census 2011. Central Bureau of Statistics, Nepal.

\section{RESULTS}

\section{Existing Local Strategies}

From the interviews we distilled a variety of strategies that local people rely on to maintain and advance their livelihoods in very challenging circumstances. These strategies are represented in Table 3 and vary along the dimension 


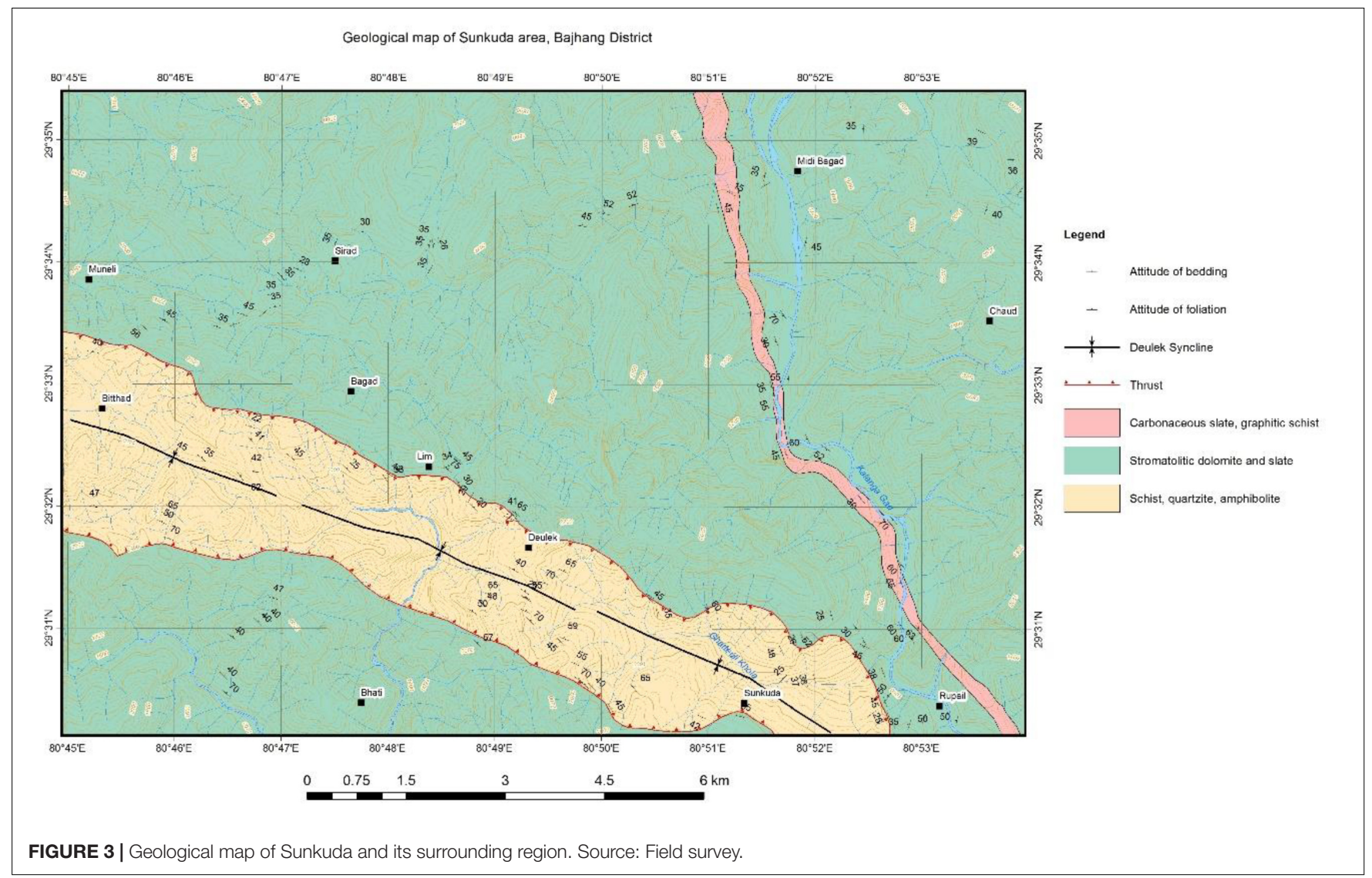

from absorptive to adaptive to transformative strategies (Mao et al., 2017).

The experiential knowledge base about landslides is everexpanding: performing the daily farming tasks (fetching water, getting fodder and timber) in the landslide season (monsoon) being highly dependent on vigilant observation. Common sense harbingers of landslide activity, like rapid increases in stream turbidity, precipitation intensity, incipient movement of slope materials, and appearance of new fissures on hillslopes are carefully studied to assess risk. As a result, in the living memory of the inhabitants only one person from the slope settlements ever died in the landslide event, the other two fatalities being outsiders visiting the village.

While losing one's home is certainly a blow, the traditional construction systems permit easy recycling of materials, unless they have degraded badly. The earth walls can be converted back into mud and used for building a new house. The years of close-up vigilant observation of cracks and crevices made the inhabitants of Sunkuda and Bajedi experts in determining whether a house or a farm outbuildings can survive another monsoon. It is land shortage that poses a problem: since no compensation is granted for lost land or property, the only remaining option is relaying on family and kinship networks for shelter up until the next remittance flow.

Both heavily affected households and the ones that have been spared from the most severe impacts (e.g., loss of a house, loss of the agricultural fields) are equally concerned about the recent intensification of the land movement processes. In the absence of formal support, the community members have developed and applied a number of locally available strategies to deal with landslide risk: from banning the grazing of animals from the affected areas, through re-directing water flows away from the landslide are during monsoon, to different afforestation schemes. While some of the measures are considered "mildly successful," the overall efficacy of these strategies is rather low. Agricultural fields are the most affected: the rain-fed bari-land and in particular, the irrigated khat-land terraces crack and fracture, and finally crumble and collapse. Depending on the extent of the damage, they are either considered completely unrestorable, or take weeks of manual labor to repair and prepare for the next sowing season. At the same time, the traditional agricultural base of the livelihood options in our research sites is also considered to be the source of resilience. As opposed to occupations that require equipment or the stocking of merchandise which can be lost in a landslide event, agricultural production may usually continue after the hazard occurs, albeit at a smaller scale or in a far-off location.

Switching to new, more resistant crop varieties that produce more yield in the eroded terrain is a common strategy, supported by the Nepalese agricultural extension services. The role of livestock in the household production cycle has also changed: previously considered to be mainly manure producers (a large 


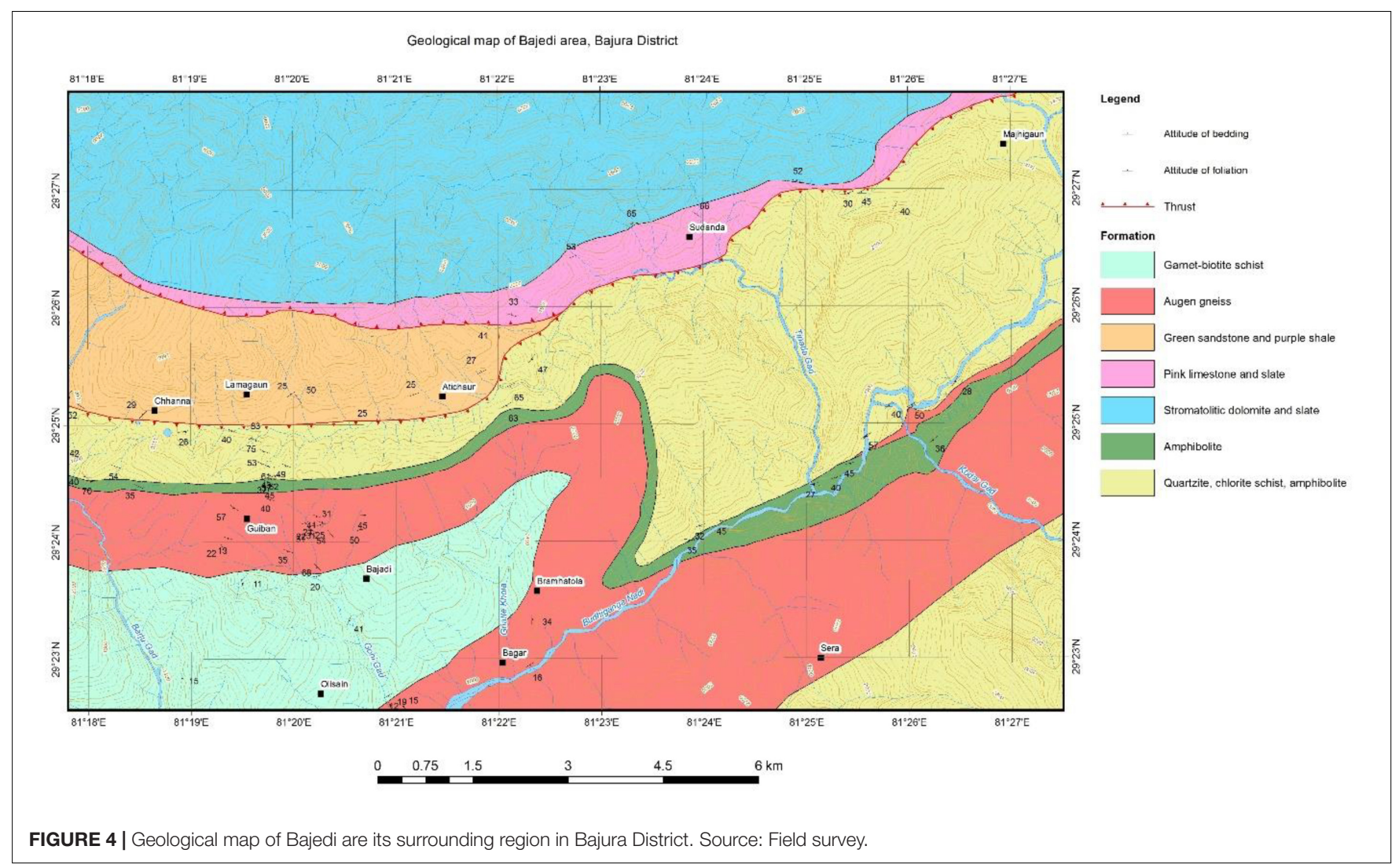

proportion of the Sunkuda and Bajedi settlements do not consume meat for traditional and spiritual reasons), livestock is now reared and sold for cash as there are not enough fields to use up all the manure.

In response to the impacts of landslides on agriculture, most of the affected households choose to diversify their livelihood options: by starting a trade or seeking wage employment in services. These jobs, however, are in short-supply, and as more and more land is lost with each monsoon, the only remaining option is outmigration. In our study areas, the respondents declared that every single household has at least one person working in neighboring India or one of the Gulf Countries, and the remittances they generate are in fact the only steady cash flow to the villages. This is in line with the recent research findings which reveal that at least three quarters of the households in Western Nepal have at least 1 working abroad migrant (Jaquet et al., 2015, 2016). The average remittance cash flow was estimated to be US\$ 206 per month and used mainly for basic need fulfillment (food and goods) and for investment in agriculture.

\section{Decision-Making Process Unfolded - Challenges of Outmigration and Policy Response}

The responses of our interviewees reveal a wide array of strategies that the inhabitants of Sunkuda and Bajedi have been applying over the years in order to manage their uncertain livelihoods. At the same, even though some of them are considered effective in managing the risk, they are not seen as warrantors of community survival in the long run.

When tracing the household trajectories of the affected households, two strategies form an universal pattern. These are reliance on kinship networks (family and neighbors) and outmigration (Figure 5). Interestingly, there two strategies are partly at odds with one another: leaving the village means weakening the kinship bonds and opting out of social networks.

Recent research findings confirm that water-induced hazards are the key driver of labor migration for nearly $80 \%$ household in the Nepalese Himalayas (Banerjee et al., 2011; Gautam, 2017), having a negative effect on both the migrants and the populations left behind. Studies in other parts of Nepal have found that migration has a negative effect on agriculture in the form of labor shortages and land abandonment (Adhikari and Hobley, 2011). Distorted family life, shortage of labor in the village and exacerbated inequalities are among the key drivers of social disintegration and further impoverishment (Chapagain and Gentle, 2015; Jaquet et al., 2016; Sapkota et al., 2016). Labor migrants are also not likely to be better off themselves, because they lack the social ties, education, and resources required to overcome the administrative and monetary constraints on the way to better and more secure jobs (Gautam, 2017).

Apart from the socio-economic effects of population shifts, our findings also reveal the mutually reinforcing connection between outmigration and increased landslide occurrence. 
TABLE 3 | Existing local strategies, example quotes by various informants.

Strategy
Daily observations/means of calculating
risk
Shifting endangered households
upward (moving house)
Seasonal shifting (having two houses or
constructing temporary housing for the
time of the monsoon in a safer place)
Changing role of livestock: from manure
providers to meat cash

Crop diversification and/or intensification

Redirecting active streams away from the landslide site

Afforestation

Employment diversification

Relying on kinship and family ties

Outmigration

\section{Example quote from informants}

(...) If the outside surrounding is very menacing then we do not walk out much, we wait until the rain stops. If it is crucial to go outside and make sure, watch carefully, then we guess if it is okay or not by looking at the land/surrounding environmental condition. We are always alert and cautious; aware that even if we have some urgent errands to run, we should first measure the outside situation. No work is more important than our life, isn't it? (...) Thalamel Tole, Budiganga, Bajura

(...) What can we do when our house is swept away by landslide and there is no place for us to live? We don't have any other alternative expect that moving to safer temporary places. When our houses and the surrounding areas starts getting cracks, that is when we know it is risky to live in that house. Then we move to safer place for shelter. (...) Guiban, Chhededaha, Bajura

(...) There are a total of 41 households in our village of which five households have moved away. The houses have cracked but we put a roof so that we can live temporarily here in winter. There are three, no, four households who live here during winter and elsewhere in monsoon season. (...) Gumla, Chhededaha, Bajura

(...) There is no meaning keeping more livestock when there are no family members to look after it and when there is shortage of fodder, water and everything. In our fields we use the manure from our cattle only but the proportion of land has reduced due to landslide, so we don't need more manure! Sadly, we have less land which means less grasses to feed the cattle therefore we keep less livestock (...) Gumla, Chhededaha, Bajura (...) So, now we rear the cattle/goats and sell them in order to get money for our immediate food and other basic needs (.. . ) Gumla, Chhededaha, Bajura (...) In the past we used to cultivate a breed of paddy known as "Jodan" but since it did not give a desired/sufficient yield we stopped cultivating that breed. I think the reasons behind low productivity these days are because our fertile lands/fields have been swept away by the landslide and erosions and there is decrease in rainfall as well. These days we use new variety of paddy. Some of the crops varieties are recommended by the agriculture officials while we also experiment on our own by seeing it from the nearby villages. (...) Nimani, Budiganga, Bajura

(...) During monsoon, because of the rainfall, the water outflow increases to which we, the villagers, respond by diverting such water away from the landslide affected area. If it isn't done then it can cause the cracks coming down here in our village to aggravate the landslide. So as a preventive measure, we divert the rainwater effluence to other side of the village by making a canal to flow such excessive water. (...) Guiban, Chhededaha, Bajura

(...) We ourselves, the people of this community, started planting trees which was successful to have turned into a community forest later on. So this is one of the efforts the locals have done to fight against this adversity, or to lessen the adversity of landslide. Also, we have restricted grazing cattle in open fields and forest. (...) Nimani, Budiganga, Bajura (...) We have tried several afforestation programs from our side but since we have to plant the tree saplings in monsoon season and the landslide occurs more during that time, the mission has not been successful at all. Adhikari Tole/Dalit Tole, Kadagaun, Bitthadchir, Bajhang

(...) So in order to fulfil the basic needs throughout the year people are engaged in some sort of employment. Majority of people are involved or employed within the village, some work as teachers, and other people have different occupation, making things, services, making do. We have these people, they are engaged in other occupations here, so, overall, everything is well in our village. (...) Thuma, Budiganga, Bajura

(... ) My house is in the peak of this landslide. I've no hope of living there. I don't want to leave my brothers so I'll move to the land that belongs to me along with my brothers. (...) Gumla, Chhededaha, Bajura

(...) People from our village do go out of the country to get better job opportunities. The male population of our village mainly goes to India to work as laborers for about 5-6 months each year. It is seasonal. But what else can we do, we need employment to survive. We cannot make a living by staying in this village and also we cannot just depend upon the outcome from agriculture in a risky place like this. Our land is going! Washed away. Therefore, by Baishak (April-May) we leave to India for jobs. We have 83 households in this village where every 2-3 men per house go to India for employment. Only the children and women stay behind, to look after our homes, and what is left of crops and cattle. (...) Guiban, Chhededaha, Bajura One member of each household goes to India for employment and they return after $2-4$ years. We are surviving based on the income of this one member of our families because they are earning money by doing jobs in India; otherwise the crops that we grow, this food isn't even enough for more than 2-3 months (. . .). (After the latest landslide) we do not have the seeds of wheat to sow for this year. Barbelka, Bitthadchir, Bajhang
Though in literature, outmigration is usually seen as the effect of landslides, we find that it is also the root cause: migrants leave behind arable land (terraces) that the remaining household members are no longer able to sustain. It is in fact this abandoned land (in particular, the irrigated Khat-land) that is considered to be the most landslide-prone (Figure 6). Formerly irrigated terraces, once collapsed, deteriorate into open landslide much faster than any other type of land cover (including over-grazed pastures and deforested hills). A vicious cycle is formed, where outmigration is driven by the hazard, resulting in decrease in uphill land management, which in turn exacerbates shallow landslips (Gerrard and Gardner, 2002; Munroe et al., 2013; Sapkota et al., 2016; Ojha et al., 2017).

At the same time, outmigration of just one family member often allows the left-behind family to move to another location (to more stable uphill land for house construction or to the fertile downhill land in the river valleys). Though not sustainable in the long-term, remittances from outmigration allow the households to remain relatively food-secure and often enable the younger household members to access education and occupational training opportunities (see e.g., Marino and Lazrus, 2015). 


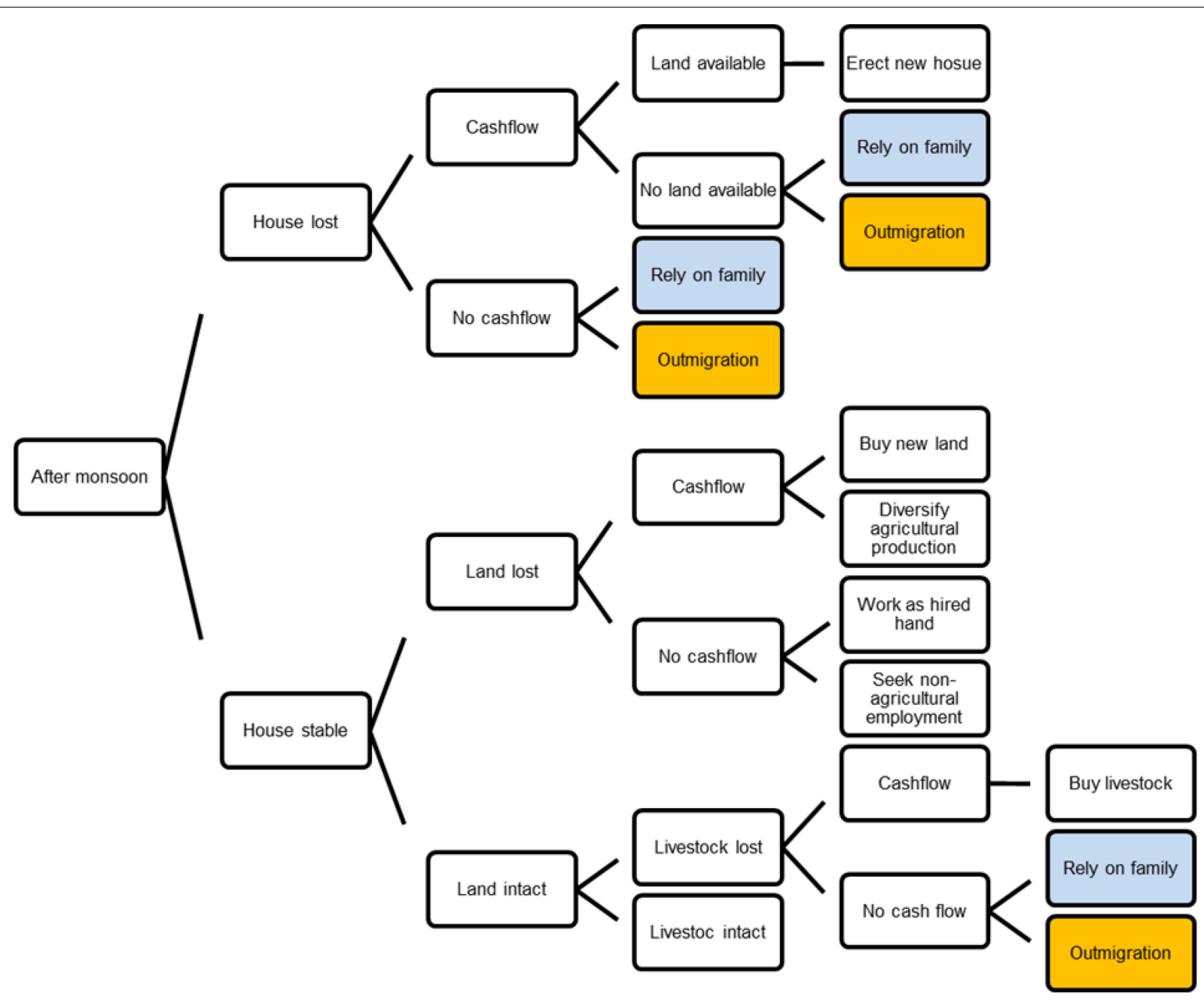

FIGURE $\mathbf{5}$ | Decision making process.

\section{Potential for Citizen Science}

As previously stated, local knowledge is key to increasing resilience to chronic landslide hazards. However, to date, it has not been fully harnessed by practitioners and policy-makers (Hiwasaki et al., 2014). In this part of the paper we explain how citizen science approaches can help integrate local knowledge with science and technology, making it useful for policies, education, and actions related to disaster risk reduction.

\section{Participatory Science, Participatory Environmental Monitoring, Virtual Citizen Science}

Citizen science emerged and gained popularity in the Western academe as a result of a rapid expansion of information and communication technologies (ICTs) (Haklay M., 2013). Scientists in various disciplines, in particular, ecology and conservation scholars, discovered the potential to cut the costs of research and bring their projects to scale: by mobilizing volunteers to collect environmental observations (bird counting, taking water samples) and sending them via their ICT devices to an online database, they were able to obtain panel data of unprecedented scope and scale (Liebenberg et al., 2017; Cieslik et al., 2018). This became known as participatory environmental monitoring: engaging the citizens in collecting observations that help scientists build better models.

Around the same time, a new source of geographic information has become available in the form of user-generated online content, supported by technologies known as Web 2.0 (Goodchild, 2007; Elwood et al., 2012). Also referred to as participatory internet or the social web, Web 2.0 denotes a wide range of interactive websites that emphasize usability, democratic access and interoperability (Haklay et al., 2008). In particular, the launch of Google Maps and Google Earth, both opensource and user friendly, popularized the use of geospatial data by the public. Some examples of user-generated geo-referenced data repositories include GeoCommons, OpenStreetMap and Wikimapia (Coleman et al., 2009; Meier et al., 2012). Making high-resolution satellite data freely available to the general public (Natural Earth Data, Esri Open Data, USGS Earth Explorer, etc.) opened new possibilities for science-society collaborations, allowing the scientists to harness the work power of hundreds 


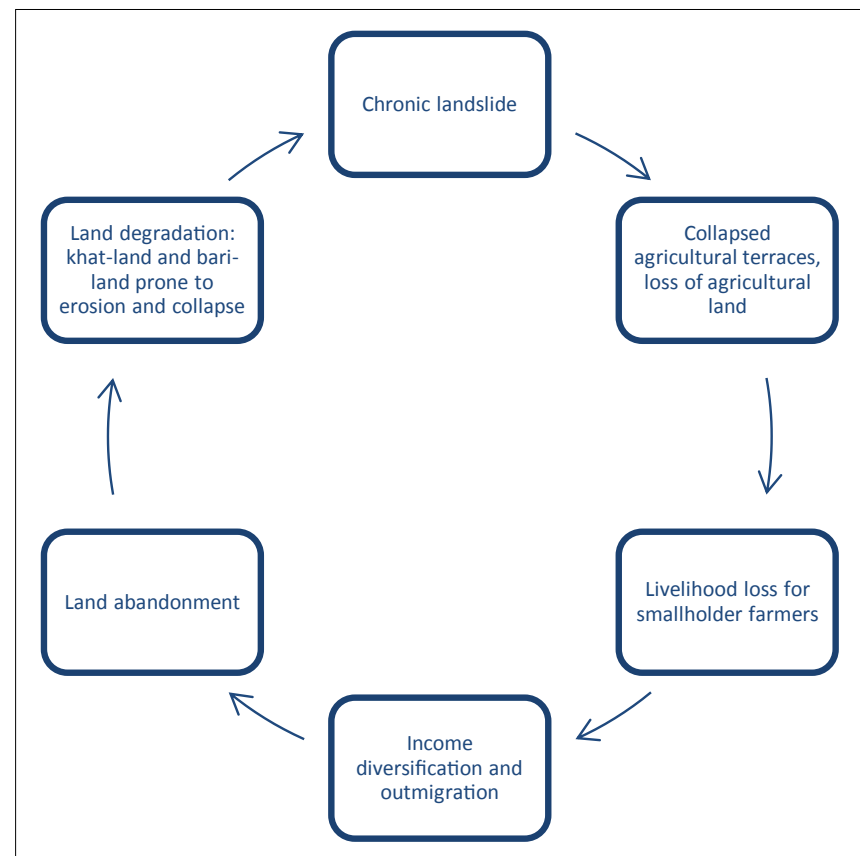

FIGURE 6 | Landslide and livelihoods cycle.

of volunteers around the globe to create and analyze big data (Hong et al., 2007; Farahmand and Aghakouchak, 2013). Recognized as "neogeography," these initiatives were quickly integrated in both science (data crowdsourcing) and public benefit organizations (monitoring and accountability) (Liu and Palen, 2010; Haklay M.M., 2013). Contrary to the environmental and conservation science initiatives, neogeographers are often physically completely disconnected from the reality that they are mapping, which is why we choose to term them "virtual" citizen scientists (see also De La Ville et al., 2002; Table 3).

In the development context, including local stakeholders in the research process dates back to the early 1970s. Robert Chambers and Paul Freire are among the many participatory development scholars of who argued that in order to put the marginalized at the center of the processes of development policy, they need to first be included in development research (Wisner, 2006). Contrary to citizen science, which is geared toward big data and scientific modeling, participatory research in development (including participatory rural appraisal, participatory action research and "community science") was always very context specific and focused on addressing a pressing local issue with the concerned local stakeholders (Table 3).

Even though, in principle, citizen science is also aimed at addressing pressing social and environmental problem, citizen science projects have a much longer timeframe horizon, extending into several years or even decades (see e.g., the E-Bird project by Cornell University). Due to the often dramatic, near-subsistence socio-economic conditions of the communities in development contexts, mobilizing them for such extensive volunteer work is not very ethical, and in a number of cases, not even possible without monetary compensation or other form of incentive (Hufton, 2017). The projects that have managed to achieve citizen participation in such contexts are often, though original and interesting in design, much more modest in scale and scope (see e.g., the projects of the Extreme Citizen Science ExCite from UCL London) (Table 4).

Against this background, we propose that a successful application of citizen science requires a combination of all three citizen-science sub-categories. In the sections below, we first provide a brief overview of citizen science project in disaster contexts. Then, we explain and give examples of how the different approaches are best suited for different types of social and scientific problems as well as different stakeholder levels.

\section{Citizen Science and Disaster Response}

As described above, citizen science provides a useful approach for both community engagement and low-cost, real-time production of scientific data. As such, they are well suited for disaster contexts, where broad and timely collection and provisioning of information is essential for effective risk management: preparedness, response, recovery, and but also adaptation, mitigation and resilience building. It provides an alternative to traditional top-down information flow and optimize the efforts of relief organizations.

While most of the existing projects are largely considered successful attempts of citizen - scientists integration (Table 1), it should also be noted that a vast majority relies can be classified as "virtual citizen science." They come from two broad categories: volunteered geographic information (VGI), or usergenerated content with geotags (hidden codes that link content to geographic locations) and social media enabled mapping platforms (like Ushahidi or CrisisMappers that link up with Facebook and Twitter feeds) (Coleman et al., 2009; Gao et al., 2011). While extremely useful in facilitating the on-the-ground work (monitoring and coordinating relief progress, improving, accuracy and security), these approaches do not necessarily build on local knowledge and capacities. The idea of recognizing locallevel stakeholders as informed experts of their own environments does not fit in with technology-driven paradigm of algorithms and big data. In the next section, we describe an attempt of a more engaged approach in the case studies of our project.

\section{Starting Citizen Science Activities in the Study Sites}

The Citizen Science in Schools (CSIS) program that has just started in the two case-study sites was designed around the core concepts of (i) integrating local knowledge with science and technology to make it useful for policy, education and action, and (ii) to increase resilience in remote communities. Two schools were selected in the field sites, one each in Bajhang and Bajura, with children attending aged from 10 to 16 . These schools were selected on the basis of hazard proximity (landslides), their facilities (electricity, cellular phone reception), and willingness of staff to participate on a long-term basis. The criteria provided a platform for highly contextualized citizen science activities to be designed that built upon the participants' knowledge of how local hazards affected their day to day lives, deepened understandings of Landslide-EVO activities at their school and 
TABLE 4 | Citizen-science typology.

\begin{tabular}{|c|c|c|c|c|}
\hline & Category & $\begin{array}{l}\text { Participatory science } \\
\text { (community science) }\end{array}$ & $\begin{array}{l}\text { Participatory environmental } \\
\text { monitoring }\end{array}$ & $\begin{array}{l}\text { Virtual citizen } \\
\text { science }\end{array}$ \\
\hline \multirow[t]{3}{*}{ Why? } & Disciplinary origin & $\begin{array}{l}\text { Development studies and } \\
\text { anthropology }\end{array}$ & Ecology & Geography/GIS \\
\hline & Principal area of application & The Global South & The Global North & International \\
\hline & Objective & Empowering the subaltern & $\begin{array}{l}\text { Scaling/cost cutting - doing } \\
\text { science }\end{array}$ & Scaling/cost cutting \\
\hline \multirow[t]{8}{*}{ How? } & Participant motivation & Addressing a pressing problem & Contribution to science & $\begin{array}{l}\text { Satisfaction, } \\
\text { curiosity }\end{array}$ \\
\hline & Range & Site-Specific & Site specific & Global \\
\hline & Relationship & Embedded, engaged & Embedded, engaged & Detached \\
\hline & Situation & On-site & On-site & Remote \\
\hline & Time horizon & Short & Long & Long \\
\hline & Transaction cost & Medium & High & Low \\
\hline & Role of technology & Marginal & Amplifier & Enabler \\
\hline & Mode & Real-life & Real-life & Virtual/cyber \\
\hline \multirow[t]{2}{*}{ Examples } & Example projects/approaches & $\begin{array}{l}\text { Participatory Rural Appraisal (PRA); } \\
\text { Community Based Project } \\
\text { Management }\end{array}$ & E-Bird & $\begin{array}{l}\text { Open Street } \\
\text { Mapping (OSM) }\end{array}$ \\
\hline & Notable scholars & Paulo Freire, Robert Chambers & Muki Haklay, Rick Bonney & Steve Coast \\
\hline
\end{tabular}

in the surrounding area, and enriched the project's qualitative database. Both schools had Landslide-EVO low cost rain gauges installed in their grounds in early 2018. The initial lesson took place in May 2019 and was focused on monsoonal precipitation patterns and their relationship with chronic landslides in the area. Both classes' students demonstrated prior knowledge about the connection between monsoonal rainfall and increased seasonal landslide occurrence.

Preliminary observations from CSIS align with some theoretical assertions surrounding the benefits of citizens science outlined earlier. Thus the intermediate value added from CSIS lesson was to create a common language between the lived experience and more scientized hydrological hazard explanations. This scientific lexicon is then used by students when sharing knowledge of hazard events with their parents and the wider community, increasing resilience through demystification of the hazard (Mercer et al., 2010; Walshe and Nunn, 2012). This initial benefit will be compounded at the homes of selected students through participatory environmental monitoring of precipitation levels for 1-2 years. These data will be sent to Landslide-EVO researchers on a monthly basis via the head teachers of the schools. Additionally, the data will provide verification of readings from previously installed rain gauges in the area as well as increase the spatial and temporal distribution of the data set (Bonney et al., 2009; Buytaert et al., 2014). Future CSIS lessons will explore warning signs of potential hazards, including OSM mapping of landslides and crack monitoring, to build local risk knowledge and provide novel policy relevant data.

\section{Addressing Policy Challenges}

Effective integration of citizen science in development research and policy requires customizing methods and data sources for the specific problem. Here, we are particularly interested in the case of chronic hazards - like the shallow, seasonal landslides in Sunkuda and Bajedi.

Looking back at the three key challenges at national level for effective policy response (underreporting, trivialization of the problem and misinformation, section "The Underestimated Hazard: the Destructive Significance of Seasonal Landslides") we find that the emergent trends in citizen science (in particular, participatory environmental monitoring) hold considerable promise to bring the wealth of local knowledge to scale. Participatory monitoring is a process through which local stakeholders engage in structured collection of observations which are then compiled into comprehensive databases. In this way, the key stakeholders share control over the content, the process and the results of the reporting process. Amplified by technology, in particular, ICT4D, participatory environmental monitoring can help ameliorate the chronic landslide underreporting issue. A good example of such an intervention is the Cooperative Open Online Landslide Repository (COOLR) - a NASA-led, online spatial analytics platform that allows individual citizen observers to report a landslide occurrence anywhere on the globe. Gradual build-up of the database should in turn draw attention to the staggering scale of the land loss problem, triggering timely and appropriate government response (Petley et al., 2005).

Involving key stakeholders in the knowledge co-production process may in turn help demystify the many misconceptions about the efficacy of the various mitigation measures at the level of regional governments. Observing, documenting and classifying local environmental knowledge about the immediate environment may help tease-out key factors that make particular preventive practices work in one locality and fail in another.

Building landslide resilience requires precise, real-time hazard estimates for the spatial distribution of future landslides, their temporal frequency and intensity. This can be achieved with 
the help of virtual citizen science (Cyber Science): an approach where volunteers around the globe perform detailed analyses of the existing databases, looking for spatiotemporal patterns and building prediction models.

\section{DISCUSSION AND CONCLUSION}

In this paper, we presented a case study of two mountain communities dealing with a chronic landslide hazard. We identified and categorized the strategies employed by the inhabitants of Sunkuda and Bajedi to manage their livelihoods on ever-shrinking land. These strategies reveal a wealth of experiential knowledge that should be integrated in responsive policy making. This is in line with findings in Cameroon and Uganda (Kervyn et al., 2015), where a broad range of relevant landslide resilience strategies were derived from focus group meetings with stakeholders. Our finding that seasonal migration is a livelihood strategy for remote communities in Nepal is in line with Gautam (2017), but we add insights on how landslides interplay with migration dynamics, building upon earlier studies on this topic, like Sudmeier-Rieux et al. (2012).

When trying to navigate the complexities of living with a chronic hazard, the effective application of either adaptation or mitigation measures is not enough: finding a balance between persistence and flexibility is key to achieving relatively resilient living. Accordingly, both the merits and tradeoffs of the different strategies need to be considered in order to develop an appropriate policy response. Sustainable and responsible planning should include hazard mapping, in particular, slope susceptibility data and settlement exclusion zones. Also, land accessibility should be carefully reviewed and analyzed as it may reveal why people continue to settle in hazard-prone areas. At the same time, for such research to be of value, it should take into account the unique epistemological viewpoints of the concerned stakeholders: the members of the affected communities as well as the lower governance structures directly involved in regional decision-making.

In our analysis we argue that local knowledge needs to be integrated with science before it can be used in planning, education, and policy. Citizen science provides a useful approach to demonstrating how local knowledge can be used to both anticipate and mitigate hazards, and to support better planning. Even though a number of citizen science projects look for active engagement with individual citizen-volunteers, different forms of citizen science can be more suited for different level stakeholders. While diligently crafted slope susceptibility maps might not be of much use to individual households (i.e., they do not provide information of sufficient granularity or certainty to plan household-level land use), they can provide invaluable planning material for local governance structures (e.g., strategically planning future interventions for the most hazard prone settlements). Similarly, though engaging local-level stakeholders in remote-sensing data analysis might not make much sense (insufficient infrastructure to gather, process and visualize data at local level), national-level officials can both participate in, and benefit from the process (Figure 7).

While some approaches to citizen science attempt to draw a straight line from individual actions or behaviors (e.g., participation) to policy influence, we argue that intermediate outcomes may be equally important. By participating in the scientific process and working hand-in-hand with interdisciplinary scientists, different stakeholders achieve a better understanding of physical and biological processes in their immediate environment and are able to make linkages between previously dissociated phenomena.

Despite these promising insights, it is important to note that the role and validation of local knowledge is determined by interaction between informal and formal institutions different levels. Giving more consideration to the power relations that

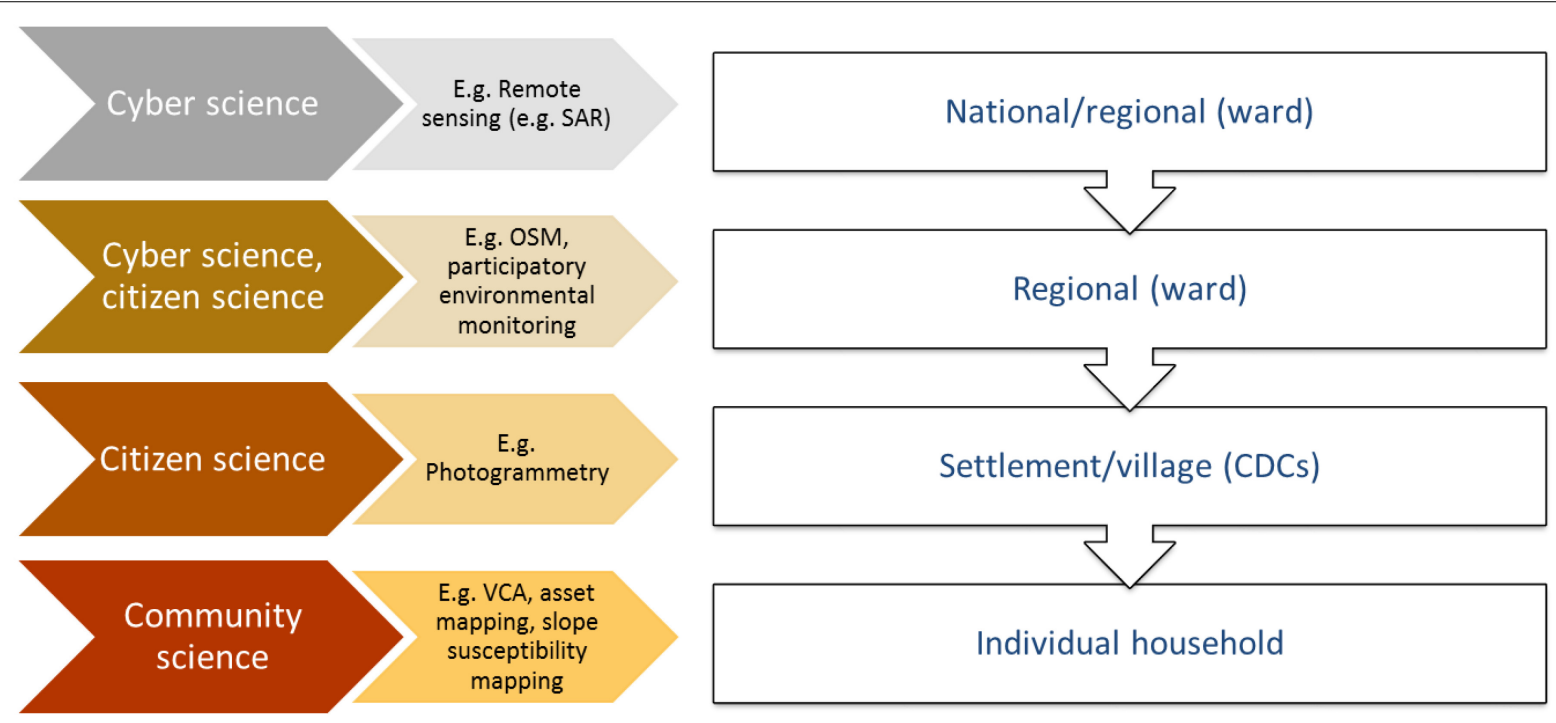

FIGURE 7 | Stakeholder levels for different types of participatory science. 
endorse or invalidate local knowledge is key to correctly identify and address the structural constraints to the use of local knowledge across scales (Naess, 2013).

We fully acknowledge that the theory-building potential of our study is limited. We used non-probability sampling which does not allow for wide generalizations, and our results are very context-specific. At the same time, our findings are consistent across the range of different interviews, with the same recurring topics and causality patterns Further research on other and larger communities and in different contexts would be very valuable to test the generalizability of our findings. We are also not yet in the position to evaluate the citizen science activities implemented within the Landslide-EVO project, as these have only just began in the study sites. By sharing the preliminary insights from the project we follow the tradition of the so called "diagnostic studies" (Hounkonnou et al., 2004; Röling et al., 2004 for more reference). Diagnostic studies tend to provide a situation analysis, followed by a discussion of the feasibility of the proposed intervention (in our case, interdisciplinary citizen-science based activities). Diagnostic studies illustrate the process of developing an understanding of a given social reality and drawing conclusions pertaining to the planned course of action. As such, diagnostic studies are a useful resource for researchers and practitioners alike: they show under what assumptions projects are deployed in a particular site. There are also other limitations that should be acknowledged: researcher bias, social desirability bias and situation bias might have influenced the results and interpretation of the study. At the same time, we attempted to counterbalance these failures with ongoing critical reflection, peer audit and consultations with local partners.

To conclude, we stress that citizen science - based research needs to be individually tailored for specific communities, not only because of the geological and ecological differences between localities but also in consideration of the capabilities and willingness of local governance structures and residents to engage meaningfully with scientists. Due to the chronic nature of the landslide hazards, a very long-term perspective is needed to enable effective modeling, in particular in relation to making predictions and projections. Accordingly, we would

\section{REFERENCES}

Adhikari, J., and Hobley, M. (2011). Everyone Is Leaving-Who Will Sow Our Fields? The Effects of Migration from Khotang District to the Gulf and Malaysia. Kathmandu: Swiss Agency for Development and Cooperation.

Alcántara-Ayala, I. (2004). Flowing mountains in Mexico. Mt. Res. Dev. 24, 10-13. doi: 10.1659/0276-4741(2004)024\\%5B0010:fmim \\%5D2.0.co;2

Arouri, M., Nguyen, C., and Youssef, A. B. (2015). natural disasters, household welfare, and resilience: evidence from rural vietnam. World Dev. 70, 59-77. doi: 10.1016/j.worlddev.2014.12.017

Banerjee, S., Gerlitz, J. Y., and Hoermann, B. (2011). Labour Migration as a Response Strategy to Water Hazards in the Hindu Kush-Himalayas. Kathmandu: ICIMOD.

Barik, M. G., Adam, J. C., Barber, M. E., and Muhunthan, B. (2017). Improved landslide susceptibility prediction for sustainable forest management in an altered climate. Eng. Geol. 230, 104-117. doi: 10.1016/j.enggeo.2017.09.026 like to discourage universal application of citizen science approaches - which have become a buzzword in the development sector - and instead propose a carefully crafted combination of participatory science, citizen science and virtual citizen science. Conceptualized as such, citizen science-based research can prove very effective in providing practical recommendations for households and policy makers at various administrative levels.

\section{AUTHOR CONTRIBUTIONS}

All authors listed have made a substantial, direct and intellectual contribution to the work, and approved it for publication.

\section{FUNDING}

This manuscript was realized within the interdisciplinary interuniversity consortium L-EVO. The authors acknowledge the financial support from the Natural Environment Research Council (NERC) and Department for International Development (DFID) under the United Kingdom Science for Humanitarian Emergencies and Resilience (SHEAR) program (Grant Number NE/P000452/1).

\section{ACKNOWLEDGMENTS}

The fieldwork for this manuscript was made possible thanks to the cooperation between Wageningen University and Practical Action Nepal. The authors are indebted to Practical Action team who made this data collection possible by sharing their insights and facilitating the cooperation with the communities of Bajura and Bajhang. In particular, this research would not have been possible without the assistance of Dinanath Bhandari, Bharat Raj, Saugat Paudel, and Elina Shrestha, to whom the authors extend their warmest gratitude. Last but not least, we would like to thank all of our interviewees for volunteering their time to talk to us and for allowing us to gain insight into their lives.

Barrett, C. B., and Constas, M. A. (2014). Toward a theory of resilience for international development applications. Proc. Natl. Acad. Sci. U.S.A. 111, 14625-14630. doi: 10.1073/pnas.1320880111

Barrios, R. E. (2014). 'Here, I'm Not at Ease': anthropological perspectives on community resilience. Disasters 38, 329-350. doi: 10.1111/disa.12044

Barrios, R. E. (2016). Resilience: a commentary from the vantage point of anthropology. Ann. Anthropol. Pract. 40, 28-38. doi: 10.1111/napa.12085

Béné, C., Mehta, L., McGranahan, G., Cannon, T., Gupte, J., and Tanner, T. (2018). Resilience as a policy narrative: potentials and limits in the context of urban planning. Clim. Dev. 10, 116-133. doi: 10.1080/17565529.2017.1301868

Bonney, R., Cooper, C. B., Dickinson, J., Kelling, S., Phillips, T., Rosenberg, K. V., et al. (2009). Citizen science: a developing tool for expanding science knowledge and scientific literacy. Bioscience 59, 977-984. doi: 10.1525/bio.2009.59.11.9

Bonney, R., Shirk, J. L., Phillips, T. B., Wiggins, A., Ballard, H. L., Miller-rushing, A. J., et al. (2014). Next steps for citizen science. Science 343, 1436-1437. doi: $10.1126 /$ science. 1251554 
Broothaerts, N., Poesen, J., Van Rompaey, A., and Getahun, K. (2012). Spatial patterns, causes and consequences of landslides in the gilgel gibe catchment, ethiopia. Catena 97, 127-136. doi: 10.1016/j.catena.2012.05.011

Brosius, J. P., Lowenhaupt Tsing, A., and Zerner, C. (1998). Representing communities: histories and politics of community-based natural resource management. Soc. Nat. Resour. 11, 157-168. doi: 10.1080/08941929809381069

Buytaert, W., Zulkafli, Z., Grainger, S., Acosta, L., Alemie, T. C., Bastiaensen, J., et al. (2014). Citizen science in hydrology and water resources: opportunities for knowledge generation, ecosystem service management, and sustainable development. Front. Earth Sci. 2:26. doi: 10.3389/feart.2014.00026

Campbell, L. M., and Vainio-Mattila, A. (2003). Participatory development and community-based conservation: opportunities missed for lessons learned? Hum. Ecol. 31, 417-438.

Chapagain, B., and Gentle, P. (2015). Withdrawing from agrarian livelihoods: environmental migration in Nepal. J. Mt. Sci. 12, 1-13. doi: 10.1007/s11629014-3017-1

Che, V. B., Kervyn, M., Ernst, G. G. J., Trefois, P., Ayonghe, S., Jacobs, P., et al. (2011). Systematic documentation of landslide events in Limbe area (Cameroon): their geometry, sliding mechanism, controlling and triggering factors. Nat. Hazards 59, 47-74. doi: 10.1007/s11069-011-9738-3

Chu, H. J., and Chen, Y. C. (2018). Crowdsourcing photograph locations for debris flow hot spot mapping. Nat. Hazards 90, 1259-1276. doi: 10.1007/s11069-0173098-6

Cieslik, K. J., Leeuwis, C., Dewulf, A. R. P. J., Lie, R., Werners, S. E., Wessel, M., et al. (2018). Addressing socio-ecological development challenges in the digital age: exploring the potential of environmental virtual observatories for connective action (EVOCA). NJAS Wageningen J. Life Sci. 86-87, 2-11. doi: 10.1016/j.njas.2018.07.006

Cochran, E. S., Lawrence, J. F., Christensen, C., and Jakka, R. S. (2009). The quakecatcher network: citizen science expanding seismic horizons. Seismol. Res. Lett. 80, 26-30. doi: 10.1785/gssrl.80.1.26

Cohen, D., and Schwarz, M. (2017). Tree-root control of shallow landslides. Earth Surf. Dynam. 5, 451-477. doi: 10.5194/esurf-5-451-2017

Coleman, D. J., Georgiadou, Y., Labonte, J., Observation, E., and Canada, N. R. (2009). Volunteered geographic information: the nature and motivation of produsers ${ }^{\circledR}$. Int. J. Spat. Data Infrastruct. Res. 4, 332-358.

Cox, R. S., and Perry, K. M. E. (2011). Like a fish out of water: reconsidering disaster recovery and the role of place and social capital in community disaster resilience. Am. J. Commun. Psychol. 48, 395-411. doi: 10.1007/s10464-0119427-0

Cruden, D. M., and Varnes, D. J. (1996). Landslide Types and Processes. Landslides: Investigation and Mitigation. Washington, DC: Transportation Research Board.

Davoudi, S. (2018). Just resilience. City Community 17, 3-7. doi: 10.1111/cico. 12281

De La Ville, N., Chumaceiro Diaz, A., and Ramirez, D. (2002). Remote sensing and gis technologies as tools to support sustainable management of areas devastated by landslides. Environ. Dev. Sustain. 4, 221-229.

De Longueville, B., Luraschi, G., Smits, P., Peedell, S., De Groeve, T., and Commission, E. (2010). C itizens as sensors for natural hazards. Geomatica 64, 41-59.

de Milliano, C., Faling, M., Clark-Ginsberg, A., Crowley, D., and Gibbons, P. (2015). "Resilience: the holy grail or yet another hype?," in The Humanitarian Challenge, eds P. Gibbons and H.-J. Heintze (Cham: Springer International Publishing), 17-30. doi: 10.1007/978-3-319-13470-3_2

Degrossi, L. C. L., Albuquerque, J. P., de Fava, M. C., and Mendiondo, E. M. (2014). "Flood citizen observatory: a crowdsourcing-based approach for flood risk management in Brazil," in Proceedings of the 26th International Conference on Software Engineering and Knowledge Engineering, São Carlos.

Dekens, J. (2007). Local Knowledge for Disaster Preparedness: A Literature Review. Kathmandu: International Centre for Integrated Mountain Development (ICIMOD).

Dhital, M. R. (2015). “Geology of the Nepal Himalaya," in Regional Perspective of the Classic Collided Orogen. Switzerland: Springer.

Elwood, S., Goodchild, M. F., and Sui, D. Z. (2012). Researching volunteered geographic information: spatial data, geographic research, and new social practice. Ann. Assoc. Am. Geogr. 102, 571-590. doi: 10.1080/00045608.2011. 595657
Farahmand, A., and Aghakouchak, A. (2013). A satellite-based global landslide model. Nat. Hazards Earth Syst. Sci. 13, 1259-1267. doi: 10.1016/j.envsoft.2016. 12.006

Folke, C., Carpenter, S., Elmqvist, T., Gunderson, L., Holling, C. S., and Walker, B. (2002). Resilience and sustainable development: building adaptive capacity in a world of transformations. Ambio 31, 437-440. doi: 10.1579/0044-7447-31.5.437

Folke, C., Carpenter, S. R., Walker, B., Scheffer, M., Chapin, T., Rockström, J., et al. (2010). Resilience thinking: integrating resilience, adaptability and transformability. Ecol. Soc. 15:20.

Gao, H., Barbier, G., and Goolsby, R. (2011). Harnessing the crowdsourcing power of social media for disaster relief. IEEE Intelligent Systems 26, 10-14. doi: 10. 1109/MIS.2011.52

Gardner, J., and Dekens, J. (2007). Mountain hazards and the resilience of socialecological systems: lessons learned in India and Canada. Nat. Hazards 41, 317-336. doi: 10.1007/s11069-006-9038-5

Gautam, Y. (2017). Seasonal migration and livelihood resilience in the face of climate change in Nepal. Mt. Res. Dev. 37, 436-445.

Gaventa, J., and Barrett, G. (2010). So What Difference Does It Make? Mapping the Outcomes of Citizen Engagement. Falmer: University of Sussex.

Gentle, P., and Maraseni, T. N. (2012). Climate change, poverty and livelihoods: Adaptation practices by rural mountain communities in Nepal. Environ. Sci. Policy 21, 24-34. doi: 10.1016/j.envsci.2012.03.007

Gerrard, J., and Gardner, R. (2002). Relationships between landsliding and land use in the likhu khola drainage basin. Middle Hills Nepal 22, 48-55. doi: 10.1659/0276-4741(2002)022\%5B0048:rblalu\%5D2.0.co;2

Glade, T. (2003). Landslide occurrence as a response to land use change: a review of evidence from New Zealand. Catena 51, 297-314. doi: 10.1016/s0341-8162(02) 00170-4

Glade, T., and Crozier, M. (2005). "The nature of landslide hazard impact," in Landslide Hazard and Risk, eds M. Glade and M. Anderson Crozier (Hoboken, NJ: John Wiley), 43-74.

Goodchild, M. F. (2007). Citizens as voluntary sensors: spatial data infrastructure in the world of Web 2.0. Int. J. Spat. Data Infrastruct. Res. 2, 24-32.

Goodchild, M. F., and Glennon, J. A. (2010). Crowdsourcing geographic information for disaster response: a research frontier. Int. J. Digit. Earth 3, 231-241. doi: 10.1080/17538941003759255

Guzzetti, F. (2000). Landslide fatalities and the evaluation of landslide risk in Italy. Eng. Geol. 58, 89-107. doi: 10.1016/s0013-7952(00)00047-8

Guzzetti, F., Cesare, A., Cardinali, M., Fiorucci, F., Santangelo, M., and Chang, K. (2012). Earth-science reviews landslide inventory maps: new tools for an old problem. Earth Sci. Rev. 112, 42-66. doi: 10.1016/j.earscirev.2012.02.001

Guzzetti, F., Peruccacci, S., Rossi, M., and Stark, C. P. (2008). The rainfall intensityduration control of shallow landslides and debris flows: an update. Landslides 5 , 3-17. doi: 10.1007/s10346-007-0112-1

Haklay, M. (2013). "Citizen science and volunteered geographic information: overview and typology of participation," in Crowdsourcing Geographic Knowledge, eds D. Sui, S. Elwood, and M. Goodchild (Dordrecht: Springer).

Haklay, M., Singleton, A., and Parker, C. (2008). Web map- ping 2.0: the neogeography of the GeoWeb. Geogr. Compass 2, 2011-2039. doi: 10.1111/j. 1749-8198.2008.00167.x

Haklay, M. M. (2013). Neogeography and the delusion of democratisation. Environ. Plan. A 45, 55-69. doi: 10.1068/a45184

Hassanzadeh, R., and Nedovic-Budic, Z. (2014). Assessment of the contribution of crowd sourced data to post-earthquake building damage detection. Int. J. Inform. Syst. Crisis Response Manag. 6, 1-37. doi: 10.4018/ijiscram.2014010101

Heckathorn, D. D. (2011). Comment: snowball versus respondent-driven sampling. Sociol. Methodol. 41, 355-366. doi: 10.1111/j.1467-9531.2011.01 244.x

Hermelin, M., and Bedoya, G. (2008). Community participation in natural risk prevention: case histories from Colombia. Geol. Soc. Lond. Spec. Public. 305, 39-51. doi: 10.1144/sp305.5

Hilley, G. E., Bürgmann, R., Ferretti, A., Novali, F., and Rocca, F. (2004). Dynamics of slow-moving landslides from permanent scatterer analysis. Science 304, 1952-1955. doi: 10.1126/science.1098821

Hiwasaki, L., Luna, E., and Shaw, R. (2014). Process for integrating local and indigenous knowledge with science for hydro-meteorological disaster risk reduction and climate change adaptation in coastal and small island 
communities. Int. J. Disaster Risk Reduct. 10, 15-27. doi: 10.1016/j.ijdrr.2014. 07.007

Hong, Y., Adler, R., and Huffman, G. (2007). Use of satellite remote sensing data in the mapping of global landslide susceptibility. Nat. Hazards 43, 245-256. doi: 10.1007/s11069-006-9104-z

Hounkonnou, D., Offei, S. K., Roling, N. G., Tossou, R., van Huis, A., Struik, P. C., et al. (2004). Diagnostic studies: a research phase in the convergence of sciences programme. NJAS Wageningen J. Life Sci. 52, 3-4.

Hufton, A. (2017). Author's corner: providing incentives and ensuring quality in citizen science. Scientific Data Updates. Available at: http://blogs.nature.com/scientificdata/2017/06/13/authors-corner-providingincentives-and-ensuring-quality-in-citizen-science/

Jacobs, L., Kabaseke, C., Bwambale, B., Katutu, R., Dewitte, O., Mertens, K., et al. (2019). The geo-observer network: a proof of concept on participatory sensing of disasters in a remote setting. Sci. Total Environ. 670, 245-261. doi: 10.1016/j. scitotenv.2019.03.177

Jalbert, K., and Kinchy, A. J. (2015). Sense and influence: environmental monitoring tools and the power of citizen science. J. Environ. Policy Plan. 18, 379-397. doi: 10.1080/1523908x.2015.1100985

Jaquet, S., Schwilch, G., Hartung-hofmann, F., Adhikari, A., and Sudmeier-rieux, K. (2015). Does outmigration lead to land degradation? Labour shortage and land management in a western Nepal watershed. Appl. Geogr. 62, 157-170. doi: 10.1016/j.apgeog.2015.04.013

Jaquet, S., Shrestha, G., Kohler, T., and Schwilch, G. (2016). The effects of migration on livelihoods, land management, and vulnerability to natural disasters in the harpan watershed in Western Nepal. Mt. Res. Dev. 36, 494-505. doi: 10.1659/ mrd-journal-d-16-00034.1

Kervyn, M., Jacobs, L., Maes, J., Che, V. B., and De Hontheim, A. (2015). Landslide resilience in equatorial Africa: moving beyond problem identification. Belgian J. Geogr. 1, 1-19.

Kirschbaum, D., Stanley, T., and Zhou, Y. (2015). Spatial and temporal analysis of a global landslide catalog. Geomorphology 249, 4-15. doi: 10.1016/j.geomorph. 2015.03.016

Kirschbaum, D. B., Adler, R., Hong, Y., Hill, S., and Lerner-Lam, A. (2010). A global landslide catalogue for hazard applications: method, results, and limitations. Nat. Hazards 52, 561-575. doi: 10.1007/s11069-009-9401-4

Lacasse, S., and Nadim, F. (2009). "Landslide risk assessment and mitigation strategy," in Landslides - Disaster Risk Reduction, eds K. Sassa and P. Canuti (Berlin: Springer), 31-61. doi: 10.1007/978-3-540-69970-5_3

Le Coz, J., Patalano, A., Collins, D., Guillén, N. F., García, C. M., Smart, G. M., et al. (2016). Crowdsourced data for flood hydrology: feedback from recent citizen science projects in argentina, france and New Zealand. J. Hydrol. 541, 766-777. doi: 10.1016/j.jhydrol.2016.07.036

Leeuwis, C., Cieslik, K. J., Aarts, M. N. C., Dewulf, A. R. P. J., Ludwig, F., Werners, S. E., et al. (2018). Reflections on the potential of virtual citizen science platforms to address collective action challenges: lessons and implications for future research. NJAS Wageningen J. Life Sci. 86-87, 146-157. doi: 10.1016/j. njas.2018.07.008

Liang, W. T., Lee, J. C., Chen, K. H., and Hsiao, N. C. (2017). Citizen earthquake science in Taiwan: from science to hazard mitigation. J. Disaster Res. 12, 1174-1181. doi: 10.20965/jdr.2017.p1174

Liebenberg, L., Steventon, J., Brahman, N., Benadie, K., Minye, J., Langwane, H., et al. (2017). Smartphone icon user interface design for non-literate trackers and its implications for an inclusive citizen science. Biol. Conserv. 208, 155-162. doi: 10.1016/j.biocon.2016.04.033

Liu, S. B., and Palen, L. (2010). the new cartographers: crisis map mashups and the emergence of neogeographic practice sophia B. Cartography 37, 69-90. doi: 10.1559/152304010790588098

Maes, J., Mertens, K., Jacobs, L., Bwambale, B., Vranken, L., Dewitte, O., et al. (2019). Social multi-criteria evaluation to identify appropriate disaster risk reduction measures: application to landslides in the Rwenzori Mountains, Uganda. Landslides 16, 1793-1807. doi: 10.1007/s10346-0181030-0

Mao, F., Clark, J., Karpouzoglou, T., Dewulf, A., Buytaert, W., and Hannah, D. M. (2017). HESS opinions: a conceptual framework for assessing sociohydrological resilience under change. Hydrol. Earth Syst. Sci. 21, 3655-3670. doi: 10.5194/hess-21-3655-2017

Marchezini, V., Trajber, R., Olivato, D., Muñoz, V. A., de Oliveira Pereira, F., and Oliveira Luz, A. E. (2017). Participatory early warning systems: youth, citizen science, and intergenerational dialogues on disaster risk reduction in Brazil. Int. J. Disaster Risk Sci. 8, 390-401. doi: 10.3390/ijerph14070749

Marino, E., and Lazrus, H. (2015). Migration or forced displacement? the complex choices of climate change and disaster migrants in shishmaref, alaskaand nanumea, tuvalu. Hum. Organ. 74, 341-350. doi: 10.17730/0018-7259-74.4.341

McCormick, S. (2012). After the cap: risk assessment, citizen science and disaster recovery. Ecol. Soc. 17, 31-41.

McKinley, D. C., Miller-Rushing, A. J., Ballard, H. L., Bonney, R., Brown, H., CookPatton, S. C., et al. (2017). Citizen science can improve conservation science, natural resource management, and environmental protection. Biol. Conserv. 208, 15-28.

Meier, P., Cochran, E. S., Lawrence, J. F., Christensen, C., Jakka, R. S., Goodchild, M. F., et al. (2012). Crisis mapping in action: how open source software and global volunteer networks are changing the world, one map at a time. J. Hydrol. 80, 571-590.

Mercer, J., Kelman, I., Taranis, L., and Suchet-Pearson, S. (2010). Framework for integrating indigenous and scientific knowledge for disaster risk reduction. Disasters 34, 214-239. doi: 10.1111/j.1467-7717.2009.01126.x

Miles, M. B., and Huberman, M. A. (1994). Qualitative Data Analysis: An Expanded Sourcebook. London: Sage.

Munroe, D. K., Berkel, D. B., Van Verburg, P. H., and Olson, J. L. (2013). Alternative trajectories of land abandonment: causes, consequences and research challenges. Curr. Opin. Environ. Sustain. 5, 471-476. doi: 10.1016/j. cosust.2013.06.010

Naess, L. O. (2013). The role of local knowledge in adaptation to climate change. Wires Clim. Change 4, 99-106. doi: 10.1002/wcc.204

Ojha, H. R., Shrestha, K. K., Subedi, Y. R., Shah, R., Nuberg, I., Heyojoo, B., et al. (2017). Agricultural land under-utilisation in the hills of Nepal: investigating socio-environmental pathways of change. J. Rural Stud. 53, 156-172. doi: 10.1016/j.jrurstud.2017.05.012

Olsson, L., Jerneck, A., Thoren, H., Persson, J., and O’Byrne, D. (2015). Why resilience is unappealing to social science: theoretical and empirical investigations of the scientific use of resilience. Sci. Adv. 1:e1400217. doi: 10. 1126/sciadv.1400217

Pelling, M., and Manuel-Navarrete, D. (2011). From resilience to transformation: the adaptive cycle in two mexican urban centers. Ecol. Soc. 16:11.

Persichillo, M. G., Bordoni, M., and Meisina, C. (2017). The role of land use changes in the distribution of shallow landslides. Sci. Total Environ. 574, 924-937. doi: 10.1016/j.scitotenv.2016.09.125

Petley, D. N., Dunning, S. A., and Rosser, N. J. (2005). "The analysis of global landslide risk through the creation of a database of worldwide landslide fatalities," in Landslide Risk Management, eds O. Hungr, R. Fell, R. Counture, and E. Ebergardt (Amsterdam: Balkema), 367-374.

Petley, D. N., Hearn, G. J., Hart, A., Rosser, N. J., Dunning, S. A., Oven, K., et al. (2007). Trends in landslide occurrence in Nepal. Nat. Hazards 43, 23-44. doi: 10.1007/s11069-006-9100-3

Petrone, A., and Perti, F. (2013). "Soil bioengineering measures in latin america: authochtonal cuttings suitability," in Landslide Science and Practice, eds C. Margottini, P. Canuti, and K. Sassa (Berlin: Springer), 325-330.

Pisano, L., Zumpano, V., Malek, Z., Rosskopf, C. M., and Parise, M. (2017). Variations in the susceptibility to landslides, as a consequence of land cover changes: a look to the past, and another towards the future. Sci. Total Environ. 60, 1147-1159. doi: 10.1016/j.scitotenv.2017.05.231

Riessman, C. (2008). Narrative Methods for the Human Sciences. Thousand Oaks: Sage Publications.

Robinson, O. C. (2014). Sampling in interview-based qualitative research: a theoretical and practical guide. Qual. Res. Psychol. 11, 25-41. doi: 10.1080/ 14780887.2013.801543

Röling, N. G., Hounkonnou, D., Offei, S. K., Tossou, R., and Van Huis, A. (2004). Linking science and farmers' innovative capacity: diagnostic studies from Ghana and Benin. NJASWagening. J. Life Sci. 52, 3-4.

Roncoli, C., Ingram, K., and Kirschen, P. (2002). Reading the rains: local knowledge and rainfall forecasting among farmers of Burkina Faso. Soc. Nat. Res. 15, 411-430.

Sapkota, P., Keenan, R. J., Paschen, J. A., and Ojha, H. R. (2016). Social production of vulnerability to climate change in the rural middle hills of Nepal. J. Rural Stud. 48, 53-64. doi: 10.1016/j.jrurstud.2016.09.007

Schuller, M. (2012). Killing With Kindness: Haiti, International Aid, and NGOs. New Brunswick: Rutgers University Press. 
Shaw, R., Noralene, U., and Baumwoll, J. (eds) (2008). Indigenous Knowledge for Disaster Risk Reduction: Good Practices And Lessons Learnt from Asia-Pacific Region. Bangkok: UNISDR.

Sidle, R. C., Gallina, J., and Gomi, T. (2017). Landscape and urban planning the continuum of chronic to episodic natural hazards: implications and strategies for community and landscape planning. Landsc. Urban Plan. 167, 189-197. doi: 10.1016/j.landurbplan.2017.05.017

Sidle, R. C., Ziegler, A. D., Negishi, J. N., Nik, A. R., Siew, P., and Turkelboom, F. (2006). Erosion processes in steep terrain-truths, myths, and uncertainties related to forest management in Southeast Asia. Ecol. Manag. 224, 199-225. doi: 10.1016/j.foreco.2005.12.019

Silvertown, J. (2009). A new dawn for citizen science. Trends Ecol. Evol. 24, 467-471. doi: 10.1016/j.tree.2009.03.017

Stokes, A., Douglas, G. B., Fourcaud, T., Giadrossich, F., Gillies, C., Hubble, T., et al. (2014). Ecological mitigation of hillslope instability: ten key issues facing researchers and practitioners. Plant Soil 377, 1-23. doi: 10.1007/s11104-0142044-6

Stone, J., Barclay, J., Simmons, P., Cole, P. D., Loughlin, S. C., Ramón, P., et al. (2014). Risk reduction through community-based monitoring: the vigías of Tungurahua, Ecuador. J. Appl. Volcanol. 3:11.

Sudmeier-Rieux, K., Jaquet, S., Basyal, G. K., Derron, M., Devkota, S., Jaboyedoff, M., et al. (2013). "A neglected disaster: landslides and livelihoods in centraleastern Nepal," in Landslide Science and Practice, eds C. Margottini, P. Canuti, and K. Sassa (Berlin: Springer).

Sudmeier-Rieux, K., Jaquet, S., Derron, M. H., Jaboyedoff, M., and Devkota, S. (2012). A case study of coping strategies and landslides in two villages of Central-Eastern Nepal. Appl. Geogr. 32, 680-690. doi: 10.1016/j.apgeog.2011. 07.005

Tobin, G. A., Whiteford, L. M., Jones, E. C., and Murphy, A. D. (2011). The role of individual well-being in risk perception and evacuation for chronic vs. acute natural hazards in Mexico. J. Appl. Geogr. 31, 700-711. doi: 10.1016/j.apgeog. 2010.12.008

Turner, N. J., and Clifton, H. (2009). It's so different today: climate change and indigenous lifeways in British Columbia. Canada. Glob. Environ. Change 19, 180-190. doi: 10.1016/j.gloenvcha.2009.01.005

Vaciago, G. (2013). "The safeland compendium of landslide risk mitigation measures," in Landslide Science and Practice, eds C. Margottini, P. Canuti, and K. Sassa (Berlin: Springer-Verlag), 683-689. doi: 10.1007/978-3-642-31319$6 \_87$
Van Den Eeckhaut, M., Moeyersons, J., Nyssen, J., Abraha, A., Poesen, J., Haile, M., et al. (2009). Spatial patterns of old, deep-seated landslides: a case-study in the northern Ethiopian highlands. Geomorphology 105, 239-252. doi: 10.1016/ j.geomorph.2008.09.027

Vlaeminck, P., Meartens, M., Laeminck, P., Maertens, M., Isabirye, M., Vanderhoydonks, F., et al. (2016). Coping with landslide risk through preventive resettlement. optimal designing strategies through choice experiments for mount elgon region, Uganda. Land Use Policy 51, 301-311. doi: 10.1016/j.landusepol.2015.11.023

Wald, D. J., Quitoriano, V., Worden, B., Hopper, M., and Dewey, J. W. (2011). USGS “Did You Feel It?” internet-based macroseismic intensity maps. Ann. Geophys. 54, 688-707.

Walker, B., Holling, C. S., Carpenter, S. R., and Kinzig, A. (2004). Resilience, adaptability and transformability in social-ecological systems. Ecol. Soc. 9:5.

Walshe, R. A., and Nunn, P. D. (2012). Integration of indigenous knowledge and disaster risk reduction: a case study from baie martelli, pentecost Island, Vanuatu. Int. J. Disaster Risk Sci. 3, 185-194. doi: 10.1007/s13753-012-0019-x

White, I., and O'Hare, P. (2014). From rhetoric to reality: which resilience, why resilience, and whose resilience in spatial planning? Environ. Plan. C Gov. Policy 32, 934-950. doi: 10.1068/c12117

Wisner, B. (2006). "Self-assessment of coping capacity: participatory, proactive and qualitative engagement of communities in their own risk management," in Measuring Vulnerability To Natural Hazards, Towards Disaster Resilient Societies, ed. J. Birkmann (Tokyo: UNU Press), 316-328.

Zook, M., Graham, M., Shelton, T., and Gorman, S. (2010). Volunteered geographic information and crowdsourcing disaster relief: a case study of the haitian earthquake. SSRN 2, 7-33.

Conflict of Interest: The authors declare that the research was conducted in the absence of any commercial or financial relationships that could be construed as a potential conflict of interest.

Copyright (c) 2019 Cieslik, Shakya, Uprety, Dewulf, Russell, Clark, Dhital and Dhakal. This is an open-access article distributed under the terms of the Creative Commons Attribution License (CC BY). The use, distribution or reproduction in other forums is permitted, provided the original author(s) and the copyright owner(s) are credited and that the original publication in this journal is cited, in accordance with accepted academic practice. No use, distribution or reproduction is permitted which does not comply with these terms. 


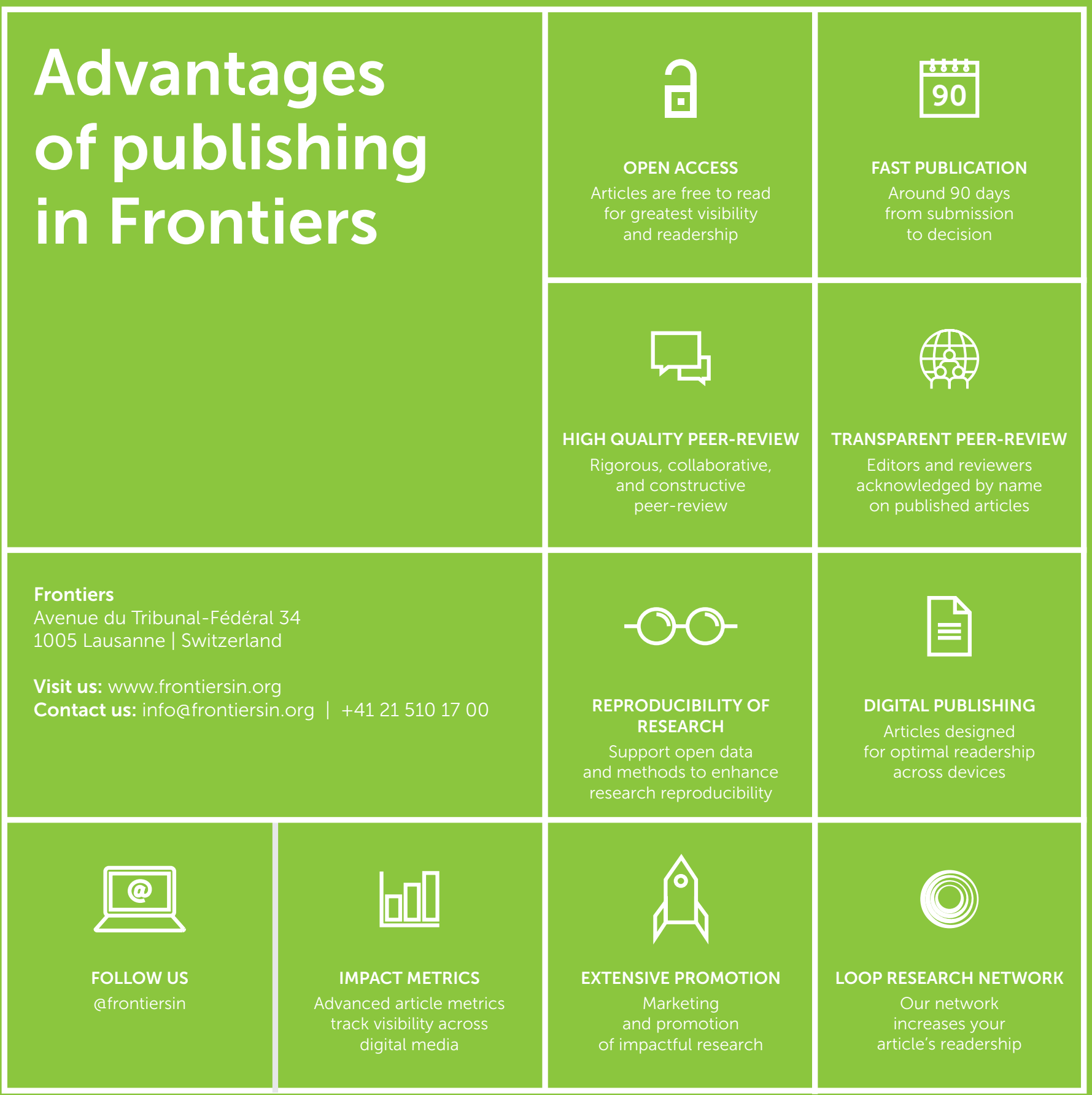

